\title{
Testing to Evaluate the Suitability of Waste Forms Developed for Electrometallurgically Treated Spent Sodium-Bonded Nuclear Fuel for Disposal in the Yucca Mountain Repository
}

prepared by

Chemical Engineering Division

Argonne National Laboratory

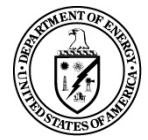




\section{About Argonne National Laboratory}

Argonne is managed by The University of Chicago for the U.S. Department of Energy under contract W-31-109-Eng-38. The Laboratory's main facility is outside Chicago, at 9700 South Cass Avenue, Argonne, Illinois 60439. For information about Argonne and its pioneering science and technology programs, see www.anl.gov.

\section{Availability of This Report}

This report is available, at no cost, at http://www.osti.gov/bridge. It is also available on paper to the U.S. Department of Energy and its contractors, for a processing fee, from:

U.S. Department of Energy

Office of Scientific and Technical Information

\section{P.O. Box 62}

Oak Ridge, TN 37831-0062

phone (865) 576-8401

fax (865) 576-5728

reports@adonis.osti.gov

\section{Disclaimer}

This report was prepared as an account of work sponsored by an agency of the United States Government. Neither the United States Government nor any agency thereof, nor The University of Chicago, nor any of their employees or officers, makes any warranty, express or implied, or assumes any legal liability or responsibility for the accuracy, completeness, or usefulness of any information, apparatus, product, or process disclosed, or represents that its use would not infringe privately owned rights. Reference herein to any specific commercial product, process, or service by trade name, trademark, manufacturer, or otherwise, does not necessarily constitute or imply its endorsement, recommendation, or favoring by the United States Government or any agency thereof. The views and opinions of document authors expressed herein do not necessarily state or reflect those of the United States Government or any agency thereof, Argonne National Laboratory, or The University of Chicago. 
ANL-05/43

TESTING TO EVALUATE THE SUITABILITY OF WASTE FORMS DEVELOPED FOR ELECTROMETALLURGICALLY TREATED SPENT SODIUM-BONDED NUCLEAR FUEL FOR DISPOSAL IN THE YUCCA MOUNTAIN REPOSITORY

by

W.L. Ebert

Chemical Engineering Division

Argonne National Laboratory 9700 South Cass Avenue

Argonne, Illinois 60439-4837

September 2005 
INTENTIONALLY LEFT BLANK 


\section{ACKNOWLEDGMENTS}

This report provides a compilation and summary of work performed by the following scientists and engineers at the Argonne National Laboratory-East in Illinois and Argonne National Laboratory-West in Idaho, which is now part of the Idaho National Laboratory:

at Argonne National Laboratory-East in Illinois:

J.P. Ackerman, D.P. Abraham, T.H. Bauer, L.L. Briggs, N.L. Dietz, D.W. Esh, T.H. Fanning, J.K. Fink, M.C. Hash, A. Hebden, S.-Y. Jeong, L. Leibowitz, M.A. Lewis, J.-S. Luo, S.M. McDeavitt, E.E. Morris, L.R. Morss, M.C. Petri, J.W. Richardson, M.K. Richmann, L.J. Simpson, C.T. Snyder, Y. Tsai, R.A. Wigeland, D.J. Wronkiewicz, and V.N. Zyryanov.

at Argonne National Laboratory-West in Idaho, now part of the Idaho National Laboratory:

M.L. Adamic, T.L. Barber, S.A. Barker, K.J. Bateman, T.J. Battisti, D.G. Cummings, T. DiSanto, S.M. Frank, K.M. Goff, M.L. Gougar, K.L. Howden, D.E. Janney, S.G. Johnson, D.D. Keiser, Jr., K.C. Marsden, M. Noy, T.P. O’Holleran, M.F. Simpson, W. Sinkler, A.R. Warren, and B.R. Westphal.

Work was supported by the U.S. Department of Energy, Office of Nuclear Energy, Science and Technology under contract W-31-109-Eng-38. 


\section{ACRONYMS}

AFSM

ANL

ASTM

BDAT

BSC

CDSP

CRWMS

CSNF

CWF

DOE

DSNF

DWPF

EA

EA glass

EBR-II

EMT

EPA

FFTF

HFEF

HIP

HLW

ILS

INL

INTEC

LaBS

LEU

MCC-1

MT

MTHM

MWF

$\mathrm{NL}(i)$

OCRWM
Accessible free salt measurement

Argonne National Laboratory

American Society for Testing and Materials (ASTM International)

Best-demonstrated available technology

Bechtel SAIC Company

Co-disposal packages

Civilian Radioactive Waste Management System

Commercial spent nuclear fuel

Ceramic waste form

U.S. Department of Energy

DOE-managed spent nuclear fuel

Defense Waste Processing Facility

Environmental Assessment (for Yucca Mountain repository)

Environmental Assessment benchmark glass

Experimental Breeder Reactor-II

Electrometallurgical treatment

U.S. Environmental Protection Agency

Fast Flux Test Facility

Hot Fuel Examination Facility

Hot isostatic press

High-level radioactive waste

Interlaboratory study

Idaho National Laboratory

Idaho National Technology and Engineering Center

Lanthanide borosilicate

Low-enriched uranium

Material Characterization Center-Static Leach Test Number 1 metric tons

metric tons of heavy metal

Metallic waste form

Normalized elemental mass loss (based on element $i$ )

DOE Office of Civilian Radioactive Waste Management 


\begin{tabular}{|c|c|}
\hline $\mathrm{PC}$ & Pressureless consolidation \\
\hline PCT & Product consistency test \\
\hline RCRA & Resource Conservation and Recovery Act \\
\hline $\mathrm{RH}$ & Relative humidity \\
\hline RIP & Repository Integration Program \\
\hline RWS & Rapid water soluble \\
\hline SBW & Sodium-bearing waste \\
\hline SEM & Scanning electron microscope (or microscopy) \\
\hline SLZ & Salt-loaded zeolite \\
\hline SNF & Spent nuclear fuel \\
\hline SR & Site Recommendation \\
\hline SRS & Savannah River Site \\
\hline $\mathrm{S} / \mathrm{V}$ & Solid surface area-to-solution volume ratio \\
\hline TCLP & Toxicity characteristic leaching procedure \\
\hline TEM & Transmission electron microscope (or microscopy) \\
\hline TSPA & Total System Performance Assessment \\
\hline TSPA-LA & Yucca Mountain System license application \\
\hline TTT & Time-temperature-transformation \\
\hline UTS & Universal Treatment Standard \\
\hline VHT & Vapor hydration test \\
\hline WAPS & Waste Acceptance Product Specifications \\
\hline WASRD & Waste Acceptance System Requirements Document \\
\hline WCP & Waste Form Compliance Plan \\
\hline WTP & (Hanford) Waste Treatment and Immobilization Plant \\
\hline WVDP & West Valley Demonstration Project \\
\hline XAFS & X-ray absorption fine structure spectroscopy \\
\hline XRD & X-ray diffraction \\
\hline
\end{tabular}




\section{CONTENTS}

ACKNOWLEDGMENTS ...................................................................................................

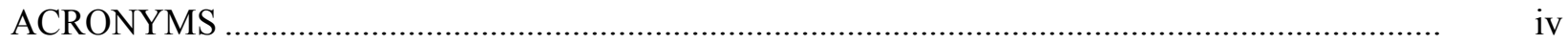

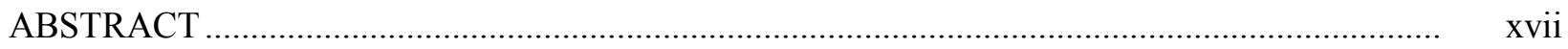

EXECUTIVE SUMMARY ............................................................................................

I. INTRODUCTION AND BACKGROUND ….................................................... I-1

I.A. $\quad$ Electrometallurgical Treatment Wastes and Waste Forms ................................... I-2

I.B. The Ceramic Waste Form for Salt Wastes ............................................................ I-2

I.C. The Metallic Waste Form for Metallic Wastes ..................................................... I-4

I.D. Approach to Qualifying CWF and MWF for Disposal ....................................... I-5

I.E. High-Level Radioactive Waste Glass..................................................................... I-6

II. WASTE ACCEPTANCE SYSTEM REQUIREMENTS DOCUMENT ........................... II-1

II.A. Compliant Waste Forms ................................................................................. II-2

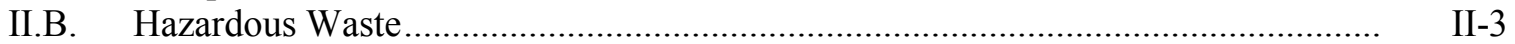

II.C. Chemical Composition....................................................................................... II-3

II.D. Crystalline Phase Projection and Phase Stability .................................................. II-3

II.E. Product Consistency ......................................................................................... II-3

II.F. $\quad$ Radionuclide Inventory …............................................................................ II-4

II.G. Time-Temperature-Transformation Diagrams .................................................... II-5

II.H. Canister Criticality ........................................................................................... II

II.I. Nonconforming Waste Forms ............................................................................ II-5

III. TOTAL SYSTEM PERFORMANCE ASSESSMENT FOR THE YUCCA

MOUNTAIN REPOSITORY ..................................................................................... III

III.A. HLW Glass Degradation Model in TSPA ............................................................... III-2

III.A.1. HLW Glass Degradation Rate................................................................... III-2

III.A.2. HLW Glass Surface Area ......................................................................... III-3

III.A.3. HLW Radionuclide Inventory …………................................................ III-4

IV. THE CERAMIC WASTE FORM ............................................................................ IV-1

IV.A. Composition and Microstructure of the CWF .................................................... IV-1

IV.A.1. Salt Composition ............................................................................. IV

IV.A.2. Zeolite Composition and Structure ..................................................... IV-1

IV.A.3. Binder Glass Composition .................................................................. IV -2

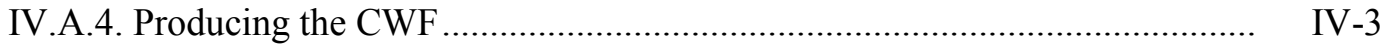

IV.A.5. CWF Phase Composition .................................................................... IV -4

IV.A.6. CWF Microstructure ........................................................................ IV

IV.A.7. Distribution of Radionuclides .................................................................... IV

IV.A.8. Compositional Variability of CWF Made with Different Amounts of Salt and Binder Glass ............................................................................. IV-11

IV.A.9. Thermal Stability of CWF Phase Composition ......................................... IV-16

IV.A.9.1. XRD of Heat-Treated CWF Materials ................................... IV-16

IV.A.9.2. Quantification of Halite in Nominal CWF Composition .......... IV-17

IV.A.9.3. Time-Temperature-Transformation Diagram........................... IV-19 


\section{CONTENTS (continued)}

IV.B. Degradation of CWF IV-23

IV.B.1. Aqueous Corrosion Characteristics of the CWF Matrix Phases ................. IV-23

IV.B.1.1. Test Method ASTM C1220 (MCC-1 Test) ............................... IV-23

IV.B.1.2. Test Method ASTM C1285 (PCT) ....................................... IV-24

IV.B.1.3. Vapor Hydration Test (VHT) ............................................. IV-26

IV.B.2. Release of Occluded Salt from Sodalite................................................. IV-26

IV.B.3. Immersion Test Results .................................................................... IV

IV.B.4. Solution Exchange Tests with a 110-ppm $\mathrm{H}_{4} \mathrm{SiO}_{4}$ Solution..................... IV-30

IV.B.5. Release of U and Pu During CWF Degradation................................... IV-32

IV.B.6. Radiation Damage .......................................................................... IV

IV.B.7. Degradation of CWF in Humid Air........................................................ IV-44

IV.C. Development of a Mechanistic Model for CWF Degradation ............................. IV-48

IV.C.1. Mechanistic Model for HLW Glass Degradation.................................. IV -48

IV.C.2. Modeling CWF Dissolution ............................................................. IV -50

IV.C.2.1. Intrinsic Rate Constant, $\mathrm{pH}$ Dependence, and Temperature

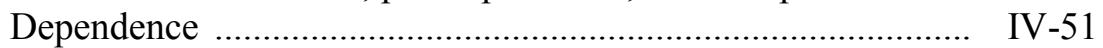

IV.C.2.2. Solubility Product .......................................................... IV-58

IV.C.2.3. Parameter Values Used in CWF Degradation Model................ IV-61

IV.D. CWF in Repository Modeling .................................................................... IV-62

IV.D.1. Simplified CWF Degradation Rate ....................................................... IV-62

IV.D.1.1. Comparison of Rates Using Model Parameters for HLW Glass and CWF ........................................................... IV-63

IV.D.1.2. Effect of Modeled Exposure Conditions .................................. IV-63

IV.D.2. CWF Surface Area ....................................................................... IV-65

IV.D.3. CWF Radionuclide Inventory ........................................................ IV-65

IV.E. Monitoring the Consistency of CWF Products ….............................................. IV-66

IV.E.1. Application of the PCT to CWF ......................................................... IV-66

IV.E.1.1. Monitoring the Test Response ................................................. IV-67

IV.E.1.2. Suitability of the PCT Procedure to the CWF .......................... IV-68

IV.E.2. Effects of Crushing CWF ..................................................................... IV-68

IV.E.3. Sensitivity of PCT Response to CWF Composition .............................. IV-70

IV.E.4. Precision of PCT with CWF................................................................ IV-77

IV.E.4.1. Replicate Tests at ANL .................................................... IV-78

IV.E.4.2. Interlaboratory Study........................................................... IV-79

IV.E.5. Discussion Regarding the Use of PCT with CWF .............................. IV-85

IV.E.6. Comparison of CWF and EA Glass PCT Responses .............................. IV-87

IV.E.7. PCT with Radioactive CWF Materials................................................. IV-88

IV.F. Co-Disposal of CWF and MWF Products....................................................... IV-88

IV.G. Effects of Processing Conditions on PC CWF ................................................. IV-91

IV.H. Deliquescence of Dissolved CWF ............................................................ IV-93

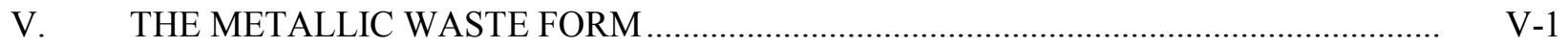

V.A. Composition and Microstructure of the MWF ................................................... V-1

V.A.1. Host Phases ........................................................................................... V V-1

V.A.2. Radionuclide Inventory and Distribution .............................................. V V-2

V.A.3. Physical Properties ..................................................................................... V-6

V.A.4. Thermal Stability of Phase Composition.................................................. V-6

V.B. Production of the MWF .............................................................................. V-7 


\section{CONTENTS (continued)}

Page

V.C. Degradation Behavior of the MWF ...................................................................... V-7

V.C.1. Electrochemical Corrosion Tests ............................................................... V-8

V.C.2. Aqueous Corrosion Tests ........................................................................ V-12

V.C.2.1. Results of Long-Term Partial Solution Exchange Tests ........... V V-14

V.C.2.2. Results of Short-Term Solution Exchange Tests...................... V V-18

V.C.3. Results of Vapor Hydration Tests ............................................................. V-19

V.C.4. Unsaturated (Drip) Tests ................................................................. V V-21

V.D. Microscopic Examination of Oxidation Layers on Test Samples ........................... V-22

V.E. Monitoring the Consistency of MWF Products .................................................. V-23

V.F. MWF Degradation Model ......................................................................... V-26

V.G. Comparison with the Defense HLW Glass Degradation Model ........................... V-29

V.H. Hazardous Characteristics ..................................................................... V-30

VI. ACCOUNTING FOR EMT WASTE FORMS IN TSPA CALCULATIONS..................... VI-1

VI.A. Dissolved Radionuclide Concentration Limits in TSPA...................................... VI-1

VI.B. Treatment of Radionuclide-Bearing Colloids in TSPA........................................ VI-2

VI.B.1. Colloids from CWF ............................................................................. VI-3

VI.B.2. Colloids from MWF ........................................................................ VI-3

VI.C. Simulations and Statistical Comparisons …......................................................... VI-4

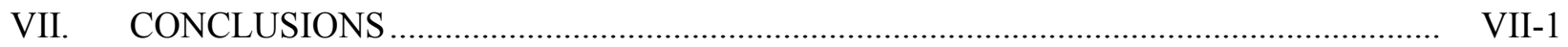

VIII. REFERENCES ........................................................................................... VIII-1

APPENDIX A: CWF and MWF Compositions and Inventories in TSPA................................... A-1

APPENDIX B: Annotated Bibliography of Technical Publications ........................................... B-1 


\section{TABLES}

Page

1. Defense HLW Glass Degradation Model Parameters ......................................................... xvii

III-1. Average Radionuclide Inventory in HLW per Canister ............................................... III-4

III-2. Information Used to Determine Radionuclide Inventory for TSPA-LA ............................ III-5

III-3. Codisposal Configurations to Accommodate DSNF ................................................... III-5

IV-1. Composition of 300-Driver Salt ....................................................................... IV-1

IV-2. Composition of Binder Glass .............................................................................. IV-3

IV-3. Measured and Estimated Distribution of Radionuclides in CWF ................................. IV-12

IV-4. Elemental Compositions of 300 Driver Salt, Zeolite 4A, and Binder Glass ...................... IV-13

IV-5. Formulation and Measured Compositions of Salt-Loaded CWF Materials ...................... IV-14

IV-6. Relative XRD Peak Areas for Replicate Analyses of Material PC10402 ......................... IV-19

IV-7. Estimated Elemental Distributions in CWF ...................................................... IV-28

IV-8. U,Pu-Doped CWF Materials used in Corrosion Tests ................................................. IV-33

IV-9. Calculated Compositions of U,Pu-Doped CWF Materials............................................... IV-34

IV-10. Results of RWS Tests with U,Pu-Doped CWF Materials .............................................. IV-34

IV-11. Results of Seven-Day PCT Conducted with U,Pu-Doped CWF Materials at $90^{\circ} \mathrm{C} \ldots \ldots \ldots \ldots . . . \quad$ IV-35

IV-12. Results of Seven-Day PCT with Pu-238-Doped CWF Material after 0.2, 2, and 4 Years

IV-13. NL(Si) for MCC-1 Tests with Sodalite, Binder Glass, HIP CWF, and PC CWF ............... IV-52

IV-14. Normalized Dissolution Rates Based on Silicon Release …......................................... IV-55

IV-15. Model Parameter Values for Sodalite, Binder Glass, and HIP CWF for

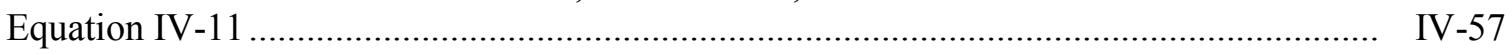

IV-16. Model Parameter Values for Sodalite, Binder Glass, and HIP CWF for Equation IV-12

IV-17. Orthosilicic Acid Concentrations and $\mathrm{pH}$ in PCTs with Sodalite, Binder Glass, and HIP CWF 


\section{TABLES (continued)}

Page

IV-18. Composition of HIP CWF in Two Size Fractions......................................................... IV-70

IV-19. Results of Three Sets of Triplicate RWS and PCT with 5-kg CWF Made with 50 Mass \% Binder Glass ............................................................................................ IV-79

IV-20. Results of RWS and PCT with 10 CWF Products Made with 50 Mass \%

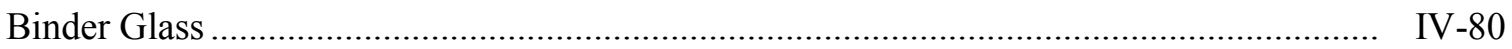

IV-21. Results of PCT Conducted with CWF in Interlaboratory Study …................................ IV-83

IV-22. Comparison of Precision of PCT Conducted with CWF and Three Borosilicate Glasses ...................................................................................... IV-83

IV-23. Comparison of NC(i) for PCT with CWF and EA Glass ........................................... IV-87

IV-24. Results of Seven-day PCT with Radioactive CWF ................................................... IV-88

IV-25. Test Data for Co-Disposal Tests ................................................................................ IV-90

IV-26. Results of Co-Disposal Tests ........................................................................... IV-91

IV-27. Results of Tests with PC CWF Made under Different Processing Conditions .................... IV-92

IV-28. Compositions of PCT Solutions ............................................................................. IV-95

IV-29. Concentration Factors for Solutions in Isopiestic Tests Relative to the Initial PCT Solutions

IV-96

V-1. Results for Chemical Analyses of Core-Drilled Samples ................................................ V-4

V-2. Compositions of Phases in U-Bearing MWF Materials .............................................. V-5

V-3. Phase Compositions after Heat Treatments.............................................................. V-7

V-4. Solution Compositions for Electrochemical Tests …................................................... V-9

V-5. Corrosion Rates measured by Polarization Resistance for

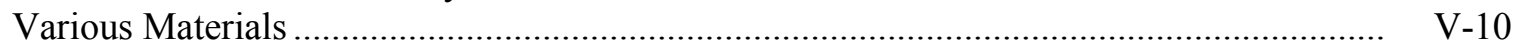

V-6. Corrosion Rates Measured by Polarization Resistance for Various Materials

V-7. Corrosion Rates Measured in SJ-13, SJ-13 Spiked with $\mathrm{NaCl}$, and Concentrated SJ-13

V-8. Cumulative NL(U) at $50^{\circ} \mathrm{C}$ through 70 Days for Tests with Leachants Spiked with 10,000 and $1,000 \mathrm{ppm} \mathrm{Cl}^{-}$and without $\mathrm{NaCl}$. 


\section{TABLES (continued)}

Page

V-9. Chemical Analyses of Core-Drilled and Drill Shaving Samples of MWF Ingots................ V-27

V-10. Results of TCLP Tests with MWF …........................................................................ V-31

\section{FIGURES}

I-1. Flow Diagram of EMT Process ......................................................................... I-3

I-2. Production-Scale Non-Radioactive CWF Product ....................................................... I-4

I-3. Production-Scale Fully Radioactive MWF Product .................................................... I-5

IV-1. SEM Photomicrograph of a Cross-Sectioned SLZ Particle with U,Pu-Doped Salt ............. IV-3

IV-2. XRD Overlay Plot of Starting Materials Zeolite 4A, Binder Glass, and $\mathrm{LiCl} / \mathrm{KCl}$ Eutectic Salt and XRD Spectra of Nominal PC CWF Material ................... IV-5

IV-3. Photomicrographs Showing Microstructures of U,Pu-Doped HIP CWF and U,Pu-Doped PC CWF

IV-4. Optical Micrograph of Halite Inclusions within Binder Glass of HIP CWF...................... IV-8

IV-5. TEM Photomicrograph of Halite and Mixed Actinide-Rare Earth Element Oxides Inclusion Phases in HIP CWF

IV-6. TEM Photomicrograph of Actinide/Rare Earth Element Oxide Inclusions within Binder Glass in HIP CWF

IV-7. XANES Results for Pu $\mathrm{L}_{\mathrm{III}}$ Edge of CWF Material Made with Pu-Bearing $\mathrm{LiCl} / \mathrm{KCl}$ Salt and $\mathrm{Pu}(\mathrm{IV})$ Standard

IV-8. TEM Image of a Sodalite/Glass Interface Showing Evidence of a Clay Phase ................... IV-11

IV-9. Amounts of Halite, Nepheline, and Sodalite Formed in Salt-Loaded CWF Materials ......... IV-15

IV-10. XRD Spectrum of PC CWF Samples Heated at $400^{\circ} \mathrm{C}$ for 1 Year and Heated at $850^{\circ} \mathrm{C}$ for $100 \mathrm{~h}$.

IV-11. Amounts of Halite and Sodalite in Long-Term Heat-Treated CWF Samples Heated for 1 Week, 4 Weeks, 3 Months, 6 Months, and 1 Year. 


\section{FIGURES (continued)}

IV-12. Relative Amounts of Halite, Sodalite, and Nepheline in Short-Term, Heat-Treated CWF Samples Heated for $4,28,52$, or 100 hours at $600,700,800$, or $850^{\circ} \mathrm{C}$

Page

IV-21

IV-13. Area Percent Values for Three Halite Peaks in XRD with PC CWF Material PC10402 with $0,4.57,5.46$, and 7.30 Mass $\%$ Added $\mathrm{NaCl}$

IV-14. Time-Temperature-Transformation Plot for Heat-Treated CWF Products.

IV-22

IV-15. Results of Solution Exchange Tests with Salt-Loaded Zeolite and Sodalite

IV-27

IV-16. Dissolution of CWF in MCC-1 Tests and PCTs (not water-washed)

IV-28

IV-17. Results of MCC-1 Tests at $90^{\circ} \mathrm{C}$ with Sodalite and Binder Glass

IV -29

IV-18. Results of Solution Exchange Tests with HIP CWF and PC CWF in $110 \mathrm{ppm}_{4} \mathrm{SiO}_{4}$ Leachant Solution.

IV-30

IV-19. Photomicrographs of Cross-Sectioned Samples of and HIP CWF and

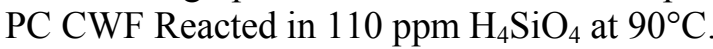

IV-31

IV-20. SEM Photomicrograph Showing Preferential Dissolution at Sodalite/Binder Glass Interfaces in Sample of HIP CWF Reacted in MCC-1 Test at $120^{\circ} \mathrm{C}$.

IV -32

IV-21. Normalized Mass Losses of B, Cs, Na, Si, Pu, and U from HIP U,Pu-Loaded CWF and PC U,Pu-loaded CWF GPC0030m in PCT at $90^{\circ} \mathrm{C}$ and a 1:10 Mass Ratio......

IV-36

IV-22. Normalized Mass Losses in PCT at $90^{\circ} \mathrm{C}$ and a 1:10 Mass Ratio with HIP U,Pu-Loaded CWF and PC U,Pu-Loaded CWF GPC0030m.

IV-23. Distribution of Released $\mathrm{U}$ and $\mathrm{Pu}$ in $\mathrm{PCT}$ at $90^{\circ} \mathrm{C}$ and a $1: 10$ Mass Ratio IV -38

IV-24. TEM Iimages Showing Aggregated Aluminosilicate Colloidal Particles and Pu-Bearing Crystallite Associated with Aluminosilicate Particles.

IV-25. Absorption XAFS Spectra of Filtrant and $\mathrm{PuO}_{2}$ Standard

IV -40

IV-26. Colloid Size Distribution in 450-nm Filtrate from Seven-Day PCT

IV-41

IV-27. Bright Field Transmission Electron Micrographs Showing Plutonium-Bearing Particles in the Binder Glass near Sodalite Domains 


\section{FIGURES (continued)}

Page

IV-29. Comparison of NL(B) Values Attained in Excess-Water VHTs with CWF ...................... IV-47

IV-30. Photomicrographs of Surface and Cross-Section of CWF Reacted in

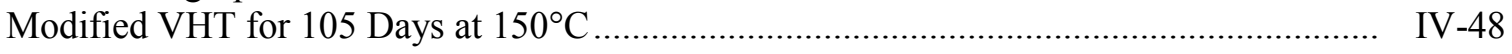

IV-31. Schematic Flow Diagram of CWF Degradation Model .................................................. IV-51

IV-32. Rates Measured in Short-Term MCC-1 Tests for Sodalite, Binder Glass,

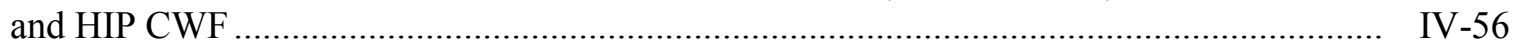

IV-33. Comparison of Regressed Rates for Sodalite, Binder Glass and CWF .............................. IV-57

IV-34. Results of 3-Day MCC-1 Tests with CWF in Al-Doped and Si-Doped pH Buffers............ IV-58

IV-35. Results of PCTs with Sodalite, Binder Glass, and HIP CWF and including PCTs with PC CWF

IV-36. Comparison of Rates Calculated with Defense HLW Glass Degradation Model Using Parameter Values for HLW Glass and for CWF

IV-37. Scanning Electron Photomicrographs of $-100+200$ Mesh Size Fraction of PC CWF before and after Washing and of Cross-Sectioned -100 +200 Mesh Size Fraction Particles of PC CWF and HIP CWF

IV-38. Correlation between the $\mathrm{Cl}^{-}$Concentration in the RWS Solution and the Halite Content in Bulk PC CWF

IV-39. Correlations between $\mathrm{I}^{-}$and $\mathrm{Cl}^{-}$and $\mathrm{Na}$ and $\mathrm{Cl}^{-}$in RWS of PC CWF.

IV-72

IV-40. Concentrations of B, Cl, Na, and Si in Seven-Day PCT Conducted with PC CWF

IV-72

IV-41. Chloride Release in RWS with Salt-Loaded CWF Materials IV-74

IV-42. B Concentrations Measured in Triplicate Seven-Day PCT IV-75

IV-43. Normalized Elemental Mass Losses in Seven-Day PCT with Salt-Loaded CWF Materials

IV-44. Correlation of the Mass Fractions of $\mathrm{Al}, \mathrm{Cl}, \mathrm{Na}$, and $\mathrm{Si}$ with the Mass Fraction of B in Salt-Loaded CWF Products

IV-45. Results of RWS and PCTs with 10 Replicate CWF Products IV-81

IV-46. Total NL(i) for Replicate PC CWF Samples Made with 50\% Binder Glass IV-82 


\section{FIGURES (continued)}

IV-47. Mean Values of Solution Concentrations Measured in ILS

Page

IV-47. Mean Values of Solution Concentrations Measured in ILS

IV-48. Plots of $k$-Statistic Values and Critical Value of 1.98 for Comparing Intralaboratory Consistency and $h$-Statistic Values and Critical Values of \pm 1.92 for Comparing Interlaboratory Consistency for Six Participants Conducting Triplicate Tests

IV-49. Schematic Cross-Section Geometry of Intact and Collapsed Configurations Canisters

IV-50. $\mathrm{Cl}^{-}$Concentration and Molar Concentrations of $\mathrm{Cl}^{-}$and $\mathrm{Na}$ vs. S/V Ratio Used in Co-Disposal Tests

IV-51. Effect of Processing Conditions on NL(Cl) and NL(B).

IV-52. Water Uptake Isotherms for PCT Salts from CWF1, Test CWF2, and Test EA6 ......

V-1. Microstructure of SS-15Zr MWF Containing about 50 Volume \% Stainless Steel and 50\% Intermetallic Phase and Regions in Intermetallic Enriched in U

V-2. Galvanic Current Measured in Tests with MWF Materials SS-15Zr and SS-15Zr-1Nb-1Pd-1Rh-1Ru and AISI 1018 steel in SJ-13 Solution

V-3. Radionuclide Releases Measured in Solution Exchange Tests with SJ-13 Water at $90^{\circ} \mathrm{C}$

V-4. Releases of U and Tc Measured in Solution Exchange Tests in SJ-13 Water at $90^{\circ} \mathrm{C}$.......

V-5. Releases of U and Tc Measured in Long-Term Solution Exchange Tests with SS-15Zr-11U-0.6Ru-0.3 Tc in SJ-13 Water at $90^{\circ} \mathrm{C}$.

V-6. Cumulative Release of U vs. Cumulative Reaction Time for Tests.

V-7. Release of U from MWF in Excess-Water VHTs at $70^{\circ} \mathrm{C}, 90^{\circ} \mathrm{C}, 150^{\circ} \mathrm{C}$, and $200^{\circ} \mathrm{C}$

V-8. Results of Unsaturated (drip) Tests with SS-15Zr-1Nb-1 Ru-1Rh-1Pd-2U-1Tc in EJ-13 Groundwater at $90^{\circ} \mathrm{C}$

V-9. TEM Photomicrographs of Oxide Layers Formed over Stainless-Steel Phase and Intermetallic Phase on MWF Reacted at $200^{\circ} \mathrm{C}$ for 91 Days in Immersion Test

V-10. TEM Photomicrograph of Flocculated Iron Oxide Colloids Overlaying Stainless Steel/Intermetallic Interface in Vapor-Reacted MWF Sample. 


\section{FIGURES (continued)}

V-11. Comparison of MWF Degradation Rates Measured in 70-Day MCC-1 Tests at 50, 70 , and $90^{\circ} \mathrm{C}$ and from Empirical MWF Model with Defense HLW Glass

Degradation Model at 50 and $90^{\circ} \mathrm{C}$

VI-1. Normalized Cumulative Release of ${ }^{129}$ I and Cumulative Release of ${ }^{237} \mathrm{~Np}$

from Waste Forms in Simplified TSPA-VA Model Calculations, in g....

VI-6 


\title{
TESTING TO EVALUATE THE SUITABILITY OF WASTE FORMS DEVELOPED FOR ELECTROMETALLURGICALLY TREATED SPENT SODIUM-BONDED NUCLEAR FUEL FOR DISPOSAL IN THE YUCCA MOUNTAIN REPOSITORY
}

\author{
W.L. Ebert
}

\begin{abstract}
The results of laboratory testing and modeling activities conducted to support the development of waste forms to immobilize wastes generated during the electrometallurgical treatment of spent sodium-bonded nuclear fuel and their qualification for disposal in the federal high-level radioactive waste repository are summarized in this report. Tests and analyses were conducted to address issues related to the chemical, physical, and radiological properties of the waste forms relevant to qualification. These include the effects of composition and thermal treatments on the phase stability, radiation effects, and methods for monitoring product consistency. Other tests were conducted to characterize the degradation and radionuclide release behaviors of the ceramic waste form (CWF) used to immobilize waste salt and the metallic waste form (MWF) used to immobilize metallic wastes and to develop models for calculating the release of radionuclides over long times under repository-relevant conditions. Most radionuclides are contained in the binder glass phase of the CWF and in the intermetallic phase of the MWF. The release of radionuclides from the CWF is controlled by the dissolution rate of the binder glass, which can be tracked using the same degradation model that is used for highlevel radioactive waste (HLW) glass. Model parameters measured for the aqueous dissolution of the binder glass are used to model the release of radionuclides from a CWF under all water-contact conditions. The release of radionuclides from the MWF is elementspecific, but the release of $U$ occurs the fastest under most test conditions. The fastest released constituent was used to represent all radionuclides in model development. An empirical aqueous degradation model was developed to describe the dependence of the radionuclide release rate from a MWF on time, $\mathrm{pH}$, temperature, and the $\mathrm{Cl}^{-}$ concentration. The models for radionuclide release from the CWF and MWF are both bounded by the HLW glass degradation model developed for use in repository licensing, and HLW glass can be used as a surrogate for both CWF and MWF in performance assessment calculations. Test results indicate that the radionuclide release from CWF and MWF is adequately described by other relevant performance assessment models, such as the models for the solution chemistries in breached waste packages, dissolved concentration limits, and the formation of radionuclide-bearing colloids.
\end{abstract}




\section{EXECUTIVE SUMMARY}

Laboratory tests have been conducted to support (1) the development of waste form materials to immobilize the salt and metallic waste streams generated during the electrometallurgical treatment (EMT) of spent sodium-bonded nuclear fuel and (2) qualification of those waste forms for disposal in the federal high-level radioactive waste repository. Salt wastes (primarily the eutectic $\mathrm{KCl}-\mathrm{LiCl}$ salt electrolyte with small amounts of fission products, rare earth and actinide elements) will be immobilized using the ceramic waste form (CWF). The CWF is multi-phase material of approximately 70 mass \% sodalite $\left[\mathrm{Na}_{8}\left(\mathrm{AlSiO}_{4}\right)_{6} \mathrm{Cl}_{2}\right], 25$ mass \% borosilicate glass, and 5 mass \% of a mixture of halite and various actinide and rare earth element oxide inclusion phases within the glass. Most of the radionuclides in the CWF are sequestered as insoluble oxides (actinides and rare earth element fission products) that form as inclusions within the binder glass. Small amounts of some radionuclides are dissolved in the glass (alkali metal fission products) or incorporated into the sodalite and halite phases (iodine). Metallic waste streams (primarily stainless steel cladding hulls) will be immobilized using the metallic waste form (MWF). The MWF is made by adding Zr to the waste stream to generate a material containing nearly equal amounts of an iron solid solution phase and a Laves $\mathrm{Fe}_{2} \mathrm{Zr}$ intermetallic phase with the gross composition SS-15Zr10U. Most of the radionuclides (primarily actinides) in the MWF are sequestered within the intermetallic phase, although small amounts of Mo and Tc are contained in the iron phase. Zr will be added to the waste stream to ensure that enough of the intermetallic phase will form to alloy all the radionuclides, and depleted $U$ will be added to down-blend the fraction of U-235 in the waste.

Various tests and analyses were performed with CWF and MWF materials to (1) characterize the degradation behaviors and radionuclide release modes, (2) support development of mechanistic degradation models and measure model parameter values, and (3) generate a data base to support qualification of the waste forms for disposal. The approach taken to support qualification was to demonstrate that the EMT waste forms meet criteria for high-level radioactive waste (HLW) glass listed in the Waste Acceptance System Requirements Document (WASRD) and that the radionuclide release due to waste form degradation could be taken into account in Total System Performance Assessment (TSPA) calculations by using the dissolution rate of HLW glass as a surrogate for dissolution of both CWF and MWF. This is a reasonable approach because the radionuclide release is calculated in TSPA as the product of the dissolution rate, surface area, and radionuclide inventory of the waste form, and values of these parameters can be determined for each waste form and used to calculate the total release. The surface areas are readily calculated and the average inventory to be used in TSPA calculations already includes the CWF and MWF inventories. Comparisons of the waste form dissolution mechanisms and rates under the anticipated disposal conditions can provide confidence in using the defense HLW glass degradation model developed for use in TSPA as a surrogate to account for the impact of the EMT waste forms on repository performance.

The WASRD “establishes waste acceptance technical requirements for the U.S. Department of Energy's (DOE) Civilian Radioactive Waste Management System (CRWMS)" and lists "acceptance criteria imposed by the CRWMS on spent nuclear fuel (SNF) and high-level waste (HLW) delivered into the CRWMS" (DOE, 2002, Section 1.1). Various requirements are described in that document for the waste form materials themselves, such as phase composition, radionuclide content, product consistency, and chemical durability; the canistered waste forms, such as criticality and thermal outputs; and the canisters, such as materials, dimensions, the maximum weight, labeling, handling fixtures, required levels of surface decontamination, etc. The WASRD addresses interface requirements between DOE offices responsible for production, transport, and disposal of HLW waste. Because EMT waste forms are to be qualified as HLW rather than spent fuel, the requirements for HLW glass listed in the WASRD have been used as guidance in the tests and analyses conducted to qualify the CWF and MWF. The general requirements for HLW waste forms include compliance with the Nuclear Waste Policy Act of 1982 (as amended) and with hazardous waste regulations established by the U.S. Environmental Protection Agency (EPA); HLW that 
is regulated as hazardous waste under the Resource Conservation and Recovery Act (RCRA) Subtitle C will not be accepted for disposal. [The toxicity characteristic leaching procedure (TCLP) is used to demonstrate that the waste form is not characteristically hazardous. If the waste is characteristically hazardous, either the results of TCLP must be compared with universal treatment standard (UTS) values to show the waste form is not characteristically hazardous or the waste form must be excluded based on treatment by the best-demonstrated available technology (BDAT), which in the case of HLW is vitrification.] All HLW must be sealed in disposable canisters. These general requirements are assumed to be immutable and must be met by all waste forms. Additional safeguard and security requirements may be added by DOE in the future, although these are not expected to impact the development and qualification of the EMT waste forms.

Other requirements are waste form-specific. The only WASRD requirements regarding waste form durability are that the borosilicate glass be sealed inside an austenitic stainless steel canister and that waste form production be controlled such that the normalized releases of $\mathrm{Li}, \mathrm{Na}$, and $\mathrm{B}$ from the glass are less than the releases of those elements from the Environmental Assessment (EA) glass, as measured in the product consistency test (PCT) or equivalent (DOE 2002, Section 4.8.1). It is stated in the WASRD that requirements listed for borosilicate glass waste forms also apply to the Immobilized Plutonium Waste Form (IPWF), which is a waste form developed to immobilize excess weapons-grade plutonium waste for disposal, but is not currently planned for use. Based on the approach taken by DOE for qualifying the IPWF, it is assumed that the requirements for HLW glass will be applied to the EMT waste forms. It is the responsibility of the waste form producer to demonstrate compliance with these requirements by using methods specified for HLW glasses or alternative methods. For example, as discussed in this report, tests have shown that the PCT is appropriate for monitoring the consistency of the CWF, but it is not appropriate for the MWF. Instead, the consistency of MWF products can be monitored by measuring the $\mathrm{Zr}$ content. The other specific requirements address the canister used to house the waste forms, including design, criticality, and thermal output limits.

Thirteen technical information needs are listed in WASRD Section 5.4.1, some of which have not yet been defined. These needs are not presented as acceptance requirements and do not impose ranges or limits on the waste forms. Rather, they identify information regarding the waste forms that may be needed for future design decisions, modeling, and analyses within the CRWMS. Some of the needs are addressed in this report because they were the bases for some of the research and development work done to support qualification of the EMT waste forms. Key technical information needs relevant to qualifying nonstandard waste forms include the following (the numbers are those used in Section 5.4.1 of the WASRD):

(1) the chemical composition and phase composition projections for vitrified HLW,

(2) estimates of the total facility inventory and individual canister inventory of radionuclides,

(3) the Time-Temperature-Transformation diagrams for the vitrified HLW and identification of temperature limits (if any) necessary to preserve the properties of the vitrified HLW,

(4) identification of the method to be used to assure consistency of production batches, and

(10) information required to assess canister criticality, both pre and post closure.

The effects of temperature on the stabilities of the EMT waste form materials have been measured using X-ray diffraction and microscopy. Heat treatments of CWF materials indicate that a slight increase in the halite content occurs with increased temperature and time, which is probably due to the dissolution of small amounts of sodalite into the borosilicate binder glass. Chloride salts have low solubilities in borosilicate glasses and $\mathrm{NaCl}$ is left as residue as the sodalite dissolves into the glass. Tests with glass compositions simulating the dissolution of sodalite into the binder glass indicate this has a negligible effect on the durability of the glass. PCTs conducted with heat-treated materials to evaluate the impact of the slight change in phase content on the durability of the CWF indicate the effect is negligible. 
TSPA calculations will be conducted by DOE as part of the Yucca Mountain repository license application. The purpose of these calculations is to show that doses that could be incurred by a reasonably maximally exposed individual are within regulatory limits. The calculations will account for features, events, and processes that may affect the repository performance under various scenarios. The current TSPA includes models to calculate the release of radionuclides due to the degradation of commercial spent nuclear fuel (CSNF), DOE-managed spent nuclear fuel (DSNF), and HLW glass. Other models address the compositions of seepage waters in breach waste packages, dissolved concentration limits, colloid formation, and various transport issues. The requirements developed for accepting wastes for disposal have focused, in part, on supporting the design, development, and licensing of the mined geologic repository. Showing that the EMT waste forms can be accounted for in TSPA dose calculations was a key objective in the testing program, and is believed to be an important factor in their acceptance.

Our approach to support qualification of the EMT waste forms is to demonstrate that the HLW glass degradation model can be used as a surrogate to account for radionuclides released as the CWF and MWF degrade. This means that there will be no need to distinguish between canisters with HLW glass and canisters with CWF and MWF in TSPA calculations, just like there is no need to distinguish the canisters of HLW glass from Savannah River, Hanford, or West Valley. Three terms are used to calculate the release of radionuclides from HLW glass: the specific glass degradation rate, the surface area of glass contacted by water, and the mass fraction of radionuclides in the glass. Our approach is to show that the three terms used to calculate the release of radionuclides from HLW glass represent (or provide a conservative upper bounds to) the corresponding terms for the CWF and MWF. The surface areas of CWF and MWF in a canister accessible to water are much lower than that modeled for HLW glass. In addition to the smaller geometric surface area, a multiplication factor of between 4 and 17 is used to account for thermal fracturing of glass, whereas fracturing has not been detected in CWF or MWF materials. This bounds the geometric surface area of the three CWF products (about $6 \mathrm{~m}^{2}$ ) or two CWF products (about $4.0 \mathrm{~m}^{2}$ ) plus two MWF products (about $0.8 \mathrm{~m}^{2}$ ) that could be placed in a HLW canister, even if a fourfold increase is conservatively imposed to account for possible cracking. The radionuclide inventories to be used for HLW glass already include contributions from the CWF and MWF and can be used to represent CWF and MWF. The number of canisters of EMT waste is so much smaller than those with HLW glass, their inclusion has negligible effect on the per-package average contents of radionuclides that affect repository performance. Therefore, the key comparison is between the degradation rate of HLW glass and those of the CWF and MWF. This is done by comparing the degradation behaviors of the CWF and MWF materials measured in various laboratory tests with the behaviors of HLW glasses that were used to develop the defense HLW glass degradation model in the same tests. The same mechanistic rate expression is used as the basis of the CWF and HLW glass degradation models. The expression is given in Eq. 1. This expression includes terms for $\mathrm{pH}$ dependence $(\eta)$, temperature dependence $\left(E_{a}\right)$, a rate coefficient $\left(k_{0}\right)$, and a reaction affinity term that is based on how far the solution is from equilibrium $(1-\mathrm{Q} / \mathrm{K})$. For borosilicate glass, the reaction affinity depends primarily on the activity of orthosilicic acid, and $\mathrm{Q}$ is the activity in solution and $\mathrm{K}$ is the solubility limit.

$$
\text { rate }=k_{0} \bullet 10^{\eta \bullet p H} \bullet \exp \left(\frac{-E_{a}}{R T}\right) \cdot\left(1-\frac{Q}{K}\right)
$$

Values of $\mathrm{k}_{0}, \eta$, and $\mathrm{E}_{\mathrm{a}}$ were measured under test conditions in which the value of the affinity term remained nearly constant. Separate parameter values were determined for dissolution in acidic and alkaline solutions. The same test method that was used to determine these parameter values for HLW glass was used to measure parameter values for CWF and for the separate sodalite and binder glass phases. Because dissolution of the binder glass will dominate CWF degradation under all repositoryrelevant conditions, the model parameters determined from tests with binder glass are used to model CWF degradation. 
In the defense HLW glass degradation model to be used in TSPA, the values of $k_{0}$ and the affinity term were combined into a single parameter $k_{E}$. The rate expression for HLW glass dissolution in TSPA is the sum of the expressions for dissolution in acidic and alkaline solutions:

$$
\text { rate }_{G}=k_{E_{-} a c i d} \bullet 10^{\eta \_a c i d} \bullet p H \cdot \exp \left(\frac{-E_{a_{-} \text {acid }}}{R T}\right)+k_{E_{-} \text {alkaline }} \bullet 10^{\eta \text { alkaline } p H} \bullet \exp \left(\frac{-E_{a_{-} \text {alkaline }}}{R T}\right)
$$

A range of values for $k_{E}$ was determined from the rates measured in various laboratory tests to represent maximum and minimum dissolution rates to represent the range of water exposure conditions that may occur. The maximum value of the rate coefficient in alkaline solutions was determined from the results of seven-day PCTs with several representative glasses. These tests were selected because the feedback effect is significant and similar to that attained prior to the formation of alteration phases that consume silica and cause an increase in the rate. The maximum value of the rate coefficient in acidic solutions was determined from the results of the Material Characterization Center-Static Leach Test Number 1 (MCC-1) tests. This is because solution feedback has not been observed to slow degradation rates in acidic solutions. The minimum values were determined from the results of unsaturated (drip) tests for acidic solutions and vapor hydration tests for alkaline solutions. The values of $k_{E}$ were calculated using the rate and $\mathrm{pH}$ measured in the test and the test temperature. The model parameters that were measured for use with HLW glasses are summarized in Table 1. Although HLW glasses are likely to degrade at rates that are much lower than those calculated using the minimum parameter value, the HLW glass degradation model is intended to provide a representative rate while accounting for uncertainty. All uncertainties are contained in the values of $k_{E}$, including uncertainties in the rate expression and model parameter values as well as uncertainties in how the disposed glass is represented in the model.

Table 1. Defense HLW Glass Degradation Model Parameters

\begin{tabular}{|l|c|c|c|c|}
\hline Range & $\eta$ & $E_{a}, \mathrm{~kJ} / \mathrm{mol}$ & $k_{E}$, Maximum, $\mathrm{g} /\left(\mathrm{m}^{2} \mathrm{~d}\right)$ & $k_{E}$, Minimum, $\mathrm{g} /\left(\mathrm{m}^{2} \mathrm{~d}\right)$ \\
\hline \multicolumn{5}{|c|}{ Measured for HLW Glass } \\
\hline Acid solutions & -0.49 & 31 & $1.15 \times 10^{7}$ & $8.41 \times 10^{3}$ \\
\hline Alkaline solutions & 0.49 & 69 & $3.47 \times 10^{4}$ & 28.2 \\
\hline \multicolumn{5}{|c|}{ Measured for CWF } \\
\hline Acid solutions & -0.36 & 72 & $1.26 \times 10^{11}$ & not determined \\
\hline Alkaline solutions & 0.64 & 83 & $1.40 \times 10^{4}$ & not determined \\
\hline
\end{tabular}

Degradation of the CWF and release of radionuclides is controlled by the dissolution of the sodalite and binder glass phases. Occluded salts are not leached from the sodalite structure, and, except for those exposed at the surface of the waste form, halite and oxide inclusion phases cannot be contacted by water until the binder glass has dissolved. When that happens, halite will dissolve immediately and the insoluble oxide phases may be released as colloids as the surrounding glass dissolves. The intrinsic dissolution rate of sodalite is slightly higher than that of the binder glass, but sodalite is much less soluble than the binder glass. In dilute solutions, sodalite dissolves as fast or faster than binder glass initially, but dissolution of sodalite essentially stops at relatively low silica concentrations when the solution becomes saturated with respect to sodalite which is about $55 \mathrm{mg} / \mathrm{L} \mathrm{H}_{4} \mathrm{SiO}_{4}$. The silica contents of tuff groundwaters from near the disposal site exceed the solubility of sodalite, and dissolution of the binder glass will dominate the CWF degradation rate and radionuclide release under all likely disposal conditions.

The binder glass is a borosilicate glass with a composition similar to that of borosilicate waste glasses. The same mechanistic model used to calculate the degradation rate of HLW glasses in TSPA calculations 
can be used to calculate the degradation rates of both the binder glass and sodalite phases of the CWF. The model used for HLW glass dissolution was adapted from the model developed for aluminosilicate minerals, such as sodalite. The mechanistic model includes terms for the effects of temperature, $\mathrm{pH}$, and dissolved silica on the rate. Tests were conducted with the individual sodalite and binder glass phases as well as with CWF to measure model parameter values. As is the case for HLW glasses, the dissolution rates have a "V-shaped" $\mathrm{pH}$ dependence in which the minimum rate occurs at near-neutral $\mathrm{pH}$ value and the rates increase as the $\mathrm{pH}$ increases or decreases. Although the dissolution mechanism in acidic solutions is not well-understood, this is probably a result of the hydrolysis of Al-O bonds being the dominant reaction in acidic solutions and hydrolysis of Si-O bonds being the dominant reaction in alkaline solutions. The dissolution rates of sodalite and the binder glass decrease as the concentration of dissolved silica increases. The efficiency of dissolved silica in slowing the dissolution rate depends on the solubility limit of the dissolving phase. Glass is thermodynamically unstable and does not have a true solubility limit. Pseudo-solubility limits are used to model glass dissolution where the solubility limit represents the concentration at which the dissolution rate becomes immeasurably low. Tests have shown the pseudo-solubility limits for sodalite and the binder glass are about 16 and $108 \mathrm{mg} \mathrm{Si} / \mathrm{L}$, respectively. The pseudo-solubility limits for HLW glasses are even higher. This means that the buildup of Si in solution will have a greater slowing effect on the dissolution of CWF than effect on the dissolution of HLW glasses.

The model parameters determined for CWF (the values measured for the binder glass are used to provide an upper bound for the CWF) can be used in the HLW glass degradation model to directly compare the degradation rates of CWF with those of HLW glass over the range of conditions likely to be modeled in TSPA. Separate parameter values were determined for application of the defense HLW glass degradation model to CWF. These are included in Table 1. Only the parameter values needed to calculate the maximum rates of CWF dissolution were determined for comparison with HLW glass. The $\mathrm{pH}$ dependencies for the CWF are lower for acidic solutions and higher in alkaline solutions than those used in the TSPA HLW glass degradation model. The temperature dependencies of the CWF degradation rate are higher than those used in the HLW degradation model for both acidic and alkaline solutions. In the HLW glass degradation model, the effect of dissolved silica is assumed to be constant and to lower the dissolution rate by about $90 \%$. Tests have shown that dissolved silica has the same slowing effect on CWF dissolution. Therefore, the results of 7-day PCTs were used to determine the maximum value of $k_{E}$ for CWF in alkaline solutions and the results of MCC-1 tests were used to determine the maximum value of $k_{E}$ for acidic solutions.

The corrosion and release of radionuclides from the MWF occurs through an oxidation-dissolution mechanism in which metallic components exposed at the surface are first oxidized and form an oxide layer and the outer surface of the layer dissolves. Formation of the oxide layer slows the release of all components to solutions. The release rates of all radionuclides were modeled to equal that of the most efficiently released constituent, which was usually U. The MWF corrosion behavior was studied using electrochemical, immersion, and vapor tests, including contact solutions containing up to 10,000 ppm dissolved $\mathrm{Cl}^{-}$. The release of constituents as a function of time is well-represented by an empirical logarithmic fit, and a model rate expression was developed to include measured dependences on the $\mathrm{pH}$, temperature, and $\mathrm{Cl}^{-}$concentration:

$$
\text { release rate }=\frac{a_{\max } \times \ln (1+b t)}{T_{e}}
$$

The parameter $T_{e}$ gives the time over which the oxide layer provides an effective diffusion barrier. This is conservatively limited to 1 year, which is the longest duration of most experiments. Values of the model parameters $a_{\max }$ and $b$ capture the dependencies on temperature $\left({ }^{\circ} \mathrm{C}\right), \mathrm{pH}$, and the $\mathrm{Cl}^{-}$concentration: 


$$
\begin{gathered}
\ln \left(b \times a_{\max }\right)=-0.10105+\left(0.015112+5.8201 \times 10^{-6} \times\left[\mathrm{Cl}^{-}\right]\right) \times \mathrm{T}-0.69848 \times p H \\
\ln a_{\max }=7.9812+\left(2.3938 \times 10^{-4} \times\left[\mathrm{Cl}^{-}\right]\right)-1.2273 \times p H
\end{gathered}
$$

The rates at $40^{\circ} \mathrm{C}$ and $90^{\circ} \mathrm{C}$ calculated with the defense HLW glass degradation model are compared with the rates calculated using the model parameters for CWF given in Table 1 and with the MWF model in Figs. 1a and 1b, respectively. These comparisons indicate that the maximum rates calculated with the defense HLW glass degradation model bound the rates for dissolution of CWF and MWF. (Note that the range of $\mathrm{pH}$ values to be modeled in TSPA is about 4.5 to 8.5 .)

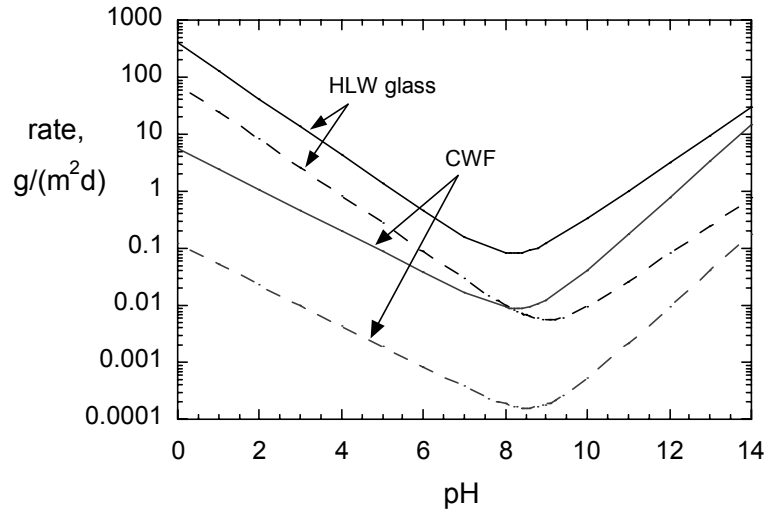

(a)

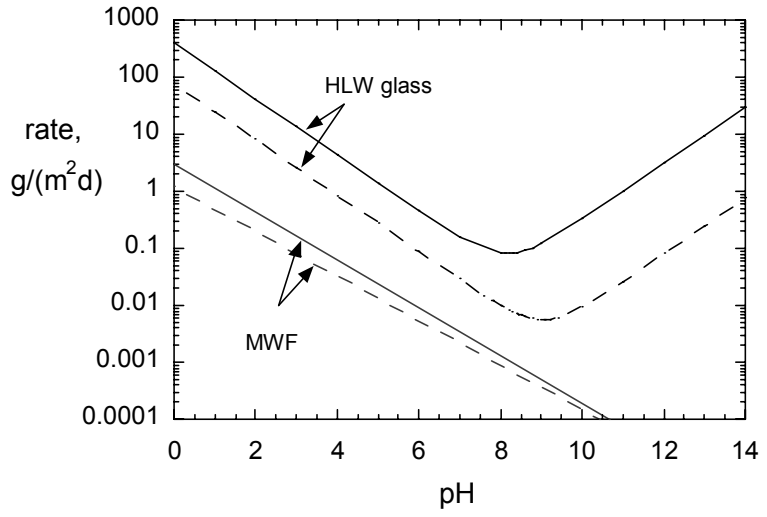

(b)

Fig. 1. Dissolution rates for (a) HLW glass and CWF and (b) HLW glass and MWF at $90^{\circ} \mathrm{C}$ (solid lines) and $40^{\circ} \mathrm{C}$ (dashed lines).

About two-thirds of the HLW glass will be disposed in 4.5-m (long) canisters and about one-third will be disposed in 3.0-m (short) canisters. The CWF and MWF will be disposed in 3.0-m (short) canisters. Since individual waste packages will not be differentiated in TSPA calculations, the geometric surface area of HLW glass was calculated to be about $7.2 \mathrm{~m}^{2}$ based on the number of long and short canisters. In addition, the surface area of HLW glass is multiplied by between 4 and 17 to account for thermal fracturing. The geometric surface areas of each CWF and MWF product will be about 2.0 and $0.38 \mathrm{~m}^{2}$, respectively, and canisters will contain either three CWF products or two CWF products and one MWF product. The CWF and MWF are not expected to fracture, so the HLW glass surface area provides a very conservative surrogate for the surface areas of the CWF and MWF.

In TSPA calculations, a distribution of degradation rates will be calculated by repeated samplings of parameter values during probabilistic simulations of various repository environments. This allows uncertainties and variabilities in the environment and models to be accounted for in the TSPA calculations. In the defense HLW glass degradation model, the variabilities and uncertainties in the amount of water contacting the glass over time, in the range of HLW glass compositions to be disposed and differences in the corrosion behaviors, etc., are all taken into account by the range of values used for $k_{E}$. The range in $k_{E}$ was based on the results of tests with various waste glass compositions under various water exposure conditions. Neither the CWF model nor the MWF model includes explicit representations of uncertainty or variability regarding either how well the models represent the either the corrosion behaviors measured in the laboratory tests or how well corrosion in the laboratory tests represent corrosion in the disposal system. In many aspects, the uncertainties regarding the CWF and MWF are the same as those regarding HLW glass. Many of the same test methods used to develop the HLW glass 
model were used to study CWF and MWF degradation and to develop those models. Although the mechanism for MWF degradation is different than those for HLW glass and CWF, comparisons of the empirical test responses provide confidence that the radionuclide release rates are adequately taken into account.

Considering the waste form durabilities, the surface areas that could be exposed in a breached waste package, and the radionuclide inventories, the release rates of radionuclides from HLW glass that are calculated using the Defense HLW Glass Degradation Model are likely to bound the radionuclide release rates from the EMT waste forms over the full range of repository conditions to be modeled. Radionuclide release from the EMT waste forms is consistent with other TSPA models, including those addressing the chemistries of seepage water in breached waste packages, the concentration limits of dissolved radionuclides, and the formation and transport of radionuclide-bearing colloids. 


\section{INTRODUCTION AND BACKGROUND}

A testing program has been in progress at Argonne National Laboratory (ANL) to show that the waste forms developed to immobilize waste streams from the electrometallurgical treatment (EMT) of spent sodium-bonded nuclear fuel are suitable for disposal in the Yucca Mountain repository. The purpose of this report is to summarize the corrosion and radionuclide release behaviors of these waste forms that have been determined based on key analytical and testing results, and the models developed to calculate the release of radionuclides. These are put into the contexts of meeting requirements established by the U.S. Department of Energy (DOE) regarding the chemical, physical, and radiological properties of highlevel radioactive waste (HLW) glass waste forms, most of which are applicable to the EMT waste forms, and addressing the impacts of the waste forms on the performance of the repository as modeled in performance assessment calculations.

The DOE inventory of sodium-bonded spent nuclear fuel includes about 3.4 metric tons of heavy metal (MTHM) driver fuel and 57 MTHM blanket fuel. About 3.1 MTHM driver fuel and 22 MTHM blanket fuel are from the ANL Experimental Breeder Reactor No. II (EBR-II) facility in Idaho, 0.3 MTHM driver fuel from the Hanford Fast Flux Test Facility (FFTF), and about 34 MTHM blanket fuel from the Detroit Edison Fermi Nuclear Power Plant facility. These fuels are not suitable for direct disposal in the repository because they contain metallic sodium, which must be managed as hazardous material controlled under the Resource Conservation and Recovery Act (RCRA). After development and demonstration of the EMT procedure at ANL (Benedict et al. 1999), DOE made the decision to treat all sodium-bonded fuel except Fermi-1 blanket fuel using this process (Federal Register, 2000). Because of its different physical characteristics, DOE decided to store the Fermi-1 fuel while alternatives are evaluated, although EMT remains an option for this waste. The waste forms developed to dispose EMT wastes are to be qualified for disposal as HLW rather than as spent fuel.

The separation and refining of uranium using EMT will generate about 9900 and $22450 \mathrm{~kg}$ of low enriched uranium (LEU) from treatment of driver and blanket spent fuels, respectively, plus high-level radioactive salt and metallic waste streams that must be immobilized for disposal. The recovered uranium will be stored until DOE decides on its future use, and the wastes will be immobilized in suitable waste forms and disposed in the high-level radioactive waste repository. This report provides (1) an overview of work conducted to develop, test, and model waste forms, (2) a summary of the corrosion behaviors of the waste forms and models to calculate their capacity to contain radionuclides, and (3) a discussion of how the test results support qualification of the waste forms for disposal in the federal high-level radioactive waste repository. A bibliography of published reports and papers that address specific issues and form part of the data base supporting qualification is also provided.

The approach taken to demonstrate the suitability of the EMT waste forms for disposal includes showing that (1) the waste forms meet the acceptance requirements that have been developed for borosilicate HLW glasses and promulgated in the DOE Waste Acceptance System Requirements Document (WASRD), and (2) the performance of the waste forms can be adequately represented by the model developed for licensing the Yucca Mountain repository. This is done using the results of tests conducted to identify the processes that control degradation of the EMT waste form matrices and the release of radionuclides, and tests conducted to develop mechanistic models for these processes. These tests support long-term modeling and establish confidence that the tests and analyses conducted as part of the waste form acceptance procedure provide a reliable measure of waste form durability. 


\section{I.A. Electrometallurgical Treatment Wastes and Waste Forms}

The electrometallurgical treatment process uses a molten salt electrolyte to separate uranium from the rest of the fuel by dissolution and electrotransport. A schematic flow diagram of the process is provided in Fig. I-1. Details of the electrorefiner design and operation are given elsewhere (Goff et al., 1996). The EBR-II driver fuels, Idaho National Technology and Engineering Center (INTEC) driver fuels, and FFTF fuels will be combined and treated in the Mk-IV electrorefiner. The EBR-II blanket fuel will be treated in the $\mathrm{Mk}-\mathrm{V}$ electrorefiner. Chopped fuel rods are placed in metal baskets and immersed in a molten LiCl$\mathrm{KCl}$ eutectic salt that is spiked with 2 mole \% actinide chlorides to initiate the refining process. The fuel is electrorefined using a steel mandrel as the cathode and the baskets as anodes. The electrorefiner is operated at about $500^{\circ} \mathrm{C}$. The anode baskets containing the chopped fuel are rotated within the electrorefiner during treatment. By careful control of the current and voltage, reactive components of the fuel are oxidized and dissolved into the salt, while uranium is reduced to the metal and accumulates on the steel mandrel. Fission products and actinides accumulate in the eutectic salt as chloride salts dissolve. The electrorefiner is run until limiting amounts of either sodium or plutonium accumulate in the salt. Sodium raises the liquidus temperature of the salt and is limited to about 6 mass \% to ensure safe operation of the electrorefiner, whereas the accumulation of plutonium is limited by criticality. When either the sodium or plutonium limit is reached, salt is removed from the electrorefiner for disposal. This is referred to as the "throwaway option" for the salt and is the current baseline plan. Potential recycling options for the salt are being studied. The uranium is recovered, diluted to low enrichment by adding depleted uranium, and then cast into ingots in a cathode processor. Small amounts of salt that are entrained with the uranium are volatilized in the cathode processor and recovered, then added to the salt waste. The cladding hulls are recovered from the anode baskets for disposal. The salt and metal wastes will be transferred from the electrorefiner to the Hot Fuel Examination Facility (HFEF) where they will be incorporated into waste forms for disposal. The waste forms will be stored at the Radioactive Scrap and Waste Facility at the Idaho National Laboratory (INL) site until shipment to the repository.

\section{I.B. The Ceramic Waste Form for Salt Wastes}

Salt wastes are composed of the $\mathrm{LiCl}-\mathrm{KCl}$ salt electrolyte used in the electrorefiner plus radionuclides that were oxidized to form chloride salts during treatment. The salt waste will contain about 8 mass $\%$ total actinides (with maximum amounts of about 5 mass $\% \mathrm{Pu}$ or 7 mass $\% \mathrm{U}$ ), with enrichments up to about $64 \%$ for driver fuel. The average radionuclide inventory for the ceramic waste form (CWF) projected to the year 2040 is given in Appendix A, Table A.3. Also given in Table A.3 is the average curie content for HLW in a short (3-m-long) canister, which is the weighted average for HLW glass, CWF, and metallic waste form (MWF). The EMT waste salts are not amenable to direct vitrification in borosilicate waste forms because borosilicate glasses have a low capacity for $\mathrm{Cl}$. Typically, only about $1 \% \mathrm{Cl}$ can be dissolved into a borosilicate glass. To overcome this limitation, a two-step process has been developed in which the waste salt is first occluded within a zeolite matrix, and then the zeolite is microencapsulated in a borosilicate glass (Battisti et al., 2002; Goff et al., 1996; Lewis et al., 1997; Simpson et al., 2001). The salt recovered from the electrorefiner will be size-reduced to facilitate occlusion in zeolite by crushing and grinding under an argon atmosphere. The crushed salt will be mechanically mixed with dried zeolite $4 \mathrm{~A}$ in a V-mixer at a salt loading of about 10 mass $\%$ then heated to about $500^{\circ} \mathrm{C}$ for 16 hours to occlude salt within the zeolite cages. The zeolite will be dried to a water content of $<1$ mass $\%$ before being mixed with the salt to facilitate salt loading. The salt-loaded zeolite (SLZ) will then be mixed with a borosilicate binder glass in a V-mixer (without heating) at a 3:1 mass ratio. The mixture will be loaded into fill cans and then the processed at about $915^{\circ} \mathrm{C}$ for about 72 hours. As the mixture is heated above about $850^{\circ} \mathrm{C}$ during the encapsulating step, the SLZ converts to the mineral sodalite, $\mathrm{Na}_{8}\left(\mathrm{AlSiO}_{4}\right)_{6} \mathrm{Cl}_{2}$, which incorporates most of the occluded salt into its structure. The glass becomes sufficiently fluid during processing to infiltrate and microencapsulate the grains of or sodalite, and the resulting material is a glass bonded sodalite material referred to as the CWF. 


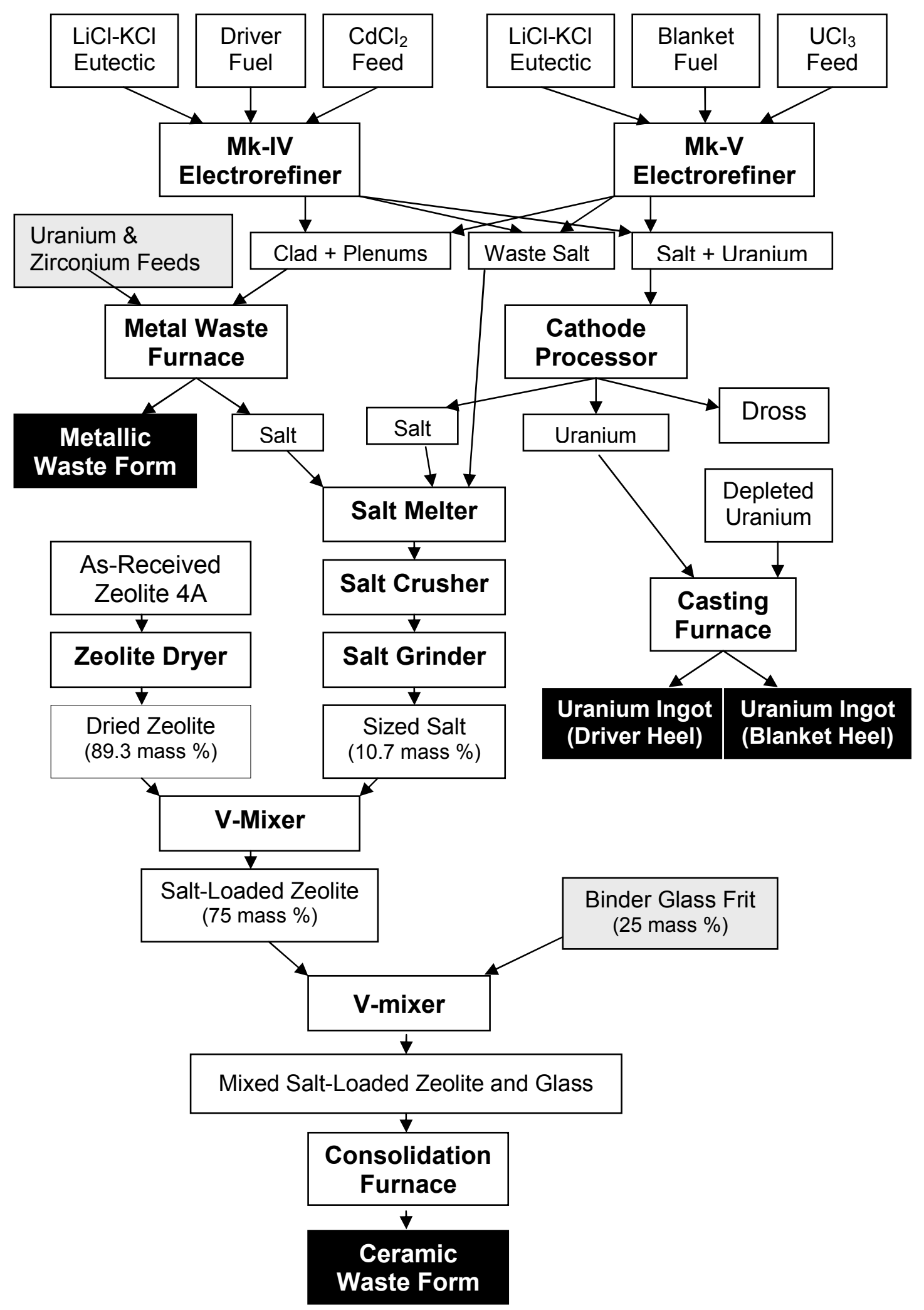

Fig. I-1. Flow Diagram of EMT Process. 
Based on the amount of salt loaded into the zeolite and the relative amounts of zeolite and glass, the CWF will contain about 8 mass \% salt. Depending on the number of driver and blanket fuel rods processed in each batch, CWF products may contain 0.2 to 0.6 mass \% low-enriched uranium (LEU) and up to about 0.5 mass \% Pu. An estimated 50,950 kg CWF will be produced. The CWF will be in the form of right cylinder up to $1 \mathrm{~m}$ tall with an outer diameter of about $0.5 \mathrm{~m}$, and two or three CWF products can be packaged in a standard (3-m-long) HLW canister. Each CWF product will weigh about $400 \mathrm{~kg}$. Figure I-2 shows a photograph of a full-scale non-radioactive CWF product. This demonstration product is shorter than planned for actual waste forms.

\section{I.C. The Metallic Waste Form for Metallic Wastes}

The metallic waste stream is composed primarily of irradiated stainless steel and Zircaloy cladding hulls, plus residual zirconium from driver fuel rods. These materials are inert to electrochemical treatment. That is, they are not oxidized and do not dissolve into the salt under the operating conditions that are used. Stainless steel cladding will account for more than $90 \%$ of the metal waste stream that will be generated from the EBR-II inventory. The average radionuclide inventory for the MWF projected to the year 2040 is given in Appendix A, Table A.3. The metallic waste stream will be immobilized by melting it in an induction furnace with added zirconium and depleted uranium at about $1600^{\circ} \mathrm{C}$ to produce an alloyed MWF. Salt carried over with the cladding hulls will be volatilized when the metal is melted, recovered, and added to the salt waste stream. Zirconium will be added to the metallic waste stream during melting to alloy radionuclides and produce waste form ingots that have consistent compositions, phase assemblages, and microstructures. The MWF will be composed of nearly equal amounts of two predominant phases interspersed on a microscopic scale: an $\mathrm{Fe}-\mathrm{Cr}-\mathrm{Ni}-\mathrm{Zr}$ mixture (which is referred to as the intermetallic phase and is similar to the Laves $\mathrm{Zr}(\mathrm{Fe}, \mathrm{Cr}, \mathrm{Ni})_{2+x}$ phase) and an iron solid solution phase. The iron solid solution may contain ferrite or a mixture of ferrite and austenite phases, depending on

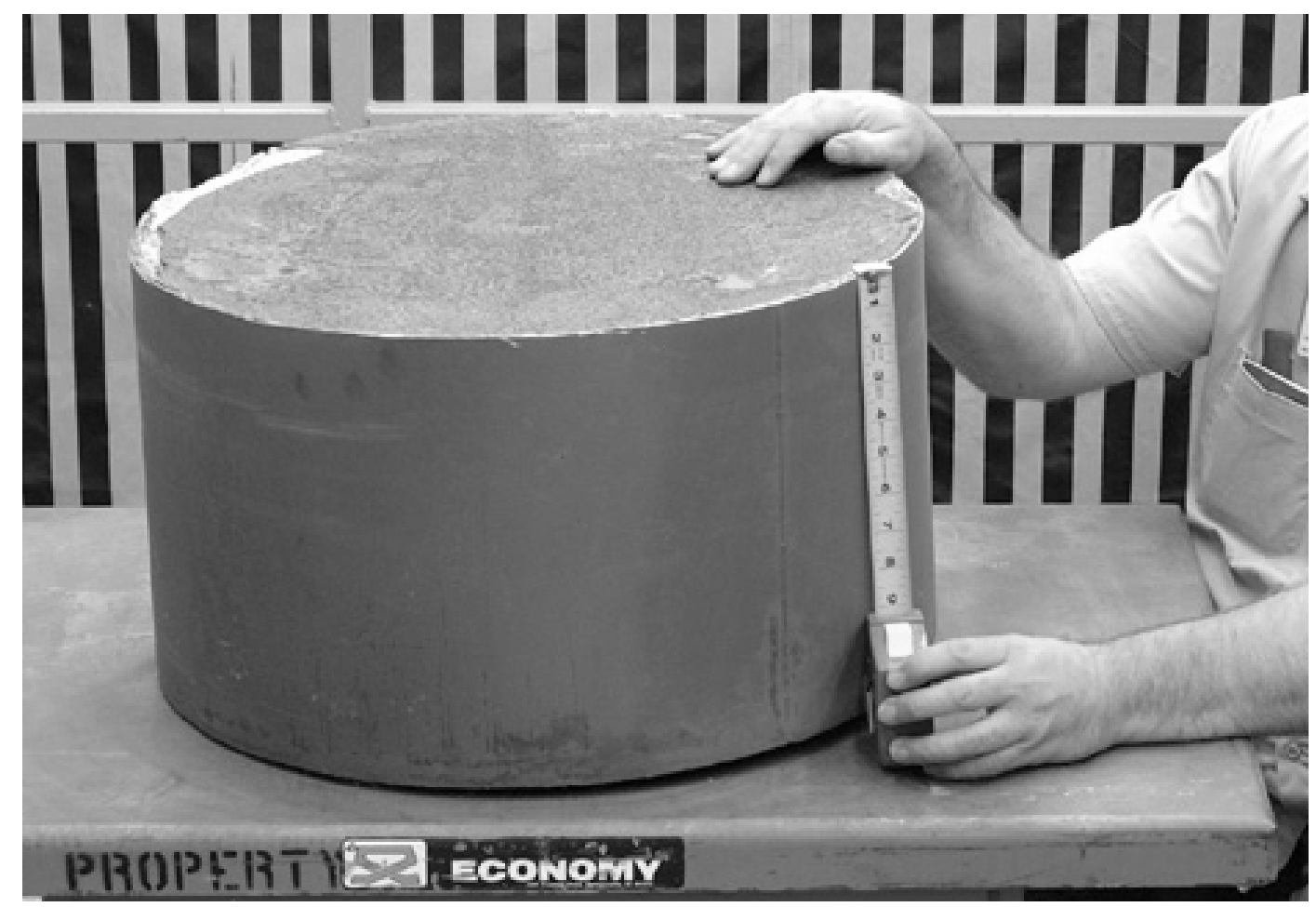

Fig. I-2. Production-Scale Non-radioactive CWF Product. 
whether Type 304 or Type 316 stainless steel cladding is being immobilized. Depleted uranium will also be added to the metallic waste stream during melting to reduce the enrichment to less than 20 mass \% ${ }^{235} \mathrm{U}$. The amounts of zirconium and uranium to be added will be determined based on knowledge of the waste stream composition and controlled to produce waste forms having consistent compositions, phase assemblages, and microstructures. The acceptable range for zirconium content is 5 to 20 mass \% with a target of 15 mass \%. The lower limit of this ranges provides enough of the intermetallic to ensure all of the radionuclides in the metallic waste stream are alloyed and the upper limit ensures that the MWF has high physical integrity. The maximum uranium content is 11 mass \% based on criticality limits, and the target uranium content is 10 mass $\%$.

The MWF products will be cast as ingots sized to fit in the same ANL canisters used to store the CWF products. The disk-shaped ingots will be about 14 to 16 inches in diameter and up to 5 inches thick, and will weigh about $12 \mathrm{~kg}$. An ingot formed in a pilot-scale melter is shown in Fig. I-3. It is currently estimated that $5850 \mathrm{~kg}$ of MWF will result from EMT treatment of sodium-bonded spent fuel. The number of MWF ingots that can be placed in a canister will be limited by the lifting capabilities at the Idaho facility. It is currently expected that one or two MWF ingots will be placed in an ANL canister between two CWF products. The ANL canister will be dimensioned to fit within a standard 3-m-long DOE HLW canister. The ANL canisters will be placed inside the standard 3-m-long DOE canisters prior to shipping to the repository.

\section{I.D. Approach to Qualifying CWF and MWF for Disposal}

Borosilicate glass is the standard waste form for high-level wastes and the available guidance for waste acceptance addresses the borosilicate HLW glasses being made with tank wastes at DOE facilities. Because they are not homogeneous borosilicate glasses, the CWF and MWF developed for EMT-treated sodium-bonded spent fuel are considered nonstandard HLW waste forms with regard to waste

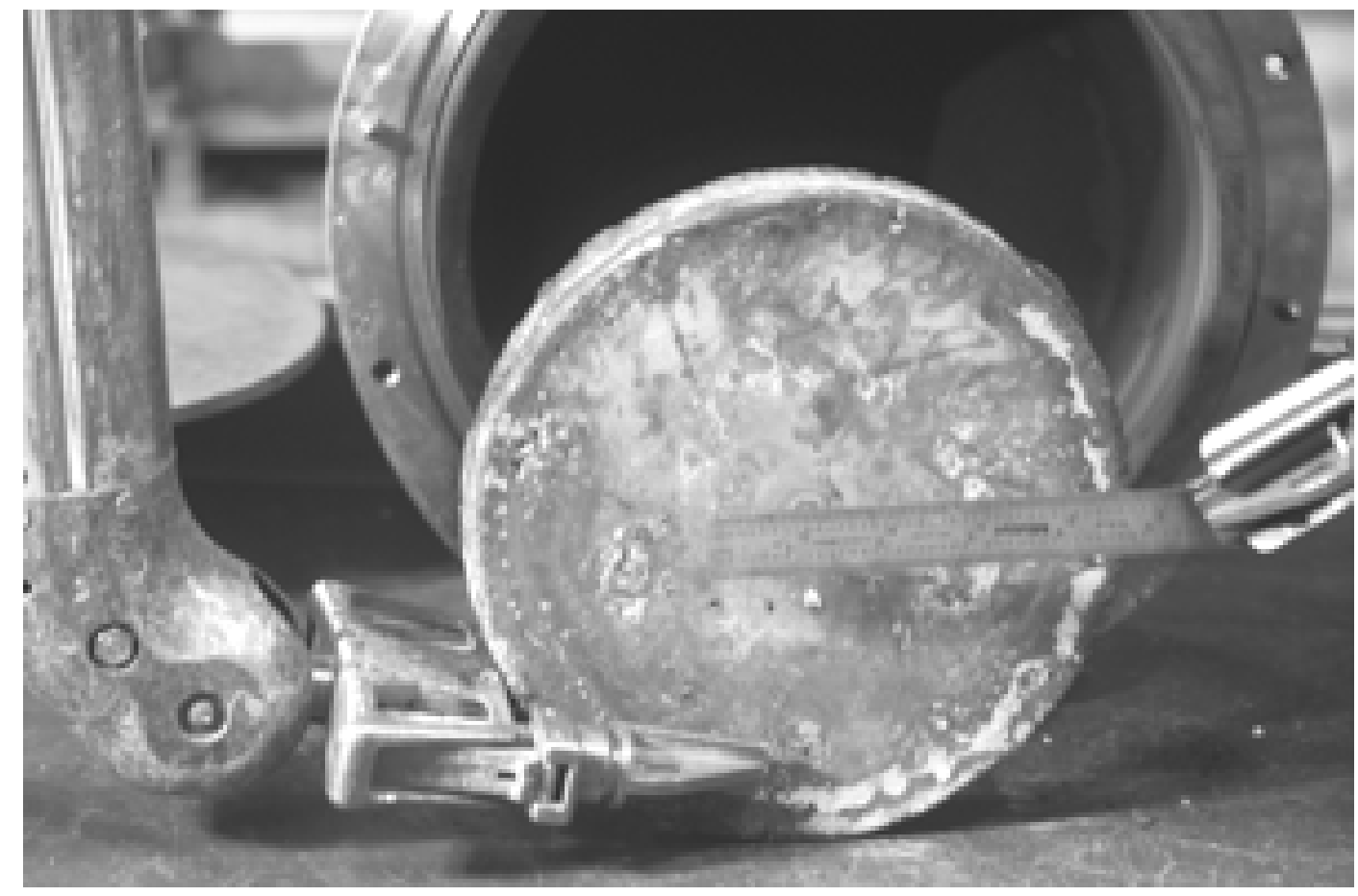

Fig. I-3. Production-Scale Fully Radioactive MWF Product. 
acceptance requirements. The approach taken to support qualification of these waste forms for disposal is to use specific requirements for HLW glass when possible and to address the underlying issues of those requirements specified for HLW glass that are not directly applicable to the CWF or MWF. Many of the key issues behind the requirements for HLW glass pertain to the performance of the engineered disposal system. Although waste forms are not subjected to specific performance requirements, the capacity of the waste forms to retain radionuclides during long-term disposal must be taken into account when calculating the integrated performance of the disposal system, since the waste form degradation provides the source terms. In the DOE total system performance assessment (TSPA) being developed to support the Yucca Mountain system license application (TSPA-LA), models have been developed to calculate the release and transport of radionuclides during degradation of commercial spent nuclear fuel, DOEmanaged spent nuclear fuel (DSNF), and borosilicate HLW glass during and beyond the regulated service life. As mentioned, the EMT waste forms are to be qualified for disposal as high-level waste rather than spent fuel, and canisters with CWF and MWF could be co-disposed with HLW glass and DSNF in waste packages. Although the CWF and MWF may not be identified specifically in the application to design and construct the Yucca Mountain repository, radionuclides from sodium-bonded spent nuclear fuel are included in the HLW inventory that will be used in TSPA calculations for the license application (see Appendix A.).

The approach taken to demonstrate the suitability of the CWF and MWF for disposal includes showing that (1) the waste forms meet the acceptance requirements that have been developed for borosilicate HLW glasses and are given in the DOE WASRD, and (2) the performance of the waste forms can be adequately represented by the model for HLW glass degradation used in TSPA-LA. This approach makes use of initial tests conducted to identify processes that controlled degradation of the waste form matrices and release of radionuclides and subsequent tests conducted to develop mechanistic models for those processes. These tests also support long-term modeling and establish confidence that the tests and analyses conducted as part of waste form acceptance provide a reliable measure of waste form durability in the repository.

Two sources have been used for guidance in qualification testing. The first is the WASRD, which "establishes waste acceptance technical requirements for the U.S. Department of Energy's (DOE) Civilian Radioactive Waste Management System (CRWMS)" and lists "acceptance criteria imposed by the CRWMS on spent nuclear fuel (SNF) and high-level waste (HLW) delivered into the CRWMS" (DOE, 2002, Section 1.1). The second is the collection of models that will be used in TSPA calculations to be conducted by Bechtel SAIC Company (BSC) for the DOE Office of Civilian Radioactive Waste Management (OCRWM). Those calculations will be used as part of the TSPA-LA to show that the combined performance of the waste forms, engineered system, and host geology will meet regulatory containment requirements. The objectives of many WASRD requirements are to assure that the physical, chemical, and radiological properties of the actual waste forms are adequately represented in the TSPA calculations used to show that the integrated repository system meets safety and regulatory requirements. The requirements in the WASRD have evolved as the design of the engineered repository and TSPA models have matured. For example, the current version of the WASRD (revision 04) is much less prescriptive than earlier versions. We interpret this to mean that acceptable waste form performance in the disposal system (as modeled in TSPA-LA) is the predominant acceptance criterion regarding the waste forms.

\section{I.E. High-Level Radioactive Waste Glass}

Borosilicate glass was selected by DOE as the waste form of choice for high-level radioactive wastes after a three-year study of seven alternative waste forms (e.g., Bernadzikowski et al., 1983). High-silica glass, glass marbles fixed in a lead matrix, carbon coated sol-gel particles, concretes, and polyphase titanatebased and aluminum-based ceramics were considered as alternatives. Acceptable chemical durability, 
compositional flexibility, good mechanical strength, ease of remote processing, amenability to continuous processing, and industrial experience in the electrical manufacture of glass were important attributes that contributed to the selection of the borosilicate glass waste form product and process. Other beneficial attributes included the ability to test, model, and confidently predict how changes in chemical composition affect properties important to processing and chemical durability, and the ability to predict the effect of thermal history on devitrification products and composition of the residual glass.

Much has been learned regarding the production of borosilicate waste glasses and their chemical and radiological properties. Process models have been developed to formulate processable and durable compositions for a wide range of waste stream compositions (e.g., Jantzen et al., 1994), and durability models have been developed to calculate dissolution rates for long-term disposal under different conditions (e.g., Grambow, 1985). 


\section{WASTE ACCEPTANCE SYSTEM REQUIREMENTS DOCUMENT}

The OCRWM has provided the WASRD (DOE, 2002) to addresses the acceptance of commercial spent nuclear fuel (CSNF), DSNF, naval spent nuclear fuel, and HLW for disposal in the planned Yucca Mountain repository. Requirements are described in that document for the waste form materials, such as phase composition, radionuclide content, product consistency, and chemical durability; for the canistered waste forms, such as criticality and thermal outputs; and for the canisters themselves, such as material, dimensions, maximum weight, labeling, handling fixtures, required levels of surface decontamination, etc. The WASRD addresses interface requirements between the DOE offices that are responsible for the production, transport, and disposal of HLW waste. Because EMT waste forms are to be qualified as HLW rather than spent fuel, the requirements for HLW glass listed in the WASRD have been used as guidance for qualifying the CWF and MWF. In the following section, several key issues regarding qualification of HLW glasses are discussed first as they pertain to HLW glass, and then how they are being addressed for the CWF and MWF.

The responsibilities of the waste-form producers include characterizing and packaging waste for shipment to the CRWMS and preparing documents needed to verify compliance with the CRWMS wasteacceptance criteria. The general approach for HLW glasses made by the DOE Office of Environmental Management is summarized in the Waste Acceptance Product Specifications (WAPS) for Vitrified HighLevel Waste Forms (DOE, 1996). Details regarding how the information and documentation requirements will be met by a specific producer (e.g., identifying which test methods will be used to meet requirements and information needs) are to be provided in a Waste Form Compliance Plan (WCP). Evidence that waste forms comply with the requirements are to be provided in Waste Form Qualification Reports. Similar documents are being developed for the EMT waste forms (O'Holleran et al., 1999a, O'Holleran et al., 1999b). Insights taken from the HLW glass WAPS are used in developing the qualification programs for the EMT waste forms.

The general requirements for HLW waste forms include compliance with the Nuclear Waste Policy Act of 1982 (as amended) and with hazardous waste regulations established by the U.S. Environmental Protection Agency (EPA); HLW that is regulated as hazardous waste will not be accepted for disposal. All HLW must be sealed in disposable canisters. These general requirements are assumed to be immutable and must be met by all waste forms. Additional safeguard and security requirements may be added in the future, and will need to be addressed for the EMT waste forms.

The standard vitrified waste form is identified to be a borosilicate glass sealed inside an austenitic stainless steel canister. The waste-form producer must demonstrate control of waste-form production by comparing production samples or process-control information to the Environmental Assessment (EA) benchmark glass using the Product Consistency Test (PCT) or equivalent. The PCT has been standardized as the American Society for Testing and Materials (ASTM) International standard test method C1285-02 (ASTM, 2005a). The C1285 standard includes two methods: PCT Method A was developed specifically to monitor waste glass consistency and PCT Method B was developed for research purposes. The use of Method A is implied in the WASRD. The ASTM standard test method C1285 was modified in 2002 to include testing of glass ceramics such as the CWF within its scope.

Thirteen technical information needs are listed in WASRD Section 5.4.1, some of which have not yet been defined. These needs are not acceptance requirements and do not impose ranges or limits on the waste forms. Rather, they identify information regarding the waste forms that is needed for future design decisions, modeling, and analyses. Some of the information needs had been listed as requirements in earlier versions of the WASRD. Some of the needs are addressed here because they were the bases for some of the research and development work done to support qualification of the EMT waste forms. Key 
technical information needs relevant to qualifying non-standard waste forms include the following (the numbers are those used in the WASRD):

(1) the chemical composition and phase composition projections for vitrified HLW,

(2) estimates of the total facility inventory and individual canister inventory of radionuclides,

(3) the Time-Temperature-Transformation (TTT) diagrams for the vitrified HLW and identification of temperature limits (if any) necessary to preserve the properties of the vitrified HLW,

(4) identification of the method to be used to assure consistency of production batches, and

(10) information required to assess canister criticality, both pre and post closure (WASRD Section 5.4.1).

In addition, Section 5.4.2 of the WASRD states that

...the waste form producer must report annually on the production of HLW waste forms, projections of remaining production, and any production trends that may influence the properties of the canistered waste forms relative to the information provided in Section 5.4.1. Annual reports must also identify non-conforming waste forms and the status of actions to address the non-conforming conditions.

The requirements in the WASRD and WAPS for vitrified high-level waste forms are assumed to be responsive to the range of waste forms to be submitted for disposal and the results of repository-system performance-assessment calculations rather than being prescriptive. That is, the capability of the disposal system to meet safety and regulatory requirements will determine the ultimate acceptance criteria. It is assumed that the OCRWM requirements documented in the WASRD will be flexible enough to accommodate advances in technologies that provide cost benefit and reliability to the DOE offices responsible for waste-form production. For example, increasing the waste loading in HLW glass will provide cost savings by reducing the number of canisters, although the waste glasses will likely contain more inclusions. Likewise, flexibility is expected for waste streams that are not amenable to direct vitrification, such as the EMT waste forms. It is assumed that the requirements in the WASRD addressing the durability and phase stability of vitrified HLW (WASRD requirement 4.8.1; WAPS requirements 1.1, 1.3, and 1.4) and the maximum weight of filled HLW canisters (WASRD requirement 4.8.4) can be modified so that waste forms that are shown not to impact the capability of the disposal system to meet safety and regulatory requirements are accepted for disposal. For example, "the mean concentrations of lithium, sodium, and boron in the leachate" of a PCT solution may not be relevant to the durability or consistency of some waste forms. It is not expected that requirements addressing criticality (WASRD requirement 4.8.12; WAPS requirement 3.10) and hazardous waste (WAPS requirement 1.5) will be modified regardless of waste-form performance.

\section{II.A Compliant Waste Forms}

The acceptance requirements in the WASRD and WAPS for vitrified high-level waste forms are intended to provide confidence that the chemical, physical, and radiological properties of vitrified waste forms supplied for disposal can be taken into account when designing and evaluating the performance of the engineered disposal system. The initial versions of both the WASRD and WAPS for vitrified high-level waste forms were issued before the disposal system was designed or evaluated. Those requirements can now be compared with the current design of the disposal system. The long-term performance of the engineered disposal system is being calculated using a total system approach in which the combined performance of natural and engineered barriers is evaluated. These barriers include, for example, the durability of the waste form, low radionuclide solubility limits, the presence of a robust corrosionresistant waste package, the small amounts of water available in the hydrologically unsaturated geologic environment, the restricted groundwater transport, and the sorptive properties of the host rock. Submodels 
have been developed to determine the efficiency of the integrated effects of all barriers on containment, although separate performance requirements are not imposed on individual barriers, including waste-form durability. The submodels will be used in TSPA calculations to support the license application and demonstrate that the Yucca Mountain disposal system meets safety and regulatory requirements.

\section{II.B. Hazardous Waste}

Listed and characteristic hazardous components in the waste form are regulated under RCRA. Analysis of the waste will determine if it is characteristically hazardous waste. The toxicity characteristic leaching procedure (TCLP) is used to demonstrate that the waste form is not characteristically hazardous. The WASRD states:

The CRWMS shall only accept HLW and/or SNF that is not subject to regulation as hazardous waste under the Resource Conservation and Recovery Act (RCRA) Subtitle C for disposal in the first geologic repository licensed by NRC under the Nuclear Waste Policy Act (NWPA). Prior to acceptance for disposal, Producers/Custodians must determine and document that RCRA-regulated wastes are not present, and develop appropriate data to assure relevant state and/or U.S. Environmental Protection Agency (EPA) RCRA requirements are addressed. WASRD section 4.2.2

If the waste is characteristically hazardous, either the results of TCLP must be compared with universal treatment standard (UTS) values to show the waste form is not characteristically hazardous or the waste form must be excluded based on treatment by the best-demonstrated available technology (BDAT), which in the case of HLW is vitrification.

\section{II.C. Chemical Composition}

The concentrations of all elements present at greater than 0.5 mass $\%$ in the waste form are to be reported on an oxide basis. Several interlaboratory studies have been conducted to determine the precision and accuracy with which glass compositions can be measured (e.g., Smith and Marschman, 1994; Ebert and Wolf, 2000). Those studies did not include glasses with radionuclides.

\section{II.D. Crystalline Phase Projection and Phase Stability}

The WASRD does not place a limit on the crystal content of a waste form. Information regarding crystalline phase projection and phase stability is required in Section 5.4.1 of the WASRD. The WAPS Section 1.4 specifies that the waste-form producer will provide data on the glass transition temperature $\left(T_{g}\right)$ and TTT diagrams and will certify that the waste-form temperature did not exceed $400^{\circ} \mathrm{C}$ after initial cool-down (this was a requirement in earlier versions of the WASRD). It is assumed that the assemblage of crystalline phases in HLW glass will be determined from the feed composition based on correlations between composition and devitrification products that are established before operation. A standardized method to generate TTT diagrams is being developed in ASTM International subcommittee C26.13 for Repository Waste Acceptance. However, a standardized method is not currently available and may not be available before license application. The impact of this requirement on qualification of the alternative waste forms is expected to depend on the varieties of crystalline phases that are formed and the sensitivity of their formation to the feed composition.

\section{II.E. Product Consistency}

The PCT method was developed specifically to monitor the consistency of vitrified borosilicate waste glasses and show that the chemical durabilities of all glass waste forms have been consistently controlled. 
The PCT procedure has been standardized as ASTM International test method C1285, and its use is specified in the WAPS for vitrified high-level waste forms and WASRD (although the WASRD provides the option to use of an equivalent method). Compliance with the consistency requirement is based on comparison of the test response with the response of the environmental assessment benchmark glass (EA glass) for the concentrations of lithium, sodium, and boron. The compliance of HLW glass will be demonstrated by process control and using an established relationship between the composition of a glass and its PCT response. This approach is being successfully used for waste glasses produced at the defense waste processing facility (DWPF) currently and will likely also be employed at Hanford.

The suitability of the PCT to monitor the consistency of an alternative waste form must be demonstrated and the elements used to measure the extent of degradation need to be identified. It is recognized in the ASTM International standard C1285 that the concentrations of lithium, sodium, and boron, which are used for borosilicate glasses, may not represent the durability of all waste glasses. The standard states:

[The] elements to be analyzed in the leachate are those that represent the maximum dissolution of the glassy waste form. For example, elements that are not sequestered in precipitates that participate in surface alteration reactions and are also not solubility limited are good indicators of waste form durability. In the case of a multi-phase glass ceramic waste form it may be important to analyze for elements from each significant phase present. Extensive testing of any glass or glass ceramic waste form must be performed to determine what these elements are.

In addition, it must be established that crushing and sieving a multi-phase alternative waste form provides a test sample that is representative of the bulk material, that the PCT response is sensitive to variations in the waste form that may occur (e.g., differences in composition and phase assemblages), and the PCT can be conducted as precisely with the alternative waste form as with borosilicate glass. If the PCT is not appropriate to monitor the consistency or measure the degradation rate of an alternative waste form, another method must be developed to demonstrate that the alternative waste form is compliant with the WASRD requirement and TSPA-LA.

The primary role of the EA glass is to benchmark the highest acceptable PCT response for waste glasses and, therefore, the lowest acceptable waste glass durability. It is reasonable to question whether the EA glass provides an appropriate benchmark for alternative waste form such as the CWF. Also, the concentrations of boron, lithium, or sodium may not provide an accurate measure of the maximum degradation rate of an alternative waste form. In that case, the fractional release of the fastest released element(s) representing the phase(s) containing radionuclides can be compare with the fractional releases of $\mathrm{B}, \mathrm{Li}$, and $\mathrm{Na}$ from the EA glass. In other words, the relative dissolution rates of the waste form and EA glass can be compared directly even though comparison of the releases of specific elements may not be meaningful.

The PCT has been shown to be applicable to the CWF and can be used to track the relative amounts of salt and glass in the CWF as well as its chemical durability (see Section IV.D). The response in PCTs conducted with CWF materials is dominated by dissolution of the binder glass, which also controls the durability under disposal conditions. An alternative method is required to track the consistency of the MWF. The gross zirconium concentration has been shown to provide an effective means of monitoring MWF consistency. This is because the zirconium content determines the amount of the intermetallic phase that is formed.

\section{II.F. Radionuclide Inventory}

Both the total facility inventory and the individual canister inventories are to be estimated for radionuclides either with half-lives greater than 10 years or that will ever be present at greater than $0.05 \%$ 
of the total radioactive inventory. The radionuclide content of HLW glass waste forms is determined by analyzing the waste feed prior to vitrification. The radionuclide inventories in the EMT waste forms will likewise be determined by analysis of the waste streams prior to immobilization and by process control.

\section{II.G. Time-Temperature-Transformation Diagrams}

The TTT diagrams document the conditions favorable for devitrification to occur in HLW glasses. The WASRD requires the upper temperature at which the properties of the waste form are preserved to be identified, since the performance of HLW glasses may be compromised by devitrification. The crystals themselves are not expected to affect the glass durability, rather, changes in the glass composition may affect its durability. The WAPS for vitrified high-level waste forms specifies that TTT diagrams will be provided that identify "the duration of exposure at any temperature that causes significant changes in either the phase structure or the phase composition" (WAPS Section 1.4.1). This is intended to provide confidence that the consistency of the waste form has not changed due to deviations from the target phase composition. This information is important during processing to avoid the possible formation of crystals in the glassmelt as the melter idles during processing upsets or repairs. (This is an issue with melter operation, but not necessarily with glass durability.) It will also indicate if crystallization (devitrification) will occur while the glass cools in the canister.

The CWF is a composite that contains about 75 mass $\%$ crystalline components and 25 mass $\%$ binder glass. The issue with the CWF is whether off-normal thermal histories during production will impact the phase assemblage and its performance, in particular its chemical durability. Thermal history may affect which phases form, the relative amounts of each phase, and the PCT response of the CWF. The MWF is alloyed at about $1600^{\circ} \mathrm{C}$. Thermal history will not affect the performance of the MWF.

\section{II.H. Canister Criticality}

The WASRD requires the calculated value of the effective neutron multiplication factor $\mathrm{k}_{\text {eff }}$ for an individual canister to be 0.95 or less at the time of acceptance (WASRD Section 4.8.12). The WAPS for vitrified high-level waste forms requires $k_{\text {eff }}$ to be less than 0.90 (WAPS Section 3.10). For the EMT waste forms, this will be calculated based on the radionuclide inventories in the CWF and MWF.

\section{II.I. Nonconforming Waste Forms}

The producer is required to report the status of waste-form production to OCRWM annually, including the identification of nonconforming waste forms and actions to address nonconforming conditions (WASRD Section 5.4.2). This includes deviations from the WCP as well as from the WASRD requirements. It is assumed that, like nonconforming HLW glass, nonconforming CWF or MWF products will not be reworked and that either additional containment steps or special dispensation for acceptance will be required, depending on nature of the nonconformance. 


\section{TOTAL SYSTEM PERFORMANCE ASSESSMENT FOR THE YUCCA MOUNTAIN REPOSITORY}

The capacity of the integrated Yucca Mountain repository system to meet safety and regulatory standards over the regulatory period (and beyond) is being evaluated using TSPA calculations. The repository is being designed to provide a multiple barriers against radionuclide release and uses a defense-in-depth approach to ensure safety. The approach utilizes the natural transport limitations of the hydrologically unsaturated Yucca Mountain environment, engineered barriers to mitigate the contact of waste by groundwater, low chemical solubility limits for most radionuclides, and the intrinsic durabilities of the waste forms themselves. The TSPA calculations take into consideration the combined effects of these barriers in mitigating radionuclide release and transport. Previous TSPA calculations have been conducted for use in the Yucca Mountain site Viability Assessment and Site Recommendation. The DOE is currently developing the TSPA model for use in the license application (TSPA-LA). A key purpose of this report is to describe the relationship between the EMT waste forms and that assessment.

Separate models have been developed by DOE for degradation and subsequent radionuclide release from commercial spent nuclear fuel (SNF), DOE SNF, and borosilicate HLW glass. For qualification of the EMT waste forms, the primary issue to be addressed is the durability of the waste forms relative to that of HLW glass. Our recommended approach for taking into account the release of radionuclides from the EMT waste forms in TSPA is to use the HLW glass degradation model as a surrogate for both CWF and MWF degradation. The release rate of radionuclides from HLW glass is calculated as the product of three terms:

$$
{\text { release } \text { rate }_{R N}=\text { rate }_{G} \times S \times f(R N)}
$$

where rate $_{G}$ is the glass degradation rate, $S$ is the glass surface area, and $f(R N)$ is the mass fraction of radionuclides in the glass (i.e., the radionuclide inventory). Corresponding terms can be defined for radionuclide release from the CWF and MWF. Since the projected radionuclide inventories of the CWF and MWF are already included in the average HLW glass inventory (see Appendix A), and that inventory can be used for all three waste forms, the suitability of the HLW glass degradation model as a surrogate for CWF and MWF can be evaluated based on comparisons of the waste form degradation rates and surface areas.

Sensitivity calculations conducted to prioritize the components of TSPA-LA indicate that radionuclide release due to degradation of HLW glasses has only a minor impact on total dose, and HLW glass degradation does not contribute significantly to the post-closure safety strategy of the Yucca Mountain repository. Therefore, flexibility is expected regarding the acceptance of nonstandard HLW waste forms, although this is a decision that must be made by OCRWM. Several issues regarding the compliance of alternative waste forms, based on consideration of how HLW glass degradation is modeled in TSPA-LA, are listed below.

- The fractional release rates of radionuclides are calculated in TSPA-LA as the product of the glass degradation rate, the exposed glass surface area, and the radionuclide inventory in the glass. Differences in the values of these terms used for HLW glass and for alternative waste forms must be addressed.

- The TSPA-LA glass degradation model calculates the dissolution rate of a single, homogeneous glass phase. All radionuclides are contained in the glass phase, and the release rate of every radionuclide is the same as the glass degradation rate. For some alternative waste forms, the release of radionuclides from more than one phase must be addressed. This may require 
identifying the release of particular radionuclides with the degradation rates of specific phases, then determining a single rate to represent release from the waste form.

- The glass degradation rate is calculated in the TSPA glass degradation model as a function of $\mathrm{pH}$ and temperature. The rate is scaled by a dissolution rate coefficient having a range of possible values determined from rates measured in laboratory tests under different water exposure conditions. The TSPA calculations will be representative of (or will provide an upper bound to) a non-standard waste form if the degradation rate of the non-standard waste form is less than the maximum rate calculated by the TSPA model.

- The exposed surface area of HLW glass is calculated by multiplying the geometric surface area of the glass (based on canister dimensions and fill height) by an exposure factor. A range of values from 4 to 17 is used for the exposure factor to take into account uncertainties in the extent of cracking, the accessibility of water to tight cracks, and the lower glass dissolution rates in tight cracks compared with free surfaces. Cracking in alternative waste forms that exceeds a factor of 12 times the geometric surface area must be addressed.

- An average inventory for all HLW is assigned to all waste glasses in TSPA-LA calculations. The current glass inventory used for TSPA-LA calculations includes 44,000 metric tons (MT) from Hanford, 11,600 MT from DWPF, 630 MT from the West Valley Demonstration Project (WVDP), and 2013 MT from INL. Waste from Hanford, DWPF, and WVDP will be vitrified as HLW glasses. The inventory for INL waste includes calcine, which may be directly disposed, sodium-bearing waste (SBW), which may be vitrified, and sodium-bonded nuclear fuel, which will be subjected to EMT and immobilized as CWF and MWF.

\section{III.A. HLW Glass Degradation Model in TSPA}

The fractional release rate due to HLW glass degradation is calculated as the product of three terms: the HLW glass degradation rate, the exposed surface area, and the radionuclide inventory. These terms are discussed below.

\section{III.A.1. HLW Glass Degradation Rate}

In the glass degradation model developed for TSPA calculations (BSC, 2004), the glass-degradation rate is used to define the release rates of radionuclides because radionuclides cannot be released from the glass any faster than the glass dissolves. In the case of radionuclides that are chemically bonded within the glass network, those bonds must be contacted by water and hydrolyzed before the radionuclide can be transported from the waste glass. Even radionuclides that are not tightly bonded in the glass are not released until the glass dissolves to allow water to contact them because they cannot diffuse through the glass. For example, ${ }^{99} \mathrm{Tc}$ is present in HLW glass predominantly as either the pertechnetate anion or in a metallic phase, neither of which is strongly bonded within the glass matrix. The glass-degradation rate is calculated as the product of solution $\mathrm{pH}$ and temperature terms and a rate coefficient, and has the algebraic form given in Eq. III-2.

$$
\text { rate }_{G}=k_{E} \bullet 10^{\eta \bullet p H} \bullet \exp \left(\frac{-E_{a}}{R T}\right)
$$

where $k_{E}$ is the rate coefficient, $\eta$ is the $\mathrm{pH}$ dependence coefficient, and $E_{a}$ is the temperature dependence coefficient. Degradation of borosilicate waste glasses has a "V-shaped" $\mathrm{pH}$ dependence, where the rates 
are minimal at near-neutral solutions and increase as the $\mathrm{pH}$ increases or decreases. Separate coefficients values are used to calculate the rates for dissolution in acidic and alkaline solutions. In the TSPA model, the sum of the rates calculated with the expressions for acidic and alkaline solutions will be used. One or the other term will dominate except for $\mathrm{pH}$ values where the expressions for the acidic and alkaline legs are nearly equal.

Single values of the $\mathrm{pH}$ and temperature coefficients ( $\eta$ and $E_{a}$, respectively) were determined experimentally for dissolution in acidic and alkaline solutions. Ranges of rate coefficient values $\left(k_{E}\right)$ were selected to account for the ranges of glass compositions (and durabilities) from different producers and variations in the water-contact mode in the disposal system over time. The maximum values of the rate coefficients were determined from dissolution rates of glasses immersed in water and the minimum values of the rate coefficients were determined from dissolution rates of glasses contacted by water vapor (for alkaline solutions) or dripping water (for acidic solutions). The maximum and minimum glass degradation rates used in the TSPA model are calculated as the sums of the expressions for dissolution in acidic and alkaline solutions using Eqs. III-3a and III-3b, respectively:

$$
\begin{aligned}
& \text { rate }_{G_{-} \max }=1.15 \times 10^{7} \bullet 10^{-0.49 \bullet p H} \bullet \exp \left(\frac{-31}{R T}\right)+3.47 \times 10^{4} \cdot 10^{0.49 \bullet p H} \bullet \exp \left(\frac{-69}{R T}\right) \\
& \text { rate }_{G_{-} \min }=8.41 \times 10^{3} \bullet 10^{-0.49 \bullet p H} \bullet \exp \left(\frac{-31}{R T}\right)+28.2 \cdot 10^{0.49 \bullet p H} \bullet \exp \left(\frac{-69}{R T}\right)
\end{aligned}
$$

where rate $_{G_{-} \max }$ and rate $_{G_{-} \min }$ are the maximum and minimum rates, the values of $k_{E}$ have units $\mathrm{g} /\left(\mathrm{m}^{2} \bullet \mathrm{d}\right)$, the $\mathrm{pH}$ is measured at room temperature, $R$ is the ideal gas constant, and $T$ is temperature in Kelvin. In TSPA calculations, values of $k_{E}$ will be selected from the ranges bounded by maximum and minimum values of $1.15 \times 10^{7}$ and $8.41 \times 10^{3} \mathrm{~g} /\left(\mathrm{m}^{2} \bullet \mathrm{d}\right)$ for acidic solutions and $8.41 \times 10^{3}$ and $28.2 \mathrm{~g} /\left(\mathrm{m}^{2} \bullet \mathrm{d}\right)$ for alkaline solutions. Both ranges of $k_{E}$ are assigned triangular distributions with the minimum values also being the most probable values.

\section{III.A.2. HLW Glass Surface Area}

The glass surface area is calculated by multiplying the geometric surface area by an exposure factor that accounts for thermal and impact cracking, the accessibility of water to fractures, and lower glass degradation rates within tight cracks. Approximately two-thirds of the disposed HLW glass canisters will be 4.5 -m-long canisters and one-third will be $3-\mathrm{m}$-short canisters. The dimensions of the HLW glass log were taken to be the weighted average of the geometric surface areas of logs in long canisters from Hanford and short canisters from DWPF and WVDP. (Canisters with INEEL calcine, immobilized SBW, CWF, or MWF were not included in the calculation of the dimensions or mass of an average glass log.) The weighted average geometric surface area of the glass $\log$ is $7.2 \mathrm{~m}^{2}$. This value was divided by the weighted average mass to obtain a specific surface area $\left(\mathrm{m}^{2} / \mathrm{kg}\right)$ that is used to track the available surface area as the glass corrodes. The specific surface area used in the HLW glass degradation model is $2.70 \times 10^{-3} \mathrm{~m}^{2} / \mathrm{kg}$. The surface area that remains as the glass dissolves during the simulation is calculated as the product of the remaining mass, the specific surface area, and the exposure factor. The mass of unreacted glass that remains is calculated by subtracting the sum of the masses dissolved in all previous time steps $\left(\Sigma \mathrm{M}_{\mathrm{t}}\right)$ from the initial mass $(2,710 \mathrm{~kg})$. The geometric surface area is first calculated as the product of the specific surface area and the mass, and then multiplied by an exposure factor. The exposure factor is selected from a triangular distribution of values between a minimum and most probably value of 4 and a maximum value of 17 . The equation used to calculate the available glass surface area is 


$$
S=f_{\text {exposure }} \bullet 2.70 \times 10^{-3} \mathrm{~m}^{2} / \mathrm{kg} \bullet\left(2710 \mathrm{~kg}-\Sigma M_{t} \mathrm{~kg}\right)
$$

This equation allows the loss of surface area as HLW glass dissolves to be taken into account in TSPA.

\section{III.A.3. HLW Radionuclide Inventory}

The average inventory of HLW glasses to be used in TSPA-LA calculations is given in the Initial Radionuclide Inventories report (BSC, 2003). In this report, the average concentrations of the radionuclides having the greatest impact on the TSPA-LA dose calculations in waste forms from Hanford, DWPF, WVDP, and INEEL are weighted by the number of canisters expected from each site. The average inventory assigned to HLW glass in TSPA-LA is given in Table III-1. The number of canisters from each site that were used to determine the average inventory is given in Table III- 2 . Note that Table III-2 includes CWF and MWF, plus canisters of HLW from INTEC (see Appendix A). The radionuclide inventories in waste forms received from different sites will not be distinguished in TSPA calculations. The uncertainty in the inventory is represented by the uncertainty in the waste loadings at different sites, which is expressed in the number of canisters. Uncertainty multipliers of $0.70,1$, and 1.5 are applied to the values in Table III-1 to define the minimum, most likely, and maximum masses of radionuclides per canister, respectively.

Waste will be placed in various waste packages for disposal; CSNF and naval fuel will be disposed in separate packages. The HLW glass and DSNF will be placed in co-disposal packages (CDSPs). The package configurations are given in Table III-3, which was presented in the Initial Radionuclide Inventories report (BSC, 2003) to accommodate all DSNF within 3412 CDSPs. It was recognized in the inventory model that the total number of HLW canisters in Table III-3 is not consistent with the numbers given in Table III-2, but Table III-3 puts into perspective the fraction of waste packages that will contain HLW. The EMT waste forms are expected to be packaged with other HLW waste in short canisters, and to be disposed with short canisters of DSNF in configuration 6. The 3412 CDSPs that contain waste glass and DSNF are less than half of the 7472 packages containing CSNF. The repository performance will be dominated by CSNF due to the greater number of packages and greater amounts of most radionuclides in CSNF.

Table III-1. Average Radionuclide Inventory in HLW per Canister ${ }^{\mathrm{a}}$

\begin{tabular}{|c|c|c|c|c|c|}
\hline Nuclide & $\begin{array}{c}\text { Grams per } \\
\text { Waste Package }\end{array}$ & Nuclide & $\begin{array}{c}\text { Grams per } \\
\text { Waste Package }\end{array}$ & Nuclide & $\begin{array}{c}\text { Grams per } \\
\text { Waste Package }\end{array}$ \\
\hline Ac-227 & $2.07 \mathrm{E}-04$ & $\mathrm{~Pb}-210$ & $3.69 \mathrm{E}-10$ & Tc-99 & $1.10 \mathrm{E}+03$ \\
\hline Am-241 & $4.07 E+01$ & Pu-238 & $4.24 \mathrm{E}+01$ & Th-229 & 3.58E-03 \\
\hline Am-243 & $6.24 \mathrm{E}-01$ & Pu-239 & $6.06 \mathrm{E}+02$ & Th-230 & 8.81E-04 \\
\hline C-14 & 0 & $\mathrm{Pu}-240$ & $5.01 \mathrm{E}+01$ & Th-232 & $3.23 E+04$ \\
\hline Cl-36 & 0 & Pu-241 & $1.32 \mathrm{E}+00$ & U-232 & $4.43 \mathrm{E}-04$ \\
\hline $\mathrm{Cm}-245$ & 5.89E-02 & $\mathrm{Pu}-242$ & $4.22 \mathrm{E}+00$ & U-233 & $2.11 \mathrm{E}+01$ \\
\hline Cs-135 & $138 E+02$ & Ra-226 & $2.63 \mathrm{E}-05$ & U-234 & $2.53 E+01$ \\
\hline Cs-137 & $3.28 \mathrm{E}+02$ & Ra-228 & $6.51 \mathrm{E}-06$ & U-235 & $1.53 \mathrm{E}+03$ \\
\hline $\mathrm{I}-129$ & $7.89 \mathrm{E}+01$ & Se-79 & $7.61 \mathrm{E}+00$ & U-236 & $6.50 \mathrm{E}+01$ \\
\hline $\mathrm{Np}-237$ & $1.08 \mathrm{E}+02$ & $\mathrm{Sn}-126$ & $1.85 \mathrm{E}+01$ & U-238 & $2.57 E+05$ \\
\hline $\mathrm{Pa}-231$ & $1.66 \mathrm{E}+00$ & Sr-90 & $1.89 \mathrm{E}+02$ & & \\
\hline
\end{tabular}

${ }^{\mathrm{a}}$ From BSC 2003 (Table 21). 
Table III-2. Information Used to Determine Radionuclide Inventory for TSPA-LA

\begin{tabular}{|l|c|c|c|}
\hline \multicolumn{1}{|c|}{ Producer } & Waste Form & Number of Canisters & Percent of Total \\
\hline Hanford & Glass & $9202^{\text {a }}$ & 55.0 \\
\hline $\begin{array}{l}\text { Savannah River } \\
\text { Site (SRS) }\end{array}$ & Glass & 5978 & 35.7 \\
\hline West Valley & Glass & 260 & 1.6 \\
\hline INEEL INTEC & Calcine and glass & 1190 & 7.1 \\
\hline ANL-W & CWF and MWF & 100 & 0.6 \\
\hline Total & & 16,730 & 100.0 \\
\hline
\end{tabular}

${ }^{a}$ Planning case based on contractual fill levels. Estimates range from a minimum of 7071 canisters for advanced technology and a maximum fill level to a maximum of 13,205 canisters for a minimum fill level.

Table III-3. Codisposal Configurations to Accommodate DSNF

\begin{tabular}{|c|c|c|c|c|c|c|c|}
\hline $\begin{array}{c}\text { Configuration } \\
\text { Number }\end{array}$ & $\begin{array}{c}\text { Waste } \\
\text { Packag } \\
\text { e Type }\end{array}$ & $\begin{array}{c}\text { Number } \\
\text { of Waste } \\
\text { Package } \\
\text { s }\end{array}$ & $\begin{array}{l}\text { Spent Nuclear } \\
\text { Fuel Unit }\end{array}$ & $\begin{array}{c}\text { Max } \\
\text { Number of } \\
\text { Units per } \\
\text { Package }\end{array}$ & $\begin{array}{l}\text { Number of } \\
\text { Glass } \\
\text { Canisters } \\
\text { per } \\
\text { Package }\end{array}$ & $\begin{array}{l}\text { Glass } \\
\text { Unit }\end{array}$ & Shorthand \\
\hline 1 & CSNF & 4,299 & PWR assembly & 21 & 0 & & $21 \mathrm{PWF}$ AP \\
\hline 2 & CSNF & 95 & PWR assembly & 21 & 0 & & $21 \mathrm{PWF}$ CR \\
\hline 3 & CSNF & 163 & PWR assembly & 12 & 0 & & 12 PWF AP \\
\hline 4 & CSNF & 2,831 & BWR assembly & 44 & 0 & & 44 BWF \\
\hline 5 & CSNF & 84 & BWR assembly & 24 & 0 & & 24 BWF \\
\hline 6 & CDSP & 1,403 & Short canister & 1 & 5 & short & $1 \mathrm{~S} / 5 \mathrm{~S}$ \\
\hline 7 & CDSP & 1,608 & Long canister & 1 & 5 & long & $1 \mathrm{~L} / 5 \mathrm{~L}$ \\
\hline 8 & CDSP & 192 & Wide canister & 1 & 3 & long & $1 \mathrm{~W} / 3 \mathrm{~L}$ \\
\hline 9 & CDSP & 7 & None & 0 & 5 & long & $0 / 5 \mathrm{~L}$ \\
\hline 10 & CDSP & 202 & $\mathrm{MCO}$ & 2 & 2 & long & $2 \mathrm{MCO} / 2 \mathrm{~L}$ \\
\hline 11 & Naval & 144 & Canister & 1 & 0 & & Naval \\
\hline 12 & Naval & 156 & Canister & 1 & 0 & & Naval \\
\hline
\end{tabular}

${ }^{a}$ Table 17 from ANL-WIS-MD-000020 Rev00.

It should be noted that DOE is currently considering producing an additional HLW glass to immobilize excess weapons-grade $\mathrm{Pu}$, which would result in additional canisters from Savannah River Site (SRS) and additional waste packages in Configuration 6. This will also increase the average Pu inventory. 
III-6 


\section{THE CERAMIC WASTE FORM}

The CWF was developed to immobilize salt waste generated during the EMT of spent sodium-bonded nuclear fuel. Direct vitrification of salt wastes in a standard borosilicate HLW glass is not possible due to the low solubility of chloride salts in borosilicate glass. In the CWF, the chloride salts are immobilized as part of the alumino-silicate mineral sodalite, which is microencapsulated by a borosilicate glass. Radionuclides are immobilized within the glass as either dissolved components or stable oxide inclusion phases. This section summarizes tests and analyses conducted to characterize the phase composition and microstructure of the CWF, determine modes by which the immobilizing matrix degrades and radionuclides are released, and develop a mechanistically-based analytical model that can be used to calculate the release rates of radionuclides over long times in the repository environment. Data generated during the development, testing, and modeling of the CWF has been published in internal and open literature reports and papers. Many of these are listed in Appendix B with brief annotations regarding the content of the report or paper.

\section{IV.A. Composition and Microstructure of the CWF}

\section{IV.A.1. Salt Composition}

Upper limits are placed on the concentrations of sodium and radionuclides that will be dissolved into the eutectic salt to ensure safe and efficient operation of the EMT electrorefiner. When these limits are reached, the salt must either be disposed of or reconditioned and recycled (for example, by using an ion exchange column). The composition of the salt used in the development of the CWF was based on the assumption that 300 driver rods could be treated before the batch of eutectic salt would need to be replaced. This is referred to as the "300-driver salt for the throwaway option," and that composition is given in Table IV-1. Most of the CWF materials used in the testing program were made with using salt of this target composition. Some CWF materials were made using 300-driver salt with added $\mathrm{UCl}_{3}$ or mixtures of $\mathrm{UCl}_{3}$ and $\mathrm{PuCl}_{3}$ to span the ranges of $\mathrm{U}$ and $\mathrm{Pu}$ contents expected to be immobilized.

Table IV-1. Composition of 300-Driver Salt

\begin{tabular}{|c|c|}
\hline Salt & Mass $\%$ \\
\hline $\mathrm{BaCl}_{2}$ & 1.20 \\
\hline $\mathrm{CeCl}_{3}$ & 2.33 \\
\hline $\mathrm{CsCl}$ & 2.51 \\
\hline $\mathrm{EuCl}_{3}$ & 0.05 \\
\hline $\mathrm{KI}$ & 0.15 \\
\hline
\end{tabular}

\begin{tabular}{|c|c|}
\hline Salt & Mass \% \\
\hline $\mathrm{LaCl}_{3}$ & 1.22 \\
\hline $\mathrm{LiCl}-\mathrm{KCl}$ & 69.82 \\
\hline $\mathrm{NaCl}$ & 14.95 \\
\hline $\mathrm{NdCl}_{3}$ & 3.90 \\
\hline $\mathrm{PrCl}_{3}$ & 1.15 \\
\hline
\end{tabular}

\begin{tabular}{|c|c|}
\hline Salt & Mass \% \\
\hline $\mathrm{RbCl}$ & 0.33 \\
\hline $\mathrm{SmCl}_{3}$ & 0.69 \\
\hline $\mathrm{SrCl}_{2}$ & 1.00 \\
\hline $\mathrm{YCl}_{3}$ & 0.70 \\
\hline & \\
\hline
\end{tabular}

\section{IV.A.2. Zeolite Composition and Structure}

Commercially available zeolite $4 \mathrm{~A}$ is used to make CWF. It has structural cages that are used to occlude the waste salt (Richardson, 1997; Simpson, 2003). The zeolite that is used is an aggregate of approximately 5 - $\mu \mathrm{m}$-sized polycrystalline grains that are bound together with a proprietary clay binder. It is sized to approximately $-60+200$ mesh $(74-250 \mu \mathrm{m})$ to facilitate handling and mixing without compromising the efficiency of salt occlusion. The zeolite received from the vendor may contain up to about $20 \%$ water, but is dehydrated to a water content of $<1$ mass $\%$ before being used to occlude salt (Goff et al., 1999). A small amount of residual water must be left in the zeolite to ensure that the cage structure is retained. A sample of the dehydrated zeolite is rehydrated prior to use to verify that its cage structure was not damaged during the dehydration step. The zeolite 4A unit cell structure contains an 
alpha cage having a $0.42-\mathrm{nm}$ aperture surrounded by 8 beta cages having $0.22-\mathrm{nm}$ apertures. The size of each aperture restricts the occlusion of some ions. For example, cesium ions can only enter alpha cages.

The waste salt is crushed to a similar size as the zeolite prior to occlusion to facilitate mixing. The salt and zeolite are mechanically mixed and blended in a V-mixer at about $500^{\circ} \mathrm{C}$ for about $15-20$ hours. This results in molten salt migrating into the zeolite cages to form of what is referred to as SLZ. The relative amounts of zeolite 4A and salt that are mixed are controlled to ensure all the salt becomes occluded in the zeolite. Enough salt is added to load the targeted amount of $3.8 \mathrm{Cl}^{--}$per pseudo unit cell of the zeolite 4A, which corresponds to a mixture with about 10.7 mass \% salt and 89.3 mass \% zeolite. The processing range of salt loading is 3.4-3.9 $\mathrm{Cl}^{-}$per pseudo unit cell of the zeolite, with a target of 3.9 (Goff et al., 1999). Slightly less salt than the stoichiometric maximum of $4 \mathrm{Cl}^{-}$per cell is mixed with the zeolite to minimize the amount of residual, non-occluded salt that remains after blending. Before it is used to make CWF, a sample of the SLZ is subjected to the so-called "free chloride test" to verify that an acceptable fraction of the salt was occluded. In this test, a measured mass of SLZ is immersed in a volume (mass) of demineralized water that is 60 times the mass of the SLZ sample for 60 seconds at room temperature. The resulting solution is then decanted, passed through a $0.45-\mu \mathrm{m}$ pore-size filter, and analyzed for $\mathrm{Cl}^{-}$. This provides a measure of the fraction of salt that was not occluded in the zeolite. This test is based on the premise that the non-occluded salt is immediately dissolved when contacted by water, whereas the occluded salt must diffuse out of the zeolite cages (or water must diffuse into the cages) before the salt dissolves. The "percent free chloride" value is calculated using the measured $\mathrm{Cl}^{-}$concentration as:

$$
\% \text { free chloride }=100 \times \frac{\text { solution } \text { volume, } m L \times\left[\mathrm{Cl}^{-}\right], \mathrm{g} / \mathrm{mL}}{\text { mass } S L Z, g}
$$

Occlusion of the salt is considered to be acceptably complete if the percent free chloride value is less than $0.5 \%$ (Goff et al., 1999).

Figure IV-1 shows a scanning electron microscopy photomicrograph of part of a single granule of SLZ made with simulated 300-driver salt doped with $\mathrm{UCl}_{3}$ and $\mathrm{PuCl}_{3}$. The granule is one of several that was embedded in epoxy resin and prepared as a polished cross section for examination with a scanning electron microscope (SEM). The individual zeolite grains within the aggregate are clearly visible. The small light spots decorating the perimeter of the granule are mixed actinide-rare earth element oxides. These were formed when the rare earth element chlorides reacted with the residual water in the zeolite during the blending step. The small amount of residual water present in the dried zeolite (approximately 1 mass \%) is sufficient to oxidize all of the rare earth elements in the salt. Oxygen from the zeolite structure is not consumed during the oxidation. Note that whereas the rare earth oxides are constrained to the outer perimeter of the zeolite granule, two halite crystals are seen in the interior of the cross-sectioned granule. The halite crystals appear to be overlaying zeolite crystals and may have been displaced during polishing or may have recrystallized on the surface after polishing.

\section{IV.A.3. Binder Glass Composition}

A commercially available borosilicate glass (PEMCO Corp., Baltimore, MD) provided in a nominal size range of $-60+325$ mesh $(74-250 \mu \mathrm{m})$ is used to consolidate the zeolite granules into a monolithic product. The similar sizes of zeolite and binder glass are used to facilitate their mixing prior to consolidation. The measured composition of the binder glass is given in Table IV-2. The glass has a lower glass transition temperature than borosilicate HLW glasses and is sufficiently fluid to infiltrate and encapsulate the zeolite (or sodalite) at $850^{\circ} \mathrm{C}$. The nominal CWF composition includes 25 mass $\%$ binder glass mixed with 75 mass \% SLZ. (The processing range is $20-30$ mass \% binder glass.) The composition 


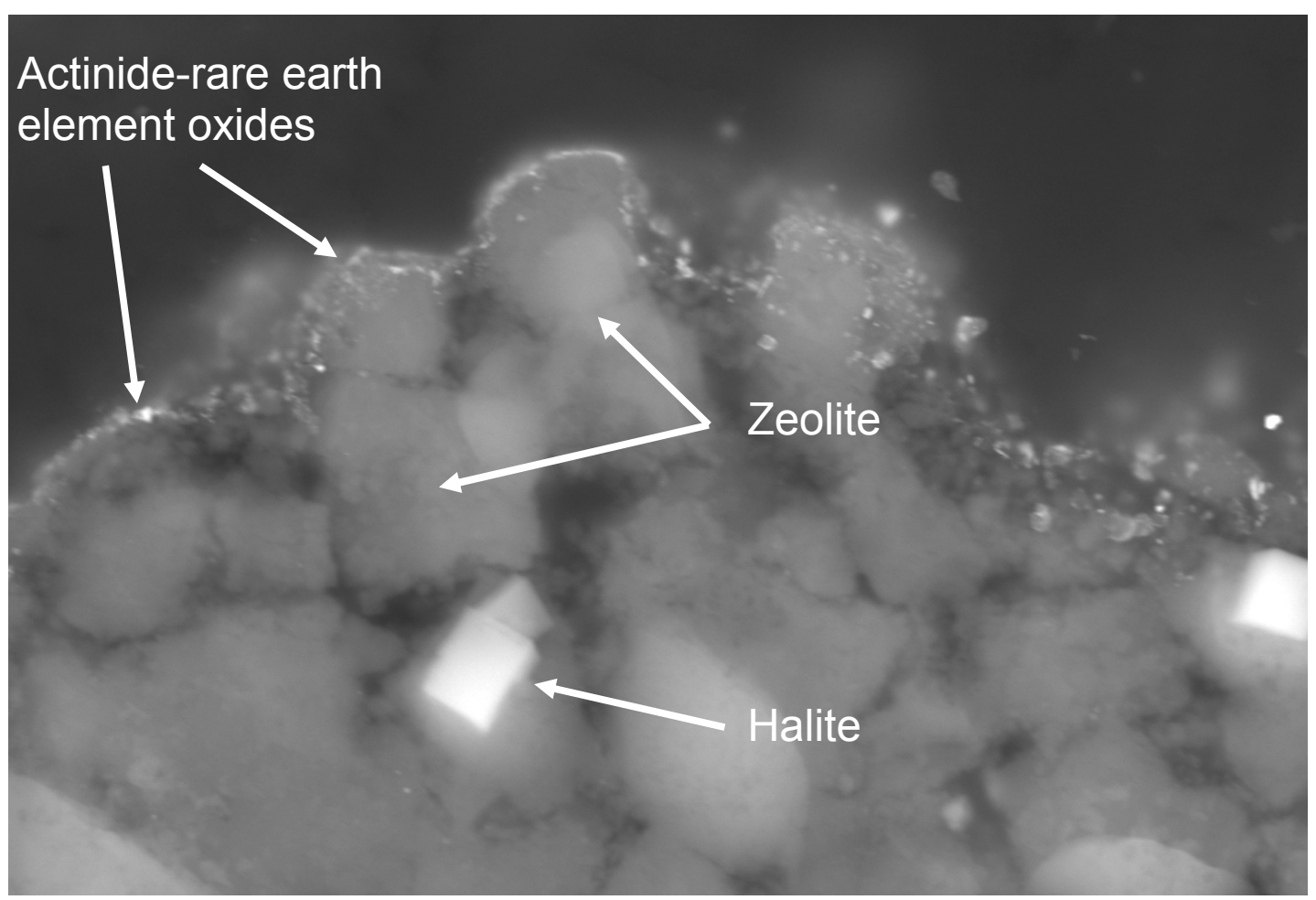

Fig. IV-1. SEM Photomicrograph of a Cross-Sectioned SLZ Particle with U,Pu-Doped Salt.

Table IV-2. Composition of Binder Glass

\begin{tabular}{|c|c|c|c|c|c|c|c|c|}
\hline Oxide & $\mathrm{Al}_{2} \mathrm{O}_{3}$ & $\mathrm{~B}_{2} \mathrm{O}_{3}$ & $\mathrm{BaO}$ & $\mathrm{CaO}$ & $\mathrm{K}_{2} \mathrm{O}$ & $\mathrm{Na}_{2} \mathrm{O}$ & $\mathrm{SiO}_{2}$ & $\mathrm{SrO}$ \\
\hline Mass $\%$ & 7.60 & 19.65 & 0.02 & 1.33 & 0.45 & 6.64 & 64.29 & 0.02 \\
\hline
\end{tabular}

of the binder glass changes slightly as small amounts of sodalite dissolve into the binder glass during processing. Although the amount that dissolves will be small under normal processing conditions, exposure to higher temperatures for long times will result in the dissolution of a significant amount of sodalite into the glass (Lewis et al., 2002). However, tests with glasses formulated to simulate the dissolution of moderate amounts of sodalite into binder glass (e.g., 20 mass \%) indicate the durability of the binder glass is not significantly changed and may even be enhanced (Jeong et al., 2002). This is because increasing the amounts of aluminum and silicon generally improves the durability of borosilicate glasses. In the case of CWF, the chloride released as sodalite dissolves into the binder glass will generate additional halite inclusion phases.

\section{IV.A.4. Producing the CWF}

During the initial development of the CWF, materials were made using a hot isostatic press (HIP) (Benedict et al., 1999; Goff et al., 1999). The HIP CWF materials were made at temperatures between $850^{\circ} \mathrm{C}$ and $900^{\circ} \mathrm{C}$ and pressures ranging from 14,500 to 25,000 psi. An alternative processing method referred to as "pressureless consolidation" (PC) was developed during the EMT process demonstration phase to simplify operations and increase throughput during processing. Early tests to study the corrosion mechanism and the disposition of radionuclides were conducted using various HIP CWF materials and much of the insight gained from tests and analyses with HIP CWF materials is being utilized to support 
qualification of the PC CWF. Several PC CWF materials were made using different amounts of SLZ and binder glass and processed at different temperature and times. The physical and chemical properties of these materials were evaluated (Lewis et al., 2002; Ebert et al. 2005). Some of those results will be discussed in this report. The standard processing conditions currently used to make PC CWF materials are $915^{\circ} \mathrm{C}$ for 16 hours at ambient pressure using the same relative amounts of SLZ and binder glass and similar particle sizes that were used for the HIP process. The resulting PC CWF materials are composed of the same component phases as HIP CWF materials and have very similar microstructures. As will be shown, an important benefit of PC CWF materials is that halite and oxide phases that form as inclusions in the binder glass are distributed throughout the binder glass, whereas these phases accumulated at the periphery of sodalite domains in HIP CWF materials. In effect, the absence of applied pressure in the PC method is compensated for by the higher temperatures to attain a more fluid glassmelt and longer heating times. (In practice, a steel plate is placed on top of the mixture to help consolidate the material during processing. This provides some pressure during consolidation.) However, the PC CWF materials are more porous than HIP CWF materials (Lewis et al., 2001); the porosity is closed. The bulk density of the PC CWF waste form is about $15 \%$ lower than that of the HIP CWF (about 2,000 kg/m $\mathrm{m}^{3}$ for PC CWF compared to $2,330 \mathrm{~kg} / \mathrm{m}^{3}$ for HIP CWF). The better packing efficiency of PC CWF in the HLW containers due to the absence of a HIP will offset the lower density of the PC CWF, so about the same amounts of HIP CWF or PC CWF could be disposed in a standard 3-m (short) HLW waste container.

The PC method was selected in 2000 for use in the inventory reduction phases (Federal Register, 2000). Selection of the PC method was supported by scoping tests conducted with the PC CWF that showed qualification of PC CWF products for disposal was not less likely than qualification of the HIP CWF products (Lewis et al., 2002). Other tests have been conducted with PC CWF to (1) develop a mechanistically based kinetic model and measure model parameters for calculating long-term dissolution behavior under disposal conditions, (2) determine the effects of process conditions on the microstructure and chemical durability, and (3) measure the consistency with which PC CWF waste forms can be produced. As described in this report, the understanding of the CWF is based on the combined results of tests and analysis conducted with HIP CWF and PC CWF materials.

\section{IV.A.5. CWF Phase Composition}

At a temperature between about $800^{\circ} \mathrm{C}$ and $850^{\circ} \mathrm{C}$, the SLZ transforms into the mineral sodalite following the net reaction given in Eq. IV-2:

$$
\underset{\text { zeolite } 4 \mathrm{~A}}{\mathrm{Na}_{12}\left(\mathrm{AlSiO}_{4}\right)_{12}}+\underset{\text { salt }}{4 \mathrm{NaCl}} \rightarrow \underset{\text { sodalite }}{2} \underset{\mathrm{Na}_{8}\left(\mathrm{AlSiO}_{4}\right)_{6} \mathrm{Cl}_{2}}{\rightarrow}
$$

Neither the mechanism by which the SLZ transforms to sodalite nor the extent to which the zeolite cage structure is retained during transformation is known. The transformation of SLZ to sodalite results in the replacement of the alpha cage in the zeolite with another beta cage in the sodalite. Although the reaction is written for the consumption of $\mathrm{NaCl}$, other alkali metals and halides can be incorporated into the sodalite structure. For example, iodosodalite has been synthesized (Strachan and Badad, 1979). Test results suggest that about $90 \%$ of the iodine from the waste salt is contained in sodalite (see Section IV.E.4.1), but other analyses indicate that Cs is not incorporated into sodalite (Lambregts and Frank, 2002). Most of the Li from the salt appears to be dissolved in the binder glass.

Figure IV-2 shows the powder X-ray diffraction (XRD) spectra for the salt, binder glass, and zeolite starting materials, and for a typical PC CWF product. The crystalline content of the PC CWF is 


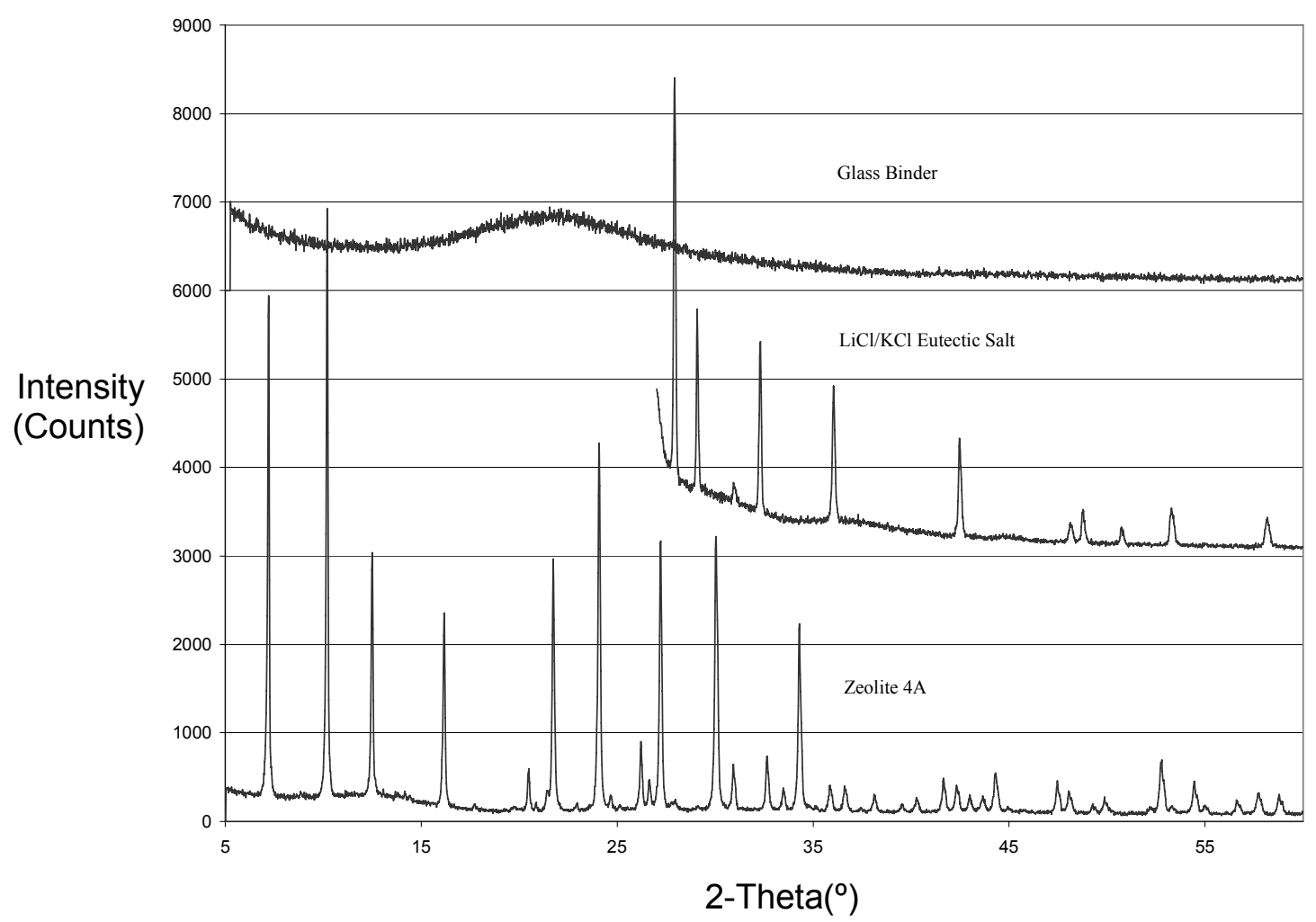

(a)

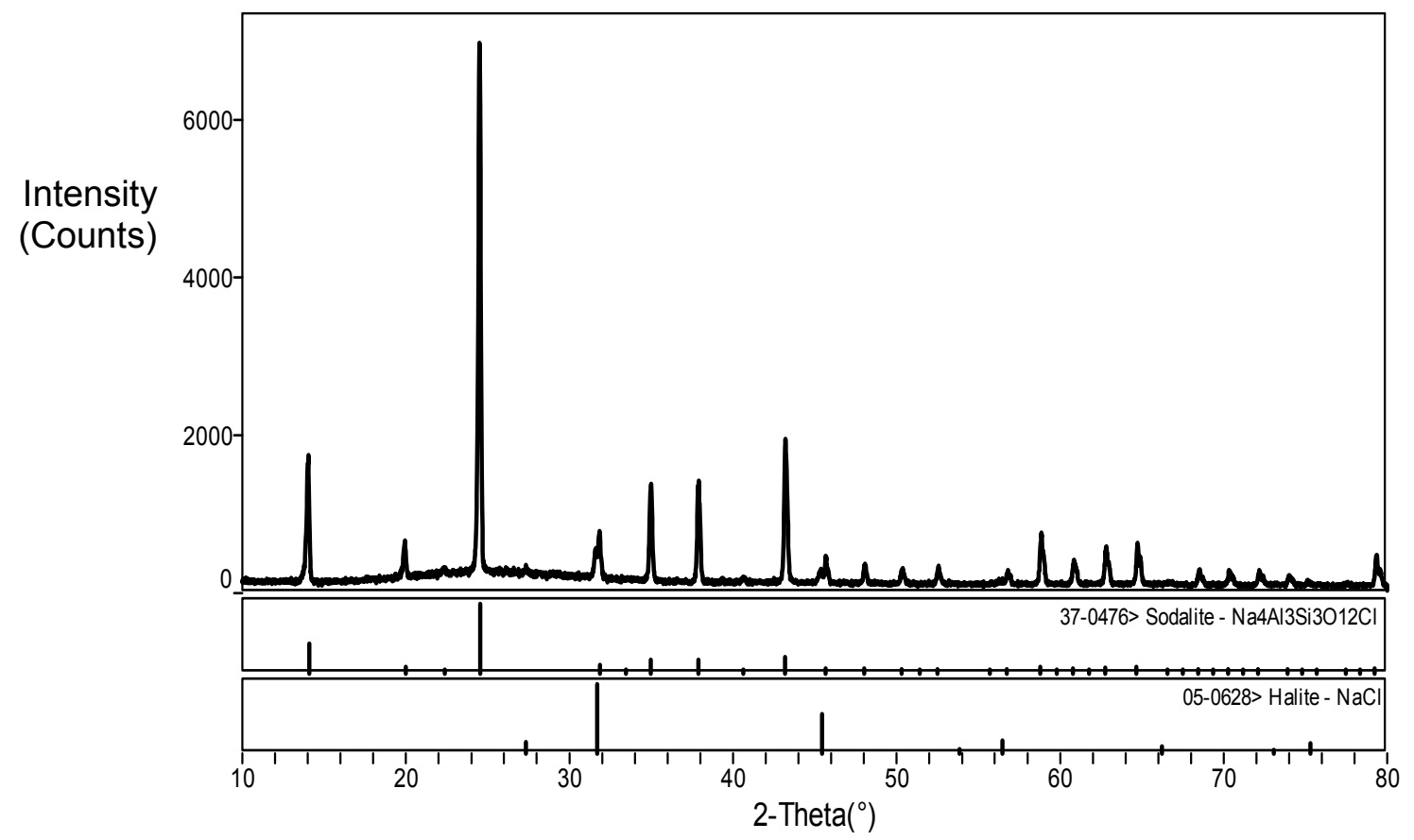

(b)

Fig. IV-2. (a) XRD Overlay Plot of Starting Materials Zeolite 4A, Binder Glass, and $\mathrm{LiCl} / \mathrm{KCl}$ Eutectic Salt and (b) XRD Spectra of Nominal PC CWF Material. Ribbon bars show locations and relative intensities for sodalite and halite reference spectra. 
predominantly sodalite, but includes a small amount of halite $(\mathrm{NaCl})$. The ribbon bars under the PC CWF spectrum locate the peaks and relative intensities of sodalite and halite in reference spectra. Halite is detected in all HIP CWF and PC CWF materials at about 1-2 mass \%. It is presumed to form from salt lost during the conversion of zeolite to sodalite, as well as from the small amount of residual nonoccluded salt associated with the SLZ. The amount of salt occluded in the zeolite is decreased slightly from the stoichiometric amount to reduce the amount of halite formed in the CWF. The target salt loading of $3.8 \mathrm{Cl}^{-}$per pseudo unit cell of the zeolite leads to the formation of small amounts of nepheline, $\mathrm{Na}_{4}\left(\mathrm{AlSiO}_{4}\right)_{4}$, according to the net reaction given in Eq. IV-3a

$$
\underset{\text { zeolite } 4 \mathrm{~A}}{\mathrm{Na}_{12}\left(\mathrm{AlSiO}_{4}\right)_{12}}+3.8 \mathrm{NaCl} \rightarrow \underset{\text { sodalite }}{1.90 \mathrm{Na}_{8}\left(\mathrm{AlSiO}_{4}\right)_{6} \mathrm{Cl}_{2}}+\underset{\text { nepheline }}{0.15 \mathrm{Na}_{4}\left(\mathrm{AlSiO}_{4}\right)_{4}}
$$

Sodalite can decompose to form nepheline and halite:

$$
\underset{\text { sodalite }}{\mathrm{Na}_{8}\left(\mathrm{AlSiO}_{4}\right)_{6} \mathrm{Cl}_{2}} \rightarrow \underset{\text { nepheline }}{1.5 \mathrm{Na}_{4}\left(\mathrm{AlSiO}_{4}\right)_{4}}+\underset{\text { halite }}{2 \mathrm{NaCl}}
$$

Nepheline has not been detected in XRD spectra of most PC CWF materials, but has been detected in spectra of some products made using SLZ with substoichiometric salt contents (Ebert et al., 2005). The XRD detection limit for nepheline is not known, but is presumed to be about 1 mass \%. The effect of the salt-loading on the amounts of halite and nepheline formed in PC CWF materials is described in Section IV.A.7. The formation of nepheline may also be sensitive to the processing conditions, perhaps the pressure. Unreacted zeolite has not been detected in XRD analysis of any HIP CWF or PC CWF materials. Examination of HIP CWF and PC CWF materials with transmission electron microscopy (TEM) has revealed the presence of other unidentified silicate and oxide phases in trace amounts (e.g., Sinkler et al., 2000; Moschetti et al. 2000).

\section{IV.A.6. CWF Microstructure}

Figure IV-3 shows scanning electron micrographs (backscattered electron image) of polished crosssections of HIP CWF and PC CWF materials made with 300 driver salt doped with $\mathrm{UCl}_{3}$ and $\mathrm{PuCl}_{3}$. Several sodalite domains can be seen embedded in glass; the sodalite has a mottled appearance and is lighter than the binder glass in Fig. IV-3a, but is darker than the binder glass in Fig. IV-3b. The size of the sodalite domains in the CWF materials are in the same range as the zeolite granules used to make them, and the conversion of the SLZ to sodalite appears to be nearly isovolumetric. Both CWF materials were made with $-100+200$ mesh granular zeolite and resulted in 100- $\mu \mathrm{m}$-sized regions of sodalite embedded in binder glass.

The sodalite domains in the HIP CWF (Fig. IV-3a) are surrounded by small pores, some of which had contained halite inclusions that were dissolved during sample preparation. Pores are also present in the PC CWF material, but are more evenly distributed. Figure IV-4 shows an optical micrograph of the region near a sodalite/glass interface of a nonradioactive HIP CWF material. The small circular features on the glass side of the interface are halite inclusions (Luo et al., 2000). A halite inclusion is shown in higher magnification in a transmission electron micrograph in Fig. IV-5. Typically, CWF materials contain about 1-2 mass \% halite inclusions. Electron diffraction analysis of several halite inclusions during examination with a TEM indicated that the inclusions are single crystals with a face-centered cubic morphology. The spherical appearance of the halite inclusions in the binder glass can be explained as follows: When $\mathrm{NaCl}$ is expelled from SLZ during transformation to sodalite, it forms small spherical droplets of molten $\mathrm{NaCl}$ that are not soluble in the molten glass. These become mixed with the binder glass in PC CWF materials but remain near the sodalite domains in the HIP CWF materials due to differences in the processing 


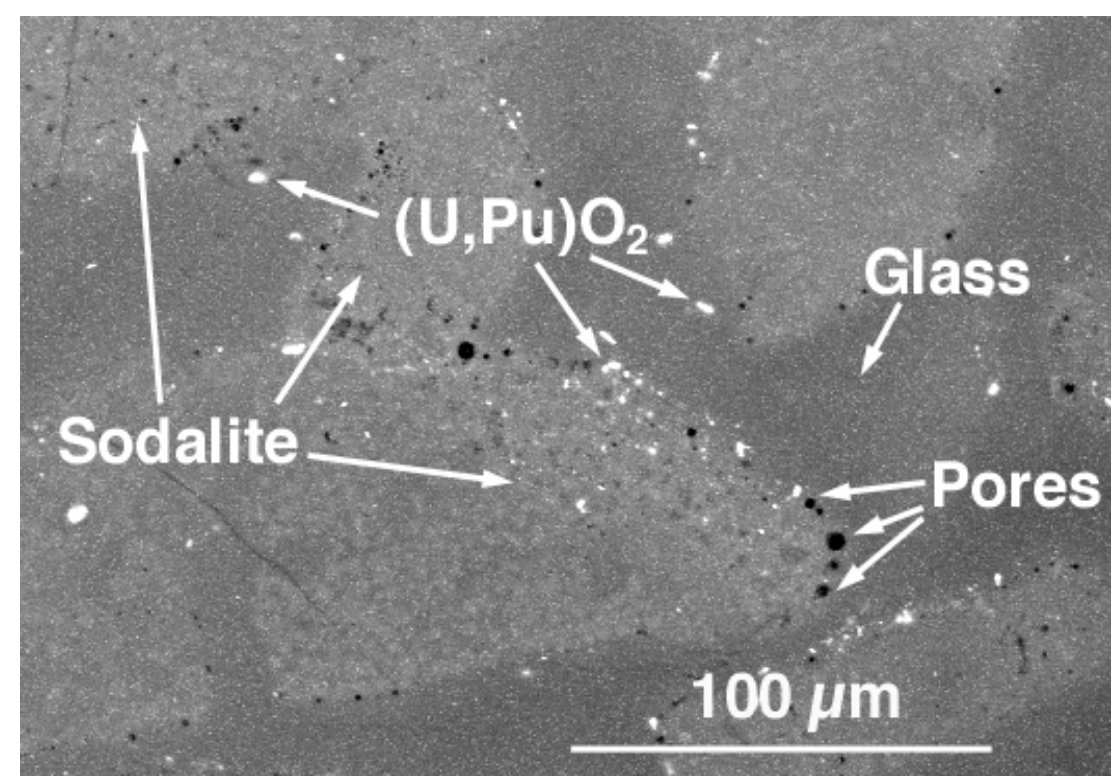

(a)

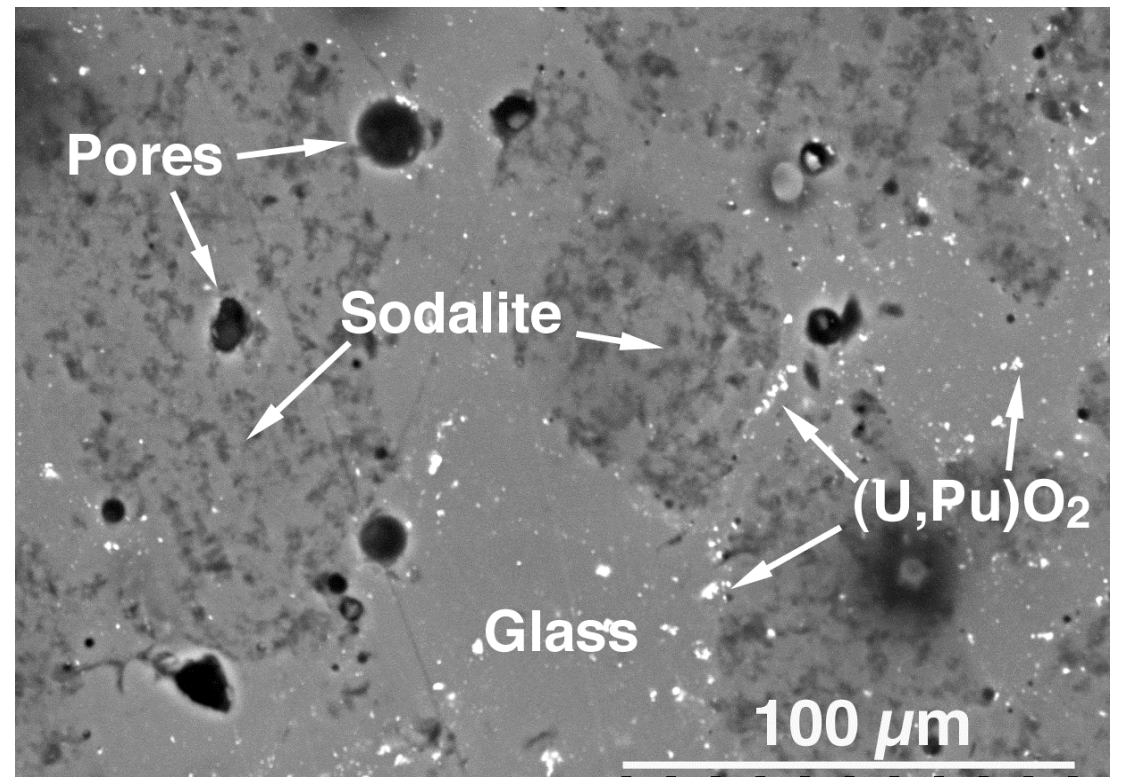

(b)

Fig. IV-3. Photomicrographs Showing Microstructures of (a) U,PuDoped HIP CWF and (b) U,Pu-Doped PC CWF. 


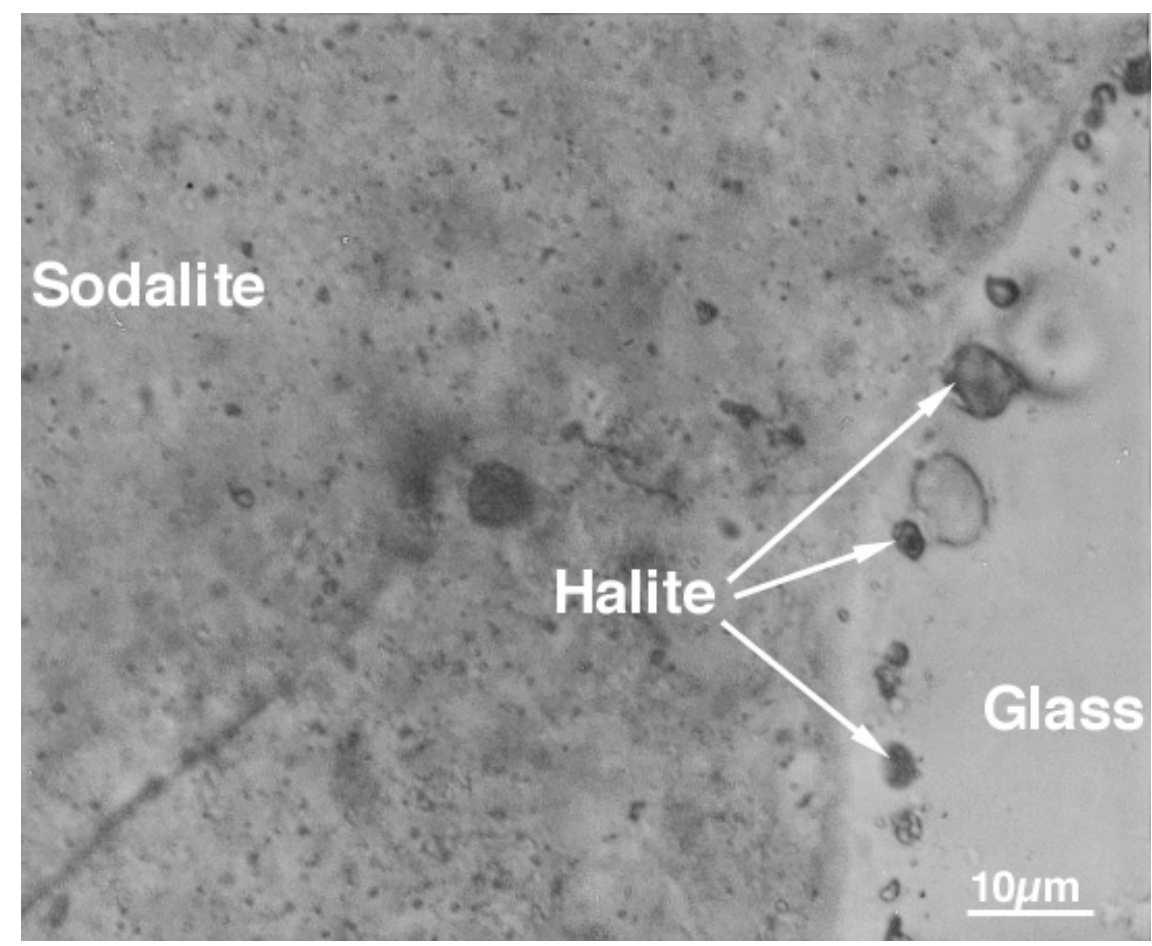

Fig. IV-4. Optical Micrograph of Halite Inclusions within Binder Glass of HIP CWF.

temperature and time. As the CWF materials cool after processing, the glass hardens first while the salt remains molten, so spherical inclusions of molten $\mathrm{NaCl}$ are formed in the binder glass. Halite then crystallizes within the pores as the CWF continues to cool. The specific volume of the halite crystal that forms is smaller than that of the molten $\mathrm{NaCl}$, so the crystals shrink slightly within the pores and leave a small void.

Figure IV-5 also shows an abundance of smaller dark phases included in the binder glass of HIP CWF made with 300 driver salt that was doped with $\mathrm{UCl}_{3}$ and $\mathrm{PuCl}_{3}$. These inclusions form are shown at higher magnification in Fig. IV-6. Most crystallites are in the 20- to 50-nm size range. Figure IV-7 shows the results of an X-ray absorption near edge spectroscopy analysis of a CWF material made with Pu-doped salt a a $\mathrm{PuO}_{2}$ reference standard (Richmann et al., 2001). These are mixed actinide and rare earth element oxides. These crystallites formed when the salt was occluded in the zeolite and become dispersed in the molten glass during processing. Both $\mathrm{UCl}_{3}$ and $\mathrm{Pu} \mathrm{Cl}_{3}$ are oxidized as they are converted from chlorides to oxides during the salt-loading step. The chlorides react with the small amount of residual water that had been retained in the zeolite after drying and the oxidation does not consume oxygen from the zeolite structure.

Trace amounts of other phases have been detected by TEM analyses of some CWF samples (Sinkler et al. 1999; Sinkler et al. 2000). For example, Fig. IV-8 shows microcrystallites of a clay embedded in the binder glass (Ebert et al., 1999). These are probably pieces of the clay binder used to aggregate the zeolite that did not dissolve into the binder glass when the CWF was processed. A few small crystals of various silicate phases were also detected in this and other samples. These phases are too rare and too small to measurably affect the performance of the CWF, and, other than noting their presence, not attempt was made to catalogue the phases or track their occurrence. 


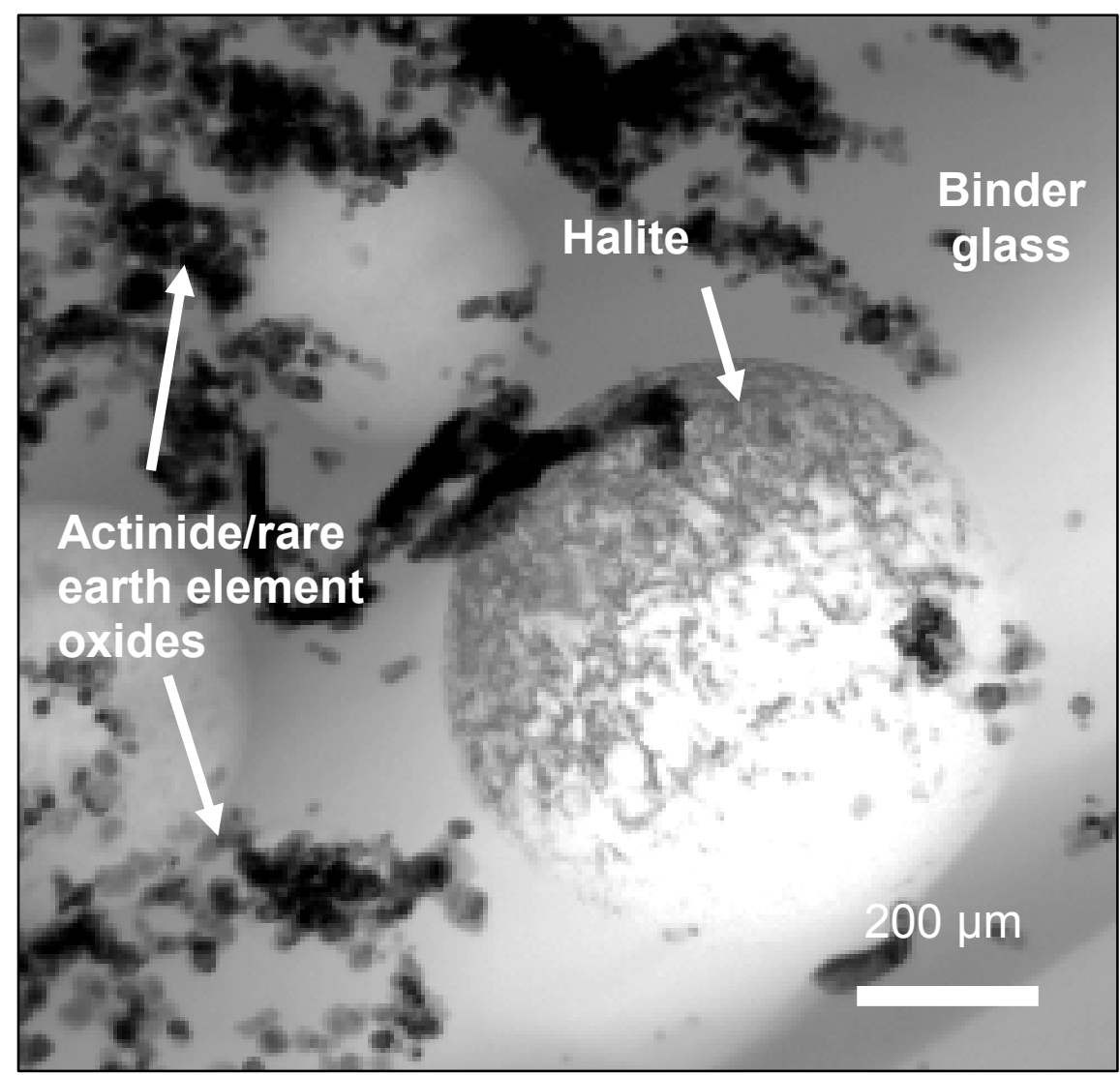

Fig. IV-5. TEM Photomicrograph of Halite and Mixed Actinide-Rare Earth Element Oxides (dark features) Inclusion Phases in HIP CWF.

The major difference between the microstructures of the HIP CWF and PC CWF materials is the distribution of halite and oxide inclusions within the binder glass: They are located within a few micrometers of the sodalite domains in HIP CWF materials, but fairly evenly distributed throughout the binder glass in PC CWF materials. This is probably due to the higher fluidity of the binder glass at the higher temperatures used to make PC CWF materials and longer processing time. As will be shown later, the high concentration of halite inclusions and pores near the sodalite/glass interface in HIP CWF materials promotes dissolution of glass in that region, whereas dissolution of glass in PC CWF is more uniform. This impacts the release of radionuclide-bearing inclusion phases that have distributions similar to halite (and pores). Nepheline is not commonly seen in TEM examinations of CWF materials, and it may be difficult to distinguish from sodalite.

\section{IV.A.7. Distribution of Radionuclides}

The distribution of the radionuclides present in CWF that contribute the most dose (see Appendix A) between sodalite, binder glass, halite, and oxide inclusions within the binder glass is summarized in Table IV-3. The distributions of some radionuclides between the various phases could be determined by direct observation (usually of a nonradioactive isotope of the same element). The distributions of some radionuclides that are present at concentrations that are too low to detect using surface analytical techniques could be inferred from the results of corrosion tests. For example, corrosion tests indicate that the distribution of $\mathrm{I}^{-}$mimics that of $\mathrm{Cl}^{-}$, and that small proportions of each are incorporated into halite (see Section IV.B.2.1). Like $\mathrm{Cl}^{-}$, most of the $\mathrm{I}^{-}$is in sodalite. The distributions of radionuclides that could 


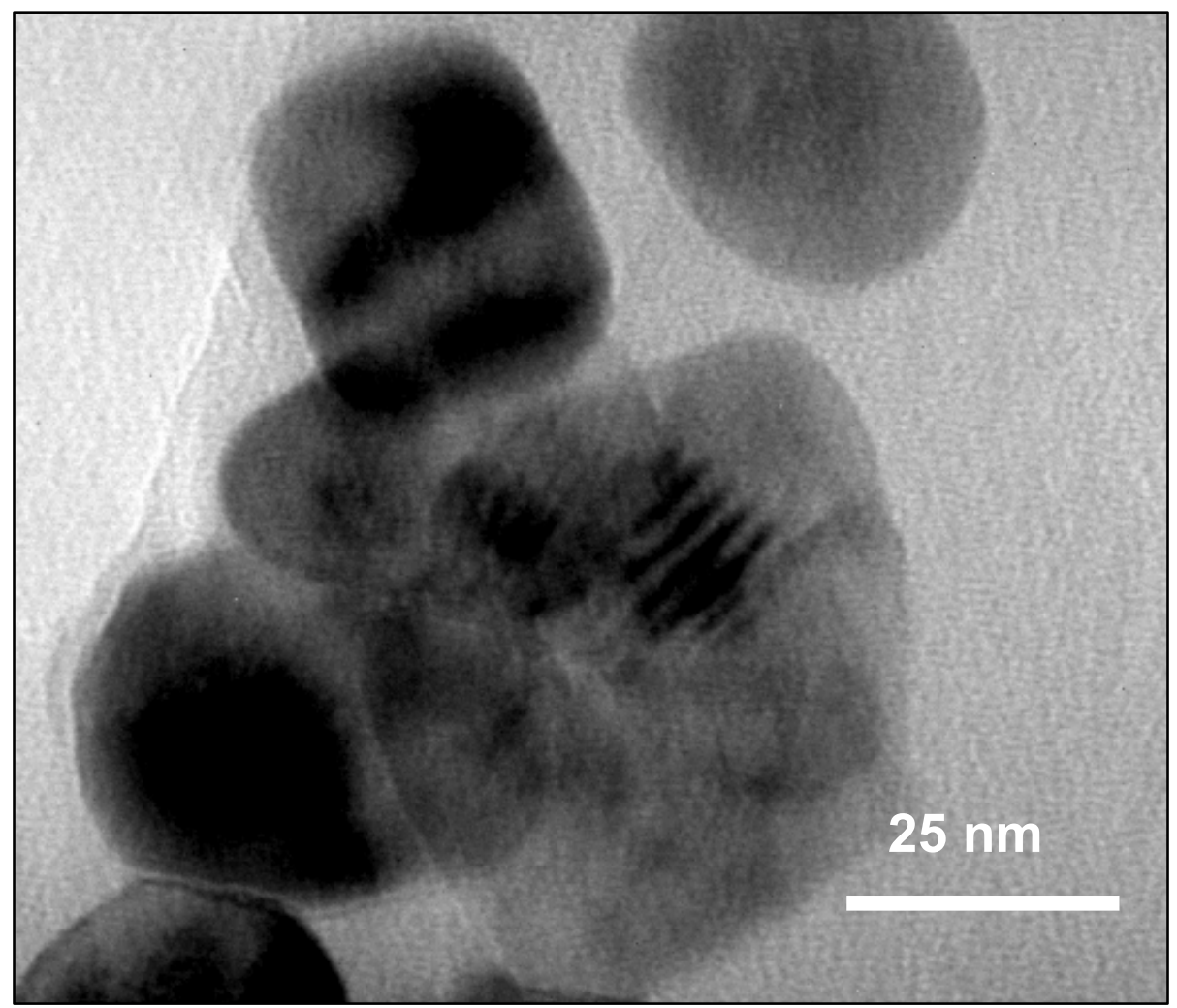

Fig. IV-6. TEM Photomicrograph of Actinide/Rare Earth Element Oxide Inclusions within Binder Glass in HIP CWF.

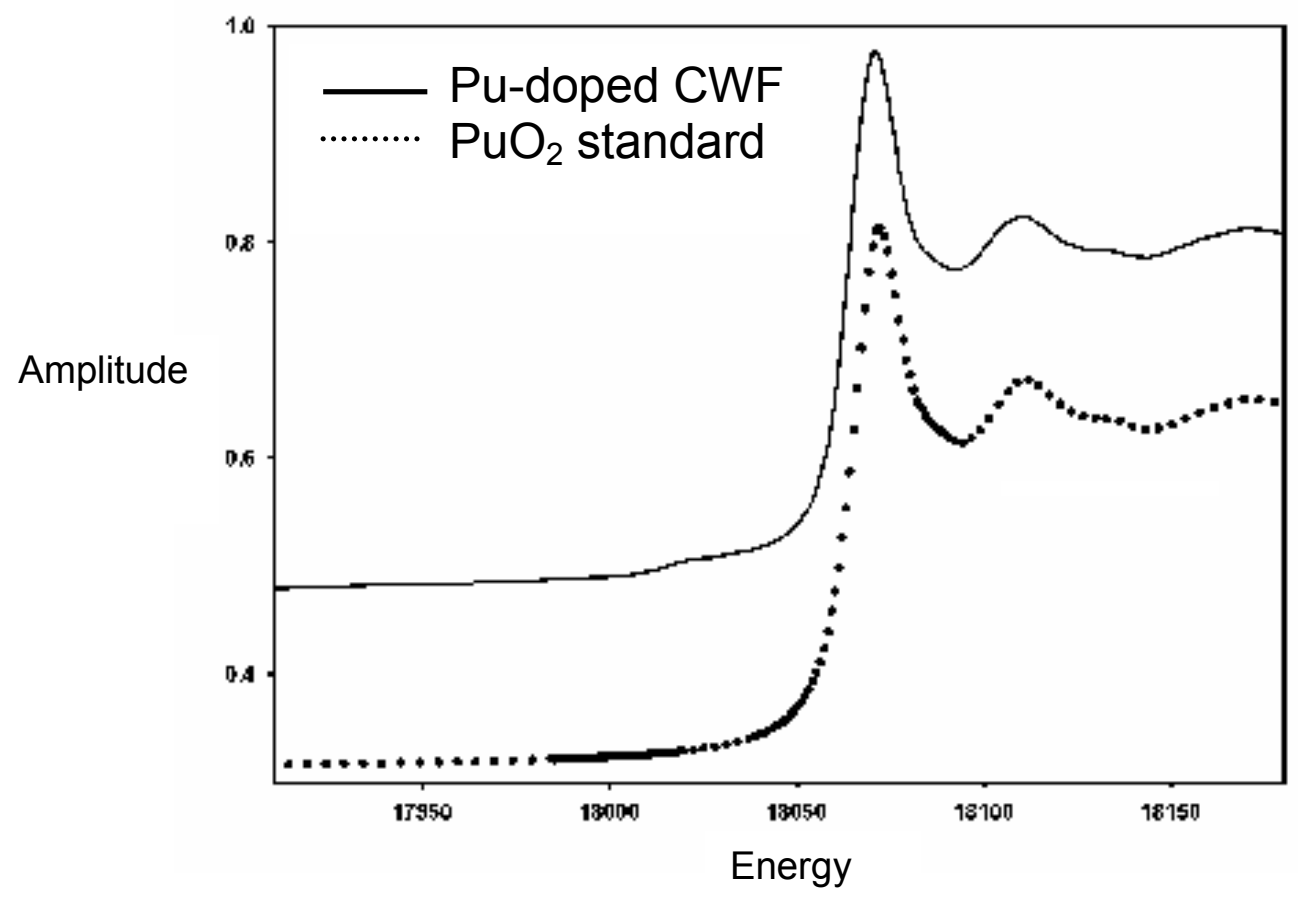

Fig. IV-7. XANES Results for Pu $\mathrm{L}_{\text {III }}$ Edge of CWF Material Made with Pu-Bearing LiCl/KCl Salt and Pu(IV) Standard. 


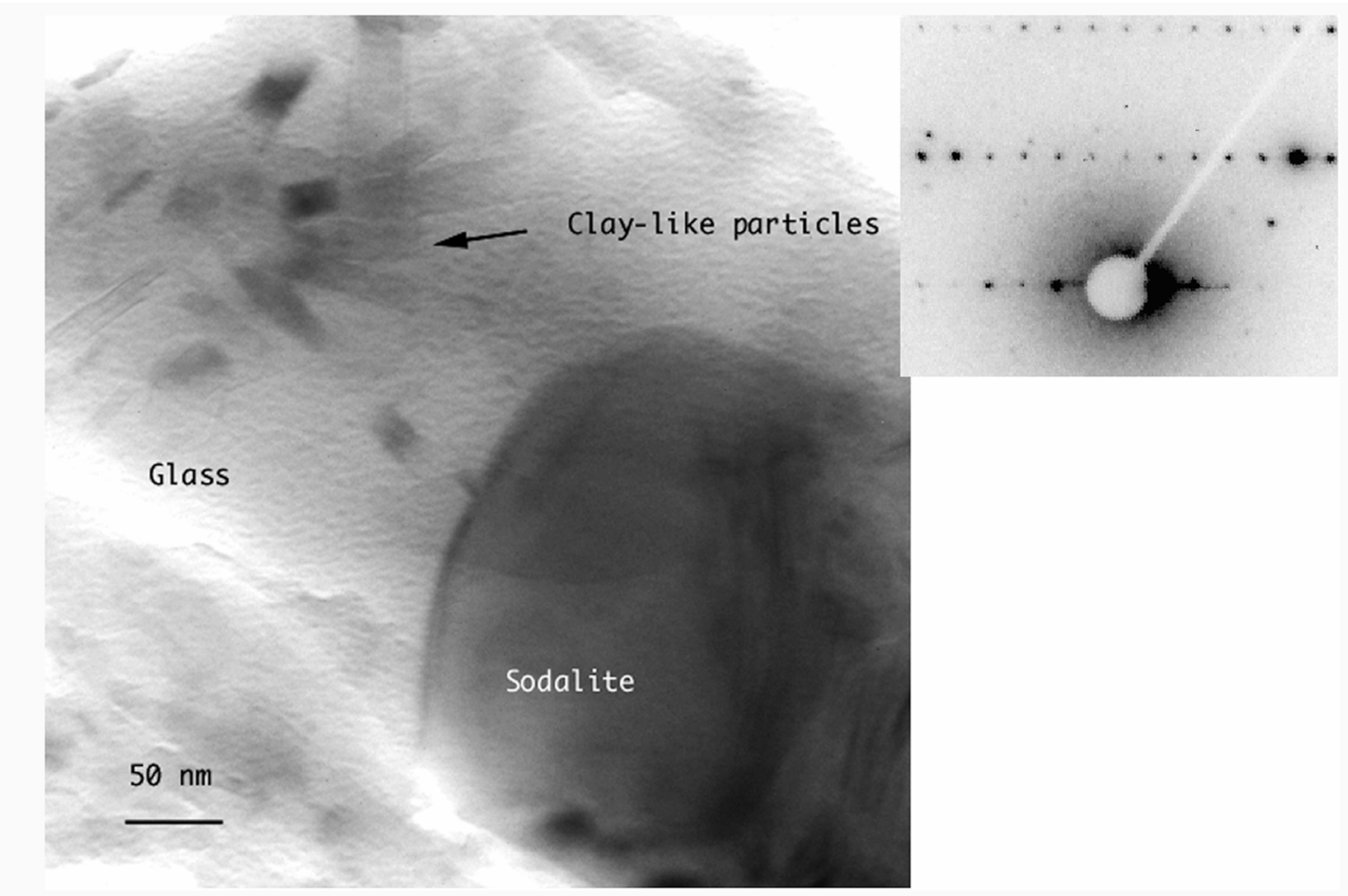

Fig. IV-8. TEM Image of a Sodalite/Glass Interface Showing Evidence of a Clay Phase. Electron diffraction insert (upper right) shows a d-spacing of $1.0 \mathrm{~nm}$, which is characteristic of clays.

not be detected by solids analysis or in test solutions were assigned based on chemical similarities to other elements. For example, all of the rare earth element radionuclides are expected to have the same distribution as $\mathrm{Nd}$, which is found in oxide inclusion phases. Analysis of CWF made with excess $\mathrm{CsCl}$ indicated that Cs was not retained in sodalite (Lambregts and Frank, 2002). Based on corrosion tests (see Section IV.B.2.1), a small fraction of the Cs is present in halite. Most of the Cs is dissolved in the binder glass. At least trace amounts of all radionuclides are expected to be dissolved in the binder glass. Although it was originally intended to contain radionuclides in the waste salt, the primary role served by the sodalite phase in CWF is sequestering $\mathrm{Cl}^{-}$(plus the stoichiometric amount of $\mathrm{Na}$ ), which is necessary to consolidate the CWF.

\section{IV.A.8. Compositional Variability of CWF Made with Different Amounts of Salt and Binder Glass}

A series of laboratory-scale CWF products were made using a range of salt and glass loadings to study the effect of composition on the phase composition. One set of CWF products was made with zeolites loaded with 5.0, 7.5, 10.7, 12.5, and 15.0 mass \% simulated 300 driver salt mixed with 25 mass $\%$ binder glass to study the effect of salt loading. Another set was made with zeolite loaded with 10.7 mass \% salt mixed with 20.0, 22.5, 25.0, 27.5, and 30.0 mass \% binder glass to study the effect of glass loading (Ebert et al., 2005). Products were made by occluding the salt at $500^{\circ} \mathrm{C}$, mixing the SLZ with binder glass, and then processing at $915^{\circ} \mathrm{C}$ for 16 hours. Three CWF materials were made with the target loadings of 10.7 mass \% salt and 25 mass \% to measure the repeatability of making the materials and the test responses. Analytical samples were prepared by crushing and sieving the CWF materials to isolate the $-100+200$ mesh size fraction for use and PCT (see Section IV.E.) and the $-200+325$ mesh size fraction for XRD. 
Table IV-3. Measured and Estimated Distribution of Radionuclides in CWF

\begin{tabular}{|c|c|c|c|c|c|c|}
\hline Radionuclide & $\begin{array}{c}\text { Ci per } \\
\text { Canister }\end{array}$ & Sodalite & Binder Glass & Halite & $\begin{array}{l}\text { Oxide Inclusion } \\
\text { in Binder Glass }\end{array}$ & Basis $^{a}$ \\
\hline Am-241 & $1.89 \mathrm{E}+01$ & & & & major & $\mathrm{C}$ \\
\hline Ba-137m & $3.31 \mathrm{E}+03$ & & major ? ${ }^{b}$ & & & $\mathrm{C}$ \\
\hline Cs-135 & 1.66E-01 & & major & minor & & $A, D$ \\
\hline Cs-137 & $3.51 \mathrm{E}+03$ & & major & minor & & $A, D$ \\
\hline Eu-154 & 8.56E-01 & & & & major? & $\mathrm{C}$ \\
\hline Eu-155 & 5.37E-01 & & & & major? & C \\
\hline $\mathrm{I}-129$ & 3.52E-03 & major & & minor & & $\mathrm{D}$ \\
\hline $\mathrm{Np}-237$ & 1.41E-02 & & & & major? & $\mathrm{C}$ \\
\hline Pu-238 & $2.72 \mathrm{E}+00$ & & & & major & $A$ \\
\hline Pu-239 & $1.75 \mathrm{E}+02$ & & & & major & $\mathrm{A}$ \\
\hline $\mathrm{Pu}-240$ & $1.55 \mathrm{E}+01$ & & & & major & $\mathrm{A}$ \\
\hline Pu-241 & $1.64 \mathrm{E}+01$ & & & & major & $\mathrm{A}$ \\
\hline Sr-90 & $2.77 \mathrm{E}+03$ & & major? & & & C \\
\hline U-234 & $2.92 \mathrm{E}-02$ & & & & major & $\mathrm{A}$ \\
\hline $\mathrm{U}-238$ & $2.88 \mathrm{E}-03$ & & & & major & $\mathrm{A}$ \\
\hline $\mathrm{Y}-90$ & $2.78 \mathrm{E}+03$ & & & & major? & $\mathrm{C}$ \\
\hline
\end{tabular}

${ }^{\mathrm{a}}$ Basis of distribution: $\mathrm{A}=$ direct analysis of solid, $\mathrm{D}=$ dissolution behavior, $\mathrm{C}=$ chemical surrogate

b "major ?" means expected based on chemistry, but not measured.

Samples of the $-100+200$ mesh size fractions were dissolved in a mixture of $\mathrm{HCl}, \mathrm{HNO}_{3}$, and $\mathrm{HF}$, and the solutions were chemically analyzed. The elemental compositions of the 300-driver salt, zeolite 4A, and binder glass are given in Table IV-4. The amounts of salt in the SLZ and the amounts of SLZ and binder glass used to make the different salt-loaded CWF products are summarized in Table IV-5 with the measured compositions of the PC CWF products. The chemical compositions vary little for the series of materials. This is because most of the components in the zeolite are also present in the binder glass. The number of $\mathrm{Cl}^{-}$per unit cell of zeolite calculated for each product based on the salt loading are included in Table IV-5. The salt-loadings in Products S1A and S2C are below the processing range, and the saltloadings in Products S4A and S5B are above than the processing range.

The materials made for testing contained up to about 3 volume $\%$ of millimeter-sized inclusions of a powdery white material that was not encapsulated by binder glass during processing. This was attributed to "clumping" of small amounts of salt and SLZ that was observed to occur during processing. Since clumping can occur during actual waste salt processing, these materials may be more representative of actual waste forms than laboratory test materials in which nuisance occurrences such as clumping are usually eliminated to optimize the product. A small amount of the powdery inclusion material was removed from Product G2A for XRD analysis. The XRD results indicated that it contained sodalite and halite in the same relative amounts as measured to be in Product G2A itself. To evaluate the impact of clumping, two additional materials (Products S1B and S3B, respectively) were made using SLZs with 20 and 25 mass \% salt that had been screened to remove the clumps before processing. No inclusions were visible in the CWF materials made with the screened SLZs, but the XRD spectra of the materials made with the unscreened and screened SLZs were indistinguishable. 
Table IV-4. Elemental Compositions of 300 Driver Salt, Zeolite 4A, and Binder Glass

\begin{tabular}{|c|c|c|c|}
\hline Element & $\begin{array}{c}\text { 300 Driver } \\
\text { Salt }\end{array}$ & Zeolite 4A & Binder Glass \\
\hline $\mathrm{Al}$ & - & 18.83 & 3.95 \\
\hline $\mathrm{B}$ & - & - & 5.99 \\
\hline $\mathrm{Ba}$ & 0.79 & 0.01 & 0.02 \\
\hline $\mathrm{Ca}$ & - & 0.03 & 0.93 \\
\hline $\mathrm{Cl}$ & 59.45 & - & - \\
\hline $\mathrm{Ce}$ & 1.22 & - & - \\
\hline $\mathrm{Cs}$ & 1.82 & - & - \\
\hline $\mathrm{Eu}$ & 0.03 & - & - \\
\hline $\mathrm{I}$ & 0.12 & - & - \\
\hline $\mathrm{K}$ & 21.08 & 0.04 & 0.37 \\
\hline $\mathrm{La}$ & 0.64 & - & - \\
\hline $\mathrm{Li}$ & 5.49 & - & - \\
\hline $\mathrm{Na}$ & 5.23 & 14.87 & 4.83 \\
\hline $\mathrm{Nd}$ & 1.96 & - & - \\
\hline $\mathrm{Pr}$ & 0.54 & - & - \\
\hline $\mathrm{Rb}$ & 0.23 & - & - \\
\hline $\mathrm{Si}$ & - & 18.70 & 29.50 \\
\hline $\mathrm{Sm}$ & 0.35 & - & - \\
\hline $\mathrm{Sr}$ & 0.05 & - & 0.02 \\
\hline $\mathrm{Y}$ & 0.19 & - & - \\
\hline
\end{tabular}

Test samples were prepared by size-reducing large chunks that had been removed from the 400 -g product. Analytical cuts were made at two stages during the crushing to accurately represent the source material, including the powdery inclusions. Material in the $-200+325$ mesh size fraction was isolated for XRD analysis. Spectral peaks were matched to those for reference sodalite, halite, and nepheline based on measured d-spacings and relative intensities. The relative areas of major sodalite, halite, and nepheline peaks for the various salt-loaded CWF samples are compared in Fig. IV-9. Halite peaks were not observed in Products S1A or S2C, which were made with SLZ containing 5.0 and 7.5 mass \% salt, but similar amounts of halite were detected in the other salt-loaded CWF materials. Small amounts of nepheline were detected in all materials, but about ten times more was detected in Product S1A and about five times more was detected in Product S2C than in the other products. These findings are qualitatively consistent with Eq. IV-3a in that nepheline will form if there is less than a stoichiometric amount of salt available to react with the zeolite. The use of more salt than the processing range in materials S4A and S5B did not lead to the formation of significantly more halite than was formed in the materials made with the target salt loading of 10.7 mass \% (S3A, S3C, S3E, G1A, G2A, G4A, and G5A); neither did it result in less nepheline being formed. These results indicate that the occluded salt is more completely transformed to sodalite in CWF made with salt loadings lower than the target of 10.7 mass \%, with the excess zeolite being transformed to nepheline. Salt loadings higher than the target of 10.7 mass \% (at least up to 20 mass \%) did not result in the generation of excess halite. This suggests that the efficiency of SLZ transforming to sodalite increases with higher salt loadings.

The amount of glass used to make the CWF does not affect the relative amounts of sodalite, halite, and nepheline that form. This is consistent with the hypothesis that sodalite, halite, and nepheline phases result from the transformation of SLZ and that the glass serves primarily as a binder to consolidate the crystalline phases and does not participate in the other reactions. This study indicates that similar amounts of halite and nepheline are generated in CWF materials made with salt contents outside the processing range of 3.4-3.9 $\mathrm{Cl}^{--}$per pseudo unit cell of the zeolite (10.6-11.2 mass \% salt) up to at least 20 mass \% salt. 
Table IV-5. Formulation and Measured Compositions of Salt-Loaded CWF Materials, as Mass Fraction

\begin{tabular}{|c|c|c|c|c|c|c|c|c|}
\hline Product & $\begin{array}{c}\text { Salt in } \\
\text { SLZ }\end{array}$ & $\begin{array}{c}\text { SLZ in } \\
\text { CWF }\end{array}$ & $\begin{array}{c}\text { Glass in } \\
\text { CWF }\end{array}$ & Al & B & Ba & Ca & Cl \\
\hline S1A & 0.050 & 0.750 & 0.250 & 0.149 & 0.0138 & 0.00225 & 0.00174 & 0.0283 \\
\hline S2C & 0.075 & 0.750 & 0.250 & 0.143 & 0.0145 & 0.00242 & 0.00180 & 0.0354 \\
\hline S3A & 0.107 & 0.750 & 0.250 & 0.137 & 0.0144 & 0.00255 & 0.00177 & 0.0438 \\
\hline S3C & 0.107 & 0.750 & 0.250 & 0.138 & 0.0146 & 0.00261 & 0.00174 & 0.0437 \\
\hline S3E & 0.107 & 0.750 & 0.250 & 0.121 & 0.0146 & 0.00249 & 0.00174 & 0.0466 \\
\hline S4A & 0.125 & 0.750 & 0.250 & 0.137 & 0.0153 & 0.00269 & 0.00176 & 0.0497 \\
\hline S5B & 0.150 & 0.750 & 0.250 & 0.133 & 0.0147 & 0.00284 & 0.00174 & 0.0543 \\
\hline G1A & 0.107 & 0.800 & 0.200 & 0.143 & 0.0118 & 0.00230 & 0.00155 & 0.0599 \\
\hline G2A & 0.107 & 0.775 & 0.225 & 0.144 & 0.0131 & 0.00237 & 0.00167 & 0.0528 \\
\hline G4A & 0.107 & 0.725 & 0.275 & 0.141 & 0.0167 & 0.00284 & 0.00177 & 0.0440 \\
\hline G5A & 0.107 & 0.700 & 0.300 & 0.127 & 0.0175 & 0.00295 & 0.00194 & 0.0423 \\
\hline
\end{tabular}

\begin{tabular}{|c|c|c|c|c|c|c|c|c|}
\hline Product & $\mathrm{Ce}$ & $\mathrm{Cr}$ & $\mathrm{Cs}$ & $\mathrm{Eu}$ & $\mathrm{Fe}$ & $\mathrm{K}$ & $\mathrm{La}$ & $\mathrm{Li}$ \\
\hline S1A & 0.000333 & 0.000327 & 0.00064 & 0.000008 & 0.00140 & 0.00859 & 0.00018 & 0.00175 \\
\hline S2C & 0.000142 & 0.000224 & 0.00103 & 0.000006 & 0.00140 & 0.0111 & 0.00004 & 0.00242 \\
\hline S3A & 0.000128 & 0.000371 & 0.00140 & 0.000007 & 0.00160 & 0.014 & 0.00004 & 0.00340 \\
\hline S3C & 0.000133 & 0.000297 & 0.00146 & 0.000007 & 0.00153 & 0.01502 & 0.00004 & 0.00338 \\
\hline S3E & 0.000124 & 0.000413 & 0.00139 & 0.000006 & 0.00172 & 0.0149 & 0.00004 & 0.00355 \\
\hline S4A & 0.000116 & 0.000475 & 0.00166 & 0.000006 & 0.00163 & 0.0173 & 0.00003 & 0.00399 \\
\hline S5B & 0.000119 & 0.000556 & 0.00200 & 0.000006 & 0.00196 & 0.0199 & 0.00004 & 0.00505 \\
\hline G1A & 0.000127 & 0.000787 & 0.00200 & 0.000007 & 0.00203 & 0.0207 & 0.00004 & 0.00542 \\
\hline G2A & 0.000104 & 0.000633 & 0.00173 & 0.000005 & 0.00155 & 0.0187 & 0.00004 & 0.00466 \\
\hline G4A & 0.000144 & 0.000197 & 0.00144 & 0.000005 & 0.00118 & 0.0147 & 0.00005 & 0.00325 \\
\hline G5A & 0.000148 & 0.000319 & 0.00137 & 0.000005 & 0.00140 & 0.0142 & 0.00004 & 0.00312 \\
\hline
\end{tabular}

\begin{tabular}{|c|c|c|c|c|c|c|c|c|}
\hline Product & $\mathrm{Mg}$ & $\mathrm{Mn}$ & $\mathrm{Mo}$ & $\mathrm{Na}$ & $\mathrm{Ni}$ & $\mathrm{Nd}$ & $\mathrm{P}$ & $\mathrm{Pb}$ \\
\hline S1A & 0.00006 & 0.00003 & 0.00001 & 0.130 & 0.00012 & 0.00052 & 0.00006 & 0.00001 \\
\hline S2C & 0.00006 & 0.00005 & 0.00001 & 0.128 & 0.00008 & 0.00037 & 0.00007 & 0.00001 \\
\hline S3A & 0.00006 & 0.00006 & 0.00001 & 0.123 & 0.00012 & 0.00035 & 0.00006 & 0.00001 \\
\hline S3C & 0.00006 & 0.00004 & 0.00001 & 0.125 & 0.00010 & 0.00038 & 0.00006 & 0.00000 \\
\hline S3E & 0.00006 & 0.00008 & 0.00001 & 0.111 & 0.00013 & 0.00036 & 0.00006 & 0.00001 \\
\hline S4A & 0.00006 & 0.00009 & 0.00001 & 0.124 & 0.00024 & 0.00034 & 0.00007 & 0.00001 \\
\hline S5B & 0.00006 & 0.00008 & 0.00001 & 0.116 & 0.00024 & 0.00030 & 0.00007 & 0.00001 \\
\hline G1A & 0.00005 & 0.00010 & 0.00001 & 0.126 & 0.00029 & 0.00037 & 0.00006 & 0.00000 \\
\hline G2A & 0.00006 & 0.00009 & 0.00001 & 0.129 & 0.00011 & 0.00027 & 0.00006 & 0.00000 \\
\hline G4A & 0.00006 & 0.00004 & 0.00001 & 0.123 & 0.00009 & 0.00040 & 0.00007 & 0.00000 \\
\hline G5A & 0.00006 & 0.00004 & 0.00001 & 0.117 & 0.00012 & 0.00041 & 0.00008 & 0.00000 \\
\hline
\end{tabular}

\begin{tabular}{|c|c|c|c|c|c|c|c|c|}
\hline Product & $\mathrm{Pr}$ & $\mathrm{Rb}$ & $\mathrm{Si}$ & $\mathrm{Sr}$ & $\mathrm{Ti}$ & $\mathrm{Y}$ & $\mathrm{Zr}$ & $\begin{array}{c}\mathrm{Cl}^{-} \text {per } \\
\text { unit cell }\end{array}$ \\
\hline $\mathrm{S} 1 \mathrm{~A}$ & 0.00016 & 0.00007 & 0.203 & 0.00032 & 0.00122 & 0.00008 & 0.00028 & 1.51 \\
\hline $\mathrm{S} 2 \mathrm{C}$ & 0.00009 & 0.00010 & 0.204 & 0.00041 & 0.00124 & 0.00003 & 0.00028 & 2.32 \\
\hline $\mathrm{S} 3 \mathrm{~A}$ & 0.00009 & 0.00016 & 0.197 & 0.00052 & 0.00120 & 0.00003 & 0.00028 & 3.43 \\
\hline $\mathrm{S} 3 \mathrm{C}$ & 0.00009 & 0.00016 & 0.200 & 0.00051 & 0.00121 & 0.00003 & 0.00028 & 3.43 \\
\hline $\mathrm{S} 3 \mathrm{E}$ & 0.00008 & 0.00016 & 0.192 & 0.00051 & 0.00119 & 0.00003 & 0.00028 & 3.43 \\
\hline $\mathrm{S} 4 \mathrm{~A}$ & 0.00008 & 0.00019 & 0.203 & 0.00057 & 0.00120 & 0.00003 & 0.00028 & 4.09 \\
\hline S5B & 0.00007 & 0.00023 & 0.203 & 0.00064 & 0.00115 & 0.00005 & 0.00028 & 5.05 \\
\hline G1A & 0.00008 & 0.00024 & 0.198 & 0.00063 & 0.00114 & 0.00004 & 0.00023 & 3.43 \\
\hline G2A & 0.00006 & 0.00022 & 0.196 & 0.00065 & 0.00117 & 0.00005 & 0.00025 & 3.43 \\
\hline G4A & 0.00009 & 0.00016 & 0.217 & 0.00051 & 0.00121 & 0.00004 & 0.00031 & 3.43 \\
\hline G5A & 0.00009 & 0.00016 & 0.208 & 0.00052 & 0.00115 & 0.00003 & 0.00033 & 3.43 \\
\hline
\end{tabular}




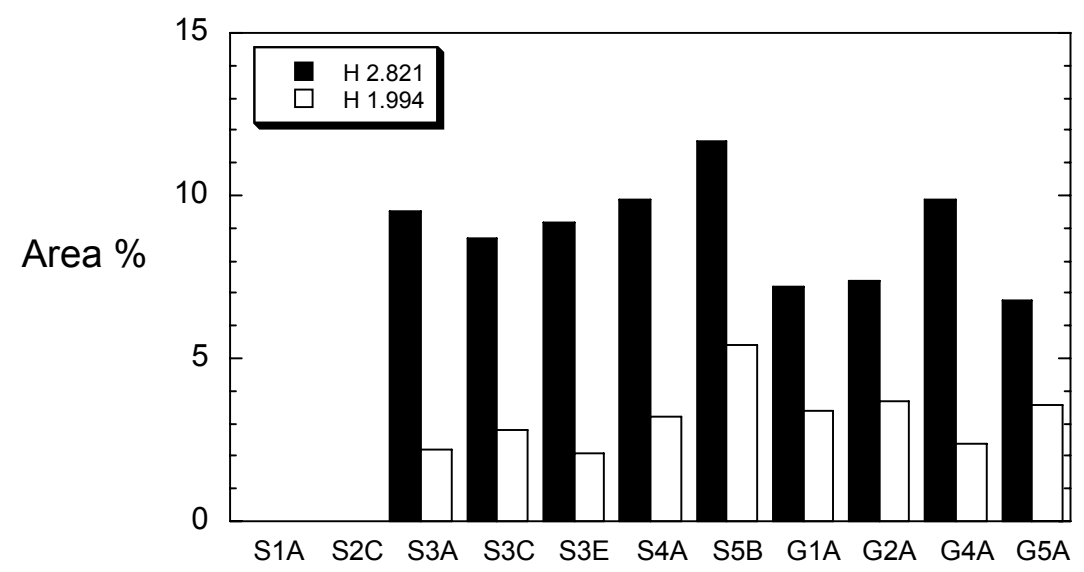

(a)

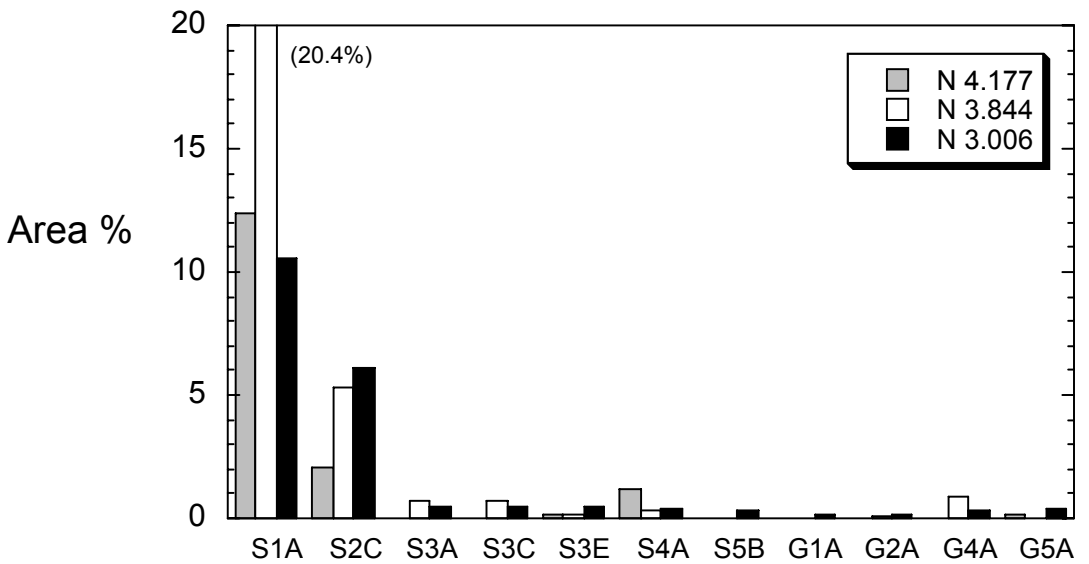

(b)

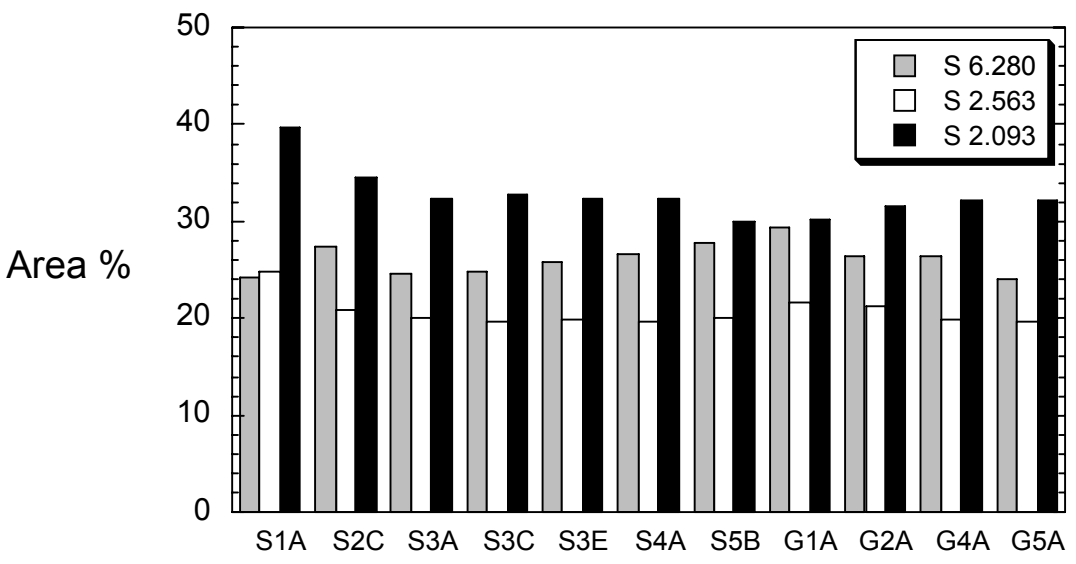

(c)

Fig. IV-9. Amounts of (a) Halite, (b) Nepheline, and (c) Sodalite Formed in Salt-Loaded CWF Materials. Amounts were determined as area \% values of several XRD peaks (d-spacings in $\AA$ are given in legends of plots). 


\section{IV.A.9. Thermal Stability of the CWF Phase Composition}

The OCRWM WASRD requires that waste form producers provide TTT information to assure that unplanned heating (e.g., due to a process upset) will not adversely affect the durability of high-level radioactive waste forms. Although the concern regards devitrification of glass waste forms, the possible effects of heating on the durability of the CWF must also be evaluated. To support qualification, tests were conducted to identify any changes in the phase assemblage of the CWF due to heat-treatments at various temperatures and durations, including the relative amounts of each phase.

In contrast to standard borosilicate glass waste forms, which typically contain only about 1 or 2 volume $\%$ crystalline inclusion phases, the CWF contains about 75 volume \% crystalline phases and 25 volume \% borosilicate binder glass. Despite the relatively low binder glass content, the chemical durability of the CWF under repository-relevant conditions depends strongly on the durability of the binder glass phase. This is discussed in Section IV.B. Changes in the glass composition that occur due to changes in the phase assemblage, such as the formation of new alumino-silicate phases, could affect the durability of the glass and, therefore, the durability of the CWF. Previous work has shown that the dissolution of sodalite into the binder glass slightly enhances the glass durability, presumably by increasing its aluminum and silicon content. (Jeong et al., 2002, Section 3.6) However, an increase in the halite content could lower the durability of the CWF. Therefore, a key objective in this series of tests and the TTT diagram to be constructed was to determine changes in the halite and nepheline contents as CWF material was heated. Insight into changes in the halite content was provided directly by XRD analysis of the heat-treated materials and indirectly by the rapid water soluble (RWS) tests that were conducted prior to PCTs.

Samples from two series of heat-treatment studies were analyzed with XRD to measure the phase composition and provide data for constructing the TTT diagram (Ebert et al., 2005). The first set of CWF samples had been heat-treated at $400^{\circ} \mathrm{C}$ and $500^{\circ} \mathrm{C}$ for durations between one week and one year; these are referred to as long-term heat-treated CWF materials. A second set of samples were heat-treated at 600 , 700,800 , or $850^{\circ} \mathrm{C}$ for durations between 4 and 100 hours; these are referred to as short-term heat-treated CWF materials. The short-term heat-treated materials provide insight into the impact of exceeding processing parameters of time and temperature. The phase stability of the short-term heat-treated CWF materials is also pertinent to waste form behavior under a volcanic intrusion event in the repository. The long-term heat-treated materials provide insight into the stability of waste forms during storage prior to emplacement in the repository.

\section{IV.A.9.1. XRD of Heat-Treated CWF Materials}

The CWF source materials used in the heat treatments had been prepared previously with the nominal proportions of salt, zeolite, and binder glass with 75.0 mass \% SLZ and 25.0 mass \% binder glass and heated at $915^{\circ} \mathrm{C}$ for 16 hours then cooling at about $5^{\circ} \mathrm{C}$ per minute. The CWF product that was heat treated is referred to as PC10402. Test samples were prepared by first core-drilling 1.5-cm-diameter cylinders from the CWF products and then cutting the cores into 3-cm-long samples using a low-speed saw with a diamond wafering blade. The coring and cutting steps were performed using absolute ethanol as the cutting fluid to minimize loss of exposed halite inclusions. Enough samples were prepared for treatment of two specimens under each time-temperature condition to provide sufficient material to conduct XRD analysis and one PCT. Several samples were retained for use in replicate XRD analysis and PCTs as a "no heat" CWF source material for comparison with the heat-treated samples and to provide a measure of the uncertainty in the analyses and testing.

The heat treatments at $600,700,800$, and $850^{\circ} \mathrm{C}$ were conducted in a small electrical furnace that was adjusted to the desired temperature and allowed to stabilize. Two samples that were to be heat-treated at that temperature for the same duration were placed in a platinum crucible, which was then placed into the 
furnace. Samples to be heated at the same temperature but for different durations were placed in the furnace at the appropriate times so that they could be cooled simultaneously. At the end of the heat treatment, the power to the furnace was turned off with the samples left in the furnace. For example, the oven temperature cooled from $800{ }^{\circ} \mathrm{C}$ to $240^{\circ} \mathrm{C}$ after 3.5 hours, which is assumed to be fast enough to retain the crystal phase assemblage. Other samples of PC CWF that had been heat-treated at $400^{\circ} \mathrm{C}$ and $500^{\circ} \mathrm{C}$ for up to one year were also analyzed.

The XRD analyses were conducted with crushed samples in the $-200+325$ mesh size fraction. The complete results are provided elsewhere (Ebert et al., 2005). The following summarizes the analyses and results. Most of the spectral peaks could be identified by matching with peaks in sodalite, halite, and nepheline reference spectra based on d-spacings and relative peak intensities. Five samples of the source material were analyzed with XRD to determine the repeatability of the analysis. Figure IV-10 shows the XRD spectra of samples that were heat-treated at $400^{\circ} \mathrm{C}$ for 1 year and at $850^{\circ} \mathrm{C}$ for 100 hours. Ribbon bars are shown below the spectrum to identify the peak locations and relative intensities of reference spectra of sodalite (file No 37-0476), nepheline (file No. 35-0424), and halite (File No. 05-0628) in the International Centre for Diffraction Data powder diffraction file data base. The few remaining peaks that did not match those of sodalite, nepheline, or halite could not be matched to any other reference material in the data base. Table IV-6 provides a summary of the relative peak areas matched to peaks in reference spectra of halite, sodalite, and nepheline for the replicate analyses. The sodalite $3.624 \AA$ peak was the most intense peak in all spectra and the areas of all peaks are given relative to the area of that peak. No peaks matched to the major nepheline peaks.

The relative amounts of sodalite, nepheline, and halite were assessed based on the relative areas of the major peaks for each component. Figures IV-11 and IV-12 compare the areas of the major peaks measured in spectra of the materials heat treated at $400^{\circ} \mathrm{C}$ and $500^{\circ} \mathrm{C}$ for long durations and at $600-850^{\circ} \mathrm{C}$ for shorter durations, respectively. The sodalite $3.624 \AA$ peak was the most intense peak in all spectra and the heights and areas of all other peaks are give relative to height and area of that peak. The horizontal lines drawn in Figs. IV-12a and IV-12b show the average peak areas in spectra with the source CWF material. (A sample of the source material used in treatments at $400^{\circ} \mathrm{C}$ and $500^{\circ} \mathrm{C}$ was not available, and it is assumed that the halite, sodalite, and nepheline contents are similar to PC10402.) Similar amounts of halite were detected in all samples, although there was some variability in the peak areas. Quantitation of the halite peaks is discussed in Section IVA.7. Nepheline was detected in samples treated at $800^{\circ} \mathrm{C}$ and $850^{\circ} \mathrm{C}$, but only a few peaks were matched with nepheline in samples heated at lower temperatures and most of these matches are probably fortuitous. The nepheline peaks were not quantified.

\section{IV.A.9.2. Quantification of Halite in Nominal CWF Composition}

The halite content of the nominal CWF source material PC10402 used in the short-term heat-treatment study discussed above was measured with XRD using the method of standard addition. A cored sample of CWF material PC10402 that had been prepared as part of the short-term heat treatment series was crushed with a laboratory mill and sieved to isolate about $2.55 \mathrm{~g}$ of the $-200+325$ mesh size fraction, and analytical grade $\mathrm{NaCl}$ was crushed and sieved to -200 mesh. Samples of the crushed CWF were weighed into vials and small amounts of salt were added to generate samples with 4.57, 5.46, and 7.30 mass \% added $\mathrm{NaCl}$. The mixtures were passed through a 200 -mesh sieve to improve mixing and then analyzed with XRD. The peak area values for the major halite peaks at $2.821,1.994$, and $1.628 \AA$ are plotted against the amount of added $\mathrm{NaCl}$ in Fig. IV-13. The averages of the area \% values determined from replicate analyses of $\mathrm{PC} 10402$ (without added $\mathrm{NaCl}$ ) are plotted at $0 \%$ added $\mathrm{NaCl}$ in the figure. Linear regression was used to extrapolate data for each peak to $\mathrm{y}=0$ to determine the halite content of the CWF, which are: $1.83,1.86$, and 1.20 mass $\%$ based on the three fits. (The value $\mathrm{X}=0$ on the plot represents no added $\mathrm{NaCl}$ ). The average halite content of the crystalline phases is 1.6 mass $\%$. It must be remembered 


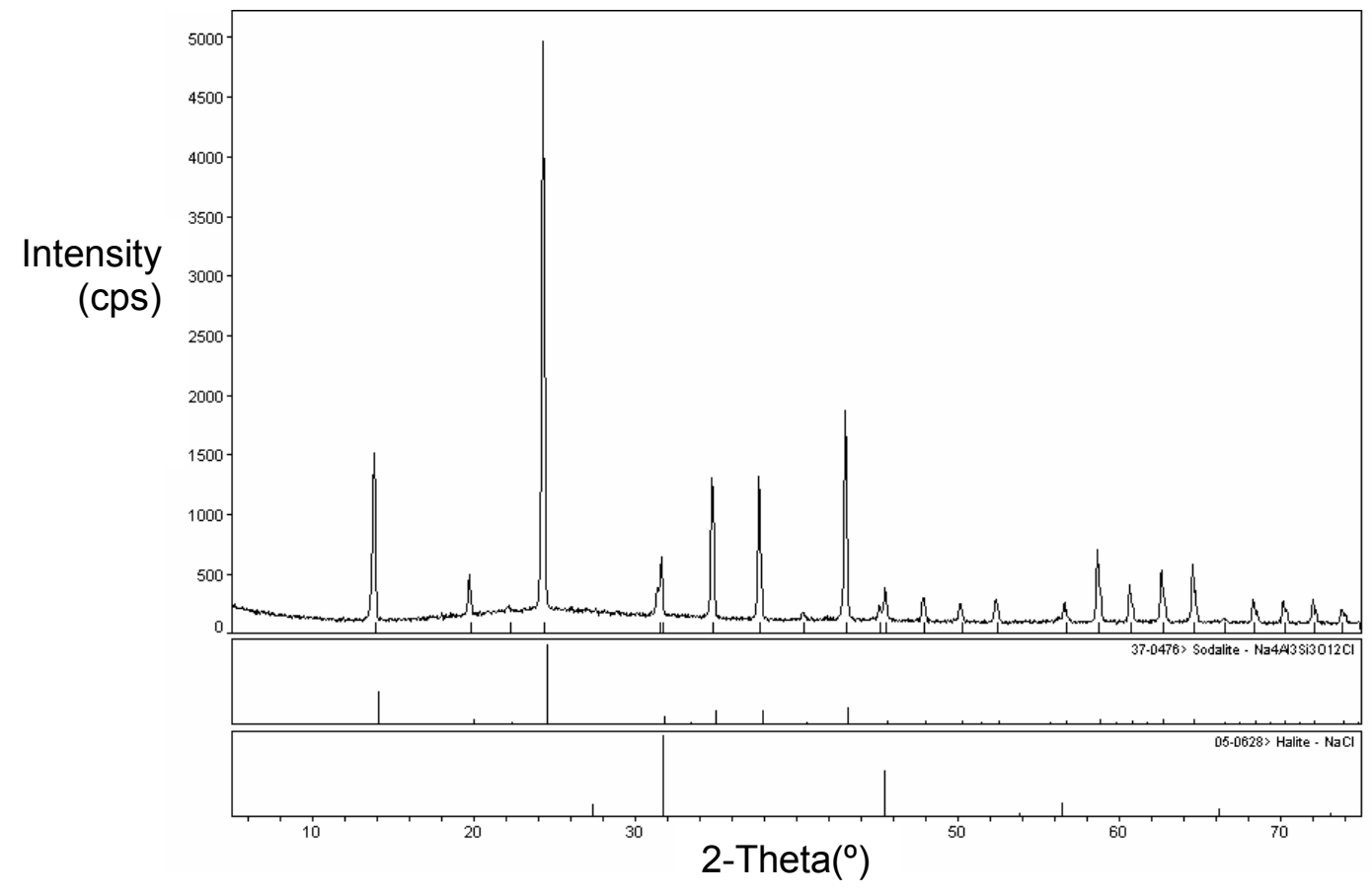

(a)

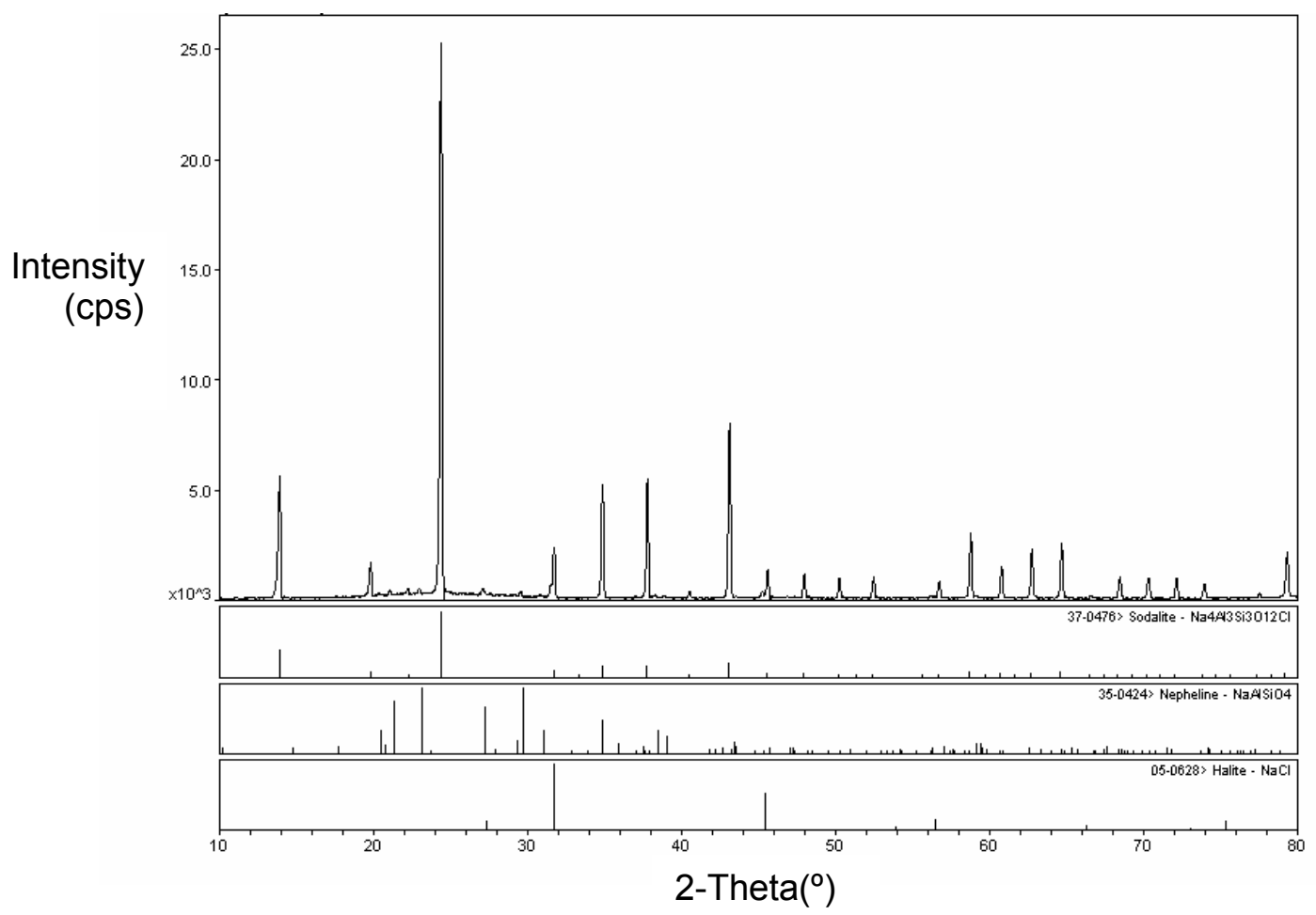

(b)

Fig. IV-10. XRD Spectrum of PC CWF Samples (a) Heated at $400^{\circ} \mathrm{C}$ for 1 Year and (b) Heated at $850^{\circ} \mathrm{C}$ for $100 \mathrm{~h}$. 
Table IV-6. Relative XRD Peak Areas for Replicate Analyses of Material PC10402 ${ }^{\mathrm{a}}$, in \%

\begin{tabular}{|c|c|c|c|c|c|c|}
\hline $\begin{array}{c}\text { d-spacing } \\
(\AA)\end{array}$ & Analysis 1 & Analysis 2 & Analysis 3 & Analysis 4 & Analysis 5 & mean $\pm 2 s^{b}$ \\
\hline \multicolumn{7}{|c|}{ Halite } \\
\hline 3.26 & 1.0 & 0.9 & nd & nd & nd & $0.4 \pm 1.0$ \\
\hline 2.821 & 5.6 & 6.1 & 5.6 & 5.6 & 4.5 & $5.5 \pm 1.2$ \\
\hline 1.994 & 2.4 & 2.3 & 2.6 & 2.5 & 2.6 & $2.5 \pm 0.3$ \\
\hline 1.628 & 0.6 & 0.8 & 0.7 & 0.9 & 0.6 & $0.7 \pm 0.3$ \\
\hline 1.41 & nd & nd & nd & nd & nd & 0 \\
\hline \multicolumn{7}{|c|}{ Sodalite } \\
\hline 6.28 & 23.8 & 26.9 & 25.8 & 23.9 & 27.0 & $25.5 \pm 3.2$ \\
\hline 3.624 & 100 & 100 & 100 & 100 & 100 & $100 \pm 0$ \\
\hline 2.563 & 18.4 & 18.5 & 18.2 & 18.3 & 20.8 & $18.8 \pm 2.2$ \\
\hline 2.373 & 18.6 & 18.9 & 18.3 & 19.1 & 19.7 & $18.9 \pm 1.1$ \\
\hline 2.093 & 28.2 & 27.2 & 25.6 & 27.0 & 28.7 & $27.3 \pm 2.4$ \\
\hline \multicolumn{7}{|c|}{ Nepheline } \\
\hline 4.3335 & nd & nd & nd & nd & nd & 0 \\
\hline 4.1766 & nd & nd & nd & nd & nd & 0 \\
\hline 3.8438 & nd & nd & nd & nd & nd & 0 \\
\hline 3.2731 & nd & nd & nd & nd & nd & 0 \\
\hline 3.0059 & nd & nd & nd & nd & nd & 0 \\
\hline 2.8864 & nd & nd & nd & nd & nd & 0 \\
\hline 2.3395 & nd & nd & nd & nd & nd & 0 \\
\hline
\end{tabular}

a "nd" indicates that a quantifiable peak was not detected at this d-spacing.

${ }^{\mathrm{b}}$ Mean \pm 2 standard deviations for 5 analyses; nd assigned value of 0 .

that this is the percentage of the crystalline phases in the CWF that are halite, not the percentage of CWF that is halite. Assuming that the glass content of CWF remained $25 \%$, the halite content of the CWF is about $0.75 \times 1.6$ mass $\%=1.2$ mass $\%$.

Heat treatments resulted in an increase in the area \% of the $2.821 \AA$ peak from about $5.5 \%$ in the sample that wasn't heat-treated to a $11.8 \%$ in the sample heated at $600^{\circ} \mathrm{C}$ for 28 hours. This indicates that the halite content had doubled. The $2.821 \AA$ peak with the greatest area was measured for the sample heated at $400^{\circ} \mathrm{C}$ for 4 weeks: $14.7 \%$. If the calibration of CWF material PC10402 is applicable, this indicates a 2.7 times increase in the halite content. Neither the long-term heat-treated CWF materials nor the shortterm heat-treated CWF materials indicate that the halite content depends on either the temperature or heating time.

\section{IV.A.9.3. Time-Temperature-Transformation Diagram}

The results of the heat treatment tests are summarized in a TTT diagram in Fig. IV-14. The ordinate is the treatment temperature and the abscissa is the duration the sample was heated. The 16 hours that the source material was heated during processing was added to all test durations. The dots show the timetemperature conditions that were evaluated. The conditions for the source material are included. Halite was detected in all samples. Conditions for which nepheline was detected in test samples are indicated by squares, including samples in which only a few peaks matched minor nepheline peaks. 


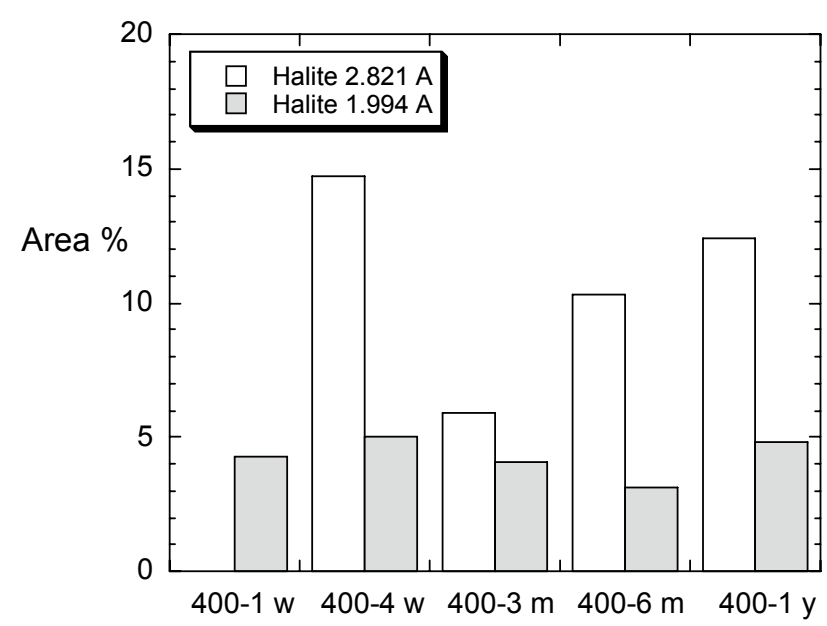

(a)

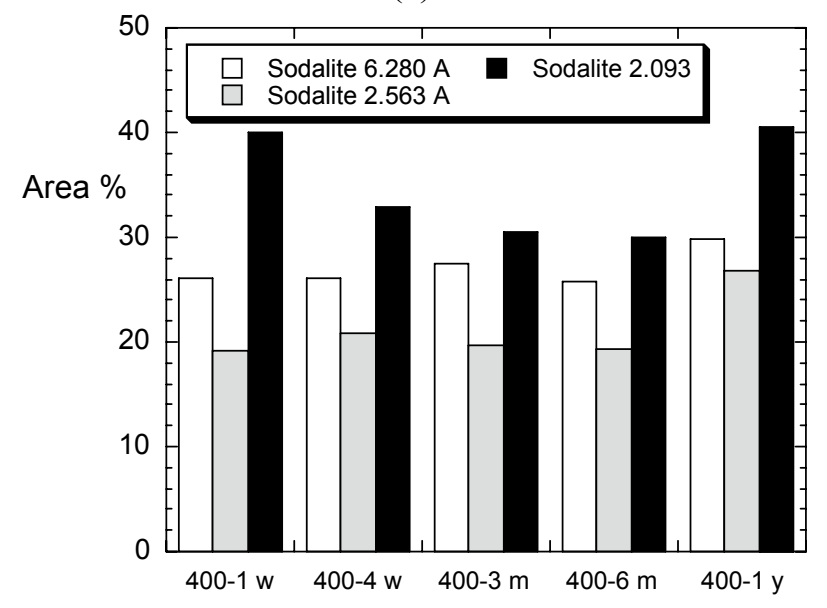

(c)

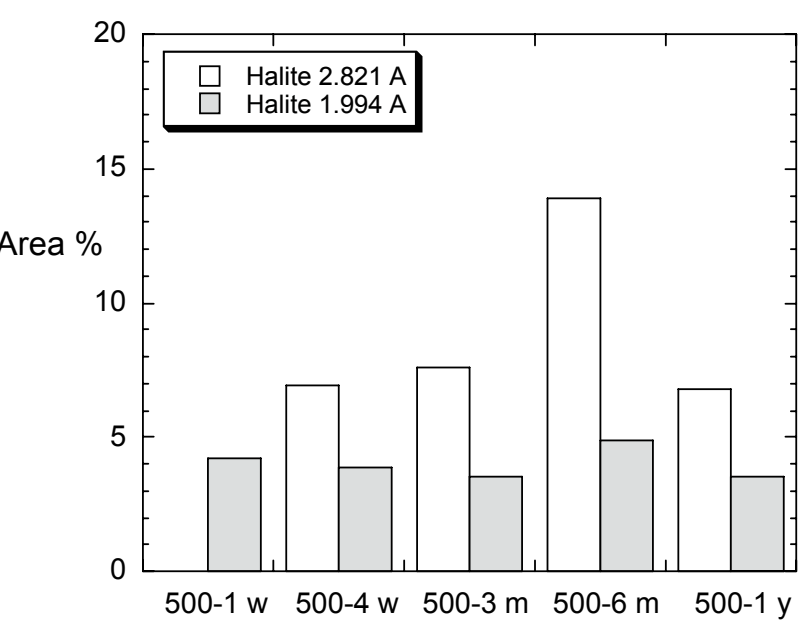

(b)

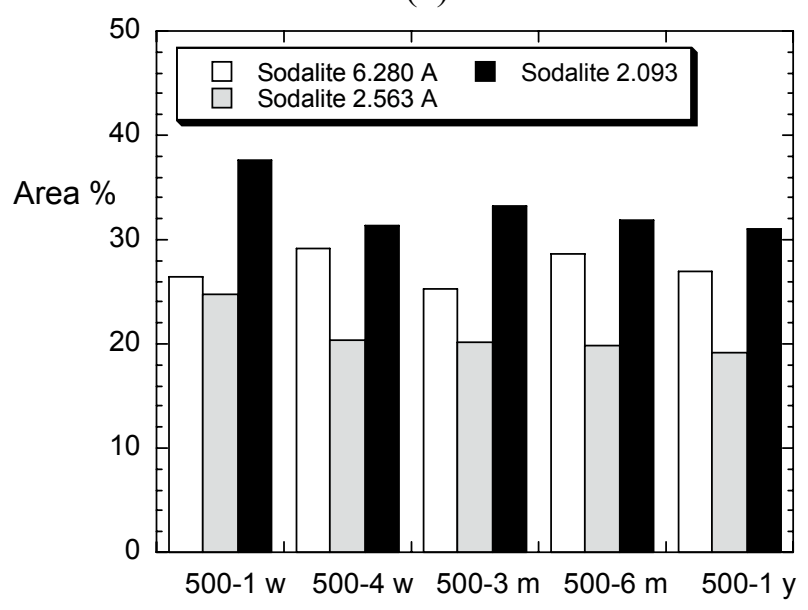

(d)

Fig. IV-11. Amounts of Halite and Sodalite in Long-Term Heat-Treated CWF Samples Heated for 1 Week, 4 Weeks, 3 Months, 6 Months, and 1 Year (based on area \%): Halite in Samples Heated at (a) $400^{\circ} \mathrm{C}$ and (b) $500^{\circ} \mathrm{C}$ and Sodalite in Samples Heated at (c) $400^{\circ} \mathrm{C}$ and (d) $500^{\circ} \mathrm{C}$.

The parabolic curve drawn in Fig. IV-14 qualitatively illustrates the TTT curve for the in-growth of nepheline to detectable levels. The curve is a simple empirical fit to the test results and is not intended to imply any knowledge of nucleation or growth kinetics. It was drawn to the left of samples in which only a few (possibly fortuitous) nepheline peaks were matched. Nepheline was not detected in several samples that lie to the right of the curve. These samples may contain concentrations of nepheline below the XRD detection limit. The nose of the TTT curve, which is the minimum time required to form nepheline, is drawn at 0.7 days at $850^{\circ} \mathrm{C}$. This is because two peaks were matched to nepheline for the sample heated at $850^{\circ} \mathrm{C}$ for four hours (plus the 16 hours it was processed at $915^{\circ} \mathrm{C}$ ). No major nepheline peak was detected in the samples heated at $600^{\circ} \mathrm{C}, 700^{\circ} \mathrm{C}$, or $800^{\circ} \mathrm{C}$ for 4 hours. Neither was nepheline detected in the CWF source material used to generate the TTT diagram (which was made by heating at $915^{\circ} \mathrm{C}$ for about 16 hours). Neither the detection limit for nepheline not the sensitivity of the XRD peak heights (or areas) to the nepheline content was determined. The curve represents the minimum time needed for a detectable amount of nepheline to grow in the CWF at a particular temperature. Depending on the time actual waste forms are processed at $915^{\circ} \mathrm{C}$ and their cooling rates after processing, the potential exists that small amounts of nepheline may nucleate and grow. However, as discussed in Section IV.E.1.2, this will not be detrimental to the chemical durability of the waste form. 


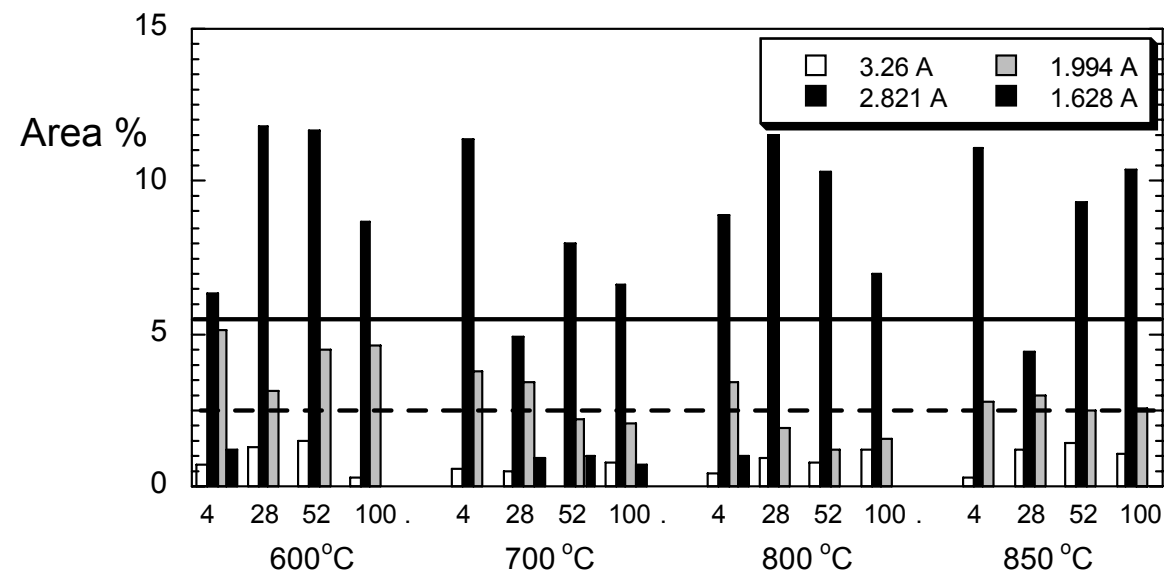

(a)

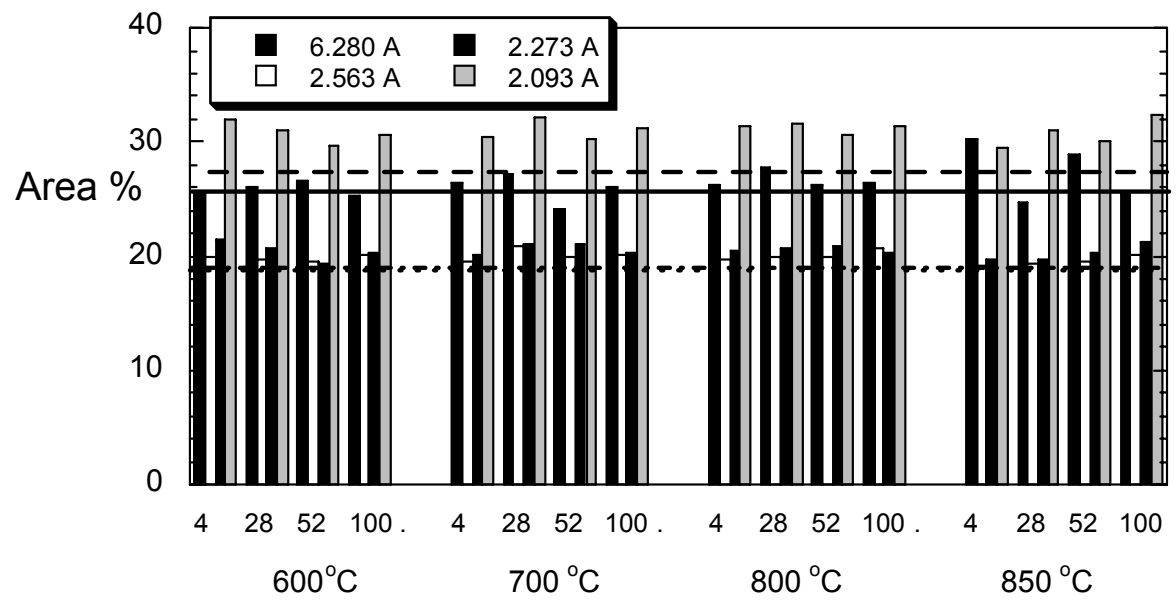

(b)

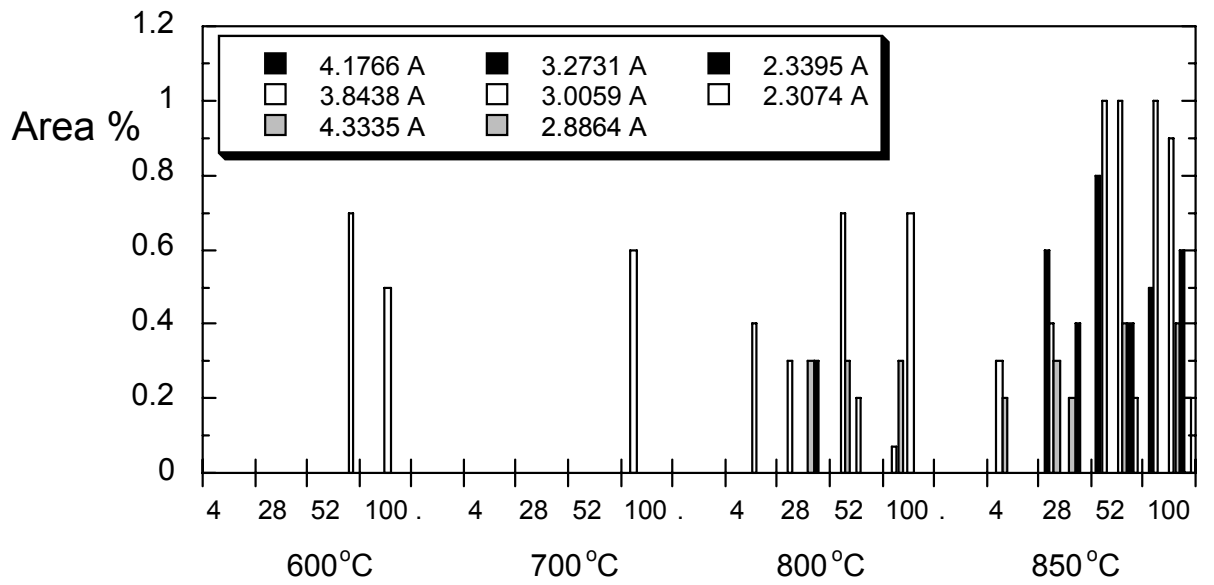

(c)

Fig. IV-12. Relative Amounts of (a) Halite, (b) Sodalite, and (c) Nepheline in Short-Term, Heat-Treated CWF Samples Heated for 4, 28, 52, or 100 hours at $600,700,800$, or $850^{\circ} \mathrm{C}$ (based on area \%). Horizontal lines show mean values measured for CWF source material PC10402 without heat treatment. 


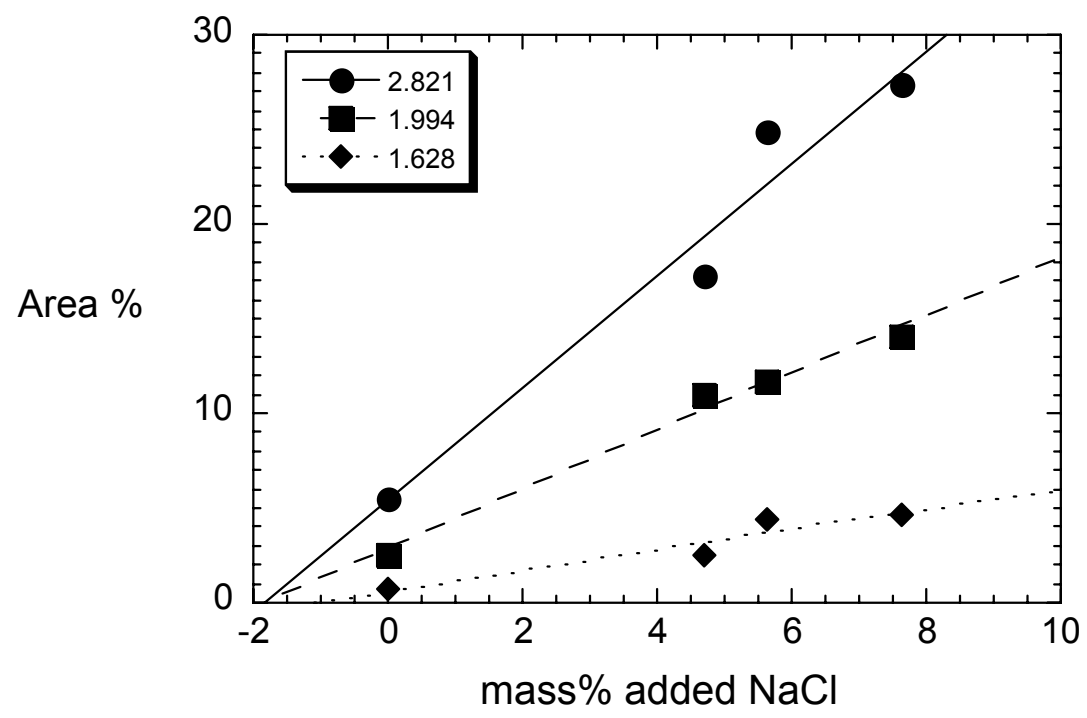

Fig. IV-13. Area Percent Values for Three Halite Peaks in XRD with PC CWF Material PC10402 with 0, 4.57, 5.46, and 7.30 Mass \% Added $\mathrm{NaCl}$.

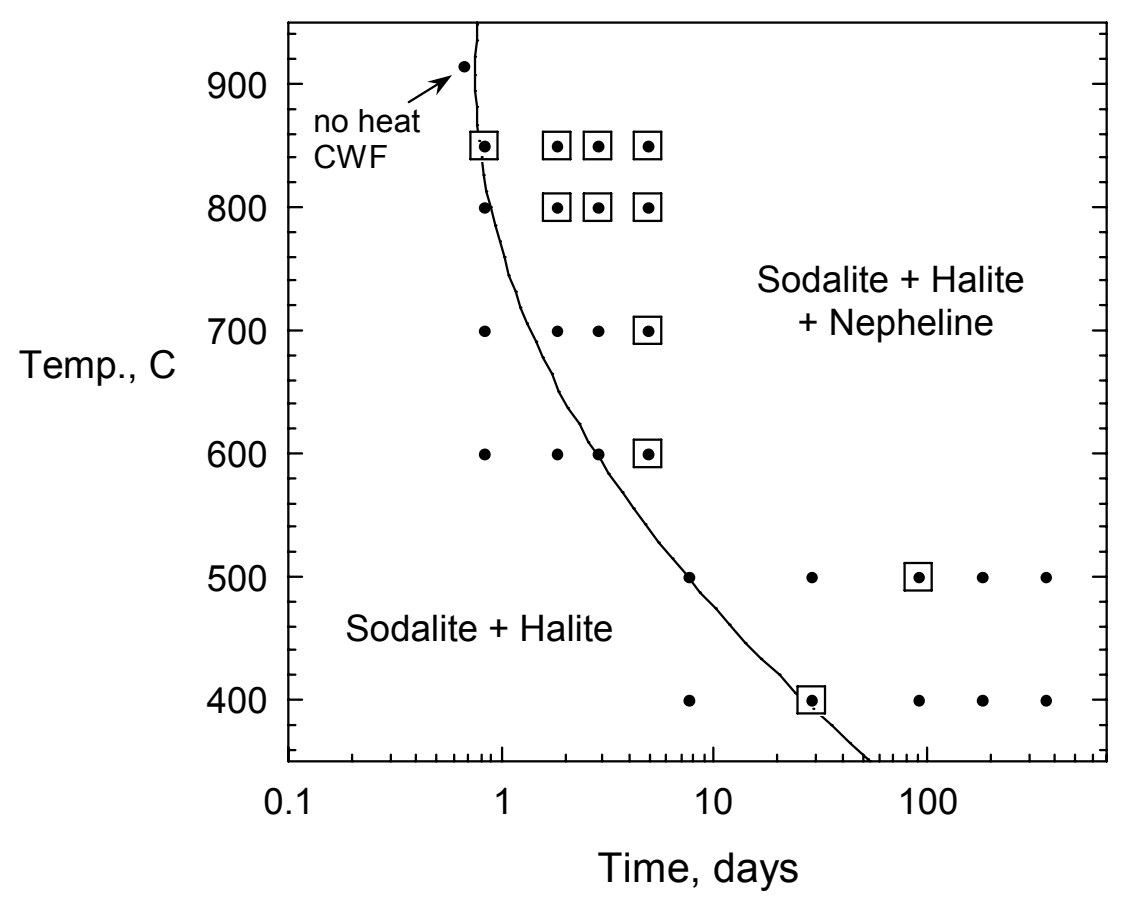

Fig. IV-14. Time-Temperature-Transformation Plot for Heat-Treated CWF Products. Halite was detected in all samples and all temperature-time conditions that were evaluated $(\bullet)$. Samples in which at least 1 nepheline peak was detected are identified by squares. The line shows an empirical TTT curve for nepheline formation. 


\section{IV.B. Degradation of CWF}

Tests to study the degradation behavior of CWF materials were conducted both with consolidated CWF materials and with the separate component phases to understand both chemical and physical interactions. Different test conditions were used to distinguish or highlight the dissolution of a particular phase, including the test duration, temperature, and solid surface area-to-solution volume (S/V) ratio. For example, some tests were conducted for short durations and at low $\mathrm{S} / \mathrm{V}$ ratios to maintain dilute solutions and minimize the feedback effects of dissolved components on the dissolution rate. Other tests were conducted at high $\mathrm{S} / \mathrm{V}$ ratios to generate solutions with high concentrations of dissolved components that had a significant impact on the dissolution rate.

Most of the tests conducted to characterize the corrosion behavior, develop a degradation model, and measure model parameter values were conducted with HIP CWF materials, which was the baseline waste form production method during EMT development and when the tests were run. Later tests were conducted with PC CWF materials to measure the reproducibility of the consistency test method, study composition effects, and measure the thermal stability of the phase composition. Several tests that had been conducted with HIP CWF were repeated using PC CWF to confirm that the corrosion behavior was the same for both materials, and some tests were conducted with both HIP CWF and PC CWF. Key tests conducted to understand the CWF corrosion mechanism and measure radionuclide release are discussed in the following sections.

\section{IV.B.1. Aqueous Corrosion Characteristics of the CWF Matrix Phases}

Test methods developed to study HLW glass corrosion were used to study CWF corrosion (Simpson and Wronkiewicz, 1997). Many of the tests conducted to study the aqueous corrosion behavior of the CWF were based on two methods that have been standardized by the ASTM: test method C1220 for static tests with monolithic samples and test method C1285 for static tests with crushed samples. In general, test method C1220 was used to study corrosion in dilute solutions to highlight the effect of the material and test method C1285 was used to study corrosion in concentrated solutions to highlight solution feedback effects. Comparisons of tests conducted under conditions that maintained dilute aqueous solutions with those that result in concentrated solutions provide valuable insight into degradation behavior of the CWF and its component phases.

\section{IV.B.1.1. Test Method ASTM C1220 (MCC-1 Test)}

The ASTM C1220 method (ASTM, 2005b) originated as Material Characterization Center Test Number 1 (Strachan et al., 1981), and is referred to herein as the MCC-1 test. The standard MCC-1 test is conducted by immersing a monolithic sample in the appropriate volume of demineralized water to achieve a sample surface area-to-solution volume $(\mathrm{S} / \mathrm{V})$ ratio of $10 \mathrm{~m}^{-1}$. (This corresponds to $10 \mathrm{~mL}$ solution per $\mathrm{cm}^{2}$ of sample area.) The $\mathrm{S} / \mathrm{V}$ ratio is commonly used to describe static test conditions. The test vessel is sealed and placed in an oven and left undisturbed for the desired test duration. At the end of the test duration, the concentrations of dissolved components in the test solution are measured. The concentrations of key elements in the solution are usually normalized to the $\mathrm{S} / \mathrm{V}$ ratio of the test and to the mass fraction of the element in the material being tested in what is referred to as the normalized mass loss, NL(i), which is calculated using Eq. IV-4

$$
N L(i)=\frac{C(i)-C^{\circ}(i)}{(S / V) \bullet f(i)}
$$


where $C(i)$ is the concentration of element $\mathrm{i}$ in the test solution, $C^{o}(i)$ is the concentration of element $\mathrm{i}$ in the leachant, and $f(i)$ is the mass fraction of element $i$ in the material used in the test. Note that NL(i) has the units of mass material per unit surface area (e.g., the mass and surface area of CWF), not the mass of the element used to calculate it. The surface area of the test sample is calculated geometrically based on the measured dimensions of the test sample. The extent of dissolution is determined based on the release of a particular element $i$, and will vary depending on which element is selected. Matrix elements with high solubility limits are most often used to represent the extent of matrix dissolution (e.g., sodalite and binder glass). The normalized mass loss calculation allows for direct comparisons of tests conducted with different materials, at different $\mathrm{S} / \mathrm{V}$ ratios, and using the solution concentrations of different elements.

The use of NL(i) to directly compare the dissolution rates of the homogeneous sodalite and binder glass phases with that of the multiphase CWF merits some discussion. Consider first the case of boron, which has a concentration of about 5.99 mass \% in the binder glass but is not contained in the zeolite or salt components (see Table IV-4). Since the nominal CWF is composed of 25 mass \% binder glass, the net B concentration in the CWF is 1.50 mass \%. Values of NL(B) for tests with CWF are calculated with Eq. IV-4 using the B concentration measured in the test solution and $f(B)=0.015$. The value of the denominator in Eq. IV-4 is the same whether B is only considered to be released from the $25 \%$ of the total CWF surface area that is binder glass with a B concentration of 5.99 mass $\%$, or if it is considered to be released from the entire CWF surface area containing an average B concentration of 1.50 mass $\%$.

The dissolution rate is determined from the results of tests conducted for different durations. The normalized dissolution rate is calculated using the normalized mass values as

$$
N R(i)=\frac{\Delta N L(i)}{\Delta t}
$$

In most cases, the normalized dissolution rate is determined from the slope of a plot of NL(i) against the test duration.

\section{IV.B.1.2. Test Method ASTM C1285 (PCT)}

Test method C1285 was developed to monitor the consistency of HLW glass waste forms during production, and is commonly referred to as the PCT (ASTM, 2005a). The ASTM standard includes two test methods: PCT method A and PCT method B. Method A is used to monitor the consistency of HLW glasses and is conducted using specified test conditions: crushed glass in the $-100+200$ mesh size fraction, demineralized water at a water-to-sample mass ratio of 10:1, Type 304L stainless steel vessel, and a seven-day test duration. Method B allows for other test conditions and is used to study the corrosion behavior.

The standardized PCT procedure is conducted using the $-100+200$ mesh size fraction. The crushed glass is washed prior to the test with water and then ethanol to remove fines generated during crushing. The same procedure is used to prepare the CWF for PCT, except that the crushed CWF is washed first with absolute ethanol and then with water. The PCT procedure addresses the presence of soluble phases in step 19.6.1 by recommending that the dissolution of the soluble phases during the wash steps be taken into account by analyzing the solution from the wash steps (ASTM, 2005a). The CWF contains a small amount of halite that is a soluble inclusion phase. For the CWF, the halite content is determined by first washing the crushed material with absolute ethanol to remove most of the fines, drying the material, and then briefly immersing it in demineralized water to dissolve the halite that is accessible at the surface. The ethanol wash solution is not analyzed because only the halite dissolved from the $-100+200$ mesh fraction to be used in the PCT is of interest — not halite in fines. Because halite is sparingly soluble in absolute 
ethanol, any $\mathrm{Na}$ and $\mathrm{Cl}^{-}$(and other components) present in the ethanol wash solution is assumed to have been in fines of crushed CWF and is ignored. For PCT conducted with CWF, the water wash step is referred to as the RWS test, and the solution that is generated is referred to as the RWS solution. The RWS test is conducted at the same CWF mass/water volume ratio that is used in the PCT, namely $10 \mathrm{~mL}$ water for every gram CWF. The CWF is either swirled in the water or ultrasonicated for about 1 minute, and then the RWS solution is decanted and passed through a $0.45-\mu \mathrm{m}$ pore-size filter to remove any suspended CWF particles. The RWS solution is typically analyzed for $\mathrm{Cl}^{-}$to determine the amount of halite that dissolved, although concentration of $\mathrm{Na}$ is sometimes measured instead. Since the CWF surface area-to-solution volumes are the same, the amounts of $\mathrm{Na}^{2}$ and $\mathrm{Cl}^{-}$dissolved in the RWS test can be added directly to the amounts of $\mathrm{Na}$ and $\mathrm{Cl}^{-}$released in the PCT to determine the total releases.

The RWS step was not used early in the testing program. Instead, a method referred to as the "accessible free salt measurement" (AFSM) was used. The AFSM was conducted by immersing a sample of crushed CWF in the $-200+325$ mesh size fraction in demineralized water and ultrasonicating for two minutes. The solution was then decanted and passed through a $0.1-\mu \mathrm{m}$ pore-size filter and analyzed for $\mathrm{Cl}^{-}$. The CWF used in early PCTs was washed with absolute ethanol to remove fines, but was not washed with water. The RWS step is simply a modification of the AFSM that makes use of the same size fraction used in the PCT and removes halite from the surface of the sample that is used in the PCT. The response of the sodalite and binder glass phases (and those of other inclusion phases) in the PCT is measured in demineralized water rather than a $\mathrm{NaCl}$ brine solution.

Although the PCT is conducted using a measured mass of crushed material, the surface area must be known to calculate NL(i) using Eq. IV-4 and dissolution rate. For convenience, the surface area and solution volume are often expressed in terms of the $\mathrm{S} / \mathrm{V}$ ratio that occurs in Eq. IV-4 because the solution concentrations are measured in the PCT test solutions. The solution volume is usually determined by the mass of demineralized water added when the test was started (the density is taken to be $1.00 \mathrm{~g} / \mathrm{cm}^{3}$ ). The surface area is calculated as the product of the mass of material used in the test and the specific surface area of the crushed material. The specific surface area is usually calculated from the particle size and density as given in Eq. IV-6:

$$
S_{p}=\frac{6}{\rho \bullet d}
$$

where $\rho$ is the density of the glass and $d$ is the diameter of the particle. The specific surface area has units of $\mathrm{m}^{2} / \mathrm{g}$. Although Eq. IV-6 is based on modeling the particles as spheres, the geometric shape that is used has an insignificant effect on the specific surface area that is calculated. Standard U.S. Series 100 and 200 mesh sieves have openings of 150 and $75 \mathrm{~m}$, so the $-100+200$ mesh fraction has an average particle diameter of $112 \mu \mathrm{m}$ (based on the arithmetic average). Most HLW glasses have densities near $2.7 \mathrm{~g} / \mathrm{cm}^{3}$, which gives a specific surface area of about $0.020 \mathrm{~m}^{2} / \mathrm{g}$. The $\mathrm{S} / \mathrm{V}$ ratio in a standard PCT conducted with HLW glass at a water-to-sample mass ratio of $10: 1$ is about $2000 \mathrm{~m}^{-1}$. The $\mathrm{S} / \mathrm{V}$ ratio of a PCT conducted with a less dense material, such as PC CWF, at a mass ratio of 10:1 will be greater than $2000 \mathrm{~m}^{-1}$ because less dense materials have higher specific surface areas. A meaningful comparison of PCT results of different materials must account for differences in the $\mathrm{S} / \mathrm{V}$ ratios due to differences in density. The bulk densities of HIP CWF and PC CWF materials are about $2.3 \mathrm{~g} / \mathrm{cm}^{3}$ and $2.0 \mathrm{~g} / \mathrm{cm}^{3}$, respectively. The PC CWF has a lower density because it contains about 10\% (closed) porosity. However, much of this porosity is lost when the PC CWF is crushed because the material fractures through pores, and the densities of crushed HIP CWF and PC CWF are essentially the same. From Eq. IV-6, a density of 2.3 $\mathrm{g} / \mathrm{cm}^{3}$ gives specific surface area of about $0.023 \mathrm{~m}^{2} / \mathrm{g}$. The standard PCT conducted with $1 \mathrm{~g} \mathrm{CWF}$ in $10 \mathrm{~g}$ water will have an $\mathrm{S} / \mathrm{V}$ ratio of $2300 \mathrm{~m}^{-1}$. 


\section{IV.B.1.3. Vapor Hydration Test (VHT)}

Modified vapor hydration tests (VHTs) were conducted at temperatures between 40 and $200^{\circ} \mathrm{C}$ to measure the release of soluble components at $100 \%$ relative humidity $(\mathrm{RH})$ under conditions in which both the water vapor uptake and CWF dissolution rates impact the release, but vapor transport limits are negligible. The VHT is usually conducted with just enough water added to the vessel to generate a film of water on the sample and saturate the vapor. A static film of water remains on the sample throughout the test, and components released as the material corrodes accumulate in the film, and alteration phases commonly precipitate on the sample. In the modified VHTs, an amount of water in excess of that needed to form a film on the sample and saturate the vapor is added at the beginning of the test. As the solution becomes more concentrated, additional water vapor can be taken up by the solution to dilute it and maintain equilibrium with the vapor phase. Since the amount of water that can remain on the sample is limited by gravity and surface tension, some of the solution will eventually drip off the waste form into the bottom of the test vessel. The dripping solution will carry dissolved waste form components with it. Fresh water vapor will continue to condense into the solution that remains on the sample as long as there is a gradient in the activity of water between the solution and the vapor. A reflux cycle in which water vapor condenses on the sample and solution drips off the sample will be maintained as long as the glass dissolves to maintain a deliquescent solution and water vapor is available to condense. The modified VHTs are interrupted periodically to remove the solution from the bottom of the vessel for analysis and replace it with fresh water. The accumulation of soluble components over time is used to measure the extent of CWF dissolution. The combined rate of water accumulation on the sample, waste form degradation, and solution dripping off the sample can be calculated from these results.

\section{IV.B.2. Release of Occluded Salt from Sodalite}

Since salt is occluded into the zeolite by diffusion of molten salt into the zeolite cages, it is expected that salt can diffuse out of the cages when the SLZ is contacted by water. It might also be expected that salt could diffuse out of the sodalite cages in the CWF. The release of salt from SLZ and from sodalite was addressed with a series of leach tests. Tests were conducted with individual grains of SLZ and with grains of sodalite made by heating the SLZ grains. These grains were typically $4-10 \mu \mathrm{m}$ in size. A small amount of glass was mixed with the SLZ when the sodalite was made because it was thought at the time that glass was needed to catalyze the conversion of SLZ to sodalite. (This has since been shown not to be the case.) The tests were conducted by immersing the SLZ and the sodalite in demineralized water at room temperature, then replacing the solution with fresh water after various immersion times. The solution was decanted from the test vessel and filtered before analysis. In anticipation of diffusion-controlled release with a square-root-of-time dependence, the solution replacement times were increased from several minutes to several weeks over the course of the test.

In total, samples of each material were exposed to eight charges of water over the 56-day total test duration. The concentrations of major cations in these solutions were measured in each solution. The results are shown in Fig. IV-15. In these plots, the releases of salt components are normalized to the release of silicon to show that release of salt components from the SLZ is diffusion-controlled, but that release salt components from the sodalite is not. Silicon is not present in the occluded salt, and its release is due to dissolution of the zeolite or sodalite. The releases of $\mathrm{Li}, \mathrm{Na}$, and $\mathrm{Cl}$ from the $\mathrm{SLZ}$ are all greater than the release of silicon (i.e., the data lie above the horizontal line drawn at a ratio of 1), but the releases of these ions from sodalite are similar to the release of silicon. This indicates that although these mobile ions readily diffuse out of the zeolite cages in the SLZ, they do not diffuse out of the sodalite. The amounts released to solution decrease with time because the small sample particles become depleted of these ions. The amounts of $\mathrm{Sr}$ and $\mathrm{Nd}$ in solution are probably solubility-limited and do not provide a reliable indication of their leachability. The release of Cs from the SLZ appears to occur slower than the 


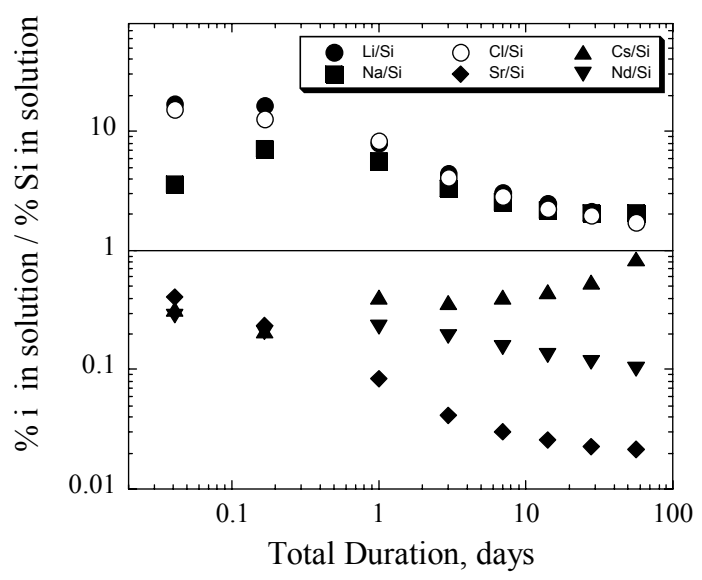

(a)

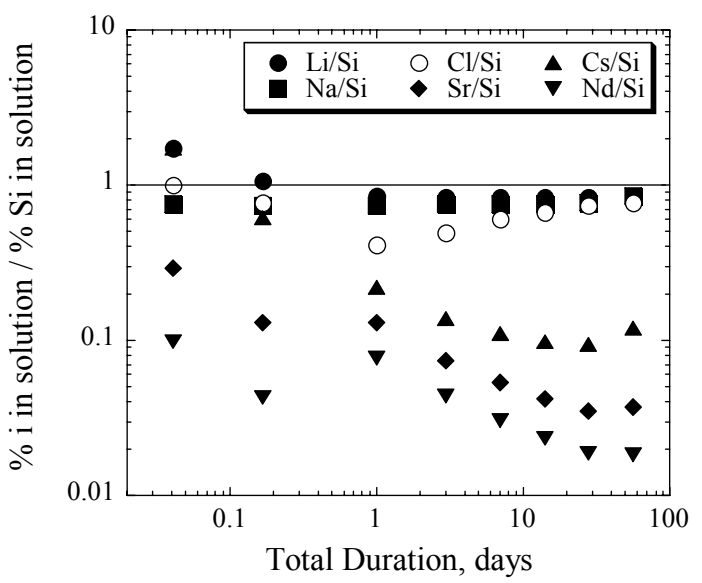

(b)

Fig. IV-15. Results of Solution Exchange Tests with (a) Salt-Loaded Zeolite and (b) Sodalite.

zeolite dissolves. This may reflect different release rates for elements occluded in the alpha and beta cage structures, or different dissolution rates for the two cages. The aperture of the beta cage is too small to accommodate Cs. Later tests showed that Cs is not incorporated into sodalite (Lambregts and Frank, 2002); sodalite provides only beta cages.

\section{IV.B.3. Immersion Test Results}

Many series of MCC-1 tests and PCTs have been conducted to study various aspects of CWF corrosion behavior, and selected results are presented in subsequent sections addressing specific aspects of CWF corrosion. Figures IV-16a and 16b show the results of representative MCC-1 tests and PCTs conducted for duration up to one year. The data at each duration represent the results from a separate batch test. (The PCTs were conducted with CWF that was washed with absolute ethanol to remove fines, but was not washed with water.) The different time dependencies of the $\mathrm{NL}(\mathrm{Cl}), \mathrm{NL}(\mathrm{B}), \mathrm{NL}(\mathrm{Na})$, and $\mathrm{NL}(\mathrm{Si})$ values indicate differences in the dissolution behaviors of the halite, binder glass, and sodalite phases under these different test conditions. Halite dissolution results in the release of $\mathrm{Na}$ and $\mathrm{Cl}$, glass dissolution results in the release of $\mathrm{B}, \mathrm{Na}$, and $\mathrm{Si}$, and sodalite dissolution results in the release of $\mathrm{Cl}, \mathrm{Na}$, and $\mathrm{Si}$. $\mathrm{By}$ comparing the release of each element with its relative abundance in each phase, the results reveal the extent to which each phase has dissolved under the MCC-1 and PCT conditions. The mass fractions of $\mathrm{Na}, \mathrm{Cl}, \mathrm{Si}$, and $\mathrm{B}$ in each of the three phases can be estimated based on the chemical formulas of halite and sodalite, and the binder glass compositions from Table IV-4, and by assuming that the CWF is composed of 3 mass \% halite, 70 mass \% sodalite, and 25 mass \% binder glass. The remaining $2 \%$ is due to sparingly soluble oxide and silicate inclusion phases, which are neglected for the present purposes. Changes in the binder glass composition due to small amounts of sodalite that may dissolve into the binder glass during processing are also neglected. The distributions of $\mathrm{Na}, \mathrm{Cl}, \mathrm{Si}$, and $\mathrm{B}$ between the three phases are given in Table IV-7 (this is different from the composition of the phase). Values are given as fractions of the total amounts of each element in the CWF that are in each phase. The ratios of the fractions of each element in each phase can be compared to the corresponding ratios in the test solutions as expressed by the normalized mass loss values. The values in Table IV-5 allow for comparisons with the NL(i) values, which are also calculated in terms of the mass fractions of elements in the CWF rather than the composition of each phase.

Consider first the relative releases of $\mathrm{Na}$ and $\mathrm{Cl}$. The ratio of the relative amounts of $\mathrm{Cl}$ and $\mathrm{Na}$ in the CWF that are present in halite is $0.258 / 0.074=3.5$ and the ratio present in sodalite is $0.742 / 0.849=0.87$. 


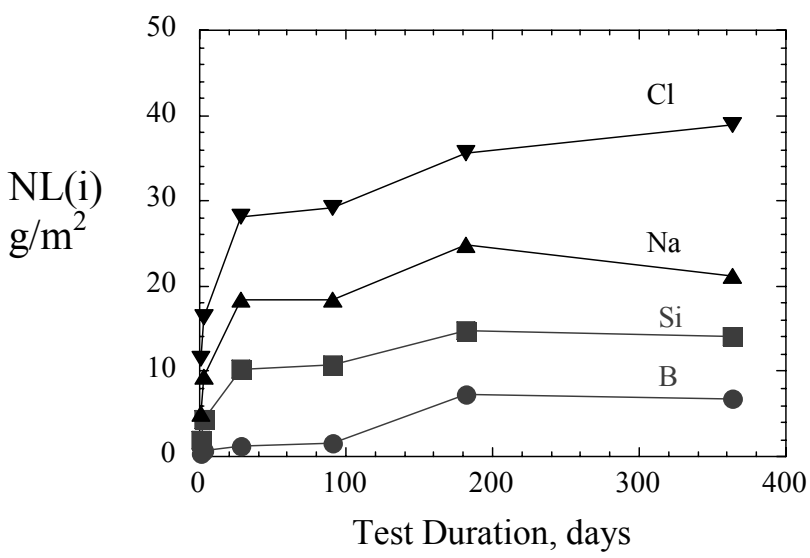

(a)

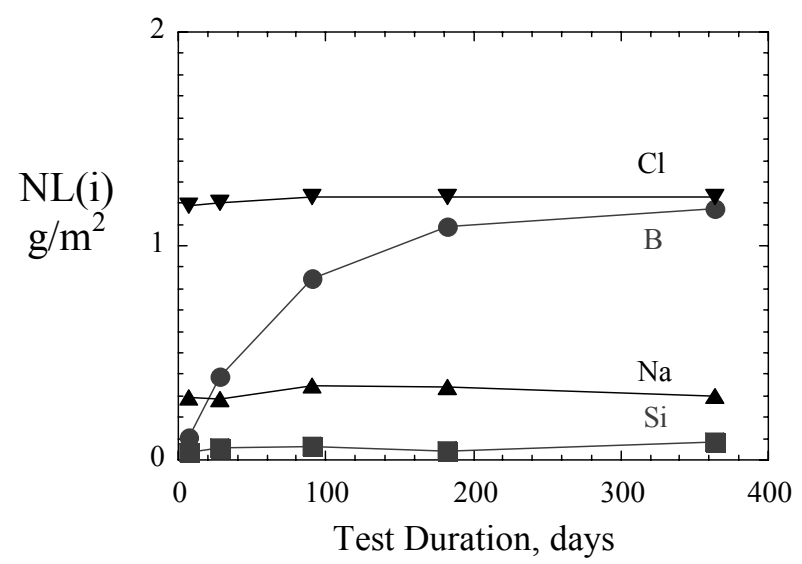

(b)

Fig. IV-16. Dissolution of CWF in (a) MCC-1 Tests and (b) PCTs (not water-washed).

Table IV-7. Estimated Elemental Distributions in CWF, as Mass Fraction

\begin{tabular}{|l|l|c|c|}
\hline \multicolumn{1}{|c|}{ Element } & Halite & Binder Glass & Sodalite \\
\hline In CWF: & 0.03 & 0.25 & 0.70 \\
\hline $\mathrm{Na}$ & 0.074 & 0.077 & 0.849 \\
\hline $\mathrm{Cl}^{-}$ & 0.258 & 0 & 0.742 \\
\hline $\mathrm{Si}$ & 0 & 0.373 & 0.627 \\
\hline $\mathrm{B}$ & 0 & 100 & 0 \\
\hline
\end{tabular}

This means that fraction of the total $\mathrm{Cl}$ that is present in halite is greater than the fraction of the total $\mathrm{Na}$, whereas a greater fraction of the total $\mathrm{Na}$ than the total $\mathrm{Cl}$ is present in sodalite. The composition of halite gives a $\mathrm{Cl} / \mathrm{Na}$ mass ratio of $35.5 / 23.0=1.54$, but the mass fraction of $\mathrm{Cl}$ that is present in the halite is 3.5 times greater than the mass fraction of $\mathrm{Na}$ that is in halite. It is the ratio of the fractions of elements in each phase that is being compared with the ratio of the normalized mass values. Therefore, $\mathrm{NL}(\mathrm{Cl}) / \mathrm{NL}(\mathrm{Na})$ ratios near 3.5 indicate that $\mathrm{Na}$ and $\mathrm{Cl}$ are released only due to halite dissolution, and ratios near 0.87 indicate that they are released only due to sodalite dissolution. The values of both $\mathrm{NL}(\mathrm{Cl})$ and NL(Na) increase continually with test duration under dilute solution conditions in MCC-1 tests (Fig. IV-16a), but the ratio remains near 1.5. This indicates that the $\mathrm{Na}$ and $\mathrm{Cl}$ released in the $\mathrm{MCC}-1$ tests result from dissolution of both halite and sodalite In the PCTs, the values of NL(Cl) and NL(Na) attain relatively high values within the first three days but remain nearly constant thereafter (Fig. IV-16b). The ratio $\mathrm{NL}(\mathrm{Cl}) / \mathrm{NL}(\mathrm{Na})$ is 4.0 . This indicates that essentially all of the $\mathrm{Na}$ and $\mathrm{Cl}$ released in the PCTs is due to dissolution of halite. The observation that very little additional $\mathrm{Na}$ or $\mathrm{Cl}$ is released after the shortest PCT duration studied indicates that only the halite exposed at the outer surface of the CWF is dissolved. Although the $\mathrm{NL}(\mathrm{Cl}) / \mathrm{NL}(\mathrm{Na})$ ratios attained in the PCTs are much higher than those attained in the MCC-1 tests, the absolute values of both $\mathrm{NL}(\mathrm{Cl})$ and $\mathrm{NL}(\mathrm{Na})$ are much lower in PCTs than they are in MCC-1 tests.

While the dissolution of halite occurs at the surface of CWF monoliths in MCC-1 tests just as it does in PCTs, the relative impact of halite dissolution on the MCC-1 test solution is dwarfed by dissolution of sodalite. The relative releases of Si and B are used as indicators of the relative extents of sodalite and binder glass dissolution. Silicon is present in both sodalite and the binder glass, whereas B is present only 
in the binder glass. The ratios of the fractions of the total amounts of $\mathrm{B}$ and $\mathrm{Si}$ in the $\mathrm{CWF}$ are $0.10 / 0.373=2.68$ for the binder glass and 0.0 for sodalite. Therefore, NL(B)/NL(Si) ratios near 2.68 indicate preferential dissolution of the binder glass relative to sodalite and ratios near zero indicate preferential dissolution of sodalite. Under the dilute solution conditions maintained in the MCC-1 tests (Fig. IV-16a), the ratio NL(B)/NL(Si) is about 0.1 at the shortest test duration and increases to about 0.5 after 1 year. Dissolution of sodalite clearly dominates CWF degradation under MCC-1 test conditions. Under PCT conditions, the ratio increases with test duration from about 2 initially to 12 after a year (Fig. IV-16b) and dissolution of binder glass dominates as the solution becomes more concentrated. The continued increase in the $\mathrm{NL}(\mathrm{B}) / \mathrm{NL}(\mathrm{Si})$ ratio at longer test durations is due to the degradation behavior of borosilicate glasses rather than the relative rates of sodalite and binder glass dissolution. The increase in the $\mathrm{Si}$ concentration slows the release of both $\mathrm{Si}$ and $\mathrm{B}$ from the glass.

The series of MCC-1 tests and PCTs discussed above provide the following insight into the dissolution behavior of the CWF: halite inclusions exposed at the outer surface of CWF materials dissolve immediately when contacted by water. Halite inclusions within the bulk CWF are shielded from water by both the sodalite and binder glass and cannot dissolve until the sodalite or binder glass phases dissolve to provide a pathway for water to contact them. Dissolution of sodalite occurs faster than dissolution of the binder glass when the dissolved Si concentrations are low (in MCC-1 tests), but dissolution of the binder glass occurs faster than dissolution of sodalite when the dissolved $\mathrm{Si}$ concentrations are high (in the PCTs). Insight from models developed for the dissolution of aluminosilicate minerals and borosilicate waste glasses suggested that solution feedback affected the dissolution rates of both sodalite and the binder glass.

The effect of the Si concentration on the relative dissolution rates of sodalite and binder glass was minimized by conducting short-term MCC-1 tests with the pure phases. Figure IV-17 shows the results of MCC-1 tests that indicate the dissolution rates of sodalite and borosilicate glass in highly dilute solutions are the same, within the experimental uncertainty. The high Si concentrations generated in the PCTs essentially stop sodalite from dissolving, but does not stop the binder glass from dissolving. As will be shown in Section IV.C.2.2, the solubility of sodalite is much lower than the "apparent solubility" of the binder glass. Glass is thermodynamically unstable and the apparent solubility refers to a solution composition in which the dissolution rate becomes immeasurably low.

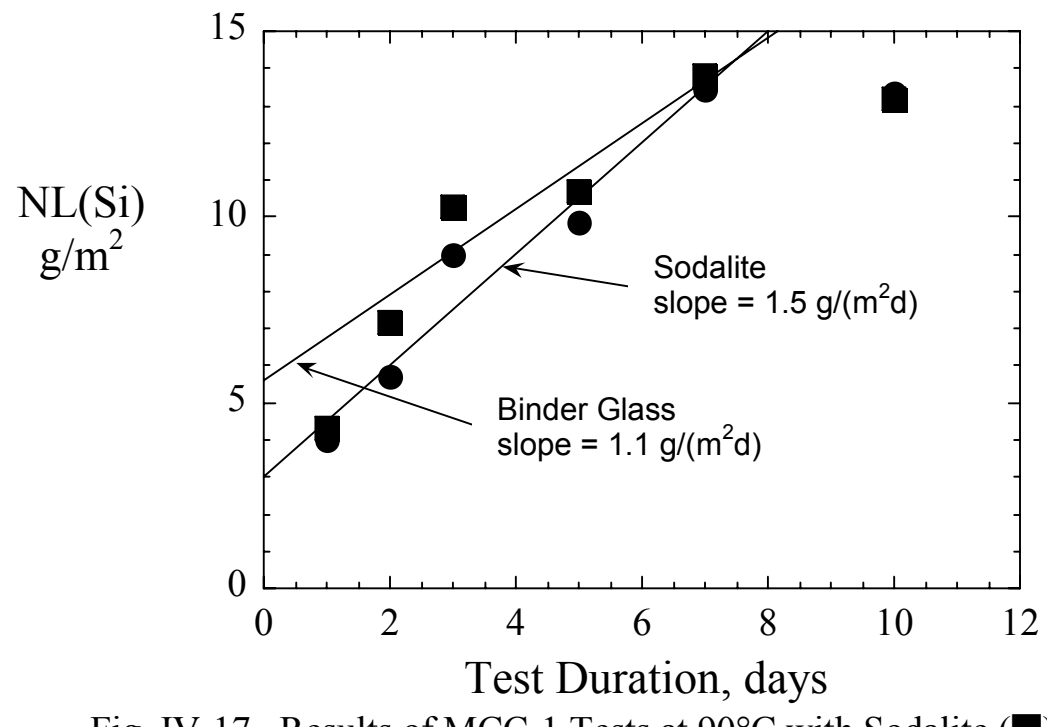

Fig. IV-17. Results of MCC-1 Tests at $90^{\circ} \mathrm{C}$ with Sodalite and Binder Glass $(\mathbf{O})$. 


\section{IV.B.4. Solution Exchange Tests with a 110-ppm $\mathrm{H}_{4} \mathrm{SiO}_{4}$ Solution}

A series of solution exchange tests were conducted in which monolithic samples of HIP CWF and PC CWF were reacted in a solution spiked with $110 \mathrm{ppm}_{4} \mathrm{SiO}_{4}(32 \mathrm{ppm} \mathrm{Si})$ in a modified MCC-1 test (Fanning et al., 2003). The solution is saturated with respect to sodalite, but not with respect to the binder glass (see Section IV.C.2.2). The tests were interrupted every 10 or 11 days, the solutions were removed for analysis and replaced with an equal amount of fresh leachant solution, and the test was continued. The exchange frequency was extended to 21 days after the initial five exchanges, and the final interval was 11 days. The release of B as NL(B) is plotted against the cumulative reaction time in Fig. IV-18 for tests with PC CWF and HIP CWF. The results for 10- and 11-day test intervals are shown by open symbols and the results for 21-day test intervals are shown by filled symbols. The increase in NL(B) is linear for both materials, but differs with the exchange interval. This is attributed to the increase in the $\mathrm{Si}$ concentrations between exchanges, which is greater during the 21-day intervals than during the 10- and 11-day intervals. The Si concentrations increase to $38.4 \pm 0.8 \mathrm{ppm}$ Si for tests with PC CWF and $37.9 \pm$ $0.4 \mathrm{ppm}$ Si for tests with HIP CWF during the 21-day intervals and to $33.9 \pm 0.6 \mathrm{ppm}$ Si for tests with PC CWF and $34.6 \pm 1.0 \mathrm{ppm}$ Si for tests with HIP CWF during the 10- and 11-day intervals. Separate regression lines are drawn for the different intervals to show the dissolution rates. The rates for the short and long exchange intervals are 0.21 and $0.13 \mathrm{~g} /\left(\mathrm{m}^{2} \mathrm{~d}\right)$ in tests with HIP CWF, and 0.17 and $0.087 \mathrm{~g} /\left(\mathrm{m}^{2} \mathrm{~d}\right)$ in tests with PC CWF. These values represent the average rates over each test interval and are not intrinsic to the material. They also provide insight into the relative effects of solution feedback for the two materials.

The rates determined from the release of B indicate dissolution of the binder glass only. It is presumed that net dissolution of sodalite does not occur. Figure IV-19 shows SEM photomicrographs of polished cross-sections of reacted samples recovered from the solution exchange tests. The dissolution of the HIP CWF occurs primary near the boundaries of sodalite and binder glass (see Figs. IV-19a and IV-19b),

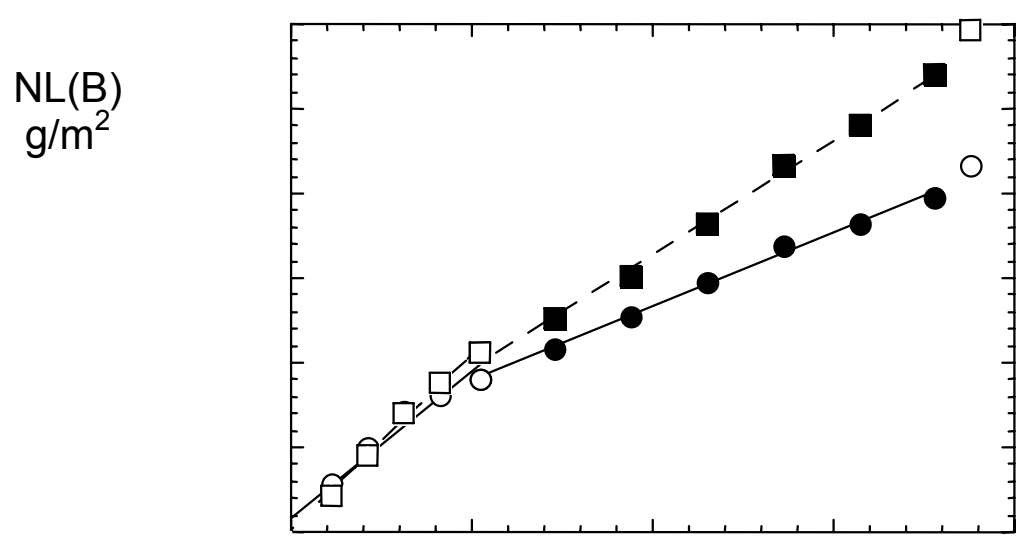

Fig. IV-18. Results of Solution Exchange Tests with HIP CWF and

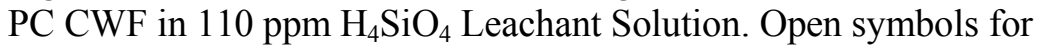
10 or 11-day exchange interval and filled symbols for 21-day exchange interval. 


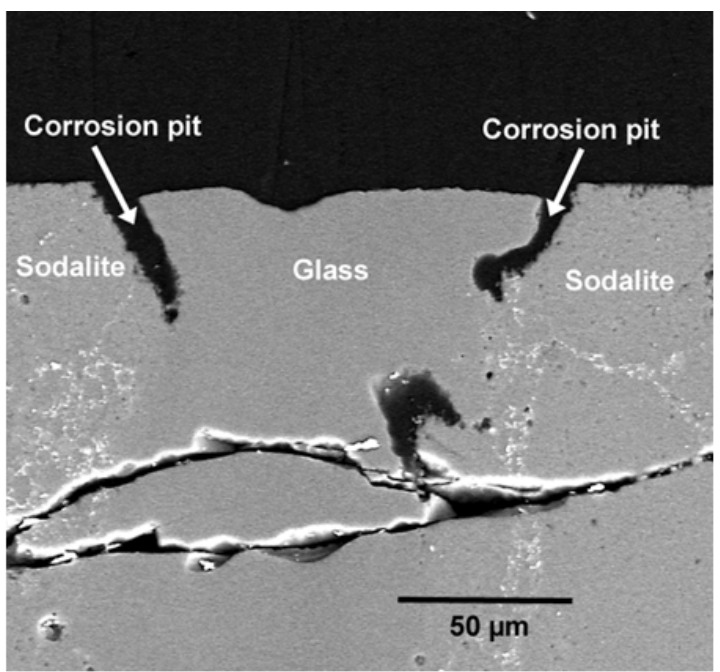

(a)

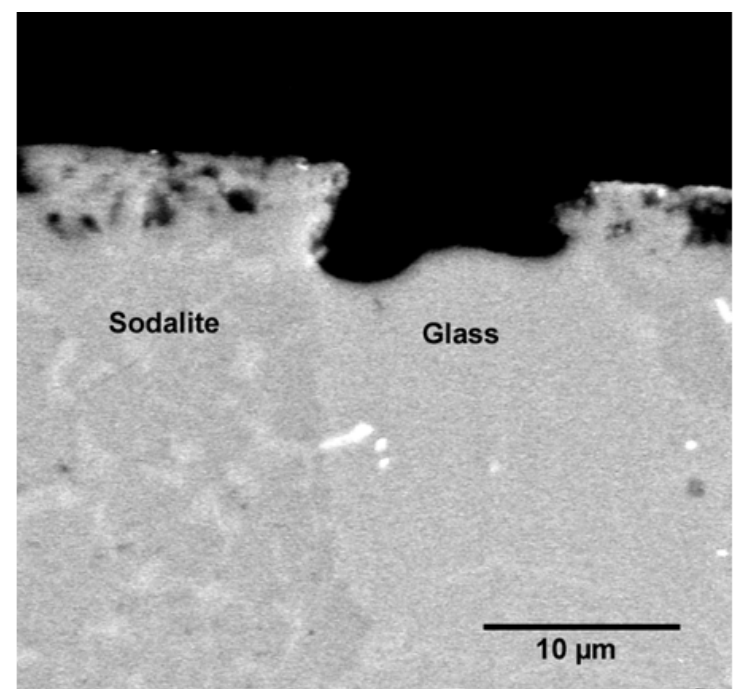

(c)

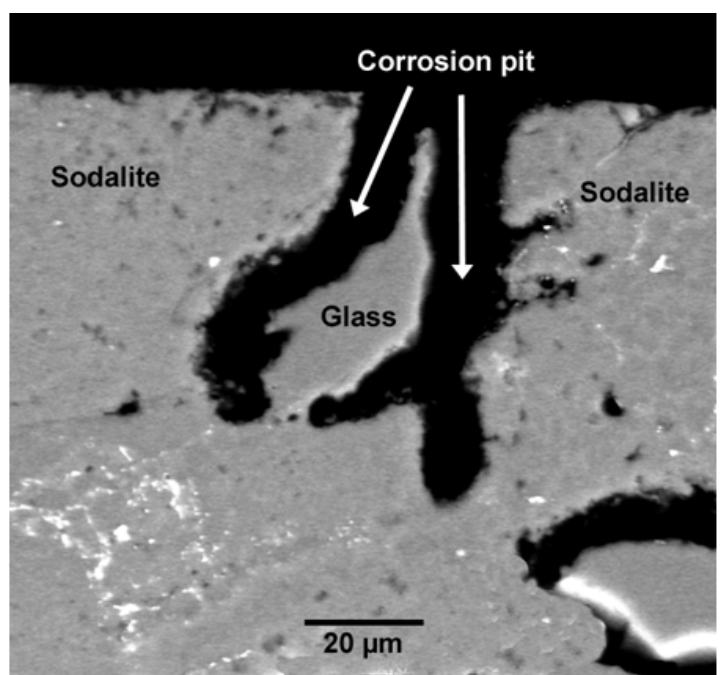

(b)

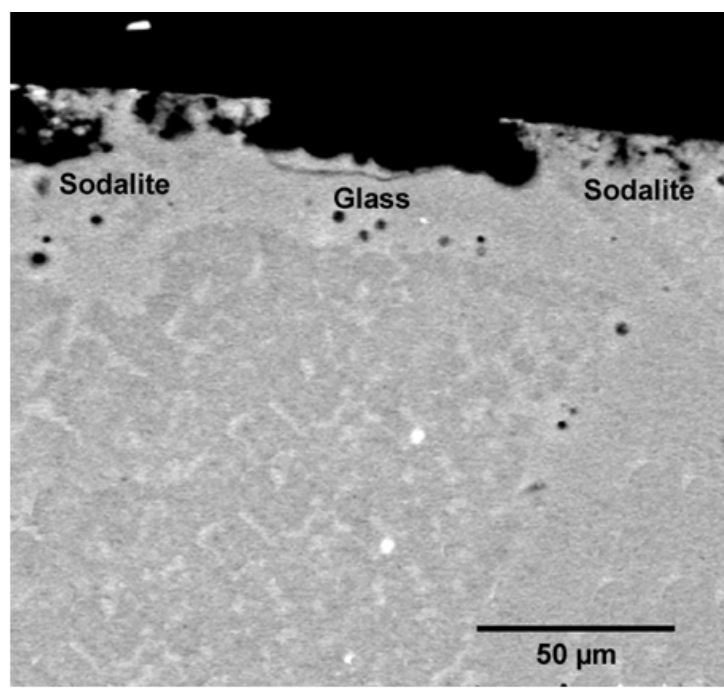

(d)

Fig. IV-19. Photomicrographs of Cross-Sectioned Samples of [(a) and (b)] HIP CWF and [(c) and (d)] $\mathrm{PC} \mathrm{CWF}$ Reacted in $110 \mathrm{ppm} \mathrm{H}_{4} \mathrm{SiO}_{4}$ at $90^{\circ} \mathrm{C}$.

whereas the dissolution of the binder glass occurs uniformly in the PC CWF (see Figs. IV-19c and IV-19d). The difference is attributed to differences in the distribution of pores and halite inclusions. In the HIP CWF materials, most pores and inclusion phases are located in the binder glass near the sodalite, whereas they are more uniformly distributed throughout the binder glass in PC CWF (compare Figs. IV-3a and IV-3b). Preferential dissolution at the sodalite/glass interface is seen in other tests with HIP CWF. For example, Fig. IV-20 shows the surface of a HIP CWF sample reacted for about three months at $120^{\circ} \mathrm{C}$ in an MCC-1 test. Preferential dissolution at the binder glass/sodalite boundaries is obvious. The fact that radionuclides are not concentrated at the interface of the sodalite and binder glass is an important benefit of PC CWF compared to HIP CWF, since most radionuclides are contained in oxide inclusion phases that have a distribution in the binder glass similar to that of halite and pores. The release of radionuclides from PC CWF is expected to be nearly congruent with dissolution of the binder glass, whether the radionuclides are dissolved in the binder glass or are present as inclusion phases. Finally, the 


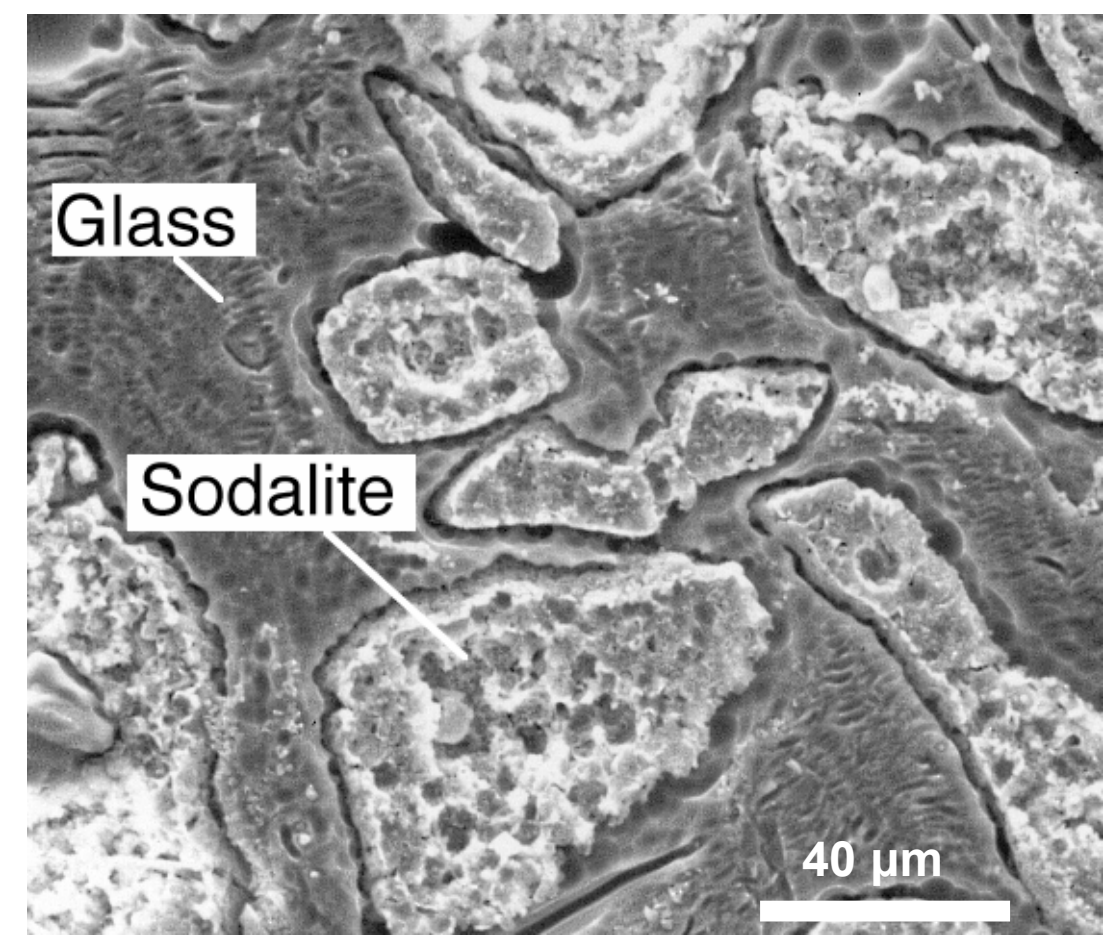

Fig. IV-20. SEM Photomicrograph Showing Preferential Dissolution at Sodalite/Binder Glass Interfaces in Sample of HIP CWF Reacted in a MCC-1 Test at $120^{\circ} \mathrm{C}$.

coarse texture of the sodalite surfaces seen in Fig. IV-20 is due to the dissolution of binder glass from between the individual sodalite grains within each domain. This is also seen by the pores generated in the sodalite near the surface in Figs. IV-19a-19d.

\section{IV.B.5. Release of U and Pu During CWF Degradation}

A series of tests was conducted with HIP CWF and PC CWF materials made with salts containing amounts of $\mathrm{U}$ and $\mathrm{Pu}$ that span the likely range of waste form compositions to study the release behaviors of these radionuclides as the CWF corrodes (Morss and Ebert, 2001; Morss et al., 2002a; Morss et al., 2002b). Four different U,Pu-loaded HIP CWF materials were made using zeolites with residual water contents of 0.12 or 3.5 mass \% and salts doped with either 5.25 mass $\% \mathrm{U}+1.76$ mass \% Pu or with 1.76 mass $\% \mathrm{U}+5.30$ mass $\% \mathrm{Pu}$. These resulted in two CWF materials with 0.421 mass $\% \mathrm{U}+0.141$ mass \% $\mathrm{Pu}$ (CWF 237m and CWF 239m) and two with 0.141 mass \% U + 0.426 mass \% Pu (CWF 238m and CWF 240m) (Morss et al., 2002b, Table 20B). The letter " $\mathrm{m}$ " following the CWF identifier indicates that a mixture of crushed material from several products was used in the PCTs. The microstructures of these materials were examined with SEM, and samples were crushed and sieved to isolate the $-100+200$ mesh size fractions for use in PCTs.

The PC method was selected as the baseline process when the tests with the HIP CWF materials were in progress. PC CWF materials were made with the same starting materials for comparison, but only the materials made with 0.141 mass $\% \mathrm{U}$ and 0.426 mass \% Pu were used in corrosion tests. Material GPC00202 was consolidated at $875^{\circ} \mathrm{C}$ for 24 hours. Four additional PC CWF products were consolidated at $915^{\circ} \mathrm{C}$ for 16 hours when the baseline PC processing conditions were changed. Samples were prepared by crushing and consolidating material from the four products, and the mixture is referred to as 
GPC $0030 \mathrm{~m}$. The formulation and processing conditions for the materials used in this series of corrosion tests are summarized in Table IV-8. The calculated compositions (based on the as-batched salt compositions) are given in Table IV-9. Water in the zeolite was neglected in the calculations.

The PCTs with the four U,Pu-loaded HIP CWF materials were conducted at $90^{\circ} \mathrm{C}$ and $120^{\circ} \mathrm{C}$, at CWFto-water mass ratios of 1:10 and 1:20, and for durations between seven and 365 days. Tests with the two PC CWF materials were conducted at $90^{\circ} \mathrm{C}$ and $120^{\circ} \mathrm{C}$, at a CWF-to-water mass ratio of 1:10, and for durations between 7 and 365 days. The RWS test was conducted with samples of the source materials, and the results are given in Table IV-10. The amounts of released $\mathrm{Cl}^{-}$are much higher for the PC CWF materials. The releases of $\mathrm{B}, \mathrm{Cs}, \mathrm{Na}, \mathrm{Si}, \mathrm{U}$, and $\mathrm{Pu}$ in PCTs conducted under different test conditions and with different materials were compared to evaluate the effects of composition and processing conditions on both the releases of $\mathrm{U}$ and $\mathrm{Pu}$ and the chemical durabilities of the different materials. The results of tests conducted with the 4 U,Pu-loaded HIP CWF and one of the U,Pu-loaded PC CWF materials at $90^{\circ} \mathrm{C}$ with a CWF-to-water mass ratio of 1:10 are summarized in Table IV-11 and plotted in Fig. IV-21. Notice the steady increase in the NL(B) values for tests with the four HIP CWF materials, which are all about five times higher than the values for tests with the PC CWF material. The releases of other components are slightly higher from the HIP CWF materials than from the PC CWF material. The NL(B) values are higher in tests with $238 \mathrm{~m}$ than the values in tests with the other HIP CWF materials. Neither the releases of the other matrix components $(\mathrm{Na}$ and $\mathrm{Si}$ ) nor the releases of radionuclides $(\mathrm{Cs}, \mathrm{Pu}$, and $\mathrm{U})$ show a strong time dependence. Also, the releases of these elements from $238 \mathrm{~m}$ are similar to their releases from the other HIP CWF materials. The higher release of B from the HIP CWF materials is the most significant difference between the two materials. Figure IV-22 compares the releases of different elements from the HIP CWF and PC CWF material. The average values for tests with the 4 HIP CWF materials are plotted. The release of $\mathrm{B}$ bounds the releases of other elements, including $\mathrm{Cs}, \mathrm{Pu}$, and $\mathrm{U}$.

The amounts of each element in the dissolved and colloidal fractions and the amounts that were fixed to test vessel walls were measured and compared. The colloidal fractions were determined by passing the solution sequentially through 450 - and $100-\mathrm{nm}$ syringe filters and a 5-nm centrifuge filter. The filtrate from the 5-nm filtration step was considered to be dissolved. The amounts fixed to the vessel were dissolved using a nitric acid strip procedure. Figure IV-23 compares the amounts of $U$ and $\mathrm{Pu}$ found in each fraction for the different tests. The majority of both (about $85 \%$ of the total $\mathrm{Pu}$ ) were fixed to the vessel. The $\mathrm{U}$ and $\mathrm{Pu}$ is believed to be reduced and plated onto the steel surface. A small amount of $\mathrm{U}$ but negligible $\mathrm{Pu}$ was found to be dissolved. This is consistent with the solubility limits of $\mathrm{U}$ and $\mathrm{Pu}$ at the solution $\mathrm{pH}$ values attained in these tests, which were typically between 8.5 and 9.0 for both materials. $\mathrm{The} \mathrm{Pu}($ and $\mathrm{U}$ ) that was removed from the vessel by the acid strip is including in the normalized mass loss values plotted in Figs. IV-21 and IV-22. This provides in a conservative estimate of the amounts released from the CWF and available for transport.

Appreciable fractions of both $\mathrm{U}$ and $\mathrm{Pu}$ (about $15 \%$ of the total $\mathrm{Pu}$ ) were associated with colloids, mostly in the 5- to $100-\mathrm{nm}$ size range. Several Pu-bearing colloidal particles recovered from the test solutions were also examined with solids analysis techniques including TEM and X-ray absorption fine structure spectroscopy (XAFS). Figure IV-24 shows one or more colloids that were collected by wicking drops of

Table IV-8. U,Pu-Doped CWF Materials used in Corrosion Tests

\begin{tabular}{|c|c|c|c|}
\hline Salt doped with: & $\begin{array}{c}\text { Zeolite with } \\
0.12 \% \text { residual water }\end{array}$ & $\begin{array}{c}\text { Zeolite with } \\
3.5 \% \text { residual water }\end{array}$ & Parameters \\
\hline $0.44 \% \mathrm{U}$ and $0.15 \% \mathrm{Pu}$ & $237 \mathrm{~m}$ & $239 \mathrm{~m}$ & $\mathrm{HIP}$ at $850^{\circ} \mathrm{C}, 14,500 \mathrm{psi}, 1 \mathrm{~h}$ \\
\hline $0.15 \% \mathrm{U}$ and $0.44 \% \mathrm{Pu}$ & $238 \mathrm{~m}$ & $240 \mathrm{~m}$ & $\mathrm{HIP}$ at $850^{\circ} \mathrm{C}, 14,500 \mathrm{psi}, 1 \mathrm{~h}$ \\
\hline $0.15 \% \mathrm{U}$ and $0.44 \% \mathrm{Pu}$ & GPC00202 & - & $\mathrm{PC}$ at $875^{\circ} \mathrm{C}, 24 \mathrm{~h}$ \\
\hline $0.15 \% \mathrm{U}$ and $0.44 \% \mathrm{Pu}$ & GPC0030m & - & $\mathrm{PC}$ at $915^{\circ} \mathrm{C}, 16 \mathrm{~h}$ \\
\hline
\end{tabular}

${ }^{\mathrm{a}} 0.15$ mass $\%$ residual water. 
Table IV-9. Calculated Compositions of U,Pu-Doped CWF Materials, in Mass \%

\begin{tabular}{|c|c|c|c|c|}
\hline \multirow{2}{*}{ Element } & \multicolumn{2}{|c|}{ HIP CWF } & \multicolumn{2}{|c|}{ PC CWF } \\
\hline & $237 m$ and $239 m$ & $238 \mathrm{~m}$ and $240 \mathrm{~m}$ & GPC00202 & GPC0030m \\
\hline $\mathrm{Al}$ & 13.6 & 13.6 & 13.6 & 13.6 \\
\hline B & 1.50 & 1.50 & 1.50 & 1.50 \\
\hline $\mathrm{Ba}$ & 3.8 & 0.068 & 0.068 & 0.068 \\
\hline $\mathrm{Ca}$ & 0.26 & 0.26 & 0.26 & 0.26 \\
\hline $\mathrm{Ce}$ & 0.090 & 0.090 & 0.090 & 0.090 \\
\hline $\mathrm{Cl}$ & 4.59 & 4.58 & 4.58 & 4.58 \\
\hline $\mathrm{Cr}$ & 0.003 & 0.003 & 0.003 & 0.003 \\
\hline Cs & 0.014 & 0.14 & 0.14 & 0.14 \\
\hline $\mathrm{Cu}$ & 0.001 & 0.001 & 0.001 & 0.001 \\
\hline Eu & 0.002 & 0.002 & 0.002 & 0.002 \\
\hline $\mathrm{Fe}$ & 0.067 & 0.067 & 0.007 & 0.067 \\
\hline 1 & 0.008 & 0.008 & 0.008 & 0.008 \\
\hline $\mathrm{K}$ & 1.58 & 1.58 & 1.58 & 1.58 \\
\hline $\mathrm{La}$ & 0.047 & 0.047 & 0.047 & 0.047 \\
\hline $\mathrm{Li}$ & 0.389 & 0.389 & 0.389 & 0.389 \\
\hline $\mathrm{Mg}$ & 0.053 & 0.053 & 0.053 & 0.053 \\
\hline $\mathrm{Mn}$ & 0.001 & 0.001 & 0.001 & 0.001 \\
\hline $\mathrm{Na}$ & 11.6 & 11.6 & 11.6 & 11.6 \\
\hline $\mathrm{Nd}$ & 0.153 & 0.153 & 0.153 & 0.153 \\
\hline $\mathrm{Ni}$ & 0.001 & 0.001 & 0.001 & 0.001 \\
\hline $\mathrm{Pr}$ & 0.045 & 0.045 & 0.045 & 0.045 \\
\hline $\mathrm{Pu}$ & 0.141 & 0.426 & 0.426 & 0.385 \\
\hline $\mathrm{Rb}$ & 0.016 & 0.016 & 0.016 & 0.016 \\
\hline $\mathrm{Si}$ & 19.9 & 19.9 & 19.9 & 19.9 \\
\hline $\mathrm{Sm}$ & 0.027 & 0.027 & 0.027 & 0.027 \\
\hline $\mathrm{Sr}$ & 0.045 & 0.045 & 0.045 & 0.045 \\
\hline $\mathrm{Ti}$ & 0.117 & 0.117 & 0.117 & 0.117 \\
\hline$U$ & 0.421 & 0.141 & 0.141 & 0.112 \\
\hline $\mathrm{Y}$ & 0.022 & 0.022 & 0.022 & 0.022 \\
\hline $\mathrm{Zn}$ & 0.132 & 0.132 & 0.132 & 0.132 \\
\hline $\mathrm{Zr}$ & 0.132 & 0.132 & 0.132 & 0.132 \\
\hline
\end{tabular}

Table IV-10. Results of RWS Tests with U,Pu-Doped CWF Materials

\begin{tabular}{|c|l|c|}
\hline \multicolumn{2}{|c|}{ Material } & {$\left[\mathrm{Cl}^{-}\right], \mathrm{mg} / \mathrm{L}$} \\
\hline \multirow{3}{*}{ HIP CWF } & $237 \mathrm{~m}$ & 16.8 \\
\cline { 2 - 3 } & $238 \mathrm{~m}$ & 14.3 \\
\cline { 2 - 3 } & $239 \mathrm{~m}$ & 46.0 \\
\cline { 2 - 3 } & $240 \mathrm{~m}$ & 88.7 \\
\hline \multirow{2}{*}{ PC CWF } & GPC00202 & $334 \pm 80$ \\
\cline { 2 - 3 } & GPC0030m & $402 \pm 27$ \\
\hline
\end{tabular}


Table IV-11. Results of Seven-Day PCT Conducted with U,Pu-Doped CWF Materials at $90^{\circ} \mathrm{C}$

\begin{tabular}{|c|c|c|c|c|c|c|}
\hline Material & $\mathrm{NL}(\mathrm{B})$ & $\mathrm{NL}(\mathrm{Cs})$ & $\mathrm{NL}(\mathrm{Na})$ & $\mathrm{NL}(\mathrm{Si})$ & $\mathrm{NL}(\mathrm{Pu})$ & $\mathrm{NL}(\mathrm{U})$ \\
\hline \multicolumn{7}{|c|}{7 days } \\
\hline $237 \mathrm{~m}$ & 0.22 & 0.038 & 0.14 & 0.095 & 0.017 & 0.015 \\
\hline $238 m$ & 0.29 & 0.061 & 0.19 & 0.13 & 0.029 & 0.039 \\
\hline $239 m$ & 0.19 & 0.043 & 0.13 & 0.090 & 0.015 & 0.011 \\
\hline $240 m$ & 0.18 & 0.030 & 0.11 & 0.089 & 0.005 & 0.009 \\
\hline $\mathrm{GPC}^{2} 0202^{\mathrm{a}}$ & $0.070 \pm 0.015$ & $0.063 \pm 0.012$ & $0.23 \pm 0.07$ & $0.089 \pm 0.018$ & $0.0066 \pm 0.0030$ & $0.0071 \pm 0.0013$ \\
\hline $\mathrm{GPC}^{2} 030 \mathrm{~m}^{\mathrm{a}}$ & $0.077 \pm 0.012$ & $0.044 \pm 0.001$ & $0.13 \pm 0.01$ & $0.081 \pm 0.003$ & $0.0033 \pm 0.0002$ & $0.0019 \pm 0.0003$ \\
\hline \multicolumn{7}{|c|}{14 days } \\
\hline GPC0030m & 0.094 & 0.055 & 0.14 & 0.087 & 0.0021 & 0.0023 \\
\hline \multicolumn{7}{|c|}{28 days } \\
\hline $237 \mathrm{~m}$ & 0.46 & 0.061 & 0.14 & 0.17 & 0.050 & 0.027 \\
\hline $238 m$ & 0.69 & 0.052 & 0.16 & 0.15 & 0.035 & 0.021 \\
\hline $239 m$ & 0.46 & 0.038 & 0.12 & 0.10 & 0.018 & 0.005 \\
\hline $240 \mathrm{~m}$ & 0.50 & 0.074 & 0.15 & 0.18 & 0.076 & 0.019 \\
\hline GPC0030m & 0.13 & 0.055 & 0.11 & 0.10 & 0.0023 & 0.0035 \\
\hline \multicolumn{7}{|c|}{56 days } \\
\hline GPC0030m & 0.11 & 0.047 & 0.10 & 0.10 & 0.0036 & 0.0046 \\
\hline \multicolumn{7}{|c|}{91 days } \\
\hline $237 \mathrm{~m}$ & 0.63 & 0.057 & 0.18 & 0.14 & 0.044 & 0.021 \\
\hline $238 m$ & 1.36 & 0.086 & 0.24 & 0.22 & 0.050 & 0.041 \\
\hline $239 m$ & 0.77 & 0.038 & 0.20 & 0.13 & 0.010 & 0.006 \\
\hline $240 m$ & 0.70 & 0.052 & 0.14 & 0.17 & 0.019 & 0.012 \\
\hline \multicolumn{7}{|c|}{182 days } \\
\hline $237 \mathrm{~m}$ & 0.92 & 0.087 & 0.14 & 0.17 & 0.062 & 0.020 \\
\hline $238 m$ & 1.7 & 0.048 & 0.17 & 0.14 & 0.031 & 0.029 \\
\hline $239 m$ & 1.0 & 0.045 & 0.13 & 0.14 & 0.048 & 0.021 \\
\hline $240 m$ & 0.91 & 0.086 & 0.20 & 0.26 & 0.042 & 0.068 \\
\hline GPC0030m & 0.077 & 0.049 & 0.036 & 0.054 & 0.0035 & 0.0059 \\
\hline \multicolumn{7}{|c|}{365 days } \\
\hline $237 \mathrm{~m}$ & 1.1 & 0.052 & 0.17 & 0.18 & 0.039 & 0.058 \\
\hline $238 m$ & 2.1 & 0.067 & 0.24 & 0.19 & 0.039 & 0.035 \\
\hline $239 m$ & 1.4 & 0.051 & 0.13 & 0.16 & 0.042 & 0.062 \\
\hline $240 m$ & 1.1 & 0.028 & 0.091 & 0.14 & 0.015 & 0.020 \\
\hline GPC0030m & 0.26 & 0.14 & 0.11 & 0.17 & 0.010 & 0.016 \\
\hline
\end{tabular}

${ }^{\mathrm{a}}$ Mean \pm standard deviation of triplicate tests. 


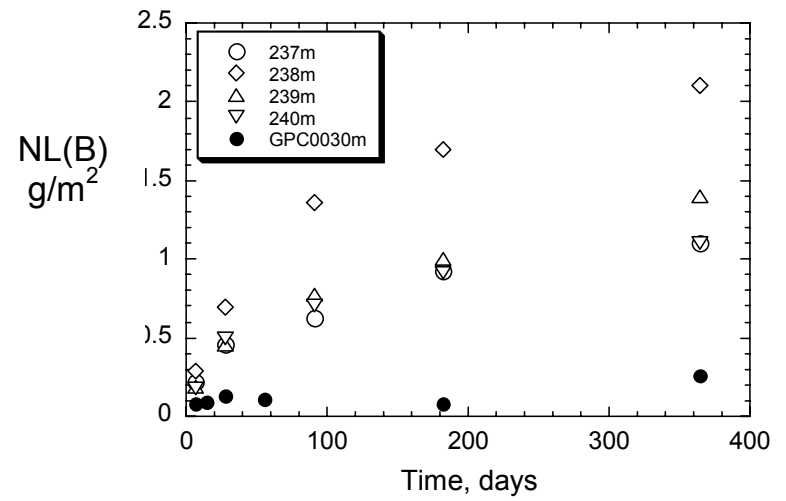

(a)

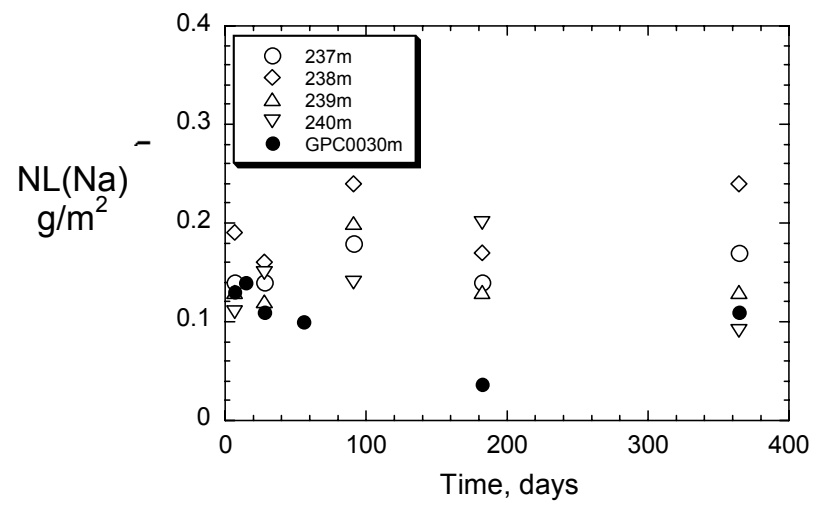

(c)

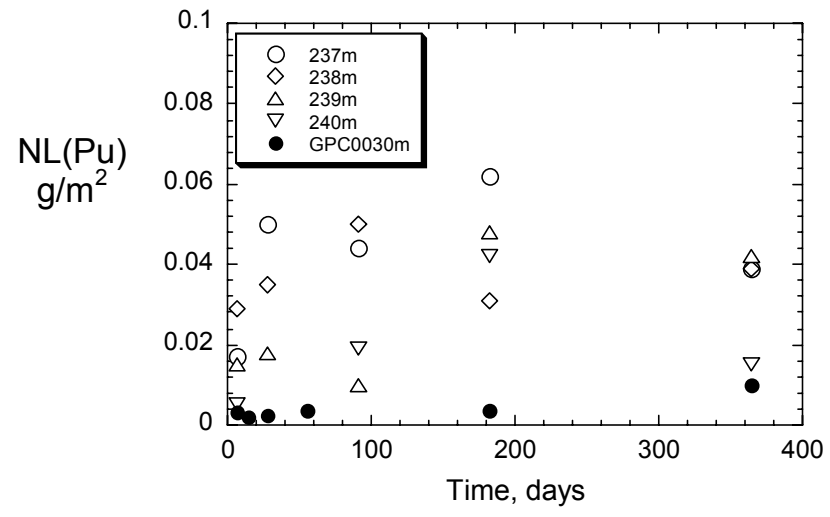

(e)

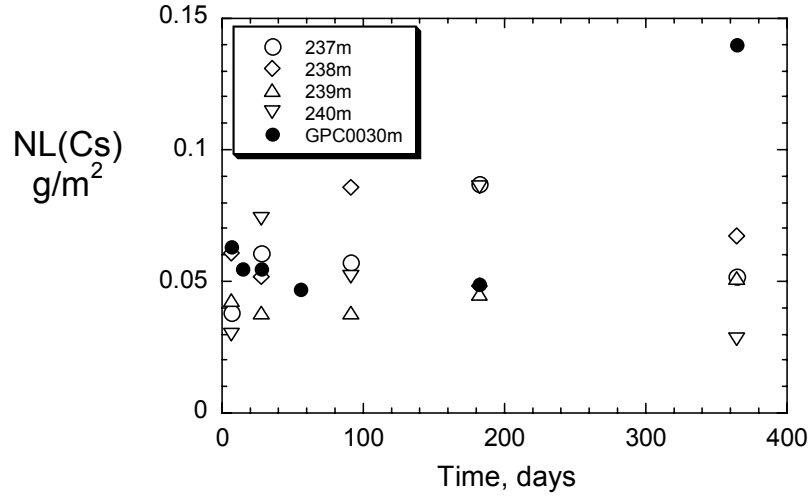

(b)

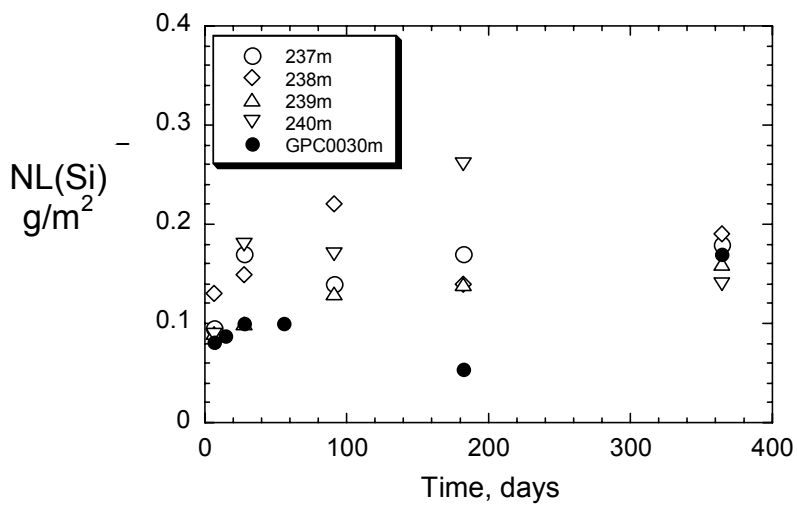

(d)

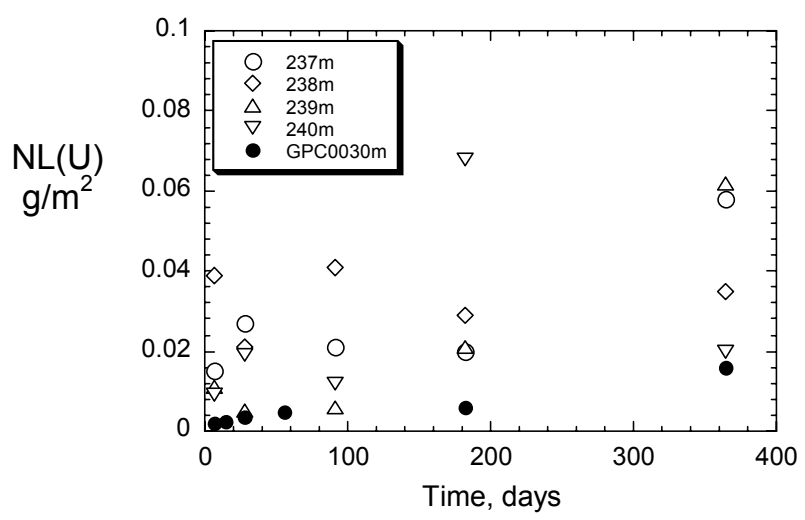

(f)

Fig. IV-21. Normalized Mass Losses of (a) B, (b) Cs, (c) Na, (d) Si, (e) Pu, and (f) U from HIP U,Pu-Loaded CWF and PC U,Pu-loaded CWF GPC0030m in PCT at $90^{\circ} \mathrm{C}$ and a 1:10 Mass Ratio. 


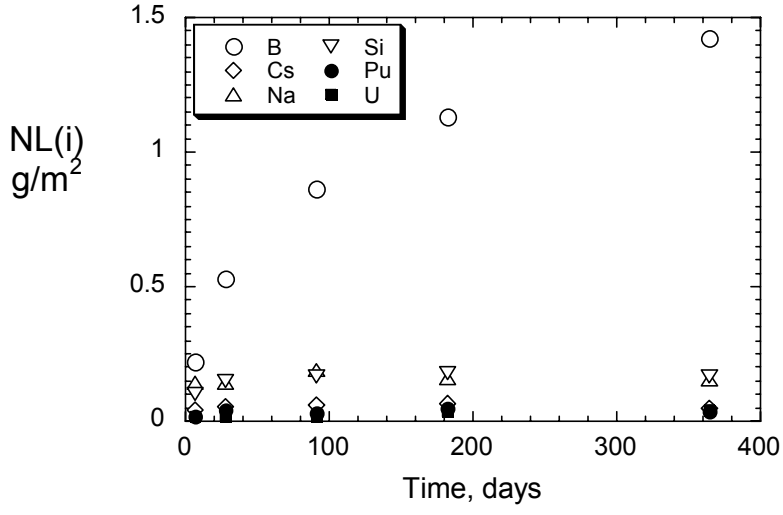

(a)

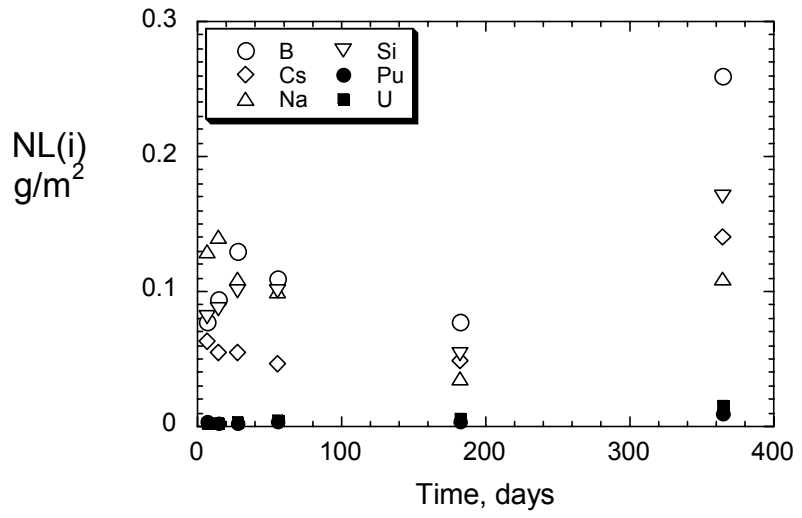

(b)

Fig. IV-22. Normalized Mass Losses in PCT at $90^{\circ} \mathrm{C}$ and a 1:10 Mass Ratio with (a) HIP U,Pu-Loaded CWF (average of tests with 237m, 238m, 239m, and 240m) and (b) PC U,Pu-Loaded CWF GPC0030m.

the test solution through holey carbon TEM grids. Figure IV-24a shows aggregates of $40-\mu \mathrm{m}$-sized aluminosilicate particles. The dark feature in the center of Fig. IV-24b is crystallite of $(\mathrm{U}, \mathrm{Pu}) \mathrm{O}_{2}$. Plutonium was only detected in a few percent of the TEM samples generated using this method. The 5-nm centrifuge filter that was used remove small-sized colloids from the solution of a test conducted at $120^{\circ} \mathrm{C}$ was analyzed at the ANL Advanced Photon Source. This filter was selected for analysis because solution analyses indicated it had retained the most $\mathrm{Pu}$. The plutonium associated with the colloids was determined by XAFS to be $\mathrm{PuO}_{2}$. The near-edge spectrum is shown in Fig. IV-25 superimposed with the spectrum of a $\mathrm{PuO}_{2}$ reference sample (Morss et al., 2002a; Morss et al., 2002b).

Dynamic light scattering analysis was used to estimate the size distribution of the colloids. Samples were taken from the filtrates passed through a $450 \mathrm{~nm}$ pore-size filter. This coarse filtration step assured that particles of CWF were not entrained in the analyzed solutions. Figure IV-26 shows the typical bimodal size distribution that best described the solutions. Comparison with the TEM image shown in Fig. IV-24b suggests that the two modes seen in light scattering results correspond to small (U,Pu) $\mathrm{O}_{2}$ crystallites and the larger aluminosilicates. The maximum peak height of the smaller size distribution corresponds to a particle size of $8 \mu \mathrm{m}$ and the maximum of the larger size distribution corresponds to a particle size of about $120 \mu \mathrm{m}$ (Morss et al, 2002a; Morss et al., 2002b). The two size fractions correspond well with the sequential filtration analysis of the test solutions, the results of which were shown in Fig. IV-23b. This indicates that $\mathrm{Pu}$ accounts for a greater fraction of the small-sized colloids than the large-sized colloids, which probably means most of the $(\mathrm{U}, \mathrm{Pu}) \mathrm{O}_{2}$ crystallites are not attached to aluminosilicate colloids. In fact, the $(\mathrm{U}, \mathrm{Pu}) \mathrm{O}_{2}$ crystallite(s) seen in Fig. IV-24b may not have been associated with the aluminosilicate particle(s) in the test solution, but may have simply been deposited on it when the solution was filtered.

The $(\mathrm{U}, \mathrm{Pu}) \mathrm{O}_{2}$ crystallites found in solution are almost certainly those formed during salt occlusion and become encapsulated as inclusions in the binder glass during consolidation (e.g., see Fig. IV-1). The Pu in HIP CWF was previously identified as being consistent with $\mathrm{PuO}_{2}$. (Richmann et al., 2001). The combined results of XAFS, sequential filtration, and dynamic light scattering indicate that the $\mathrm{PuO}_{2}$ crystallites in the CWF are released intact as the waste form dissolves. The low solubility of $\mathrm{PuO}_{2}$ ensures that the dissolved concentrations remain low, although it is likely that interactions with the steel vessels affected the dissolved concentrations and facilitated the transport of Pu away from the corroding CWF. 


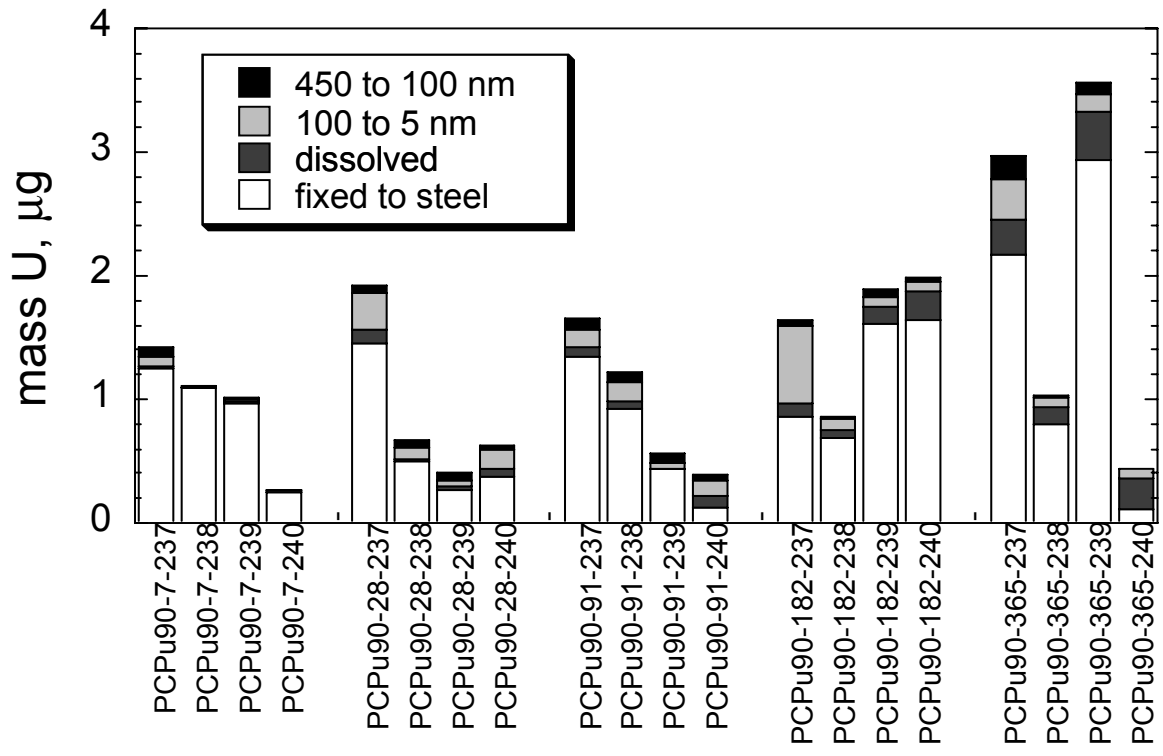

(a)

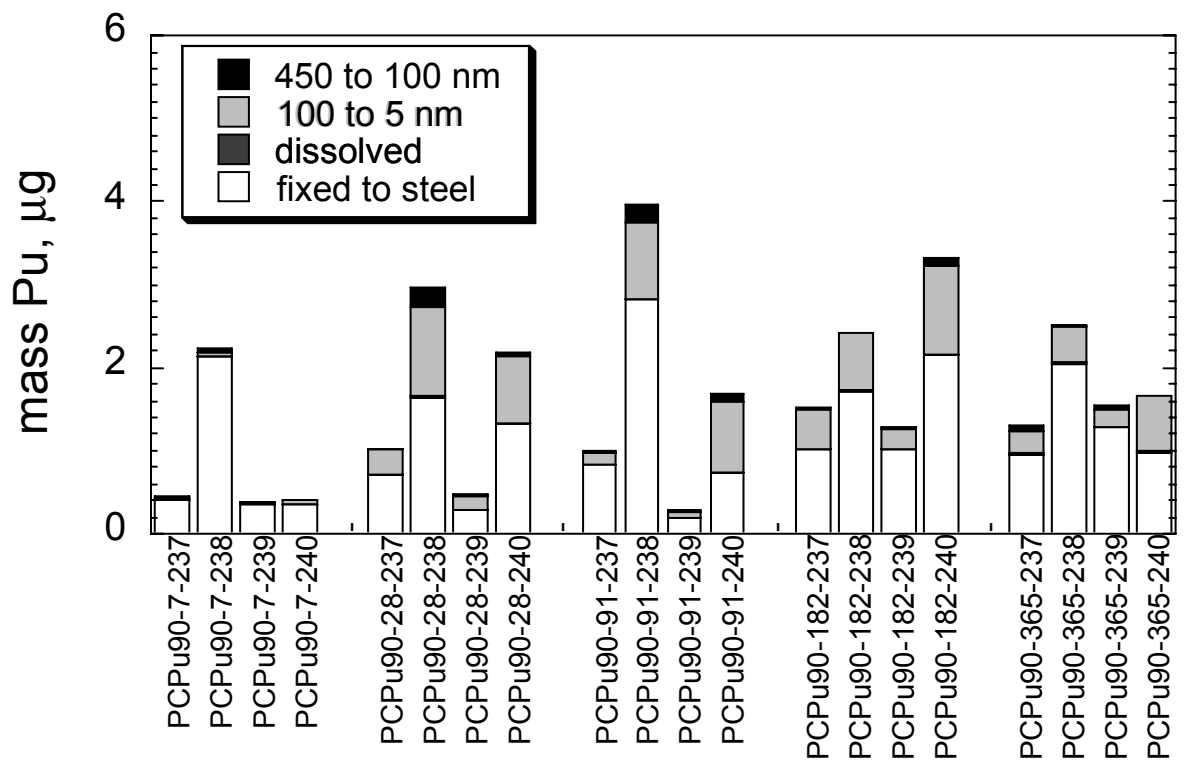

(b)

Fig. IV-23. Distribution of Released $\mathrm{U}$ and $\mathrm{Pu}$ in $\mathrm{PCT}$ at $90^{\circ} \mathrm{C}$ and a 1:10 Mass Ratio. 


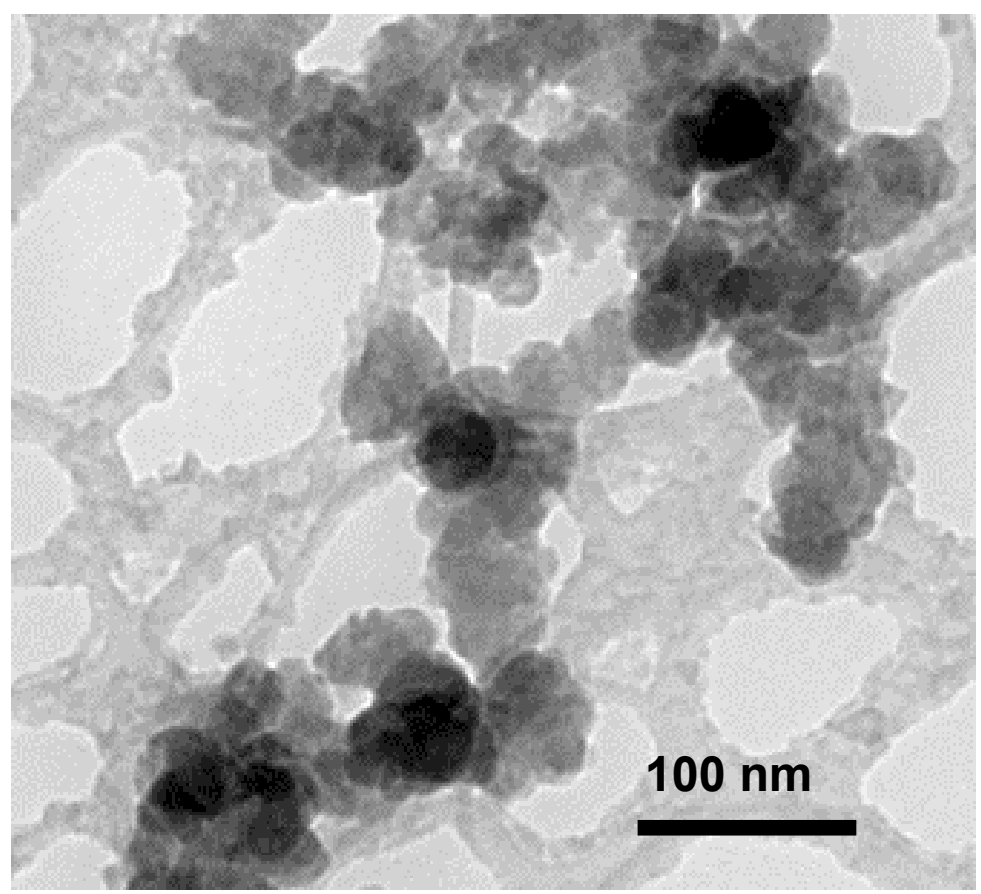

(a)

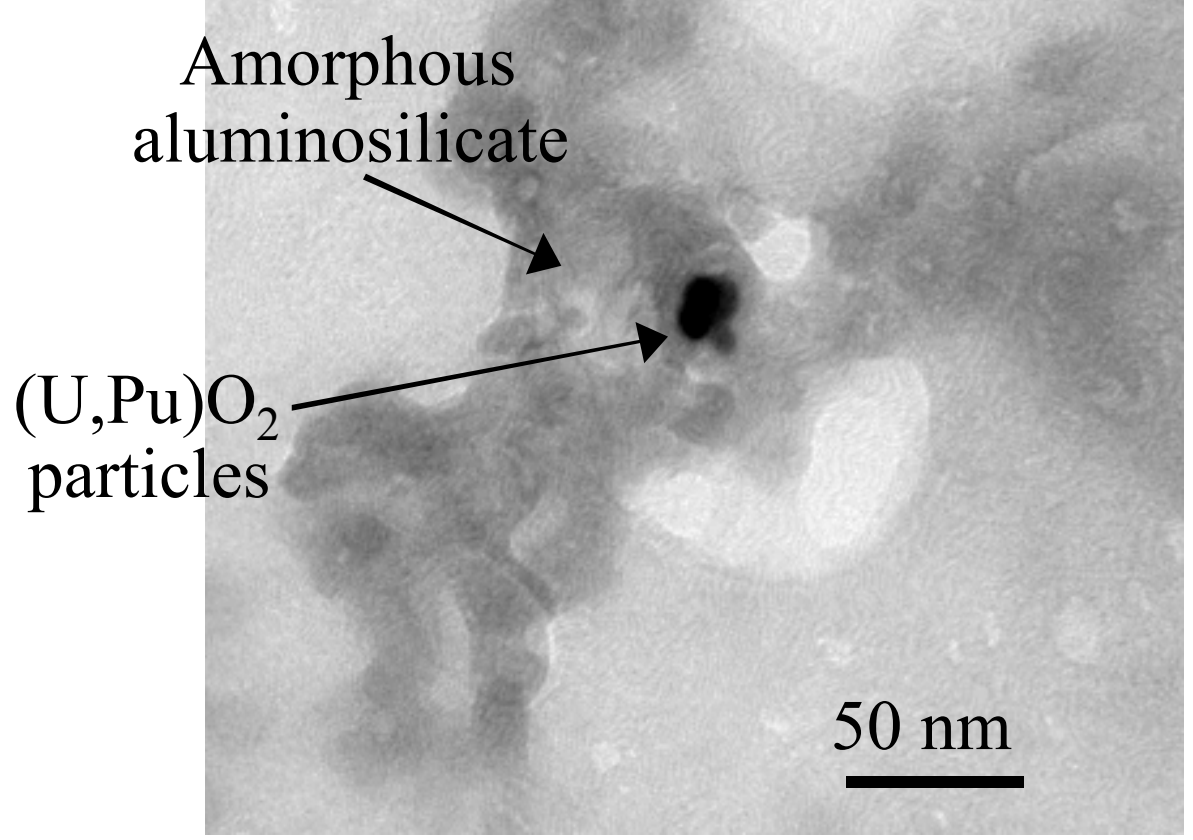

(b)

Fig. IV-24. TEM Images Showing (a) Aggregated Aluminosilicate Colloidal Particles and (b) Pu-Bearing Crystallite Associated with Aluminosilicate Particles. Particles were removed from the test solution by wicking through a holey carbon TEM grid, which can be seen in the background. 


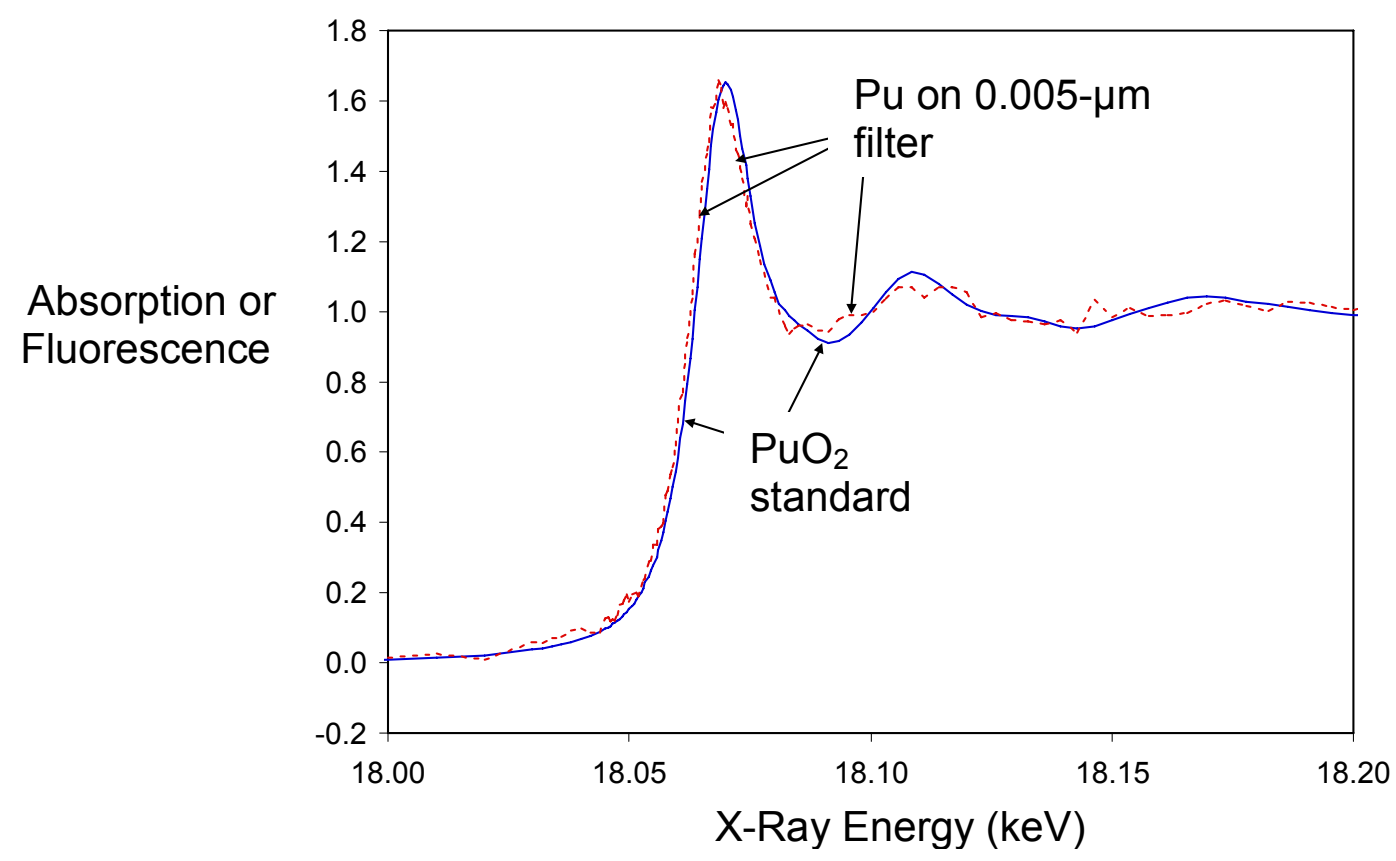

Fig. IV-25. Absorption XAFS Spectra of Filtrant (dotted line) and $\mathrm{PuO}_{2}$ Standard (solid line).

\section{IV.B.6. Radiation Damage}

A CWF material was made using salt doped with $\mathrm{Pu}-238$ and $\mathrm{Pu}-239$ to study the effect of alpha particles and recoil nuclei generated by radioactive decay (Barber et al., 2002; Frank et al., 2000; Frank, 2002; Frank et al., 2002). Although CWF will contain about 100 times more Pu-239 than Pu-238 (see Appendix A), a higher Pu-238 loading was used to provide a higher alpha flux to enhance (accelerate) the impact on the physical and chemical properties of the CWF. The material was made by first converting metallic $\mathrm{Pu}$ to $\mathrm{PuCl}_{3}$ in the salt, occluding the salt into zeolite $4 \mathrm{~A}$, and then mixing the $\mathrm{SLZ}$ with binder glass at the nominal 3:1 ratio. The mixture was consolidated using a hot uniaxial press at about $750^{\circ} \mathrm{C}$ and $34 \mathrm{MPa}$. The $\mathrm{Pu}$ content in the salt was about 10 times higher than that expected in actual waste forms. Several physical and chemical properties of the Pu-238 doped CWF material were tracked for about four years. The density was measured by buoyancy after accumulated doses from $4.9 \times 10^{16}$ to $1.1 \times 10^{18}$ alpha decays $/ \mathrm{g}$ and determined to remain constant $\left(2.423 \pm 0.005 \mathrm{~g} / \mathrm{cm}^{3}\right)$. The relative amounts and unit cell dimensions of sodalite, nepheline, halite, and $\mathrm{PuO}_{2}$ were measured with XRD. It was found that the unit cell volume of $\mathrm{PuO}_{2}$ increased by about $0.7 \%$ after an accumulated dose of about $1 \times 10^{17}$ alpha decays/g and remained constant through an accumulated dose of about $1 \times 10^{18}$ alpha decays/g. The expansion of the $\mathrm{PuO}_{2}$ lattice is due, in part, to the ingrowth of bigger U-234 atoms. The unit cell volume of sodalite increased about $0.3 \%$, with most of the increase occurring after an accumulated dose of about $7 \times 10^{17}$ alpha decays/g. Based on the microstructure of the CWF, the slight increase in the sodalite cell indicates that alpha particles passed from $\mathrm{PuO}_{2}$ inclusion phases through the binder glass for distances of at least a few tenths of a micromenter to penetrate sodalite. For example, Fig. IV-27 shows TEM photomicrographs of $\mathrm{PuO}_{2}$ inclusions surrounding sodalite domains. Microscopic examination by SEM and TEM showed no changes in the microstructure or elemental compositions of the individual phases. No microcracking or evidence of de-bonding is seen. It is likely that the porosity of the CWF minimizes changes in the density due to the swelling of crystalline phases and prevents the propagation of cracks. 


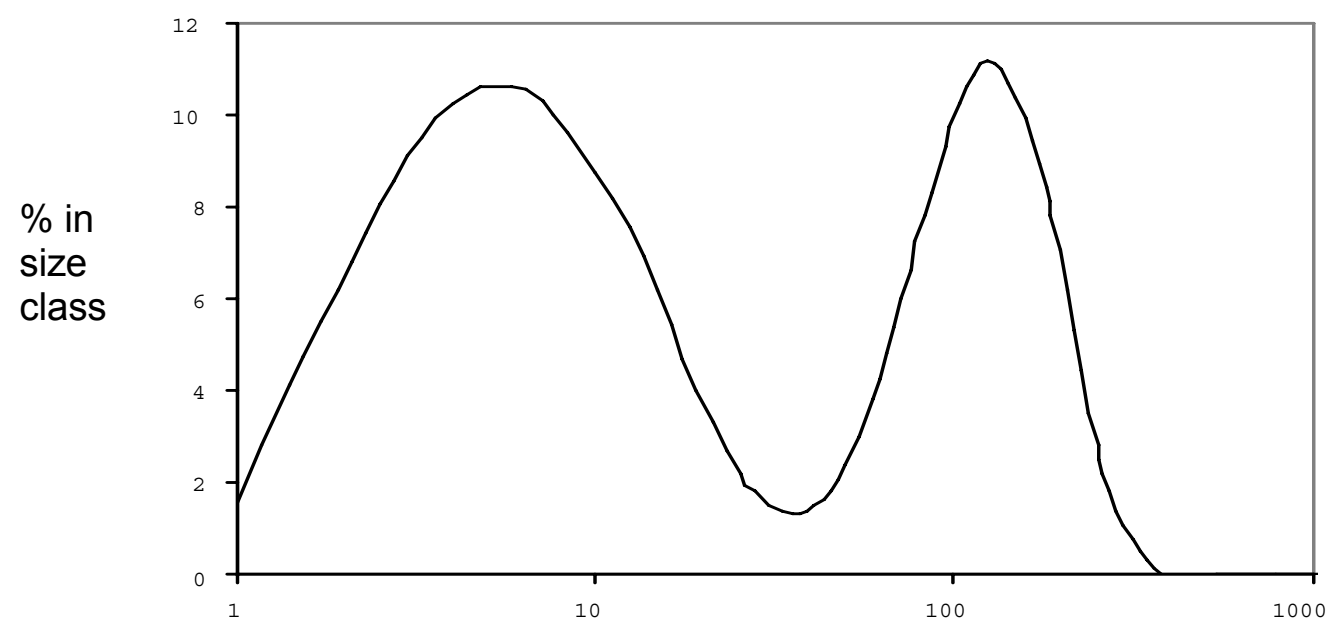

(a)

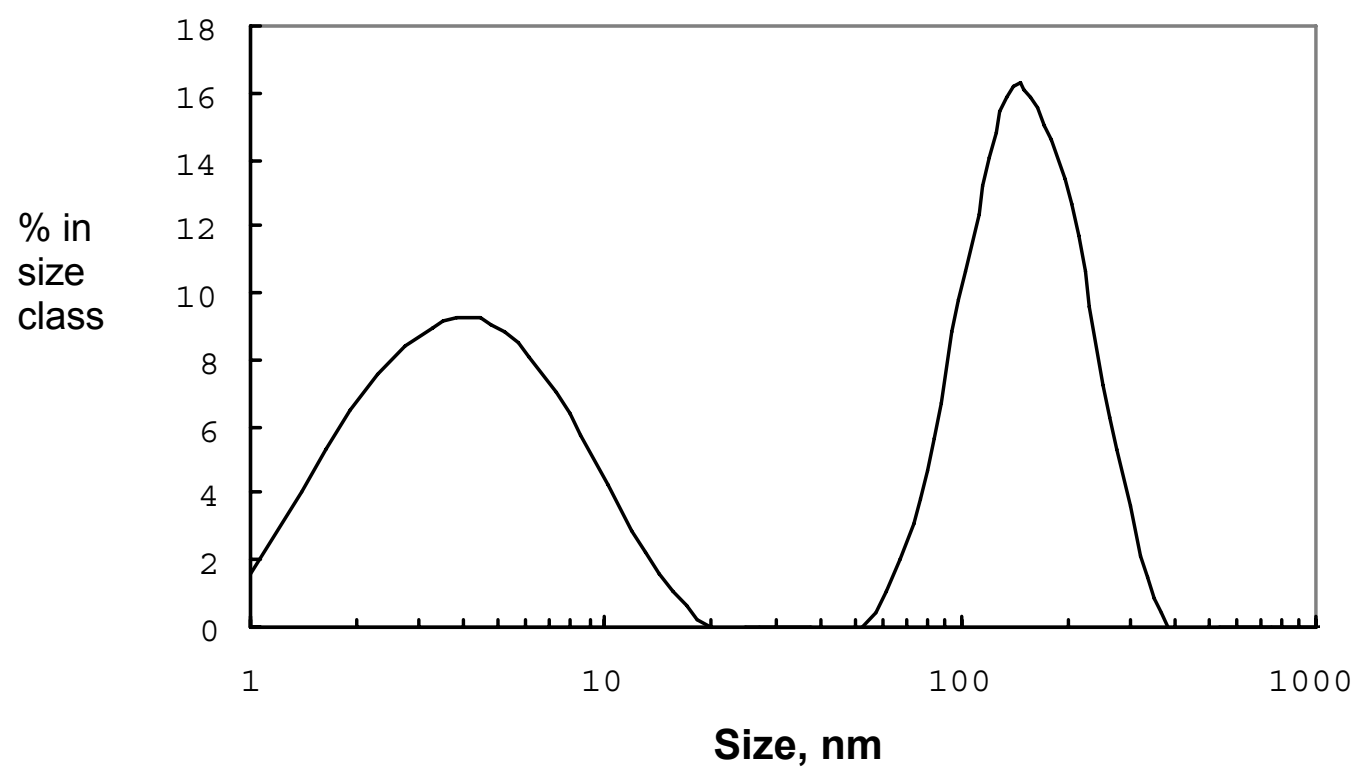

(b)

Fig. IV-26. Colloid Size Distribution in 450-nm Filtrate from Seven-Day PCT (a) Measured Several Hours after the Test was Terminated and (b) Measured 6 Days after Test Termination. 


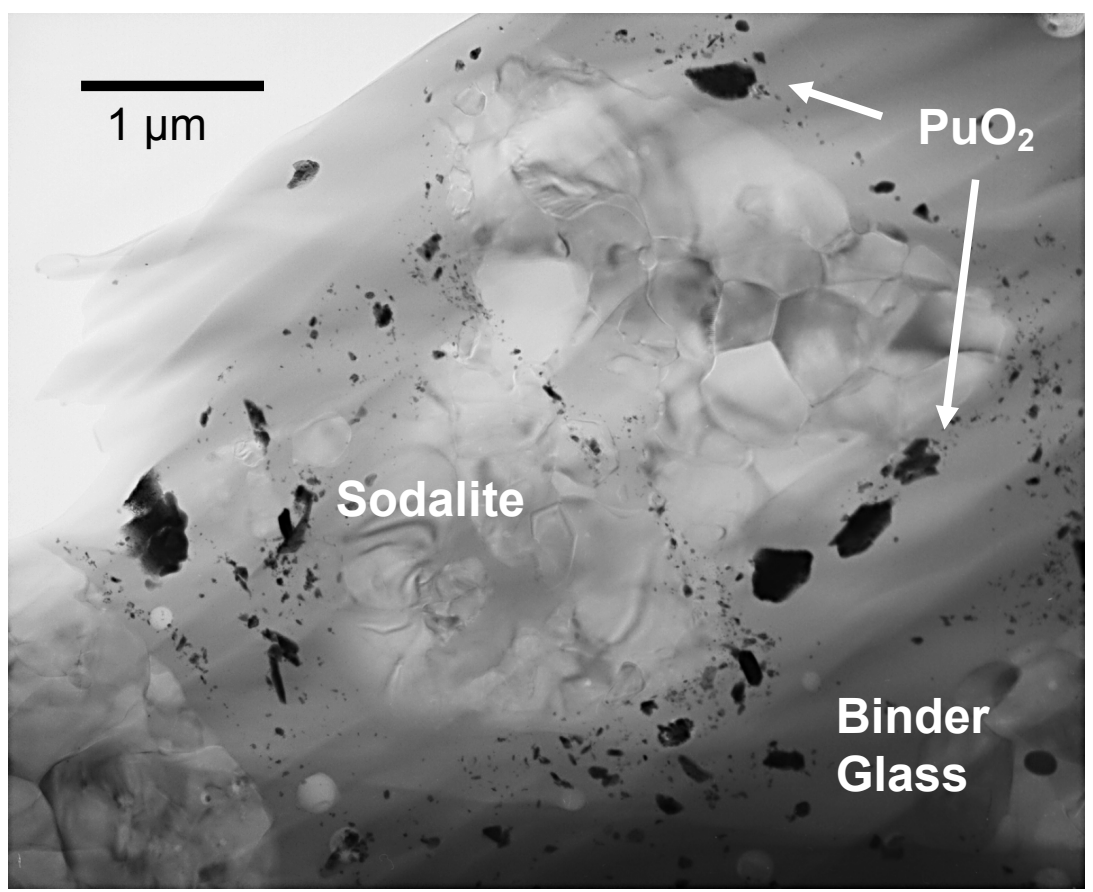

(a)

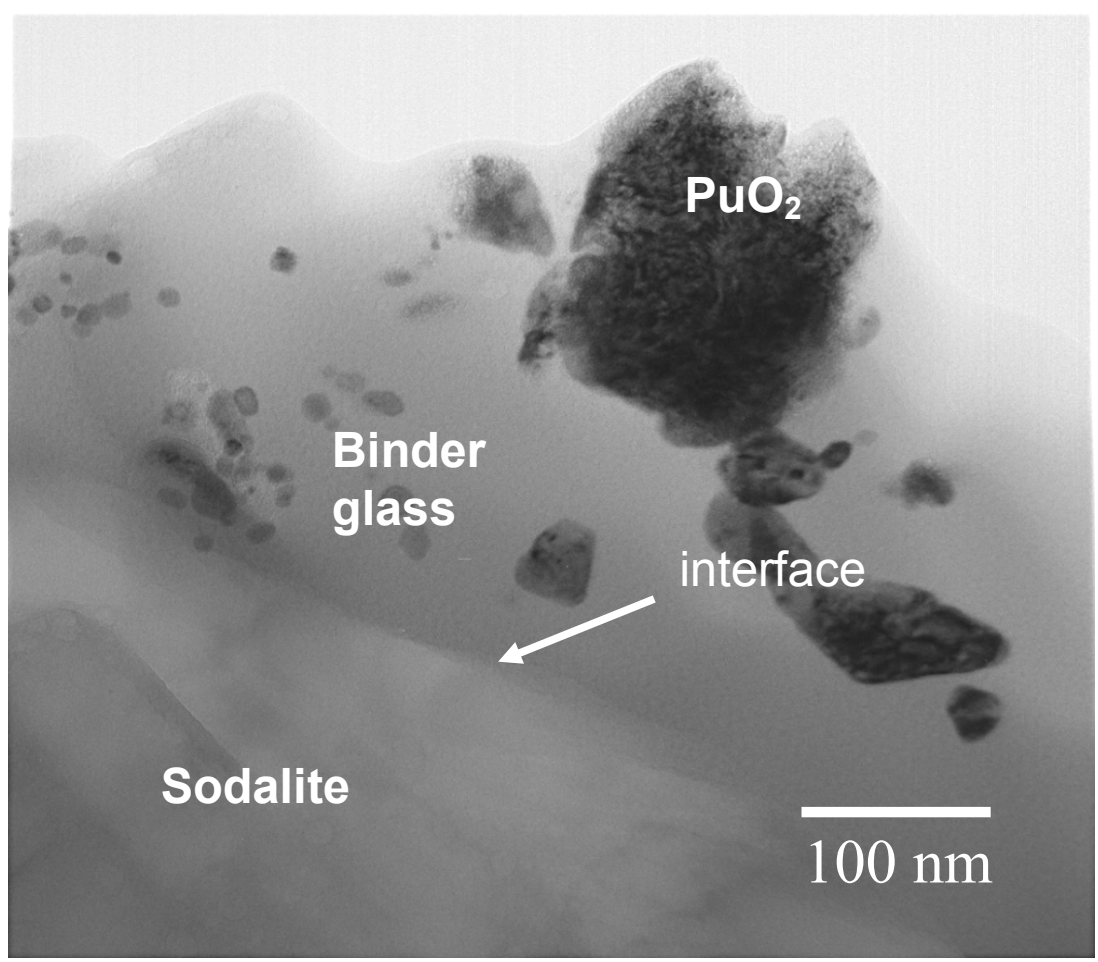

(b)

Fig. IV-27. Bright Field Transmission Electron Micrographs Showing Plutonium-Bearing Particles in the Binder Glass near Sodalite Domains. The arrow in (b) shows the interface between the sodalite and binder glass, which appears as a slight difference in brightness. 
The chemical durability measured with seven-day PCT about 0.2 years after the material was made (with a cumulative dose of $5.0 \times 10^{16}$ alpha decays/g), after about two years (with a cumulative dose of $7.4 \times 10^{17}$ alpha decays/g), and after about four years (with a cumulative dose of $7.4 \times 10^{17}$ alpha decays/g). The PCT results are summarized in Table IV-12. The PCT responses of B, which reflects the amount of binder glass that has dissolved, and $\mathrm{Si}$, which reflects the amounts of both binder glass and sodalite that have dissolved, do not vary significantly after the three self-radiation periods. Most of the Cs and $\mathrm{Li}$ are believed to be dissolved in the binder glass, and the releases of these elements are fairly constant. The releases of $\mathrm{Na}, \mathrm{Cl}$, and I, which are contained in both sodalite and halite, are statistically higher after four years of self-radiation. The releases of $\mathrm{Pu}$ and $\mathrm{Nd}$ also increase by statistically significant amounts, although very little of either is released (probably due to their limited solubilities). The significance of higher releases of components that are present in the CWF at very low concentrations should be interpreted with caution. For example, $\mathrm{Cs}$ and $\mathrm{Nd}$ are present in the salt at 0.56 and 0.66 mass \%, and present in the CWF with mass fractions of about 0.00043 and 0.00053 . Likewise, $\mathrm{Pu}-238$ and $\mathrm{Pu}-239$ are present in the salt at 12.2 and 17.3 mass \%, and present in the CWF with mass fractions of about 0.0098 and 0.014 , respectively. Calculations of the normalized mass losses based on these elements include high uncertainties, including their likely inhomogeneous distribution in the CWF.

The self-radiation study would have benefited from tests with a control sample that had not been doped. Those tests would have addressed the possibility that radiation effects had become saturated in all samples and provided a basis for determining changes in the elemental releases. In the absence of a control, the averages of seven-day PCTs conducted with the Pu-239 and U-238 loaded HIP CWF (which received a small dose from the $\mathrm{Pu}-239$ ) and with $\mathrm{HIP} \mathrm{CWF}$ made without $\mathrm{Pu}$ (which received no dose) are included for comparison. Although the salt compositions used to make these CWF differed slightly from that used for the self-irradiation studies, that is not expected to affect the dissolution behaviors of the final materials. The $\mathrm{Pu}-239$ doped $\mathrm{CWF}$ contained about the same amount of $\mathrm{Pu}-239$ as the sum of $\mathrm{Pu}-238$ and $\mathrm{Pu}-239$ in the self-irradiation material. The results for most elements show little effect of the alpha decay dose or even the presence of $\mathrm{Pu}$ on the durability. The values of NL(B) and NL(Li) are higher for the selfradiated samples than for the $\mathrm{Pu}-239$ doped $\mathrm{CWF}$ and the CWF without added $\mathrm{Pu}$ in the second and third analyses. This may indicate a slight decrease in the binder glass durability due to self-radiation, but the

Table IV-12. Results of Seven-Day PCT with Pu-238-Doped CWF Material after 0.2, 2, and 4 Years [NL(i) $\left.\mathrm{g} / \mathrm{m}^{2}\right]$

\begin{tabular}{|c|c|c|c|c|c|}
\hline \multirow{2}{*}{ Element } & \multicolumn{3}{|c|}{ Pu-238 loaded CWF } & Pu,U-loaded CWF & CWF without Pu $^{\mathrm{c}}$ \\
\cline { 2 - 6 } & $\begin{array}{c}5 \times 10^{16} \\
\text { decays/g }\end{array}$ & $\begin{array}{c}5 \times 10^{17} \\
\text { decays/g }\end{array}$ & $\begin{array}{c}1 \times 10^{18} \\
\text { decays/g }\end{array}$ & $\begin{array}{c}<<5 \times 10^{16} \\
\text { decays/g }\end{array}$ & no dose \\
\hline $\mathrm{Al}$ & $0.035 \pm 0.004$ & $0.034 \pm 0.003$ & $0.026 \pm 0.006$ & $0.11 \pm 0.03$ & $0.031 \pm 0.005$ \\
\hline $\mathrm{B}$ & $0.23 \pm 0.02$ & $0.35 \pm 0.04$ & $0.32 \pm 0.06$ & $0.22 \pm 0.05$ & $0.10 \pm 0.01$ \\
\hline $\mathrm{Cl}$ & $0.38 \pm 0.04$ & $0.74 \pm 0.07$ & $1.17 \pm 0.24$ & $0.39 \pm 0.33$ & $1.2 \pm 0.1$ \\
\hline $\mathrm{Cs}$ & $0.15 \pm 0.05$ & $0.35 \pm 0.04$ & $0.21 \pm 0.04$ & $0.043 \pm 0.013$ & $1.1 \pm 0.1$ \\
\hline $\mathrm{I}$ & not analyzed & $0.21 \pm 0.05$ & $1.78 \pm 0.36$ & $0.34 \pm 0.28$ & $0.61 \pm 0.08$ \\
\hline $\mathrm{K}$ & $0.09 \pm 0.07$ & $0.13 \pm 0.02$ & $0.14 \pm 0.02$ & $0.080 \pm 0.025$ & $0.16 \pm 0.05$ \\
\hline $\mathrm{Li}$ & $0.44 \pm 0.04$ & $0.48 \pm 0.03$ & $0.58 \pm 0.12$ & $0.42 \pm 0.02$ & $0.32 \pm 0.06$ \\
\hline $\mathrm{Na}$ & not analyzed & $0.23 \pm 0.01$ & $0.74 \pm 0.14$ & $0.14 \pm 0.03$ & $0.28 \pm 0.004$ \\
\hline $\mathrm{Nd}$ & $0.0012 \pm 0.0001$ & $0.0048 \pm 0.0005$ & $0.024 \pm 0.004$ & $0.020 \pm 0.015$ & $0.0022 \pm 0.0013$ \\
\hline $\mathrm{Pu}$ & $0.0007 \pm 0.0002$ & $0.0020 \pm 0.0002$ & $0.0048 \pm 0.0010$ & $0.014 \pm 0.009$ & - \\
\hline $\mathrm{Si}$ & not analyzed & $0.038 \pm 0.004$ & $0.036 \pm 0.008$ & $0.100 \pm 0.018$ & $0.036 \pm 0.004$ \\
\hline
\end{tabular}

${ }^{\mathrm{a}}$ Frank et al., 2002

${ }^{\mathrm{b}}$ Morss et al., 2002b, Appendix B, Table 24B.

${ }^{\mathrm{c}}$ Ebert et al., 1999, Appendix $\mathrm{C} 1$ average of seven-day tests at $90^{\circ} \mathrm{C}$. 
differences are within the ranges seen for PCT with different CWF materials. The effects of radiation on HLW glasses have been studied for several years and provide insight into the likelihood that self-radiation affects the binder glass durability.

For example, tests were conducted with a borosilicate HLW glass to study the effect of self-radiation (Wellman et al., 2005). Those tests were conducted with borosilicate glass samples that had been made about 20 years previously with different mixtures of $\mathrm{Pu}-239$ and $\mathrm{Pu}-238\left(1 \mathrm{mass} \%\right.$ total $\left.\mathrm{PuO}_{2}\right)$ and had achieved different accumulated doses up to $2.6 \times 10^{18}$ alpha decays/g when the measurements were made. The glass dissolution rates as measured over the $\mathrm{pH}$ range $9,10,11$, and 12 at $80-88^{\circ} \mathrm{C}$ were not affected by differences in the accumulated dose. The authors concluded that self-radiation did not affect the glass dissolution rates.

Considering the CWF degradation mechanism, it is unlikely that self-radiation will lead to a significant increase in the release of radionuclides. This is because the $\mathrm{PuO}_{2}$ and rare earth element oxide phases are present as inclusions in the binder glass, and the durability of the binder glass would have to be lowered for enhanced release of $\mathrm{Pu}$ and rare earth elements due to self-irradiation. The responses in the seven-day PCTs described above are dominated by phases that are exposed at the surface, so that self-radiation effects may have enhanced their measured release. However, the radiation effects on phases in the bulk material will be mitigated by the durability of the binder glass.

\section{IV.B.7. Degradation of CWF in Humid Air}

Yucca Mountain is hydrologically unsaturated and the repository environment is expected to remain unsaturated throughout its service life. Under the expected disposal conditions, waste packages will be exposed to humid air having a RH between about $70 \%$ and $100 \%$ after the initial 300 - to 400-year period when water is driven away from the repository by the thermal load of the spent fuel. Water vapor can accumulate on waste forms due to thermal gradients or the hygroscopic nature of the waste form and their corrosion products. (Both HLW glass and CWF waste forms will be cooler than commercial spent fuel and DSNF.) Borosilicate glasses and CWF materials are hygroscopic and will sorb water vapor even at very low relative humidities. In the case of $\mathrm{CWF}$, the initial uptake of water vapor will be driven by dissolution of halite inclusion phases exposed at the surface to generate sodium chloride solutions. The deliquescent nature of these solutions can drive the accumulation of water in a breached waste package that could lead to the advective release of radionuclides as waste forms corrode. Although the principles of interactions between ionic solutions and water vapor are well-known, the interactions between waste solutions and vapor have not been studied to a significant extent and have not been measured or modeled for repository licensing.

A series of scoping tests was conducted to provide a qualitative indication of whether corrosion in humid air is a potentially important pathway for the release of radionuclides from the CWF. Three modified VHTs were conducted with CWF materials at $40,70,90$, and $150^{\circ} \mathrm{C}$. Prior to starting the tests, the CWF samples to be used in one test at each temperature were immersed briefly in demineralized water to dissolve the halite exposed at the surface. The wash water was analyzed. Tests were conducted with prewashed CWF to distinguish the effect of halite on the corrosion behavior in humid air from that of sodalite and binder glass. It was speculated that the formation of a $\mathrm{NaCl}$ solution when $\mathrm{CWF}$ was first exposed to water vapor would increase the uptake of water vapor and accelerate corrosion relative to tests with the pre-washed samples. The pre-washed CWF samples represent the waste form after the halite exposed at the surface was washed away. Another series of modified VHTs were conducted with pure binder glass to distinguish the effects of sodalite and the binder glass on CWF corrosion in humid air.

The results of VHTs with the CWF and prewashed CWF materials and with the binder glass conducted at $90^{\circ} \mathrm{C}$ are plotted in Fig. IV-28 as the cumulative values of NL(i) vs. the cumulative test duration. 
Tests One and Two designate duplicate tests with CWF or binder glass, and Test Three designates the test conducted with the pre-washed CWF sample. The Na released into the wash solutions is not included in the cumulative releases that are plotted. Pre-washing the CWF clearly reduces the amount of that is $\mathrm{Na}$ released: the Na released in Test Three is due to dissolution of sodalite and binder glass (see Fig. IV-28c). However, pre-washing the CWF does not affect the releases of B or Si significantly (see Figs. IV-28a and IV-28b). The release of $\mathrm{B}$ from the binder glass is much greater than from the CWF (compare Figs. IV-28a and IV-28d), but the releases of $\mathrm{Na}$ and $\mathrm{Si}$ are similar from the binder glass and CWF. This is because $\mathrm{Na}$ and $\mathrm{Si}$ are released due to the dissolution of sodalite from the CWF as well as binder glass.

The fact that the CWF is a multiphase material complicates interpretation of the test results. Boron is present only in the binder glass phase, and NL(B) reflects dissolution of that phase directly. Silicon is present in both the binder glass and sodalite (at mass fractions of about 0.295 and 0.187 , respectively). Since there is almost three times as much sodalite as binder glass in the CWF, about $66 \%$ of the silicon is contained in sodalite and $34 \%$ in the binder glass. Sodium is present in all three major phases: about $90 \%$ is contained in sodalite, $7 \%$ in binder glass, and 3\% in halite. The relative releases of $\mathrm{B}$ and $\mathrm{Si}$ reflect the relative extents of binder glass and sodalite dissolution: preferential dissolution of binder glass will result in values of $\mathrm{NL}(\mathrm{B})$ being significantly higher than values of $\mathrm{NL}(\mathrm{Si})$, which was seen in tests with the binder glass (compare Figs. IV-28d and IV-28e), whereas preferential dissolution of sodalite is indicated when the values of $\mathrm{NL}(\mathrm{Si})$ are similar to or greater than the values of $\mathrm{NL}(\mathrm{B})$.

The NL(B) values for the replicate tests with CWF and binder glass are shown in Fig. IV-29. Lines are drawn showing linear regression to the averages of the three tests conducted with CWF and the two tests conducted with binder glass at each temperature. The results of sampling tests with CWF over the first 14 days and the results of subsequent samplings are regressed separately. Comparing the results of tests with CWF to those with binder glass shows that the binder glass is about 10 times more reactive when it is by itself than when it is part of the CWF under these test conditions (comparing the long-term rates in Figs. IV-29b and IV-29e with those in Figs. IV-29c and IV-29f) The relative releases of B and Si provide added insight into the dissolution behavior. The observation that NL(B) is about 10 times higher than $\mathrm{NL}(\mathrm{Si})$ in tests with the binder glass, whereas the values of NL(B) are less than three times higher than NL(Si) in tests with CWF indicates that about one-third of the Si released in tests with CWF is due to sodalite dissolution. This is because the dissolution rates of borosilicate glasses decrease as $\mathrm{Si}$ accumulates in solution, and the buildup of $\mathrm{Si}$ in tests with CWF occurs faster than in tests with binder glass alone due to dissolution of sodalite.

As seen in Fig. IV-28a and IV-28b, the value of NL(B) is similar to or greater than the value of NL(Si) in most samplings, which indicates that more binder glass than sodalite is dissolving in tests at all temperatures. This is confirmed by the examination of the reacted samples. Figure IV-30a shows a SEM image of the surface of a CWF sample reacted at $150^{\circ} \mathrm{C}$ for 105 days. The binder glass has dissolved away in preference to sodalite. The sodalite and binder glass phases are difficult to distinguish based on contrast because the electron densities are very similar, but the two phases have distinct textures. Numerous pits have formed in the binder glass, whereas the sodalite has a coarser-grained appearance than the glass; the coarseness of the sodalite is due to the dissolution of glass from pores between sodalite grains. Figure IV-30b shows a SEM image of a cross-sectioned sample with arrows pointing to areas where the binder glass has dissolved preferentially to sodalite (the binder glass is slightly darker than sodalite). Note the similarities to samples reacted in immersion tests in dilute solutions in Figs. IV-19 and IV-20. Note also the abundance of micrometer-sized pores seen in Fig. IV-30b in both the glass and sodalite domains of the bulk material. Although some of the pores had probably contained halite that was dissolved during sample preparation, most were probably voids formed when the CWF was made. The PC CWF materials commonly contain about $10 \%$ closed porosity. 


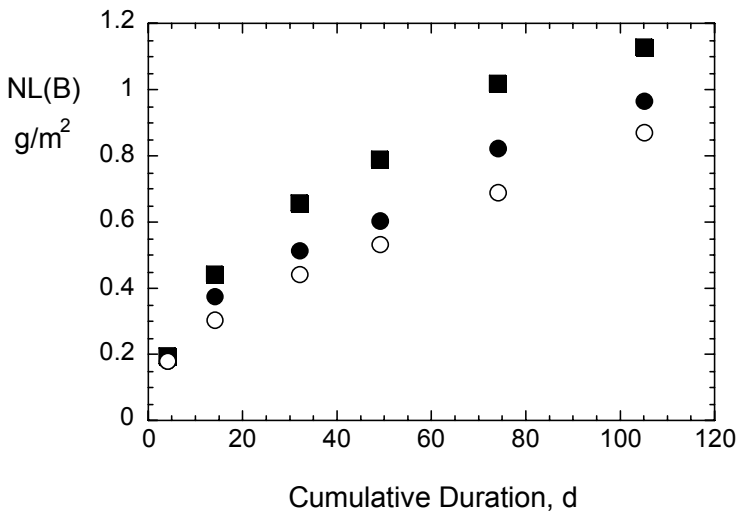

(a)

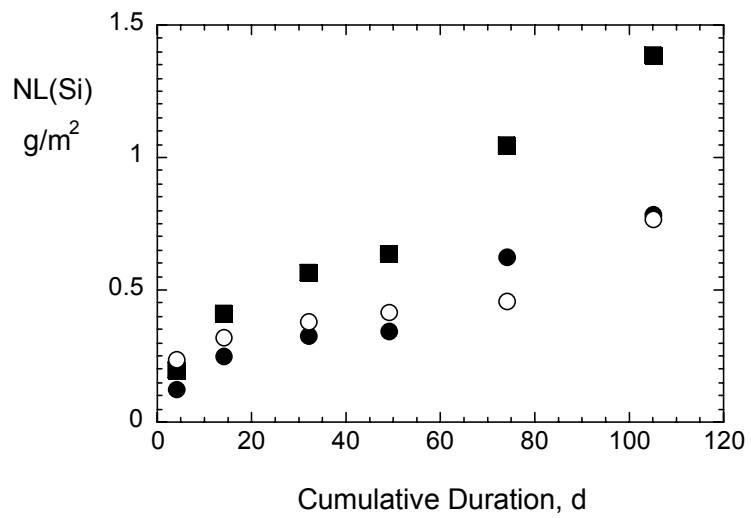

(b)

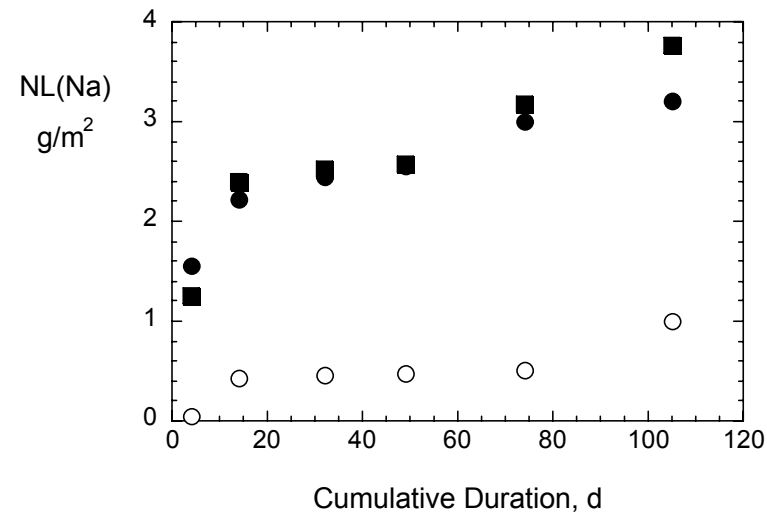

(c)

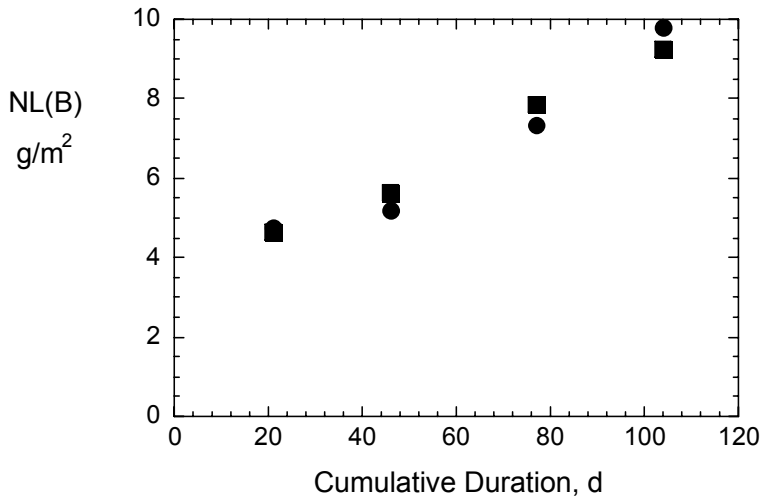

(d)

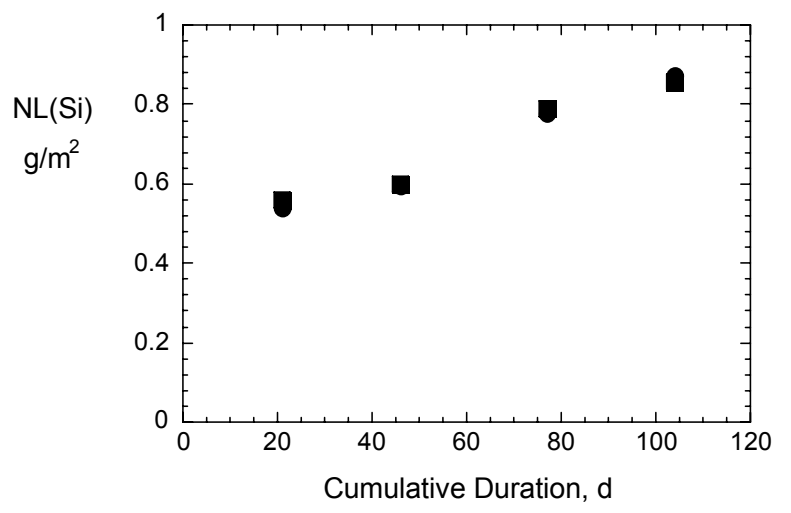

(e)

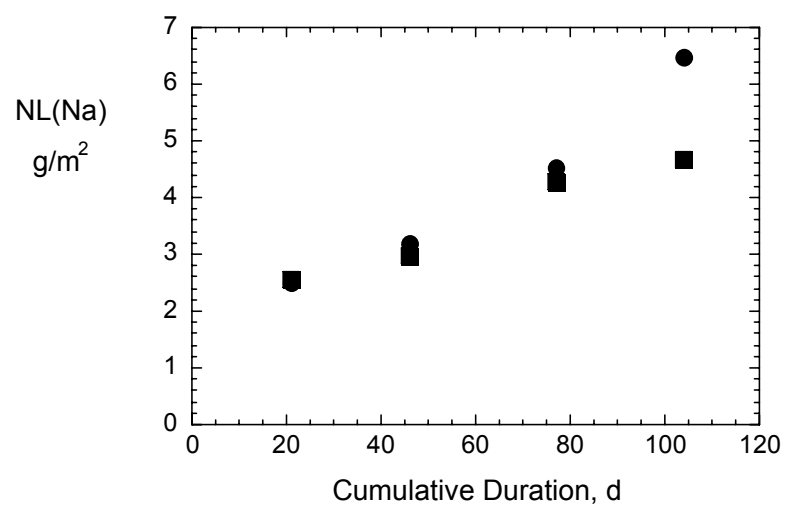

(f)

Fig. IV-28. Modified VHTs Conducted at $90^{\circ} \mathrm{C}$ with CWF: (a) NL(B), (b), NL(Si), and (c) NL(Na) and with binder glass: (d) NL(B), (e) NL(Si), and (f) NL(Na). Test $1(\mathbf{O})$, Test 2 (ם), and Test $3(\mathrm{O})$. 


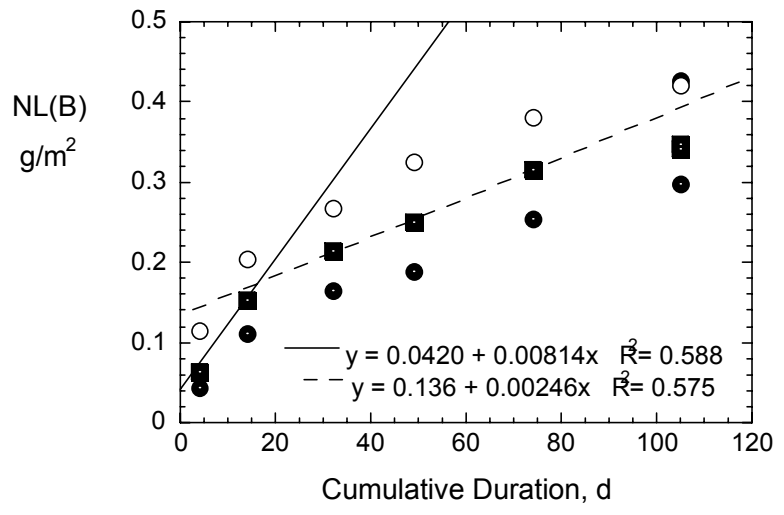

(a)

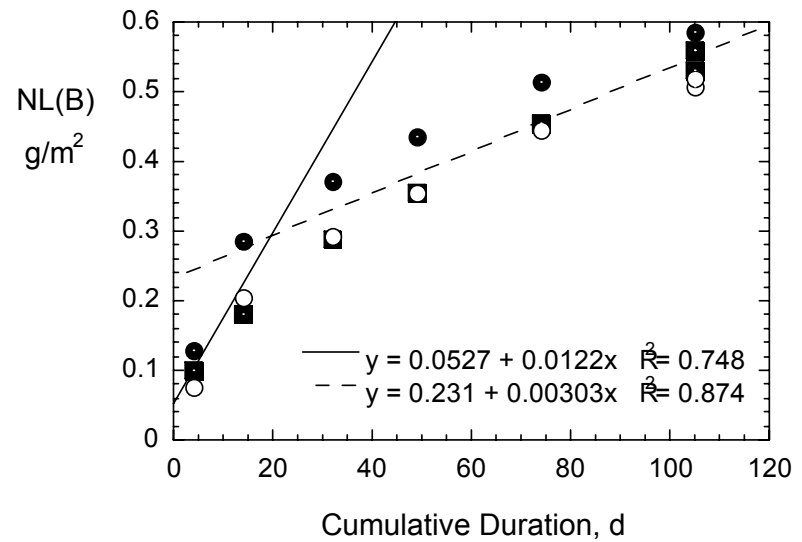

(b)

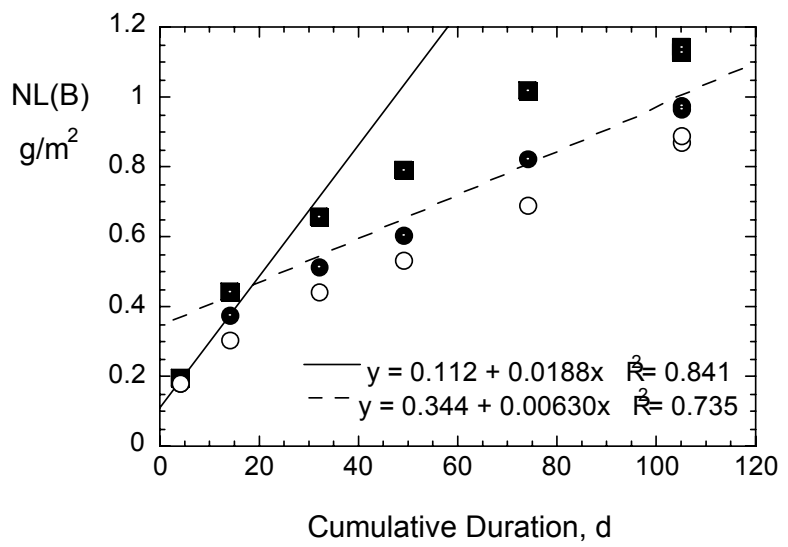

(c)

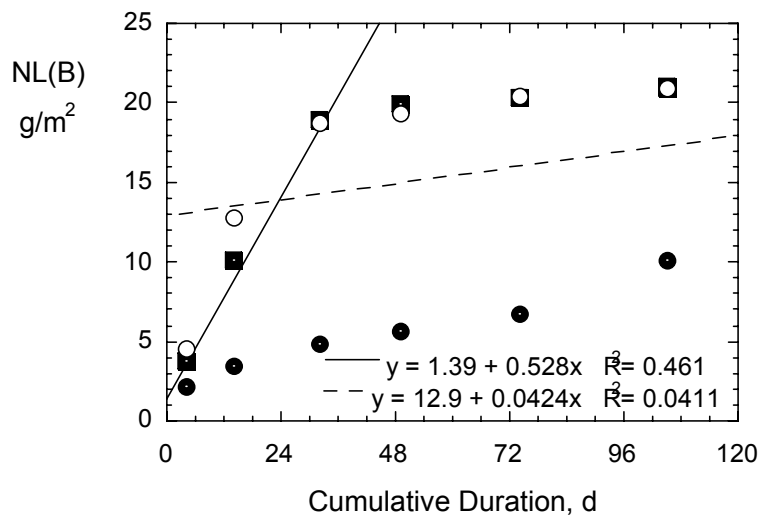

(d)

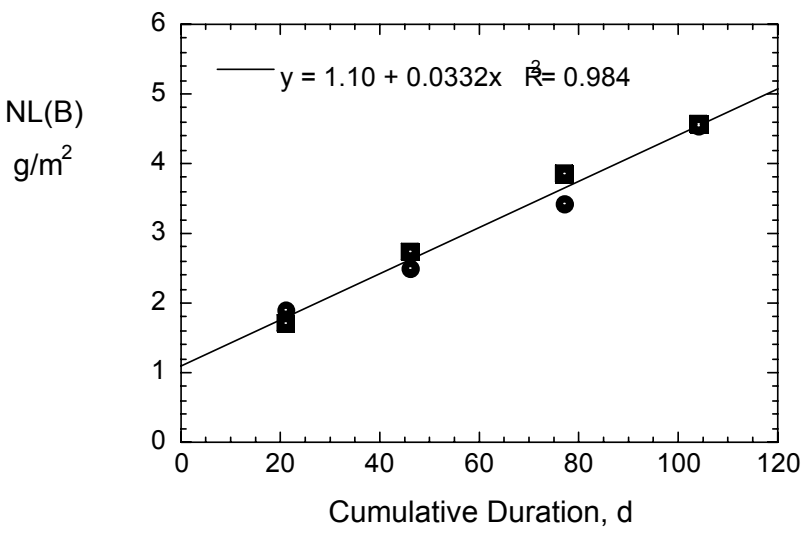

(e)

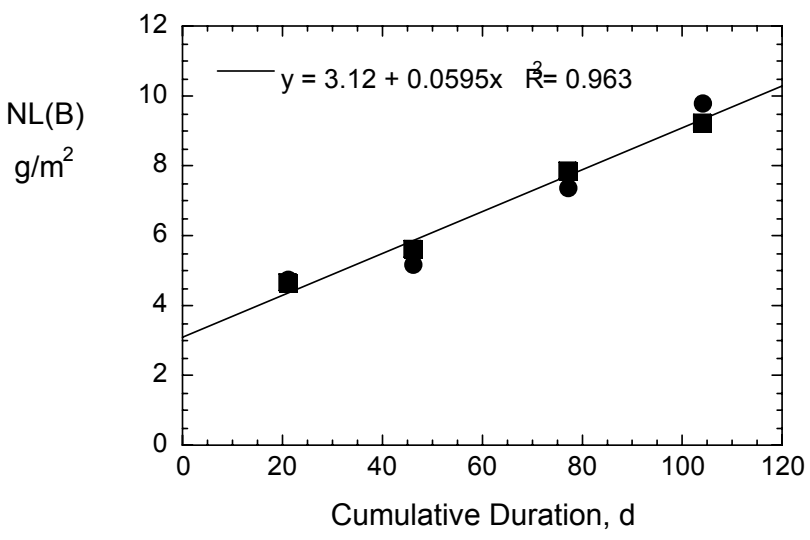

(f)

Fig. IV-29. Comparison of NL(B) Values Attained in Excess-Water VHTs with CWF at (a) $40^{\circ} \mathrm{C}$, (b) $70^{\circ} \mathrm{C}$, (c) $90^{\circ} \mathrm{C}$, and (d) $150^{\circ} \mathrm{C}$, and with Binder Glass at (e) $70^{\circ} \mathrm{C}$, and (f) $90^{\circ} \mathrm{C}$. (O) Test 1 , ( $\mathbf{\square}$ ) Test 2, and $(\bigcirc)$ Test 3. Separate lines regressed to averages of tests with CWF after 4 and 14 days, and after 32 through 135 days. 


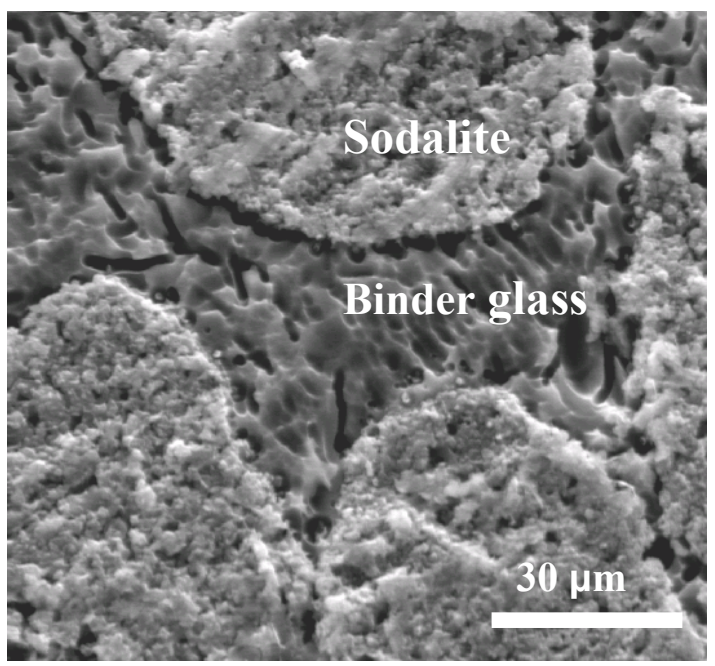

(a)

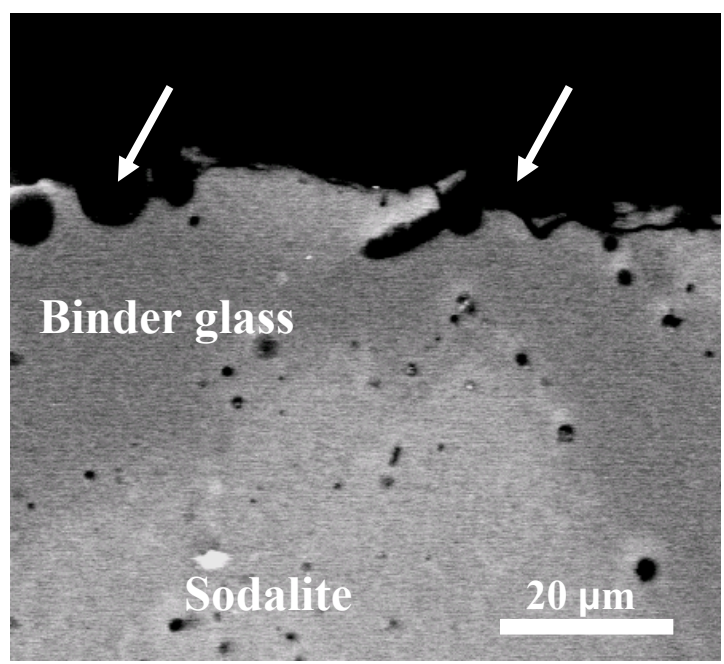

(b)

Fig. IV-30. Photomicrographs of (a) Surface and (b) Cross-Section of CWF Reacted in Modified VHT for 105 Days at $150^{\circ} \mathrm{C}$.

The similarities between the values of $\mathrm{NL}(\mathrm{B})$ and $\mathrm{NL}(\mathrm{Si})$ attained in tests with $\mathrm{CWF}$ and the corresponding values in tests with pre-washed CWF at all temperatures indicate that removing halite from the sample surfaces prior to the test did not affect the reactivity of the binder glass or sodalite. The similar releases also suggest that the presence of halite does not have a major impact on the capacity of the CWF to take up water vapor at $100 \% \mathrm{RH}$, although the role of halite on water vapor uptake may be more crucial at lower humidities.

\section{IV.C. Development of a Mechanistic Model for CWF Degradation}

In this section, the development of a model to calculate the dissolution behavior of the CWF over long time periods in a range of environments is summarized. Tests conducted to characterize the degradation behavior of CWF in aqueous solutions indicated that dissolution could be expressed in terms of the primary component phases sodalite and binder glass. It was hypothesized that same rate expression that is used for the degradation of defense HLW glass in the TSPA model (BSC 2004) could also be applied to the sodalite and binder glass phases individually. Application of the defense HLW glass degradation model to the binder glass is reasonable because the binder glass is a borosilicate glass having a composition similar to borosilicate glass frits used to produce HLW glasses. Application of the model to sodalite is also reasonable because it was originally developed to model the dissolution of aluminosilicate minerals. Sodalite is an aluminosilicate mineral. The degradation behaviors of the individual sodalite and binder glass phases and that of CWF materials are similar to that of borosilicate HLW glasses, and they have similar dependencies on temperature, $\mathrm{pH}$, and the dissolved Si concentration. Therefore, tests were conducted to measure model parameter values for CWF and its component sodalite and binder glass phases. The following sections summarize the derivation of the model used for HLW glass degradation and its application to the CWF.

\section{IV.C.1. Mechanistic Model for HLW Glass Degradation}

The mechanistic model developed for dissolution of aluminosilicate minerals (Aagaard and Helgeson, 1982) was adapted to model dissolution of borosilicate waste glasses (Grambow, 1985; Grambow and Strachan, 1988). The net reaction is given in Eq. IV-7: 


$$
\begin{gathered}
\equiv \mathrm{Si}-\mathrm{O}-\mathrm{Si}(\mathrm{OH})_{3}+\mathrm{H}_{2} \mathrm{O} \rightarrow \equiv \mathrm{Si}-\mathrm{OH}+\mathrm{Si}(\mathrm{OH})_{4} \\
\equiv \mathrm{Si}-\mathrm{OH}+\mathrm{Si}(\mathrm{OH})_{4} \rightarrow \equiv \mathrm{Si}-\mathrm{OSi}(\mathrm{OH})_{3}+\mathrm{H}_{2} \mathrm{O}
\end{gathered}
$$

Dissolution occurs due to hydrolysis of the bond between a silicon atom that is part of the structure and an oxygen atom of an adjacent $\mathrm{OSi}(\mathrm{OH})_{3}$ group (see Lasaga and Gibbs, 1990). These are shown in bold font in Eq. IV-7a. A hydrogen bond is formed between an $\mathrm{H}$ atom of the incoming water molecule and the oxygen, and a bond forms between the oxygen atom of the water and the $\mathrm{Si}$ atom of the terminal $\mathrm{Si}(\mathrm{OH})_{3}$ group (shown in bold font in Eq. IV-7a). The activated complex is illustrated in Eq. IV-7c:

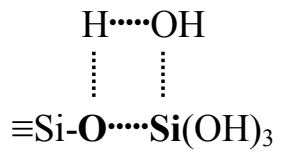

The original bond between the $\mathrm{O}$ and $\mathrm{Si}$ (shown in bold font) is broken, the $\mathrm{H}$ atom is transferred from the water to the oxygen of the glass to form a silanol group, and the $\mathrm{OH}$ of the water bonds with the $\mathrm{Si}$ atom (shown in bold font) to form a molecule of orthosilicic acid $\left(\mathrm{H}_{4} \mathrm{SiO}_{4}\right)$ that is released into solution. Reactions in Eqs. IV-7a and IV-7b are written for Si, but analogous hydrolysis reactions occur with other elements in the glass network (e.g., Al-O-Si, B-O-Si, U-O-Si, etc.), to release other species into solution. The reverse reaction can occur as shown in Eq. IV-7b, and becomes more significant as the concentration of orthosilicic acid increases. The net rate is the difference between the rates of the forward and reverse reactions in Eqs. IV-7a and IV-7b, and can be expressed in terms of the forward reaction rate using nonequilibrium thermodynamics as (Aagaard and Helgeson, 1982)

$$
\text { rate }_{\text {net }}=\text { rate }_{f} \bullet\left(1-\frac{Q}{K}\right)
$$

where $Q$ and $K$ are the ion activity product and solubility product of the solution, respectively. The term in parenthesis is referred to as the chemical affinity term. Glass dissolution is modeled by including only orthosilicic acid in the $Q$ and $K$ terms. When the solution is very dilute and the value of $Q$ is near 0 , the value of the affinity term is 1 and dissolution occurs at the so-called forward rate, rate $_{f}$, which depends on the glass composition, $\mathrm{pH}$, and temperature. As the concentration of orthosilicic acid increases, the value of $Q$ (and the value of the affinity term) decreases and the net rate becomes less than the forward rate. In the limit where orthosilicic acid reaches its solubility limit and $Q=K$, the value of the affinity term (and the rate) becomes zero.

The expression for the forward rate is empirical. Tests have shown the forward rate to have a power law dependence on the $\mathrm{pH}$ and an Arrhenius dependence on the temperature. A rate coefficient term $k_{0}$ is used to account for the dependence on glass composition and other parameters and constants are included explicitly. The forward rate is expressed as

$$
\text { rate }_{f}=k_{0} \bullet 10^{\eta \bullet p H} \bullet \exp \left(\frac{-E_{a}}{R T}\right)
$$

where $\eta$ is the coefficient for the $\mathrm{pH}$ dependence and $E_{a}$ is the coefficient for the temperature dependence, $R$ is the ideal gas constant and $T$ is the temperature in Kelvin. Inserting Eq. IV-9 into Eq. IV-8 gives the net dissolution rate as 


$$
\text { rate }_{n e t}=k_{0} \bullet 10^{\eta \bullet p H} \bullet \exp \left(\frac{-E_{a}}{R T}\right) \bullet\left(1-\frac{Q}{K}\right)
$$

In the HLW glass degradation model developed for TSPA, the rate expression in Eq. IV-10 was simplified by combining the $k_{0}$ and $(1-Q / K)$ terms into a single term $k_{E}$ (see Eq. III-1). Values of $\eta, E_{a}$, and $k_{E}$ were determined experimentally.

\section{IV.C.2. Modeling CWF Degradation}

Radionuclides in the CWF will become available for transport as the sodalite and binder glass phases dissolve. Radionuclides that are dissolved in the binder glass will be released from the glass and radionuclide contained in inclusion phases will be exposed to water at the rate that the binder glass dissolves. The behaviors of the inclusion phases will be controlled by their chemistries and size. Halite inclusions are highly soluble, but the actinide/rare earth element oxides are sparingly soluble, but small enough to be released as colloids. Although few radionuclides are contained in sodalite, its dissolution will affect the dissolution rate of the binder glass through both chemical and physical effects. The primary chemical effect is through its contributions to the Si concentration and $\mathrm{pH}$. The primary physical effect is blocking access to the binder glass.

The degradation model developed for the CWF considers the simultaneous dissolution of sodalite and binder glass and utilizes insights gained from testing (Fanning et al., 2001; Fanning et al., 2002; Fanning et al., 2003; Fanning, 2003). The model is summarized in the simple flow diagram given in Fig. IV-31. When the CWF is contacted by ground water, both the sodalite and binder glass phases will dissolve at rates that depend on the temperature, $\mathrm{pH}$, and $\mathrm{Si}$ concentration of the water. The surface that is contacted is assumed to be composed of 75 area \% sodalite and 25 area \% binder glass, which is approximately the same as the mass and volume ratios. As each phase dissolves, new surfaces will be exposed and the relative surface areas of each phase will change. Based on the results of the solution exchange tests discussed in Section IV.B.2.2., the amount of binder glass that dissolves is expected to greatly exceed the amount of sodalite that dissolves, and the fractional surface area of sodalite is expected to increase and the fractional surface area of binder glass decrease. Dissolution of binder glass will make radionuclides available for transport directly and expose inclusion phases to water. The inclusion phases are modeled to be uniformly distributed in the CWF and to be available for transport as soon as they are contacted by water (Fanning et al., 2003). Because they cannot be contacted by water until the binder glass dissolves, the inclusion phases become available at the same rate the binder glass dissolves. It was determined that sodalite does not host a significant amount of radionuclides (probably only about 0.7 mass \% ${ }^{129} \mathrm{I}$ ) (see Section IV.A.7) and that sodalite is more durable than the binder glass in solutions with more than about $32 \mathrm{mg} \mathrm{Si} / \mathrm{L}$ (see Section IV.B.2.2). Tuff ground water itself contains about $30 \mathrm{mg} \mathrm{Si} / \mathrm{L}$ at ambient temperatures, and exposure to rock at higher temperatures will increase the Si content. In the case of water vapor condensation, very little CWF would have to dissolve to generate solutions that were saturated with respect to sodalite. In the CWF degradation model, therefore, the durability of the CWF is taken to be that of the less durable binder glass. In effect, the dissolution rate of the binder glass is used as an upper bound for the dissolution of sodalite and the rate that all radionuclides are available. This is identical to the treatment of radionuclides in HLW glass.

It is not our intention to calculate the degradation rate of CWF and release rates of radionuclides separately for use in TSPA-LA; rather, the objective is to show that the radionuclide release rates that are calculated for defense HLW glass represent or provide an upper bound to the release rates from CWF under the same conditions. Confidence in the use of the HLW glass degradation model to represent CWF degradation is enhanced by the similarity in the underlying mechanisms for HLW glass and CWF degradation. 


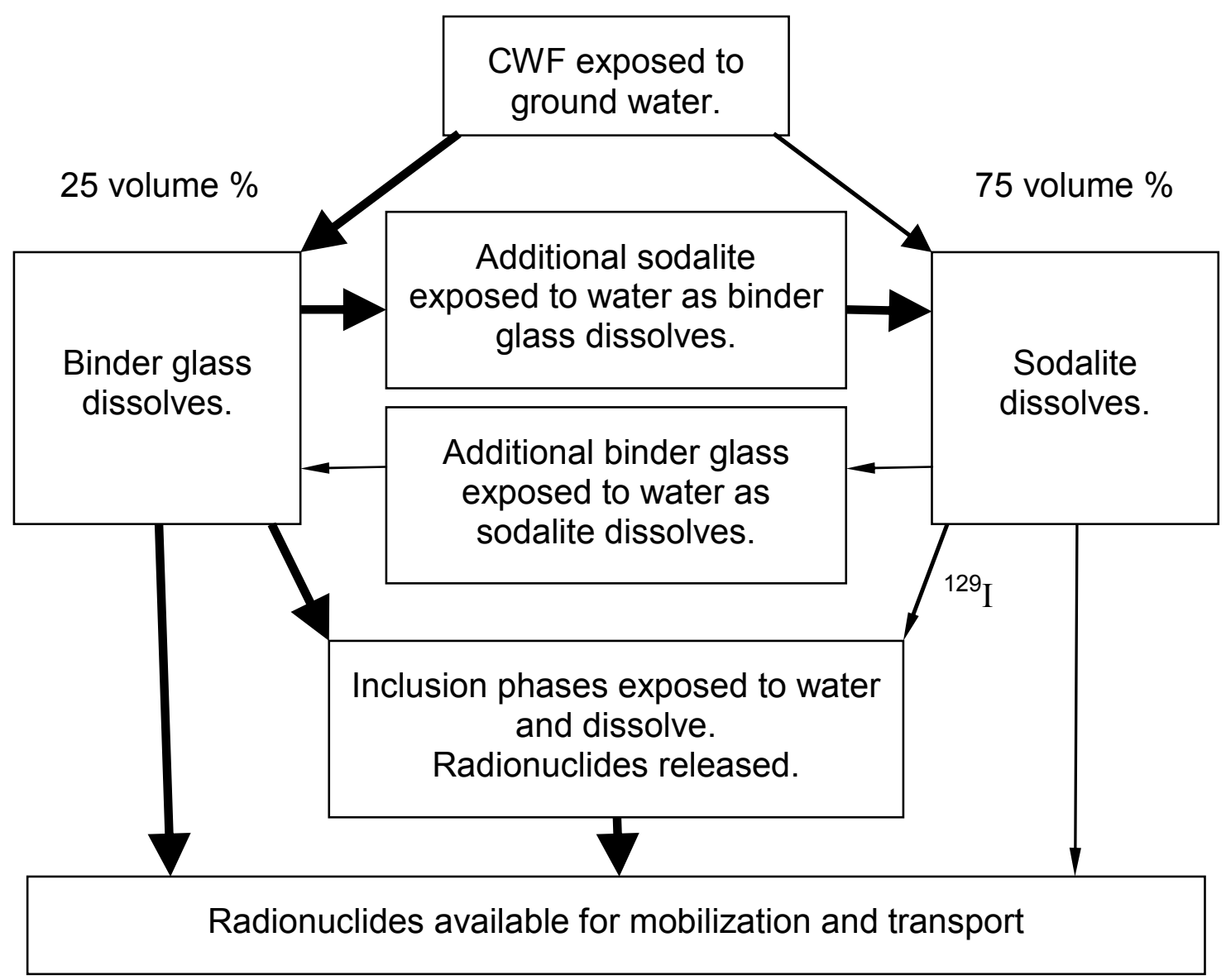

Fig. IV-31. Schematic Flow Diagram of CWF Degradation Model. The thicker arrows indicate that the model assumes binder glass dissolves faster than sodalite under disposal conditions.

\section{IV.C.2.1. Intrinsic Rate Constant, pH Dependence, and Temperature Dependence $\left(k_{\theta}, \eta\right.$ and $\left.E_{a}\right)$}

Use of the rate expression in Eq. IVC-9 to model CWF dissolution has been evaluated by first measuring values for the model coefficients $\eta, E_{a}$, and $k_{0}$ for CWF and for its component sodalite and binder glass phases, and then comparing calculated rates with calculated for defense HLW glass. Values of the intrinsic rate constant $\left(k_{0}\right), \mathrm{pH}$ dependence $(\eta)$, and temperature dependence $\left(E_{a}\right)$ were all determined from the dissolution rates measured in tests in which the value of the affinity term is maintained near 1 and the other variables are held constant. Separate sets of parameter values were determined for HIP CWF, sodalite, and binder glass. An initial series of MCC-1 tests was conducted with the separate sodalite and binder glass materials, and with HIP CWF at $20,40,70$, and $90^{\circ} \mathrm{C}$. The purpose of these was to provide data to verify the prediction of the CWF dissolution model for the sodalite, binder glass, and $\mathrm{CWF}$. Tests were conducted in dilute $\mathrm{pH}$ buffer solutions to maintain a nearly constant $\mathrm{pH}$; see (Fanning et al., 2003; Jeong et al., 2002; Morss et al., 1999) for details regarding the tests. Tests were also conducted at $70^{\circ} \mathrm{C}$ and $3 \mathrm{pH}$ values with $\mathrm{PC} \mathrm{CWF}$ for comparison with the model parameters determined from tests with HIP CWF. The values of $\mathrm{NL}(\mathrm{Si})$ determined from these tests with sodalite, binder glass, HIP CWF, and PC CWF are summarized in Table IV-13. Additional tests were conducted at $70^{\circ} \mathrm{C}$ using 
Table IV-13. NL(Si) for MCC-1 Tests with Sodalite, Binder Glass, HIP CWF, and PC CWF, in g/m²

\begin{tabular}{|c|c|c|c|c|c|c|c|c|c|}
\hline \multicolumn{10}{|c|}{ Tests with Sodalite } \\
\hline \multirow{6}{*}{$20^{\circ} \mathrm{C}$} & Time (d) & $\mathrm{pH} 4.8^{\mathrm{a}}$ & $\mathrm{pH} \mathrm{6.1^{ \textrm {a } }}$ & $\mathrm{pH} 7.3^{\mathrm{b}}$ & $\mathrm{pH} 8.3^{\mathrm{c}}$ & pH 9.1 ${ }^{\mathrm{c}}$ & & & \\
\hline & 7 & 8.74 & 0.17 & 0.06 & 0.02 & 0.18 & & & \\
\hline & 14 & 14.8 & 0.33 & 0.13 & 0.54 & 0.51 & & & \\
\hline & 28 & 18.6 & 0.34 & 0.12 & 0.46 & 0.41 & & & \\
\hline & 56 & 21.4 & 0.47 & 0.12 & 0.58 & 0.50 & & & \\
\hline & 91 & 25.3 & 0.64 & 0.18 & 0.84 & 0.69 & & & \\
\hline \multirow{6}{*}{$40^{\circ} \mathrm{C}$} & Time (d) & $\mathrm{pH} 4.9^{\mathrm{a}}$ & $\mathrm{pH} 6.0^{\mathrm{a}}$ & pH $7.2^{b}$ & $\mathrm{pH} \mathrm{8.3^{ \textrm {c } }}$ & pH 9.6 ${ }^{\mathrm{c}}$ & & & \\
\hline & 7 & 9.89 & 0.438 & 0.509 & 1.23 & 1.04 & & & \\
\hline & 14 & 13.1 & 0.638 & 0.732 & 1.48 & 1.34 & & & \\
\hline & 28 & 16.6 & 2.93 & 0.915 & 2.27 & 1.88 & & & \\
\hline & 56 & 5.00 & 3.90 & 1.28 & 2.74 & 2.92 & & & \\
\hline & 91 & 23.0 & 5.62 & 1.55 & 3.73 & 3.54 & & & \\
\hline \multirow{8}{*}{$70^{\circ} \mathrm{C}$} & Time (d) & $\mathrm{pH} 4.9^{\mathrm{a}}$ & $\mathrm{pH} 6.4^{\mathrm{a}}$ & pH $7.2^{b}$ & pH 8.3 & pH 9.4 ${ }^{\mathrm{c}}$ & pH 5.74 & $\mathrm{pH} 7.95^{\mathrm{e}}$ & pH 9.49 \\
\hline & 2 & & & & & & 1.98 & 1.73 & 1.72 \\
\hline & 3 & 8.13 & 3.22 & 2.08 & 2.68 & 3.13 & 2.56 & 2.25 & 1.86 \\
\hline & 5 & 11.4 & 4.05 & 2.71 & 4.68 & 4.31 & 3.28 & 3.11 & 3.15 \\
\hline & 7 & & & & & & 2.80 & 3.75 & 3.40 \\
\hline & 9 & 17.4 & 6.76 & 2.98 & 5.28 & 5.14 & & & \\
\hline & 10 & & & & & & 5.11 & 3.68 & 4.25 \\
\hline & 12 & 16.7 & 7.21 & 3.17 & 5.07 & 6.60 & & & \\
\hline \multirow{5}{*}{$90^{\circ} \mathrm{C}$} & Time (d) & pH 5.1 ${ }^{\mathrm{a}}$ & $\mathrm{pH} 6.0^{\mathrm{a}}$ & pH 7.0 & pH 8.1 ${ }^{\mathrm{c}}$ & pH 9.2 ${ }^{\mathrm{c}}$ & pH 10.2 & & \\
\hline & 1 & 2.94 & 4.02 & 2.90 & 3.72 & 4.00 & 10.0 & & \\
\hline & 2 & 5.18 & 4.99 & 4.25 & 5.30 & 5.70 & 14.6 & & \\
\hline & 3 & 11.5 & 6.08 & 4.57 & 7.21 & 8.18 & 15.1 & & \\
\hline & 5 & 13.8 & 6.61 & 4.68 & 7.69 & 8.84 & - & & \\
\hline \multicolumn{10}{|c|}{ Tests with Binder Glass } \\
\hline \multirow{6}{*}{$20^{\circ} \mathrm{C}$} & Time (d) & $\mathrm{pH} \mathrm{4.8}{ }^{\mathrm{a}}$ & $\mathrm{pH} \mathrm{6.1^{ \textrm {a } }}$ & $\mathrm{pH} 7.3^{\mathrm{b}}$ & $\mathrm{pH} 08.3^{\mathrm{c}}$ & $\mathrm{pH} 9.1^{\mathrm{c}}$ & & & \\
\hline & 7 & 0 & 0 & 0 & 0 & 0.05 & & & \\
\hline & 14 & 0.03 & 0.01 & 0.02 & 0.08 & 0.18 & & & \\
\hline & 28 & 0.01 & 0.01 & 0.0 & 0.09 & 0.21 & & & \\
\hline & 56 & 0.01 & 0.01 & 0 & 0.09 & 0.37 & & & \\
\hline & 91 & 0.02 & 0.04 & 0.02 & 0.20 & 0.62 & & & \\
\hline \multirow{6}{*}{$40^{\circ} \mathrm{C}$} & Time (d) & $\mathrm{pH} \mathrm{4.9}{ }^{\mathrm{a}}$ & $\mathrm{pH} \mathrm{6.0} 0^{\mathrm{a}}$ & pH 6.8 & $\mathrm{pH} 7.2^{\mathrm{b}}$ & $\mathrm{pH} \mathrm{7.8}{ }^{\mathrm{b}}$ & $\mathrm{pH} 8.3^{\mathrm{c}}$ & $\mathrm{pH} \mathrm{9.6}{ }^{\mathrm{c}}$ & \\
\hline & 7 & 0.062 & 0.054 & 0.007 & 0.052 & 0.023 & 0.168 & 0.678 & \\
\hline & 14 & 0.049 & 0.060 & 0.013 & 0.068 & 0.039 & 0.263 & 1.06 & \\
\hline & 28 & 0.076 & 0.079 & 0.024 & 0.075 & 0.050 & 0.586 & 1.84 & \\
\hline & 56 & 0.123 & 0.063 & 0.035 & 0.057 & 0.129 & 0.747 & 2.75 & \\
\hline & 91 & 0.242 & 0.117 & - & 0.076 & - & 1.647 & 3.21 & \\
\hline \multirow{8}{*}{$70^{\circ} \mathrm{C}$} & Time (d) & $\mathrm{pH} 5.1^{\mathrm{a}}$ & $\mathrm{pH} \mathrm{6.0^{ \textrm {a } }}$ & $\mathrm{pH} 7.2^{\mathrm{b}}$ & $\mathrm{pH} 8.3^{\mathrm{c}}$ & $\mathrm{pH} \mathrm{9.6^{ \textrm {c } }}$ & $\mathrm{pH} \mathrm{5.74}{ }^{\mathrm{d}}$ & $\mathrm{pH} 7.95^{\mathrm{e}}$ & $\mathrm{pH} \mathrm{9.49^{ \textrm {T } }}$ \\
\hline & 2 & & & & & & 0.051 & 0.281 & 0.996 \\
\hline & 3 & 0.107 & 0.061 & 0.075 & 1.38 & 2.78 & 0.048 & 0.298 & 2.06 \\
\hline & 5 & 0.165 & 0.092 & 0.101 & 1.80 & 3.85 & 0.061 & 0.410 & 3.18 \\
\hline & 7 & & & & & & 0.083 & 0.318 & 3.11 \\
\hline & 9 & 0.208 & 0.095 & 0.064 & 2.25 & 4.77 & & & \\
\hline & 10 & & & & & & 0.103 & 0.531 & 3.90 \\
\hline & 12 & 0.344 & 0.127 & 0.185 & 6.06 & 2.42 & & & \\
\hline \multirow{5}{*}{$90^{\circ} \mathrm{C}$} & Time (d) & pH 5.1 ${ }^{\mathrm{a}}$ & $\mathrm{pH} \mathrm{6.0}{ }^{\mathrm{a}}$ & $\mathrm{pH} \mathrm{7.0}$ & $\mathrm{pH} 8.1^{\mathrm{c}}$ & $\mathrm{pH} 9.2^{\mathrm{c}}$ & pH 10.2 & & \\
\hline & 1 & 0.075 & 0.157 & 0.068 & 1.74 & 4.32 & 13.2 & & \\
\hline & 2 & 0.129 & 0.225 & 0.136 & 2.52 & 7.17 & 20.8 & & \\
\hline & 3 & 0.252 & 0.331 & 0.211 & 4.50 & 9.12 & 23.8 & & \\
\hline & 5 & 0.190 & 0.376 & 0.292 & 5.30 & 10.5 & - & & \\
\hline
\end{tabular}


Table IV-13. (conttinued)

\begin{tabular}{|c|c|c|c|c|c|c|c|c|c|}
\hline \multicolumn{10}{|c|}{ Tests with HIP CWF } \\
\hline \multirow{6}{*}{$20^{\circ} \mathrm{C}$} & Time (d) & $\mathrm{pH} \mathrm{4.8^{ \textrm {a } }}$ & $\mathrm{pH} 6.1^{\mathrm{a}}$ & $\mathrm{pH} 7.3^{\mathrm{b}}$ & $\mathrm{pH} \mathrm{8.3^{ \textrm {c } }}$ & $\mathrm{pH} 9.1^{\mathrm{c}}$ & & & \\
\hline & 7 & 7.01 & 0.11 & 0.05 & 0.03 & 0.25 & & & \\
\hline & 14 & 11.7 & 0.24 & 0.11 & 0.34 & 0.45 & & & \\
\hline & 28 & 16.5 & 0.28 & 0.08 & 0.28 & 0.33 & & & \\
\hline & 56 & 19.4 & 0.71 & 0.13 & 0.49 & 0.52 & & & \\
\hline & 91 & 21.7 & 1.12 & 0.21 & 0.75 & 0.62 & & & \\
\hline \multirow{6}{*}{$40^{\circ} \mathrm{C}$} & Time (d) & $\mathrm{pH} 4.9^{\mathrm{a}}$ & $\mathrm{pH} 6.0^{\mathrm{a}}$ & $\mathrm{pH} 7.2^{\mathrm{b}}$ & $\mathrm{pH} 8.3^{\mathrm{c}}$ & $\mathrm{pH} \mathrm{9.6^{ \textrm {C } }}$ & & & \\
\hline & 7 & 9.76 & 0.495 & 0.378 & 0.684 & 0.844 & & & \\
\hline & 14 & 10.1 & 0.652 & 0.498 & 1.15 & 1.18 & & & \\
\hline & 28 & $9.53^{\mathrm{a}}$ & $1.77^{a}$ & 0.662 & 1.44 & 2.01 & & & \\
\hline & 56 & 13.8 & 2.68 & 0.720 & 2.02 & 2.46 & & & \\
\hline & 91 & 19.9 & 3.90 & 1.09 & 2.67 & 2.83 & & & \\
\hline \multirow{6}{*}{$70^{\circ} \mathrm{C}$} & Time (d) & pH 5.1 ${ }^{\mathrm{a}}$ & $\mathrm{pH} 6.0^{\mathrm{a}}$ & $\mathrm{pH} 7.2^{\mathrm{b}}$ & $\mathrm{pH} 8.3^{\mathrm{c}}$ & $\mathrm{pH} \mathrm{9.6^{ \textrm {C } }}$ & $\mathrm{pH} \mathrm{5.74}$ & $\mathrm{pH} 7.95^{\mathrm{e}}$ & $\mathrm{pH} \mathrm{9.49^{ \textrm {f } }}$ \\
\hline & 2 & & & & & & 1.21 & 1.44 & 1.78 \\
\hline & 3 & 4.77 & 1.36 & 1.44 & 2.51 & 2.41 & 1.77 & 2.16 & 2.56 \\
\hline & 5 & 8.89 & 2.47 & 1.93 & 3.34 & 3.53 & 1.68 & 2.13 & 3.40 \\
\hline & 7 & 11.3 & 3.33 & 2.20 & 4.34 & 4.41 & 2.76 & 2.39 & 3.72 \\
\hline & 10 & $14.7^{b}$ & 4.70 & 2.36 & 5.24 & 4.54 & 3.38 & 2.39 & 4.71 \\
\hline \multirow{5}{*}{$90^{\circ} \mathrm{C}$} & Time (d) & pH 5.1 ${ }^{a}$ & $\mathrm{pH} 6.0^{\mathrm{a}}$ & $\mathrm{pH} 7.0^{\mathrm{b}}$ & $\mathrm{pH} 8.1^{\mathrm{c}}$ & $\mathrm{pH} \mathrm{9.2^{ \circ }}$ & $\mathrm{pH} 10.2^{\mathrm{g}}$ & & \\
\hline & 1 & 1.43 & 2.85 & 1.85 & 2.70 & 4.22 & 11.0 & & \\
\hline & 2 & 4.80 & 3.76 & 2.80 & 4.32 & 6.06 & 15.6 & & \\
\hline & 3 & 7.26 & 5.10 & 3.81 & 5.96 & 8.10 & 17.5 & & \\
\hline & 5 & 8.99 & 5.50 & 4.61 & 7.91 & 10.3 & 27.2 & & \\
\hline \multicolumn{10}{|c|}{ Tests with PC CWF } \\
\hline \multirow{6}{*}{$20^{\circ} \mathrm{C}$} & Time (d) & pH 5.95 ${ }^{\mathrm{a}}$ & pH 8.37 & $\mathrm{pH} 9.81^{\mathrm{c}}$ & & & & & \\
\hline & 7 & 0.19 & 0.12 & 0.23 & & & & & \\
\hline & 14 & 0.21 & 0.22 & 0.28 & & & & & \\
\hline & 28 & 0.28 & 0.27 & 0.49 & & & & & \\
\hline & 56 & 0.38 & 0.50 & 1.22 & & & & & \\
\hline & 91 & 0.48 & 0.60 & 1.38 & & & & & \\
\hline \multirow{6}{*}{$70^{\circ} \mathrm{C}$} & Time (d) & pH 6.2 & $\mathrm{pH} \mathrm{8.2^{ \textrm {c } }}$ & $\mathrm{pH} \mathrm{9.5^{ \textrm {c } }}$ & & & & & \\
\hline & 2 & 0.07 & 0.82 & 2.03 & & & & & \\
\hline & 3 & 0.10 & 1.17 & 2.20 & & & & & \\
\hline & 5 & 0.17 & 1.59 & 2.85 & & & & & \\
\hline & 7 & 0.14 & 1.87 & 3.85 & & & & & \\
\hline & 10 & 0.27 & 2.35 & 4.52 & & & & & \\
\hline
\end{tabular}

${ }^{\text {a }}$ Potassium hydrogen phthalate $+\mathrm{LiOH}$.

${ }^{\mathrm{b}}$ Nitric acid + tris(hydroxymethyl)aminomethane.

${ }^{\mathrm{c}}$ Boric acid + $\mathrm{LiOH}$.

${ }^{\mathrm{d}}$ 2-(N-morpholino)ethanesulfonic acid.

${ }^{e}$ Piperazine-N,N'-bis(3-propanesulfonic acid).

${ }^{\mathrm{f}} \mathrm{N}, \mathrm{N}, \mathrm{N}, \mathrm{N}$ '-tetraethylethylenediamine.

${ }^{\mathrm{g}} \mathrm{LiOH}$. 
non-complexing buffer solution to verify that tests in the standard buffers were not affected by chemical interactions with the buffer components. The results of those tests are included in Table IV-13.

The solution concentrations of Si were used to measure the extent of dissolution as NL(Si) and calculate the normalized dissolution rate $\mathrm{NR}(\mathrm{Si})$. Silicon was used instead of B because sodalite does not contain B. Both sodalite and the binder glass contain $\mathrm{Si}$, and $\mathrm{Si}$ provides an overall measure of CWF dissolution regardless of which phase dominates the test response. Parameter values for the HLW glass model were determined from rates based on B release, which are usually higher than rates based on Si release. The B-based dissolution rates are more representative of ${ }^{99} \mathrm{Tc}$ release from borosilicate glasses than rates based on $\mathrm{Si}$, but both the $\mathrm{B}$ - and $\mathrm{Si}$-based release rates bound the release of other radionuclides (see Section IV.B.3). Since the CWF inventory does not include ${ }^{99}$ Tc (see Appendix A, Table A.1), the Si-based rates adequately represent the release of important radionuclides.

Linear regression was used to determine the dissolution rates for each $\mathrm{pH}$, temperature, and material. For MCC-1 tests at a particular temperature and $\mathrm{pH}$, the value of $\mathrm{NL}(\mathrm{Si})$ is expected to increase with time in a linear fashion over a short time span. The glass is expected to react at a high rate initially due to stresses imposed by polishing, scratches, etc., and then to react at a low rate when the Si concentration becomes high enough that the solution feedback effects are significant. The rate is nearly linear between these limits, and is taken to be the forward rate $\left(k_{f}\right)$. The forward rates measured at various temperatures and $\mathrm{pH}$ values are summarized in Table IV-14. The rates are plotted in Fig. IV-32. The sodalite, binder glass, and HIP CWF all show the same V-shaped pH-dependence that is modeled in the HLW glass degradation model. The lines drawn for the acid and alkaline legs in Fig. IV-32 were determined by linear regression of all test results using the logarithmic form of Eq. IV-10, which is given in Eq. IV-11:

$$
\log \text { rate }=\log k_{0}+\eta \bullet p H-\frac{E_{a}}{R T \ln 10}
$$

Eq. IVC-11 was parameterized using the function in Eq. IV-12:

$$
\log \text { rate }=C_{0}+C_{1}\left(p H-C_{p H}\right)+C_{2}\left(\frac{1}{T}-C_{T}\right)
$$

where $C_{p H}$ and $C_{T}$ represent the average $\mathrm{pH}$ and inverse temperature of the data used in the regression; see Fanning et al. (2003) for details regarding the regression and modeling. For each material, separate values of $k_{0}, \eta$, and $E_{a}$ were determined for use at all temperatures for the acidic and alkaline legs and the parameter values are summarized in Table IV-15 for Eq. IV-11 and in Table IV-16 for Eq. IV-12. The uncertainties in the regressed values are about $10-20 \%$.

The rates regressed for sodalite, binder glass, and CWF are compared in Fig. IV-33. The dissolution rate of the CWF under these test conditions is essentially the sum of the dissolution rates of sodalite and the binder glass, because the Si concentrations remain low and feedback effects are small. Dissolution of sodalite occurs faster than binder glass and dominates CWF dissolution at $\mathrm{pH}$ values less than about 9.3 (shown by the vertical dashed line in Fig. IV-33). It is worth noting that the solution $\mathrm{pH}$ values attained in short-term MCC-1 tests with CWF typically range between about 8.5 and 9.2. This is why the dissolution rates of sodalite and the binder glass in the short-term MCC-1 tests discussed in Section IVB2.3 were about the same. Likewise, the solution $\mathrm{pH}$ values attained in seven-day PCTs (and in longer-term PCTs) are typically near 9 (e.g., Lewis and Ebert, 2000; Lewis, et al., 2000; Lewis et al., 2001; Lewis et al., 2002). However, the value of the affinity term is much lower in all PCTs than in the short-term MCC-1 tests. 
Table IV-14. Normalized Dissolution Rates Based on Silicon Release, g/( $\left.\mathrm{m}^{2} \mathrm{~d}\right)$

\begin{tabular}{|c|c|c|c|}
\hline $\mathrm{pH}$ & Sodalite & Binder Glass & HIP CWF \\
\hline \multicolumn{4}{|c|}{ Tests at $20^{\circ} \mathrm{C}$} \\
\hline 4.8 & $0.48^{a}$ & 0.0002 & $0.49^{\mathrm{a}}$ \\
\hline 6.1 & 0.005 & 0.0004 & 0.0120 \\
\hline 7.3 & 0.001 & 0.0002 & 0.0016 \\
\hline 8.3 & 0.007 & 0.0002 & 0.0072 \\
\hline 9.8 & 0.004 & 0.0006 & 0.0037 \\
\hline \multicolumn{4}{|c|}{ Tests at $40^{\circ} \mathrm{C}$} \\
\hline 4.9 & $0.14 \pm 0.03$ & $0.0027 \pm 0.003$ & $0.13 \pm 0.02$ \\
\hline 6.0 & $0.062 \pm 0.010$ & $0.00096 \pm 0.00006$ & $0.041 \pm 0.004$ \\
\hline 6.8 & - & $0.00056 \pm 0.00008$ & - \\
\hline 7.2 & $0.012 \pm 0.001$ & $0.00060 \pm 0.00015$ & $0.0074 \pm 0.0010$ \\
\hline 7.8 & - & $0.0021 \pm 0.0003$ & - \\
\hline 8.3 & $0.029 \pm 0.003$ & $0.0055 \pm 0.0039$ & $0.022 \pm 0.0002$ \\
\hline 8.3 & $0.030 \pm 0.001$ & $0.0056 \pm 0.0012$ & $0.020 \pm 0.005$ \\
\hline 9.6 & $0.030 \pm 0.003$ & $0.043 \pm 0.0044$ & $0.023 \pm 0.005$ \\
\hline \multicolumn{4}{|c|}{ Tests at $70^{\circ} \mathrm{C}$} \\
\hline 4.9 & $1.0 \pm 0.3$ & - & - \\
\hline 5.1 & - & $0.025 \pm 0.001$ & $1.4 \pm 0.1$ \\
\hline $5.7^{b}$ & $0.33 \pm 0.09$ & $0.0071 \pm 0.0009$ & $0.26 \pm 0.03$ \\
\hline 6.0 & - & $0.0093 \pm 0.0019$ & $0.48 \pm 0.01$ \\
\hline 6.4 & $0.48 \pm 0.08$ & - & - \\
\hline 7.2 & $0.11 \pm 0.03$ & $0.016 \pm 0.002$ & $0.19 \pm 0.03$ \\
\hline $8.0^{b}$ & $0.25 \pm 0.07$ & $0.027 \pm 0.010$ & $0.21 \pm 0.04$ \\
\hline 8.3 & $0.23 \pm 0.13$ & $0.22 \pm 0.004$ & $0.40 \pm 0.03$ \\
\hline 9.4 & $0.36 \pm 0.05$ & - & - \\
\hline $9.5^{\mathrm{b}}$ & $0.33 \pm 0.04$ & $0.33 \pm 0.08$ & $0.34 \pm 0.04$ \\
\hline 9.6 & - & $0.50 \pm 0.02$ & $0.50 \pm 0.03$ \\
\hline \multicolumn{4}{|c|}{ Tests at $90^{\circ} \mathrm{C}$} \\
\hline 5.1 & $2.6 \pm 0.6$ & $0.088 \pm 0.20$ & $1.8 \pm 0.4$ \\
\hline 6.0 & $0.64 \pm 0.15$ & $0.056 \pm 0.012$ & $0.67 \pm 0.18$ \\
\hline 7.0 & $0.38 \pm 0.20$ & $0.056 \pm 0.006$ & $0.69 \pm 0.11$ \\
\hline 8.1 & $0.98 \pm 0.29$ & $0.93 \pm 0.21$ & $1.3 \pm 0.1$ \\
\hline 9.2 & $1.2 \pm 0.3$ & $1.5 \pm 0.4$ & $1.5 \pm 0.2$ \\
\hline 10.2 & $2.6 \pm 1.2$ & $5.3 \pm 1.3$ & $3.3 \pm 0.8$ \\
\hline \multicolumn{4}{|c|}{ Tests with PC CWF at $20^{\circ} \mathrm{C}$} \\
\hline 5.95 & - & - & 0.0035 \\
\hline 8.37 & - & - & 0.0057 \\
\hline 9.81 & - & - & 0.014 \\
\hline \multicolumn{4}{|c|}{ Tests with $\mathrm{PC} C W F$ at $70^{\circ} \mathrm{C}$} \\
\hline 6.2 & - & - & 0.502 \\
\hline 8.2 & - & - & 0.471 \\
\hline 9.5 & - & - & 0.424 \\
\hline
\end{tabular}

${ }^{a}$ Revised from Jeong et al., 2002.

${ }^{\mathrm{b}}$ Tests in non-complexing buffers. 


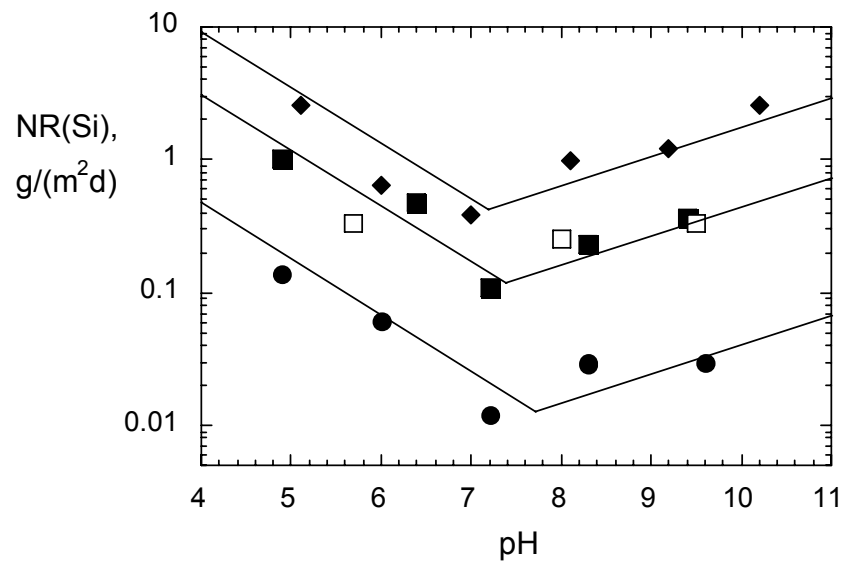

(a)

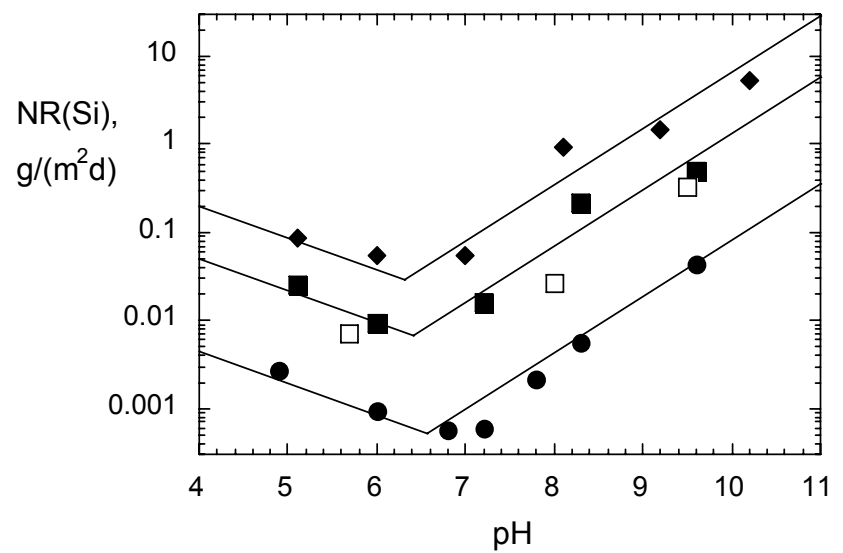

(b)

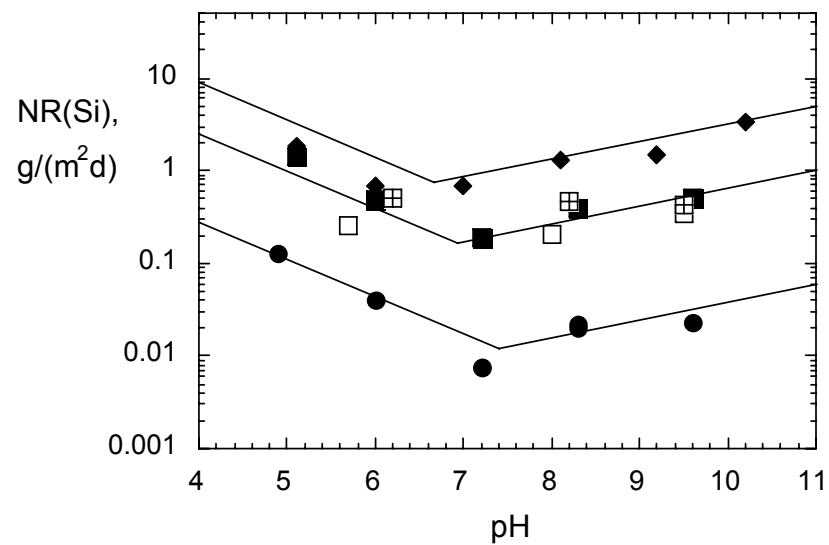

(c)

Fig. IV-32. Rates Measured in Short-Term MCC-1 Tests for (a) Sodalite, (b) Binder Glass, and (c) HIP $\mathrm{CWF}$ at $(\bullet) 40^{\circ} \mathrm{C},(\bullet) 70^{\circ} \mathrm{C}$, and $(\diamond) 90^{\circ} \mathrm{C}$. Tests with non-complexing buffers indicated by open squares. Tests with PC CWF indicated by $[\biguplus]$. 
Table IV-15. Model Parameter Values for Sodalite, Binder Glass, and HIP CWF for Equation IV-11

\begin{tabular}{|l|c|c|c|c|c|c|c|}
\hline \multicolumn{1}{|c|}{ Material } & $\mathrm{pH}$ Range & $\begin{array}{c}\text { Standard } \\
\text { Error }\end{array}$ & $\mathrm{C}_{0}$ & $\mathrm{C}_{1}$ & $\mathrm{C}_{2}$ & $\mathrm{C}_{\mathrm{pH}}$ & $\mathrm{C}_{\mathrm{T}}$ \\
\hline \multirow{2}{*}{ Sodalite } & Acidic & 0.165 & -0.604 & -0.424 & -2937 & 6.078 & 0.002955 \\
\cline { 2 - 8 } & Alkaline & 0.094 & -0.695 & 0.219 & -3682 & 8.450 & 0.002935 \\
\hline \multirow{2}{*}{ Binder Glass } & Acidic & 0.068 & -2.109 & -0.357 & -3750 & 5.696 & 0.002989 \\
\cline { 2 - 8 } & Alkaline & 0.277 & -1.283 & 0.644 & -4355 & 8.271 & 0.002978 \\
\hline \multirow{2}{*}{ HIP CWF } & Acidic & 0.230 & -0.598 & -0.404 & -3388 & 6.056 & 0.002955 \\
\cline { 2 - 8 } & Alkaline & 0.117 & -0.620 & 0.187 & -4389 & 8.470 & 0.002935 \\
\hline
\end{tabular}

Table IV-16. Model Parameter Values for Sodalite, Binder Glass, and HIP CWF for Equation IV-12

\begin{tabular}{|l|c|c|c|c|c|}
\hline \multirow{2}{*}{ Material } & $\mathrm{pH}$ Range & $\log \mathrm{k}_{0}$ & $\mathrm{k}_{0}, \mathrm{~g} /\left(\mathrm{m}^{2} \mathrm{~d}\right)$ & $\eta$ & $\mathrm{E}_{\mathrm{a}}, \mathrm{kJ} / \mathrm{mol}$ \\
\hline \multirow{2}{*}{ Sodalite } & Acidic & 10.7 & $5.01 \times 10^{10}$ & -0.42 & 56 \\
\cline { 2 - 6 } & Alkaline & 8.26 & $1.82 \times 10^{8}$ & 0.22 & 71 \\
\hline \multirow{2}{*}{ Binder Glass } & Acidic & 11.1 & $1.26 \times 10^{11}$ & -0.36 & 72 \\
\cline { 2 - 6 } & Alkaline & 6.36 & $2.29 \times 10^{6}$ & 0.64 & 83 \\
\hline \multirow{2}{*}{ CWF } & Acidic & 11.9 & $7.94 \times 10^{11}$ & -0.40 & 65 \\
\cline { 2 - 6 } & Alkaline & 10.7 & $5.01 \times 10^{10}$ & 0.19 & 84 \\
\hline
\end{tabular}

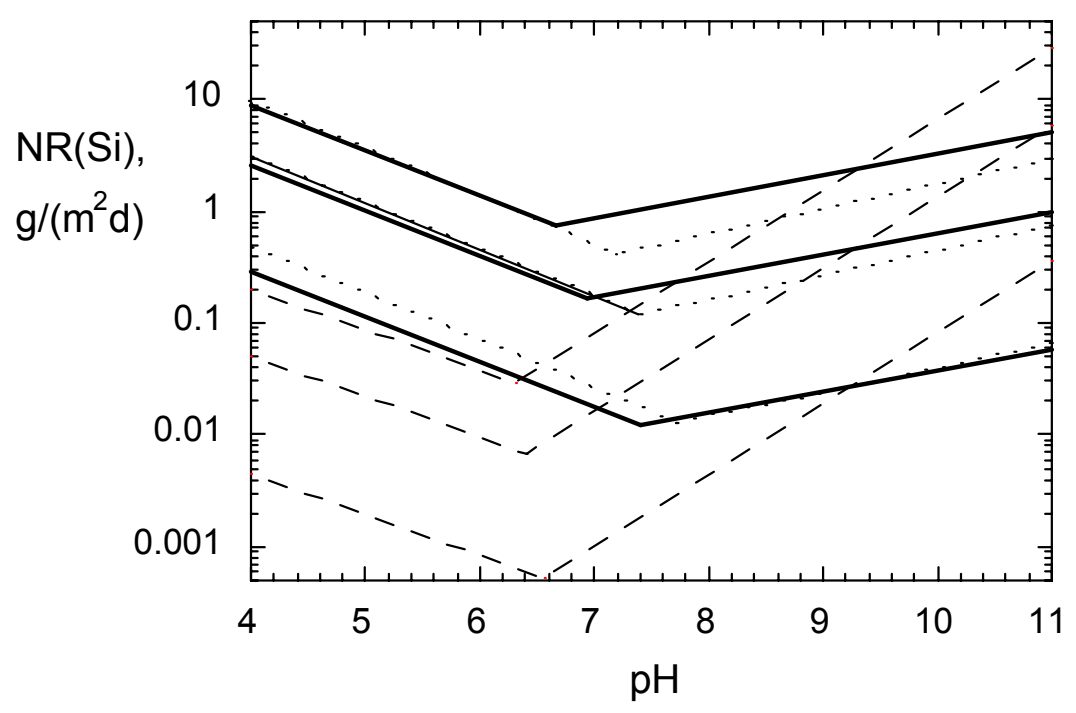

Fig. IV-33. Comparison of Regressed Rates for Sodalite (dotted lines), Binder Glass (dashed lines,) and CWF (solid lines) at 40, 70, and $90^{\circ} \mathrm{C}$. 


\section{IV.C.2.2. Solubility Product (K)}

Although modeling of HLW glass dissolution usually only includes the feedback effect of dissolved silica, the dissolution rates of some aluminosilicate minerals and some glasses have been seen to depend on the concentrations of other solutes, notably dissolved Al. Scoping tests were conducted to determine if the dissolutions rate of HIP CWF was sensitive to the presence of dissolved Al or Si. Short-term (three-day) MCC-1 tests were conducted in $\mathrm{pH} 5$ and $\mathrm{pH} 10$ buffer solutions spiked with various amounts of $\mathrm{AlCl}_{3}$ and $\mathrm{SiO}_{2}$. The releases of both $\mathrm{B}$ and $\mathrm{Si}$ were used to measure of the extent of reaction. Test results are shown in Fig. IV-34. The presence of Al in the test solution did not affect the release of either $\mathrm{B}$ or $\mathrm{Si}$ in either the acidic or alkaline solution. The presence of $\mathrm{Si}$ in the test solution slowed the releases of $\mathrm{B}$ and $\mathrm{Si}$ in alkaline solutions and the release of $\mathrm{Si}$ in acidic solutions. The release of $\mathrm{B}$ was low in all tests in acidic solutions. Note that $\mathrm{NL}(\mathrm{B})$ is greater than $\mathrm{NL}(\mathrm{Si})$ in all $\mathrm{pH} 10$ solutions, but less than $\mathrm{NL}(\mathrm{Si})$ in all $\mathrm{pH} 5$ solutions. As discussed above, the releases of $\mathrm{B}$ and Si reflect the relative dissolution rates of the sodalite and binder glass phases, and the result $\mathrm{NL}(\mathrm{B})>\mathrm{NL}(\mathrm{Si})$ indicates that more binder glass than sodalite has dissolved. Conversely, NL(Si) > NL(B) indicates that more sodalite than binder glass has dissolved. Binder glass dissolves faster than sodalite at $\mathrm{pH} 10$, but slower than sodalite at $\mathrm{pH} 5$. This is consistent with the measured effects of $\mathrm{pH}$ on the dissolution rates of sodalite and binder glass discussed above. These results indicate that dissolved Si slows the dissolution of both the sodalite and binder glass, but dissolved $\mathrm{Al}$ does not have a significant effect on the dissolution rate of either phase. As is the case for HLW glasses, only dissolved silica has a significant effect on the affinity term for CWF dissolution.

The value of the solubility product of a dissolving phase can be determined by measuring concentrations in saturated or nearly saturated solutions to estimate the solubility limits. For glass, the apparent solubility limit of Si that is used in the model can be determined by measuring its concentration when the dissolution rate has become immeasurably low. Series of PCTs were conducted with samples of sodalite, binder glass, and the HIP CWF to study the approach to saturation (or apparent saturation) over time. Tests were conducted at $90^{\circ} \mathrm{C}$ with demineralized water at $\mathrm{S} / \mathrm{V}$ ratios of 2,300 and $23,000 \mathrm{~m}^{-1}$. The test results are summarized in Table IV-17. The S/V ratio is expected to affect the rate at which the solubility limit is approached, but it may affect the solution $\mathrm{pH}$ slightly. The solubility product used in the model

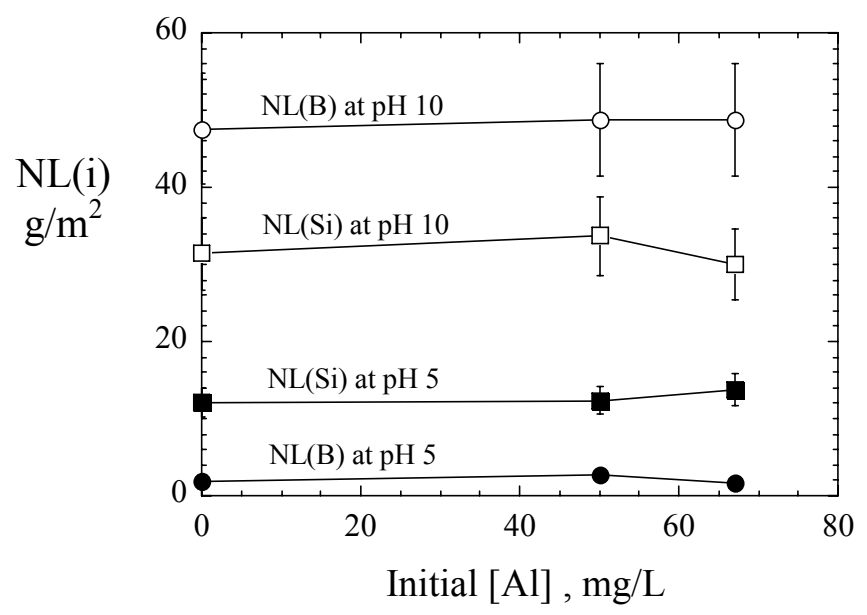

(a)

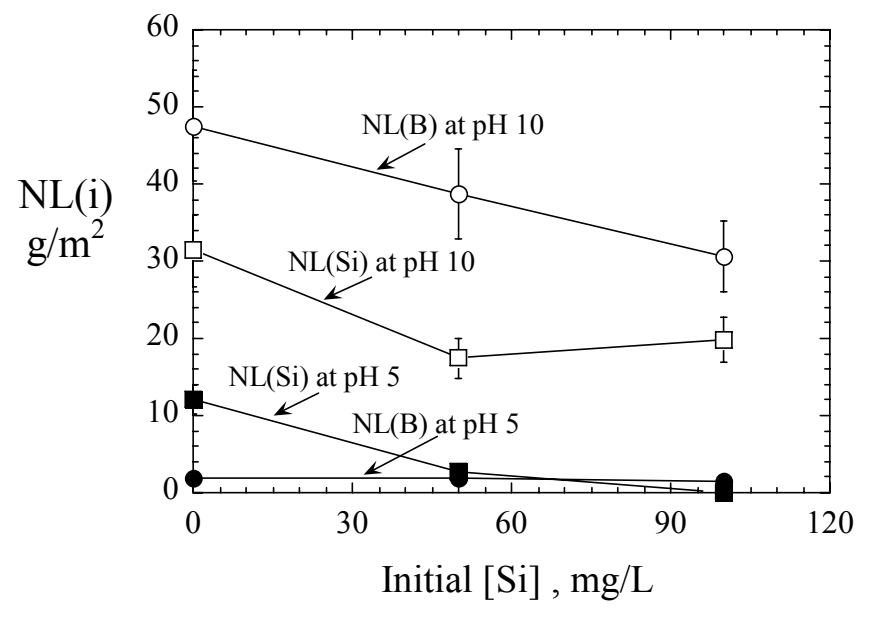

(b)

Fig. IV-34. Results of 3-Day MCC-1 Tests with CWF in (a) Al-Doped and (b) Si-Doped pH Buffers. 
Table IV-17. Orthosilicic Acid Concentrations and pH in PCTs with Sodalite, Binder Glass, and HIP CWF

\begin{tabular}{|c|c|c|c|c|c|}
\hline \multirow{2}{*}{ Duration (d) } & \multirow{2}{*}{$(\mathrm{S} / \mathrm{V}) \mathrm{t}, \mathrm{d} / \mathrm{m}$} & \multicolumn{4}{|c|}{$\mathrm{H}_{4} \mathrm{SiO}_{4}, \mathrm{mg} / \mathrm{L}(\mathrm{pH})^{\mathrm{a}}$} \\
\hline & & Sodalite $^{\mathrm{b}}$ & Binder Glass $^{\mathrm{b}}$ & $\mathrm{HIP}_{\mathrm{CWF}}^{\mathrm{C}}$ & $\mathrm{PC} \mathrm{CWF}^{\mathrm{C}}$ \\
\hline \multicolumn{6}{|c|}{ Tests at $2,300 \mathrm{~m}^{-1}$} \\
\hline 7 & $1.6 \times 10^{4}$ & $35.0(8.73)$ & $240(8.51)$ & $52.8(9.09)$ & $108(9.07)$ \\
\hline 28 & $6.5 \times 10^{4}$ & $34.9(8.66)$ & $237(8.65)$ & $78.9(8.77)$ & $136(8.99)$ \\
\hline 91 & $2.1 \times 10^{5}$ & $21.3(8.16)$ & $280(8.28)$ & 96.5 (8.65) & $153(9.14)$ \\
\hline 91 & $2.1 \times 10^{5}$ & & & $96.0(8.72)$ & $155(9.12)$ \\
\hline 182 & $4.2 \times 10^{5}$ & $36.4(8.49)$ & $229(8.41)$ & $60.0(8.62)$ & $171(9.36)$ \\
\hline 182 & $4.2 \times 10^{5}$ & & & $58.3(8.63)$ & $160(9.33)$ \\
\hline 364 & $8.4 \times 10^{5}$ & 47.7 & 253 & $116 \quad(9.00)$ & $196(9.34)$ \\
\hline 364 & $8.4 \times 10^{5}$ & & & $122(8.94)$ & $191(9.31)$ \\
\hline \multicolumn{6}{|c|}{ Tests at $23,000 \mathrm{~m}^{-1}$} \\
\hline 7 & $1.6 \times 10^{5}$ & $40.6(9.00)$ & $436(8.42)$ & $42.5(8.87)$ & $111(9.45)$ \\
\hline 28 & $6.6 \times 10^{5}$ & $9.95(8.82)$ & $398(8.26)$ & $65.8(8.91)$ & $135(9.23)$ \\
\hline 91 & $1.2 \times 10^{5}$ & $9.80(8.36)$ & $294(7.75)$ & $127 \quad(8.82)$ & $131(9.19)$ \\
\hline 91 & $1.2 \times 10^{5}$ & & & & $135(9.27)$ \\
\hline 182 & $3.9 \times 10^{6}$ & $19.2(9.39)$ & $321(8.03)$ & $97.7(8.76)$ & $137(9.46)$ \\
\hline 182 & $3.9 \times 10^{6}$ & & & & $146(9.50)$ \\
\hline 364 & $8.9 \times 10^{6}$ & & & $151 \quad(8.69)$ & $171(9.52)$ \\
\hline 364 & $8.9 \times 10^{6}$ & & & & $144(9.52)$ \\
\hline
\end{tabular}

$(K)$ only includes the concentration of non-dissociated orthosilicic acid $\left(\mathrm{H}_{4} \mathrm{SiO}_{4}\right)$. The first dissociation occurs at about $\mathrm{pH} 9.2\left(\right.$ at $\left.90^{\circ} \mathrm{C}\right)$, which corresponds to a $\mathrm{pH}$ of about 9.7 measured at room temperature. The $\mathrm{pH}$ values of the test solutions were measured (at room temperature) to be below 9.7. Therefore, the concentration of orthosilicic acid is calculated directly from the measured Si concentration. $\mathrm{The}_{4} \mathrm{HiO}_{4}$ concentrations are plotted in Fig. IV-35a. Horizontal lines representing the estimated solubility limits $(K)$ of each material are drawn at $115 \%$ of the highest measured concentration for each material to bound the estimated testing uncertainty. For tests with binder glass and HIP CWF, higher concentrations were attained in tests at $23,000 \mathrm{~m}^{-1}$ than in tests at $2,300 \mathrm{~m}^{-1}$. Higher concentrations in tests with sodalite were attained at $2,300 \mathrm{~m}^{-1}$. The solubility limit measured for sodalite is $55 \mathrm{mg} \mathrm{H}_{4} \mathrm{SiO}_{4} / \mathrm{L}(16 \mathrm{mg} \mathrm{Si} / \mathrm{L})$, which is significantly lower than the value of $369 \mathrm{mg} \mathrm{H}_{4} \mathrm{SiO}_{4} / \mathrm{L}(108 \mathrm{mg} \mathrm{Si} / \mathrm{L})$ determined for the binder glass. The solubility limit measured for $\mathrm{HIP} C W F$ is $174 \mathrm{H}_{4} \mathrm{SiO}_{4} / \mathrm{L}(51 \mathrm{mg} \mathrm{Si} / \mathrm{L})$. This is slightly higher than the average of the sodalite and binder glass solubilities weighted by their mass fractions in the CWF: $0.71 \times 55 \mathrm{mg} / \mathrm{L}+0.25 \times 369 \mathrm{mg} / \mathrm{L}=131 \mathrm{mg} / \mathrm{L}$. The use of an upper bound value of $K$ will result in a conservative estimate of the dissolution rate because $K$ appears in the denominator of the affinity term.

The solubility limits determined based on tests with HIP CWF were used for modeling work done prior to the selection of the PC process. A few long-term PCTs were conducted with a PC CWF material made with 75 mass \% SLZ and 25 mass \% binder glass. The results of those tests are included in Fig. IV-35b. Some of the results are very near to or higher than the value used as the solubility limit for the HIP CWF. However, these tests generated solutions with $\mathrm{pH}$ values between about 9.19 and 9.52 , which are slightly higher than solution generated in tests with HIP CWF. Partial dissociation of the orthosilicic acid may have occurred in tests with PC CWF, in which case the use of the measured Si concentrations to calculate the concentration of $\mathrm{H}_{4} \mathrm{SiO}_{4}$ would overestimate the solubility limit. 


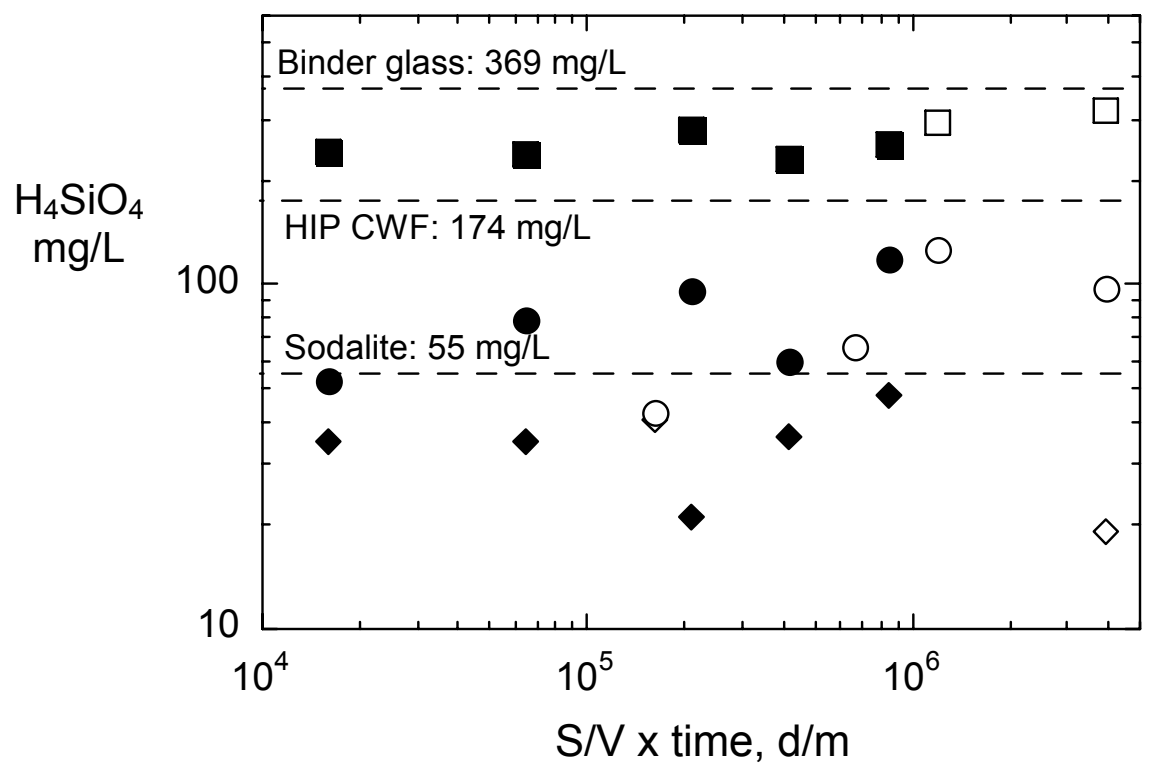

(a)

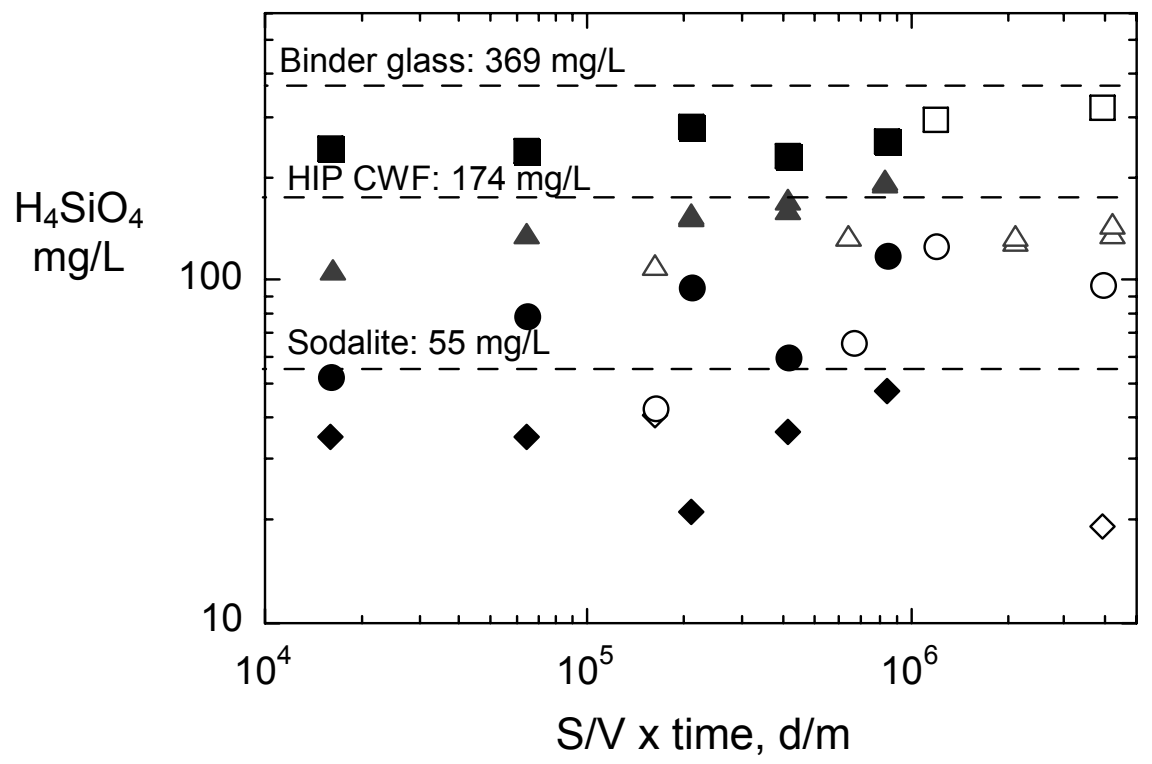

(b)

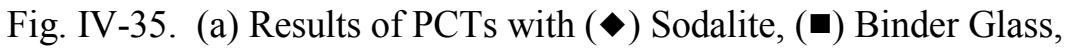
and $(\bullet)$ HIP CWF and (b) including PCTs with ( $(\boldsymbol{\Delta})$ PC CWF. Filled symbols for tests at $2,300 \mathrm{~m}^{-1}$ and open symbols for tests at $23,000 \mathrm{~m}^{-1}$. 


\section{IV.C.2.3. Parameter Values Used in CWF Degradation Model}

Degradation of the CWF will occur due to dissolution of both the sodalite and binder glass phases. No credit is taken in the CWF degradation model for the durabilities of the other phases in the waste form, including halite and the various oxide and silicate phases that contain most of the radionuclides. These phases are modeled to be available for transport as soon as they are exposed to groundwater when the sodalite and binder glass dissolve. Therefore, dissolution of the sodalite and binder glass phases provides a conservative bound on the release of radionuclides from the CWF. Although the CWF contains about three times as much sodalite as binder glass, dissolution of the binder glass will control CWF degradation under disposal conditions because of the low solubility of sodalite. The dissolved silica content of tuff groundwaters themselves will exceed the solubility of sodalite under most conditions. For example, groundwater from well J-13 contains about $35 \mathrm{mg} \mathrm{Si} / \mathrm{L}\left(120 \mathrm{mg} \mathrm{H}_{4} \mathrm{SiO}_{4} / \mathrm{L}\right)$, which exceeds the solubility of sodalite. Even higher levels of dissolved silica are expected in the concentrated groundwaters that may accumulate in a breached waste package. Therefore, binder glass is presumed to be less durable than sodalite under all anticipated repository conditions. The model parameters determined from tests with binder glass are used to provide conservative predictions of CWF performance in the disposal system. The parameter values for $k_{0}, \eta, E_{a}$, and $K$ that were measured in tests with the binder glass are used instead of those measured in tests with CWF for the following reasons. Under the dilute test conditions used to measure $k_{0}, \eta$, and $E_{a}$, dissolution of the CWF was dominated by dissolution of the sodalite component. This is seen by the similarity in the curves for CWF and sodalite in Fig. IV-33. The parameter values measured for binder glass are expected to better represent the behavior of CWF under disposal conditions wherein the solution will be saturated with respect to sodalite. The value of $K$ measured in long-term PCTs with CWF provides a reliable measure of the saturation concentration - i.e., the concentration of dissolved $\mathrm{Si}$ at which the dissolution rate becomes nil. The $\mathrm{Si}$ concentrations in the test solutions all exceed the solubility limit for sodalite and reflect the lower durability of the binder glass. However, the value of $K$ measured in tests with binder glass are used instead of the value measured for CWF to provide an additional level of conservatism to the model (Fanning, 2003; Fanning et al., 2003). The amount of conservatism provided by using the parameter values for binder glass was not determined.

The rate expression for CWF dissolution is given as Eq. IV-10:

$$
\text { rate }_{n e t}=k_{0} \bullet 10^{\eta \bullet p H} \bullet \exp \left(\frac{-E_{a}}{R T}\right) \cdot\left(1-\frac{Q}{K}\right)
$$

Separate sets of parameter values are used for the acidic and alkaline legs, and these are given in Table IV-16 for binder glass. A value of $K=369 \mathrm{mg} \mathrm{H}_{4} \mathrm{SiO}_{4} / \mathrm{L}$ was measured for binder glass, which is $3.8 \times 10^{-3} \underline{\mathrm{M} \mathrm{H}} \mathrm{H}_{4} \mathrm{SiO}_{4}$. Although the importance of $\mathrm{Si}$ feedback in acidic solutions is uncertain (see Fig. IV-34 and Section IV.C.2.2), the same value of $\mathrm{K}$ is used to model dissolution at all $\mathrm{pH}$ values. The rate expressions in the CWF degradation model are:

$$
\begin{aligned}
& \text { rate }_{\text {acidic }}=1.26 \times 10^{11} \bullet 10^{-0.36 \bullet \mathrm{pH}} \bullet \exp \left(\frac{-72 \mathrm{~kJ} / \mathrm{mol}}{R T}\right) \cdot\left(1-\frac{Q}{3.84 \times 10^{-3} \mathrm{MH}_{4} \mathrm{SiO}_{4}}\right) \\
& \text { rate }_{\text {alkaline }}=2.29 \times 10^{6} \bullet 10^{0.64 \bullet \mathrm{pH}} \bullet \exp \left(\frac{-83 \mathrm{~kJ} / \mathrm{mol}}{R T}\right) \bullet\left(1-\frac{Q}{3.84 \times 10^{-3} \mathrm{M} \mathrm{H}_{4} \mathrm{SiO}_{4}}\right)
\end{aligned}
$$

where the $\mathrm{pH}$ is at room temperature, temperature $(T)$ is in Kelvin, and the silicic acid concentration in the solution $(Q)$ is expressed as a molar concentration. 


\section{IV.D. CWF in Repository Modeling}

As described in Section III.A, the release of radionuclides is calculated as the product of the specific dissolution rate and surface area of the glass, and mass fraction of radionuclide in the glass. The defense HLW glass degradation model provides a distribution of coefficient values to calculate maximum and minimum rates as a function of temperature and $\mathrm{pH}$. The approach taken to support qualification of the EMT waste forms is to determine if the radionuclide release calculated for HLW glass can be used to represent the release from CWF and MWF based on corresponding terms for the dissolution rate, surface area, and inventory.

\section{IV.D.1. Simplified CWF Degradation Rate}

To compare the degradation rate of the CWF with that used in the defense HLW glass degradation model, maximum values of $k_{E}$ are calculated for CWF in the same way they were calculated for HLW glass. Consider first the value of $k_{E}$ for alkaline solutions, which is calculated from the average rate and $\mathrm{pH}$ value measured in a seven-day PCT. The rate is calculated as

$$
\text { rate }_{G}=k_{E} \bullet 10^{\eta \bullet p H} \bullet \exp \left(\frac{-E_{a}}{R T}\right)
$$

which can be rearranged to solve for $k_{E}$ as

$$
\log k_{E}=\log \text { rate }_{G}-\eta \bullet p H+\frac{E_{a}}{R T \ln 10}
$$

From the results of the interlaboratory study (ILS), the average B concentration was $2.25 \mathrm{mg} / \mathrm{L}$ and the average $\mathrm{pH}$ was 9.01 . The mass fraction of $\mathrm{B}$ in the $\mathrm{PC} \mathrm{CWF}$ was about 0.015 and the $\mathrm{S} / \mathrm{V}$ ratio was 2300 $\mathrm{m}^{-1}$, so $\mathrm{NL}(\mathrm{B})=0.0652 \mathrm{~g} / \mathrm{m}^{2}$, and the average rate is $0.00932 \mathrm{~g} /\left(\mathrm{m}^{2} \mathrm{~d}\right)$. Consider first treating the CWF as if it was a typical HLW glass and calculate $k_{E}$ using the parameter values for the HLW glass model $\eta=$ 0.49 and $E_{a}=69 \mathrm{~kJ} / \mathrm{mol}$ :

$$
\log k_{E}=-2.0307-0.49 \bullet 9.01+\frac{69 \mathrm{~kJ} / \mathrm{mol}}{(0.008314 \mathrm{~kJ} / \mathrm{molK})(363) 2.3026}=3.484
$$

The value of $k_{E}$ for CWF is $3.045 \times 10^{3} \mathrm{~g} /\left(\mathrm{m}^{2} \mathrm{~d}\right)$, which is less than the value $k_{E}=3.47 \times 10^{4} \mathrm{~g} /\left(\mathrm{m}^{2} \mathrm{~d}\right)$ that is used in the HLW model. The dissolution rate calculated for CWF is within the range to be considered in TSPA. Next, consider using the parameter values determined for the CWF model $\eta=0.64$ and $E_{a}=83$ $\mathrm{kJ} / \mathrm{mol}$ (values for the binder glass from Table IV-16) to calculate $k_{E}$ :

$$
\log k_{E}=-2.0307-0.64 \bullet 9.01+\frac{83 \mathrm{~kJ} / \mathrm{mol}}{(0.008314 \mathrm{~kJ} / \mathrm{molK})(363) 2.3026}=4.147
$$

The value of $k_{E}$ for CWF dissolution in alkaline solutions is $1.402 \times 10^{4} \mathrm{~g} /\left(\mathrm{m}^{2} \mathrm{~d}\right)$ and the rate in alkaline solutions is calculated as

$$
\text { rate }_{C W F_{\text {_alkaline }}}=1.40 \times 10^{4} \mathrm{~g} /\left(\mathrm{m}^{2} \mathrm{~d}\right) \bullet 10^{0.64 \bullet \mathrm{pH}} \bullet \exp \left(\frac{-83 \mathrm{~kJ} / \mathrm{mol}}{R T}\right)
$$


In the HLW glass model, no credit is taken for the affinity term in acidic solutions, and $k_{E}=k_{0}$. The value of $k_{0}$ used in the CWF model is that determined for the binder glass in acidic solutions, which is $1.26 \times 10^{11} \mathrm{~g} /\left(\mathrm{m}^{2} \mathrm{~d}\right)$ (from Table IV-16). The value of $k_{E}$ used to calculate the maximum rate in acidic solutions in the defense HLW glass model is $1.15 \times 10^{7} \mathrm{~g} /\left(\mathrm{m}^{2} \mathrm{~d}\right)$. Using the parameter values determined for the CWF model $\eta=-0.36$ and $E_{a}=72 \mathrm{~kJ} / \mathrm{mol}$ (values for the binder glass from Table IV-16), the rate in acidic solutions is calculated as

$$
\text { rate }_{C W F_{-} \text {acid }}=1.26 \times 10^{11} \mathrm{~g} /\left(\mathrm{m}^{2} \mathrm{~d}\right) \bullet 10^{-0.36 \bullet \mathrm{pH}} \bullet \exp \left(\frac{-72 \mathrm{~kJ} / \mathrm{mol}}{R T}\right)
$$

\section{IV.D.1.1. Comparison of Rates Using Model Parameters for HLW Glass and CWF}

In practice, the sum of the rates calculated using the equations for acidic and alkaline solutions is used in the defense HLW glass degradation model. The maximum rate calculated with the HLW glass degradation model is (see Eq. III-3a).

$$
\text { rate }_{G_{-} \max }=1.15 \times 10^{7} \bullet 10^{-0.49 \cdot p H} \bullet \exp \left(\frac{-31}{R T}\right)+3.47 \times 10^{4} \cdot 10^{0.49 \bullet p H} \bullet \exp \left(\frac{-69}{R T}\right)
$$

The maximum rates calculated with the defense HLW glass degradation model at 40 and $90^{\circ} \mathrm{C}$ using Eq. III-3a are plotted in Fig. IV-36a with the rates calculated as the sum of Eqs. IV-36a and IV-36b at the same temperatures. The rates calculated by the defense HLW glass degradation model using the parameters for HLW glass bounds the rates calculated with the parameters for CWF for all $\mathrm{pH}$ values, and will bound it for all repository-relevant temperatures. This is shown in Fig. IV-36b by the rates calculated at $20^{\circ} \mathrm{C}$ and $120^{\circ} \mathrm{C}$.

\section{IV.D.1.2. Effect of Modeled Exposure Conditions}

In TSPA calculations, the compositions of water entering a breached waste package under various conditions are calculated using submodel that are is described in the In-Package Chemistry Abstraction report (BSC, 2005a). These calculations take into account the combined effects of the ground water chemistry and dissolution of HLW glass, DSNF, and various metallic engineering components, and determine likely solution chemistries based on simulations with various configurations, water volumes, and material compositions. Seepage waters that enter a breached co-disposal waste package with defense HLW glass and DSNF are modeled to have $\mathrm{pH}$ values in the range 4.5 and 8.5 (BSC, 2005a, Section 6.10.1.2). The $\mathrm{pH}$ values calculated within the In-Package Chemistry Abstraction were insensitive to variations in the glass composition. Dissolution of defense HLW glasses in static or nearly static solutions results in highly alkaline solutions. This is due primarily to the release of alkali metals with the concomitant generation of hydroxide ions (see below). The solution $\mathrm{pH}$ will be buffered by dissolved carbon dioxide from the atmospheric and by orthosilicic acid and boric acid generated as the glass dissolves. The solution $\mathrm{pH}$ value will depend on the glass composition (primarily the amount of alkali metals in the glass), the volume of solution contacting the glass, the composition of the air, etc. The $\mathrm{pH}$ increase due to the dissolution of HLW glass will be counteracted by the corrosion of metallic components within the waste package, which by themselves commonly generate acidic solutions.

Although the total alkali content of CWF materials (which is about 15 mass \% total) is similar to that of HLW glasses, most alkali metals in the CWF are contained in the sodalite and halite phases, and their release from these phases will not result in as significant an increase in the $\mathrm{pH}$ as from HLW glass. Release of alkali metals from the binder glass will cause an increase in the $\mathrm{pH}$, but the binder glass only 

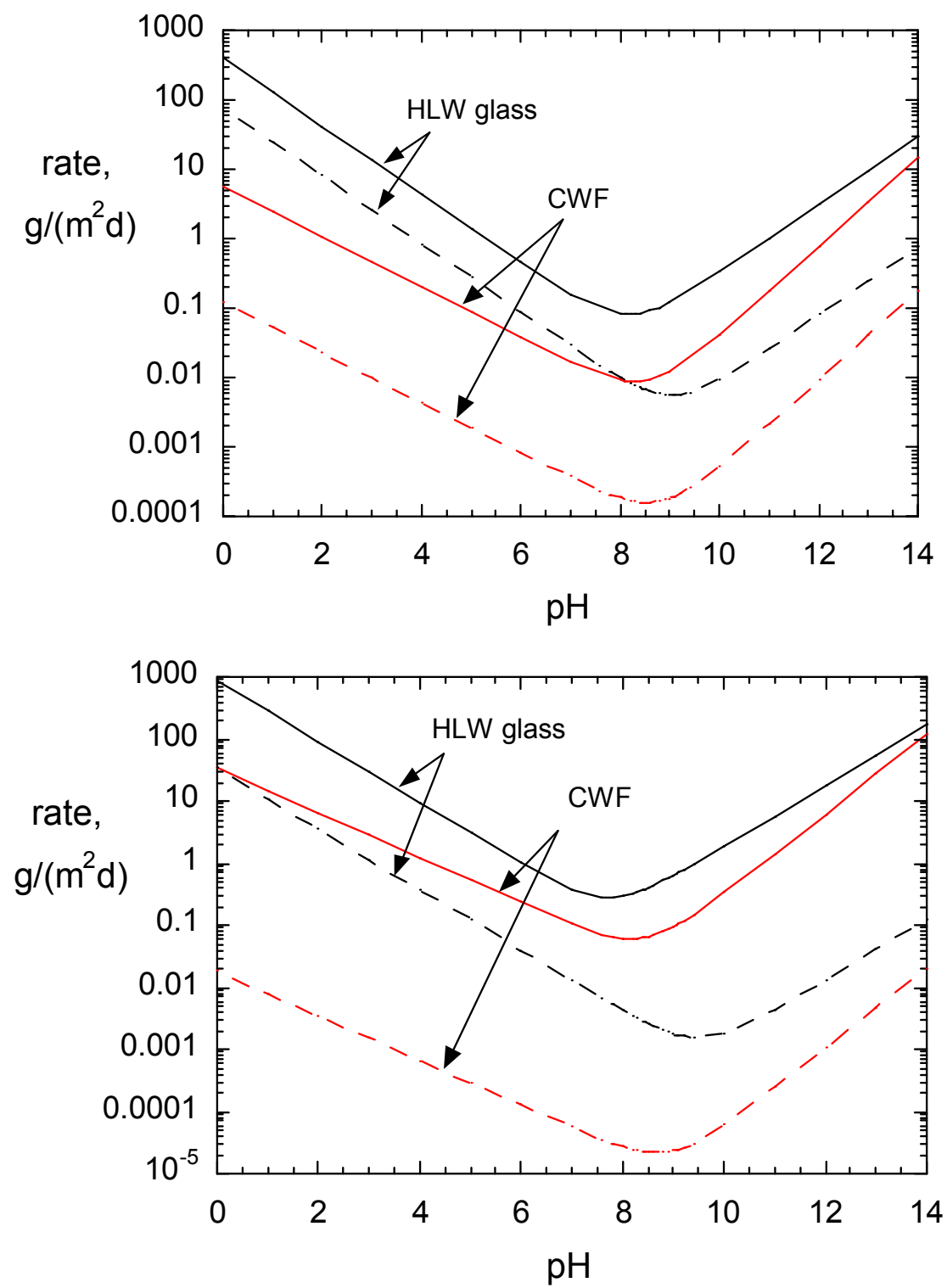

Fig. IV-36. Comparison of Rates Calculated with Defense HLW Glass Degradation Model Using Parameter Values for HLW Glass and for $\mathrm{CWF}$ (a) at $90^{\circ} \mathrm{C}$ (solid curves) and $40^{\circ} \mathrm{C}$ (dashed curves) and (b) at $120^{\circ} \mathrm{C}$ (solid curves) and $20^{\circ} \mathrm{C}$ (dashed curves).

contains about 5 mass $\%$ alkali metals and only represents about $25 \%$ of the waste form. Dissolution of CWF does not result in solutions that are as alkaline as HLW glasses. For example, PCTs with reference HLW glasses typically attain pH values between 10 and 11, whereas PCTs with CWF (and also PCTs with the binder glass alone) attain $\mathrm{pH}$ values near 9 for the same range of conditions (see Section IV-C.2.2 and Table IV-17). The $\mathrm{pH}$ values attained in tests with CWF under a wide range of conditions are consistent with the modeled range.

Using the dissolution rate calculated for HLW glass as a surrogate for the dissolution rate of CWF will provide an upper bounding value under most conditions despite differences in the $\mathrm{pH}$ values attained in breached packages with HLW glass or CWF. This is illustrated with the rates calculated at $90^{\circ} \mathrm{C}$ 
(Fig. IV-36a), where even the lowest rate that could be calculated for HLW glass (at pH 8.12) bounds the rates calculated for CWF (using the CWF model parameter values) over the $\mathrm{pH}$ range 5.09-10.47. Therefore, large differences that could occur between the $\mathrm{pH}$ values of solutions in a breached waste package with CWF and those calculated in the In-Package Chemistry model do not preclude using the HLW glass dissolution rate as a surrogate for the CWF dissolution rate.

The models in the In-Package Chemistry Abstraction report used for TSPA also provide ranges of $\mathrm{O}_{2}$ and $\mathrm{CO}_{2}$ fugacities, Eh, $\mathrm{F}^{-}$, and $\mathrm{Cl}^{-}$concentrations, and total ionic strength (BSC, 2005a). These variables are not used in the current defense HLW glass degradation model or the DSNF model. The primary impact of $\mathrm{Cl}^{-}$will be to promote localized corrosion of metallic components within the waste package, and the waste package itself, and may cause an increase in the amount of colloidal iron, which can transport radionuclides; $\mathrm{Cl}^{-}$itself is a weak ligand and is not expected to directly affect the dissolved concentrations significantly. It is not considered in the dissolved concentration limits model used for TSPA (BSC, 2005b). Degradation of DSNF, which could be packaged with canisters of CWF, is modeled to be instantaneous in TSPA calculations, so CWF degradation cannot impact the DSNF degradation rate. Corrosion of CWF will affect the $\mathrm{Cl}^{-}$concentration and total ionic strength primarily due to the dissolution of halite. The $\mathrm{Cl}^{-}$concentration is modeled in TSPA to range up to $4 \times 10^{-3}$ molal and the total ionic strength up to about 60 molal in a co-disposal package. Both are highly dependent on the flux of incoming groundwater and reactivity of components, and the maximum values are for minimal water flux and maximum corrosion rates. Based on laboratory tests, about $0.14 \mathrm{~g} \mathrm{of} \mathrm{Cl} / \mathrm{m}^{2}$ can be released from the CWF surface immediately when first contacted by water (see also discussion in Section IV.F). A canister with three CWF products will provide about $12 \mathrm{~m}^{2}$ total surface area, so that about $1.7 \mathrm{~g} \mathrm{of} \mathrm{Cl}^{-}$could be released immediately. This will have only a minor impact on the solution within the waste package.

\section{IV.D.2. CWF Surface Area}

The CWF products will be made in the shape of cylinders up to about $1 \mathrm{~m}$ tall with diameters up to about 20.4 inches. The geometric surface area of each product will be up to $2.05 \mathrm{~m}^{2}$. The CWF materials made during the process demonstration phases were not observed to crack. Most EMT waste canisters (about 90\%) will contain three CWF products, although some will contain two CWF products and one MWF product. The total geometric CWF surface area in a canister will be about $6 \mathrm{~m}^{2}$. For comparison, the geometric surface area of a HLW glass $\log$ in the pour canister will be about $8.5 \mathrm{~m}^{2}$ for the long $(4.5 \mathrm{~m})$ canisters of Hanford glass and about $4.8 \mathrm{~m}^{2}$, for the short $(3 \mathrm{~m})$ canisters of DWPF and WVDP glass. Assuming $66 \%$ of the disposed canisters are long canisters and $34 \%$ of the disposed canisters are short canisters, the average surface area of glass in a canister will be $\left(0.66 \times 8.5 \mathrm{~m}^{2}\right)+\left(0.34 \times 4.8 \mathrm{~m}^{2}\right)=7.2 \mathrm{~m}^{2}$. Thermal and impact cracking will increase the surface area of glass available for reaction, although glass within tight cracks may not be accessible to water and will not be as reactive as glass at the surface because Si will accumulate in the solutions. The defense HLW glass degradation model assumes the exposed surface area of glass will be at least four times and at most 17 times the geometric surface area, with an increase of four times the geometric surface area being most probable. For the purpose of comparison with the CWF, the exposed surface area of an average HLW glass log is taken to be the minimum value of $30 \mathrm{~m}^{2}$. Therefore, the geometric surface area of an average HLW glass canister is greater than that of three CWF products in a canister, and the HLW glass is much more likely than the CWF to be cracked.

\section{IV.D.3. CWF Radionuclide Inventory}

As discussed in Section III.A.3, the radionuclide inventory for CWF products is already included in the inventory to be used in TSPA calculations. In effect, the radionuclides in the CWF inventory are considered to be distributed equally among all HLW waste forms, including HLW glass, CWF, and MWF. It should be noted that DOE is considering including the inventory the weapons-grade Pu that will 
be immobilized in a lanthanide borosilicate (LaBS) glass and encapsulated in HLW glass at the DWPF at the SRS. The LaBS waste glass will increase the inventories of several Pu isotopes.

\section{IV.E. Monitoring the Consistency of CWF Products}

The WASRD includes a requirement that the waste form producers monitor the consistency of waste forms during production. This can be done by either testing samples of the waste forms or by controlling their production.

The WASRD requirement 4.8.1 B states:

1. The Producer shall demonstrate control of waste form production by comparing production samples or process control information, separately or in combination to the Environmental Assessment benchmark glass using the Product Consistency Test or equivalent.

2. For acceptance, the mean concentrations of lithium, sodium, and boron in the leachate, after normalization for concentrations in the glass, shall be less than those of the benchmark glass.

The PCT was developed specifically to measure the consistency of HLW glass waste form products. The solution concentrations of $\mathrm{Li}, \mathrm{Na}$, and $\mathrm{B}$ are used because they are common components in HLW glasses, have high solubility limits, and are released faster than other glass components. The release rates of these elements are expected to be higher than the release rates of radionuclides. The PCT is a crushed glass durability test that "can specifically be used to evaluate whether the durability and elemental release characteristics of waste glasses have been consistently controlled during production" (ASTM, 2005a). The PCT Method A is a seven-day test conducted with glass that has been crushed and sieved to isolate the $-100+200$ mesh size fraction and washed to remove fines under specific test conditions. It is conducted with demineralized water at $90^{\circ} \mathrm{C}$ in a stainless steel test vessel. Method A is used to monitor the consistency of HLW glasses. The PCT Method B allows for the use of different test conditions to study the glass dissolution behavior. The PCT can be thought of as a partial dissolution test. That is, the test provides a measure of the fraction of glass that dissolves under specific conditions over a seven-day test period.

The same requirements for monitoring the consistency of compliant waste forms described in Section 3.2.1 apply to alternative waste forms, although the use of the PCT to meet the consistency requirement may not be appropriate for waste forms other than homogeneous borosilicate glass. Several issues were addressed to demonstrate that the PCT is appropriate for measuring the chemical durability of the multiphase CWF. These are discussed in the following sections.

The scope of the PCT is to "evaluate the chemical durability of homogeneous glasses, phase separated glasses, devitrified glasses, glass ceramics, and/or multiphase glass ceramic waste forms" (ASTM, 2005a). These included (1) Are the radionuclides contained in the glass phase or inclusion phases (either crystalline or amorphous) and is the partitioning constant among waste forms? (2) Does the release of radionuclides require dissolution of the glass? (3) Does crushing and sieving the waste form result in a fractionation of the phases? (4) Is the composition of the test solution representative of glass dissolution? (5) Is the PCT response sensitive to changes in the consistency of the waste form, for example, significant changes in the assemblage of crystalline phases?

\section{IV.E.1. Application of the PCT to CWF}

The intent of the product consistency requirement for HLW glasses is to ensure that a consistent waste glass is produced by controlling the vitrification process and that the chemical durability of all waste 
glasses exceeds that of the EA glass. Product consistency will also be used to verify process control for CWF to ensure that each waste form is consistent with what is described in the waste qualification plan, and to provide additional evidence that the waste forms will not negatively impact the performance of the disposal system. Two basic questions need to be addressed regarding the application of the PCT to CWF:

(1) Is the PCT response resulting from the simultaneous dissolution of several phases useful for monitoring consistency of a multi-phase waste form? This requires that the phase distribution in the crushed fraction be the same as the bulk CWF, that the CWF does not preferentially fracture along phase boundaries, and that the test response represents the corrosion behavior under disposal conditions. It also requires that the relative amounts of each phase are the same in all waste forms.

(2) Does the PCT response provides an indication that the process has been controlled? In the case of HLW glasses, soluble components $\mathrm{Li}, \mathrm{Na}$, and $\mathrm{B}$ will be used to confirm that the composition of the glass is consistent with the target composition. In the case of the CWF, the releases of $\mathrm{Na}$ and $\mathrm{Cl}$ in the water wash and B and Si in the PCT provide evidence that the relative amounts of salt, zeolite, and binder glass have been controlled. Whereas the compositions of waste glasses will vary significantly between batches, the gross composition of the CWF is expected to remain fairly constant. This is because the amount of salt occluded in to the zeolite and the amount of binder glass mixed with the SLZ will be controlled within defined ranges for the processing of all CWF products. The compositions of the zeolite and binder glass components will be constant, and together will account for more than $90 \%$ of the CWF composition. The waste salt will consist primarily of $\mathrm{Li}, \mathrm{Na}$, and $\mathrm{K}$ chlorides (about $70 \%$ ), and changes in the amounts of radioactive salt components will not change the composition or durability of the CWF significantly. The composition of the waste salt will not measurably affect the PCT response.

The key issues that were considered in evaluating the suitability of the PCT for monitoring CWF production are (1) possible fractionation of phases during crushing and sieving the multiphase CWF material, (2) the sensitivity of the PCT response to variations in the CWF composition, (3) the adequate precision of PCTs conducted with CWF, and (4) the suitability of the EA glass as a benchmark for the chemical durability of the CWF. The experimental approach that was taken, the test results, and the conclusions reached regarding each of these issues are discussed below (see also Ebert et al., 2002a, 2002b; Lewis and Ebert 2000).

\section{IV.E.1.1. Monitoring the Test Response}

Use of the PCT to monitor the consistency of a waste form requires identifying elements that are good indicators of chemical durability and remain in solution during the test. Generally, elements with high solubility limits that are released from the waste form structure by rapid reactions and are not sequestered in alteration phases that may form during the test are selected for this purpose. The concentrations of alkali metals, B, and Si are commonly monitored in PCT conducted with borosilicate waste glasses. In the case of the CWF, the PCT response is due to the dissolution of sodalite and borosilicate glass binder phases. Halite exposed at the surface is expected to completely dissolve during the water wash step and is not expected to contribute to the PCT test solution. Like waste glasses, the dissolution of the binder glass can be monitored by the concentrations of $\mathrm{B}, \mathrm{Na}$, and $\mathrm{Si}$. Dissolution of sodalite can be monitored by the concentrations of $\mathrm{Na}, \mathrm{Si}$, and $\mathrm{Cl}^{-}$. Negligible amounts of sodalite or binder glass dissolve during the water wash step, so the measured concentrations of $\mathrm{Na}$ and $\mathrm{Cl}^{-}$in the RWS solution are due to dissolution of halite.

Whereas dissolution of both sodalite and binder glass contribute to the concentrations of $\mathrm{Na}$ and $\mathrm{Si}$ in the PCT step, only dissolution of binder glass contributes to the concentration of B. All CWF will be made using the same binder glass composition and the same mass ratio of binder glass and SLZ (which will result in the same mass ratio of binder glass and sodalite). The compositions of the glass binder and 
sodalite will be the same in all CWF. The two primary consistency issues are to confirm that the CWF was made with an acceptable salt loading and an appropriate amount of binder glass. Analysis of Na or $\mathrm{Cl}^{-}$in the water wash solution provides a measure of the amount of halite and analysis of boron in the PCT solution provides a measure of the amount of binder glass in the CWF. Tracking the $\mathrm{Na}$ and $\mathrm{Si}$ concentrations in the PCT solution provides a measure of the total amount of sodalite and binder glass that has dissolved in the test. Since the compositions of sodalite and binder glass will be nearly constant, their dissolution rates of can be considered to be constant in all CWFs. Therefore, the consistency of the $\mathrm{Na}$ and Si concentrations in PCT provides an indication that the relative amounts of the sodalite and binder glass in the CWF are consistent.

The use of the PCT method to monitor the consistency of the CWF is reasonable because the dissolution behaviors of both the sodalite and binder glass phases are similar to that of borosilicate HLW glasses. The release of radionuclides from both HLW glasses and CWF requires the prior dissolution of glass. In the case of HLW glasses, the radionuclides are homogeneously dissolved in the glass. In the case of CWF, glass must dissolve before inclusion phases are exposed to water.

\section{IV.E.1.2. Suitability of the PCT Procedure to the CWF}

The standardized PCT procedure is conducted using the $-100+200$ mesh size fraction. The crushed material is washed prior to the test with water and then ethanol to remove fines generated during crushing. The same procedure is used to prepare the CWF for PCT, except that the crushed CWF is washed first with absolute ethanol and then with water. The PCT procedure addresses the possible presence of soluble phases in step 19.6.1 by recommending that dissolution of the soluble phases during the wash steps be taken into account by analyzing the solution from the wash steps to remove fines (ASTM, 2005a). The CWF contains a small amount of halite that is a soluble inclusion phase. The crushed CWF is first washed several times with absolute ethanol to remove most of the fines. The fines are usually not seen in the alcohol after five rinses. The material is then dried. The ethanol wash solutions are not analyzed because only the halite dissolved from the $-100+200$ mesh fraction to be used in the PCT is of interest. Halite is sparingly soluble in absolute ethanol and the majority of $\mathrm{Na}$ and $\mathrm{Cl}^{-}$(and other components) present in the ethanol wash solution is assumed to be due to dissolved fines. Figures IV-37a and IV-37b show SEM photomicrographs of crushed CWF before and after washing.

The water wash step is referred to as the RWS test, and the solution that is generated is referred to as the RWS solution. The RWS test is conducted at the same CWF/waster mass ratio that is used in the PCT, namely, $1 \mathrm{~g} \mathrm{CWF} / 10 \mathrm{~g}$ water. The CWF and water are mixed by swirling or ultrasonicating, and then the solution is decanted and passed through a $0.45-\mu \mathrm{m}$ pore-size filter to remove any suspended CWF particles. The RWS solution is analyzed for $\mathrm{Cl}^{-}$(and sometimes for Na) to determine the amount of halite that dissolved; the concentrations of other cations are sometimes measured as well. Since the CWF surface area-to-solution volumes are the same in the RWS test and the PCT, the amounts of $\mathrm{Na}$ and $\mathrm{Cl}^{-}$ dissolved in each step can be added directly to determine the total releases. The concentrations measured in the RWS solutions provide a measure of the amount of $\mathrm{Cl}^{-}$(or halite) in the waste form, and the

concentrations of $\mathrm{B}$ and Si provide measures of the amounts of binder glass and sodalite. The seven-day tests are conducted with the CWF following the standard procedure that is used to test glass, and the solutions are usually analyzed for Al, B, Na, and Si. The solution generated during the seven-day PCT is referred to as the "test solution" to distinguish it from the RWS solution.

\section{IV.E.2. Effects of Crushing CWF}

Is the $-100+200$ mesh fraction of crushed CWF representative of the bulk waste form? This issue was addressed by comparing the microstructure of the crushed CWF with that of the bulk material and by 


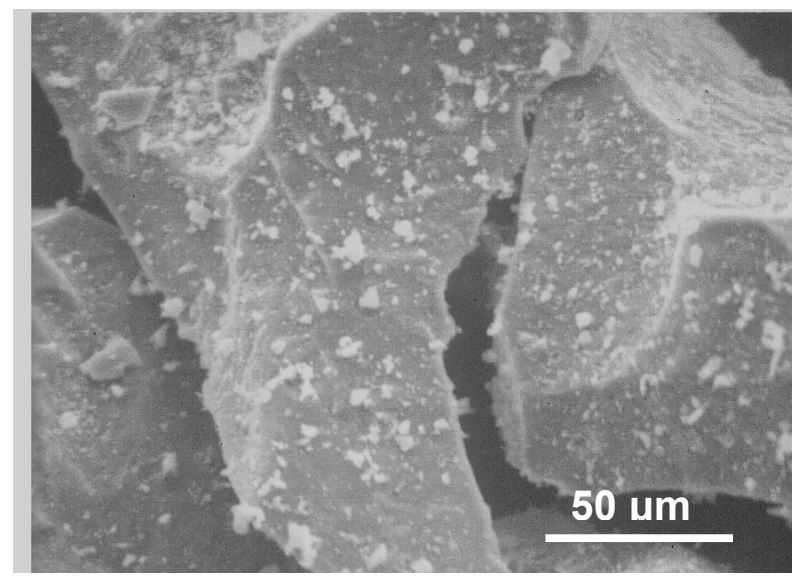

(a)

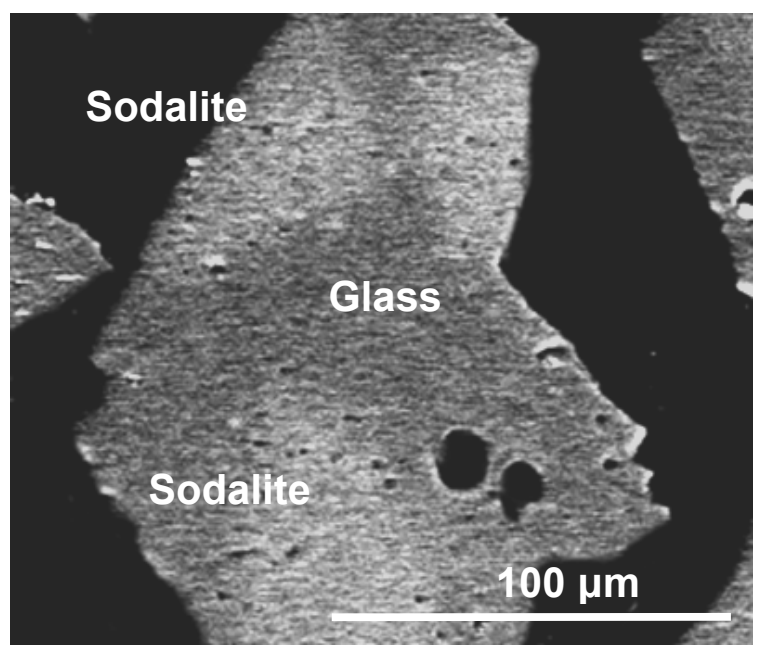

(c)

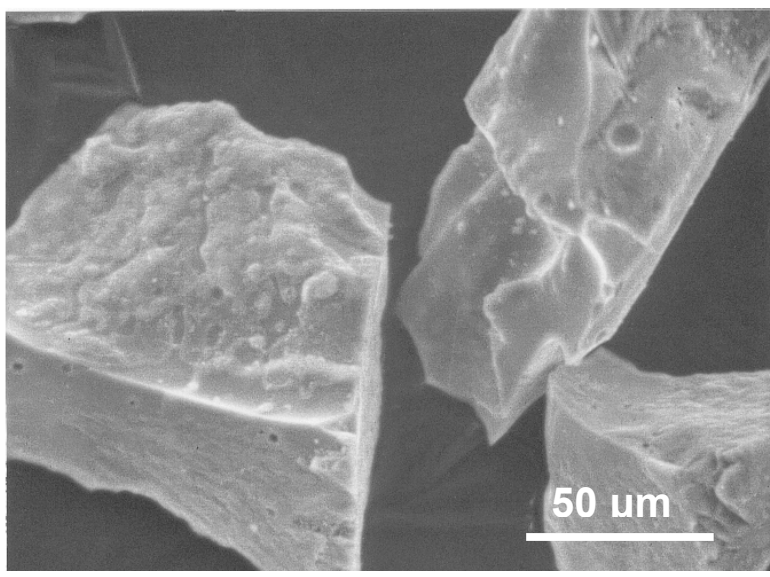

(b)

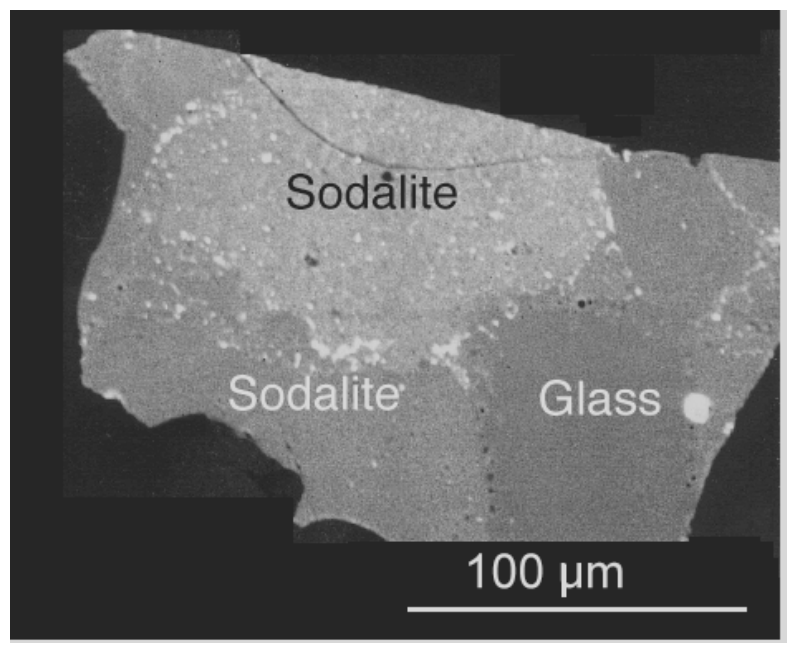

(d)

Fig. IV-37. Scanning Electron Photomicrographs of $-100+200$ Mesh Size Fraction of PC CWF (a) before and (b) after Washing and of Cross-Sectioned -100+200 Mesh Size Fraction Particles of (c) PC CWF and (d) HIP CWF.

comparing the gross compositions of various size fractions of crushed CWF. As discussed in Section II.A.3, the microstructure of the bulk CWF consists of $100-\mu \mathrm{m}$-sized domains of sodalite encapsulated in a borosilicate glass. Small inclusions of halite and various oxides and silicates are also present in the glass. Typical particles of crushed PC CWF and HIP CWF from the $-100+200$ mesh size fractions used in the PCTs are shown in Figs. IV-37c and IV-37d. The particles were fixed in epoxy, which is seen as the black surrounding each particle, and polished. The lighter areas in both particles are sodalite domains and the darker areas are binder glass. As was the case in photomicrographs of the bulk materials, small bright spots corresponding to rare earth element oxides are seen to have accumulated in the glass surrounding the sodalite domains of the HIP CWF, but these are more uniformly distributed throughout the binder glass in the PC CWF. The interfaces between the sodalite and binder glass in the PC CWF is more diffuse than in the HIP CWF. The clearer interfaces in the HIP CWF are probably due, in part, to the accumulation of pores and inclusions at the interfaces in the HIP CWF. (Clearer photomicrographs were always obtained for SEM analyses of HIP CWF than analyses of PC CWF.) Examination of the perimeters of the particles indicates that neither material fractured preferentially between regions of sodalite and glass. The surface of CWF exposed to the test solution appears to include 
sodalite, binder glass, and inclusion phases in roughly the same proportions as in the bulk CWF. Separated particles comprised of only sodalite or only binder glass were not detected in the $-100+200$ or $-200+325$ mesh size fractions of crushed PC CWF or HIP CWF. However, pulverizing the CWF finer than 325 mesh for XRD analysis did cause the phases to separate because the sodalite is more friable than the glass (Ebert et al., 2005).

The as-batched composition was calculated from the compositions and relative amounts of the salt, zeolite, and glass components used to make the CWF. The compositions of crushed HIP CWF in two size fractions were measured by dissolving the particles in acid and analyzing the resulting solutions with inductively coupled plasma-atomic emission spectroscopy. The HIP CWF was made with 25 mass \% binder glass and 25 mass \% SLZ having a salt loading of 10.7 mass \% (67 mass \% zeolite, and 8 mass \% salt). The calculated as-batched composition and measured compositions of the $-100+200$ mesh and $-200+325$ mesh size fractions are summarized in Table IV-18. The compositions of the two size fractions are identical to each other (within analytical uncertainty) and to the as-batched composition. This indicates that the sodalite and binder glass are not fractionated by crushing and sieving. It cannot be determined if inclusion phases are fractionated because of their low concentrations; the appearance of the crushed particles suggests they are not. The behavior of trace components are not monitored in the PCT because they do not provide a reliable measure of waste form consistency because of high uncertainties in their measured release and how uniformly they are distributed in the waste form.

\section{IV.E.3. Sensitivity of PCT Response to CWF Composition}

Are the RWS and PCT responses sensitive to possible processing upsets and composition variations? A possible use of the PCT with CWF will be to verify that appropriate amounts of salt waste, zeolite, and binder glass were added during processing. This requires that the PCT response be sensitive to the relative amounts of halite, sodalite, and binder glass in the CWF. This issue was addressed by comparing the PCT response in tests conducted with CWF made with different SLZ/glass ratios and under different processing conditions. When CWF materials were made by processing at different temperatures (850-925 ${ }^{\circ} \mathrm{C}$ ) and durations (4-36 hours) during development of the PC process, it was discovered that the processing conditions affected the amount of halite inclusions that formed. The RWS measurements were compared with the amounts of halite in these CWF materials measured using XRD (Lewis et al., 2002), as shown in Fig. IV-38. The results indicated that the RWS response was weakly correlated with the amount of halite in the CWF. The total $\mathrm{Cl}^{-}$content was presumed to be the same in all materials - only the distribution of $\mathrm{Cl}^{-}$between sodalite and halite was assumed to differ.

Table IV-18. Composition of HIP CWF in Two Size Fractions, in Mass \%

\begin{tabular}{|c|c|c|c|}
\hline \multirow{2}{*}{ Element } & \multirow{2}{*}{ As-Batched } & \multicolumn{2}{|c|}{ Mesh Size Fraction } \\
\cline { 3 - 4 } & & $-100+200$ & $-200+325$ \\
\hline $\mathrm{Al}$ & 10.0 & 9.2 & 9.2 \\
\hline $\mathrm{B}$ & 3.0 & 2.5 & 2.7 \\
\hline $\mathrm{Cl}$ & 3.2 & 3.2 & 3.0 \\
\hline $\mathrm{Cs}$ & 0.1 & 0.10 & 0.11 \\
\hline $\mathrm{K}$ & 1.3 & 1.3 & 1.4 \\
\hline $\mathrm{Na}$ & 9.3 & 9.6 & 9.4 \\
\hline $\mathrm{Si}$ & 23 & 23 & 24 \\
\hline
\end{tabular}




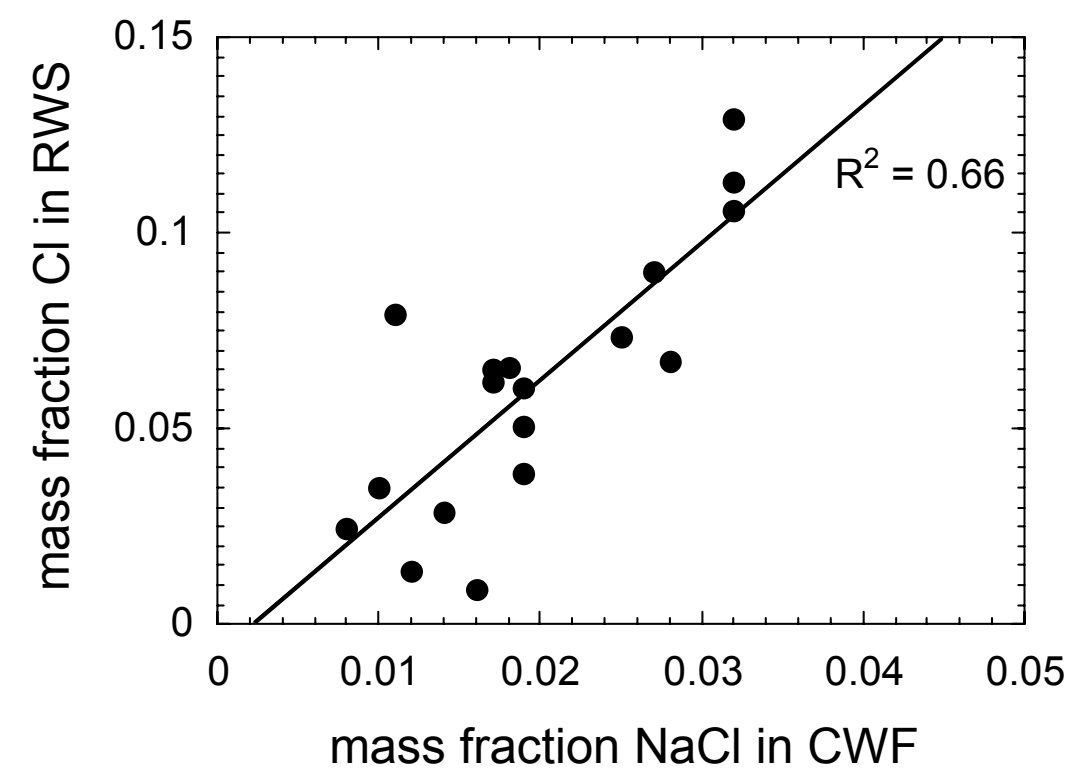

Fig. IV-38. Correlation between the $\mathrm{Cl}^{-}$Concentration in the RWS Solution and the Halite Content in Bulk PC CWF.

The RWS test solutions were also analyzed for $\mathrm{Na}$ and $\mathrm{I}^{-}$, and Fig. IV-39 shows that the normalized mass losses of both are correlated with that of $\mathrm{Cl}^{-}$(Lewis and Ebert, 2000). While it is expected that Na would be correlated with $\mathrm{Cl}^{-}$on a 1:1 molar basis according to the chemical formula of halite, this was the first evidence that $\mathrm{I}^{-}$was distributed in halite. The slope of the correlation provides the added insight that the proportions of $\mathrm{Cl}^{-}$and $\mathrm{I}^{-}$are the same in halite and sodalite (and probably also in the binder glass). The slope of the correlation with $\mathrm{Na}$ indicates that a much smaller proportion of the $\mathrm{Na}$ content is in halite, about $20 \%$ of the proportion of $\mathrm{Cl}^{-}$(see discussion in Section IV.B.2.3.) This is obvious from the compositions of sodalite, which contains $4 \mathrm{Na}$ atoms for every $\mathrm{Cl}$ atom, and the binder glass, which contains about 5 mass $\% \mathrm{Na}$ and (initially) no $\mathrm{Cl}^{-}$. Up to about 1 mass $\% \mathrm{Cl}$ can dissolve in the binder glass during production of the CWF, but more $\mathrm{Na}$ can dissolve.

To evaluate the sensitivity of the PCT response to the relative amounts of glass and sodalite, PC CWF materials were made by processing at $850^{\circ} \mathrm{C}$ for four hours with glass contents of $25,30,35,40$, and 45 mass \% glass. (The PC processing conditions have since been changed to $915^{\circ} \mathrm{C}$ for 16 hours.) The results of triplicate PCT are shown in Fig. IV-40 as the mean $\pm 2 \mathrm{~s}$ for the concentrations of $\mathrm{B}, \mathrm{Cl}, \mathrm{Na}$, and $\mathrm{Si}$. The $\mathrm{Na}$ and $\mathrm{Cl}$ is that due to dissolution of sodalite and binder glass; the masses released in the RWS test are not included. The $\mathrm{Na}$ and $\mathrm{Si}$ concentrations are not very sensitive to the amount of glass in the CWF because these elements are present in both the glass and the sodalite. The $\mathrm{Cl}^{-}$concentration in the CWF products decreases slightly because the proportion of SLZ in the CWF decreased as the amount of binder glass was increased. Differences in the $\mathrm{Cl}^{-}, \mathrm{Na}$, or Si concentrations in the PCT test solutions are not sufficient to distinguish the different CWF materials. However, the B concentrations are sufficiently different to distinguish two CWF materials having a difference of 5\% in the binder glass content. The differences in the B concentrations for CWF made with $25 \%$ and $30 \%$ binder glass is near the experimental uncertainty, but the differences are greater for CWF with higher glass loadings.

The sensitivity of the PCT to the CWF composition was re-evaluated using the series of CWF materials made using SLZs with various salt contents and various SLZ-to-glass mass ratios (see also discussion in Section IV.A.8). These materials were processed at $915^{\circ} \mathrm{C}$ for 16 hours are referred to as salt-loaded CWF 


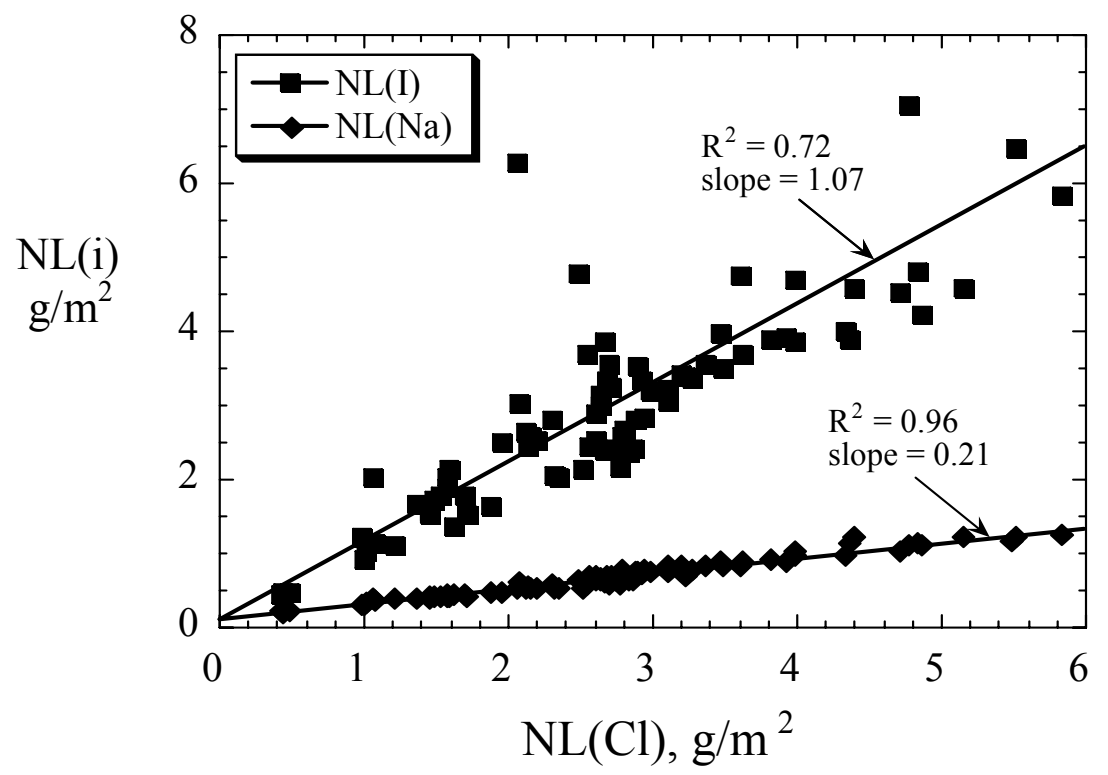

Fig. IV-39. Correlations between $\mathrm{I}^{-}$and $\mathrm{Cl}^{-}$and $\mathrm{Na}$ and $\mathrm{Cl}^{-}$in RWS of PC CWF.

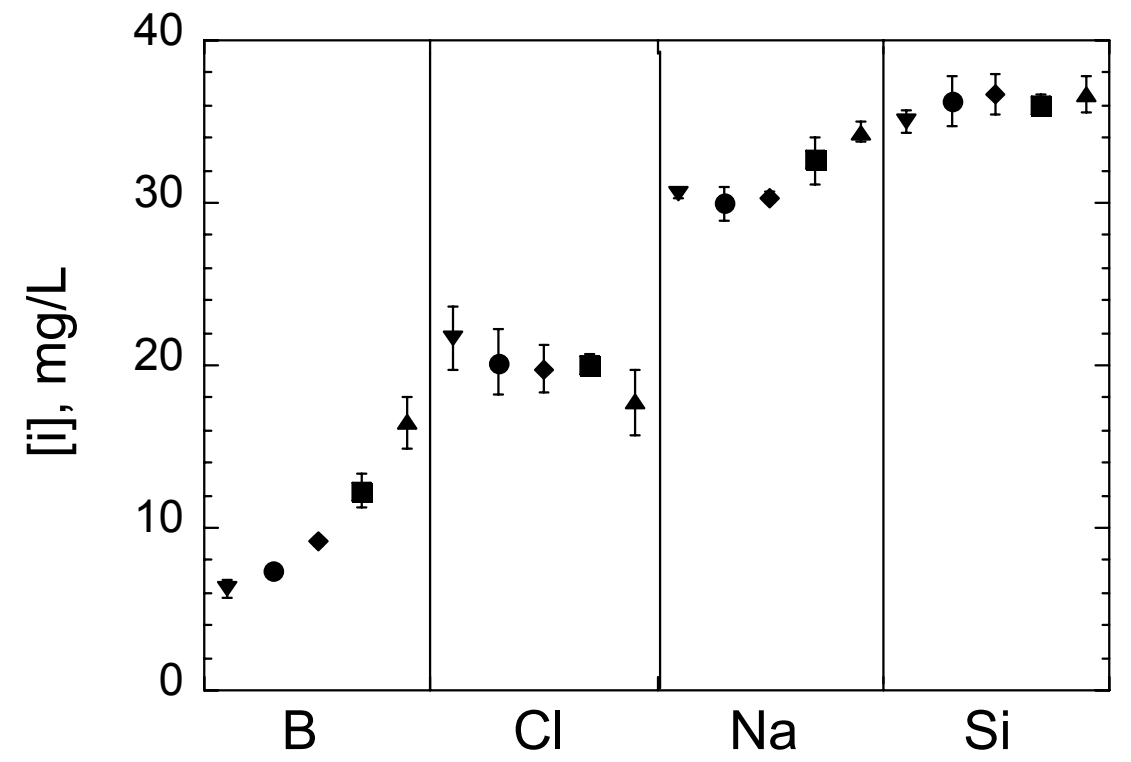

Fig. IV-40. Concentrations of B, Cl, Na, and Si in Seven-Day PCT

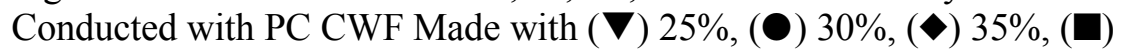
40\%, and (A) 45\% Binder Glass. 
materials (Ebert et al., 2005). They are considered to be more representative of the waste forms than the materials processed at $850^{\circ} \mathrm{C}$ for four hours. The current processing range for salt loading is 3.4 to $3.6 \mathrm{Cl}^{-}$ per formula (Goff et al., 1999), which corresponds to 10.62-11.18 mass \% salt in the SLZ. Batches of SLZ were made with 5.0, 7.5, 10.7, 12.5, and 15.0 mass \% simulated 300 driver salt. Individual CWF products were made for testing using 75 mass \% of these SLZs with 25 mass \% binder glass. Other products were made for testing by mixing the SLZ containing 10.7 mass \% salt with 20.0, 22.5, 25.0, 27.5 , or 30.0 mass $\%$ binder glass. The processing range of glass/SLZ mixtures is $20-30 \%$ mass $\%$ glass, with a target glass loading of $25 \%$ (Goff et al., 1999). Three CWF products were made with 10.7 mass \% salt and 25 mass \% binder glass to measure the repeatability of making the materials and the test responses. The materials are identified in Table IV-5.

Enough of each material in the $-100+200$ mesh size fraction was prepared to conduct three PCT. A single RWS test was conducted for each material, and values of $\mathrm{NL}(\mathrm{Cl})$ for the RWS test solutions for each product are plotted in Fig. IV-41a. The result for the test with S1A is $0.0336 \mathrm{~g} / \mathrm{m}^{2}$. Figure IV-41b shows a plot of the $\mathrm{Cl}^{-}$concentration vs. the mass fraction of $\mathrm{Cl}$ in the $\mathrm{CWF}$. The $\mathrm{Cl}^{-}$concentration was adjusted for the amounts of water and CWF used in the RWS, and is given in units of $\mathrm{mg} \mathrm{Cl}^{-}$per $\mathrm{g} \mathrm{CWF}$. The result for S1A [RWS $=0.021 \mathrm{mg} / \mathrm{g}$ and $\mathrm{f}(\mathrm{Cl})=0.0283$ ] is excluded from Fig. IV-41b. Since only the salt provides $\mathrm{Cl}$ to the $\mathrm{CWF}$, the $\mathrm{Cl}^{-}$concentration measured in the RWS test provides an indication of the amount of salt used to make the CWF over the range 7.5 to at least 15 mass \%.

The B concentrations measured in the test solutions of triplicate PCTs with materials made with different glass loadings are plotted in Fig. IV-42a. (The average responses of tests with S3A, S3C, and S3E in each of the three tests are plotted as S3. These products were all made with 25 mass \% binder glass.) The lowest concentrations are measured in tests with the material containing 20.0 mass \% binder glass and the highest concentrations are measured in tests with the material containing 30.0 mass $\%$ binder glass, but the concentrations measured in tests with materials containing intermediate amounts of binder glass are the same within experimental error. The B concentrations are plotted against the mass fraction of B in the different products in Fig. IV-42b. (The average B concentration from triplicate tests with Product S1A, which is $9.43 \mathrm{mg} / \mathrm{L}$, is plotted at $3.95 \mathrm{mg} / \mathrm{L}$ to use a smaller ordinate scale.) The B concentrations measured in the seven-day PCTs do not reflect the amounts of B or binder glass in the CWF. The B concentration is not sufficiently sensitive to distinguish between binder glass loadings over the processing range from 20 to 30 mass \%. The one outlier is Product S1A, which is interpreted to be much less durable than the other CWF products. This probably indicates that the $\mathrm{B}$ concentration is sensitive to the durability of the binder glass phase in the CWF. It is worth noting that the B contents of Products G1A and G2A are lower than the B content of Product S1A, but tests with these products have lower B concentrations, and therefore the binder glass contents. That is, the higher B concentrations in the test solutions indicate Product S1A is less durable than the other products independent of its glass content. This implies that the chemical durability of the CWF is not sensitive to binder glass contents between 20 and 30 mass \%. The B concentrations in the PCT solutions are more sensitive to the durability of the binder glass in CWF materials than the binder glass content.

The durability of the CWF materials can be compared using the values of NL(B), NL(Na), and NL(Si) for the triplicate PCT with the salt-loaded CWF materials. These are plotted in Fig. IV-43. As expected from the measured concentrations, the values of NL(B) are significantly higher in tests with S1A than in tests with materials made with more added salt. The values of NL(B) are similar in tests with the other materials. The values of $\mathrm{NL}(\mathrm{Na})$ and $\mathrm{NL}(\mathrm{Si})$ are likewise fairly insensitive to the CWF composition. The mass fractions of $\mathrm{Al}, \mathrm{Cl}, \mathrm{Na}$, and $\mathrm{Si}$ are plotted against the mass fractions of $\mathrm{B}$ in the different $\mathrm{CWF}$ materials in Fig. IV-44. This shows that only the mass fraction of B differs significantly between the different products- $\mathrm{f}(\mathrm{B})$ increases by $48 \%$. The mass fractions of $\mathrm{Al}, \mathrm{Na}$, and $\mathrm{Si}$ vary less for the different CWF products because they are present in both the binder glass and zeolite- $\mathrm{f}(\mathrm{Al})$ decreases by $23 \%$, 


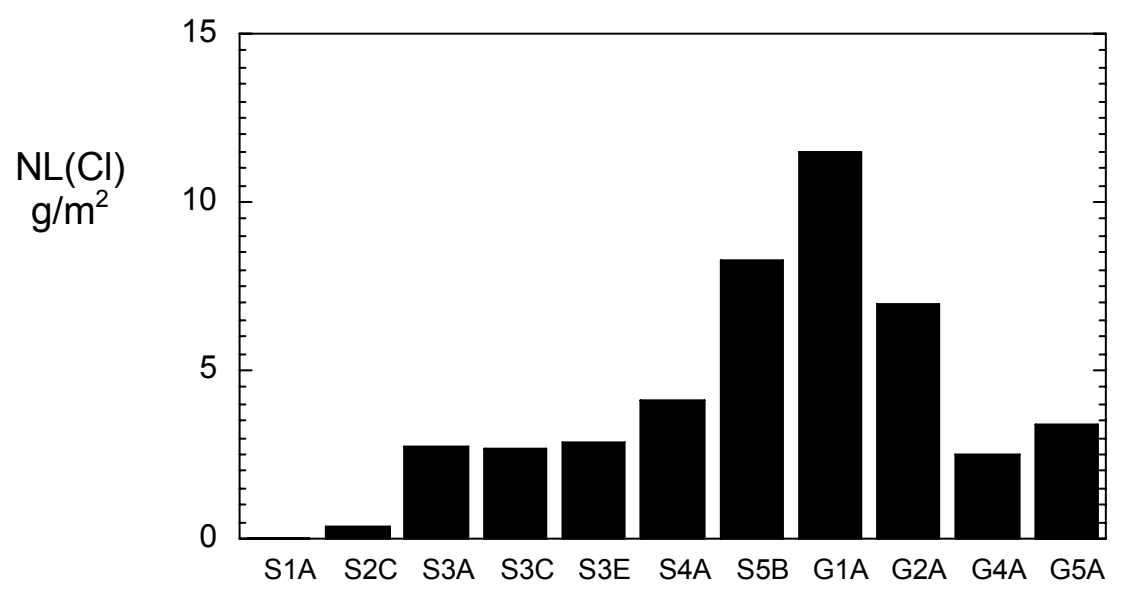

(a)

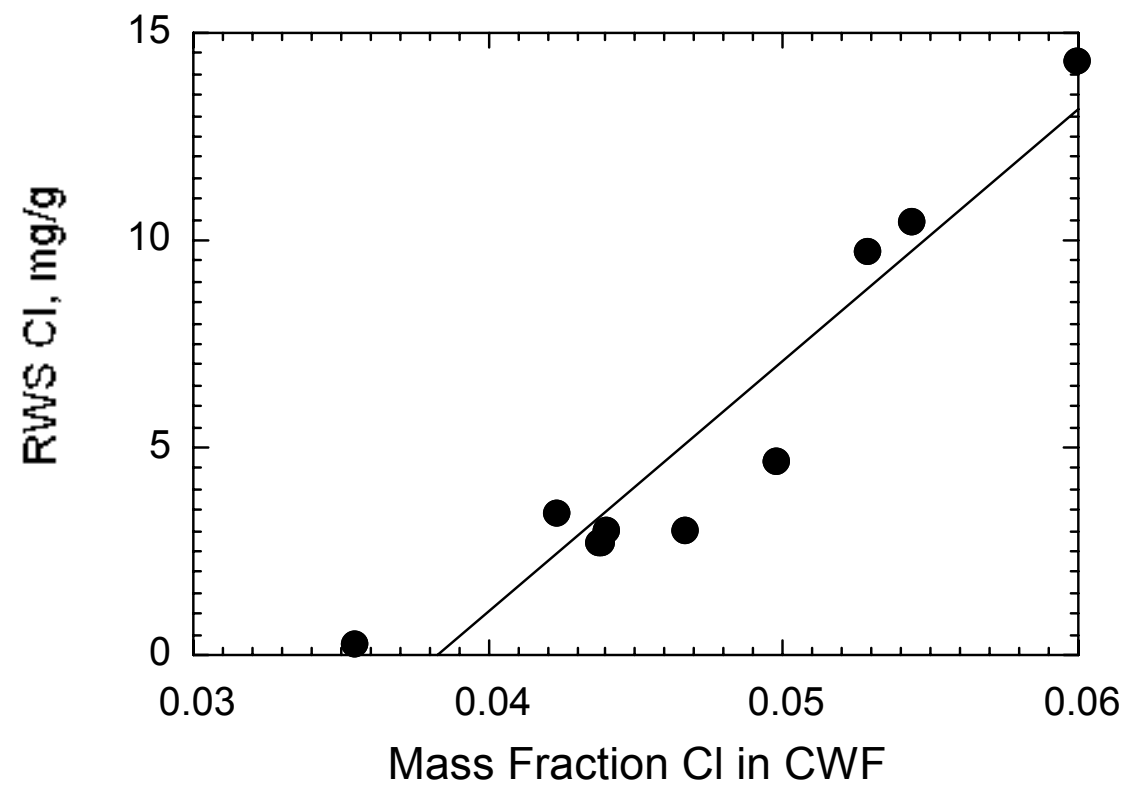

(b)

Fig. IV-41. Chloride Release in RWS with Salt-Loaded CWF Materials: (a) NL(Cl) for Salt-Loaded CWF Products and (b) $\left[\mathrm{Cl}^{-}\right]$vs. Mass Fraction $\mathrm{Cl}$ in Products. 


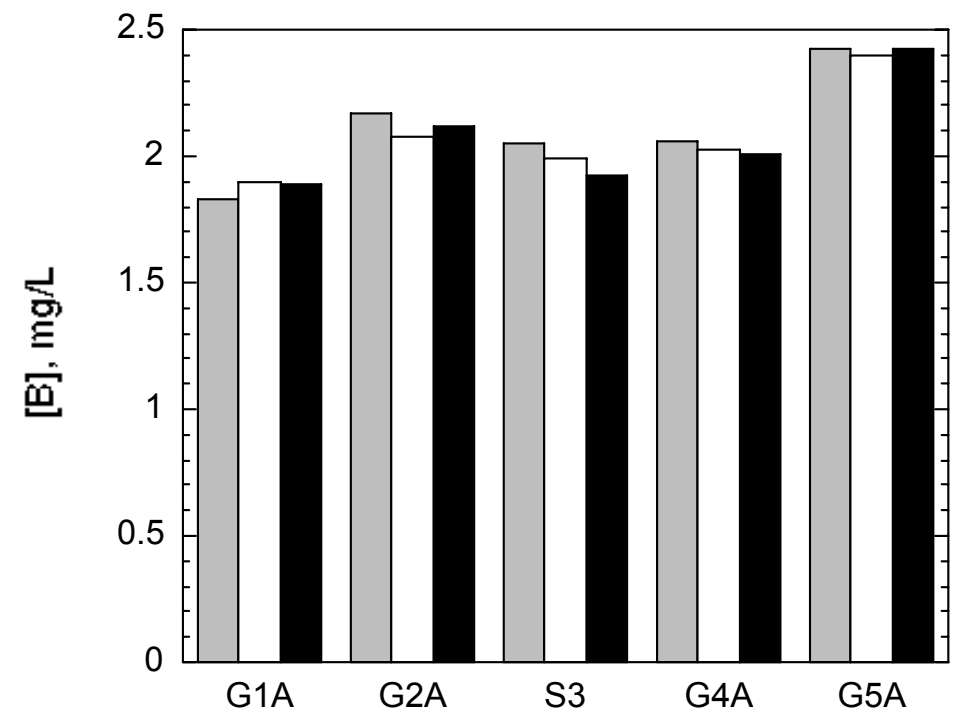

(a)

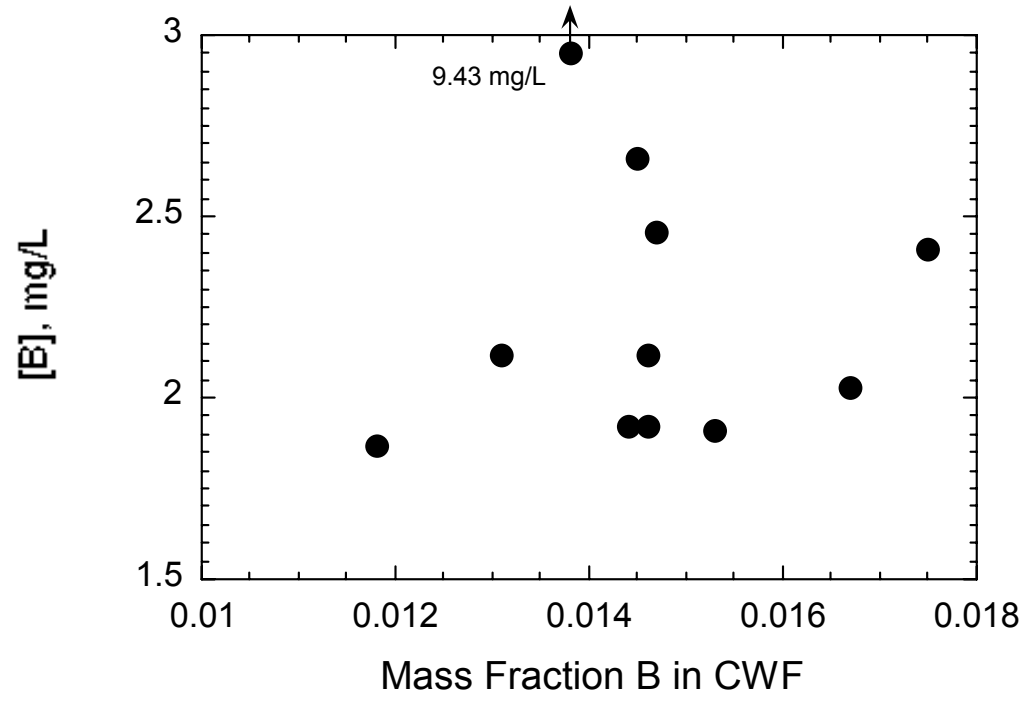

(b)

Fig. IV-42. B Concentrations Measured in Triplicate Seven-Day PCT (a) with Salt-Loaded CWF Materials Made with 20.0\% (G1A), 22.5\% (G2A), $25.0 \%$ (S3), 27.5\% (G4A), and 30.0\% (G5A) Binder Glass, and (b) B Concentration in Seven-Day PCTs vs. Mass Fraction B in CWF. 


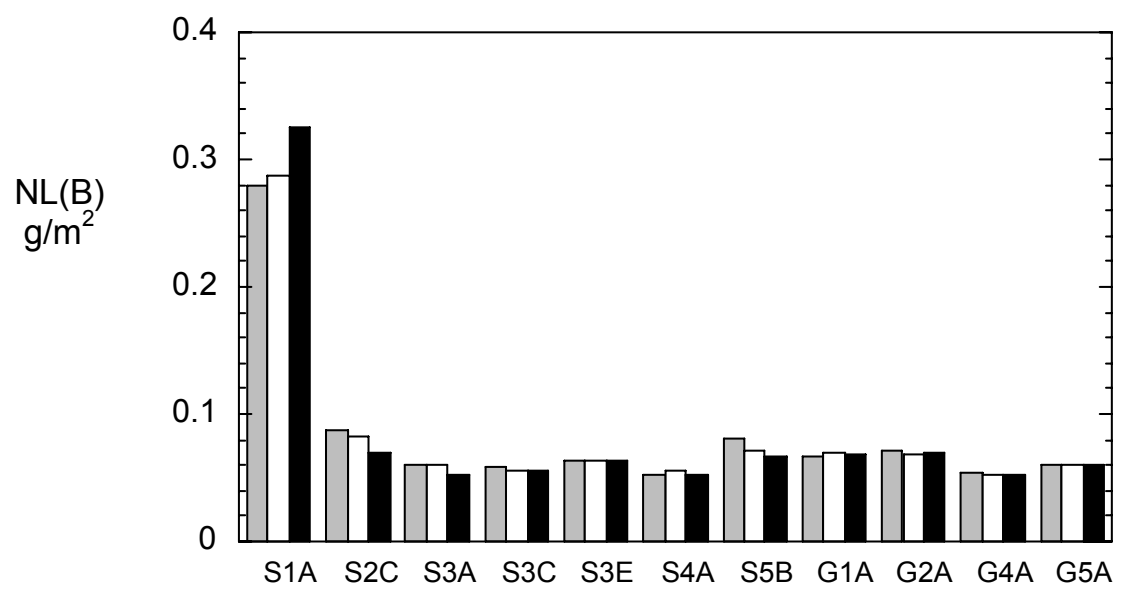

(a)

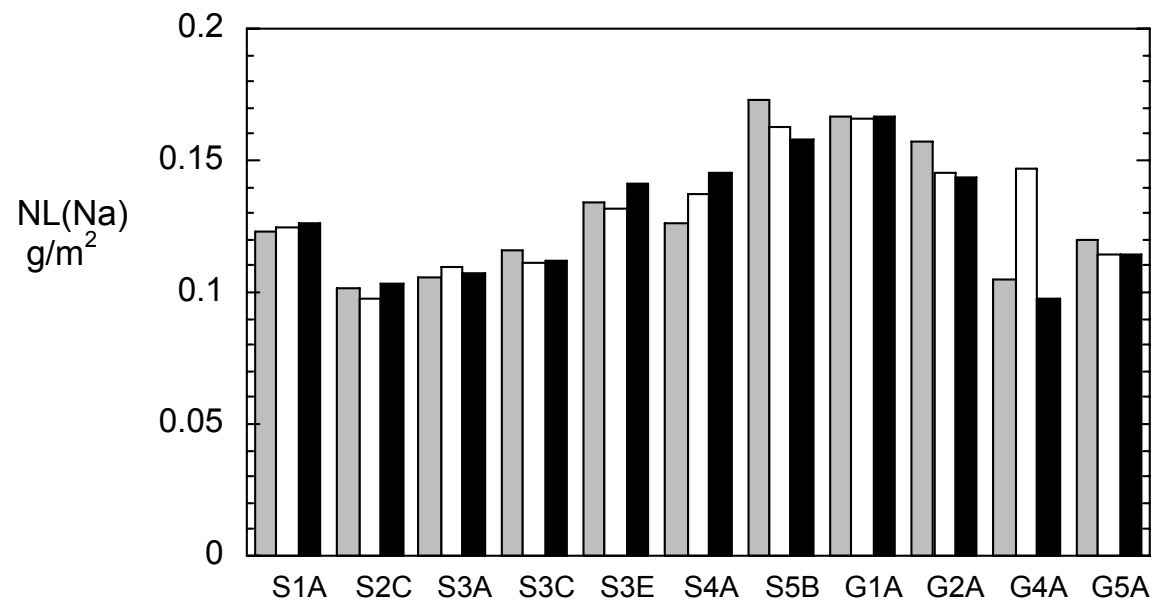

(b)

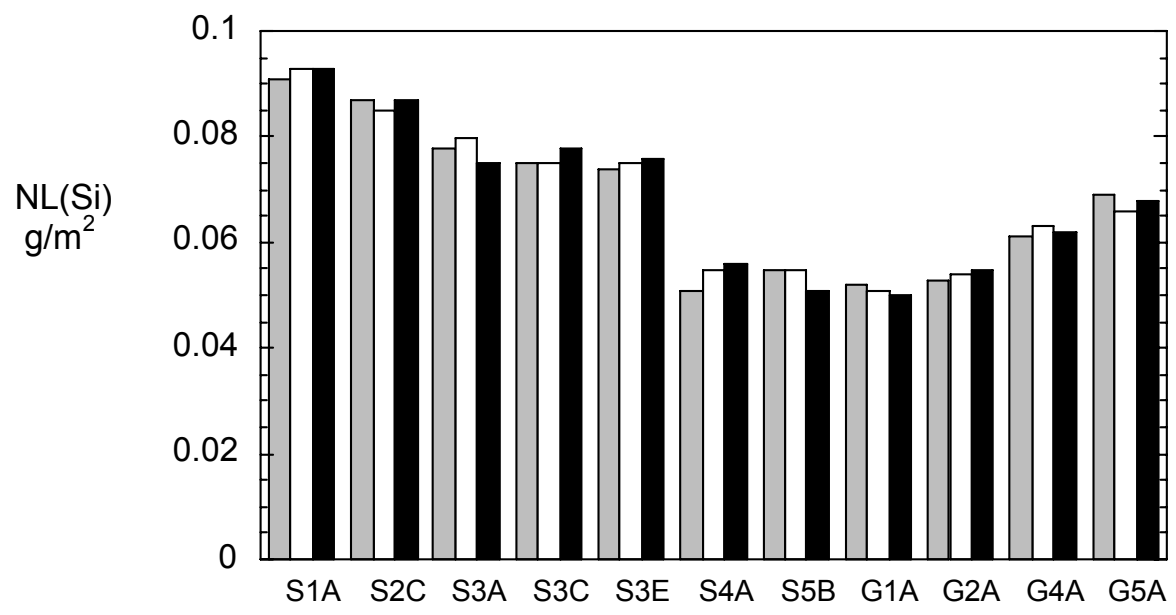

(c)

Fig. IV-43. Normalized Elemental Mass Losses in Seven-Day PCT with Salt-Loaded CWF Materials: (a) NL(B) (b) NL(Na), and (c) NL(Si) for Different Salt Loadings. 


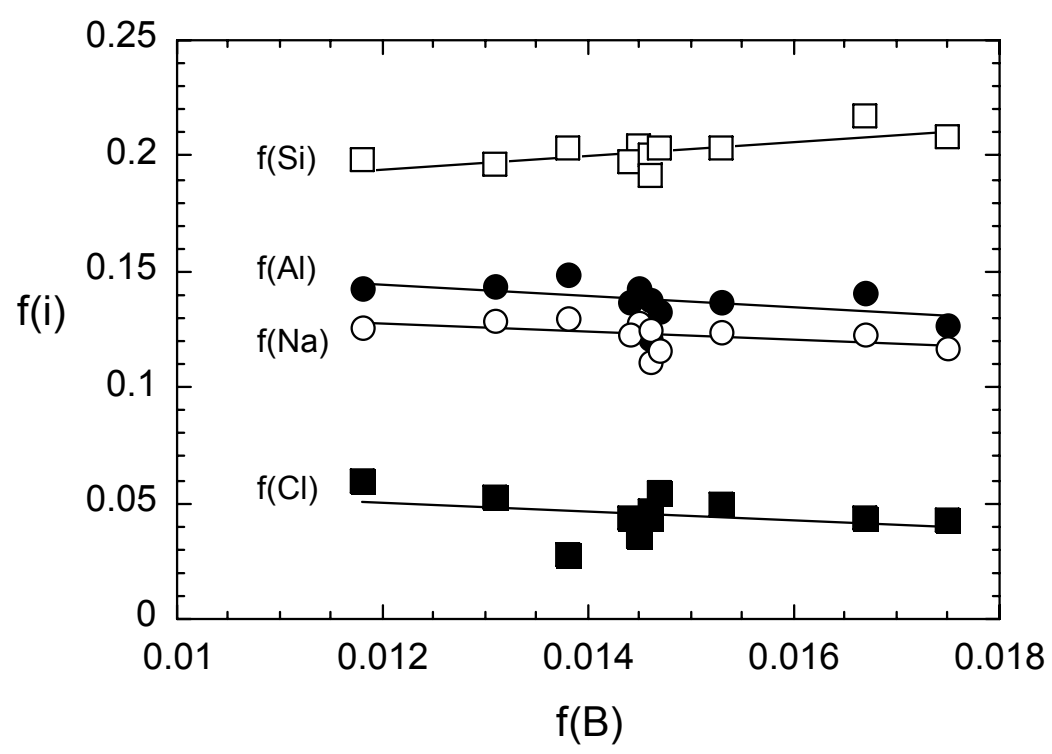

Fig. IV-44. Correlation of the Mass Fractions of Al, Cl, Na, and $\mathrm{Si}$ with the Mass Fraction of B in Salt-Loaded CWF Products.

$\mathrm{f}(\mathrm{Na})$ decreases by $16 \%$, and $\mathrm{Si}$ increases by $13 \%$ as more binder glass is added to the mixture. The B and $\mathrm{Si}$ concentrations are higher in the binder glass than in the zeolite, whereas the $\mathrm{Al}$ and $\mathrm{Na}$ concentrations are higher in the zeolite. The $\mathrm{Cl}$ content of the CWF products decreases $112 \%$ due to differences in salt loadings and the amounts of SLZ used to make them. Although $\mathrm{Cl}$ is only present in the salt, its release into the PCT solution (after halite on the surface has been dissolved in the RWS test) might provide a measure of the amount of sodalite and, by difference, the amount of binder glass. The $\mathrm{Cl}^{-}$concentration was not measured in these PCT test solutions, so the possible use of $\mathrm{Cl}^{-}$as an indicator cannot be evaluated with this data set.

The values of NL(Na) and NL(Si) are not significantly higher in tests with Product S1A than in tests with other CWF products (see Fig. IV-43). This is because most of the Na and Si are in the sodalite phase and $\mathrm{NL}(\mathrm{Na})$ and $\mathrm{NL}(\mathrm{Si})$ are not as sensitive as $\mathrm{NL}(\mathrm{B})$ to the amount of binder glass that dissolves. They also show opposite dependencies on changes in the amounts of salt and binder glass used to make the CWF products: the values of $\mathrm{NL}(\mathrm{Na})$ are highest for tests with Products S5B, G1A, and G2A, whereas the values of $\mathrm{NL}(\mathrm{Si})$ are lowest for tests with these materials. This may reflect the relative amounts of binder glass and sodalite that dissolve in the tests: a greater fraction of the $\mathrm{Na}$ content than the Si content is contained in sodalite. The dissolution of more sodalite than binder glass would lead to a greater increase in $\mathrm{NL}(\mathrm{Na})$ than $\mathrm{NL}(\mathrm{Si})$.

\section{IV.E.4. Precision of PCT with CWF}

Can the PCT be conducted with the same precision using CWF as with borosilicate glass? Several sets of replicate tests have been conducted at ANL with CWF materials made by using different processing conditions to determine if the test results were repeatable. Replicate tests were conducted with materials taken from different locations of CWF products, with replicate products made with the same starting materials using the same processing conditions, and with consolidated mixtures of crushed material from several CWF products. The test precision for CWF made using the current processing conditions $\left(915^{\circ} \mathrm{C}\right.$ for 16 hours) was quantified by conducting an ILS. The data base generated in the ILS is used to 
determine the precision that can be expected for PCTs conducted with CWF. This can be compared with the precision measured in previous interlaboratory studies with borosilicate glasses.

\section{IV.E.4.1. Replicate Tests at ANL}

Triplicate seven-day PCTs were conducted with a 5-kg CWF product made by mixing SLZ containing about 10.7 mass \% salt with 50 mass \% binder glass and processing at $850^{\circ} \mathrm{C}$ for four hours. The crushed and sieved CWF material was separated into three lots, and one set of RWS test and triplicate PCTs was conducted with each lot (Lewis et al., 2002, Table 10). The results are summarized in Table IV-19 (some of the calculated values have been corrected from those given in the referenced document). The mean, standard deviation, and relative standard deviation were calculated for the combined sets (nine tests).

One RWS and one seven-day PCT were conducted. The results are summarized in Table IV-20. These test results were discussed previously with regard to the relative amounts of each element in the RWS and PCT fractions. The total releases (RWS + PCT) are plotted in Fig. IV-16..

A series of 10 PC CWF products were made with 50\% SLZ and 50\% binder glass to study the reproducibility of processing by pressureless consolidation (Lewis et al., 2002). Samples of each CWF product were crushed and sieved to isolate the $-100+200$ mesh size fraction and subjected to an RWS test followed by a seven-day PCT. The results are plotted in Fig. IV-45, where the releases in the RWS and PCT steps are shown by the black and white bars, respectively. The relative amounts of each element released in the RWS step provides insight into their distributions in halite. Figures IV-45a and IV-45b show that fractions of $\mathrm{Cl}^{-}$and $\mathrm{I}^{-}$in the RWS tests are similar. This indicates that similar fractions of $\mathrm{Cl}^{-}$ and $\mathrm{I}^{-}$in the CWF are present in halite and in sodalite. (Recall that NL(i) is normalized to the mass fraction of element $i$ in the CWF.) The mass fraction of $\mathrm{Cl}$ is $60.7 \%$ in halite and $7.32 \%$ in sodalite. Assuming that the CWF contains 1.2 mass \% halite and $73 \%$ sodalite, about $12 \%$ of the $\mathrm{Cl}$ (and I) in the CWF is present in halite and about $88 \%$ is present in sodalite. The solubility of $\mathrm{Cl}$ in borosilicate glass is typically less than 1 mass \%, so the total $\mathrm{Cl}$ content of the CWF that is in the binder glass is probably $<0.25$ mass $\%$.

Figures IV-45c and IV-45d show that significant amounts of $\mathrm{Na}$ and $\mathrm{Cs}$ are released in the RWS tests, which indicates $\mathrm{Na}$ (of course) and some Cs are contained in halite. Since halite does not contain Al, B, or $\mathrm{Si}$, the small amounts of these elements detected in the RWS tests (see Figs IV-45e, IV-45f, and IV-45g) probably result from small amounts of fines contaminating the RWS tests. The amounts of Li in the RWS (see Fig. IV-45h) are similar to the amounts of $\mathrm{Al}, \mathrm{B}$, and $\mathrm{Si}$, which indicates that little Li is contained in halite inclusions, and that almost all of the $\mathrm{Li}$ is present in either sodalite or the binder glass. Notice that sample DTD 9 gave anomalously high RWS values for several elements. This is attributed to contamination of the RWS solution with a few particles of CWF. The $\mathrm{Al}$ and $\mathrm{Si}$ values are about ten times higher than other tests, and the $\mathrm{B}, \mathrm{Cs}$, and Li values are about two times higher. The RWS values for $\mathrm{Cl}^{-}$, $\mathrm{I}^{-}$, and $\mathrm{Na}$ are similar for all tests. These differences are interpreted to reflect both the distribution of elements between the halite, sodalite, and binder glass phases and the relative dissolution rates of these phases.

The sums of the releases in the RWS and PCT steps are plotted in Fig. IV-46 for tests with the 10 replicate samples. The high values of $\mathrm{NL}(\mathrm{Cl}), \mathrm{NL}(\mathrm{I})$, and $\mathrm{NL}(\mathrm{Na})$ are due to the rapid dissolution of halite in the RWS step. The high values of NL(B) and NL(Li) are due to the dissolution of the binder glass. The observation that $\mathrm{NL}(\mathrm{B})>\mathrm{NL}(\mathrm{Si})$ indicates that the binder glass dissolved faster than sodalite. Note the low value of NL(Cs), most of which is presumed to be contained in the binder glass. The release of Cs was anomalously low in most tests with HIP CWF and PC CWF materials, and even from 
Table IV-19. Results of Three Sets of Triplicate RWS and PCT with 5-kg CWF Made with 50 Mass \% Binder Glass, NL(i) in $\mathrm{g} / \mathrm{m}^{2}$

\begin{tabular}{|c|c|c|c|c|c|c|c|}
\hline & Set 1 & Set 2 & Set 3 & & Set 1 & Set 2 & Set 3 \\
\hline $\begin{array}{c}\text { Test } \\
\text { Solution }\end{array}$ & \multicolumn{3}{|c|}{$\mathrm{Al}$} & & \multicolumn{3}{|c|}{$\mathrm{Li}$} \\
\hline RWS & \multicolumn{3}{|c|}{0.0336} & RWS & \multicolumn{3}{|c|}{ not analyzed } \\
\hline PCT-1 & 0.0907 & 0.0905 & 0.0936 & PCT-1 & 0.637 & 0.707 & 0.712 \\
\hline PCT-2 & 0.0890 & 0.0893 & 0.0890 & PCT-2 & 0.667 & 0.709 & 0.707 \\
\hline PCT-3 & 0.0916 & 0.0898 & 0.0923 & PCT-3 & 0.689 & 0.714 & 0.713 \\
\hline \multicolumn{4}{|c|}{ mean \pm stdev $^{a}: 0.1242 \pm 0.0016(r s d=1.28 \%)$} & \multicolumn{4}{|c|}{ mean \pm stdev: $0.695 \pm 0.027(r s d=3.82 \%)$} \\
\hline $\begin{array}{c}\text { Test } \\
\text { Solution }\end{array}$ & \multicolumn{3}{|c|}{ B } & & \multicolumn{3}{|c|}{$\mathrm{Na}$} \\
\hline RWS & \multicolumn{3}{|c|}{0.0099} & RWS & \multicolumn{3}{|c|}{0.057} \\
\hline PCT-1 & 0.646 & 0.646 & 0.674 & PCT-1 & 0.204 & 0.234 & 0.225 \\
\hline РCT-2 & 0.650 & 0.657 & 0.683 & PCT-2 & 0.205 & 0.234 & 0.223 \\
\hline PCT-3 & 0.671 & 0.658 & 0.666 & PCT-3 & 0.211 & 0.235 & 0.227 \\
\hline \multicolumn{4}{|c|}{ mean \pm stdev: $0.671 \pm 0.013(r s d=1.95 \%)$} & \multicolumn{4}{|c|}{ mean \pm stdev: $0.279 \pm 0.012(r s d=4.44 \%)$} \\
\hline $\begin{array}{c}\text { Test } \\
\text { Solution }\end{array}$ & \multicolumn{3}{|c|}{$\mathrm{Cl}$} & & \multicolumn{3}{|c|}{$\mathrm{Si}$} \\
\hline RWS & \multicolumn{3}{|c|}{0.315} & RWS & \multicolumn{3}{|c|}{0.0017} \\
\hline PCT-1 & 0.260 & 0.272 & 0.300 & PCT-1 & 0.0733 & 0.0737 & 0.0757 \\
\hline PCT-2 & 0.281 & 0.267 & 0.296 & PCT-2 & 0.0736 & 0.0712 & 0.0772 \\
\hline PCT-3 & 0.278 & 0.264 & 0.310 & PCT-3 & 0.0752 & 0.0735 & 0.0748 \\
\hline \multicolumn{4}{|c|}{ mean \pm stdev: $0.596 \pm 0.017(r s d=2.93 \%)$} & \multicolumn{4}{|c|}{ mean \pm stdev: $0.0759 \pm 0.0017(r s d=2.26 \%)$} \\
\hline $\begin{array}{c}\text { Test } \\
\text { Solution }\end{array}$ & \multicolumn{3}{|c|}{ Cs } & & & & \\
\hline RWS & \multicolumn{3}{|c|}{0.0027} & & & & \\
\hline PCT-1 & 0.0215 & 0.0214 & 0.0244 & & & & \\
\hline PCT-2 & 0.0216 & 0.0204 & 0.0247 & & & & \\
\hline PCT-3 & 0.0223 & 0.0215 & 0.0252 & & & & \\
\hline
\end{tabular}

${ }^{\mathrm{a}}$ Mean \pm standard deviation for sum of RWS and PCT results and relative standard deviation.

"semi-pure" sodalite (see Fig. IV-15). The Cs content in most CWF materials was about 0.1 mass \%. It is possible that small amounts of a durable Cs-bearing alteration phase (e.g., Cs-pollucite) is formed that has not yet been detected.

\section{IV.E.4.2. Interlaboratory Study}

An ILS was conducted to evaluate the precision with which the PCT could be conducted with the CWF (Ebert et al., 2002a). The ILS was conducted following the ASTM procedure E691 (ASTM 2005c) with samples of a laboratory-scale $\mathrm{CWF}$ product that was made using the current processing conditions $\left(915^{\circ} \mathrm{C}\right.$ for 16 hours) with nominal amounts of a nonradioactive surrogate waste salt (10.7 mass \% in the SLZ) and binder glass ( 25 mass \%) for use in testing. The sample lots provided to participants were taken from a batch of CWF prepared at ANL that had been crushed, sieved, and washed with absolute ethanol to remove fines. The sample preparation steps were performed with the entire source batch to eliminate possible variations due to sample preparation and to constrain the study to the precision of test execution and solution analysis. Participants performed one water wash of the provided lot and then conducted 
Table IV-20. Results of RWS and PCT with 10 CWF Products Made with 50 Mass \% Binder Glass, NL(i) in $\mathrm{g} / \mathrm{m}^{2}$

\begin{tabular}{|c|c|c|c|c|c|c|c|c|}
\hline $\begin{array}{c}\text { Test } \\
\text { Number }\end{array}$ & Al & B & $\mathrm{Cl}$ & Cs & 1 & $\mathrm{Li}$ & $\mathrm{Na}$ & $\mathrm{Si}$ \\
\hline \multicolumn{9}{|c|}{ RWS } \\
\hline DTD1 & 0.0011 & 0.0054 & 0.821 & 0.00730 & 0.624 & 0.0105 & 0.175 & 0.0015 \\
\hline DTD2 & 0.0010 & 0.0057 & 0.915 & 0.00864 & 0.719 & 0.0124 & 0.195 & 0.0013 \\
\hline DTS3 & 0.0020 & 0.0066 & 0.857 & 0.11813 & 0.550 & 0.0233 & 0.201 & 0.0025 \\
\hline DTD4 & 0.0014 & 0.0052 & 0.814 & 0.00656 & 0.534 & 0.0175 & 0.187 & 0.0013 \\
\hline DTD5 & 0.0010 & 0.0066 & 0.774 & 0.00726 & 0.500 & 0.0193 & 0.173 & 0.0009 \\
\hline DTD6 & 0.0028 & 0.0065 & 0.846 & 0.00822 & 0.573 & 0.0215 & 0.199 & 0.0021 \\
\hline DTD7 & 0.0021 & 0.0066 & 0.667 & 0.00740 & 0.416 & 0.0162 & 0.150 & 0.0017 \\
\hline DTD8 & 0.0028 & 0.0068 & 0.741 & 0.00750 & 0.494 & 0.0179 & 0.177 & 0.0022 \\
\hline DTD9 & 0.0272 & 0.0158 & 0.778 & 0.0196 & 0.529 & 0.0354 & 0.206 & 0.0137 \\
\hline DTD10 & 0.0022 & 0.0062 & 0.753 & 0.00633 & 0.493 & 0.0166 & 0.172 & 0.0021 \\
\hline mean & 0.00436 & 0.00714 & 0.797 & 0.0197 & 0.543 & 0.0191 & 0.184 & 0.00293 \\
\hline stdev & 0.00805 & 0.00309 & 0.070 & 0.0348 & 0.083 & 0.0069 & 0.017 & 0.00382 \\
\hline \multicolumn{9}{|c|}{ РCT } \\
\hline DTD1 & 0.104 & 0.449 & 0.230 & 0.0157 & 0.189 & 0.668 & 0.185 & 0.0706 \\
\hline DTD2 & 0.101 & 0.341 & 0.222 & 0.0154 & 0.272 & 0.615 & 0.162 & 0.0679 \\
\hline DTD3 & 0.108 & 0.454 & 0.232 & 0.0201 & 0.176 & 0.667 & 0.184 & 0.0694 \\
\hline DTD4 & 0.113 & 0.431 & 0.240 & 0.0198 & 0.201 & 0.663 & 0.182 & 0.0711 \\
\hline DTD5 & 0.112 & 0.396 & 0.234 & 0.0198 & 0.180 & 0.663 & 0.174 & 0.0696 \\
\hline DTD6 & 0.109 & 0.432 & 0.223 & 0.0188 & 0.181 & 0.664 & 0.176 & 0.0704 \\
\hline DTD7 & 0.107 & 0.460 & 0.234 & 0.0191 & 0.172 & 0.667 & 0.183 & 0.0714 \\
\hline DTD8 & 0.099 & 0.510 & 0.221 & 0.0171 & 0.180 & 0.671 & 0.189 & 0.0679 \\
\hline DTD9 & 0.111 & 0.518 & 0.222 & 0.0179 & 0.177 & 0.707 & 0.198 & 0.0749 \\
\hline DTD10 & 0.093 & 0.529 & 0.206 & 0.0185 & 0.160 & 0.680 & 0.173 & 0.0688 \\
\hline mean & 0.106 & 0.452 & 0.226 & 0.0182 & 0.189 & 0.667 & 0.181 & 0.0702 \\
\hline stdev & 0.006 & 0.058 & 0.010 & 0.0017 & 0.031 & 0.022 & 0.010 & 0.0021 \\
\hline \multicolumn{9}{|c|}{ Total } \\
\hline DTD1 & 0.105 & 0.454 & 1.05 & 0.0230 & 0.812 & 0.679 & 0.360 & 0.0721 \\
\hline DTD2 & 0.102 & 0.347 & 1.14 & 0.0241 & 0.992 & 0.627 & 0.356 & 0.0693 \\
\hline DTD3 & 0.110 & 0.461 & 1.09 & 0.0282 & 0.726 & 0.691 & 0.385 & 0.0718 \\
\hline DTD4 & 0.114 & 0.436 & 1.05 & 0.0264 & 0.735 & 0.681 & 0.369 & 0.0725 \\
\hline DTD5 & 0.113 & 0.403 & 1.01 & 0.0271 & 0.680 & 0.682 & 0.347 & 0.0705 \\
\hline DTD6 & 0.112 & 0.438 & 1.07 & 0.0270 & 0.755 & 0.685 & 0.375 & 0.0725 \\
\hline DTD7 & 0.109 & 0.467 & 0.90 & 0.0265 & 0.588 & 0.683 & 0.333 & 0.0731 \\
\hline DTD8 & 0.101 & 0.517 & 0.96 & 0.0246 & 0.674 & 0.688 & 0.366 & 0.0702 \\
\hline DTD9 & 0.138 & 0.534 & 1.00 & 0.0370 & 0.706 & 0.743 & 0.404 & 0.0890 \\
\hline DTD10 & 0.096 & 0.536 & 0.96 & 0.0248 & 0.654 & 0.697 & 0.344 & 0.0709 \\
\hline mean & 0.110 & 0.459 & 1.02 & 0.0269 & 0.732 & 0.686 & 0.364 & 0.0732 \\
\hline stdev & 0.011 & 0.059 & 0.07 & 0.0039 & 0.110 & 0.028 & 0.021 & 0.0057 \\
\hline
\end{tabular}




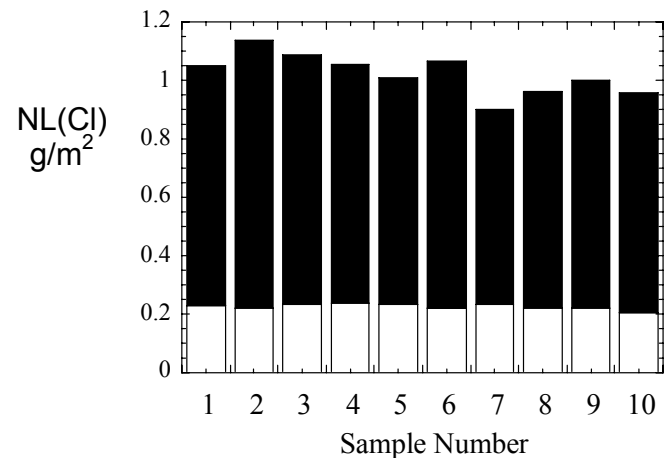

(a)

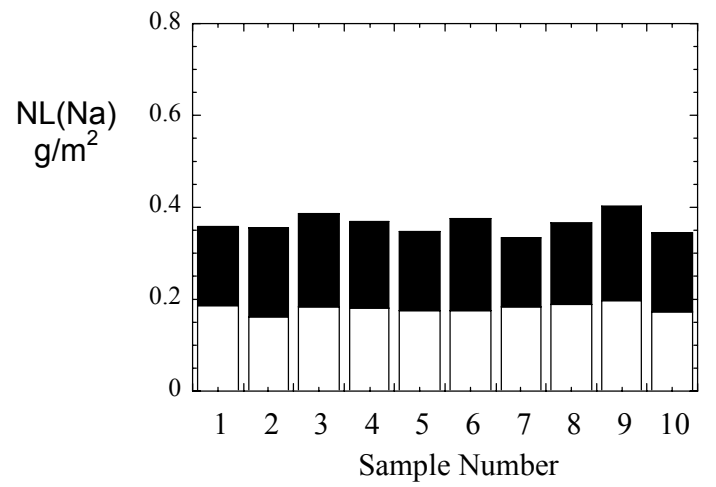

(c)

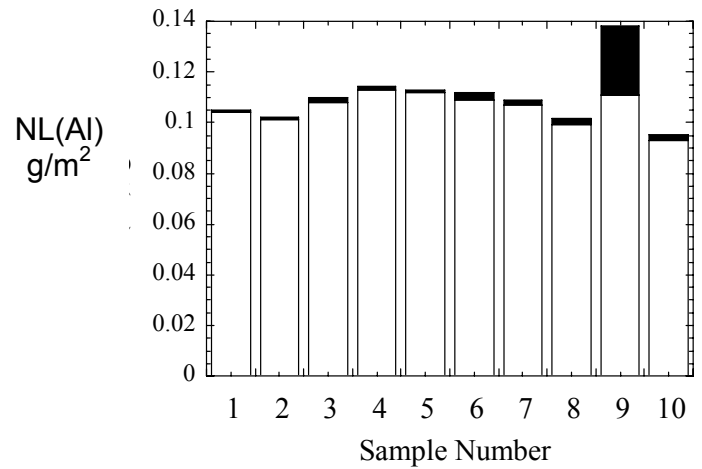

(e)

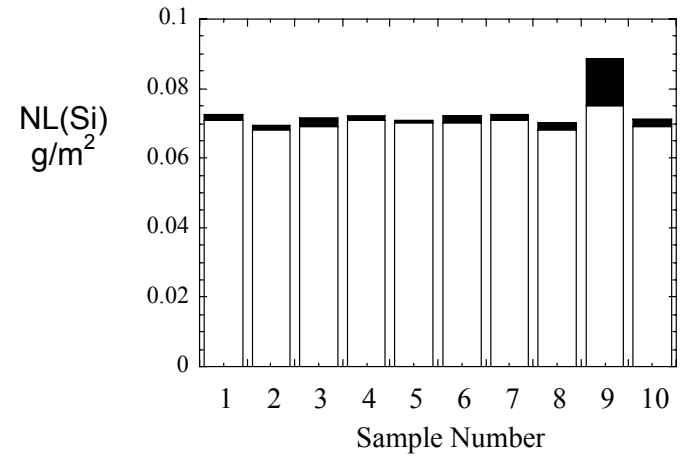

(g)

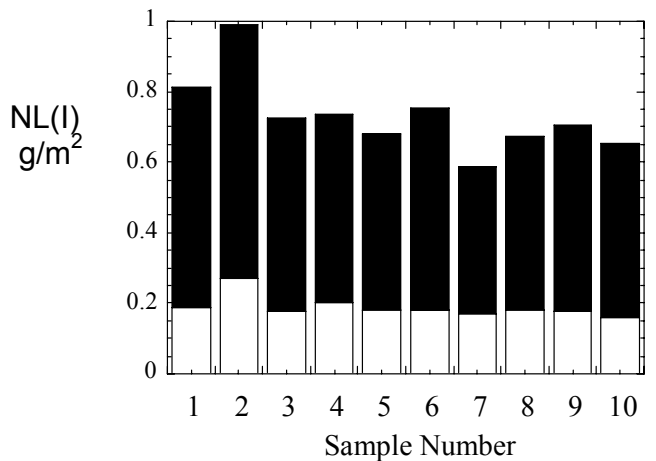

(b)

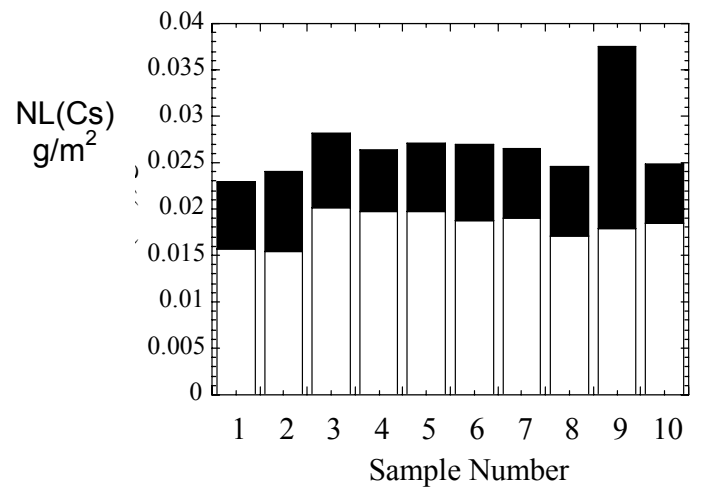

(d)

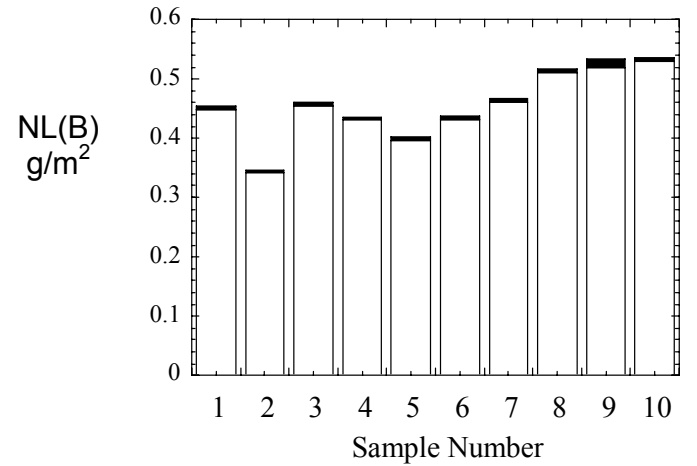

(f)

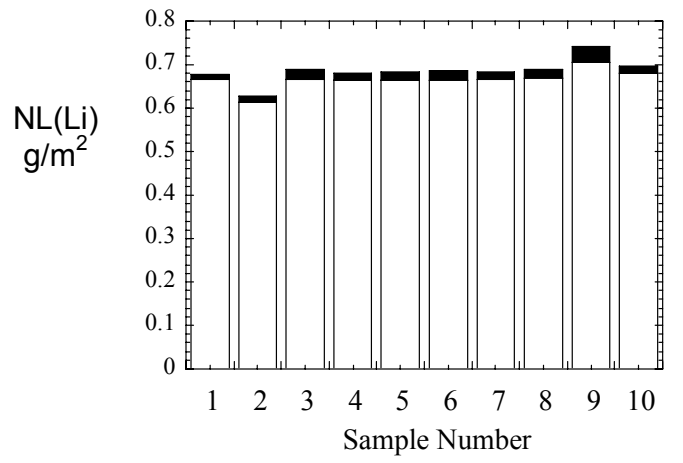

(h)

Fig. IV-45. Results of RWS and PCTs with 10 Replicate CWF Products: (a) NL(Cl), (b) NL(I), (c) $\mathrm{NL}(\mathrm{Na})$, (d) $\mathrm{NL}(\mathrm{Cs})$, (e) NL(Al), (f) NL(B), (g) NL(Si), and (h) $\mathrm{NL}(\mathrm{Li})$. 


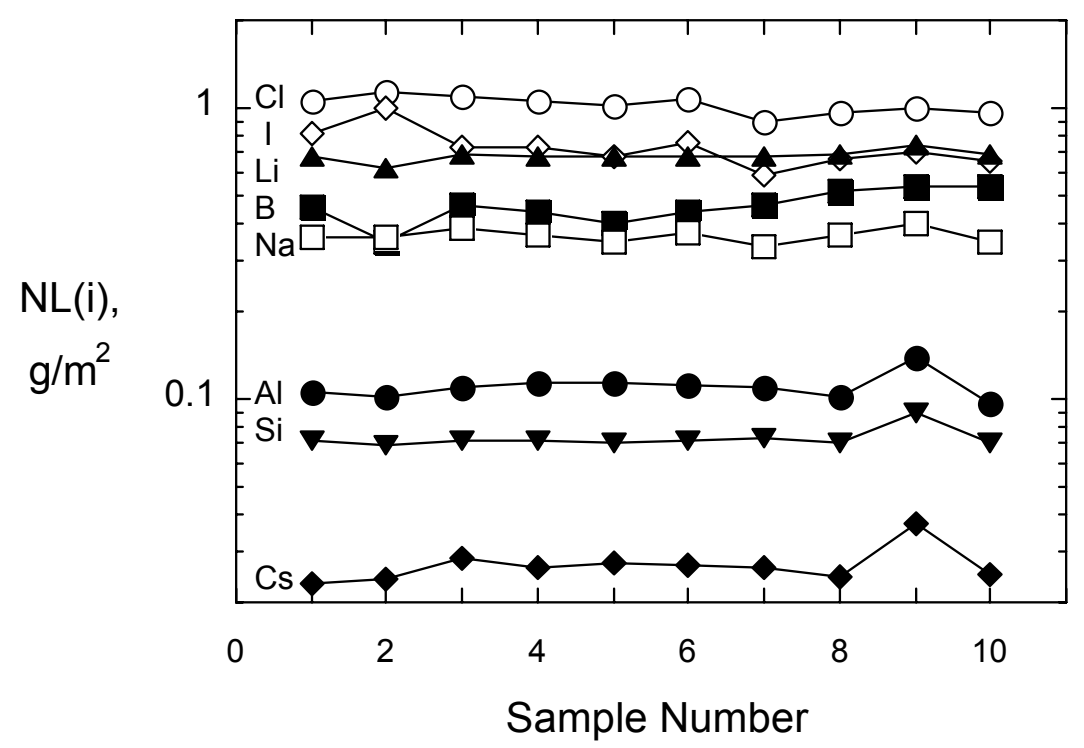

Fig. IV-46. Total NL(i) for Replicate PC CWF Samples Made with $50 \%$ Binder Glass.

triplicate seven-day PCTs at $90 \pm 2{ }^{\circ} \mathrm{C}$. Factors that may contribute to the variability in the test results include the operator, the test equipment that was used, calibration of analytical equipment, and the laboratory environment. The study provided six independent sets of triplicate PCTs, which are summarized in Table IV-21. The agreement in the RWS results is good: the relative standard deviation is about 7\%. (For comparison, the relative standard deviation in the 10 replicate samples discussed in Section IV.D.1.3.1 was 9.2\%.) The measured concentrations of Al, B, Na, and Si are plotted in Fig. IV47. The set of $\mathrm{Al}$ results provided by Participant $\mathrm{G}$ were excluded from the calculations of the test precision as an outlier. The values of the intralaboratory and interlaboratory standard deviations calculated from the data sets are summarized in Table IV-22 along with the values from previous interlaboratory studies conducted with three borosilicate glasses: HLW is a surrogate high-level waste glass, LAW is a reference low-activity waste glass, and ARM-1 is a borosilicate reference glass (not a waste glass). The statistical analyses are summarized in the following equations for the measured values $x_{p}$ provided by $p$ participants for $n$ replicate tests.

The average value measured by each participant $p$ in $n$ replicate tests is

$$
\bar{x}_{p}=\sum x_{p} / n
$$

The standard deviation for the results of replicate tests by participant $p$ is

$$
s_{p}=\left[\left(\sum\left(x_{p}-\bar{x}_{p}\right)^{2}\right) /(n-1)\right]^{1 / 2}
$$

This is a measure of the intralaboratory precision. The consensus average value from the $p$ participants is

$$
\bar{x}=\sum \bar{x}_{P} / p
$$


Table IV-21. Results of PCT Conducted with CWF in Interlaboratory Study

\begin{tabular}{|c|c|c|c|c|c|c|}
\hline & RWS & \multicolumn{5}{|c|}{ PCT } \\
\hline Data Set & {$[\mathrm{Cl}], \mathrm{mg} / \mathrm{L}$} & $\mathrm{pH}$ & {$[\mathrm{A}], \mathrm{mg} / \mathrm{L}$} & {$[\mathrm{B}], \mathrm{mg} / \mathrm{L}$} & {$[\mathrm{Na}], \mathrm{mg} / \mathrm{L}$} & {$[\mathrm{Si}], \mathrm{mg} / \mathrm{L}$} \\
\hline A & 273 & $8.96 \pm 0.02$ & $24.8 \pm 0.4$ & $2.12 \pm 0.04$ & $31.8 \pm 0.6$ & $33.3 \pm 0.6$ \\
\hline B & 235 & $9.21 \pm 0.06$ & $24.5 \pm 1.7$ & $1.81 \pm 0.07$ & $27.6 \pm 1.0$ & $31.9 \pm 1.5$ \\
\hline C & 243 & $8.92 \pm 0.08$ & $23.2 \pm 1.1$ & $1.99 \pm 0.17$ & $32.7 \pm 1.2$ & $32.0 \pm 1.4$ \\
\hline F & 242 & $8.93 \pm 0.06$ & $23.3 \pm 0.6$ & $2.70 \pm 0.10$ & $31.3 \pm 0.6$ & $35.0 \pm 0.0$ \\
\hline G & not reported & not reported & $12 \pm 1$ & $2.4 \pm 0.2$ & $27.3 \pm 7.5$ & $27.7 \pm 0.6$ \\
\hline H & 229 & $9.02 \pm 0.01$ & $25.8 \pm 0.5$ & $2.49 \pm 0.02$ & $30.5 \pm 0.3$ & $35.7 \pm 0.7$ \\
\hline Average & $244 \pm 17$ & $9.01 \pm 0.12$ & $22.2 \pm 5.2$ & $2.25 \pm 0.33$ & $30.2 \pm 2.3$ & $32.6 \pm 2.9$ \\
\hline
\end{tabular}

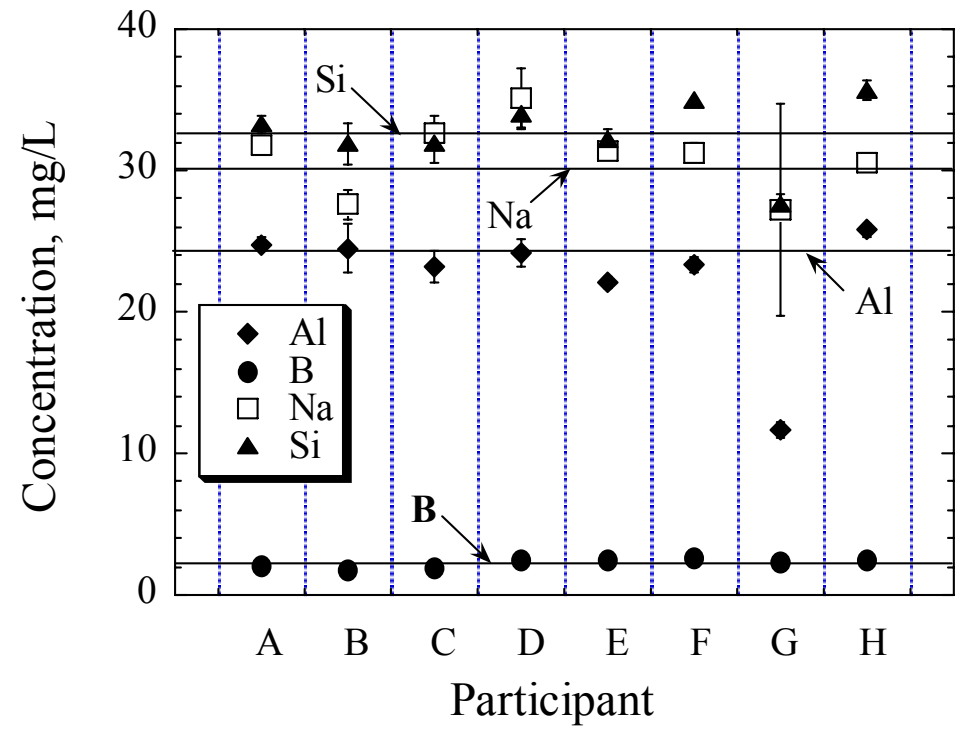

Fig. IV-47. Mean Values of Solution Concentrations Measured in ILS.

Table IV-22. Comparison of Precision of PCT Conducted with CWF and Three Borosilicate Glasses $^{\mathrm{a}}$

\begin{tabular}{|c|c|c|c|c|c|c|}
\hline & \multicolumn{2}{|c|}{ B } & \multicolumn{2}{c|}{$\mathrm{Na}$} & \multicolumn{2}{c|}{$\mathrm{Si}$} \\
\hline Test & $\mathrm{S}_{\mathrm{r}}$ & $\mathrm{S}_{\mathrm{R}}$ & $\mathrm{S}_{\mathrm{r}}$ & $\mathrm{s}_{\mathrm{R}}$ & $\mathrm{s}_{\mathrm{r}}$ & $\mathrm{S}_{\mathrm{R}}$ \\
\hline $\mathrm{CWF}^{\mathrm{d}}$ & 0.1 & 0.4 & 3.2 & 3.4 & 1.0 & 3.0 \\
\hline $\mathrm{HLW}^{\mathrm{C}}$ & 0.3 & 0.6 & 1.0 & 2.6 & 1.1 & 4.4 \\
\hline $\mathrm{LRM}^{\mathrm{d}}$ & 0.6 & 2.5 & 4.1 & 12 & 1.3 & 4.5 \\
\hline $\mathrm{ARM}^{\mathrm{c}}$ & 2.1 & 3.3 & 4.2 & 5.1 & 3.9 & 6.0 \\
\hline
\end{tabular}

${ }^{\mathrm{a}} \mathrm{S}_{\mathrm{r}}$ is intralaboratory standard deviation and $\mathrm{s}_{\mathrm{R}}$ is interlaboratory standard deviation.

${ }^{\mathrm{b}}$ Results from (Ebert et al., 2002a).

${ }^{\mathrm{c}}$ Results from (Smith and Marschman, 1994).

${ }^{\mathrm{d}}$ Results from (Ebert and Wolf, 2000). 
The pooled intralaboratory standard deviation is

$$
s_{r}=\left\lfloor\sum s_{p}^{2} / p\right\rfloor^{1 / 2}
$$

This gives the estimated standard deviation for repeatability of measurements made within a laboratory. The standard deviation of the averages for replicate tests by the same participant from the consensus average is

$$
s_{x}=\left\lfloor\left(\sum\left(\bar{x}_{p}-\bar{x}\right)^{2}\right) /(p-1)\right\rfloor^{1 / 2}
$$

The interlaboratory estimate of precision is

$$
s_{R}=\left(s_{\bar{x}}^{2}+s_{r}^{2}(n-1) / n\right)^{1 / 2}
$$

This is the reproducibility standard deviation. Smaller values of the standard deviation represent higher test precision. These results indicate that the PCT can be conducted as precisely with CWF as with borosilicate glasses.

The intralaboratory consistency can be determined by using the $k$ consistency statistic, which is defined as the standard deviation for a participant divided by the repeatability standard deviation:

$$
k=\frac{s_{p}}{s_{r}}
$$

The $k$-value provides a measure of how the variability within a particular laboratory compares with that of all laboratories combined. The $k$-values for the independent data sets are plotted in Fig. IV-48a (the Al results from Participant $\mathrm{G}$ are excluded). The critical $k$-value of 1.98 indicates the maximum variability expected for random error for six participants conducting triplicate tests. The Na results from Participant $\mathrm{G}$ exceed the critical $k$-value.

The interlaboratory consistency can be determined by using the $h$ consistency statistic, which is defined as the difference between the value measured by the participant and the consensus value, divided by the standard deviation of the averages for all participants:

$$
h=\frac{\left(\bar{x}_{p}-\bar{x}\right)}{s_{\bar{x}}}
$$

The $h$-value is used to evaluate the overall variability of the analyses. The $h$-values for the independent data sets are plotted in Fig. IV-48b (the Al results from Participant G are excluded). The critical $h$-values of \pm 1.92 (at the $0.5 \%$ significance level) indicate the maximum variability expected for random error for six participants conducting triplicate tests. All of the results are within the critical range.

This information provides evidence that the PCT, along with process records, can be used to meet the WASRD requirement for demonstrating consistency of CWF products. 


\section{IV.E.5. Discussion Regarding Use of PCT with CWF}

The two key questions regarding the use of the PCT to monitor the consistency of the CWF are (1) does the test response reflect the consistency of CWF products and that the process has been controlled, and (2) does the test response reflect its chemical durability of CWF products relative to the EA glass? The results provide evidence that the PCT can be used to monitor the consistency of CWF products and that

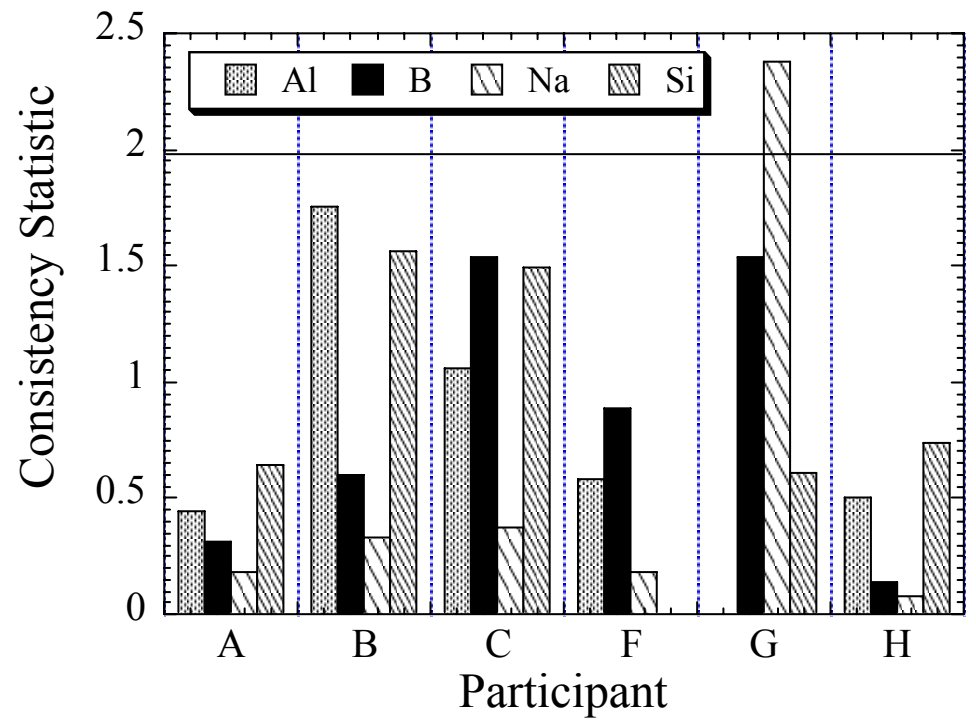

(a)

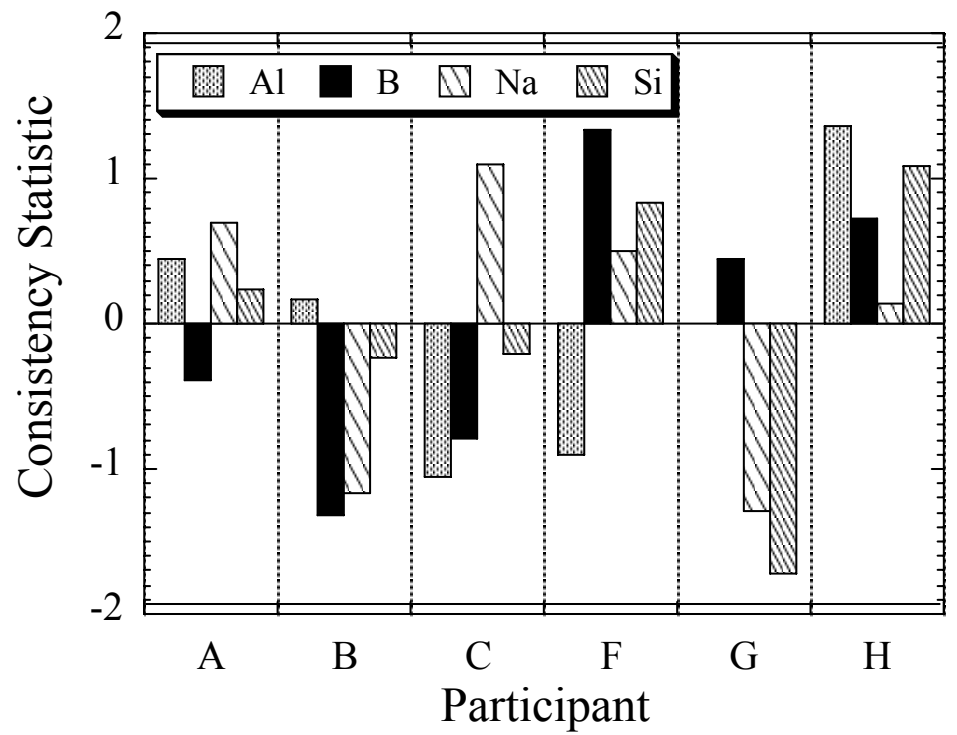

(b)

Fig. IV-48. Plots of (a) $k$-Statistic Values and Critical Value of 1.98 for Comparing Intralaboratory Consistency and (b) $h$-Statistic Values and Critical Values of \pm 1.92 for Comparing Interlaboratory Consistency for Six Participants Conducting Triplicate Tests. (The Al results from Participant $\mathrm{G}$ are excluded). 
CWF is more durable than EA glass under PCT conditions. The adequacy of comparing the PCT response of the multiphase CWF with that of the homogeneous EA glass benchmark response to demonstrate the chemical durability of the CWF merits further discussion.

The multiphase nature of the CWF and the presence of a highly soluble phase (i.e., halite) must be taken into account when using the PCT to monitor CWF consistency and comparing with PCT response of the EA glass. The CWF products will contain about 1.2 mass \% halite inclusions in the binder glass. The amount of halite inclusions in the CWF is important because the halite will contain a trace amount of ${ }^{129} \mathrm{I}$, which must be accounted for in performance calculations. (The CWF is a major contributor to the ${ }^{129} \mathrm{I}$ inventory in HLW to be disposed in Yucca Mountain.) Tests discussed previously indicate that about $12 \%$ of the ${ }^{129}$ I inventory in CWF will be contained in the halite inclusions, with most of the balance being incorporated into sodalite. The steps used to monitor the amount of halite in the CWF (i.e., the RWS step) are already in the PCT procedure. The order of the ethanol and demineralized water wash steps have simply been reversed. The same solid-to-water mass ratio that is used in the PCT (i.e., $10 \mathrm{~g}$ water per $\mathrm{g}$ solid) is used for the water wash to allow the concentrations of sodium and chloride measured in the RWS step to be added directly to their concentrations in the PCT. Negligible amounts of sodalite and binder glass dissolve during the RWS step, although small amounts may be carried over as fines not removed during the ethanol wash step.

Whereas the composition of the RWS solution is dominated by the dissolution of halite, the PCT solution evolves due to the simultaneous dissolution of sodalite and binder glass. While $\mathrm{Al}, \mathrm{Li}, \mathrm{Na}$, and $\mathrm{Si}$ are released as both sodalite and binder glass dissolve, boron is present only in the glass phase. Therefore, the $\mathrm{B}$ concentration reflects the amount of binder glass that dissolves in the test and can be used to confirm the amount of glass binder in the CWF. That is, by assuming that the dissolution rate of the binder glass does not depend on the relative amounts of sodalite and binder glass, the B concentration provides a measure of the absolute amount of binder glass in the CWF sample used in the test. This presumes the ratio of the exposed surface areas of sodalite and binder glass is the same as their mass ratio in the CWF. However, tests with CWF made using different amounts of binder glass indicate that differences in the B concentrations in seven-day PCTs are not sufficient to distinguish additions between 20 and 30 mass \% binder glass, which is the acceptable processing range, but do indicate additions of more than 30 mass \%.

Other tests to measure the dissolution rates and solubilities of sodalite and binder glass indicate that sodalite dissolves faster than the binder glass in dilute solutions, but that sodalite is much less soluble than the binder glass and dissolves much slower than binder glass in concentrated solutions. (The apparent solubility of glass reflects the very slow dissolution kinetics at high dissolved silica concentrations.) The PCT response of the CWF is dominated by dissolution of sodalite initially, but becomes dominated by binder glass dissolution after the sodalite solubility is exceeded (at about $16 \mathrm{mg}$ $\mathrm{Si} / \mathrm{L}$ ). Based on the results of short-term MCC-1 tests, sodalite dissolves at a forward rate of about 1.5 $\mathrm{g} /\left(\mathrm{m}^{2} \mathrm{~d}\right)$. About $0.023 \mathrm{~m}^{2}$ of CWF is exposed in a PCT with $1 \mathrm{~g} \mathrm{CWF}$ reacting in $10 \mathrm{~mL}$ demineralized water, about $71 \%$ of which is sodalite. The time required to release enough Si from sodalite to saturate the $10 \mathrm{~mL}$ of water can be bounded using the forward rate as:

$$
\frac{16 m g S i}{L} \bullet \frac{0.01 L}{1 g C W F} \bullet \frac{m^{2} d}{1.5 g C W F} \bullet \frac{g C W F}{0.023 m^{2}} \bullet \frac{1 g C W F}{0.71 g \text { sodalite }} \bullet \frac{1 g \text { sodalite }}{140 m g \text { Si }} \bullet \frac{24 h}{d}=1.12 h
$$

Dissolution of sodalite will become negligible after about an hour, and the PCT solution will become super-saturated with respect to sodalite as the binder glass continues to dissolve. The cessation of sodalite dissolution will make the $\mathrm{Al}, \mathrm{Na}, \mathrm{Si}$, and $\mathrm{Cl}$ contained in sodalite unavailable. Normalization of the concentrations of these elements in the PCT solution to their mass fractions in the CWF will bias the 
values of $\mathrm{NL}(\mathrm{Al}), \mathrm{NL}(\mathrm{Na}), \mathrm{NL}(\mathrm{Si})$, and $\mathrm{NL}(\mathrm{Cl})$ low. Since B is not present in sodalite, the value of NL(B) will not be affected when sodalite stops dissolving.

Most radionuclides in the CWF are either dissolved in the binder glass or present in inclusion phases in the binder glass. Dissolution of the binder glass must occur before radionuclides can be released from the $\mathrm{CWF}$. The primary role of sodalite in the CWF is to incorporate the $\mathrm{Cl}$ from the waste salt. Therefore, the PCT response of the CWF reflects the durability of the binder glass, and this provides an appropriate measure of the chemical durability of the CWF relevant to repository disposal.

\section{IV.E.6. Comparison of CWF and EA Glass PCT Responses}

The results from the interlaboratory study were used to compare the PCT response of the CWF with that of the EA glass. The measured solution concentration of a component was divided by its mass fraction to calculate the normalized concentration, NC(i); these are listed in Table IV-23. Values of NC(i) calculated for different elements and for different waste form compositions can be compared directly. The differences in NC(i) indicate that neither the CWF nor the EA glass dissolve congruently. The value of NC(i) for each component is significantly lower for PCT with CWF than for PCT with EA glass.

It should be noted that direct comparison of PCT solution results for different materials does not provide an exact comparison of the dissolution rates because different surface areas are exposed in tests conducted on a mass basis. That is, the specific surface area of material in a particular size fraction $\left(\mathrm{in}^{2} / \mathrm{g}\right) \mathrm{will}$ depend on its density. The density of crushed EA glass was measured at ANL by water displacement to be $2.65 \mathrm{~g} / \mathrm{cm}^{3}$ (Ebert et al., 1998), whereas the density of crushed CWF materials are typically about $2.30 \mathrm{~g} / \mathrm{cm}^{3}$ or less. The specific surface area of CWF will be about $2.65 \div 2.30=15 \%$ higher than that of EA glass, and the results of a seven-day PCT with $1 \mathrm{~g} \mathrm{CWF}$ will be biased $15 \%$ high relative to the results of a test with $1 \mathrm{~g}$ EA glass due to differences in the surface areas that are exposed to water. Conversely, PCT with a material that has a higher density than the EA glass will be biased low.

The PCT method is appropriate for monitoring the consistency of the CWF. Crushing and sieving the CWF does not result in the fractionation of the sodalite and binder glass phases. The response of PCT with CWF is repeatable and reproducible, and the precision of PCTs conducted with CWF are essentially the same as that for PCTs with borosilicate waste glasses. The PCT response provides a direct measure of the relative amounts of salt (by the $\mathrm{Cl}^{-}$concentration in the RWS test) and binder glass (by the B concentration), and sodalite (by the relative $\mathrm{B}$ and Si concentrations) in the CWF, and can be used to verify that the appropriate amounts of salt, zeolite, and binder glass were used to process the CWF as a part of process control. Direct comparison of the response of PCT conducted with CWF with the response of PCT conducted with EA glass is appropriate to confirm that the chemical durability of the CWF is sufficient for waste form acceptance. Based on the responses of surrogate CWF, the durability of actual CWF products are likely to meet the acceptance requirement.

Table IV-23. Comparison of NC(i) for PCT with CWF and EA Glass, in $\mathrm{g} / \mathrm{L}$

\begin{tabular}{|c|l|c|}
\hline Parameter & CWF & EA glass \\
\hline $\mathrm{NC}(\mathrm{B})$ & 0.16 & 17 \\
\hline $\mathrm{NC}(\mathrm{Li})$ & 1.4 & 9.6 \\
\hline $\mathrm{NC}(\mathrm{Na})$ & 1.8 & 13 \\
\hline $\mathrm{NC}(\mathrm{Si})$ & 0.16 & 4.0 \\
\hline
\end{tabular}




\section{IV.E.7. PCT with Radioactive CWF Materials}

Most of the tests and analyses conducted to evaluate the applicability of the PCT to CWF were conducted with non-radioactive materials. However, several CWF materials have been made with radioactive salts and subjected to PCTs, and the results of some of these tests have been discussed in previous sections. The results of several seven-day PCTs conducted with radioactive HIP CWF and PC CWF materials are summarized in Table IV-24 and compared with the results of tests with non-radioactive HIP CWF and PC CWF materials. All of the CWF materials were made with the standard amounts of salt, zeolite, and binder glass. The HIP CWF materials were processed at $850^{\circ} \mathrm{C}$ and the PC CWF materials were processed at $915^{\circ} \mathrm{C}$. The presence of radionuclides does not have a significant effect on the test response.

\section{IV.F. Co-Disposal of CWF and MWF Products}

Only a small number of MWF products will be produced and their density will be too high to place only MWF products in a DOE Standardized SNF canister. To efficiently package the waste forms and minimize the number of canisters to be disposed, it is currently planned to place one MWF product between two CWF products in the same canister, using metallic spacers to separate the waste forms. (Most canisters will contain three CWF products and no MWF.) Water that accumulates in a breached waste package could contact both waste forms, and chemical interactions between the waste forms must be considered. The most significant chemical interaction expected to occur is dissolution of halite from the $\mathrm{CWF}$ to generate solutions with high $\mathrm{Cl}^{-}$concentrations that contact the MWF. Experience with stainless steels suggests that high concentrations of dissolved $\mathrm{Cl}^{-}$could accelerate MWF corrosion. Therefore, the potential range of $\mathrm{Cl}^{-}$concentrations in a breached canister containing both $\mathrm{CWF}$ and MWF was evaluated theoretically and experimentally to provide insight for designing tests to study MWF corrosion.

Table IV-24. Results of Seven-Day PCT with Radioactive CWF, NL(i) in g/m²

\begin{tabular}{|c|c|c|c|c|c|c|}
\hline Element & HIP CWF & HIP CWF & HIP CWF & $\begin{array}{c}\text { PC CWF } \\
(\text { PC00202 })^{b}\end{array}$ & $\begin{array}{c}\text { PC CWF } \\
(\mathrm{PC} 0030 \mathrm{~m})^{\mathrm{b}}\end{array}$ & $\begin{array}{c}\text { PC CWF } \\
(\text { Advanced PC) }\end{array}$ \\
\hline $\mathrm{Al}$ & 0.082 & 0.11 & 0.031 & 0.083 & 0.094 & 0.085 \\
\hline$B$ & 0.71 & 0.22 & 0.10 & 0.073 & 0.079 & 0.050 \\
\hline $\mathrm{Ba}$ & 0.058 & 0.029 & & 0.17 & 0.15 & \\
\hline $\mathrm{Ce}$ & 0.018 & 0.022 & & 0.020 & 0.0050 & \\
\hline $\mathrm{Cl}$ & 2.18 & 0.39 & & 3.16 & 3.76 & 2.91 \\
\hline Cs & 0.22 & 0.043 & 1.1 & 0.063 & 0.044 & 0.040 \\
\hline 1 & & 0.34 & 0.61 & 0.24 & 0.28 & \\
\hline $\mathrm{K}$ & 0.14 & 0.080 & 0.16 & 0.076 & 0.055 & \\
\hline $\mathrm{Li}$ & 0.71 & 0.42 & 0.32 & 0.60 & 0.60 & 0.47 \\
\hline $\mathrm{Na}$ & 0.26 & 0.14 & 0.28 & 0.23 & 0.13 & 0.89 \\
\hline $\mathrm{Nd}$ & 0.0077 & 0.020 & 0.0022 & 0.016 & 0.0034 & \\
\hline $\mathrm{Si}$ & 0.068 & 0.10 & & 0.091 & 0.083 & 0.081 \\
\hline $\mathrm{Sr}$ & 0.052 & 0.023 & & 0.031 & 0.0029 & \\
\hline $\mathrm{Pu}$ & 0.013 & 0.014 & & 0.0018 & 0.0012 & \\
\hline$U$ & 0.010 & 0.018 & & 0.0071 & 0.0017 & \\
\hline $\bar{Y}$ & 0.020 & 0.024 & & 0.043 & 0.0039 & \\
\hline
\end{tabular}

${ }^{a}$ Moschetti et al., 2000.

${ }^{\mathrm{b}}$ Results from Morss et al., 2002b, Table 24B.

${ }^{\mathrm{c}}$ Results from Ebert et al., 1999, Appendix C1.

'Results for "Advanced PC CWF" in Lewis et al., 2002, Table 18. 
The minimum volume of water required to contact the MWF was estimated based on the nominal dimensions of a DOE 24S canister with an inner diameter of 22 inches laying horizontally with two CWF products (20-inch outer diameter) and MWF product (16-inch outer diameter) located concentrically with respect to each other and centered in the canister. The volume of water needed to fill the bottom of the canister to a level just contacting the MWF was calculated for two geometric configurations. The first configuration represents a co-disposal canister in which the internal supports remain intact and the CWF and MWF monoliths remain fixed in their original geometry. The second configuration represents a co-disposal canister in which the internal supports have failed and the CWF monoliths rest on the bottom of the canister with the MWF monolith still concentric with the CWF. The configurations are shown schematically in Fig. IV-49. Note that both the CWF and MWF will be placed in steel cans (liners) after manufacture and that these cans will be loaded into the canister; these cans were ignored in the volume calculations. Likewise, the volume at the ends of the canister and the volume occupied by the waste form support structure were ignored. About 13 and $0.9 \mathrm{~L}$ of water, respectively, are required to fill the bottoms of canisters and contact the bottom surface of the MWF in the intact and collapsed geometries.

The amount of halite $(\mathrm{NaCl})$ available at the surface of the CWF products was calculated using the results of RWS tests conducted with crushed CWF. In those tests, various amounts of crushed CWF were contacted by water at a 1:10 CWF-to-water mass ratio and resulted in solution concentrations of about $330 \mathrm{mg} / \mathrm{L} \mathrm{Cl}^{-}$. The specific surface area of the crushed CWF was about $0.023 \mathrm{~m}^{2} / \mathrm{g}$, so about $140 \mathrm{mg} \mathrm{Cl}^{-}$ per $\mathrm{m}^{2}$ of CWF was released as halite dissolved. It is presumed that the surface concentration of halite measured to be released when water contacts the surface of crushed CWF can be scaled to the surface area of a large monolithic waste forms. For example, two 1-m-long CWF waste forms have a combined surface area of about $4 \mathrm{~m}^{2}$. Multiplying the halite surface concentration of $140 \mathrm{mg} / \mathrm{m}^{2}$ by this area indicates that about $560 \mathrm{mg} \mathrm{Cl}^{-}$would be made available. Dissolving this amount of $\mathrm{Cl}^{-}$into 13 and $0.9 \mathrm{~L}$ gives concentrations of 43 and $620 \mathrm{mg} / \mathrm{L}$, respectively. Note that this calculation is extremely conservative in that it is based on the entire surface area of CWF being first contacted by water in the package, and then the water accumulating at the bottom of the package.

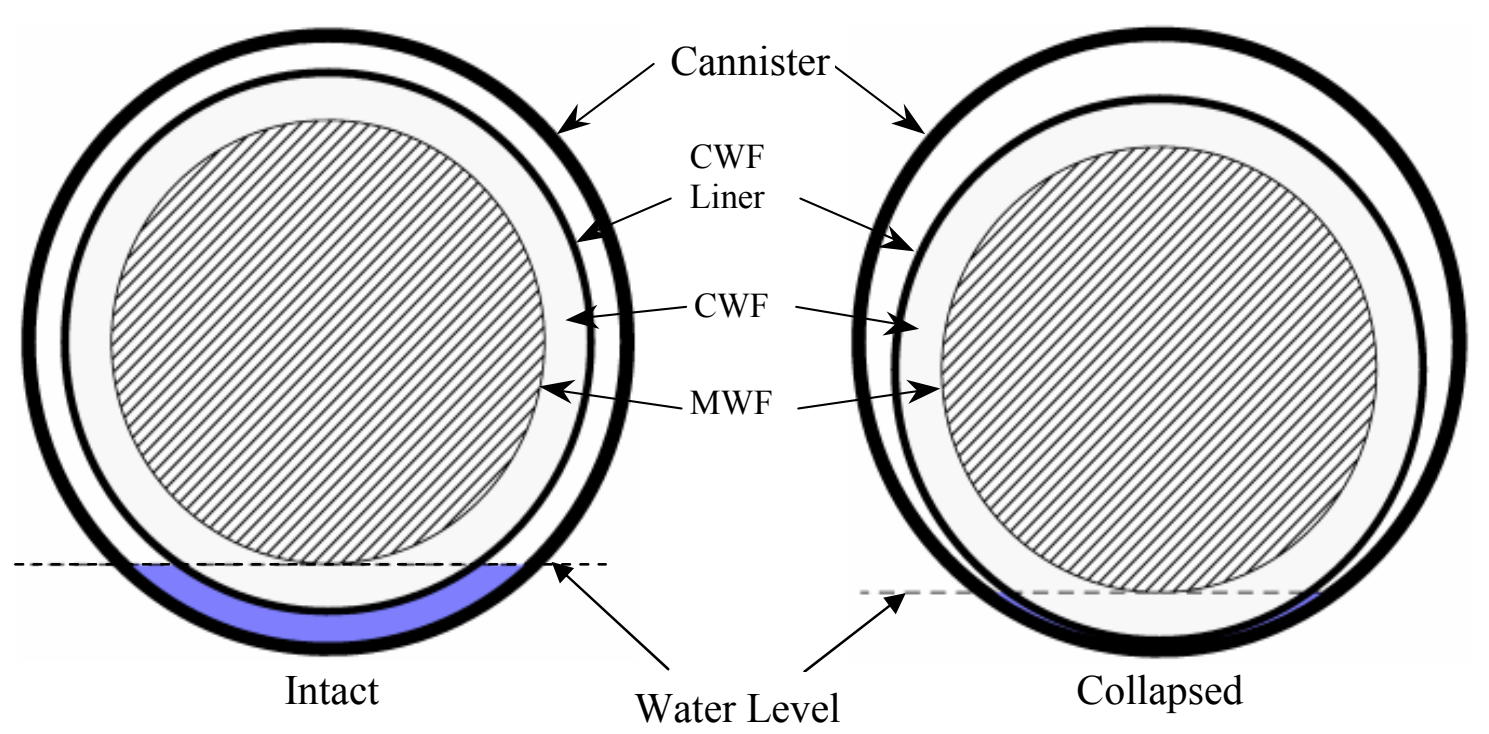

Fig. IV-49. Schematic Cross-Section Geometry of Intact and Collapsed Configurations Canisters. The dashed lines show the levels of water that first contact the MWF. 
Scoping tests were conducted to evaluate scaling the extent of halite dissolution measured in laboratory tests to provide confidence in scaling to full-size waste forms. Tests were conducted in which the CWF surface area was varied and the surface area of MWF and volume of water were kept essentially constant. High S/V ratios were attained using crushed CWF in the same $-100+200$ mesh size fraction that is used in the PCT. Low $\mathrm{S} / \mathrm{V}$ ratios were attained using monolithic CWF products made to appropriate sizes to attain $\mathrm{S} / \mathrm{V}$ ratios between $122 \mathrm{~m}^{-1}$ and $235 \mathrm{~m}^{-1}$. Square coupons were cut from the same $316 \mathrm{SS}-15 \mathrm{Zr}-10 \mathrm{U}$ MWF material used in other tests into samples about $15 \times 15 \times 2 \mathrm{~mm}$. The MWF samples were polished to a final 600-grit finish and cleaned by ultrasonicating first in deionized water and then in ethanol. The coupon dimensions were measured with a caliper and the surface area of each coupon was calculated geometrically. All were about $5.5 \mathrm{~cm}^{2}$.

The test data for these so-called co-disposal tests are given in Table IV-25. The tests with monolithic CWF samples were conducted following the MCC-1 protocol for 14 and 70 days, and tests with crushed CWF were conducted following the PCT protocol for seven days. All tests were conducted in Teflon ${ }^{\circledR}$ vessels at $90^{\circ} \mathrm{C}$ with enough water demineralized water to cover both materials. Teflon spacers were used to separate the MWF and CWF and provide free water flow in both configurations. At the end of the test duration, the test solutions were analyzed for $\mathrm{pH}, \mathrm{Cl}^{-}$concentrations, and cation concentrations.

The measured $\mathrm{pH}$ and $\mathrm{Cl}^{-}$concentrations and the normalized elemental mass losses based on the concentrations of key components are summarized in Table IV-26. Figure IV-50 shows a plot of the measured $\mathrm{Cl}^{-}$concentration vs. the $\mathrm{S} / \mathrm{V}$ ratio (for the $\mathrm{CWF}$ ). The data are consistent with a linear relationship between $\mathrm{Cl}^{-}$concentration and $\mathrm{S} / \mathrm{V}$ ratio and support the expectation that the amount of halite that dissolves when the CWF is first contacted by water is relative to the surface area. For a fixed CWF surface area, the $\mathrm{Cl}^{-}$concentration will be proportional to the volume of water that accumulates. The range of $\mathrm{S} / \mathrm{V}$ ratios expected for a breached canister containing $2 \mathrm{CWF}$ and $1 \mathrm{MWF}$ is $15 \mathrm{~m}^{-1}$ if the void space is completely filled with water, and about $4400 \mathrm{~m}^{-1}$ if the waste forms are covered by a 1- $\mu \mathrm{m}$-thick film of water, which corresponds to about $4.4 \mathrm{~mL}$ of water in the canister. This amount of water is not sufficient to fill the canister to the level needed to contact the MWF, but could contact the MWF by other flow paths. The range is shown by the arrow in Fig. IV-50a. From the line fit to the data, an S/V ratio of $4500 \mathrm{~m}^{-1}$ corresponds to $878 \mathrm{ppm} \mathrm{Cl}^{-}$. A dashed line is drawn in Fig. IV-50a at $1000 \mathrm{mg} / \mathrm{L}$ to show the bounding $\mathrm{Cl}^{-}$concentration that was used in several immersion tests with MWF materials, which bounds the expected range.

Values of NL(B), NL(Na), and NL(Si) provide, respectively, measures of the extents of dissolution of the binder glass, halite + sodalite, and binder glass + sodalite, and NL(U) provides a direct measure of $\mathrm{U}$ release from the MWF. The values of $\mathrm{NL}(\mathrm{B})$ and $\mathrm{NL}(\mathrm{Si})$ decrease as the $\mathrm{S} / \mathrm{V}$ ratio increases because of solution feedback effects that slow glass dissolution. However, $\mathrm{NL}(\mathrm{Na})$ is fairly insensitive to differences

Table IV-25. Test Data for Co-Disposal Tests

\begin{tabular}{|c|c|c|c|c|c|c|c|c|}
\hline \multirow{2}{*}{ Test ID } & \multirow{2}{*}{$\begin{array}{l}\text { Duration } \\
\text { (d) }\end{array}$} & \multicolumn{2}{|c|}{ CWF } & \multicolumn{2}{|c|}{ MWF } & \multirow{2}{*}{$\begin{array}{c}\text { Water } \\
(\mathrm{g})\end{array}$} & \multirow{2}{*}{$\begin{array}{c}\text { CWF } \\
\mathrm{S} / \mathrm{V}\left(\mathrm{m}^{-1}\right)\end{array}$} & \multirow{2}{*}{$\begin{array}{c}\text { MWF } \\
S / V\left(m^{-1}\right)\end{array}$} \\
\hline & & Mass $(\mathrm{g})$ & Area $\left(\mathrm{cm}^{2}\right)$ & Mass $(\mathrm{g})$ & Area $\left(\mathrm{cm}^{2}\right)$ & & & \\
\hline \multicolumn{9}{|c|}{ Tests with monolithic CWF samples } \\
\hline 04031-2 & 14 & 103.59 & 81.54 & 3.47 & 5.58 & 34.76 & 234 & 16.0 \\
\hline 04031-3 & 70 & 103.52 & 80.23 & 3.22 & 5.61 & 36.52 & 220 & 15.2 \\
\hline $04031-5$ & 70 & 27.12 & 38.01 & 3.19 & 5.51 & 31.10 & 122 & 17.9 \\
\hline $04031-6$ & 14 & 27.19 & 37.89 & 3.38 & 5.61 & 30.86 & 123 & 18.0 \\
\hline $\begin{array}{l}04031-7 \\
\end{array}$ & 70 & 27.21 & 36.56 & 2.97 & 5.48 & 26.39 & 138 & 21.1 \\
\hline \multicolumn{9}{|c|}{ Tests with crushed CWF samples } \\
\hline 04031-1000 & 7 & $0.87^{\mathrm{a}}$ & 200 & 3.5 & 5.58 & 20.00 & 1,000 & 27.8 \\
\hline $04031-10000$ & 7 & $6.52^{\mathrm{a}}$ & 1,500 & 3.5 & 5.63 & 15.16 & 10,000 & 36.7 \\
\hline
\end{tabular}


Table IV-26. Results of Co-Disposal Tests

\begin{tabular}{|c|c|c|c|c|c|c|c|c|}
\hline \multirow{2}{*}{ Test ID } & \multirow{2}{*}{$\begin{array}{l}\text { Duration } \\
\text { (d) }\end{array}$} & \multirow{2}{*}{$\begin{array}{c}\text { CWF S/V } \\
\left(\mathrm{m}^{-1}\right)\end{array}$} & \multirow{2}{*}{$\mathrm{pH}$} & \multirow{2}{*}{$\begin{array}{c}\mathrm{Cl}^{-} \\
(\mathrm{mg} / \mathrm{L})\end{array}$} & \multicolumn{4}{|c|}{ NL(i) $\left(\mathrm{g} / \mathrm{m}^{2}\right)$} \\
\hline & & & & & B & $\mathrm{Na}$ & $\mathrm{Si}$ & $\mathrm{U}$ \\
\hline $04031-2$ & 14 & 234 & 6.15 & 90 & 0.66 & 0.52 & 0.24 & 0.0071 \\
\hline 04031-3 & 70 & 220 & 8.19 & 75 & 0.66 & 1.8 & 0.51 & 0.0013 \\
\hline $04031-5$ & 70 & 122 & 8.30 & 9.2 & 1.1 & 3.6 & 0.35 & 0.0062 \\
\hline 04031-6 & 14 & 123 & 8.32 & 6.0 & 2.1 & 0.85 & 1.3 & 0.011 \\
\hline 04031-7 & 70 & 138 & 8.32 & 5.5 & 2.9 & 0.79 & 1.2 & 0.016 \\
\hline $04031-1000^{\mathrm{a}}$ & 7 & 1,000 & 8.80 & 198 & 0.26 & 1.0 & 0.080 & 0.0085 \\
\hline $04031-10000^{\mathrm{a}}$ & 7 & 10,000 & 9.27 & 1,945 & 0.055 & 0.94 & 0.0086 & 0.0028 \\
\hline
\end{tabular}

${ }^{\mathrm{a}}$ Test conducted with crushed CWF.

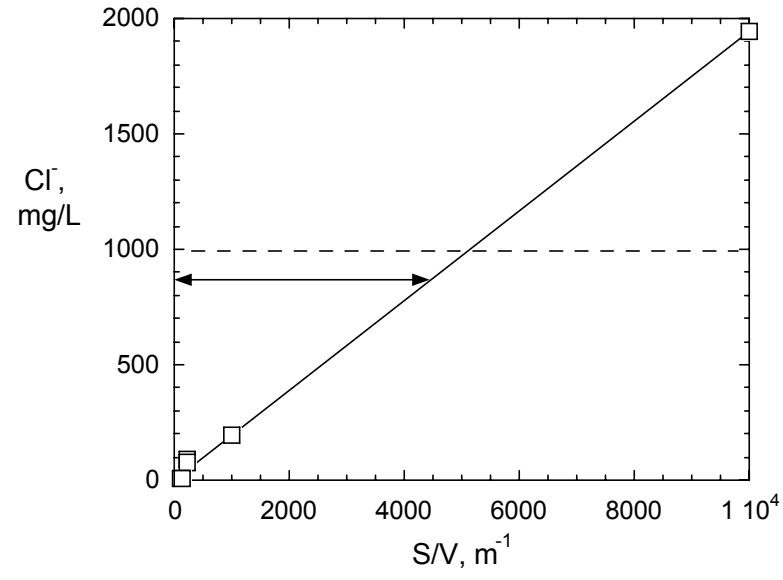

(a)

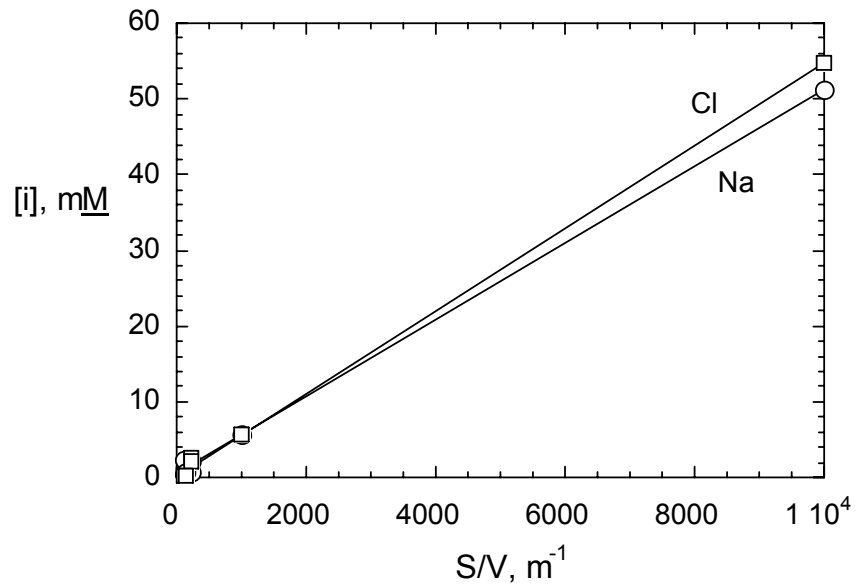

(b)

Fig. IV-50. (a) $\mathrm{Cl}^{-}$Concentration and (b) Molar Concentrations of $\mathrm{Cl}^{-}$and $\mathrm{Na} v \mathrm{vs}$ S/V Ratio Used in CoDisposal Tests (arrow shows range of $\mathrm{S} / \mathrm{V}$ ratios expected in a breached waste container).

in the $\mathrm{S} / \mathrm{V}$ ratio because most of the $\mathrm{Na}$ is released by dissolution of halite. This is because the $\mathrm{Na}$ concentration is normalized to the $\mathrm{S} / \mathrm{V}$ ratio in the calculation of $\mathrm{NL}(\mathrm{Na})$, and the $\mathrm{Na}$ concentration is linear with the S/V ratio. Figure IV-50b shows the molar concentrations of $\mathrm{Na}$ and $\mathrm{Cl}$ measured in the codisposal tests are equal within the testing uncertainty. Their congruent release indicates that the compositions of the test solutions were dominated by the dissolution of halite $(\mathrm{NaCl})$. The releases of $U$ from the MWF are not sensitive to the $\mathrm{Cl}^{-}$concentrations under these test conditions.

\section{IV.G. Effects of Processing Conditions on PC CWF}

Several tests were conducted with PC CWF materials made with different mass ratios of SLZ and binder glass, at different temperatures, and for different hold times. In one study, a suite of $36 \mathrm{PC} \mathrm{CWF} \mathrm{materials}$ was made with 75 mass $\%$ SLZ and 25 mass \% binder glass at temperatures $850^{\circ} \mathrm{C}, 875^{\circ} \mathrm{C}, 900^{\circ} \mathrm{C}$, $915^{\circ} \mathrm{C}, 925^{\circ} \mathrm{C}$, and $950^{\circ} \mathrm{C}$ for processing times of $1.4,8,16,25$, and 36 hours at-temperature (Lewis et al., 2002). The bulk densities and phase compositions of the materials were measured, and samples were subjected to seven-day PCTs. The results are summarized in Table IV-27. The bulk density increases with the processing time at all temperatures and with the processing temperature except at $950^{\circ} \mathrm{C}$. This is due to a reduction in the porosity during processing, except the binder glass and sodalite separate as the CWF is processed at $950^{\circ} \mathrm{C}$. Small amounts of nepheline are only detected after short processing times. Halite 
Table IV-27. Results of Tests with PC CWF Made under Different Processing Conditions

\begin{tabular}{|c|c|c|c|c|c|c|c|}
\hline \multirow{2}{*}{ Material ID } & \multirow{2}{*}{ Time $(\mathrm{h})$} & \multirow{2}{*}{$\begin{array}{l}\text { Bulk Density } \\
\qquad\left(\mathrm{kg} / \mathrm{m}^{3}\right)\end{array}$} & \multirow{2}{*}{$\begin{array}{c}\text { Phase } \\
\text { Composition }^{\mathrm{a}}\end{array}$} & \multirow{2}{*}{$\mathrm{Cl}$ in RWS } & \multicolumn{3}{|c|}{$\mathrm{NL}(\mathrm{i})\left(\mathrm{g} / \mathrm{m}^{2}\right)$} \\
\hline & & & & & $\mathrm{NL}(\mathrm{Cl})$ & $\mathrm{NL}(\mathrm{B})$ & $\mathrm{NL}(\mathrm{Si})$ \\
\hline \multicolumn{8}{|c|}{$850^{\circ} \mathrm{C}$} \\
\hline NLS-2 & 1 & 1,160 & $\mathrm{~S}, \mathrm{H}, \mathrm{N}$ & $0.14 \%$ & 0.306 & 1.43 & 0.109 \\
\hline NLS-15 & 4 & 1,320 & $\mathrm{~S}, \mathrm{H}, \mathrm{N}$ & $1.03 \%$ & 0.639 & 0.145 & 0.0940 \\
\hline NLS-17 & 8 & 1,490 & $\mathrm{~S}, \mathrm{H}$ & $2.40 \%$ & 1.23 & 0.0657 & 0.0857 \\
\hline NLS-26 & 16 & 1,580 & $\mathrm{~S}, \mathrm{H}$ & $3.21 \%$ & 1.63 & 0.0353 & 0.0930 \\
\hline NLS-24 & 24 & 1,640 & $\mathrm{~S}, \mathrm{H}$ & $3.64 \%$ & 1.81 & 0.0296 & 0.0912 \\
\hline NLS-27 & 36 & 1,650 & $\mathrm{~S}, \mathrm{H}$ & $3.52 \%$ & 1.77 & 0.0317 & 0.0911 \\
\hline \multicolumn{8}{|c|}{$875^{\circ} \mathrm{C}$} \\
\hline NLS-3 & 1 & 1,260 & $\mathrm{~S}, \mathrm{H}, \mathrm{N}$ & $0.32 \%$ & 0.339 & 0.467 & 0.0912 \\
\hline NLS-14 & 4 & 1,480 & $\mathrm{~S}, \mathrm{H}, \mathrm{N}$ & $2.48 \%$ & 1.33 & 0.0958 & 0.0872 \\
\hline NLS-19 & 8 & 1,630 & $\mathrm{~S}, \mathrm{H}, \mathrm{N}$ & $3.99 \%$ & 2.12 & 0.0409 & 0.0808 \\
\hline NLS-28 & 16 & 1,700 & $\mathrm{~S}, \mathrm{H}$ & $5.09 \%$ & 2.33 & 0.0330 & 0.0789 \\
\hline NLS-33 & 24 & 1,780 & $\mathrm{~S}, \mathrm{H}$ & $4.91 \%$ & 2.31 & 0.0326 & 0.0847 \\
\hline NLS-23 & 36 & 1,840 & $\mathrm{~S}, \mathrm{H}$ & $3.88 \%$ & 1.92 & 0.0208 & 0.0937 \\
\hline \multicolumn{8}{|c|}{$900^{\circ} \mathrm{C}$} \\
\hline NLS-4 & 1 & 1,340 & $\mathrm{~S}, \mathrm{H}, \mathrm{N}$ & $1.35 \%$ & 0.769 & 0.184 & 0.0898 \\
\hline NLS-10 & 4 & 1,620 & $\mathrm{~S}, \mathrm{H}$ & $5.07 \%$ & 2.55 & 0.0510 & 0.0853 \\
\hline NLS-20 & 8 & 1,780 & $\mathrm{~S}, \mathrm{H}$ & $6.51 \%$ & 3.31 & 0.0463 & 0.0824 \\
\hline NLS-29 & 16 & 1,810 & $\mathrm{~S}, \mathrm{H}$ & $6.06 \%$ & 2.84 & 0.0348 & 0.0991 \\
\hline NLS-34 & 24 & 1,930 & $\mathrm{~S}, \mathrm{H}$ & $6.15 \%$ & 2.86 & 0.0308 & 0.0847 \\
\hline NLS-18 & 36 & 1,970 & $\mathrm{~S}, \mathrm{H}$ & $5.50 \%$ & 2.71 & 0.0445 & 0.0873 \\
\hline \multicolumn{8}{|c|}{$915^{\circ} \mathrm{C}$} \\
\hline NLS-1 & 1 & 1,480 & $\mathrm{~S}, \mathrm{H}$ & $2.46 \%$ & 1.28 & 0.132 & 0.0790 \\
\hline NLS-13 & 4 & 1,710 & $\mathrm{~S}, \mathrm{H}$ & $6.49 \%$ & 3.17 & 0.0828 & 0.0795 \\
\hline NLS-21 & 8 & 1,890 & $\mathrm{~S}, \mathrm{H}$ & $6.18 \%$ & 3.21 & 0.0431 & 0.0793 \\
\hline NLS-8 & 16 & 1,950 & $\mathrm{~S}, \mathrm{H}$ & $6.07 \%$ & 2.96 & 0.0640 & 0.0855 \\
\hline NLS-36 & 24 & 2,000 & $\mathrm{~S}, \mathrm{H}$ & $6.74 \%$ & 3.15 & 0.0332 & 0.0884 \\
\hline NLS-16 & 36 & 2,010 & $\mathrm{~S}, \mathrm{H}$ & $8.21 \%$ & 3.85 & 0.0492 & 0.0827 \\
\hline \multicolumn{8}{|c|}{$925^{\circ} \mathrm{C}$} \\
\hline NLS-5 & 1 & 1,490 & $\mathrm{~S}, \mathrm{H}, \mathrm{N}$ & $2.88 \%$ & 1.54 & 0.106 & 0.0791 \\
\hline NLS-12 & 4 & 1,830 & $\mathrm{~S}, \mathrm{H}, \mathrm{N}$ & $6.55 \%$ & 3.43 & 0.0859 & 0.0668 \\
\hline NLS-22 & 8 & 1,950 & $\mathrm{~S}, \mathrm{H}$ & $7.68 \%$ & 3.70 & 0.0327 & 0.0840 \\
\hline NLS-30 & 16 & 1,970 & $\mathrm{~S}, \mathrm{H}$ & $7.35 \%$ & 3.50 & 0.0454 & 0.0890 \\
\hline NLS-35 & 24 & 2,010 & $\mathrm{~S}, \mathrm{H}$ & $9.00 \%$ & 4.18 & 0.0338 & 0.0892 \\
\hline NLS-11 & 36 & 1,990 & $\mathrm{~S}, \mathrm{H}$ & $7.90 \%$ & 4.14 & 0.0534 & 0.0728 \\
\hline \multicolumn{8}{|c|}{$950^{\circ} \mathrm{C}$} \\
\hline NLS-7 & 1 & 1,670 & $\mathrm{~S}, \mathrm{H}$ & $5.51 \%$ & 2.93 & 0.0761 & 0.0645 \\
\hline NLS-9R & 4 & 2,010 & $\mathrm{~S}, \mathrm{H}, \mathrm{N}$ & $9.78 \%$ & 4.64 & 0.0533 & 0.0789 \\
\hline NLS-25 & 8 & 2,020 & $\mathrm{~S}, \mathrm{H}, \mathrm{N}$ & $11.30 \%$ & 5.32 & 0.0355 & 0.0863 \\
\hline NLS-31 & 16 & 1,970 & $\mathrm{~S}, \mathrm{H}$ & $10.60 \%$ & 5.00 & 0.0461 & 0.0840 \\
\hline NLS-32 & 24 & 1,930 & $\mathrm{~S}, \mathrm{H}$ & $12.89 \%$ & 6.03 & 0.0467 & 0.0822 \\
\hline NLS-6 & 36 & 1,910 & $\mathrm{~S}, \mathrm{H}$ & $9.20 \%$ & 4.57 & 0.0630 & 0.0691 \\
\hline
\end{tabular}

${ }^{\mathrm{a}} \mathrm{S}=$ sodalite, $\mathrm{H}=$ halite, $\mathrm{N}=$ nepheline. 
was detected in all samples. The $\mathrm{Cl}$ release in the RWS step is expressed as the mass percent of the sample used in the test. The PCT results were calculated from the sum of masses released in the RWS and PCT steps. Figures IV-51a and IV-51b show plots of NL(Cl) and NL(B) vs. the processing temperature for PC CWF materials made with different processing times. The values of NL(Cl) are dominated by the RWS contributions and assumed to be proportional to the halite contents. The halite content increases with both the processing temperature and the processing time. However, the values of NL(B) are not sensitive to the processing conditions except for materials processed for one (not shown) and four hours. The processing of the CWF does not significantly affect the durability of the binder glass, and the differences in NL(B) seen in these tests probably reflect changes in the surface area of binder glass as the crushed glass used to make the CWF are sintered and melted. That is, the differences in NL(B) are probably due to a decrease in the surface area of binder glass exposed in the test rather than changes in the durability.

\section{IV.H. Deliquescence of Dissolved CWF}

Isopiestic tests were conducted to measure the amounts of water vapor that accumulate in solutions with fixed amounts of dissolved CWF components when they are exposed to humid air at various relative humidities. These tests were conducted to measure the importance of deliquescence by waste form solutions in unsaturated environments. As mentioned earlier, the initial dissolution of halite at the CWF surface will result in the generation of $\mathrm{NaCl}$-dominated solutions, whereas dissolution of the binder glass will result in the release of alkali metals by ion exchange and the generation of hydroxide solutions. These tests were conducted to determine if the impact of deliquescence-driven water accumulation due to CWF corrosion is significantly different that due to HLW glass corrosion, which will also occur due to hydroxide solutions.

Insight into the relative deliquescent strengths is provided by the vapor pressures of saturated $\mathrm{NaOH}$ and $\mathrm{NaCl}$ solutions. At $50^{\circ} \mathrm{C}$, the equilibrium relative humidity of a saturated $\mathrm{NaOH}$ solution is about $5 \%$ and that of a saturated $\mathrm{NaCl}$ solution is about $74 \%$. The saturation concentrations are about $87 \mathrm{M} \mathrm{NaOH}$ and $6.7 \underline{\mathrm{M} \mathrm{NaCl}}$ at $100^{\circ} \mathrm{C}$. The saturation concentration is $6.14 \underline{\mathrm{M} \mathrm{NaCl}}$ at $25^{\circ} \mathrm{C}$. The hydroxide solutions are much more deliquescent, but much more HLW or binder glass must dissolve to generate saturated solutions.

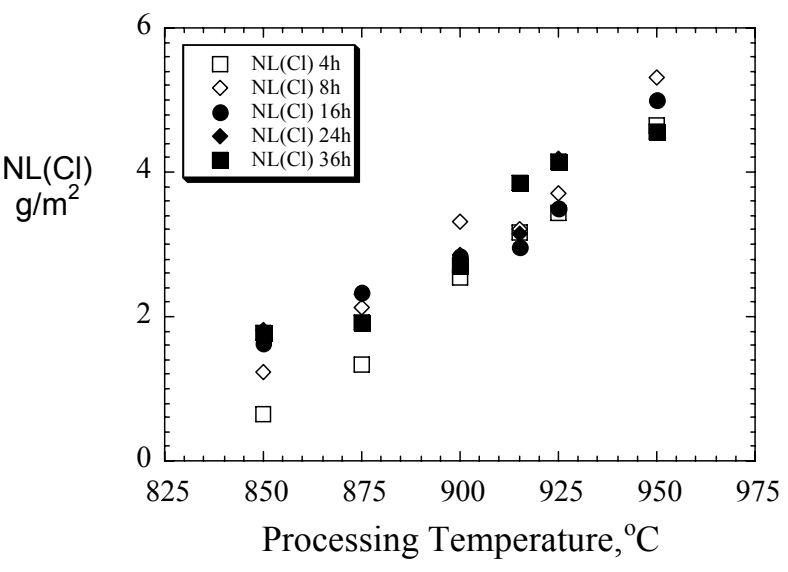

(a)

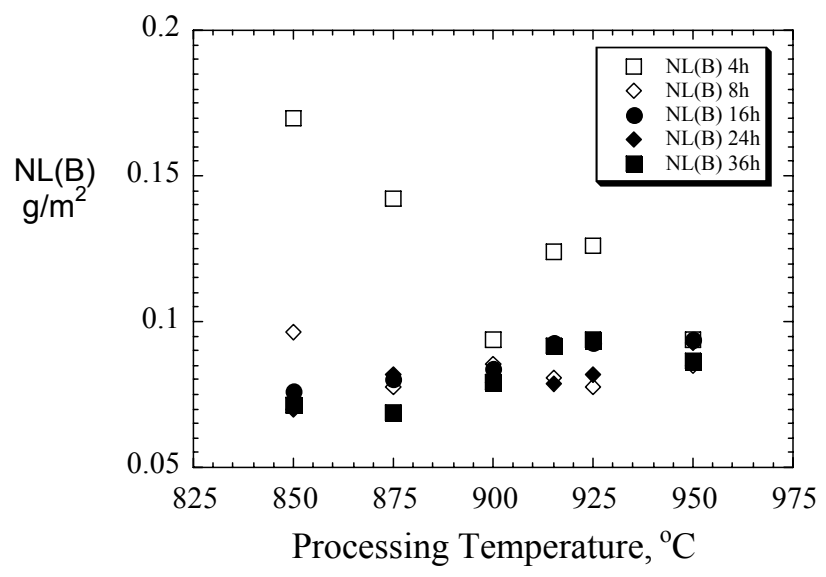

(b)

Fig. IV-51. Effect of Processing Conditions on (a) NL(Cl) and (b) NL(B). 
Samples were generated for use in isopiestic tests by evaporating the test solutions generated in seven-day PCTs with a reference CWF material (Test CWF2), with CWF that had been pre-washed with water to remove exposed halite (Test CWF1), and with the EA glass (Test EA6). Tests were conducted with prewashed CWF to measure the water uptake properties relevant to long disposal times after halite exposed at the surface has been washed away. The compositions of the PCT solutions and the RWS solution are given in Table IV-28. Several aliquots of each PCT solution were evaporated to dryness in individual sample cups to track the effects of the amount of residuals solids, which are referred to as PCT salts, on the uptake of water vapor.

Several saturated salt solutions were used to fix the relative humidities in the isopiestic tests (Greenspan, 1977). Cups with the PCT salts were placed in a test container with a saturated salt solution and the container was sealed. The total masses of the cups were tracked until a nearly constant mass was attained for each sample. The increase in mass relative to the initial mass of the dry salts was used to calculate the mass of water that was taken up. The masses of water taken up were normalized to the mass of PCT salt in the sample cup, and the ratios plotted against the relative humidity in Fig. VI-52. The scatter in the mass ratios among parallel tests conducted with different amounts of the same PCT salt represents the experimental uncertainty combined with any effects of the mass of salt, such as a reduced uptake because not all the salt was dissolved. The dependence of the mass ratio on the relative humidity was fit using a general isotherm equation developed for cooperative multilayer adsorption (Halsey, 1948). Even though the data base above about $94 \% \mathrm{RH}$ is too sparse to fit reliably, the empirical fits are good at low and moderate RH values, even though the physical mechanisms are different - uptake by deliquescent salt solutions is driven by solute-solvent interactions, whereas adsorption is driven by interactions with the surface.

These results show that water vapor will be taken up by solutions generated during CWF degradation regardless of whether the solution compositions are dominated by dissolution of halite or by the dissolution of binder glass and sodalite. The uptakes by CWF solutions were greater than that measured for solutions of dissolved EA glass. This is probably due to a greater mass of non-deliquescent salt released as EA glass degraded, and by scaling the water uptake to the total mass of dissolved solids. The absolute amount of water vapor taken up by the EA glass solutions was much greater than that taken up by the CWF solutions. That is, the total amount of water vapor that is taken up as a waste form dissolves depends on the waste form dissolution rate as well as the water uptake capacity of the solution that is generated. The isopiestic test results provide some insight regarding how representative the solutions generated in seven-day PCTs represent the solutions likely to be generated under disposal conditions. Table IV-29 presents concentration factors for the solutions that were generated under exposures at different relative humidities relative to the concentrations in the starting seven-day PCT solutions. These were calculated based on the masses of PCT solution that were evaporated initially to isolate the salts and the masses of water vapor that were taken up during the tests. The concentration factors range from about 20 to 2,000 for the CWF and EA glass, and to about 50,000 for the pre-washed CWF over the range of $75-95 \% \mathrm{RH}$ likely to occur in the repository over long disposal times. This means the dissolution rates calculated with the defense HLW glass degradation model, which are based on rates measured in seven-day PCT, are highly conservative, since the glass dissolution rate decreases with increasing $\mathrm{Si}$ concentrations. The concentration factors for the tests with CWF and pre-washed CWF are higher than those for the EA glass. This means more water vapor will be taken up as HLW glasses dissolve than as CWF dissolves. 
Table IV-28. Compositions of PCT Solutions

\begin{tabular}{|l|c|c|c|c|c|c|c|c|c|c|}
\hline \multirow{2}{*}{ Test } & \multirow{2}{*}{$\mathrm{pH}$} & \multicolumn{9}{|c|}{ Concentration $(\mathrm{mg} / \mathrm{L})$} \\
\cline { 3 - 11 } & & $\mathrm{Al}$ & $\mathrm{B}$ & $\mathrm{Cl}^{\mathrm{a}}$ & $\mathrm{K}$ & $\mathrm{Li}$ & $\mathrm{Na}$ & $\mathrm{Si}$ & $\mathrm{OH}^{\mathrm{b}}$ & TDS $^{\mathrm{c}}$ \\
\hline EA6 & 11.0 & 2.8 & 337 & & & 124 & 959 & 605 & 4,091 & 6.130 \\
\hline CWF1 & 8.54 & 23 & 2.3 & & 2.5 & 4.7 & 35.2 & 32.7 & 174 & 275 \\
\hline RWS 1 & & 0.18 & 0.16 & 387 & 1.29 & 0.426 & 251 & 0.19 & 3.25 & 257 \\
\hline CWF2 & 8.55 & 15 & 2.6 & 286 & 4.44 & 5.5 & 186 & 22.6 & 112 & 634 \\
\hline
\end{tabular}

${ }^{\mathrm{a}} \mathrm{Cl}$ content calculated assuming dissolution of $\mathrm{NaCl}$.

${ }^{\mathrm{b}} \mathrm{OH}$ content calculated assuming dissolution of $\mathrm{Al}(\mathrm{OH})_{3}, \mathrm{~B}(\mathrm{OH})_{3}, \mathrm{KOH}, \mathrm{LiOH}$, and $\mathrm{Si}(\mathrm{OH})_{4}$.

${ }^{\mathrm{c}}$ Total dissolved solids (TDS) calculated as sum of cations, $\mathrm{Cl}$, and $\mathrm{OH}$.

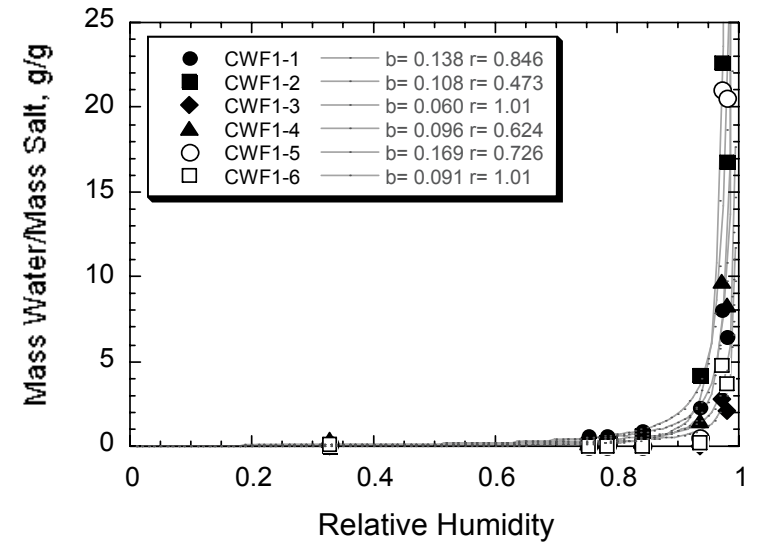

(a)

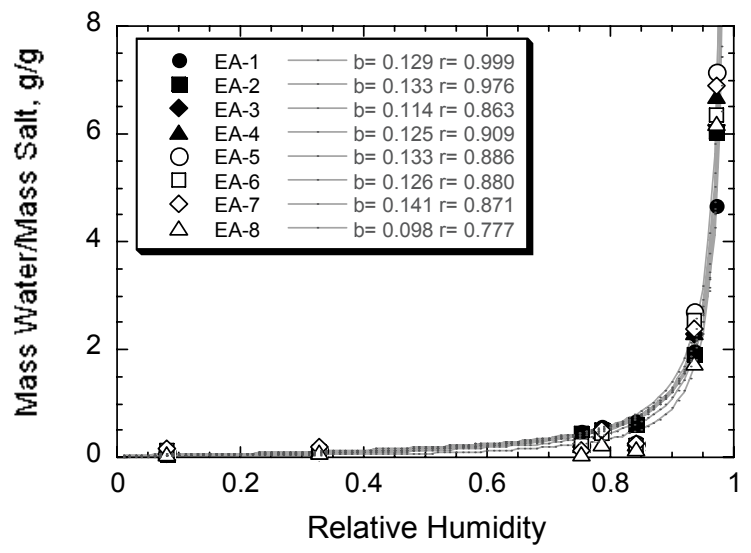

(c)

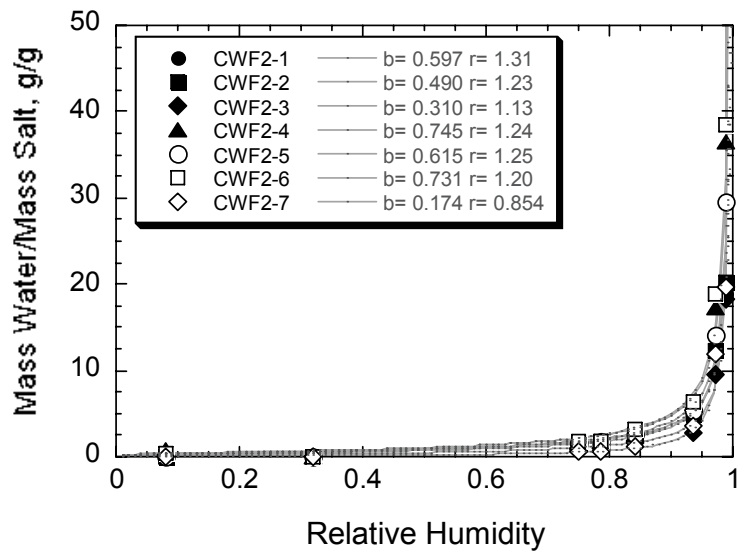

(b)

Fig. IV-52. Water Uptake Isotherms for PCT Salts from (a) CWF1, (b) Test CWF2, and (c) Test EA6. 
Table IV-29. Concentration Factors for Solutions in Isopiestic Tests Relative to the Initial PCT Solutions

\begin{tabular}{|c|c|c|c|c|c|c|c|c|c|c|}
\hline \multirow{2}{*}{$\begin{array}{c}\text { Test } \\
\text { Number }\end{array}$} & \multicolumn{10}{|c|}{ Relative Humidity (\%) } \\
\hline & 8.2 & 32.8 & 75.3 & 78.5 & 84.3 & 93.6 & 97.3 & 98 & 99 & 100 \\
\hline CWF1-1 & & 83,424 & 7,081 & 6,952 & 4,248 & 1,699 & 490 & 612 & & 121 \\
\hline CWF1-2 & & & 49,020 & 19,608 & 6,536 & 934 & 174 & 233 & & 49 \\
\hline CWF1-3 & & & & & & & 1,426 & 1,845 & & 413 \\
\hline CWF1-4 & & 10,860 & 19,608 & 11,765 & 11,765 & 2,614 & 402 & 471 & & 223 \\
\hline CWF1-5 & & 47,058 & & & & 7,843 & 187 & 191 & & 69 \\
\hline CWF1-6 & & 29,413 & & & & 19,608 & 817 & 1,060 & & 123 \\
\hline CWF2-1 & & & 938 & 862 & 598 & 316 & 132 & & 89 & 44 \\
\hline CWF2-2 & & & 1,041 & 981 & 660 & 332 & 136 & & 83 & 46 \\
\hline CWF2-3 & 13,400 & & 1,748 & 1,748 & 1,005 & 609 & 175 & & 92 & 52 \\
\hline CWF2-4 & 2,303 & & 1,084 & 1,152 & 635 & 275 & 97 & & 46 & 30 \\
\hline CWF2-5 & 48,576 & & 991 & 1,034 & 656 & 317 & 119 & & 57 & 42 \\
\hline CWF2-6 & 3,685 & & 921 & 970 & 542 & 260 & 89 & & 44 & 25 \\
\hline CWF2-7 & & & 2,848 & 2,848 & 1,424 & 475 & 140 & & 85 & 57 \\
\hline EA6-1 & 2,715 & 1,991 & 351 & 312 & 256 & 89 & 37 & & & 21 \\
\hline EA6-2 & 2,654 & 1,801 & 379 & 331 & 288 & 90 & 29 & & & 19 \\
\hline EA6-3 & 2,739 & 2,054 & 850 & 340 & 770 & 76 & 28 & & & 15 \\
\hline EA6-4 & 1,797 & 1,389 & 826 & 364 & 664 & 75 & 26 & & & 12 \\
\hline EA6-5 & 1,705 & 1,318 & 784 & 358 & 690 & 64 & 24 & & & 9 \\
\hline EA6-6 & 1,295 & 1,726 & 840 & 384 & 777 & 69 & 27 & & & 9 \\
\hline EA6-7 & 1,027 & 880 & 1,298 & 342 & 632 & 73 & 25 & & & 8 \\
\hline EA6-8 & 2,068 & 2,068 & 2,068 & 689 & 1,197 & 99 & 28 & & & 10 \\
\hline
\end{tabular}




\section{THE METALLIC WASTE FORM}

The MWF was developed to immobilize metallic waste streams generated during the EMT of spent sodium-bonded nuclear fuel (McDeavitt et al. 1996a, 1996b; McDeavitt et al. 1997). The waste streams will be composed primarily of irradiated stainless steel cladding hulls plus residual zirconium from driver fuel rods cladding hulls. The MWF was developed to immobilize the metallic waste streams. Stainless steel cladding will account for more than $90 \%$ of the metal waste stream generated from the EBR-II inventory. Zirconium will be added to the waste stream to form the Laves intermetallic $\mathrm{Zr}(\mathrm{Fe}, \mathrm{Cr}, \mathrm{Ni})_{2+\mathrm{x}}$ phase, and depleted $U$ will be added to lower the enrichment. The mixture will be cast as an ingot. The amounts of $\mathrm{Zr}$ and $\mathrm{U}$ added to the waste will be controlled to produce waste forms with consistent compositions, phase assemblages, and microstructures. An alloy with 15 mass \% $\mathrm{Zr}$ and 10 mass \% U was selected as the target for the MWF, with control limits of 5-20 mass \% $\mathrm{Zr}$ and $0-11$ mass \% U. To a first approximation, the MWF has a eutectic microstructure consisting of similar volume fractions of intermetallic and iron solid solution phases. Most of the intermetallics have a composition of approximately $\mathrm{Zr}(\mathrm{Fe}, \mathrm{Cr}, \mathrm{Ni})_{2+\mathrm{x}}$, and are commonly referred to as "Laves" intermetallics. At least three distinct crystal structures $(\mathrm{C} 14, \mathrm{C} 15$, and $\mathrm{C} 36)$ have been reported for the Laves intermetallics; Fe23Zr6-type intermetallics have also been observed. The iron solid solution phases include materials with ferritic and austenitic structures. Actinides reside almost entirely in the intermetallic phases, whereas noble metal fission products are present in both. A large amount of data has been generated during the development, testing, and modeling of the MWF and published in internal and open literature reports and papers. Selected references are cited in this report, and many others are listed in Appendix B with brief annotations regarding the content of the report or paper.

\section{V.A. Composition and Microstructure of the MWF}

\section{V.A.1. Host Phases}

Laboratory-scale samples of alloy compositions having $\mathrm{Zr}$ contents from 0 to $90 \%$ were generated and tested to select the optimum alloy composition and processing temperature for MWF production (Abraham et al. 1996a, 1996b; Abraham et al., 1997a, 1997b; McDeavitt et al., 1997; McDeavitt et al., 1998). The composition and microstructure of the MWF are affected primarily by the relative amounts of stainless steel fuel cladding and $\mathrm{Zr}$ from the driver fuel in the mixture used to make it. The cladding will account for about 98 mass \% of the metal waste stream inventory. The blanket fuel cladding is Type 304L stainless steel and the driver fuel claddings include Type 316, Type D9, and Type HT9 stainless steel. The cladding supplies $\mathrm{Fe}, \mathrm{Cr}, \mathrm{Ni}, \mathrm{Mo}, \mathrm{Mn}, \mathrm{Co}, \mathrm{Cu}, \mathrm{V}$, and $\mathrm{Si}$ to the metal waste stream, plus trace amounts of $\mathrm{Sn}, \mathrm{C}$, and S. Corrosion of the furnace and crucible during processing will contribute small amounts of these and other elements.

The main phases observed in the various MWF alloys are ferritc $(\alpha-\mathrm{Fe})$ and austenitic $(\gamma-\mathrm{Fe})$ iron solid solution phases ,the $\mathrm{C} 15$ and $\mathrm{C} 36$ structural polytypes of the $\mathrm{Zr}(\mathrm{Fe}, \mathrm{Cr}, \mathrm{Ni})_{2+x}$-type Laves intermetallics, and small amounts of the $\mathrm{Fe}_{23} \mathrm{Zr}_{6}$-type intermetallic (Abraham et al., 1996a; Abraham et al., 1997a). Other polytypes of the $\mathrm{Zr}(\mathrm{Fe}, \mathrm{Cr}, \mathrm{Ni})_{2+x}$-type intermetallics have also been reported, but are less common (Keiser et al., 2000a). The $\mathrm{Zr}(\mathrm{Fe}, \mathrm{Cr}, \mathrm{Ni})_{2+\mathrm{x}}$ intermetallic phase is the primary host for actinides in the MWF. A eutectic microstructure is observed for MWF ingots with 5-20 wt \% Zr regardless of the cladding material. For this range of $\mathrm{Zr}$ contents, immobilization of different cladding only affects the concentrations of $\mathrm{Cr}, \mathrm{Ni}$, and $\mathrm{Fe}$ present in the various phases, not the phases that are present. The absence of $\mathrm{Zr}$ results in a complex mixture of stainless steel phases and phases that are rich in noble metals. The relative amount of $\mathrm{Zr}(\mathrm{Fe}, \mathrm{Cr}, \mathrm{Ni})_{2+\mathrm{x}}$ in the MWF increases with increasing $\mathrm{Zr}$ content up to about 42 mass \%, at which concentration only the intermetallic phase is present. An alloy with 15 mass \% $\mathrm{Zr}$ was selected as the target MWF composition, with control limits of 5-20 mass \% Zr. This range was 
selected to ensure that all MWF products will have the same phase assemblage and generally consistent microstructures. The lower bound of the $\mathrm{Zr}$ range ( 5 mass \%) provides slightly more $\mathrm{Zr}$ than will be needed to sequester all noble metal fission products. The upper bound to the $\mathrm{Zr}$ range (20 mass \%) ensures that MWF products will contain enough of the stainless steel phase for adequate physical integrity. The addition of $\mathrm{Zr}$ to maintain a consistent microstructure and phase assemblage will simplify meeting the WASRD requirement that the phases present in all waste form products be identified (DOE, 2002, Section 5.4.1). Although this requirement was written for HLW glass, it will likely also apply to heterogeneous waste forms such as the MWF.

Some metallic wastes will need to be down-blended with depleted U to meet criticality limits. The control limits on the concentrations ranges are $0-11$ mass \% total U, with target concentrations of 10 mass $\%$. The upper limit is based on the criticality limit, which requires that the ${ }^{235} \mathrm{U}$ enrichment in the MWF be less than $20 \%$. The amounts of $\mathrm{U}$ and $\mathrm{Zr}$ to be added will be determined from analyses of the waste streams. It is anticipated that the mixtures of driver fuel cladding and blanket fuel cladding will be adjusted to optimize the $U$ content of the mixture to be immobilized. Driver fuel is a $U-10 \% \mathrm{Zr}$ alloy and its cladding will retain residual $\mathrm{Zr}$ after electrorefining. Blanket fuel is essentially metallic $\mathrm{U}$ and its cladding will contribute negligible $\mathrm{Zr}$. Both driver fuel cladding and blanket fuel cladding will entrain residual $\mathrm{U}$.

A SEM photomicrograph of an SS-15Zr material is shown in Fig. V-1a. The material has nearly equal amounts of the stainless steel phase (dark regions) and the intermetallic phase (light regions). Materials made with between 5 and 20 mass $\% \mathrm{Zr}$ will have proportionally more or less of the stainless steel phase, respectively (Abraham et al., 1999). Uranium will be the most abundant radionuclide present in the MWF. Visibly brighter regions of the intermetallic phase that correspond to areas in which $U$ and other actinide elements are more concentrated are observed with backscattered electron imaging in the SEM. This can be seen in Fig. V-1b, where the distribution of $U$ (and other radionuclides) in a MWF ingot containing about 9 mass \% $\mathrm{U}$ is not uniform within the intermetallic phase on a millimeter scale (Janney and Keiser, 2003). The homogeneity of the MWF is discussed further with regard to product consistency in Section V.D. The compositions of ingots cast from actual irradiated cladding are given in Table V-1 as examples of typical waste forms. Ingots CFMW05, CFMW06, and CFMW07 were cast with driver fuel cladding, and ingot CFMW08 was cast from blanket cladding. The values in the table represent the averages of replicate analyses (four samples of CFMW08 and six samples each of CFMW05, CFMW06, and CFMW07). The totals differ significantly from $100 \%$ due primarily to uncertainty in the measurement of Fe.

The compositions of the major phases formed in several MWF materials are given in Table V-2, as measured with energy-dispersive X-ray emission spectroscopy in a scanning electron microscope (Abraham et al., 1999). Neutron diffraction analysis of the SS-15Zr5-5U material indicated it was composed of 45 volume \% ferrite, 5 volume \% austenite, 34 volume \% U-Laves (21 volume \% Laves C15 and 13 volume \% Laves C36), and 17 volume \% $\mathrm{Fe}_{23} \mathrm{Zr}_{6}$-type intermetallic.

\section{V.A.2. Radionuclide Inventory and Distribution}

As discussed in Section III.A.3, the TSPA calculations will not distinguish between either the radionuclide inventories or compositions of the various HLW waste forms. A range of HLW glass compositions will be made at DOE facilities at the WVDP, the DWPF, and the Hanford Waste Treatment and Immobilization Plant (WTP). High-level wastes at the INL may also be vitrified. Variations in the tank waste compositions will result in glasses with different matrix compositions and different inventories being produced at these different facilities. An average radionuclide inventory will be assumed for all HLW waste forms (BSC, 2003). The same inventory identified in the Final Environmental Impact 


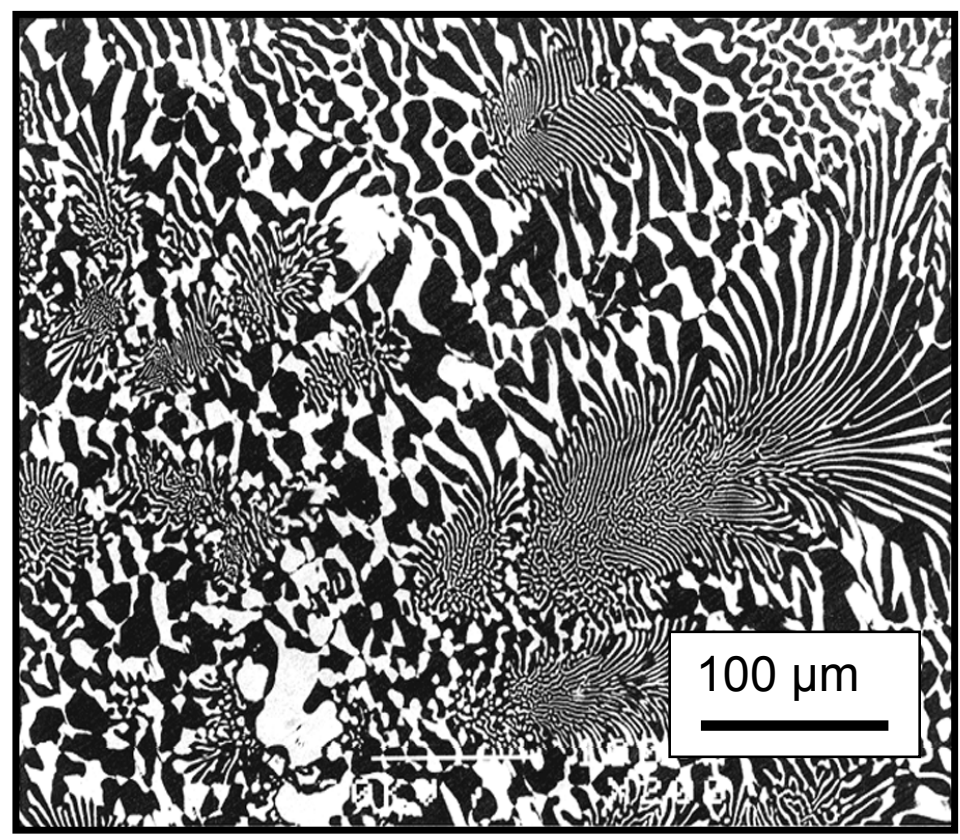

(a)

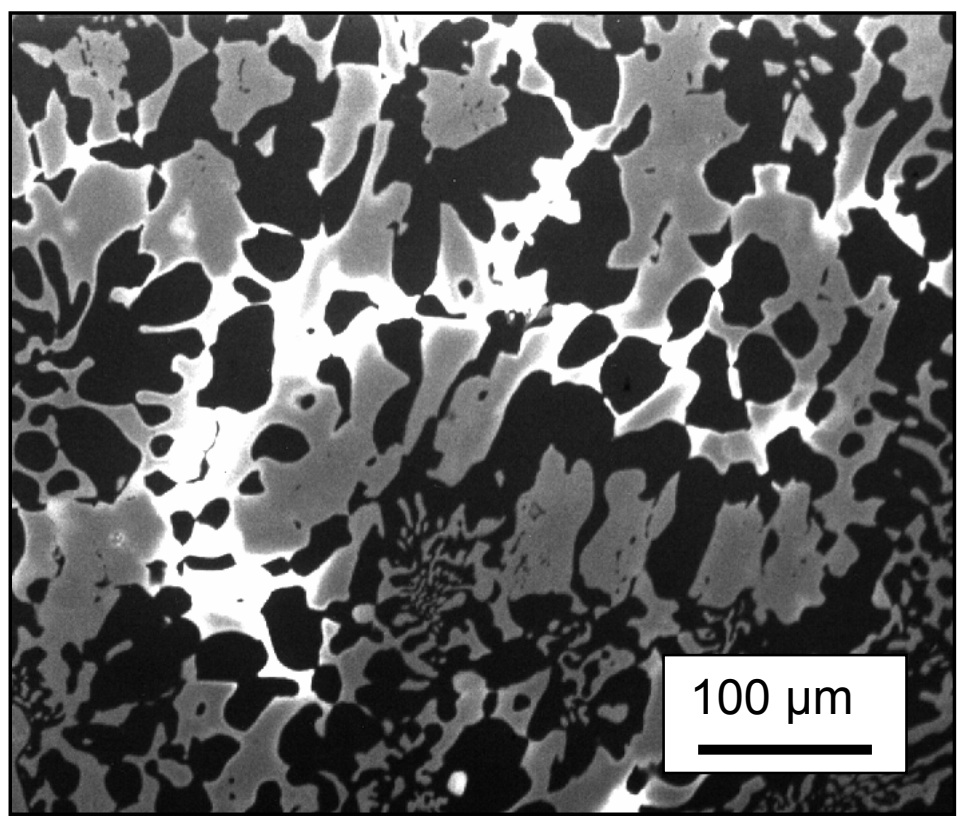

(b)

Fig. V-1. (a) Microstructure of SS-15Zr MWF Containing about 50 Volume \% Stainless Steel (dark regions) and $50 \%$ Intermetallic Phase (light regions) and (b) Regions in Intermetallic Enriched in U. 
Table V-1. Results for Chemical Analyses of Core-Drilled Samples ${ }^{\mathrm{a}}$

\begin{tabular}{|c|c|c|c|c|c|}
\hline \multirow{2}{*}{ Analyte } & \multirow{2}{*}{ Units } & \multicolumn{3}{|c|}{ MWF Made with Driver Fuel Cladding } & \multirow{2}{*}{$\begin{array}{c}\text { MWF Made with } \\
\begin{array}{c}\text { Blanket Fuel } \\
\text { Cladding }\end{array} \\
\text { CFMW08 }\end{array}$} \\
\hline & & CFMW05 & CFMW06 & CFMW07 & \\
\hline $\mathrm{Cd}$ & $\mathrm{ppm}$ & 110 & $\mathrm{bdl}^{\mathrm{b}}$ & 18 & bdl \\
\hline${ }^{144} \mathrm{Ce}$ & $\mathrm{ppb}$ & 8.5 & ND & 5.2 & bdl \\
\hline${ }^{57} \mathrm{Co}$ & $\mathrm{ppb}$ & bdl & bdl & bdl & bdl \\
\hline${ }^{60} \mathrm{Co}$ & $\mathrm{ppb}$ & 383 & 191 & 457 & 2851.4 \\
\hline $\mathrm{Cr}$ & $\%$ & 11.57 & 13.72 & 11.61 & 16.1 \\
\hline${ }^{137} \mathrm{Cs}$ & $\mathrm{ppb}$ & 1425 & 44 & $\mathrm{bdl}$ & $\mathrm{bdl}$ \\
\hline $\mathrm{Fe}$ & $\%$ & 45.00 & 61.88 & 57.34 & 61.3 \\
\hline $\mathrm{Mn}$ & $\%$ & 1.05 & 1.69 & 1.75 & 1.2 \\
\hline${ }^{54} \mathrm{Mn}$ & $\mathrm{ppb}$ & 228 & 8.2 & 154 & 4.0 \\
\hline Mo & $\%$ & 1.54 & 2.39 & 2.57 & 0.18 \\
\hline${ }^{95} \mathrm{Nb}$ & $\mathrm{ppb}$ & bdl & $\mathrm{bdl}$ & bdl & bdl \\
\hline $\mathrm{Ni}$ & $\%$ & 7.48 & 11.73 & 13.21 & 8.6 \\
\hline${ }^{237} \mathrm{~Np}$ & $\mathrm{ppm}$ & 499 & 9 & 10 & 9 \\
\hline $\mathrm{Pd}$ & $\%$ & 0.08 & 0.11 & 0.12 & bdl \\
\hline Total Pu & ppm & 32 & 7 & 4 & 82 \\
\hline${ }^{106} \mathrm{Ru}$ & $\mathrm{ppb}$ & 3123 & 420 & 2999 & 26.1 \\
\hline $\mathrm{Ru}$ & $\%$ & 0.17 & 0.66 & 0.62 & bdl \\
\hline${ }^{125} \mathrm{Sb}$ & $\mathrm{ppb}$ & 3212 & 2356 & 5600 & 31.1 \\
\hline Tc & $\%$ & 0.11 & 0.32 & 0.31 & bdl \\
\hline Total U & $\%$ & 9.34 & 2.36 & 0.93 & 4.96 \\
\hline${ }^{234} U$ & $\%$ & 0.061 & 0.016 & 0.005 & 0.0025 \\
\hline${ }^{235} \mathrm{U}$ & $\%$ & 5.42 & 1.44 & 0.44 & 0.23 \\
\hline${ }^{236} \mathrm{U}$ & $\%$ & 0.20 & 0.050 & 0.014 & 0.0079 \\
\hline${ }^{238} \mathrm{U}$ & $\%$ & 3.66 & 0.85 & 0.47 & 4.72 \\
\hline$Y$ & ppm & 23 & 4 & 68 & 45 \\
\hline $\mathrm{Zr}$ & $\%$ & 14.13 & 10.60 & 16.41 & 13.5 \\
\hline Total $^{\mathrm{C}}$ & $\%$ & 90.5382 & 105.4623 & 104.8809 & 105.8539 \\
\hline
\end{tabular}

${ }^{a}$ Compositions are averages of replicate samples.

b "bdl" means Not Detected (below detection limits).

${ }^{\mathrm{c}}$ Other elements looked for but not detected include $\mathrm{Li}, \mathrm{K}, \mathrm{Na}, \mathrm{Nd}, \mathrm{Ce},{ }^{95} \mathrm{Zr},{ }_{134 \mathrm{Cs}}{ }^{154} \mathrm{Eu}$, ${ }^{106} \mathrm{Rh},{ }^{155} \mathrm{Eu}$, and ${ }^{182} \mathrm{Ta}$. 
Table V-2. Compositions of Phases in U-Bearing MWF Materials, as Atomic \% ${ }^{\mathrm{a}, \mathrm{b}}$

\begin{tabular}{|c|c|c|c|c|c|c|c|c|c|c|c|c|c|}
\hline Phase & $\mathrm{Fe}$ & $\mathrm{Cr}$ & $\mathrm{Ni}$ & $\mathrm{Zr}$ & $\mathrm{Mn}$ & Mo & $\mathrm{Nb}$ & $\mathrm{Pd}$ & $\mathrm{Rh}$ & $\mathrm{Ru}$ & Tc & $U$ & S \\
\hline \multicolumn{14}{|c|}{ SS-15Zr-0.1Pd-0.6Ru-0.3Tc-11U } \\
\hline Ferrite & 65.9 & 26.8 & 3.1 & $<$ & 1.6 & 1 & NA & $<$ & NA & $<$ & 0.3 & $<$ & $<$ \\
\hline$F e_{2} Z r$-type & 53.3 & 6.5 & 12.1 & 21.9 & 1.5 & 0.5 & NA & $<$ & NA & $<$ & $<$ & 2.7 & $<$ \\
\hline \begin{tabular}{|l|} 
U-rich Laves \\
\end{tabular} & 49.3 & 3.1 & 18 & 8 & 1 & 0.5 & NA & $<$ & NA & $<$ & $<$ & 19.3 & $<$ \\
\hline $\mathrm{Fe}_{23} \mathrm{Zr}_{6}$-type & 58.1 & 11 & 9.5 & 17.2 & 1.1 & 1.2 & NA & $<$ & NA & $<$ & $<$ & 1.7 & $<$ \\
\hline$U-S^{c}$ & 6 & 2.8 & $<$ & 4.2 & $<$ & $<$ & NA & $<$ & NA & $<$ & 1.2 & 46.3 & 28.2 \\
\hline Zr-rich ${ }^{\mathrm{d}}$ & 1.2 & 0.2 & 0.8 & 97.2 & $<$ & $<$ & NA & $<$ & NA & $<$ & $<$ & 0.6 & $<$ \\
\hline \multicolumn{14}{|c|}{ SS-15Zr-5U } \\
\hline Ferrite & 67.5 & 23.2 & 5 & $<^{a}$ & 2.6 & 1.1 & $N A^{b}$ & NA & NA & $\mathrm{NA}$ & NA & 1.5 & $<$ \\
\hline $\mathrm{Fe}_{2} \mathrm{Zr}$-type & 49.1 & 6 & 18 & 20.6 & 2.5 & 0.9 & NA & NA & NA & $\mathrm{NA}$ & NA & 17.2 & $<$ \\
\hline U-rich Laves & 44.9 & 3.3 & 25.7 & 7.6 & 1.4 & $<$ & NA & NA & NA & NA & NA & $<$ & $<$ \\
\hline \multicolumn{14}{|c|}{ SS-15Zr-1Nb-1Pd-1Rh-1Tc-2U } \\
\hline Ferrite & 67.6 & 22.3 & 3.5 & $<$ & 1.7 & 1.3 & $<$ & 0.5 & 1.6 & 0.7 & 1.4 & $<$ & $<$ \\
\hline $\mathrm{Fe}_{2} \mathrm{Zr}$-type & 46.5 & 4.1 & 17.9 & 19.1 & 1.6 & 3.9 & 1 & 2.9 & 2 & 1.2 & $<$ & 3 & $<$ \\
\hline U-rich Laves & 43.2 & 3.3 & 22.5 & 10.9 & 1 & 0.3 & 0.9 & 2.1 & 1 & 0.6 & 0.6 & 12.2 & $<$ \\
\hline $\mathrm{Fe}_{23} \mathrm{Zr}_{6}$-type & 55.6 & 8.6 & 13.5 & 18.2 & 0.8 & 0.9 & $<$ & 0.7 & $<$ & 0.5 & $<$ & 1 & $<$ \\
\hline U-S & 6.6 & $<$ & $<$ & 4.9 & $<$ & $<$ & $<$ & $<<$ & $<$ & $<$ & $<$ & 51.9 & 34.6 \\
\hline Zr-S & 1.6 & $<$ & $<$ & 77.4 & $<$ & $<$ & $<$ & $<$ & $<$ & $<$ & $<$ & $<$ & 21 \\
\hline \multicolumn{14}{|c|}{ CFMW06 } \\
\hline Ferrite $^{e}$ & 66.6 & 25.1 & 3.9 & $<$ & 1.5 & 2.1 & $<$ & $<$ & $<$ & $<$ & $<$ & $<$ & $<$ \\
\hline Austenite $^{\dagger}$ & 70.7 & 17.3 & 8.3 & $<$ & 1.9 & 1.1 & $<$ & $<$ & $<$ & $<$ & $<$ & $<$ & $<$ \\
\hline $\mathrm{Fe}_{2} \mathrm{Zr}$-type ${ }^{\mathrm{g}}$ & 45.4 & 5.4 & 20.7 & 22.2 & 1.8 & 0.7 & $<$ & $<$ & $<$ & $<$ & $<$ & 1.2 & $<$ \\
\hline \multicolumn{14}{|c|}{ CFMWO7 $^{\text {h }}$} \\
\hline Ferrite & 66.6 & 25.0 & 3.8 & $<$ & 1.7 & 2.5 & $<$ & $<$ & $<$ & $<$ & $<$ & $<$ & $<$ \\
\hline Austenite & 69.5 & 16.6 & 8.7 & $<$ & 2.8 & 1.3 & $<$ & $<$ & $<$ & $<$ & $<$ & $<$ & $<$ \\
\hline $\mathrm{Fe}_{2} \mathrm{Zr}$-type & 45.8 & 5.8 & 20.1 & 21.7 & 1.9 & 0.3 & $<$ & $<$ & $<$ & $<$ & $<$ & 1.1 & $<$ \\
\hline \multicolumn{14}{|c|}{ CFMW08' } \\
\hline Ferrite & 70.2 & 22.8 & 4.4 & $<$ & 2.1 & 0.3 & $<$ & $<$ & $<$ & $<$ & $<$ & $<$ & $<$ \\
\hline $\mathrm{Fe}_{2} \mathrm{Zr}$-type & 49.0 & 4.5 & 20.7 & 23.1 & 1.9 & $<$ & $<$ & $<$ & $<$ & $<$ & $<$ & 1.8 & $<$ \\
\hline U-rich Laves & 42.7 & 2.2 & 25.7 & 25.7 & 8.8 & 1.7 & $<$ & $<$ & $<$ & $<$ & $<$ & 18.4 & $<$ \\
\hline $\mathrm{Fe}_{23} \mathrm{Zr}_{6}$-type & 56.5 & 7.6 & 14.7 & 18.2 & 0.9 & $<$ & $<$ & $<$ & $<$ & $<$ & $<$ & 1.6 & $<$ \\
\hline $\begin{array}{l}\text { a Entry "<" ind } \\
\text { b Entry "NA" i } \\
{ }^{\mathrm{b}} \text { Minor uraniun } \\
{ }^{\mathrm{d}} \text { Minor zirconi } \\
{ }^{\mathrm{e}} \text { Also contains } \\
{ }^{\mathrm{f}} \text { Also contains } \\
\mathrm{g} \text { Also contains } \\
\mathrm{h} \text { Also contains } \\
{ }^{\mathrm{i}} \text { Also contains } \\
\mathrm{j} \text { Also contains }\end{array}$ & $\begin{array}{l}\text { cates } n \\
\text { idicate } \\
\text { sulfid } \\
\text { m sulf } \\
0.9 \text { ato } \\
0.7 \text { ato } \\
2.7 \text { ato } \\
\text { U-Te a } \\
Z \text { Zr-S ar }\end{array}$ & $\begin{array}{l}\text { easure } \\
\text { eleme } \\
\text { e phase } \\
\text { de pha } \\
\text { mic \% } \\
\text { mic \% } \\
\text { mic \% } \\
\text { nd Zr-T } \\
\text { d meta }\end{array}$ & $\begin{array}{l}\text { e. } \\
\text { i. } \\
\text { i. } \\
\text { i. } \\
\text { e-Se pl } \\
\text { lic } \mathrm{Zr}\end{array}$ & $\begin{array}{l}\text { tration } \\
\text { ot adde }\end{array}$ & $\begin{array}{l}\text { was } r \\
\text { d to a }\end{array}$ & $\begin{array}{l}\text { orted } \\
\text { ру. }\end{array}$ & o be $n$ & gligib & or no & reporte & & & \\
\hline
\end{tabular}


Statement for Yucca Mountain will be used for TSPA calculations. That inventory is based on projected HLW inventories from WVDP, DWPF, Hanford WTP, and INL, including the EBR-II inventory. That is, waste to be immobilized in CWF and MWF is already included in the radionuclide inventory for HLW glass that will be used in TSPA calculations. Since the same inventory is used to calculate radionuclide release, this term is the same for HLW glass and the MWF. The requirement in the WASRD regarding the radionuclide inventory addresses the inventory for an individual canister. The distribution of radionuclides between phases must be known to identify what phases control the release of radionuclides for modeling purposes.

The performance of the MWF in immobilizing radionuclides depends on the chemical durabilities of the $\mathrm{Fe}_{2} \mathrm{Zr}$ intermetallic (e.g., Abraham et al., 2001) and steel phases. The corrosion of these phases appears to proceed independently and is not sensitive to solution feed-back effects. In contrast to HLW glass, for which B is released faster than all radionuclides and is used as an upper bound for the release of all radionuclides, some radionuclides are released into solution more efficiently than the matrix components of the phases in which they are contained (primarily Fe and $\mathrm{Zr}$ ). Most radionuclides, including $\mathrm{U}$, are contained within the $\mathrm{Zr}$ intermetallic phase in Laves phase polytypes $\mathrm{C} 15$ (primarily), $\mathrm{C} 36$, and $\mathrm{C} 14$ (Keiser et al., 2000a), although ${ }^{99} \mathrm{Tc}$ is present in both the steel (ferrite and austenite) and intermetallic phases (Keiser et al. 2000b). Uranium is by far the most abundant (by mass) radionuclide in the MWF (see Appendix A, Table A-2). It is likely that actinides substitute for $\mathrm{Zr}$ in the intermetallic (e.g., Janney, 2003a, 2003b, 2003c).

\section{V.A.3. Physical Properties}

Values of the density, the specific heat, the coefficient of thermal expansion, the thermal diffusivity, and the thermal conductivity at temperatures up to $900^{\circ} \mathrm{C}$ have been measured for MWF alloys made with 5, 15 , and 20 mass $\% \mathrm{Zr}$. These are referred to as SS-5Zr, SS-15Zr, and SS-20Zr, respectively. The room temperature densities of alloys with these $\mathrm{Zr}$-contents ranged from 7.56 to $7.9 \mathrm{~g} / \mathrm{cm}^{3}$ (see Section V.C.1). The density decreases with increasing amounts of the intermetallic phase, which has a lower density than the steel phase $\left(7.45 \mathrm{~g} / \mathrm{cm}^{3}\right.$ compared to $\left.7.9 \mathrm{~g} / \mathrm{cm}^{3}\right)$. The densities of all alloys increase with the addition of noble metal fission products (e.g., $\mathrm{Nb}, \mathrm{Pd}$, and $\mathrm{Ru}$ ). The specific heat for the alloys with the three different $\mathrm{Zr}$ contents varied from about $0.45 \mathrm{~J} /(\mathrm{g} \bullet \mathrm{K})$ to $0.7 \mathrm{~J} /(\mathrm{g} \bullet \mathrm{K})$ as the temperature increased from room temperature to about $1,000^{\circ} \mathrm{C}$. A peak in the curves was observed at $550^{\circ} \mathrm{C}$ due to a magnetic transition in ferrite. The thermal expansion was about the same for the SS-15Zr and SS-20Zr alloys. From $100^{\circ} \mathrm{C}$ to $900^{\circ} \mathrm{C}$, thermal expansion increased from about $1.0 \times 10^{-5} \mathrm{~K}^{-1}$ to about $1.2 \times 10^{-5} \mathrm{~K}^{-1}$. For the SS-5Zr alloy, the values ranged from about $1.4 \times 10^{-5} \mathrm{~K}^{-1}$ to about $1.7 \times 10^{-5} \mathrm{~K}^{-1}$ over the same temperature range. The thermal diffusivity increased from about $0.035 \mathrm{~cm}^{2} / \mathrm{s}$ to about $0.055 \mathrm{~cm}^{2} / \mathrm{s}$ as the temperature was increased from room temperature to about $900^{\circ} \mathrm{C}$. The thermal conductivity of the alloys increases from about $0.12 \mathrm{~W} /(\mathrm{cm} \cdot \mathrm{K})$ to about $0.22 \mathrm{~W} /(\mathrm{cm} \cdot \mathrm{K})$ as the temperature increases from room temperature to about $600^{\circ} \mathrm{C}$. The physical properties of the MWF alloys are similar to those of Type 316 stainless steel.

\section{V.A.4. Thermal Stability of Phase Composition}

The thermal stability of a SS-15Zr alloy was studied at low (about $\left.200^{\circ} \mathrm{C}\right)$ and high $\left(>1000^{\circ} \mathrm{C}\right.$ ) temperatures to represent long-term disposal and processing conditions, respectively (Abraham et al., 1999a, 1999b). The microstructure did not change significantly after heating for more than three years at $200^{\circ} \mathrm{C}$. Annealing at high temperatures resulted in an increase in the $\mathrm{Fe}_{23} \mathrm{Zr}_{6}$ content, the formation of small amounts of $\alpha-\mathrm{Zr}$, and a decrease in the austenite and $\mathrm{Fe}_{2} \mathrm{Zr}$ contents. The phase composition was tracked using in situ neutron diffraction with sample heated in a controlled-atmosphere furnace with flowing Ar gas. Spectra were collected continuously for samples annealed at (1) $1275^{\circ} \mathrm{C}$ for 34 hours, (2) $1220^{\circ} \mathrm{C}$ for 44 hours, and (3) $1084^{\circ} \mathrm{C}$ for 14 hours then $1175^{\circ} \mathrm{C}$ for 14 hours. The heat-treated samples 
were also surveyed with SEM. The phase compositions of the samples measured at the end of the heattreatments are summarized in Table V-3. Heating resulted in decreases in the austenite and $\mathrm{Fe}_{2} \mathrm{Zr} \mathrm{C} 36$ contents, with corresponding increases in the $\mathrm{Zr}_{23} \mathrm{Fe}_{6}$ and $\mathrm{Fe}_{2} \mathrm{Zr} \mathrm{C15}$ contents. The transformation was more extensive at higher temperatures. Prolonged heating at $1275^{\circ} \mathrm{C}$ resulted in a change in the microstructure due to consolidation of like phase domains; i.e., an increase in the grain sizes. These analyses show that ferrite is the preferred steel phase and $\mathrm{Fe}_{2} \mathrm{Zr} \mathrm{C} 15$ is the preferred intermetallic polytype below $1275^{\circ} \mathrm{C}$.

\section{V.B. Production of the MWF}

The MWF will be used to immobilize the metallic waste streams generated during electrometallurgical treatment in a form that is suitable for disposal in the federal high-level waste repository. The metal waste stream includes cladding hulls, fuel components and fission products that were not oxidized during treatment, and a significant amount of residual salt adhering to the hulls. As a part of the treatment process, the residual salt waste will be distilled and removed from the waste stream prior to casting the MWF (see Fig. I-1). Although demonstration studies were conducted with seven separate charges of driver fuel hulls containing between 14 and 33 mass \% waste salt, it is estimated that driver and blanket cladding hulls will contain 23 and 3 mass \% waste salt, respectively (Westphal et al., 1999). The baseline distillation conditions are $1,100^{\circ} \mathrm{C}$ for up to two hours, with an expected salt removal of 99.9 mass $\%$. The salt removed from the metallic waste stream will be added to the salt waste stream and immobilized in the CWF.

The metal waste stream and added $\mathrm{Zr}$ and $\mathrm{U}$ will be placed in a crucible and melted by induction in a casting furnace at about $1,600^{\circ} \mathrm{C}$ for about two hours to consolidate it into a monolithic, disk-shaped ingot approximately 14-16 inches in diameter and 4-5 inches high. The ingots will be placed in standard steel containers for storage until they are loaded into waste package canisters. It is currently planned that one MWF ingot will be co-disposed with two CWF in some canisters. Metal spacers will be used to keep the waste forms separated and concentric in the canister.

\section{V.C. Degradation Behavior of the MWF}

A variety of test methods were used to study the degradation behavior of the MWF. Test methods were selected based on the conceptual model that MWF degradation occurs through a two-step mechanism of oxidative dissolution in which the metal atoms at the surface are first oxidized to form an oxide layer, and then the oxide layer dissolves. Electrochemical tests were conducted to study the oxidation step and static immersion tests, solution-exchange tests, and vapor hydration tests were conducted to study the combined oxidative dissolution process. The various test methods and results are summarized in the following sections.

Table V-3. Phase Compositions after Heat Treatments

\begin{tabular}{|l|c|c|c|c|c|}
\hline \multicolumn{1}{|c|}{ Phase } & As-Cast & $1084^{\circ} \mathrm{C}, 14 \mathrm{~h}$ & $1175^{\circ} \mathrm{C}, 14 \mathrm{~h}$ & $1275^{\circ} \mathrm{C}, 27 \mathrm{~h}$ & After cooling \\
\hline Ferrite & 40 & 40 & 43 & 14 & 34 \\
\hline Austenite & 9 & 6 & 0 & 0 & 0 \\
\hline $\mathrm{Fe}_{2} \mathrm{Zr} \mathrm{C} 36$ & 32 & 20 & 9 & 58 & 43 \\
\hline $\mathrm{Fe}_{2} \mathrm{Zr} \mathrm{C} 15$ & 16 & 24 & 35 & 0 & 12 \\
\hline $\mathrm{Fe}_{23} \mathrm{Zr}_{6}$-type & 2 & 10 & 11 & 28 & 11 \\
\hline Steel $^{\mathrm{a}}$ & 49 & 46 & 43 & 14 & 34 \\
\hline Intermetallic $^{\mathrm{b}}$ & 48 & 44 & 44 & 86 & 66 \\
\hline
\end{tabular}

${ }^{a}$ Sum of ferrite and austenite.

${ }^{\mathrm{b}} \mathrm{Sum}$ of $\mathrm{Fe}_{2} \mathrm{Zr} \mathrm{C} 36, \mathrm{Fe}_{2} \mathrm{Zr} \mathrm{C15}$, and $\mathrm{Fe}_{23} \mathrm{Zr}_{6}$. 


\section{V.C.1. Electrochemical Corrosion Tests}

Polarization resistance tests and galvanic coupling tests were conducted to study the oxidation step of the MWF degradation mechanism (ASTM, 2005d). Polarization resistance is the resistance of a material to oxidation during the application of an external potential. These tests provided the oxidation rate through measurement of the current. The proportionality between the current and mass of material reacted is given by Faraday's law as

$$
m=\frac{I t a}{n F}
$$

where $I$ is the current, $t$ is time, $a$ is the atomic weight of the corroding material, $n$ is the number of equivalents exchanged, and $F$ is Faraday's constant (96,487 coulombs). The corrosion rate is obtained by dividing the mass reacted by the reaction time and specimen area $(\mathrm{A})$ :

$$
\text { rate }=\frac{m}{t A}=\frac{i_{\text {corrosion }} a}{n F}
$$

where $i_{\text {corrosion }}$ is the current density, I/A. For an alloy, a so-called alloy equivalent weight $(E W)$ replaces the atomic weight. The alloy equivalent weight is a weighted average of values of $a / n$ for the major alloying elements in the alloy.

In the polarization resistance tests, the current passing through a test specimen was measured as the applied potential was ramped through the corrosion potential of the material. The slope at the origin of a plot of potential vs. current, $\Delta \mathrm{E} / \Delta \mathrm{I}$, gives the polarization resistance $R_{p}$, which can be related to the corrosion current using Eq. V-3 (see Jones, 1992, Chapter 5.2):

$$
\frac{\Delta E}{\Delta I}=R_{p}=\frac{\mathrm{B}_{a} \mathrm{~B}_{c}}{2.3 \times\left(B_{a}+B_{c}\right) \times i_{\text {corrosion }}}
$$

where $B_{a}$ and $B_{c}$ are the anodic and cathodic Tafel constants (in volts) for the material and $i_{\text {corrosion }}$ is the current density. The resistance is not very sensitive to the values of $B_{a}$ and $B_{c}$, and both were assumed to be $0.1 \mathrm{~V}$ for all MWF alloys. The corrosion rate is calculated by combining Eqs. V-2 and V-3 and expressing as micrometers per year:

$$
\text { corrosionrate, }(\mu \mathrm{m} / y)=\frac{3.27 \times i_{\text {corrosion }} \times(\text { Eq.Wt. })}{\rho}
$$

where $i_{\text {corrosion }}$ is the measured corrosion current density $\left(\mu \mathrm{A} / \mathrm{cm}^{2}\right), E q . W t$. is the equivalent weight of the corroding material $(\mathrm{g})$, and $\rho$ is the density of the material $\left(\mathrm{g} / \mathrm{cm}^{3}\right)$. The polarization resistance measurements were used to calculate an upper bound for the corrosion rates of various MWF and other materials assuming uniform corrosion (i.e., neglecting pitting and crevice corrosion).

Polarization resistance measurements were made at room temperature using a solution simulating the composition of J-13 well water (which is referred to as SJ-13 solution), which had a pH value of about 9. Other solutions were prepared by adding $\mathrm{HCl}$ to the $\mathrm{SJ}-13$ solution to attain $\mathrm{pH} 2$ or $\mathrm{pH} 4$ solutions or $\mathrm{NaOH}$ to attain $\mathrm{pH} 10$. The measured solution compositions are given in Table V-4. Corrosion rates were calculated from the results of tests in different solutions using Eq. V-4. Rates were determined for MWF materials made with 5,15 , or 20 mass $\% \mathrm{Zr}$ and other additives, and for other relevant materials, 
including Alloy C22 (UNS No. N06022), which will be used as a corrosion-resistant layer in all waste packages. Measurements were made with three samples of each material, and the rates calculated from the measured resistances are summarized in Table V-5 in units of $\mu \mathrm{m} / \mathrm{year}$. In Table V-6, the mean and standard deviations for the triplicate tests are given in units $\mathrm{g} /\left(\mathrm{m}^{2} \mathrm{~d}\right)$ for easy comparisons with the dissolution rates measured with other test methods. The corrosion rates of all materials are highest in the $\mathrm{pH} 2$ solutions and lowest in the $\mathrm{pH} 9$ and 10 solutions. Decreasing the $\mathrm{Zr}$ content of the MWF form $20 \%$ to $15 \%$ to $5 \%$ results in a general increase in the corrosion rate (decrease in durability). Neither minor variations in minor components $(\mathrm{Nb}, \mathrm{Ru}, \mathrm{Pd}$, etc.) nor the presence of radionuclides ( $\mathrm{U}$ and $\mathrm{Tc})$ have a significant effect on the corrosion rate. All of the various MWF compositions are more durable than copper, mild steel, and AISI 1018 (low carbon steel), and all have durabilities similar to zirconium, Type 316 Stainless Steel, and Alloy C22.

The rates measured in these tests represent the oxidation of metal at the outer surface of the MWF, which must occur prior to the release of the metal ions into solution. These experiments provide insight into the effects of $\mathrm{pH}$ on the oxidation step of the dissolution process. The alloys were corrosion-resistant even under highly aggressive test conditions, such as in $\mathrm{pH} 2$ solution. The test results show that the MWF alloy exhibits corrosion resistance similar to that of Alloy C-22.

Other tests were conducted in $\mathrm{SJ}-13$ solutions spiked with $\mathrm{NaCl}$ to generate solutions containing $1,000 \mathrm{ppm}$ and $10,000 \mathrm{ppm} \mathrm{Cl}^{-}$. The results of three MWF alloys and other metals are summarized in Table V-7. The corrosion rates of all materials increase by about five times with the addition of $\mathrm{Cl}^{-}$.

A galvanic cell is formed when dissimilar alloys are coupled in contact with an electrolyte solution. Possible galvanic couplings between the MWF and Alloy C22 were studied. Alloy C22 is expected to be the most stable metal in the waste package and to act as the cathode in all galvanic couples. (The anode material will corrode in preference to the cathode material.) Tests were conducted to measure the coupling of Alloy C22 with 2 MWF materials (SS-15Zr and SS-15Zr-1Nb-1Pd-1Rh-1Ru) and with AISI 1018 steel (Fe-0.18C-0.8Mn) (Abraham et al., 1999; Abraham et al., 2000). The SJ-13 solution (pH 9) and the SJ-13 solution adjusted to $\mathrm{pH} 2$ were used as electrolytes. Figure V-2 shows the galvanic current measured in tests using the SJ-13 (pH 9) solution. Both of the MWF materials are electrochemically noble (positive current) when coupled with Alloy C22, but the AISI 1018 steel is electrochemically active (negative current) and is preferentially oxidized when coupled with Alloy C22.

Table V-4. Solution Compositions for Electrochemical Tests

\begin{tabular}{|c|c|c|c|c|c|c|c|c|c|}
\hline & \multicolumn{9}{|c|}{ Concentration $(\mathrm{mg} / \mathrm{L})$} \\
\hline $\mathrm{pH}$ & $\mathrm{Ca}$ & $\mathrm{K}$ & $\mathrm{Mg}$ & $\mathrm{Na}$ & $\mathrm{Si}$ & $\mathrm{Cl}^{-}$ & $\mathrm{HCO}_{3}^{-}$ & $\mathrm{NO}_{3}{ }^{-}$ & $\mathrm{SO}_{4}{ }^{2-}$ \\
\hline 2 & 10.9 & 5.10 & 2.12 & 49.1 & 35.1 & 443 & 4.4 & 10.5 & 17.8 \\
\hline 4 & 10.8 & 5.16 & 2.11 & 48.9 & 33.5 & 88.0 & 5.0 & 10.2 & 18.2 \\
\hline $8.2^{\mathrm{a}}$ & 6.0 & 510 & 1.90 & 5300 & 30.0 & 727 & 12,700 & 11.0 & 22.0 \\
\hline $9^{\mathrm{b}}$ & 10.2 & 5.21 & 2.09 & 50.9 & 33.8 & 4.31 & 109 & 10.1 & 18.0 \\
\hline 10 & 10.4 & 5.32 & 2.18 & 65.2 & 37.9 & 4.33 & 88.0 & 9.5 & 18.0 \\
\hline 12 & 1.07 & 57.0 & 0.99 & 396 & 36.4 & 3.93 & 89.0 & 10.9 & 18.2 \\
\hline
\end{tabular}

${ }^{\mathrm{a}}$ Concentrated SJ-13 solution.

${ }^{\mathrm{b}} \mathrm{SJ}-13$ solution. 


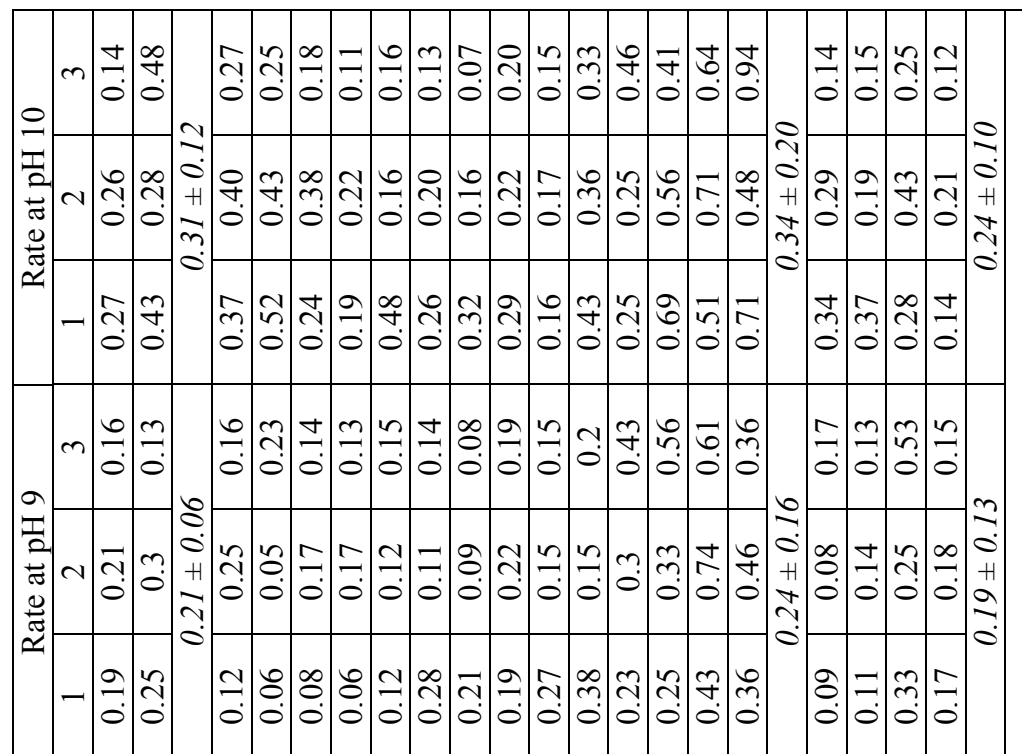

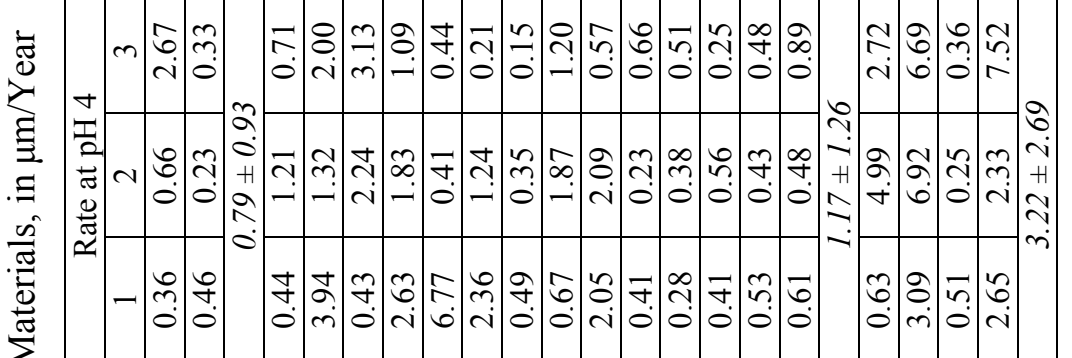

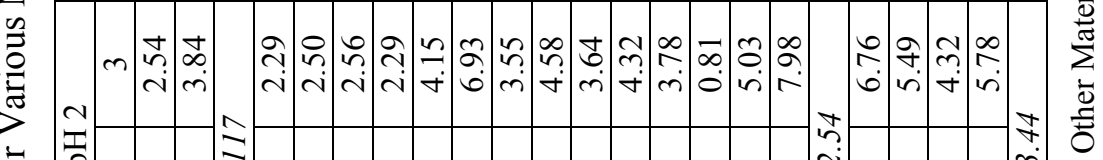

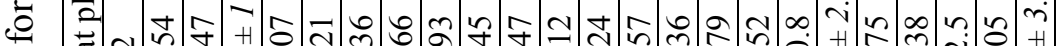

\&

$\frac{\sqrt{2}}{4}$

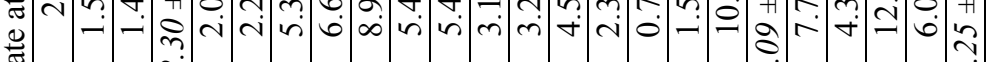

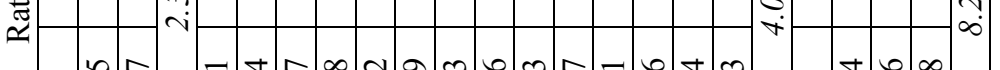

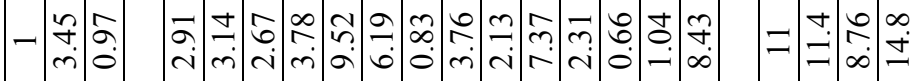

긍

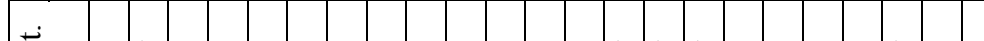

3

宁

$\frac{1}{\circ}$

르

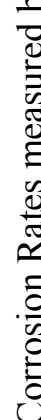

కm

先
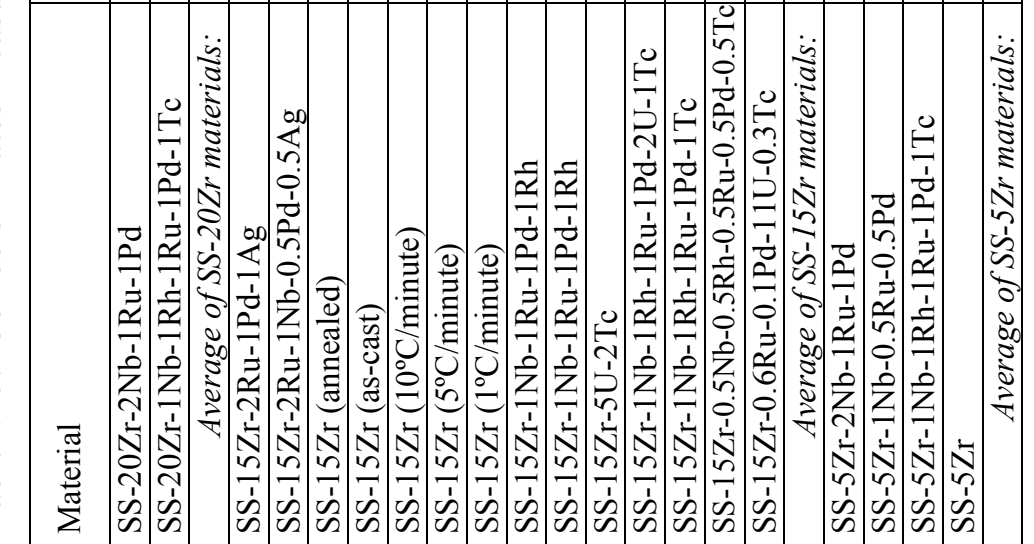

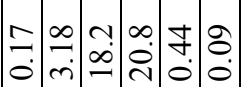

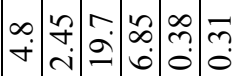

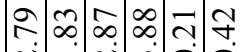

त

กิธ

ڤேं

m.

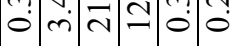

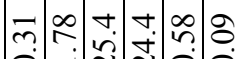

?.

ปே

$\infty$

$\circ \infty m m-0$

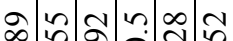

o

กิ ที

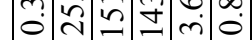

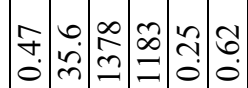

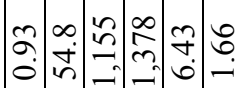

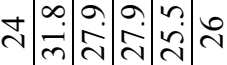

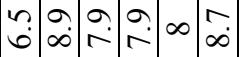

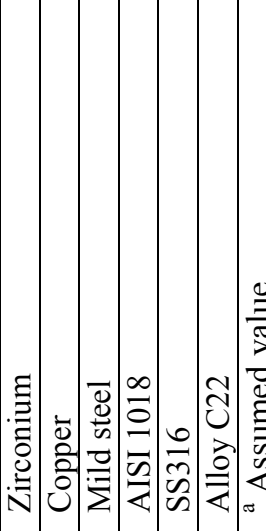




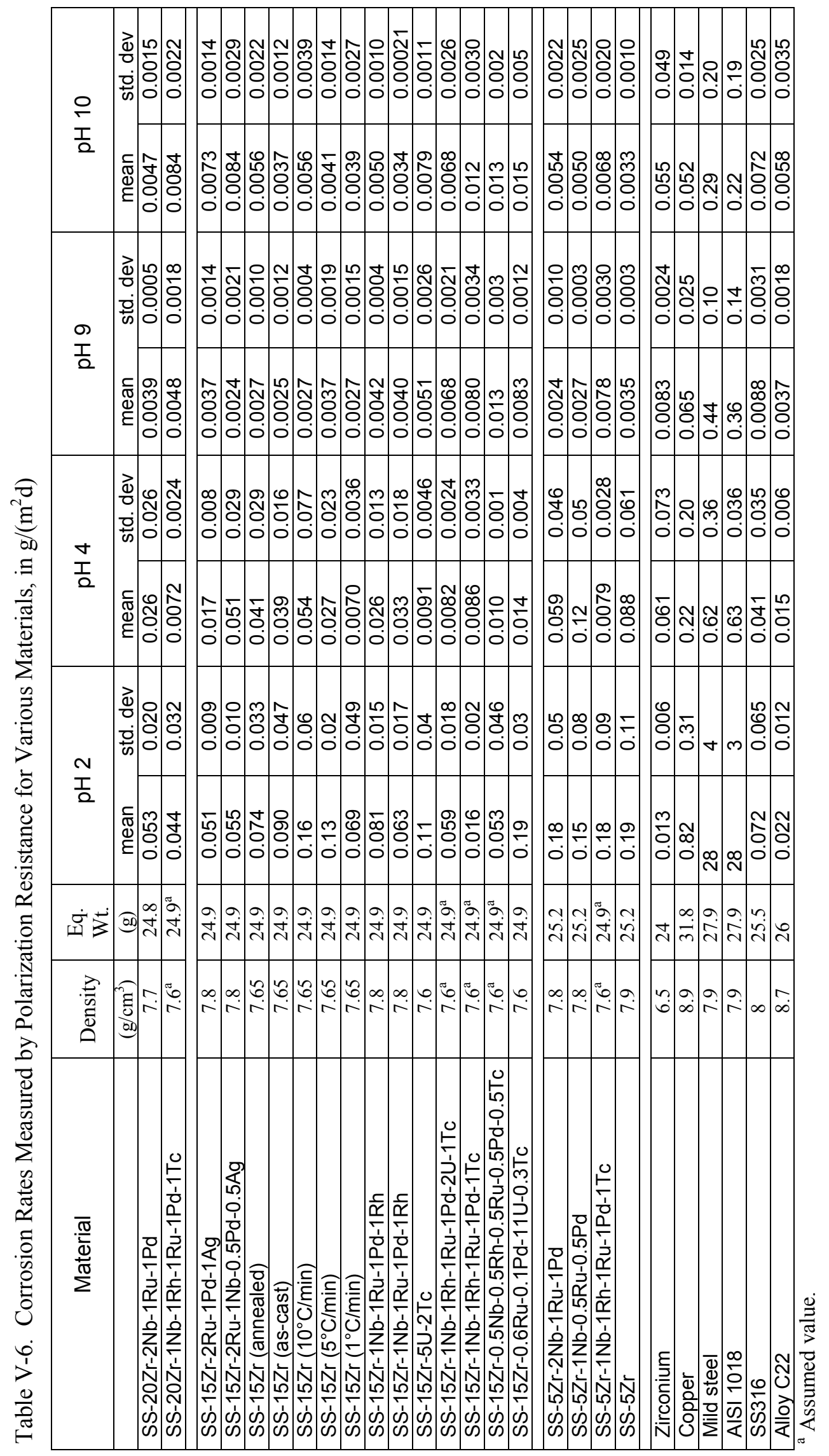


Table V-7. Corrosion Rates Measured in SJ-13, SJ-13 Spiked with NaCl, and Concentrated SJ-13

\begin{tabular}{|c|c|c|c|c|}
\hline Material & SJ-13 & $\begin{array}{c}\mathrm{SJ}-13+ \\
1,000 \mathrm{ppm} \mathrm{Cl}^{-}\end{array}$ & $\begin{array}{c}\mathrm{SJ}-13+ \\
10,000 \text { ppm } \mathrm{Cl}^{-}\end{array}$ & $\begin{array}{l}\text { Concentrated } \\
\text { SJ-13 }\end{array}$ \\
\hline & \multicolumn{4}{|c|}{$\mu \mathrm{m} / \mathrm{yr}$} \\
\hline SS-5Zr-2Nb-1Ru-1Pd & $0.11 \pm 0.05$ & $0.70 \pm 0.56$ & $0.75 \pm 0.86$ & $1.25 \pm 1.00$ \\
\hline SS-20Zr-2Nb-1Ru-1Pd & $0.19 \pm 0.03$ & $0.99 \pm 0.59$ & $2.12 \pm 1.62$ & $1.80 \pm 0.91$ \\
\hline SS-15Zr-1Nb-1Ru-1Pd-1Rh & $0.20 \pm 0.02$ & $0.52 \pm 0.17$ & $1.53 \pm 1.89$ & $2.18 \pm 2.02$ \\
\hline SS316 & $0.42 \pm 0.15$ & $1.70 \pm 0.65$ & $2.31 \pm 1.41$ & $2.18 \pm 1.40$ \\
\hline Alloy C22 & $0.17 \pm 0.09$ & $0.56 \pm 0.04$ & $0.81 \pm 0.56$ & $0.88 \pm 0.38$ \\
\hline \multirow[t]{2}{*}{ AISI 1018} & $16.9 \pm 6.60$ & $105 \pm 24$ & $176 \pm 14$ & $2.20 \pm 0.19$ \\
\hline & \multicolumn{4}{|c|}{$\mathrm{g} /\left(\mathrm{m}^{2} \mathrm{~d}\right)$} \\
\hline SS-5Zr-2Nb-1Ru-1Pd & $0.0023 \pm 0.0011$ & $0.015 \pm 0.011$ & $0.016 \pm 0.018$ & $0.026 \pm 0.021$ \\
\hline SS-20Zr-2Nb-1Ru-1Pd & $0.0040 \pm 0.0006$ & $0.021 \pm 0.012$ & $0.045 \pm 0.034$ & $0.038 \pm 0.019$ \\
\hline SS-15Zr-1Nb-1Ru-1Pd-1Rh & $0.0042 \pm 0.0004$ & $0.011 \pm 0.011$ & $0.032 \pm 0.040$ & $0.046 \pm 0.043$ \\
\hline SS316 & $0.0089 \pm 0.0032$ & $0.036 \pm 0.014$ & $0.049 \pm 0.030$ & $0.046 \pm 0.030$ \\
\hline Alloy C22 & $0.0036 \pm 0.0019$ & $0.012 \pm 0.001$ & $0.017 \pm 0.012$ & $0.019 \pm 0.008$ \\
\hline AISI 1018 & $0.36 \pm 0.14$ & $2.2 \pm 0.5$ & $3.7 \pm 0.3$ & $0.046 \pm 0.004$ \\
\hline
\end{tabular}

The galvanic potentials were about $-200 \mathrm{mV}$ and $62 \mathrm{mV}$ for the SS-15Zr and SS-15Zr-1Nb-1Pd-1Rh-1Ru samples and $-600 \mathrm{mV}$ for AISI 1018 steel. Similar results were obtained in the $\mathrm{pH} 2$ solution, but with the potentials shifted higher values and the currents were slightly higher. The currents measured in tests with both MWF samples are very small (but non-zero) and positive, indicating that the MWF is noble relative to Alloy C22. Enhanced corrosion of the MWF is not expected due to galvanic coupling with Alloy C22 or any material (e.g., carbon steel) that is part of the waste package.

\section{V.C.2. Aqueous Corrosion Tests}

Immersion tests have been conducted under a range of test configurations and conditions, including static tests and tests in which the solution is partially or completely replaced during the test. Most immersion tests were conducted with monoliths following variations of ASTM test method C1220 (ASTM, 2005b). (These are also referred to as MCC-1 tests.) This test method involves immersing a monolithic sample of known geometric surface area in a solution of known volume at a fixed temperature. At the end of the test, the solution is analyzed for dissolved components to determine how much of the test solid had dissolved. The extent of reaction is calculated from the compositions of the solution and solid, the surface area exposed in the test, and the solution volume (e.g., see Eq. IV-3 for calculation of the normalized mass loss). Changes in specimen mass can also be measured, but these are usually too small to be reliable. The surfaces of reacted solids can be examined to characterize morphological and chemical changes in the surface and identify corrosion products that may have formed. It has been found that MWF alloys are very corrosion resistant both in simulated $\mathrm{J}-13$ well water and demineralized water, and that the corrosion behaviors of MWF materials are similar over the anticipated composition range.

Static dissolution tests have also been conducted with drill shavings of MWF (Johnson et al., 2000) following the ASTM method C1285 (PCT), in which crushed samples are reacted in demineralized water at $90^{\circ} \mathrm{C}$. The extent of reaction of the MWF was found to be too low for reliable measurements of the dissolved concentrations in these tests.

Many tests were conducted with MWF materials that did not contain $U$ to understand degradation behavior and the generation of oxide layers. The results of microscopic examinations of MWF materials 


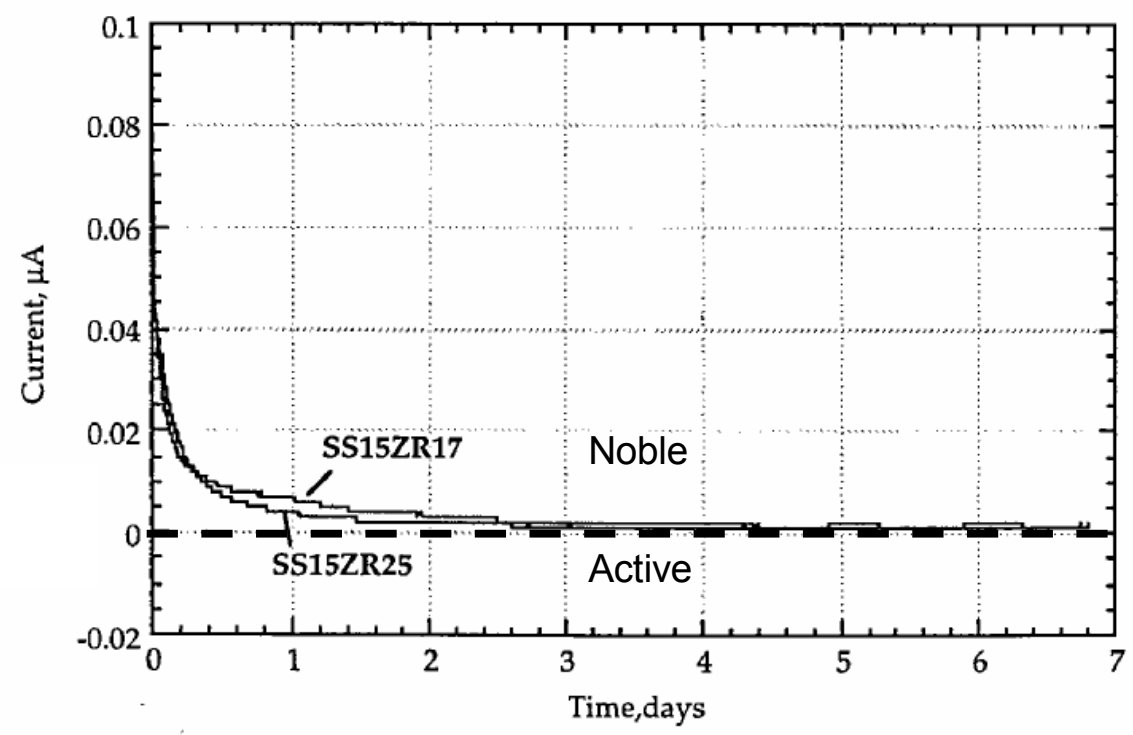

(a)

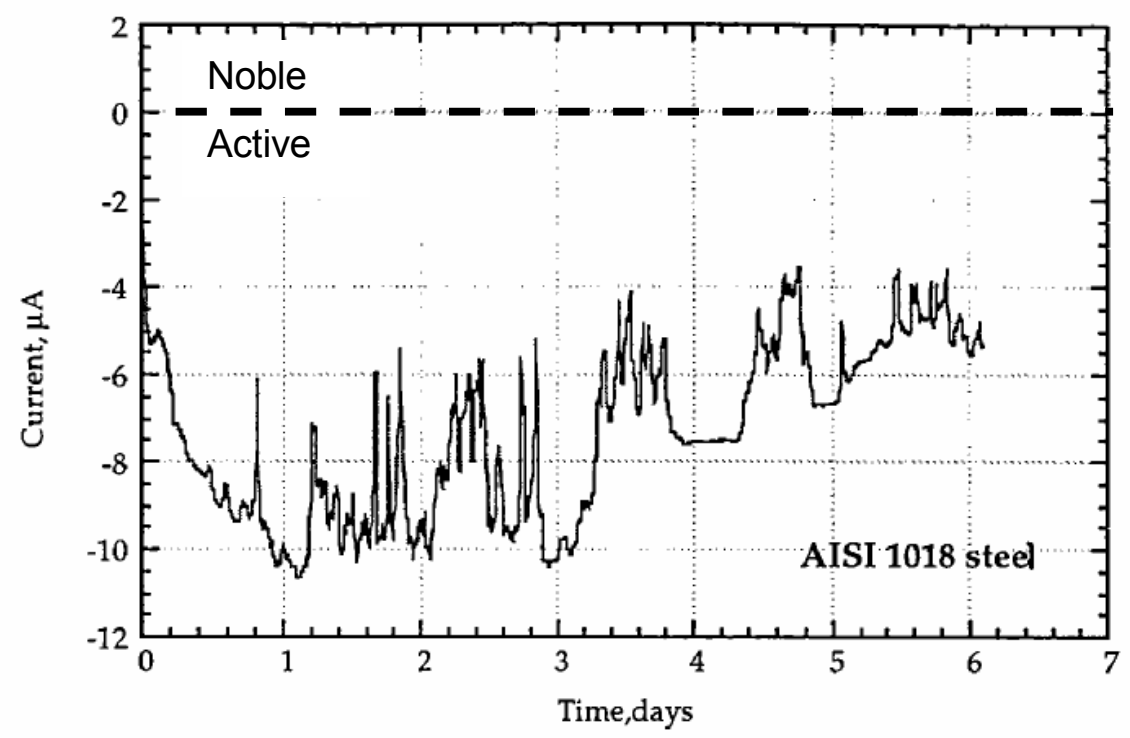

(b)

Fig. V-2. Galvanic Current Measured in Tests with (a) MWF Materials SS-15Zr and SS-15Zr-1Nb-1Pd-1Rh-1Ru and (b) AISI 1018 Steel in SJ-13 Solution. 
reacted in these tests provide valuable insights into the corrosion mechanism, but tests conducted with MWF materials without radionuclides (or surrogates) are of limited use in determining release rates for performance assessment purposes because the release of radionuclides is not limited by the degradation rate of the matrix phases (i.e., the steel and intermetallic phases). Radionuclides in the MWF become alloyed in either the stainless steel or intermetallic phase. As shown below, $U$ is typically the fastest released radionuclide, and the $U$ release rate is used to represent the release rates of all radionuclides from the MWF. This is because the U content in the MWF is high enough that solution concentrations are readily measurable and provide a direct measure of radionuclide release. Although $U$ is present only in the intermetallic phase, tests have shown $U$ to be released faster than Tc (see below), which is present in both the intermetallic and steel phases. Therefore, the results of immersion tests conducted with U-bearing MWF materials are used to provide radionuclide release rates for performance assessment calculations.

Solution exchange tests (also referred to as pulsed-flow tests) were conducted with various MWF materials containing $\mathrm{U}, \mathrm{Tc}$, or both. The solution-exchange test is conducted by immersing a monolithic sample in a solution for an interval of time, then removing a portion of the test solution (or all of the test solution) for analysis and replacing it with fresh solution. The test provides a measure of elemental release into solution as a function of time. The replacement of some or all of the test solution perturbs the solution chemistry to an extent that depends on the amount of solution that is exchanged. The degradation rates of MWF materials are not sensitive to changes in the solution concentrations of its degradation products and the effect of solution exchange on their degradation rates is negligible. Degradation is dependent on the solution $\mathrm{pH}$ (weakly) and the $\mathrm{Cl}^{-}$concentration, but these are not affected by the exchange since the $\mathrm{pH}$ and $\mathrm{Cl}^{-}$content are established by the leachant and are not affected by MWF degradation. However, periodically exchanging some of the solution with fresh leachant complicates the use of solution concentrations to determine degradation rates. The variances in the relative amounts and frequency of the exchanges in most tests conducted with MWF essentially prevent the quantitative determination of radionuclide release rates. Nevertheless, these tests provide key insight into the qualitative release behaviors of different radionuclides and the long-term durability of the MWF. The results of several exchange tests conducted with MWF materials are summarized in the following sections.

\section{V.C.2.1. Results of Long-Term Partial Solution Exchange Tests}

Solution exchange tests were conducted at $90^{\circ} \mathrm{C}$ using SJ-13 solution (see Table V-4) with MWF materials with 2 mass \% U and either 5, 15, or 20 mass \% Zr (SS-5Zr-2U, SS-15Zr-2U, or SS-20Zr-2U) and with MWF materials SS-15Zr-4NM-2U-1Tc and SS-15Zr-0.6Ru-0.1Pd-11U-0.3Tc. The tests were interrupted every one to four weeks and about $5-10 \%$ of the test solution was removed for analysis and replaced with fresh SJ-13 solution. This diluted the remaining test solution by an equivalent percentage and lowered the apparent release rate. For example, neglecting the cumulative effect of exchanging $10 \%$ of the test solution over 30 exchanges will result in a three-fold decrease in the total mass of $U$ calculated to have been released. With a $10 \%$ exchange volume, the test solution will be completely replaced after 10 exchanges. The time required for 10 exchanges is referred to as the residence time. Because neither the fraction of solution that was replaced nor the replacement interval was constant over the complete test period, these results cannot be used to quantify release rates. Nevertheless, the relative releases of $U$ and Tc can be compared under the same test conditions.

The test results are plotted against the reaction time in Figure V-3a. Curves have been fit to the data to guide the eye, but are not meant to imply any functionality. The release rate of $U$ increases as the Zr-content in the MWF decreases, although the difference is only a factor of about two between SS-20Zr-2U and SS-5Zr-2U. This shows that even significant variations in the Zr contents of 


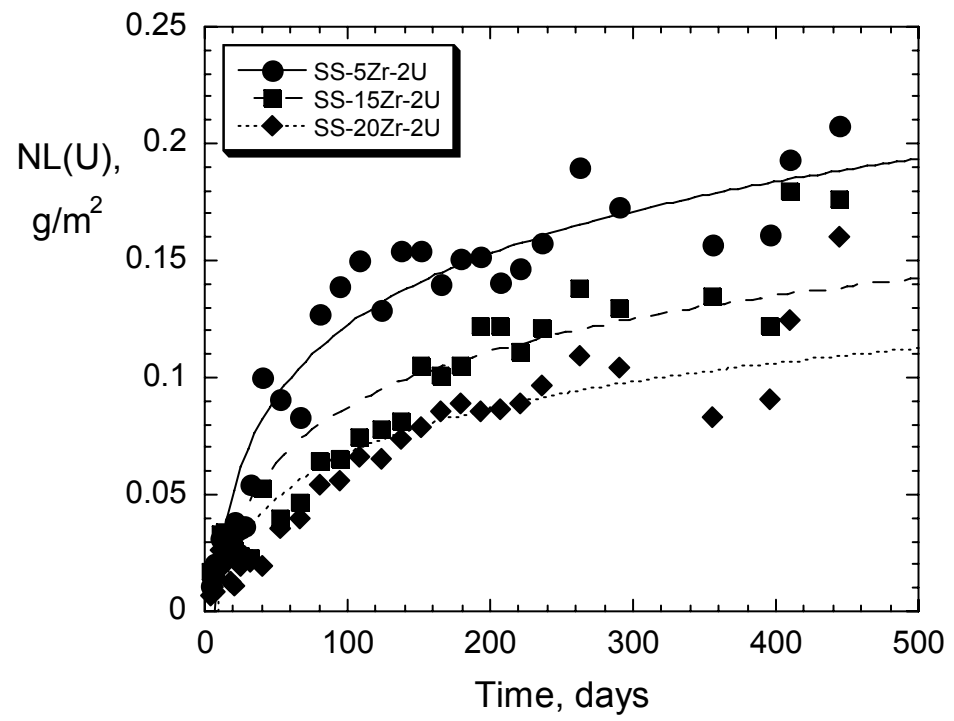

(a)

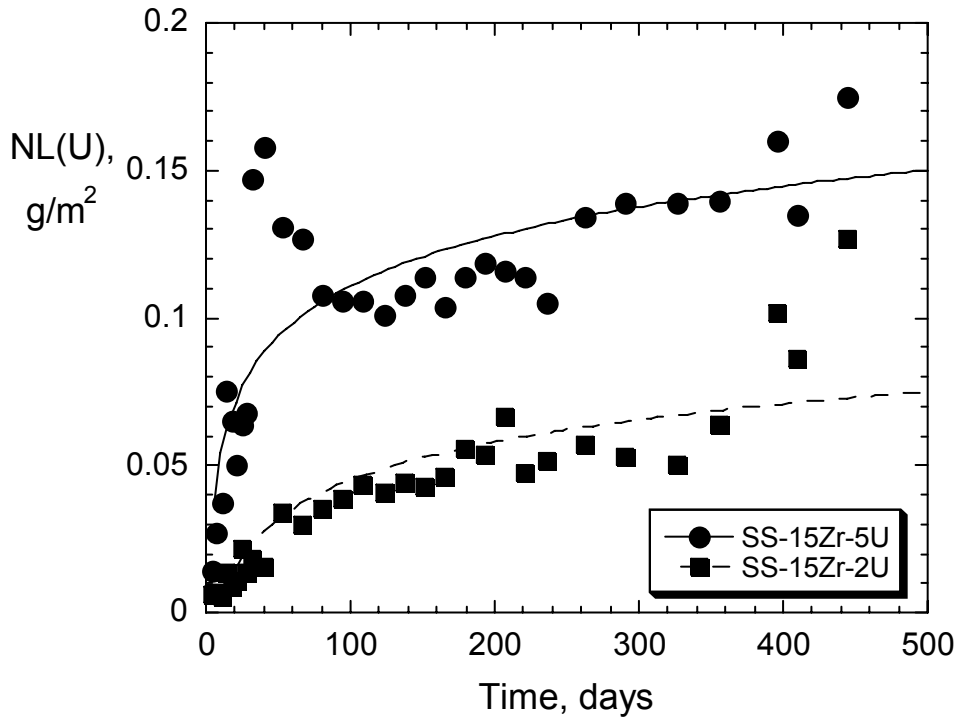

(b)

Fig. V-3. Radionuclide Releases Measured in Solution Exchange Tests with SJ-13 Water at $90^{\circ} \mathrm{C}$ : (a) NL(U) for Tests with SS-5Zr-2U, SS-15Zr-2U, and SS-20Zr-2U and (b) NL(U) for Tests with SS-15Zr-5U and SS-15Zr-2U. 
MWF products will have a small effect on the radionuclide release rate. The results of tests with SS-15Zr-5U and SS-15Zr-2U are shown in Figure V-3b. The release of U occurs from SS-15Zr-5U about twice as fast as the release from SS-15Zr-2U. Notice the relatively high value of NL(U) for the 32-day sampling of the test with SS-15Zr-5U. This cannot be attributed to analytical error because the values remain high for the next three samplings, although they decrease from the 32-day value due to the dilution that occurs during the exchanges. The sudden increase after 32 days probably resulted from water accessing a region in the sample with a high $U$ concentration. Higher values are also seen in the last three samplings of the test with SS-15Zr-2U. This is an example of how the nonuniform distribution of U (and other components) adds to scatter in the laboratory measurements and uncertainty in the rates used for TSPA calculations, and will lead to variations in the releases from actual waste forms.

The relative releases of $U$ and Tc from SS-15Zr-4NM-2U-1Tc are compared in Fig. V-4a. The release of $\mathrm{U}$ occurs about ten times faster than the release of Tc. The results are fitted with logarithmic curves to guide the eye, but are not intended to represent a particular release mechanism. The release of $U$ was also about 10 times faster than the release of Tc in tests with SS-15Zr-0.6Ru-0.1Pd-11U-0.3Tc. The results of tests with MWF materials having different amounts of noble metal fission products (NM represents the sum of the $\mathrm{Nb}, \mathrm{Pd}, \mathrm{Rh}$, and $\mathrm{Ru}$ contents) are shown in Fig. V-4b. The results are plotted with filled and open symbols to indicate a change in the frequency of the solution exchange, and fitted with separate curves. The results are well fit by logarithmic curves. The release of Tc is not sensitive to the concentrations of minor components. It is interesting to note that the release from the MWF with 0.5 mass \% Tc is about twice that from the MWF with 1 mass \% Tc, since NL(Tc) is calculated by dividing the mass of Tc released into solution by the mass fraction of Tc in the MWF. The actual Tc concentrations in the solution were similar. This points to a possible testing artifact that the surface concentrations of components present in the MWF at low levels are not likely to be the same as the bulk concentrations, and probably vary between samples. The difference in the releases of Tc from the MWF materials is probably not significant.

The results of long-term solution exchange tests with SS-15Zr-11U-0.6Ru-0.3Tc in SJ-13 water at $90^{\circ} \mathrm{C}$ are shown in Fig. V-5 (Johnson et al., 2002). About $1 \mathrm{~mL}$ of test solution (which represented 5-20 volume \%) was removed and replaced with fresh leachant every two weeks for the first three months, and approximately monthly thereafter. The values of NL(U) and NL(Tc) increase during the first 250 days but remain nearly constant in subsequent samplings, which indicates that the amounts of $U$ and Tc released from the MWF during each interval are similar to the amounts removed by sampling the solution. The curves show logarithmic fits to the results. The rates cannot be quantified because the exchange intervals (and probably the exchanged volumes, which were not reported) varied throughout the test. Note (1) that the sudden increase in NL(U) at about 200 days is probably due to the anomalously long test interval (about 125 days) and (2) that the value of $\mathrm{NL}(\mathrm{U})$ returns to a nearly constant value after three more exchanges.

Notice that the releases of U and Tc seen in Figs. V-3, V-4, and V-5 all slow with time in a logarithmic fashion, as shown by the fitted curves. The slowing of the releases is attributed to the formation of the oxide layers over time. If the release of $U$ and $T c$ by diffusion through these layers slows exponentially with time, then the cumulative (or integrated) amount released should increase logarithmically. The logarithmic release behavior is physically reasonable, and is used as a basis for the radionuclide release model developed for the MWF (see Section V.F). 


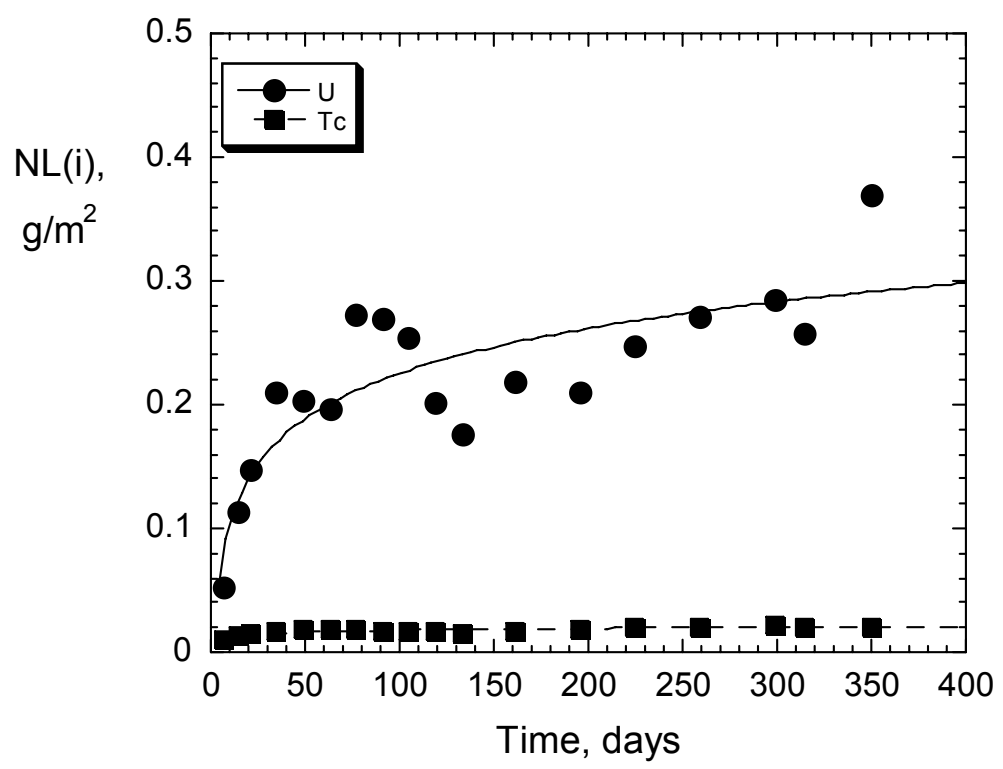

(a)

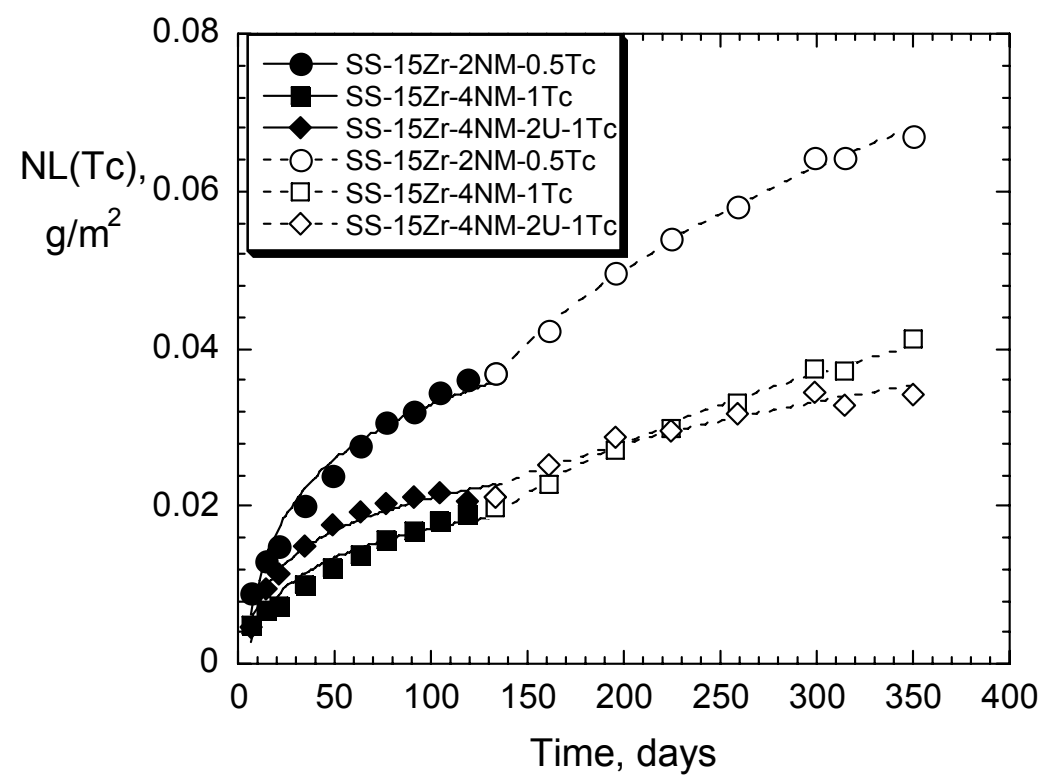

(b)

Fig. V-4. Releases of U and Tc Measured in Solution Exchange Tests in SJ-13 Water at $90^{\circ} \mathrm{C}$ : (a) NL(U) and NL(Tc) for Tests with SS-15Zr-4NM-2U-1Tc and (b) NL(Tc) for Tests with SS-15Zr-2NM-0.5Tc, SS-15Zr4NM-1Tc, and SS-15Zr-4NM-2U-1Tc. 


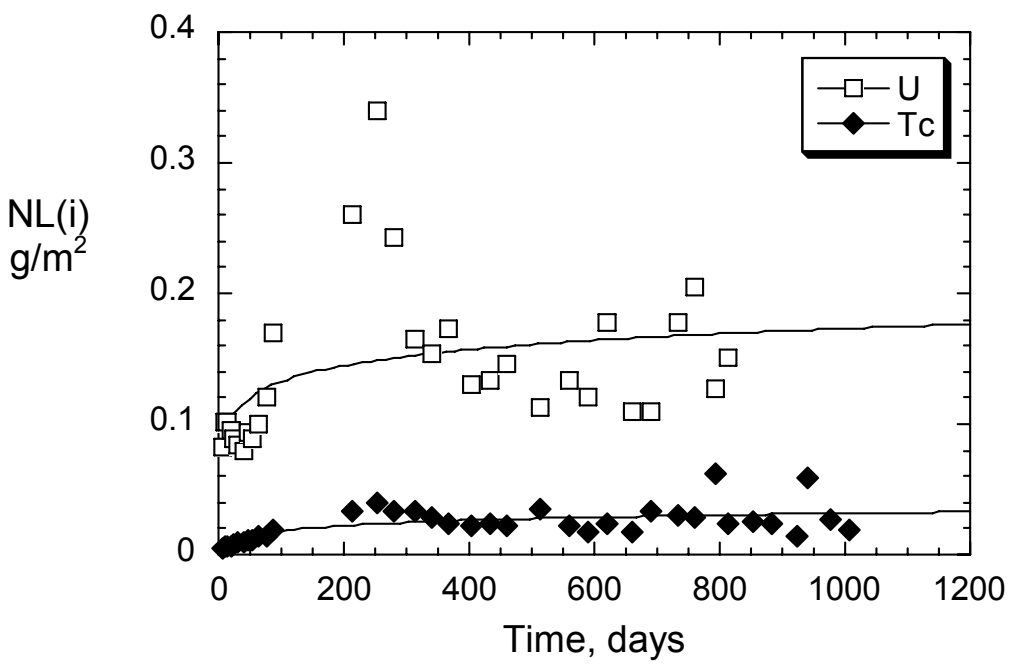

Fig. V-5. Releases of U and Tc Measured in Long-Term Solution Exchange Tests with SS-15Zr-11U-0.6Ru-0.3Tc in SJ-13 Water at $90^{\circ} \mathrm{C}$.

\section{V.C.2.2. Results of Short-Term Solution Exchange Tests}

A series of laboratory tests was conducted specifically to measure the dissolution rates of a reference MWF over a range of $\mathrm{pH}$ and temperature values for direct comparison with the rates calculated using the HLW glass degradation model (Ebert et al. 2003a, 2003b). The HLW glass degradation model includes explicit terms for the $\mathrm{pH}$ and temperature dependencies and a rate coefficient that accounts for the effects of the glass composition and solution feedback effects (i.e., the affinity term).

Test conditions were selected so that the dissolution rates of the MWF samples would be measured under conditions relevant to those represented by the HLW glass model. Unlike HLW glasses, degradation of the MWF is not significantly affected by the solution chemistry, except for the $\mathrm{Cl}^{-}$concentration, and the $\mathrm{S} / \mathrm{V}$ ratio used in the test does not affect the MWF degradation rate. However, the MWF degradation rate is expected to slow over time as an oxide layer forms at the surface. Although the mechanisms are different, it was desired that the extent to which layer formation slowed the MWF corrosion during the test would be similar to the extent to which the solution chemistry slowed glass corrosion in a seven-day PCT, which is used to determine the maximum rate in the HLW glass degradation model for corrosion in alkaline solutions. The test parameters of 70 days and $200 \mathrm{~m}^{-1}$ were selected to provide the same product of S/V and test duration as that of the seven-day PCT, which is conducted for seven days at $2000 \mathrm{~m}^{-1}$. The seven-day PCT results were used to take the slowing effect of dissolved Si into account as the glass dissolves, and the intent is to account for the slowing effect of the oxide layers on the degradation of MWF to a similar degree. Although the equivalence of test conditions is superficial because the corrosion mechanisms are different, comparison of the MWF dissolution rates measured under these conditions with the rates calculated with the glass model is not unreasonable.

Tests were conducted in Teflon ${ }^{\circledR}$ vessels (rather than stainless steel vessels) to electrically isolate the MWF and avoid plating $U$ onto the vessel. Tests were conducted using MWF coupons approximately $1.5 \mathrm{~cm} \times 1.5 \mathrm{~cm} \times 0.2 \mathrm{~cm}$ having surfaces with a $20-\mu \mathrm{m}$ finish. Commercial $\mathrm{pH}$ buffers were used as leachant solutions. These are fairly dilute solutions with little buffer capacities. These were used to impose an initial $\mathrm{pH}$ without interfering in the corrosion reactions or complexing released elements. Reagent-grade $\mathrm{NaCl}$ was added to the $\mathrm{pH}$ buffers to simulate the dissolution of halite from $\mathrm{CWF}$ that is 
co-disposed with the MWF: $1,000 \mathrm{ppm} \mathrm{Cl}^{-}$was added to represent the maximum concentration that could contact the MWF (see Section IV.F). Tests were conducted over the $\mathrm{pH}$ range 3-12 to determine if the MWF degradation rate was bounded by the HLW glass degradation model under relevant conditions. The $\mathrm{pH}$ range to be considered in TSPA calculations for a breached package with HLW glass is 4.5 to 8.5 (BSC, 2005a).

Tests were conducted at 50,70 , and $90^{\circ} \mathrm{C}$ at an $\mathrm{S} / \mathrm{V}$ ratio of $200 \mathrm{~m}^{-1}$ for a total duration of 70 days. The solutions were removed for analysis and replaced with fresh leachant after 14 and 28 days to track the $\mathrm{U}$ release over time as the oxide layers formed. This also served to maintain more constant $\mathrm{pH}$ values and dissolved oxygen contents in the test solutions. Because the solutions were completely replaced, the measured solution concentrations provide a measure of the amounts of $U$ released in each interval and their sum gives the total released.

The averages of replicate tests at 50,70, and $90^{\circ} \mathrm{C}$ are plotted in Fig. V-6 as the cumulative mass of $\mathrm{U}$ in solution against the cumulative reaction time. The release of $U$ slows over time under all test conditions, except for two anomalous results: the result at 70 days at $50^{\circ} \mathrm{C}$ and $\mathrm{pH} 8$ (Fig. V-6b) is about six times too high and the result at 70 days at $90^{\circ} \mathrm{C}$ and $\mathrm{pH} 4$ (Fig. V-6c) is about two times too high. Based on the results of previous tests, the slowing of the $U$ release is attributed to the formation of an oxide layer, although the surfaces of the reacted coupons have not been examined thoroughly. The $U$ releases are more sensitive to the $\mathrm{pH}$ than the temperature. The rate is more sensitive to the $\mathrm{Cl}^{-}$concentration in acidic solutions. Table V-8 summarizes the rates measured in MCC- 1 tests at $50^{\circ} \mathrm{C}$ with different amounts of added $\mathrm{Cl}^{-}$. The results for tests at $\mathrm{pH} 9$ and $\mathrm{pH} 12$ indicate the difference is within experimental uncertainty.

\section{V.C.3. Results of Vapor Hydration Tests (VHTs)}

Vapor hydration tests (VHTs) were developed to accelerate the corrosion of HLW glasses and promote the formation of alteration phases. In the VHT, one or more monolithic test samples are exposed to water vapor at high temperatures (typically up to $200^{\circ} \mathrm{C}$ ) in a sealed vessel. Water vapor condenses on borosilicate glass samples due to deliquescence of the glass initially and then deliquescence of the brine solution that forms as the surface of the glass is dealkalized. Continued reaction occurs between the film of water and the glass. In the standard VHT, the amount of water added to the vessel is carefully controlled to provide a saturated vapor phase plus enough water to condense on the sample without dripping off. This is important for the reaction of glass because dissolution products remain at the surface of the sample in a thin film of water, which may become highly concentrated. The chemistry of the water film affects the dissolution behavior of the glass.

Several VHTs were conducted with various MWF materials in an effort to accelerate corrosion processes. In the case of the MWF, the chemistry of the solution has little effect on the corrosion rate and high temperature was the main accelerating factor. The various MWF alloys tested were all resistant to corrosion in saturated steam environments relative to samples of pure iron and copper that were reacted for comparison, although corrosion of the MWF materials did occur and oxide layers up to about 1 mircometer thick were formed. Several of the MWF specimens recovered from VHTs were examined to study the oxide layers (Abraham et al., 2001; Dietz, 2005; Luo and Abraham, 2000). These are discussed in subsequent sections.

Excess-water VHTs were conducted with samples of SS-15Zr-10U at $70,90,150$, and $200^{\circ} \mathrm{C}$ to measure the release of $U$ under these test conditions (see Section IV.B.7 for a description of the test method). The amounts of $U$ in the solution in the bottom of the vessel and sorbed onto the vessel walls were measured. The $\mathrm{U}$ was dissolved from the vessel walls by filling the vessel with dilute $\mathrm{HNO}_{3}$ and heating at $70^{\circ} \mathrm{C}$. 


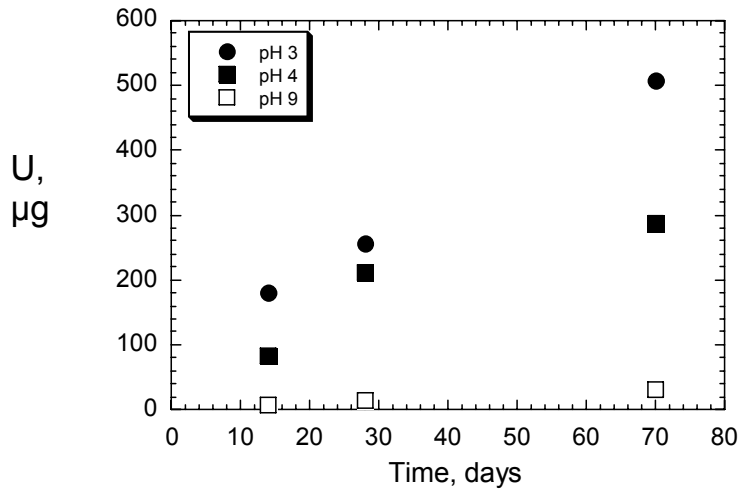

(a)

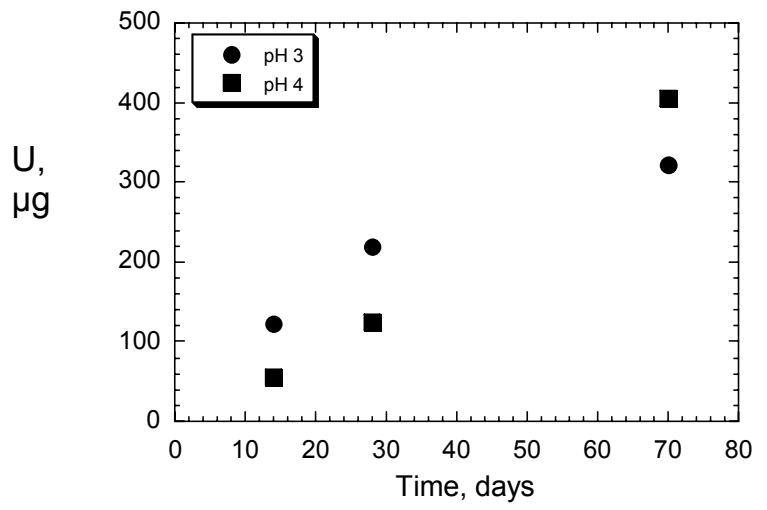

(c)

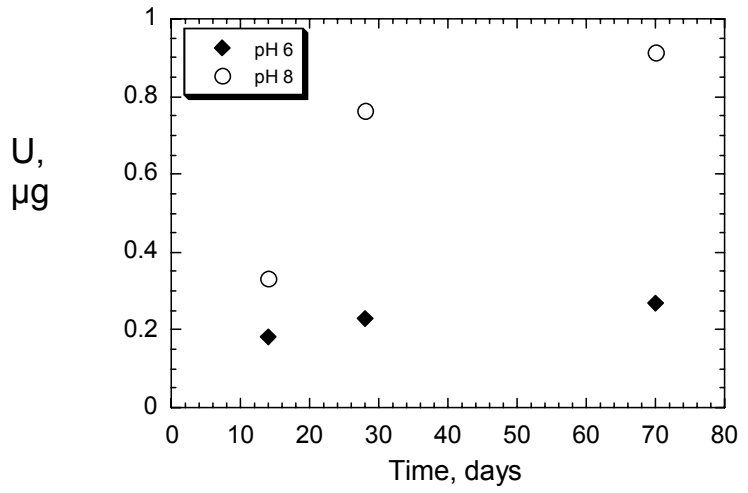

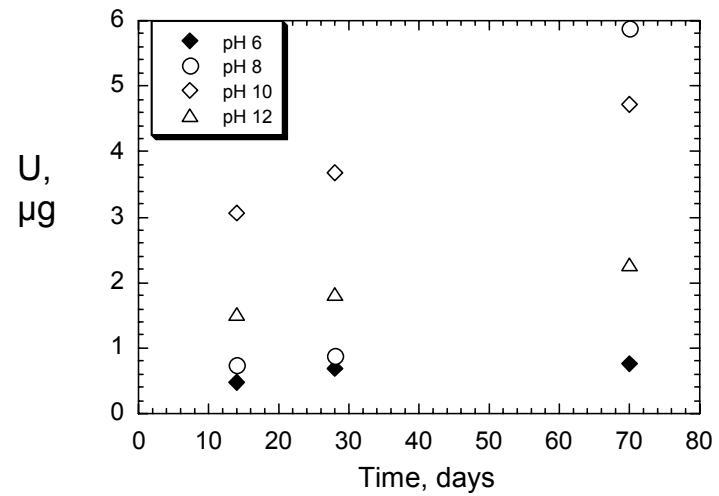

(b)

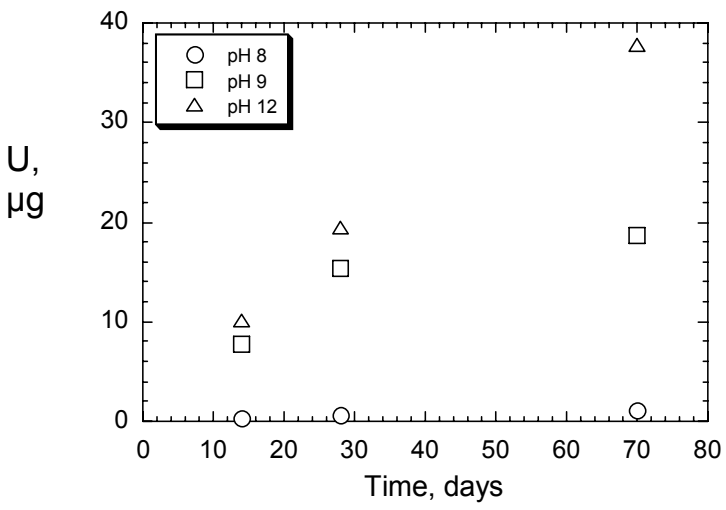

(d)

(e)

Fig. V-6. Cumulative Release of U vs. Cumulative Reaction Time for Tests at (a) and (b) $50^{\circ} \mathrm{C}$, (c) and (d) $90^{\circ} \mathrm{C}$, and (e) $70^{\circ} \mathrm{C}$. 
Table V-8. Cumulative NL(U) at $50^{\circ} \mathrm{C}$ through 70 Days for Tests with Leachants Spiked with 10,000 and $1,000 \mathrm{ppm} \mathrm{Cl}^{-}$and without $\mathrm{NaCl}$, in $\mathrm{g} / \mathrm{m}^{2}$

\begin{tabular}{|c|c|c|c|c|c|}
\hline \multirow{2}{*}{$\begin{array}{c}\text { Added } \mathrm{Cl}^{-} \\
(\mathrm{ppm})\end{array}$} & \multicolumn{5}{|c|}{$\mathrm{pH}$} \\
\cline { 2 - 6 } & 4 & 8 & 9 & 10 & 12 \\
\hline 10,000 & 36.8 & 0.107 & 0.804 & 0.805 & 0.0523 \\
\hline 1000 & 4.94 & 0.0884 & 0.239 & 0.0859 & 0.0416 \\
\hline 0 & 2.14 & 0.0126 & 0.940 & 0.0251 & 0.0694 \\
\hline
\end{tabular}

The cumulative release of $U$ from the MWF samples in duplicate tests at each temperature are shown in Fig. V-7. (Note that the sample in Test 1 at $200^{\circ} \mathrm{C}$ fell into the solution after between 56 and 81 days of reaction and again between 81 and 108 days, which resulted in significant increases in the amount of $U$ released into the solution. These data are included in Fig. V-7d to show that corrosion under excess-water VHT conditions is slower than aqueous corrosion.) All of the test specimens were immersed in water after 127 and 237 days of reaction (after 111 days for tests at $70^{\circ} \mathrm{C}$ ) to measure the amount of $U$ that had been released from the MWF but had not been flushed from the surface; the amounts were significant.

These results show that measurable amounts of $U$ are released from MWF exposed to humid air even at temperatures as low as $70^{\circ} \mathrm{C}(\mathrm{Fig}$. V-7a). The release rates measured in the tests are a combination of the rate $U$ is released from the MWF and the rate solution drips from the samples. The release was faster after the samples were rinsed, although the reason for the increase is not known. Dashed lines are drawn in Figs. V-7a, V-7b and V-7c to estimate the maximum release rates at $70^{\circ} \mathrm{C}, 90^{\circ} \mathrm{C}$, and $150^{\circ} \mathrm{C}$, which are about $5 \times 10^{-4}, 9 \times 10^{-4}$, and $6 \times 10^{-3} \mathrm{~g} /\left(\mathrm{m}^{2} \mathrm{~d}\right)$, respectively. All of the solutions recovered from the excesswater VHTs were slightly acidic (pH 5-7).

It is not understood why the U release increased after the sample was rinsed (after 127 days). It is possible that the release of $U$ from the MWF is slowed in these tests due to $U$ solubility limits in the solution on the MWF sample. The solution that had accumulated on the sample was not rinsed off during previous samplings, and the $U$ concentration was not measured directly. However, the amounts of $U$ in the rinse solutions collected after 127 days were similar to the amounts of $U$ that had accumulated in the bottom of the vessels during the test to that point. Subsequent release (i.e., beyond 127 days) showed a logarithmic time dependence in tests at $90^{\circ} \mathrm{C}$.

Finally, it is interesting to note that the release in tests conducted at $70^{\circ} \mathrm{C}$ occurs faster than the release at higher temperatures. This is attributed to the more extensive condensation of vapor and dripping expected to occur at low temperatures, although this has not been measured. Other tests have shown temperature to have a smaller effect on the release rate than seen in these tests.

\section{V.C.4. Unsaturated (Drip) Tests}

The ANL unsaturated test, sometimes referred to as the drip test, was developed to simulate conditions in the Yucca Mountain repository. In this test, small volumes of water (e.g., $0.07 \mathrm{~mL}$ ) are injected into the test vessel twice a week, where they drip onto and react with a specimen, then drip off the specimen. The solution that accumulates in the bottom of the vessel is collected and analyzed for released waste form components. Drip tests were conducted with MWF materials at $90^{\circ} \mathrm{C}$ using tuff groundwater. The results of duplicate tests with a MWF material SS-15Zr-1Nb-1Ru-1Rh-1Pd-2U-1Tc are shown in Fig. V-8. As observed in other tests, the release of $U$ occurs as fast or faster than the release of Tc under these test conditions, and the release rates of all components become extremely low beyond about 100 days. Comparison of these results with those of solution exchange tests conducted with a very similar material 


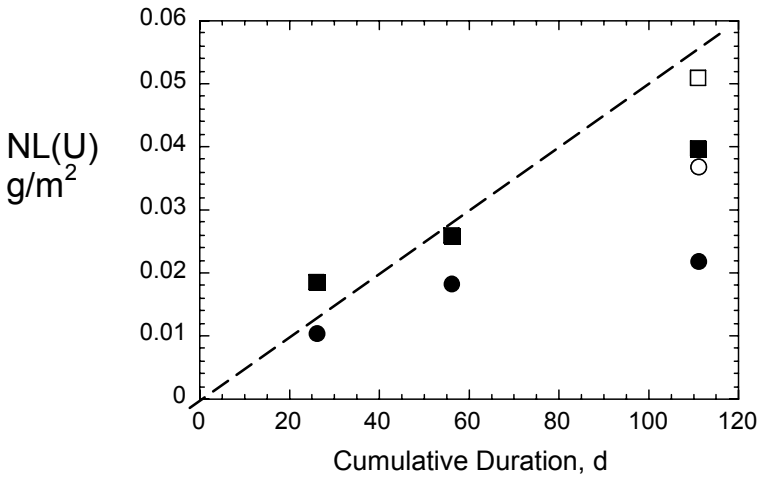

(a)

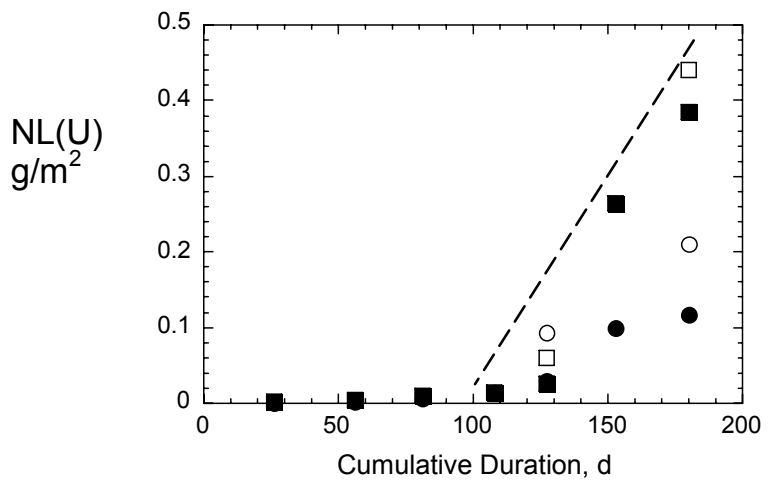

(c)

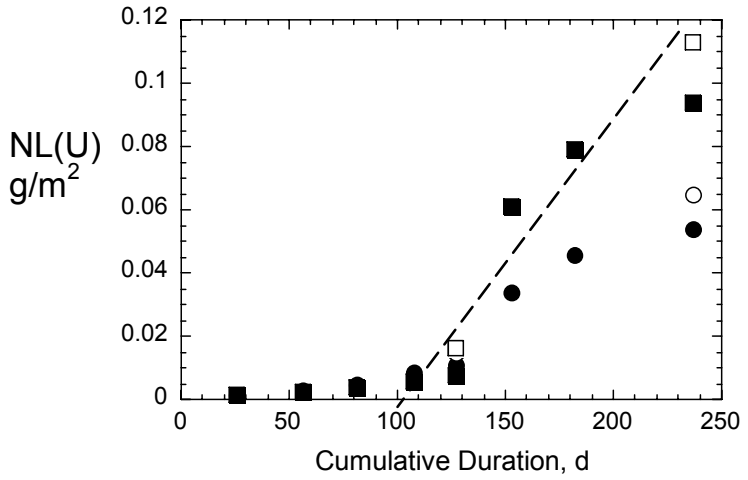

(b)

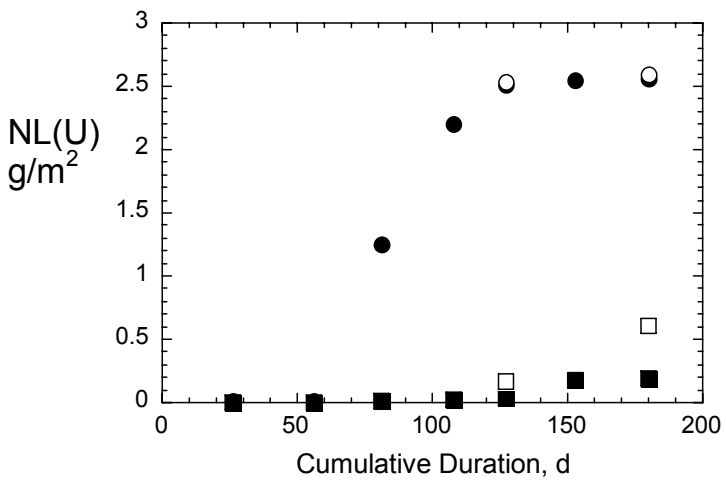

(d)

Fig. V-7. Release of U from MWF in Excess-Water VHTs at (a) $70^{\circ} \mathrm{C}$, (b) $90^{\circ} \mathrm{C}$, (c) $150^{\circ} \mathrm{C}$, and (d) $200^{\circ} \mathrm{C}$ : (O) Test 1 and (ם) Test 2. Open symbols include sample rinse solutions.

(Fig. V-4a) shows the relative releases of $U$ and Tc are almost identical. Corrosion of the MWF and release of radionuclides is not sensitive to the water exposure conditions, and is similar whether the MWF is immersed in water or contacted by dripping water. The releases are slower when exposed to humid air in the excess-water VHTs, although this is probably due to transport limitations in those test.

\section{V.D. Microscopic Examination of Oxidation Layers on Test Samples}

The results of immersion tests, vapor hydration tests, and drip tests are all consistent with the formation of surface layers that act as barriers to the release of U, Tc, and other MWF components. Several of the reacted MWF test samples were examined in cross-section with TEM to characterize the structure and composition of these surface layers (e.g., Dietz, 2005; Luo and Abraham, 2000). These samples consistently showed the presence of thin oxide layers overlying the bulk stainless steel and intermetallic phases. Representative photomicrographs of the layers overlying each phase are shown in Figs. V-9a and V-9b. The oxide layers are often seen to be comprised of sublayers with slightly different morphologies, crystal sizes, or compositions. Two sublayers are seen in the oxide overlying the steel phase in Fig. V-9a and three sublayers are seen overlying the intermetallic phase in Fig. V-9b. Thicker oxide layers are usually seen on the more reactive intermetallic phase. That the oxide layers form in situ by oxidation of the steel and intermetallic phases is evidenced by the sharp interfaces that are observed. For example, Fig. V-10 shows a cross section of the surface of a vapor-reacted sample with a clear interface between the oxide formed at the surface of an intermetallic domain (not shown) and an adjacent steel domain that has not been oxided significantly. The oxide layers formed at the surfaces of the steel and intermetallic phases 


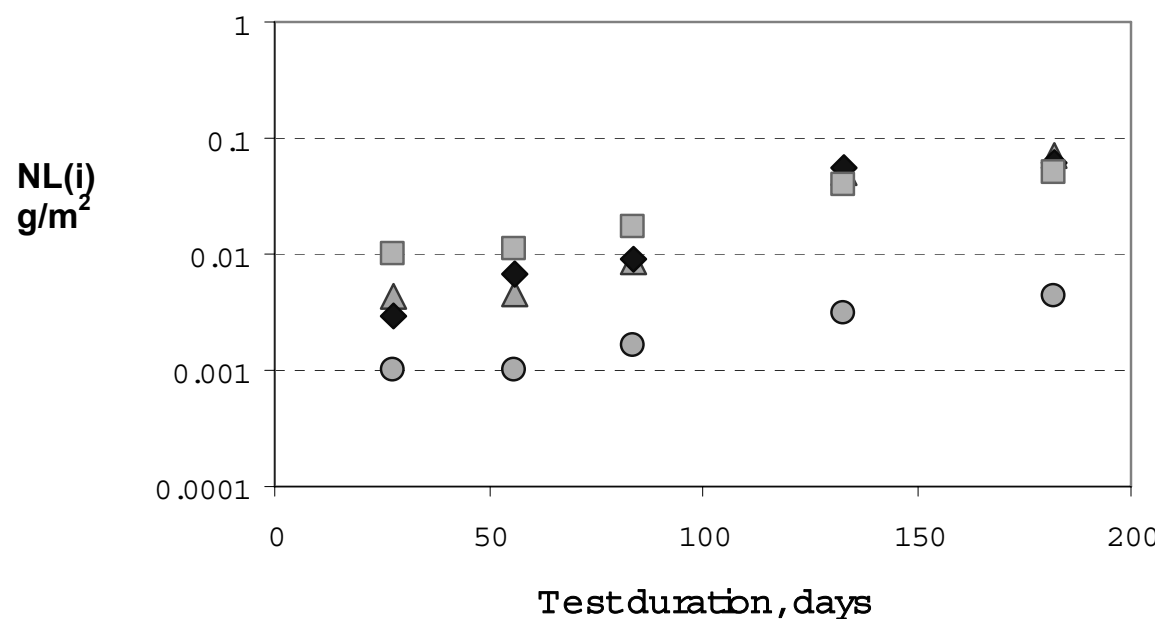

(a)

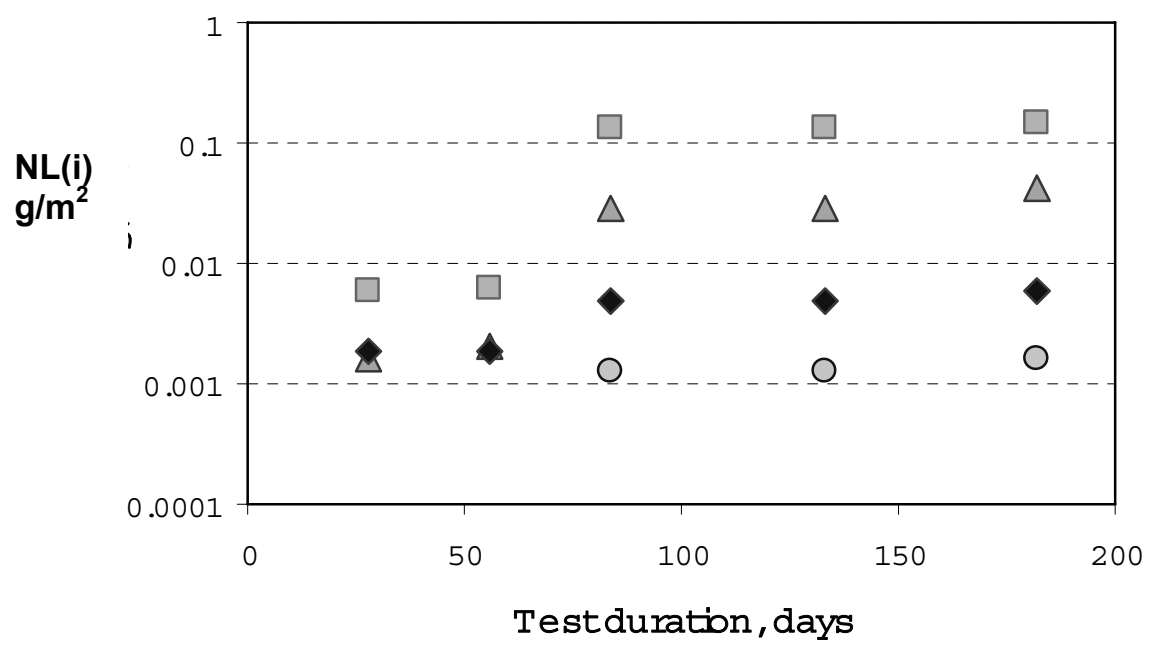

(b)

Fig. V-8. Results of Unsaturated (drip) Tests with SS-15Zr-1Nb-1

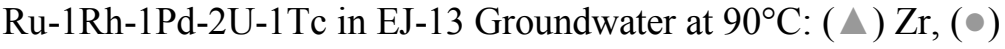
$\mathrm{Ru},(\diamond) \mathrm{Tc}$, and $(\square) \mathrm{U}$.

are presumed to combine to cover the MWF surface and provide a barrier to continued corrosion analogous to the passivation layers that form on stainless steels. Portions of the surface shown in Fig. V10 are also covered by an iron oxide phase (probably $\mathrm{Fe}_{2} \mathrm{O}_{3}$ ) that overlies both the steel and intermetallic phases. This material probably formed in the solution and settled on the surface. Flocculated iron oxide was commonly seen on vapor-hydrated samples and on some samples from immersion tests. These and other phases that may accumulate on the MWF surface as it corrodes may provide additional corrosion barriers, but are not considered separately in the model.

\section{V.E. Monitoring the Consistency of MWF Products}

The PCT method developed to monitor the consistency of HLW glasses provides a relative measure of chemical durability that is correlated with the glass composition and can be compared directly to a 


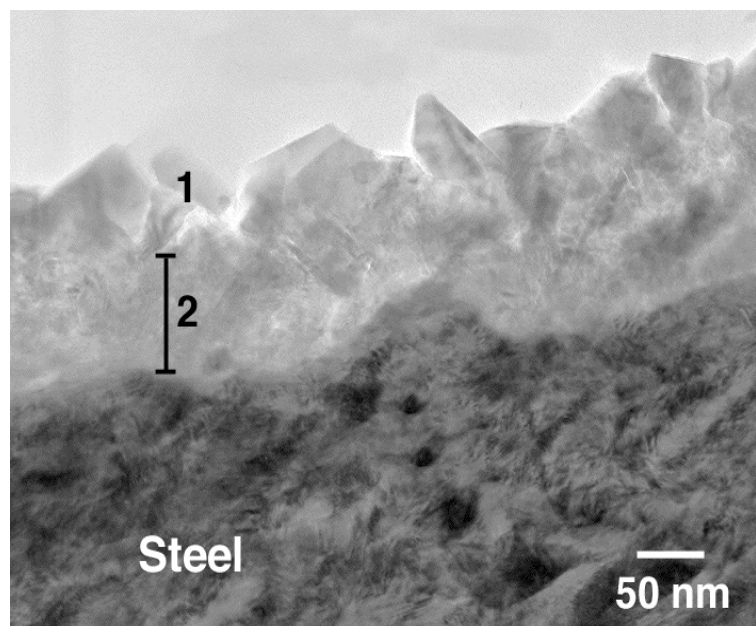

(a)

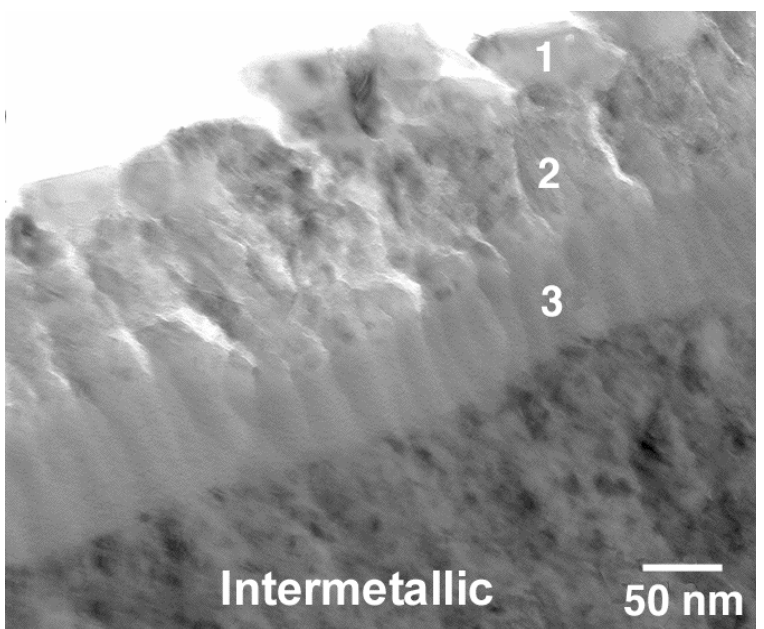

(b)

Fig. V-9. TEM Photomicrographs of Oxide Layers Formed over (a) Stainless-Steel Phase and (b) Intermetallic Phase on MWF Reacted at $200^{\circ} \mathrm{C}$ for 91 Days in Immersion Test.

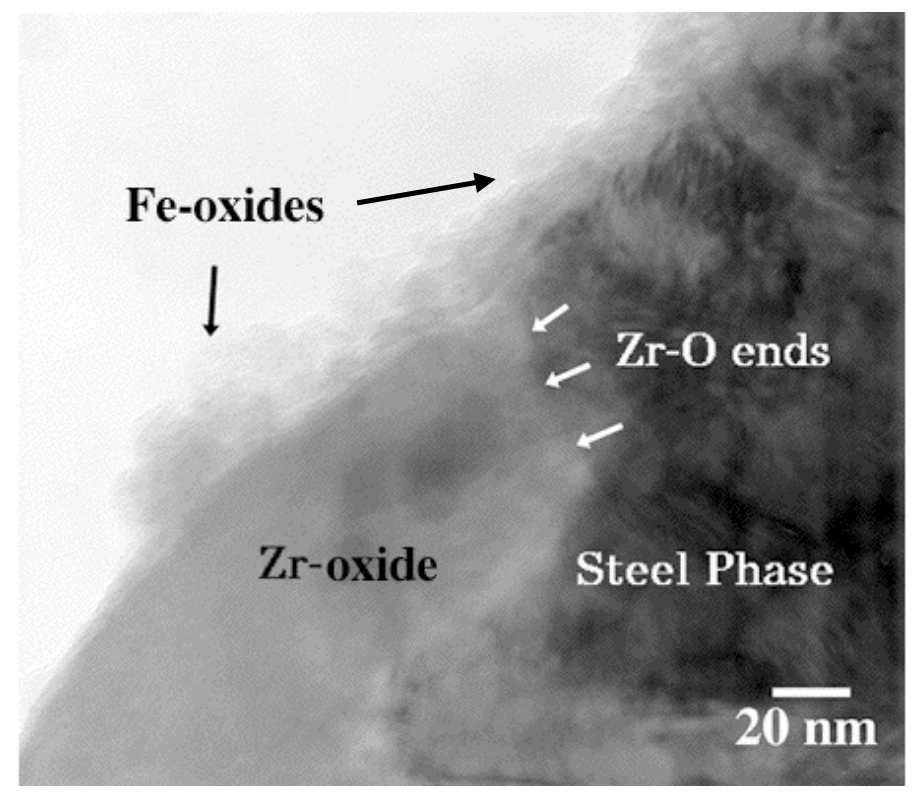

Fig. V-10. TEM Photomicrograph of Flocculated Iron Oxide Colloids Overlaying Stainless Steel/Intermetallic Interface in Vapor-Reacted MWF Sample. 
benchmark response to determine acceptability. Unfortunately, the PCT method is not practical for monitoring the consistency of the MWF products because (1) the PCT is not sufficiently sensitive to variations in the MWF composition to detect products having compositions outside production limits, and (2) the release rates of matrix elements, such as $\mathrm{Fe}$, are not related to the release rates of radionuclides, which is the key concern. A different method is needed to monitor the consistency of MWF products that meets the underlying basis of the consistency requirements in the WASRD. A major purpose of the consistency requirement is to ensure that all HLW glass be more durable than the EA glass. This requirement was established in 1993 (the initial issue date for WASRD) to allow (1) HLW glasses to be developed and produced of prior to the design of the repository and (2) the repository to be designed for glasses with a known minimum durability. The repository has now been designed and a model has been developed to calculate the impact of HLW glass degradation on repository performance. The acceptability of non-standard HLW waste forms (such as the MWF) can now be determined by comparison with the HLW glass degradation model rather than with the EA glass. In fact, the minimum durability in the HLW glass degradation model is very near the durability of the EA glass in the PCT, so that HLW glasses (and other waste forms) that are determined to be acceptable by comparison of the PCT response with that of the EA glass are also acceptable by comparison with the model. The key remaining role of product consistency requirement is to ensure that all waste form products meet their design criteria.

A method analogous to the way the PCT monitors the consistency of HLW glasses was sought for monitoring the consistency of MWF products. The approach taken was not to mimic the PCT, but to address the issues underlying the use of the PCT for HLW glasses. The chemical durability of a HLW glass determines its radionuclide release properties, and its chemical durability is determined by its composition. Therefore, composition is the key property controlled during the production of HLW glasses. The chemical durability of a HLW glass must be compromised to facilitate its production; i.e., it must have an acceptable melting temperature, viscosity, etc. For glasses made at the DOE DWPF at the Savannah River Site, the PCT responses of a wide range of glasses have been correlated with their compositions using the THERMO glass product quality model to predict durability and production properties (Jantzen et al., 1994). The PCT responses of most DWPF HLW glasses will be predicted from the composition of the vitrified melter feed using the model rather than being directly measured. That is, the predicted PCT response a given glassmelt will be compared with that measured (or predicted) for the EA glass to determine acceptability, and frit or chemicals will be added as necessary to attain a composition having an acceptable predicted durability. A similar approach will be used during vitrification of Hanford tank wastes.

The planned approach for MWF production is essentially the same as that used for HLW glasses. The composition of the metallic waste stream will be analyzed for $\mathrm{U}$ isotopes and $\mathrm{Zr}$ (or calculated based on the fuel rods treated in a particular batch) to determine how much ${ }^{238} \mathrm{U}$ and $\mathrm{Zr}$ need to be added to the feed stream. The addition of $\mathrm{Zr}$ to will affect the durability due to its effect on the microstructure and the amount of intermetallic phase that forms. Based on the results of solution exchange tests (see Section V.C), the addition of natural or depleted U to down-blend to LEU levels is not expected to have a significant affect the durability of the waste form. It is expected that the total amounts of $\mathrm{U}$ and $\mathrm{Zr}$ in the MWF products will be controlled to within $1 \mathrm{wt} \%$ of their respective target contents during production, based on analysis of the waste stream and weighing the amounts of $\mathrm{U}$ and $\mathrm{Zr}$ added to the waste stream. These measurements will be part of the production records used to verify the consistency of the MWF product. In most cases, the amount of $\mathrm{Zr}$ added will be much greater than the amount already present in the waste stream, so the measured amount of added $\mathrm{Zr}$ will provide a lower bound to the total.

The durability of HLW glasses is most sensitive to the concentrations of several glass-forming components, including $\mathrm{Si}, \mathrm{Al}$, and $\mathrm{Fe}$. Concentration ranges are not specified for any particular element; rather, the combined concentrations of all elements determine the chemical durability of the glass using the THERMO model. The elements $\mathrm{B}, \mathrm{Li}$, and $\mathrm{Na}$ are monitored in the PCT because they are released 
from the glass faster than other components as the glass dissolves and have high solubility limits, not because they contribute to the glass durability. The concentration of Si is usually measured in PCTs, but is not included in the WASRD requirement. The releases of $\mathrm{B}, \mathrm{Li}, \mathrm{Na}$, and $\mathrm{Si}$ can each be correlated with the durability of the glass. The glass durability in the defense HLW glass degradation model is based on the release of B in laboratory tests.

In contrast, the durability of the MWF depends primarily on the $\mathrm{Zr}$ content because of its effect on the amount of intermetallic phase in which most radionuclides are sequestered. The anticipated variations in the concentrations of the most abundant elements $(\mathrm{Fe}, \mathrm{Cr}$, and $\mathrm{Ni}$ ) in the metallic waste stream will not significantly affect the microstructure of the intermetallic phase or the MWF durability. The lower control limit of 5\% $\mathrm{Zr}$ addresses the need for a sufficient volume of the intermetallic phase to host all the radionuclides and the upper control limit of $20 \% \mathrm{Zr}$ is due to the need for a sufficient volume of the steel phase to ensure adequate physical robustness. By maintaining the eutectic microstructure of the $\mathrm{Zr}(\mathrm{Fe}, \mathrm{Cr}, \mathrm{Ni})_{2+\mathrm{x}}$ intermetallic and $\mathrm{Fe}$ solid solution phases, the ranges of other physical and chemical properties will be constrained. Therefore, the method used to monitor MWF product consistency must simply identify products with compositions that lie outside the eutectic range, i.e., those with $\mathrm{Zr}$-contents less than $5 \%$ or greater than $20 \%$.

Several alternative methods to determine the $\mathrm{Zr}$-content have been considered, including X-ray fluorescence, in situ XRD, X-ray spectroscopy in a SEM, and chemical analysis (Keiser et al., 2002a, 2002b). It has been recommended that direct measurement of the $\mathrm{Zr}$ content in the MWF product be used to track consistency. This can be done by in situ analysis, by drilling actual MWF products and analyzing the drill shavings, or by preparing separate witness samples in parallel with the full-scale ingots using a grab sample of the waste feed. Witness samples are analogous to grab samples of HLW glassmelts taken while they are being poured into the canister. Chemical analysis of the MWF ingots provides direct measurement of $\mathrm{Zr}$ and other components.

The compositions of drill shavings and cores cut from MWF alloys were compared to evaluate how well the composition of drill shavings represents the MWF composition. Core samples were cut from the top, middle, and bottom cross sections of three MWF ingots. The drill shavings were collected from the bottom surface of the ingot to avoid the slag layer that is present on the top of the ingot. To avoid any surface contamination that may be present on the bottom of the ingot, a 0.5 -inch hole was drilled into the ingot before shavings were collected for chemical analysis. Table V-9 gives the results for analyses of the drill shavings and the core-drill sections. Comparison of the core-drill compositions at the top, middle, and bottom reflect the homogeneity of the MWF. No statistically significant differences were observed between the measured elemental composition of the drill shaving samples and the ranges for samples obtained from the top, middle, or bottom regions of each ingot. Chemical analysis of drill shavings are representative of the bulk MWF. Coupled with the data base for MWF samples evaluated during waste form development, chemical analysis will provide sufficient information to ensure that the physical, chemical, and microstructural properties of the MWF are acceptable and to monitor product consistency.

\section{V.F. MWF Degradation Model}

Because of the paucity of data for MWF corrosion that was available at the time, the initial model developed for the MWF was a modification of a stainless steel corrosion model (Wigeland et al., 1999). It was presumed that a passivation layer forms on the MWF analogous to steel and that localized corrosion would have a small effect on radionuclide retention. For example, crevice corrosion occurs in moist regions where aqueous diffusion is severely limited. Passivation of such a site would be slowed by the unavailability of oxidants within the crevice. Crevice corrosion is enhanced by the presence of dissolved $\mathrm{Cl}^{-}$. Crevices can be formed by interfaces with other materials, porosity in the MWF, and slag. The 


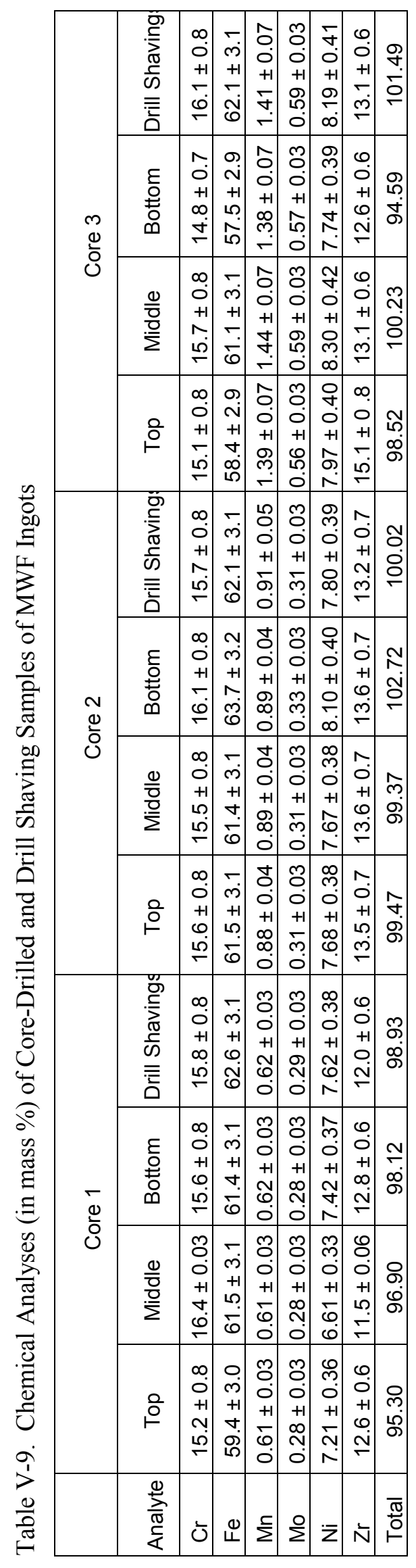


impact of crevice corrosion cracks on the release of radionuclides will depend on the volume of material that is affected. The initial model for MWF degradation was a linear combination of $80 \%$ uniform corrosion and 20\% crevice corrosion (Wigeland et al., 1999):

$$
\text { corrosion rate }=\left(10^{-0.182 p H+0.00145 p H \times T}\right) \times\left(9.4+0.006[H a]^{1.22}\right)
$$

where $\mathrm{T}$ is the temperature in ${ }^{\circ} \mathrm{C}$ and $[\mathrm{Ha}]$ is the sum of the fluoride and chloride concentrations, in $\mathrm{mg} / \mathrm{L}$.

An empirical model has since been developed for MWF degradation based on the results of electrochemical and dissolution tests with several MWF materials (Bauer et al., 2001; Bauer et al., 2002; Fink et al., 2000; Snyder et al., 2004). That model incorporates the dependencies on temperature, $\mathrm{pH}$ and $\mathrm{Cl}^{-}$that were measured in test environments ranging from $\mathrm{pH} 2$ to $\mathrm{pH} 12,25^{\circ} \mathrm{C}$ to $90^{\circ} \mathrm{C}$, and about 0 to $10,000 \mathrm{ppm} \mathrm{Cl}^{-}$. The model is based on the general result of immersion tests that the initially bare MWF surface becomes covered with oxide layers that slow the releases of radionuclides and matrix components to solution. The layers passivate the MWF surface, but credit is only taken for short time periods due to the lack of evidence regarding the long-term stability of the oxide layers. (The roles of the specific layers discussed in Section V.D are not identified in the model; rather, the rates measured by elemental releases are attributed to the general formation of layers.) The model presumes a common time dependence for the oxidation and release of constituents to solution, and the growth of oxide layers at the MWF surface. If the corrosion and release rates decrease exponentially with the growth of the oxide layers, then the cumulative release of all MWF constituents should follow the logarithmic growth form in Eq. V-5:

$$
\text { cumulative constitute release }=a \times \ln (1+b t)
$$

where $a$ and $b$ are fitting parameters and $t$ is time. The thickness of the oxide layers should increase following the same equation. The fitting parameters $a$ and $b$ have the following significance: the product $a \times b$ gives the initial release rate prior to formation of the layer, $1 / b$ gives the characteristic time required to passivate the surface, and $a$ represents the extent of corrosion necessary for the layer to significantly slow the release. The MWF does not dissolve stoichiometrically in laboratory tests due to differences in the elemental solubility limits and the formation of alteration phases.

Although there is no experimental evidence that the slowing effect of the oxide layers will diminish over time, for example by sloughing off, the model pessimistically limits the value of $T_{e}$ to $\leq 1$ year, which is the longest most test series were conducted. The average release rate over the time interval $T_{e}$ that the oxide layer remains an effective barrier is:

$$
\text { release rate }=\frac{a_{\max } \times \ln (1+b t)}{T_{e}}
$$

The term $a_{\max }$ is used to indicate that the element released the fastest under particular conditions was used to fit the model. Values of the model parameters $a_{\max }$ and $b$ capture the dependencies on temperature $\left({ }^{\circ} \mathrm{C}\right)$, $\mathrm{pH}$, and the $\mathrm{Cl}^{-}$concentration $(\mathrm{mg} / \mathrm{L})$. Expressions were determined by assuming simple linear or quadratic dependence on these variables, using a least-squares fit of the experimental data, and minimizing the number of free parameter combinations. The dependencies, which were determined by fitting results in Johnson et al. (2001) and Snyder et al. (2004), are given in Eqs. V-7a and V-7b (see Bauer et al., 2001; Bauer et al., 2002):

$$
\ln \left(b \times a_{\max }\right)=-0.10105+\left(0.015112+5.8201 \times 10^{-6} \times\left[C^{-}\right]\right) \times T-0.69848 \times p H
$$


and

$$
\ln a_{\max }=7.9812+\left(2.3938 \times 10^{-4} \times\left[\mathrm{Cl}^{-}\right]\right)-1.2273 \times p H
$$

The fitted dependencies in Eq. 7 are not unique relationships, rather they provide physically sensible fits for repository-relevant conditions. The modeled rate increases with increasing temperature and $\mathrm{Cl}^{-}$ concentration, and with decreasing pH. Equation V-6 can be rewritten in terms of the fitted dependencies as

$$
\text { bounding release rate }=\frac{a_{\max } \times \ln \left(1+\frac{b \times a_{\max }}{a_{\max }} T_{e}\right)}{T_{e}}
$$

where the cumulative release over the interval $T_{e}$ is used to provide a conservative time-independent rate that can be compared with the rates calculated with defense HLW glass degradation model. As is done for HLW glasses, a single set of model parameter values is used to represent the possible range of MWF compositions, although the range of MWF compositions will be much smaller than the range of glass compositions.

\section{V.G. Comparison with the Defense HLW Glass Degradation Model}

The effects of temperature and $\mathrm{pH}$ on the MWF degradation rate can be compared to the temperature and $\mathrm{pH}$ dependence of the defense HLW glass degradation model, but the glass model does not include a term for the effects of $\mathrm{Cl}^{-}$(HLW glass dissolution is not affected by dissolved $\mathrm{Cl}^{-}$.) Therefore, the MWF model rates are calculated using the highest practical $\mathrm{Cl}^{-}$concentration for comparison with the glass model. Tuff groundwater contains little $\mathrm{Cl}^{-}$and the greatest source of $\mathrm{Cl}^{-}$will be CWF that is packaged in the same canisters as MWF. It is likely that water in a breached package will contain $\mathrm{Cl}^{-}$due to dissolution of halite from the CWF. It was estimated that a maximum of $620 \mathrm{mg} / \mathrm{L} \mathrm{Cl}^{-}$could be dissolved in water inside a breached canister if all of the halite at the surfaces of two CWF dissolved in the minimum volume of water that would fill a horizontally emplaced waste container to a level that would contact the MWF (see Section IV.F.). Therefore, the $\mathrm{Cl}^{-}$concentration is treated as a constant rather than a variable for the purpose of comparison with the glass model.

The MWF model can also be compared with the rates measured in MCC-1 tests conducted with leachants spiked with $\mathrm{NaCl}$ (see Section V.C.4). The dissolution rate of a MWF material with the composition SS$15 \mathrm{Zr}-10 \mathrm{U}$ was measured in tests conducted at $50^{\circ} \mathrm{C}$ and $90^{\circ} \mathrm{C}$ over a range of $\mathrm{pH}$ values using buffer solutions spiked with $\mathrm{NaCl}$ to attain $1000 \mathrm{mg} / \mathrm{L} \mathrm{Cl}^{-}$. The cumulative amount of $\mathrm{U}$ released over 70 days was used to calculate the average dissolution rate for comparison with the HLW glass and MWF models (Ebert et al., 2003). The rates from tests conducted at 50, 70, and $90^{\circ} \mathrm{C}$ plotted in Fig. V-11 along with the lines showing the rates from the defense HLW glass models at these temperatures over the full $\mathrm{pH}$ range. The dashed lines in Fig. V-11 shows the rates calculated with the empirical MWF model given in Eq. V-8 calculated at $50^{\circ} \mathrm{C}$ and $90^{\circ} \mathrm{C}$ with $620 \mathrm{mg} / \mathrm{L} \mathrm{Cl}^{-}$and a time interval of 1 year. (The rates calculated with $1000 \mathrm{mg} / \mathrm{L} \mathrm{Cl}^{-}$are only slightly higher.) The MWF model is representative of the measured rates in acidic and neutral solutions, but underestimates the rates measured in alkaline solutions. The poor fit in alkaline solutions is due to the simple $\mathrm{pH}$ dependence that is used in the MWF model. The test results used to determine the MWF model parameters showed little $\mathrm{pH}$ dependence in alkaline solutions, and the model may be improved by eliminating the $\mathrm{pH}$ dependence at $\mathrm{pH}>8$.

The key finding demonstrated in Fig. V-11 is that the rates calculated with the defense HLW glass model bound the rates calculated with the MWF model and the rates measured in the MCC-1 tests over the entire $\mathrm{pH}$ range, including the rates in alkaline solutions. (The rate measured in one test at $50^{\circ} \mathrm{C}$ and $\mathrm{pH} 9$ was 


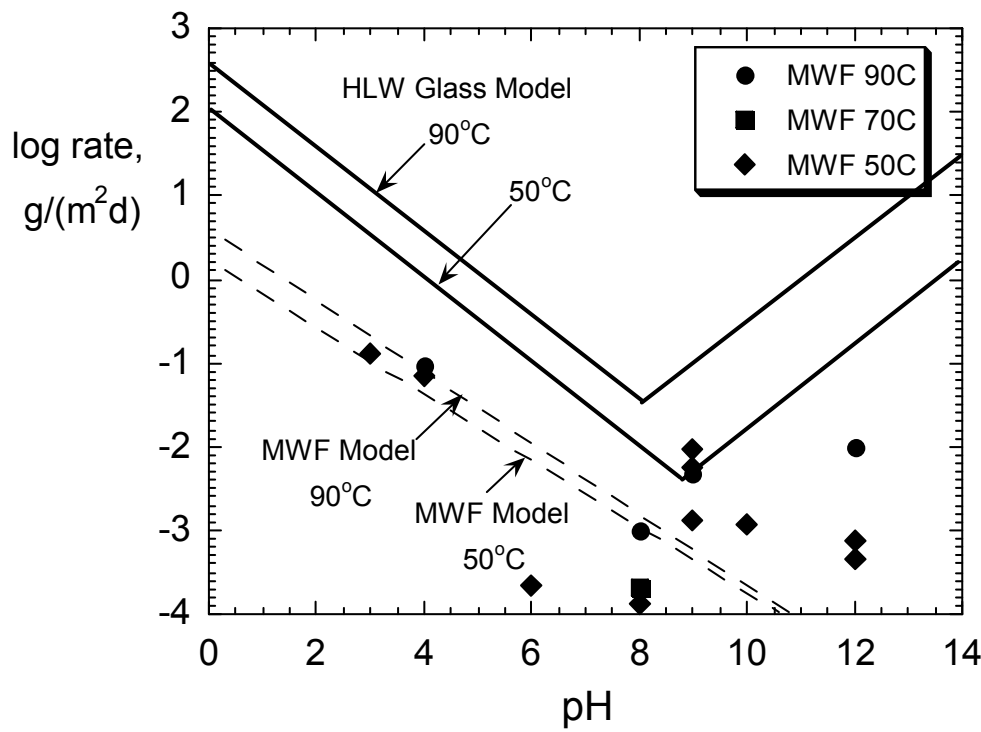

Fig. V-11. Comparison of MWF Degradation Rates Measured in 70-Day MCC-1 Tests at 50, 70, and $90^{\circ} \mathrm{C}$ (data points) and from Empirical MWF Model (dashed lines) with Defense HLW Glass Degradation Model (solid lines) at 50 and $90^{\circ} \mathrm{C}$.

slightly higher than the glass model.) It is important to note that the MWF model (and implicitly the rates from the MCC-1 tests) pessimistically ignore the likely long-term stability of the oxide layers that will probably passivate the MWF surface throughout the service life of the repository. In effect, the MWF model assumes that the oxide layers disappear and reform on an annual basis, such that the average degradation rate from the model becomes increasingly conservative over time. This is not the case in the HLW glass model because a protective layer does not form on glass, and time only affects the glass dissolution rate through changes in the Si concentration in the solution contacting the glass.

The surface area of HLW glasses that will be used in TSPA calculations is based on the dimensions of the glass pour canisters and a cracking factor based on analyses of thermally and impact-cracked glass. As discussed in Section IV.D.2 regarding the CWF, the exposed surface area of an average HLW glass log is taken to be the minimum value of $30 \mathrm{~m}^{2}$ for comparison with the MWF. The MWF ingots will be cast as ingots having a right cylinder geometry 14-16 inches in diameter and 2-5 inches thick. One or two MWF ingots will likely be co-disposed with two ceramic waste form monoliths in a disposal canister. The MWF ingots are not expected to fracture due to cooling or impact, so the geometric surface area represents the maximum surface area that can be exposed to water. The surface area of a representative ingot 16 inches $(40 \mathrm{~cm})$ in diameter and 4 inches $(10 \mathrm{~cm})$ thick is about $0.38 \mathrm{~m}^{2}$. The exposed surface area of two MWF ingots in a breached canister is about $0.76 \mathrm{~m}^{2}$.

\section{V.H. Hazardous Characteristics}

The hazardous characteristics of the MWF were evaluated because small amounts of Cd could be entrained in salts with the cladding hulls and retained in the MWF. It was concluded that the MWF did not exceed ignitability, corrosivity, or reactivity limits (Abraham et al., 1999). The toxicity characteristic was evaluated using the TCLP (Federal Register, 1990). A total of 11 samples were taken from drill shavings of three different MWF ingots made in demonstration runs with radioactive wastes. Ingots 
CFMW06 and CFMW07 were made using driver fuel with Type D9 stainless steel cladding and added Zr. They have nominal compositions of SS-10Zr-2U and SS-16Zr-1U, respectively. Ingot CFMW08 was made using blanket fuel with Type 304 stainless steel cladding plus added Type 316 stainless steel and $\mathrm{Zr}$; it has a nominal composition SS-14Zr-5U. Chemical analyses indicated that $\mathrm{Cr}$ and $\mathrm{Cd}$ were present at detectable levels (see Table V-1). The TCLP results are summarized in Table V-10, with the regulatory limits. The concentrations of all analytes were below the instrument detection limits (which varied with the day the solutions were analyzed) and all were well below the regulatory levels. The MWF products pass the TCLP and are not characteristically hazardous.

Table V-10. Results of TCLP Tests with MWF

\begin{tabular}{|c|c|c|c|c|c|c|c|c|c|}
\hline $\begin{array}{c}\text { Ingot } \\
\text { Number }\end{array}$ & $\begin{array}{l}\text { Sample } \\
\text { Number }\end{array}$ & $\mathrm{Ag}$ & As & $\mathrm{Ba}$ & $\mathrm{Cr}$ & $\mathrm{Cd}$ & $\mathrm{Hg}$ & $\mathrm{Pb}$ & $\mathrm{Se}$ \\
\hline \multirow{4}{*}{$\begin{array}{c}\text { CFWM } \\
06\end{array}$} & 5 & $<0.04$ & $<0.003$ & $<0.23$ & $<0.12$ & $<0.02$ & $<0.007$ & $<0.25$ & $<0.003$ \\
\hline & 6 & $-^{a}$ & $<0.13$ & $<1.7$ & $<0.16$ & $<0.04$ & $<0.02$ & $<0.3$ & $<0.2$ \\
\hline & 7 & $<0.1$ & - & - & $<0.16$ & $<0.04$ & $<0.02$ & $<0.3$ & - \\
\hline & 8 & - & - & - & $<0.16$ & $<0.04$ & - & $<0.3$ & - \\
\hline \multirow{4}{*}{$\begin{array}{c}\text { CFWM } \\
07\end{array}$} & 5 & $<0.04$ & $<0.003$ & $<0.23$ & $<0.12$ & $<0.02$ & $<0.007$ & $<0.25$ & $<0.004$ \\
\hline & 6 & $<0.1$ & $<0.13$ & $<1.7$ & $<0.16$ & $<0.04$ & - & $<0.3$ & $<0.2$ \\
\hline & 7 & - & - & - & $<0.16$ & $<0.04$ & - & $<0.3$ & - \\
\hline & 8 & - & - & - & $<0.16$ & $<0.04$ & - & $<0.3$ & - \\
\hline \multirow{3}{*}{$\begin{array}{c}\text { CFWM } \\
08\end{array}$} & 5 & $<0.04$ & $<0.06$ & $<0.4$ & $<0.12$ & $<0.02$ & $<0.02$ & $<0.25$ & $<0.35$ \\
\hline & 6 & $<0.04$ & $<0.06$ & $<0.4$ & $<0.12$ & $<0.02$ & $<0.02$ & $<0.25$ & $<0.35$ \\
\hline & 7 & $<0.04$ & $<0.06$ & $<0.4$ & $<0.12$ & $<0.02$ & $<0.02$ & $<0.25$ & $<0.35$ \\
\hline \multicolumn{2}{|c|}{ EPA limit $^{b}$} & 5.0 & 5.0 & 100 & 5.0 & 1.0 & 0.2 & 5.0 & 1.0 \\
\hline
\end{tabular}

a Not analyzed.

${ }^{\mathrm{b}}$ Values from Table II.2 of Federal Register (1990). 
V-32 


\section{ACCOUNTING FOR EMT WASTE FORMS IN TSPA CALCULATIONS}

The proposed approach for including the radionuclide release from CWF and MWF in TSPA calculations is to use HLW glass as a surrogate for both. That is, to treat canisters containing CWF and MWF as if they contained HLW glass. This approach is reasonable because the release of radionuclides from HLW glass is calculated as the product of three terms: the specific dissolution rate of the glass, the surface area of glass that is exposed to water, and the mass fraction of radionuclides in the glass. The specific dissolution rate of the glass is calculated in the Defense HLW Glass Degradation Model report (BSC, 2004) with the units mass glass per area per time, for example, $g /\left(\mathrm{m}^{2} \mathrm{~d}\right)$, and the surface area is calculated with units of area (BSC, 2004). The mass fraction of each radionuclide in HLW glass is provided in the Initial Inventory Abstraction report (BSC, 2002) with units of mass radionuclide per waste package, which can be converted to mass radionuclide per mass HLW glass. It has been shown by the work summarized in this report that the specific dissolution rates and surface areas of CWF and MWF in a waste canister are bounded by the values calculated for HLW glass and used in the Defense HLW Glass Degradation Model report (BSC, 2004). The radionuclide inventories of CWF and MWF products are already included in the average inventory to be used for HLW glass (BSC, 2003). The reactivities of the CWF and MWF products over the range of temperatures and seepage solutions to be considered in TSPA calculations are bounded by that modeled for HLW glass. Therefore, the radionuclide releases calculated to occur when a co-disposal waste package containing HLW glass is breached will bound the releases for a co-disposal package containing three CWF products or two CWF products and one MWF product.

Whereas the degradation rate, surface area, and radionuclide inventory are used to compare the roles of the waste forms as source terms, the release of radionuclides from the engineered repository will be controlled by the transportability of the radionuclides that have been released from the waste form. This is taken in to account in TSPA primarily through the concentrations of dissolved and suspended colloidal fractions. A fraction of most radionuclides is treated as immobile due to irreversible sorption on stationary surfaces. The following sections address the adequacy of the TSPA models for describing the EMT waste forms.

\section{VI.A. Dissolved Radionuclide Concentration Limits in TSPA}

The Dissolved Concentration Limits of Radioactive Elements report used for TSPA calculations (BSC, 2005b) provides models for the concentration limits of Th, U, Np, Pu, Am, Pr, Ra, Pb, Tc, C, I, Cs, and $\mathrm{Sr}$. The concentration limits for Th, $\mathrm{U}, \mathrm{Np}, \mathrm{Pu}, \mathrm{Am}$, and $\mathrm{Pr}$ are calculated as functions of $\mathrm{pH}$ and the $\mathrm{CO}_{2}$ fugacity, with uncertainties determined as a function of the $\mathrm{F}^{-}$concentration.

- The dissolved concentration limit of Th is controlled by the solubility of $\mathrm{ThO}_{2}$ over the full range of $\mathrm{pH}$ and $\mathrm{f}\left(\mathrm{CO}_{2}\right)$.

- The dissolved concentration limit of $\mathrm{U}$ is controlled by the solubility of schoepite $\left[\mathrm{UO}_{3} \cdot 2 \mathrm{H}_{2} \mathrm{O}\right]$ under acidic conditions and the solubility of Na-boltwoodite $\left[\mathrm{Na}_{4} \mathrm{UO}_{2} \mathrm{SiO}_{3} \mathrm{OH} \cdot 1.5 \mathrm{H}_{2} \mathrm{O}\right]$ under alkaline and high $\mathrm{f}\left(\mathrm{CO}_{2}\right)$ conditions.

- The dissolved concentration limit of $\mathrm{Pu}$ is modeled to be controlled by the solubility of $\mathrm{PuO}_{2}$.

- The dissolved concentration limit of $\mathrm{Np}$ within the waste package is modeled to be controlled by a combination of the solubilities of $\mathrm{NpO}_{2}$ and $\mathrm{NaNpO}_{2} \mathrm{CO}_{3}$, depending on the $\mathrm{pH}$ and $\mathrm{CO}_{2}$ conditions, with the uncertainty determined as a function of the $\mathrm{F}^{-}$concentration. The $\mathrm{Np}$ solubility outside of a waste package is modeled to be controlled by a combination of $\mathrm{Np}_{2} \mathrm{O}_{5}$ and $\mathrm{NaNpO}_{2} \mathrm{CO}_{3}$.

- The dissolved concentration limit of Am is controlled by the solubility of $\mathrm{AmOHCO}_{3}$ over the full range of $\mathrm{pH}$ and $\mathrm{f}\left(\mathrm{CO}_{2}\right)$.

- The dissolved concentration limit of Pr is modeled based on the limits for Th and Am. 
- Constant dissolved concentration limits are used for Ra over the $\mathrm{pH}$ ranges less than or equal to $\mathrm{pH} 7.75$, between $\mathrm{pH} 7.75$ and $\mathrm{pH} 10.00$, and above $\mathrm{pH} 10.00$.

- The dissolved concentration limit of $\mathrm{Pb}$ is set at $4.8 \times 10^{-7}$ molar.

- Tc, C, I, Cs, and Sr are modeled to be completely soluble and their dissolved concentration limits depend only on the dissolution rate of the waste form.

The dissolved radionuclide concentration limits used to model HLW glass in a co-disposal package with DSNF are applicable to radionuclides released as CWF and MWF products degrade. This is because the limits are calculated as functions of $\mathrm{pH}, \mathrm{CO}_{2}$, and $\mathrm{F}^{-}$concentrations that are either fixed by the seepage water chemistry and repository atmosphere, or will evolve similarly in waste packages with HLW glass or CWF. That is, small differences in the composition of the dissolving waste form will not significantly affect the concentration limits of the key radionuclides. Solutions generated by CWF dissolution will have slightly higher $\mathrm{Cl}^{-}$concentrations than solutions in canisters with HLW glass, but will otherwise be quite similar. Since $\mathrm{Cl}^{-}$is a weak ligand, it is not expected to affect the dissolved concentration limits of any radionuclide. The small impact of $\mathrm{Cl}^{-}$will probably be captured by the uncertainty assigned to the dissolved concentrations in terms of the $\mathrm{F}^{-}$concentration.

\section{VI.B. Treatment of Radionuclide-Bearing Colloids in TSPA}

The treatment in TSPA calculations of radionuclide-bearing colloids generated during waste form degradation is documented in the Waste Form and In-Drift Colloids-Associated Radionuclide Concentrations Abstraction and Summary report (BSC, 2005c). Although that report includes several models addressing difference aspects, they are referred to herein collectively as the colloid model. Three types of colloids are modeled: those generated by HLW glass degradation (all waste form colloids are modeled as smectite clay), those generated by corrosion of metals in the engineered barrier (all corrosion product colloids are modeled as hematite or goethite), and those present in the groundwater (seepage/groundwater colloids). Colloids formed during degradation of CSNF or DSNF are ignored as insignificant. The colloid model considers the formation of pseudocolloids by the sorption of dissolved radionuclides onto existing colloidal material (e.g., clay, and spallation colloids generated by spallation of small particulates of corroded glass). Concentrations of $\mathrm{Th}, \mathrm{Pa}, \mathrm{Pu}, \mathrm{Am}$, and $\mathrm{Cs}$ are calculated in the model, but only $\mathrm{Pu}$-bearing colloids are discussed here. The total amount of $\mathrm{Pu}$ associated with colloids is first calculated based on the difference in Pu based on the extent of waste form degradation and the dissolved $\mathrm{Pu}$ concentration limits. That difference is assigned as the colloidal fraction, which is further divided into waste form, corrosion product, and seepage/groundwater colloids. For TSPA calculations, between $90 \%$ and $99 \%$ of the $\mathrm{Pu}$ that is associated with waste form colloids is modeled to be "embedded" in the colloid, which means that the $\mathrm{Pu}$ is irreversibly attached to colloids and not subject to redissolution. The remaining Pu on waste form colloids is reversibly attached, and model using as sorption coefficient $\left(K_{d}\right)$. Other portions of the Pu released from the waste form are modeled to be associated with corrosion product colloids and to be irreversibly or reversibility attached. The proportions that are reversibly and irreversibly attached are calculated with sorption coefficients as a function of the solution $\mathrm{pH}$ and ionic strength. A minor portion is modeled to be reversibly sorbed onto groundwater colloids. The colloid abstraction does not address the size range of radionuclide-bearing colloids.

The concentration of waste form colloids is estimated using an empirical relationship between the concentration of colloids and the concentration of $\mathrm{Pu}$ that is sorbed onto colloids based on the results of tests with a surrogate HLW glass having a representative Pu content. That relationship is (Eq. 1 in BSC, 2005c):

$$
1 \text { ppm colloids }=2 \times 10^{-8} \underline{M} P u_{\text {colloidal }}
$$


With the dissolved concentration limit, this relationship provides a link between the amount of HLW that has reacted, the amount of $\mathrm{Pu}$ that was released, and the amounts of $\mathrm{Pu}$ that are dissolved and sorbed onto colloids.

The stability of colloids in solution is calculated from the $\mathrm{pH}$ and ionic strength of the solution. Colloid concentrations are negligible at ionic strengths greater than $0.05 \mathrm{M}$. A linear relationship is used to calculate the stable $\mathrm{Pu}$ concentration as a function of the ionic strength $(I)$ over the $\mathrm{pH}$ range $2-10$ and the ionic strength range 0.01-0.05 $\underline{\mathrm{M}}$ (see Eq. 2 in BSC, 2005c)

$$
P u_{\text {colloidal }}(\underline{M})=1.25 \times 10^{-7}-2.50 \times 10^{-6} \cdot I
$$

The Pu colloid concentration is modeled to be $1 \times 10^{-7} \underline{\mathrm{M}}$ for $I$ less than $0.01 \underline{\mathrm{M}}$ and $1 \times 10^{-11} \underline{\mathrm{M}}$ for $I$ greater than $0.05 \underline{\mathrm{M}}$. The ionic strength of tuff groundwaters near Yucca Mountain are less than $0.02 \underline{\mathrm{M}}$., but the ionic strength will increase due to glass dissolution. The proportion of $\mathrm{Pu}$ that is sorbed reversibly is determined using a distribution range of sorption coefficients ( $K_{d}$ values) selected so that between $90 \%$ and $99 \%$ of the $\mathrm{Pu}$ is irreversibly sorbed on waste form colloids. Although corrosion product colloids are considered in the model, the vast majority of $\mathrm{Pu}$ will sorb onto immobile corrosion products.

\section{VI.B.1. Colloids from CWF}

Most of the radionuclides immobilized in CWF products are present in sub-micrometer-size mixed oxide phases that are encapsulated within the binder glass. These phases will contain a mixture of actinide and rare earth elements, and are represented here as $\mathrm{PuO}_{2}$. Tests indicate that some of the $\mathrm{PuO}_{2}$ particles will remain suspended in solution after the binder glass dissolves and be available for transport, although most of the $\mathrm{Pu}$ will become fixed to steel. As seen in Fig. IV-23, about $70 \%$ of the Pu that was released in longterm PCTs became fixed to the steel vessel. About $25 \%$ of the Pu was suspended in 5-100-nm-size colloids and the rest was dissolved or associated with larger colloids. Further analysis indicated the colloids had a bi-modal size distribution with similar populations with sizes of about $8 \mathrm{~nm}$ and $120 \mathrm{~nm}$ (Morss et al. 2002a, 2002b). The smaller colloids are probably single crystallites of $\mathrm{PuO}_{2}$ and the larger colloids are probably aluminosilicate colloids with entrained $\mathrm{PuO}_{2}$.

The colloid model developed for TSPA does not distinguish between colloids of different sizes or whether the colloids are formed by aggregation in the solution or by spalling off the degrading waste form. Therefore, the $\mathrm{Pu}$ released as colloid-sized $\mathrm{PuO}_{2}$ crystallites when CWF degrades will not be distinguishable in the colloid model from $\mathrm{Pu}$ released from HLW glass that becomes embedded in waste form or corrosion product colloids. In addition, the solubility of the $\mathrm{PuO}_{2}$ crystallites probably mimics the reversibly attached Pu in HLW glass-generated colloids. The colloid model provides the concentration of radionuclides associated with colloids and the mass of colloidal material for use as input to subsequent transport models. These are calculated primarily based on the degradation of the waste form, with adjustments for colloid stabilities under particular $\mathrm{pH}$ and ionic strength conditions. The release behavior of $\mathrm{Pu}$ in tests with $\mathrm{U}, \mathrm{Pu}$-loaded $\mathrm{CWF}$ is very similar to the release behavior measured in the tests with HLW glass that were used to develop the TSPA model, although tests with CWF were not conducted long enough or at high enough $\mathrm{S} / \mathrm{V}$ ratios that the colloids became unstable. The $\mathrm{Pu}$ content of CWF products (up to about 0.4 mass \%) will be slightly higher than the Pu contents of most HLW glasses. The LaBS glass being developed to immobilize excess weapons-useable $\mathrm{Pu}$ will contain about 9 mass \% $\mathrm{Pu}$. The expected inclusion of LaBS glass into the HLW inventory will increase the average Pu content used in TSPA calculations. 


\section{VI.B.2. Colloids from MWF}

Although the solutions from tests with MWF were not examined for colloids, flocculated iron oxides were commonly observed on many test samples. These colloids are expected to be the same as corrosion product colloids model in TSPA calculations to be generated by engineered components and to have the same sorption characteristics. Radionuclides released from the MWF will become associated with these colloids to the same extent as radionuclides released from other waste forms. The predominant radionuclides in the MWF are Tc and $\mathrm{U}$, which are not modeled to become associated with colloids for TSPA calculations. The MWF does not contribute significantly to the total $\mathrm{Np}, \mathrm{Pu}$, or Am inventories. The release of $\mathrm{Pu}$ from the MWF is expected to be controlled by the chemistry dissolved concentration limits of $\mathrm{Pu}(\mathrm{VI})$, although the speciation has not been measured. Once in solution, $\mathrm{Pu}$ released from the MWF can become reversibly attached to other waste form colloids (including those generated as the CWF co-disposed in the same canister degrades), corrosion product colloids, and seepage/groundwater colloids. The sorption and transport behavior of $\mathrm{Pu}$ released from the MWF would be indistinguishable from that of Pu released from HLW glass and DSNF.

\section{VI.C. Simulations and Statistical Comparisons}

The Yucca Mountain repository is licensed to contain 70,000 MTHM of nuclear materials, about 90\% of which will be CSNF. The remaining 10\% will include HLW glass and DSNF. Only about 26 MT of spent sodium-bonded SNF is scheduled for treatment and disposal. This is only $0.0037 \%$ of the total and about $0.037 \%$ of HLW. It is expected that the CWF and MWF made from EMT wastes will fill 26 co-disposal waste packages (each of which contains five short HLW canisters). Although the DOE Office of Repository Design must evaluate the acceptability of these wastes for disposal, ANL has analyzed the likely impact of the EMT wastes on the repository performance to compare the performance of the CWF and MWF with other waste forms and to identify parameters that have the greatest influence on repository performance. Comparisons were made based on calculations using simplified versions of the Repository Integration Program (RIP) computer code that is used in the probabilistic assessment of the repository. As the EMT waste forms were developed and tested, comparisons to HLW glass were made between the current models for CWF and MWF and the models for HLW glass that were used in the TSPA validation assessment (DOE, 1998) and site recommendation (SR) calculations (Fanning et al., 2001; Fanning et al., 2003; Morris et al., 2001; Wigeland et al., 1999). Work is in progress for comparisons with the license application model.

The radionuclide release models for the CWF and MWF described in Sections IV-C.2.3 and V-F, respectively, have been used in comparisons with those of other waste forms in the TSPA-VA model (Fanning et al., 2003; Morris et al., 2001). However, calculations for the CWF conducted in these comparisons neglected the feedback effect of the affinity term, i.e., the value of $\mathrm{Q} / \mathrm{K}$ in Eq. IV-9 were set to zero. This gives an extremely conservative estimate of the CWF dissolution rate. For example, the value of $k_{0}$ used in the CWF model in alkaline solutions (the value for binder glass is used in the model) is $2.29 \times 10^{6} \mathrm{~g} /\left(\mathrm{m}^{2} \mathrm{~d}\right)$ (see Table IV-16), whereas the value of $k_{E}$ calculated for CWF is $3.045 \times 10^{3} \mathrm{~g} /\left(\mathrm{m}^{2} \mathrm{~d}\right)$ (see Section IV.D.1). Applying the same simplification used in the HLW glass degradation model to the CWF, the affinity term slows the dissolution of CWF by a factor of about 1,000 times! The same solution feedback effects that slow HLW glass dissolution have been shown to slow CWF dissolution under the same reaction conditions. This added level of conservatism has been used to increase the sensitivity of TSPA simulations to CWF performance to highlight any calculation errors.

Direct comparison of the modeled dissolution rates of CWF, MWF, and HLW glass alone cannot be used to determine how well radionuclides are retained in each waste form. Instead, the fractional releases must be compared to take the specific surface area and inventories into account (i.e., by using Eq. I-1). As discussed in Sections IV.D.2 and V.G, the surface areas of CWF and MWF in each HLW canister will be 
less than the average surface area of HLW glass. The same inventory can be used for HLW glass, CWF, and MWF products.

A simplified "beta version" of the TSPA-VA model was used to more efficiently compare the performance of the different waste forms; e.g., the algorithms for transport of released species through the unsaturated and saturated zones were eliminated. This has no effect on the performance of different waste forms because transport of radionuclides will be insensitive to their source. Other modifications were made to highlight comparisons of the different waste forms. For example, although the number of failed packages containing each waste form will be scaled by the number of packages, simulations were conducted assuming 1,000 packages of each waste form were present to remove the effect of the small number of packages with CWF and MWF on when the initial failure occurs and the calculated releases. (In actual TSPA calculations, the likelihood that a package with a particular waste form is breached will be proportional to the number of packages.) In addition, the water-contact environments were made the same for each waste type. Calculations were made for 10,000, 100,000, and 1,000,000 years and evaluated based on 1,000 realizations (time histories). The calculated releases of ${ }^{129} \mathrm{I}$ and ${ }^{237} \mathrm{~Np}$ over 100,000 years are shown in Figs. VI-1a and VI-1b. The release of ${ }^{129}$ I represents radionuclides for which the releases from the EBS are not solubility-limited. The releases of ${ }^{129} \mathrm{I}$ are similar from the CWF and HLW glass, and both are bounded by the release from DSNF. The normalized cumulative releases are plotted, in which the cumulative release is divided by the mass of the radionuclide in the waste form. After 10,000 years, only $0.0083 \%$ of the ${ }^{129}$ I inventory has been released from the CWF. ${ }^{129}$ I is not present in the MWF. The release of ${ }^{99} \mathrm{Tc}$ is slower from MWF (not shown) than from HLW glass. The release of ${ }^{237} \mathrm{~Np}$ is the same from CWF, MWF, and HLW glass during the first 6,500 years because it is limited by the dissolved concentration limit (the distribution ranges from 0 to $13 \mathrm{~g} / \mathrm{m}^{3}$, with a mean of $0.78 \mathrm{~g} / \mathrm{m}^{3}$ and a median of $0.3 \mathrm{~g} / \mathrm{m}^{3}$.) The cumulative release of $\mathrm{Np}$ is plotted rather than the normalized cumulative release to avoid misleading comparisons due to differences in the Np-contents of the different waste forms. The release of $\mathrm{Np}$ from CWF beyond 6,500 years and from MWF beyond about 8,000 years become lower than from HLW glass when the Np concentration is no longer solubility-limited. 


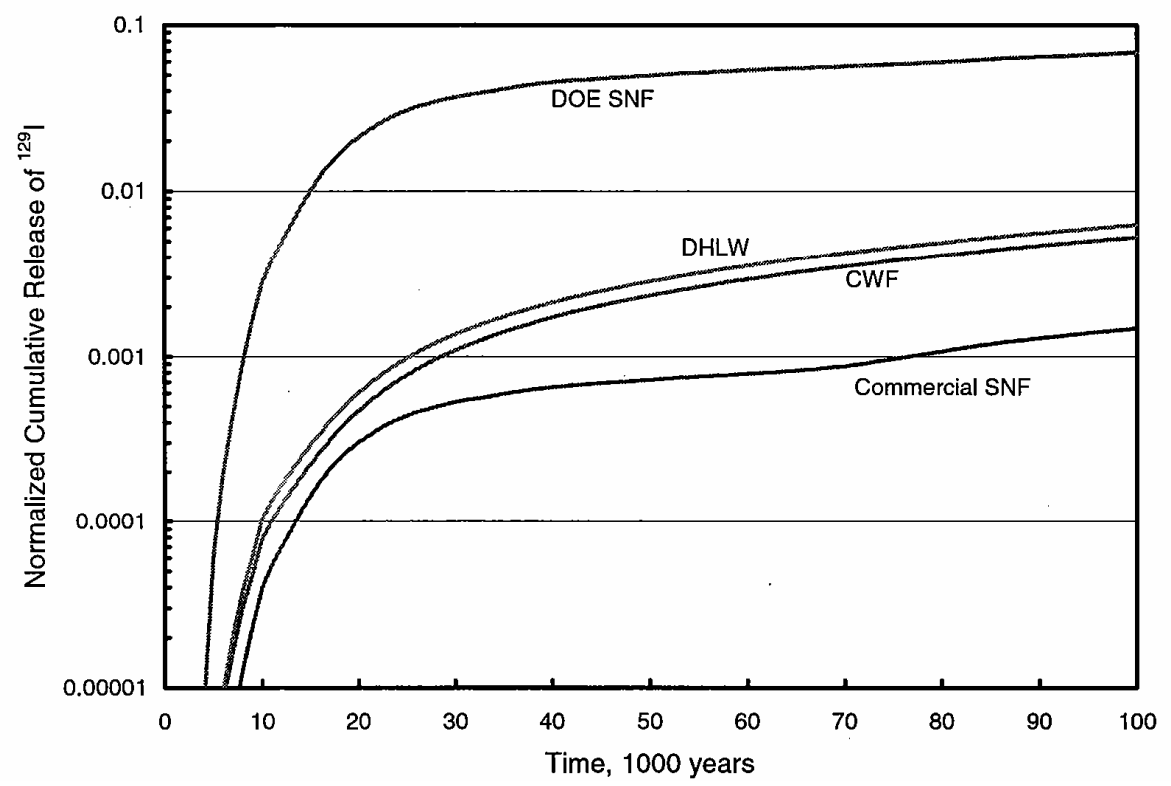

(a)

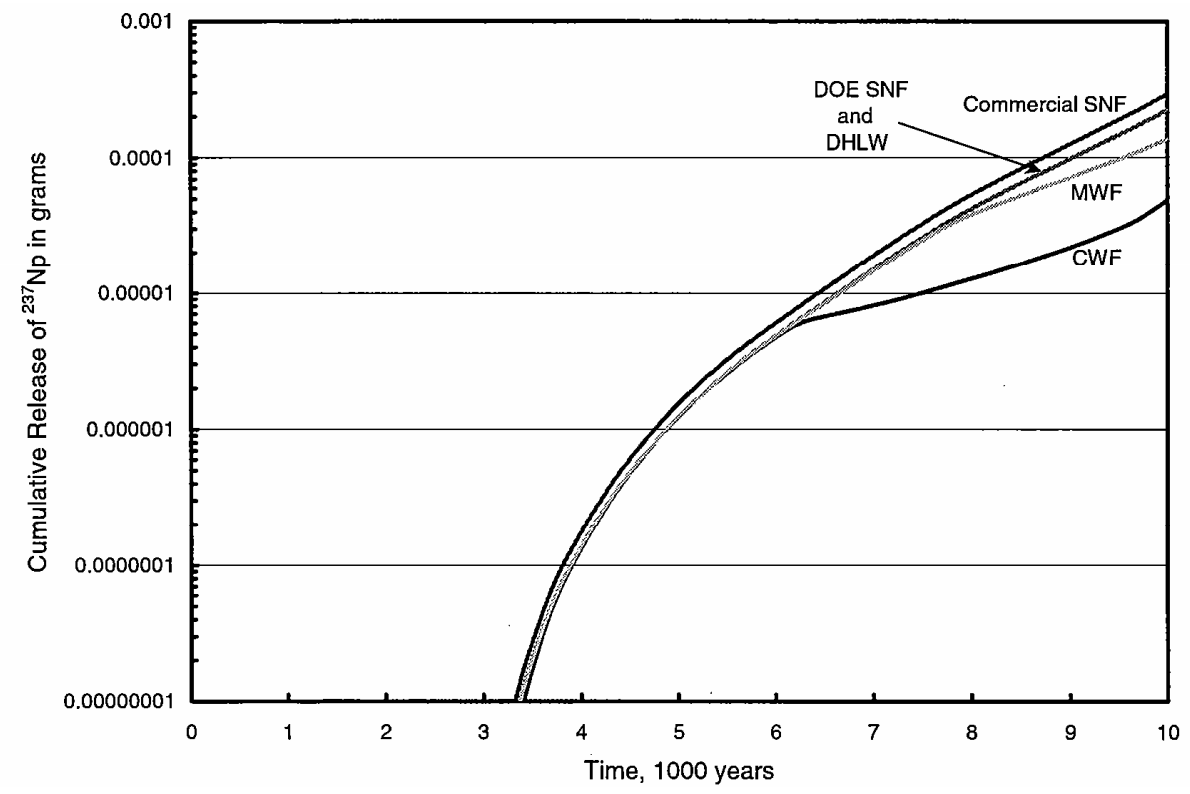

(b)

Fig. VI-1. (a) Normalized Cumulative Release of ${ }^{129}$ I and (b) Cumulative Release of ${ }^{237} \mathrm{~Np}$ from Waste Forms in Simplified TSPA-VA Model Calculations, in $\mathrm{g}$. 


\section{CONCLUSIONS}

An extensive testing program to develop and characterize waste forms to immobilize salt and metallic waste streams produced during the electrometallurgical treatment of spent sodium-bonded nuclear fuel has been completed. Activities included (1) supporting the formulation and production of a waste form for each waste stream, (2) determining the waste form degradation modes important to retaining radionuclides in a disposal system, (3) developing models to calculate long-term durability of the waste forms and radionuclide release, and (4) supporting qualification of the waste forms for acceptance into the DOE CRWMS HLW disposal system.

The CWF was developed as an effective waste form for salt wastes, in which ${ }^{90} \mathrm{Sr},{ }^{137} \mathrm{Cs},{ }^{239} \mathrm{Pu},{ }^{240} \mathrm{Pu}$, ${ }^{241} \mathrm{Pu}$, and ${ }^{241} \mathrm{Am}$ are the primary dose contributors. The sodalite phase stabilizes the chloride and most radionuclides become sequestered in sparingly soluble oxide phases that are microencapsulated in a durable borosilicate glass that binds the sodalite (and other phases) within a physically robust monolithic waste form. Essentially all actinides and rare earth elements are immobilized in mixed oxide phases. Other radionuclides are dissolved in the glass (Cs and probably Sr), sodalite (I), and halite (I) that forms from the small amounts of salt not sequestered in the sodalite. The release of radionuclides is controlled primarily by the dissolution behavior of the binder glass, since few radionuclides are contained in the sodalite and halite. Halite inclusions dissolve immediately when contacted by water. Other inclusion phases can dissolve when contacted by water, but most are sparingly soluble and are more likely to be released as colloids after the surrounding glass dissolves. Dissolution of the sodalite and binder glass occur by hydrolysis reactions that break down the silicate networks, and the dissolution rates of both are well described by the model used for HLW glass dissolution. Model parameter values were measured for sodalite, binder glass, and the CWF. Parameter values measured for the binder glass are used to model CWF degradation and radionuclide release because the binder glass is less durable than sodalite under disposal conditions due to the much lower solubility of sodalite.

The MWF was developed as an effective waste form for metallic wastes, in which ${ }^{234} \mathrm{U}$ and ${ }^{99} \mathrm{Tc}$ are the primary dose contributors. The MWF is a eutectic mixture of steel and $\mathrm{Fe}_{2} \mathrm{Zr}$-type intermetallic phases. Actinides are contained in the $\mathrm{Fe}_{2} \mathrm{Zr}$-type intermetallic phase, where they probably substitute for $\mathrm{Zr}$, and Tc is contained in both the steel and intermetallic phases. The release of radionuclides occurs by a twostep oxidation-dissolution process that leads to the formation of an oxide layer at the MWF surface. Laboratory tests showed $U$ to be released preferentially to Tc under most conditions. Generation of oxide layers over the steel and intermetallic phases lead to a rapid decrease in the release rates of both $U$ and Tc over time. The radionuclide release rates are well represented by an empirical logarithmic expression in which the rate depends on the temperature, $\mathrm{pH}$, and $\mathrm{Cl}^{-}$concentration. The model was calibrated using the $\mathrm{U}$ release rates measured in laboratory tests.

Based on comparison of the models, the releases of radionuclides from the CWF and MWF are bounded by the source term model for HLW glasses that will be used in TSPA calculations to show that the performance of the engineered repository at Yucca Mountain will meet regulatory requirements under the full range of conditions that will be considered for a breached waste package. The release rates of key radionuclides from the CWF and MWF on a per-area basis are lower than the release rates modeled for HLW glass, and the available surface areas are smaller than that modeled for HLW glass. The radionuclide inventory to be used for HLW glass already takes into account the CWF and MWF inventories. In addition to the fact that the radioactive inventory in the CWF and MWF represents less than $0.05 \%$ of the total HLW inventory, the capacities of the CWF and MWF to retain those radionuclides provides confidence that they are adequate waste forms for disposing EMT wastes. 
Specific waste acceptance issues addressed in this report are summarized below.

Compliant Waste Forms - The CWF and MWF products can be shown to be compliant with the Nuclear Waste Policy Act, as amended, by (1) meeting the general requirements for HLW and specific requirements for DOE-managed HLW described in the WASRD, and (2) not diminishing the performance of the engineered geologic repository. The CWF and MWF will be sealed in disposable canisters that are acceptable to the CRWMS system.

Hazardous Waste Requirement - The CWF and MWF products will not be subject to regulation under RCRA. Although the MWF products are likely to contain small amounts of Cd and Cr, TCLP results for representative MWF materials were far below regulatory limits for characteristic-hazardous waste.

Chemical Composition - The chemical compositions of the CWF and MWF will be determined by process knowledge of the waste stream composition and the amounts of chemicals added during their production. The capacities of the CWF and MWF to immobilize the salt and metallic waste streams are not sensitive to the compositions of the waste streams over wide processing ranges. The amount of salt loaded into zeolite and the amounts of SLZ and binder glass mixed to produce the CWF do not have a significant effect on the phase composition or chemical durability of the final product. Actinides and rare earth elements are contained in oxide inclusion phases within the binder glass and are not affected by the relative amounts of sodalite, halite, and binder glass that are present. Other radionuclides are dissolved in the glass or incorporated into the sodalite and halite phases. Likewise, the phase composition of the MWF is not sensitive to the amounts of metallic waste and added $\mathrm{Zr}$ used to make it, provided that the mixture contains at least 5 mass $\% \mathrm{Zr}$. The MWF contains similar amounts of steel and $\mathrm{Fe}_{2} \mathrm{Zr}$ intermetallic phases, and the actinides and most fission products are alloyed in the $\mathrm{Fe}_{2} \mathrm{Zr}$ intermetallic phase.

Crystalline Phase Projection and Phase Stability - The crystalline phase composition of a CWF product will be controlled by the amounts of waste salt, zeolite, and binder glass used in its production. The crystalline phases are thermally stable, although small increases in the relative amounts of nepheline and halite occur due to thermal treatment. This does not affect the chemical durability of the CWF material. The MWF is a eutectic mixture of several alloys that are thermally stable, primarily, ferrite and austenite steel solid solutions and $\mathrm{Fe}_{2} \mathrm{Zr}$-type Laves intermetallic phases. Thermal treatment of the MWF above about $1,000^{\circ} \mathrm{C}$ results in a transformation of austenite and $\mathrm{Fe}_{2} \mathrm{Zr}$ intermetallic to an $\mathrm{Fe}_{23} \mathrm{Zr}_{6}$ intermetallic.

Product Consistency - The consistency of CWF products can be tracked using the seven-day PCT and their chemical durability can be directly compared with the EA glass. The PCT is applicable to the multiphase CWF because the sodalite and binder glass phases dissolve by the same mechanism as HLW glass and are affected similarly by solution feedback. In addition, crushing the CWF does not fractionate the phases; the solution concentrations of key components are sensitive to the amounts of halite, sodalite, and binder glass; and the same precision can be attain in tests with CWF as with glass. The CWF materials made using the full processing ranges of salt-loadings, glass contents, temperatures, and durations were more durable than EA glass in seven-day PCTs.

The consistency of MWF products can be tracked by measuring the $\mathrm{Zr}$ content to ensure it exceeds 5 mass \%. The release of radionuclides is element-specific and is not sensitive to small compositional changes in the waste stream or the amounts of added $\mathrm{U}$ or $\mathrm{Zr}$, provided the $\mathrm{Zr}$ content is at least 5 mass $\%$.

Radionuclide Inventory - The radionuclide inventory will be determined by process knowledge and analyses of the waste streams. The disposition of radionuclides within each waste form has been measured using surrogate materials and products made during process demonstration runs. 
TTT Diagrams - The TTT diagrams were measured for CWF over a temperature range of $400-850^{\circ} \mathrm{C}$ for durations of four hours to one year. Sodalite and halite will be present in all CWF products, and trace amounts of nepheline are formed when the CWF is heat-treated. The chemical durability is not affected by the ingrowth of nepheline.

The thermal stability of MWF was measured at $200^{\circ} \mathrm{C}$ and $>1,000^{\circ} \mathrm{C}$. Heat-treatment at $200^{\circ} \mathrm{C}$ did not affect the microstructure. Treatment at $>1,000^{\circ} \mathrm{C}$ resulted in a transformation of austenite and the $\mathrm{Fe}_{2} \mathrm{Zr}$ $\mathrm{C} 15$ polytype intermetallic into ferrite and the $\mathrm{Fe}_{2} \mathrm{Zr} \mathrm{C} 39$ polytype intermetallic with an increase in the phase domain size relative to the as-cast material.

Waste Form Dissolution Behavior and Rate - CWF degradation occurs by the dissolution of component phases: sodalite (about 72 volume \% of CWF), binder glass (about 25 volume \%), halite (about 2 volume \%), and various oxide and silicate inclusion phases (about 1 volume \% total). Most of the radionuclides are contained in oxide phases, with some dissolved in the glass, halite, and sodalite. The release of most radionuclides requires degradation of the binder glass. Radionuclides that are dissolved in the glass will be released congruently with the matrix components, although transport will be controlled by solubility. The release of radionuclides that are containing within inclusion phases will depend on the solubility of the phase or the transportability of the phase as a colloid. Most of the $\mathrm{Pu}$ is contained in nanometer-sized mixed oxide inclusion phases. Dissolution of the binder glass slows as the $\mathrm{Si}$ concentration in the solution increases, and will be very slow in the highly concentrated solutions that are expected in the repository due to the limited amount of water.

MWF degradation occurs through an oxidation-dissolution mechanism and radionuclide release rates are element-specific; U was released faster than Tc under most laboratory test conditions. Oxide layers form over both the steel and intermetallic phases and slow the releases of all components. The oxide layers effectively passivate the MWF surface.

Waste Form Surface Area - The combined geometric surface areas of the monolithic CWF and MWF products to be placed in HLW canisters will be less than the geometric surface area of an average HLW glass product. The CWF and MWF products are not expected to crack during processing or handling, whereas the HLW glasses are expected to crack and increase the surface area available for degradation. The surface area-to-mass ratio of the CWF and MWF will be lower than that of HLW glass.

Waste Form Inventory - The amounts of some radionuclides (on a Ci-per-waste-package basis) in the CWF and MWF products will be greater than the average values to be used for HLW glass in TSPA calculations, although the average values for HLW glass already include the inventories in the CWF and MWF. Most significant are ${ }^{239} \mathrm{Pu},{ }^{240} \mathrm{Pu},{ }^{241} \mathrm{Pu}$ in the CWF, and ${ }^{99} \mathrm{Tc}$ in the MWF, which are present at levels about 10 times higher than the average to be used for HLW glass. The Pu inventory will increase when the LaBS glass containing excess weapons-usable $\mathrm{Pu}$ is included in the average.

Colloids - Actinide and rare earth element fission products will be immobilized in colloid-sized oxide phase inclusions in the CWF binder glass. Upon dissolution of the surrounding binder glass, some of these may be dispersed in the groundwater and transported as colloids. In the TSPA model, between 90 and $99 \%$ of the Pu and Am released from HLW glass is presumed to be irreversibly attached to colloids and transportable. The models that will be used to calculate concentrations and transportability of HLW glass colloids can be used to estimate these for the CWF. 
VII-4 


\section{REFERENCES}

ASTM: American Society for Testing and Materials

ASTM 2005a. Standard Test Methods for Determining Chemical Durability of Nuclear Waste Glasses: The Product Consistency Test (PCT). Standard C1285, Annual Book of ASTM Standards, Vol. 12.01. West Conshohocken, Pennsylvania: American Society for Testing and Materials.

ASTM 2005b. Test Method for Static Leaching of Monolithic Waste Forms for Disposal of Radioactive Waste. Annual Book of ASTM Standards, Vol. 12.01. West Conshohocken, Pennsylvania: American Society for Testing and Materials Standard C1220.

ASTM 2005c. Standard Practice for Conducting an Inter-laboratory Study to Determine the Precision of a Test Method. Standard E691, Annual Book of ASTM Standards, Vol. 14.02. West Conshohocken, Pennsylvania: American Society for Testing and Materials.

ASTM 2005d. Standard Practice for Conducting Potentiodynamic Polarization Resistance Measurements. Standard G59, Annual Book of ASTM Standards, Vol. 03.02. West Conshohocken, Pennsylvania: American Society for Testing and Materials.

Aagaard, P., and Helgeson, H.C. 1982. "Thermodynamics and Kinetic Constraints on Reaction Rates Among Minerals and Aqueous Solutions, I. Theoretical Considerations." American Journal of Science, 282:237-285 (1982).

Abraham, D.P.; McDeavitt, S.M.; and Park, J.Y. 1996a. "Microstructure and Phase Identification in Type 304 Stainless Steel-Zirconium Alloys." Metallurgical and Materials Transactions A, 27A:2151-2159. Warrendale, Pennsylvania: The Minerals, Metals \& Materials Society.

Abraham, D.P.; McDeavitt, S.M.; and Park, J.Y. 1996b. "Metal Waste Forms from the Electrometallurgical Treatment of Spent Nuclear Fuel." Proceedings of the Embedded Topical Meeting on DOE Spent Nuclear Fuel and Fissile Material Management held June 16-20, 1996. Reno, Nevada. pp. 123-128. La Grange Park, Illinois: American Nuclear Society.

Abraham, D.P.; Richardson, J.W., Jr.; and McDeavitt, S.M. 1997a. "Formation of the $\mathrm{Fe}_{23} \mathrm{Zr}_{6}$ Phase in an Fe-Zr Alloy.” Scripta Materialia, 37:239-244. New York, New York: Elsevier Science.

Abraham, D.P.; Richardson, J.W., Jr.; and McDeavitt, S.M. 1997b. "Laves Intermetallics in Stainless Steel-Zirconium Alloys." Materials Science and Engineering, A239-240:658-664. Amsterdam, The Netherlands: Elsevier Science.

Abraham, D.P.; McDeavitt, S.M.; Keiser, D.D., Jr.; Johnson, S.G.; Adamic, M.L.; Barker, S.A.; DiSanto, T.; Frank, S.M.; Krsul, J.R.; Noy, M.; Richardson, J.W., Jr.; and Westphal, B.R. 1999a. Metal Waste Form Handbook. Argonne National Laboratory report ANL-NT-121. Argonne, Illinois: Argonne National Laboratory.

Abraham, D.P., and Richardson, J.W. 1999b. "Phase Stability of Laves Intermetallics in a Stainless SteelZirconium Alloy." Proceedings of the Long Term Stability of High Temperature Materials Conference. Fuchs, G.E.; Dannemann, K.A.; and Deragon, T.C., eds. pp. 169-179. Warrendale, Pennsylvania. 
Abraham, D.P.; Peterson, J.J.; Katyal, N.K.; Keiser, D.D.; and Hilton, B.A. 2000. "Electrochemical Testing of Metal Waste Forms." Proceedings of the Corrosion 2000 Conference held March 26-31, 2000. Orlando, Florida. Paper No. 00205.

Abraham, D.P.; Dietz, N.L.; and Finnegan, N. 2001. "Characterization of Oxidation Products on a $\mathrm{ZrFe}_{2}-$ Type Laves Intermetallic Exposed to $200^{\circ} \mathrm{C}$ Steam." Proceedings of the Corrosion 2001 Conference. Paper No. 01139.

Barber, T.L.; DiSanto, T.; Frank, S.M.; Goff, K.M.; Johnson, S.G.; Jue, J.F.; Noy, M.; and O’Holleran, T.P. 2002. "Study of Alpha-Decay Damage in a Glass-Bonded, Sodalite Ceramic Waste." Proceedings of the DOE Spent Nuclear Fuel and Fissile Materials Management Meeting held September 17-20, 2002. Charleston, South Carolina. CD-ROM. Waste Form Testing session. La Grange Park, Illinois: American Nuclear Society.

Battisti, T.J.; Goff, K.M.; Bateman, K.J.; Simpson, M.F.; and Lind, J.P. 2002. "Ceramic Waste Form Production and Development at ANL-West." Proceedings of the DOE Spent Nuclear Fuel and Fissile Materials Management Meeting held September 17-20, 2002. Charleston, South Carolina. CD-ROM. Poster session. La Grange Park, Illinois: American Nuclear Society.

Bauer, T.H.; Abraham, D.P.; Fink, J.K.; Johnson, I.; Johnson, S.G.; and Wigeland, R.A. 2001. "Modeling Corrosion and Constituent Release from a Metal Waste Form." Proceedings of the International High-Level Radioactive Waste Management Conference held April 29-May 3, 2001. Las Vegas, Nevada. CD-ROM. Session E-3 Source Term-I: General Modeling Topics. La Grange Park, Illinois: American Nuclear Society.

Bauer, T.H.; Johnson, S.G.; and Snyder, C.T. 2002 "Modeling the Long-Term Degradation of a Metallic Waste Form." Proceedings of the DOE Spent Nuclear Fuel and Fissile Materials Management Meeting held September 17-20, 2002. Charleston, South Carolina. La Grange Park, Illinois: American Nuclear Society.

BSC: Bechtel SAIC Company

BSC 2003. Initial Radionuclide Inventories. Bechtel SAIC Company report ANL-WIS-MD-000020, Rev. 00.

BSC 2004. Defense HLW Glass Degradation Model. Bechtel SAIC Company report ANL-EBS-MD000016, Rev. 02.

BSC 2005a. In-Package Chemistry Abstraction. Bechtel SAIC Company report ANL-EBS-MD-000037, Rev. 04.

BSC 2005b Dissolved Concentration Limits of Radioactive Elements, Bechtel SAIC Company report ANL-WIS-MD-000010, Rev. 05.

BSC 2005c. Waste Form and In-Drift Colloids-Associated Radionuclide Concentrations: Abstraction and Summary. Bechtel SAIC Company report MDL-EBS-PA-000004 Rev02

Benedict, R.W.; McFarlane, H.F.; Henslee, S.P.; Lineberry, M.J.; Abraham, D.P.; Ackerman, J.P.; Ahluwalia, R.K.; Garcia, H.E.; Gay, E.C.; Goff, K.M.; Johnson, S.G.; Mariani, R.D.; McDeavitt, S.; Pereira, C.; Roach, P.D.; Sherman, S.R.; Westphal, B.R. Wigeland, R.A.; and Willit, J.L. 1999. Spent 
Fuel Treatment Demonstration Final Report. Argonne National Laboratory report ANL-NT-106. Argonne, Illinois: Argonne National Laboratory.

Bernadzikowski, T.A.; Allender, J.S.; Stone, J.A.; Gordon, D.E.; Gould, Jr., T.H.; and Westberry III, C.F. 1983. "High-Level Nuclear Waste Form Performance Evaluation." American Ceramic Society Bulletin, 62(12):1364-1368 and 1390 (1983).

Dietz, N.L. 2005.Transmission Electron Microscopy Analysis of Corroded EBR-II Metallic Waste Forms, Argonne National Laboratory report ANL-05/09. Argonne, Illinois: Argonne National Laboratory.

DOE: U.S. Department of Energy

DOE 1996. Waste Acceptance Product Specifications for Vitrified High-Level Waste Forms. U.S. Department of Energy Office, Office of Environmental Management report EM-WAPS Rev. 02. December 1996

DOE 1998. Viability Assessment of a Repository at Yucca Mountain. U.S. Department of Energy, Office of Civilian Radioactive Waste Management report DOE/RW-0508, December 1998.

DOE 2002. Waste Acceptance System Requirements Document, Rev. 4. U.S. Department of Energy, Office of Civilian Radioactive Waste Management report DOE/RW-0351, January 2002.

Ebert, W.L., and S. F. Wolf. 2000 "An Interlaboratory Study of a Standard Glass for Acceptance Testing of LowActivity Waste Glass," Journal of Nuclear Materials, 282:112-124. New York, New York: North-Holland.

Ebert, W.L., Buck, E.C., Luo, J.S., Tam, S.-W., and Bates, J.K. 1998. Corrosion Behavior of Environmental Assessment Glass in Product Consistency Tests of Extended Duration, Argonne National Laboratory report $98 / 27$.

Ebert, W.L; Esh, D.W.; Frank, S.M.; Goff, K.M.; Hash, M.C.; Johnson, S.G.; Lewis, M.A.; Morss, L.R.; Moschetti, T.L.; O’Holleran, T.P.; Richmann, M.K.; Riley, W.P., Jr.; Simpson, L.J.; Sinkler, W.; Stanley, M.L.; Tatko, C.D.; Wronkiewicz, D.J.; Ackerman, J.P.; Arbesman, K.A.; Bateman, K.J.; Battisti, T.J.; Cummings, D.G.; DiSanto, T.; Gougar, M.L.; Hirsche, K.L.; Kaps, S.E.; Leibowitz, L.; Luo, S.S.; Noy, M.; Retzer, H.; Simpson; Sun, D.; Warren, A.R.; and Zyryanov, V.N. 1999. Ceramic Waste Form Handbook. Argonne National Laboratory report ANL-NT-119. Argonne, Illinois: Argonne National Laboratory.

Ebert, W.L.; Lewis, M.A.; and Johnson, S.G. 2002a. "The Precision of Product Consistency Tests Conducted with a Glass-Bonded Ceramic Waste Form." Journal of Nuclear Materials, 305:37-51. New York, New York: North-Holland.

Ebert, W.L.; Lewis, M.A.; and Johnson, S.G. 2002b. "Application of the PCT to the EBR II Ceramic Waste Form." Proceedings of the DOE Spent Nuclear Fuel and Fissile Materials Management Meeting held September 17-20, 2002. Charleston, South Carolina. Waste Form Testing session. La Grange Park, Illinois: American Nuclear Society.

Ebert, W.L.; Lewis, M.A.; Barber, T.L.; and Johnson, S.G. 2003a. "Accounting for EBR-II Metallic Waste Form Degradation in TSPA." Scientific Basis for Nuclear Waste Management XXVI, Symposium held December 2-5, 2002. Boston, Massachusetts. Finch, R.J., and Bullen, D.B., eds. Vol. 757, pp. 71-80. Warrendale, Pennsylvania: Materials Research Society. 
Ebert, W.L.; Lewis, M.A.; Barber, T.L.; DiSanto, T.; and Johnson, S.G. 2003b. Static Leach Tests with the EBR II Metallic Waste Form. Argonne National Laboratory report ANL-03/29. Argonne, Illinois: Argonne National Laboratory.

Ebert, W.L.; Dietz, N.L.; and Janney, D.E. 2005. Effects of Heat-Treatment and Formulation on the Phase Composition and Chemical Durability of the EBR II Ceramic Waste Form. Argonne National Laboratory report ANL-05/32. Argonne, Illinois: Argonne National Laboratory.

Fanning, T.H. 2003. Confirmation of the Ceramic Waste Form Degradation and Radionuclide Release Model. Argonne National Laboratory report ANL-NT-225. Argonne, Illinois: Argonne National Laboratory.

Fanning, T.H.; Morris, E.E.; Wigeland, R.A.; Ebert, W.L.; Lewis, M.A.; and Morss, L.R. 2001. "Ceramic Waste Form Modeling in the Yucca Mountain Engineered Barrier System." Proceedings of the International High-Level Radioactive Waste Management Conference held April 29-May 3, 2001. Las Vegas, Nevada. CD-ROM. Session I-10 Source Term-V: Ceramic Waste and Colloids. La Grange Park, Illinois: American Nuclear Society.

Fanning, T.H.; Ebert, W.L.; Frank, S.M.; Hash, M.C.; Morris, E.E.; Morss, L.R.; O’Holleran, T.P.; and Wigeland, R.A. 2003. Status of Ceramic Waste Form Degradation and Radionuclide Release Modeling. Argonne National Laboratory report ANL-03/8. Argonne, Illinois: Argonne National Laboratory.

Fanning, T.H.; Bauer, T.H.; Morris, E.E.; and Wigeland, R.A. 2002. "A Generalized Definition for Waste Form Durability." Proceedings of the DOE Spent Nuclear Fuel and Fissile Materials Management Meeting held September 17-20, 2002. Charleston, South Carolina. Melt-Dilute session. La Grange Park, Illinois: American Nuclear Society.

Fanning, T.H.; Ebert, W.L.; Frank, S.M.; Hash, M.C.; Morris, E.E.; Morss, L.R.; O’Holleran, T.P.; and Wigeland, R.A. 2003. Status of Ceramic Waste Form Degradation and Radionuclide Release Modeling. Argonne National Laboratory report ANL-03/8. Argonne, Illinois: Argonne National Laboratory.

Federal Register, 1990. Toxicity Characteristic Leach Procedure. Federal Register, Vol. 55, No. 61, pp. 11798-11877 (March 29, 1990) and Vol. 55, No. 126, pp. 26986-26998 (June 29, 1990).

Federal Register, 2000. Record of Decision for the Treatment and Management of Sodium-Bonded Spent Nuclear Fuel. Federal Register, Vol. 65, No. 182, pp. 56565-56570 (September 19, 2000).

Fink, J.K.; Morris, E.E.; Abraham, D.P.; Johnson, I.; Johnson, S.G.; and Wigeland, R.A. 2000. Status of Metal Waste Form Corrosion and Release Rate Modeling. Argonne National Laboratory report ANL-NT-154. Argonne, Illinois: Argonne National Laboratory.

Frank, S.M.; Johnson, S.G.; Moschetti, T.L.; O’Holleran, T.P.; Sinkler, W.; Esh, D.; and Goff, M.K. 2000. "Accelerated Alpha Radiation Damage in a Ceramic Waste Form, Interim Results." Scientific Basis for Nuclear Waste Management XXIII, Symposium held November 29-December 2, 1999. Boston, Massachusetts. Smith, R.W., and Shoesmith, D.W., eds. Vol.608, pp. 469-474. Warrendale, Pennsylvania: Materials Research Society.

Frank, S.M. 2002. "Alpha Decay Damage Study of a Glass-Bonded Sodalite Ceramic Waste Form." Scientific Basis for Nuclear Waste Management XXV, Symposium held November 26-29, 2001. Boston, Massachusetts. McGrail, B.P., and Cragnolino, G.A., eds. Vol. 713, pp. 487-494. 
Frank, S.M.; DiSanto, T.; Goff, K.M.; Johnson, S.G.; Jue, J.-F.; Barber, T.L.; Noy, M.; O’Holleran, T.P.; and Giglio, J.J. 2002. "Plutonium-238 Alpha-Decay Damage study of a glass-bonded sodalite ceramic waste form." Journal of Testing and Evaluation, Sept 2002. West Conshohocken, Pennsylvania: American Society for Testing and Materials.

Goff, K.M.; Benedict, R.W.; Bateman, K.; Lewis, M.A.; Pereira, C.; and Musick, C.A. 1996. "Spent Fuel Treatment and Mineral Waste Form Development at Argonne National Laboratory-West." Proceedings of the Spectrum '96 Meeting, Nuclear and Hazardous Waste Management International Topical Meeting held August 18-23, 1996. Seattle, Washington. pp. 2436-2443. La Grange Park, Illinois: American Nuclear Society.

Goff, K.M.; Ackerman, J.P.; Simpson, M.F.; Hash, M.C.; Bateman, K.J.; Battisti, T.J.; Hirsche, K.L.; and Kennedy, J.R. 1999. Ceramic Waste Form Process Qualification Plan. Argonne National Laboratory report ANL-NT-118. Argonne, Illinois: Argonne National Laboratory.

Grambow, B. 1985. "A General Rate Equation for Nuclear Waste Glass Corrosion." Scientific Basis for Nuclear Waste Management IX, Symposium held November 26-29, 1984. Boston, Massachusetts. C.M. Jantzen, J.A. Stone, and R.C. Ewing, eds., Vol. 44, pp. 15-24. Pittsburgh, Pennsylvania: Materials Research Society (1985).

Grambow, B. and Strachan, D.M. 1988. A Comparison of the Performance of Nuclear Waste Glass by Modeling, Pacific Northwest Laboratory Report PNL-6698.

Greenspan, L. 1977. "Humidity Fixed Points of Binary Saturated Aqueous Solutions." Journal of Research, NBS 81A:89-96.

Halsey, G. 1948. "Physical Adsorption on Non-Uniform Surfaces," Journal of Chemical Physics 16(10), 931-937.

Janney, D.E. 2003a. "Host Phases for Actinide Elements in the Metallic Waste Form." Scientific Basis for Nuclear Waste Management XXVI, Symposium held December 2-5, 2002. Boston, Massachusetts. Finch, R.J. and Bullen, D.B., eds. Vol.757, pp. 343-348. Warrendale, Pennsylvania: Materials Research Society.

Janney, D.E. 2003b. Characterization of Host Phases for Actinides in Simulated Metallic Waste Forms by Transmission Electron Microscopy. Argonne National Laboratory report ANL-NT-221. Argonne, Illinois: Argonne National Laboratory.

Janney, D.E., and Keiser, D.D., Jr. 2003. "Actinides in Metallic Waste from Electrometallurgical Treatment of Spent Nuclear Fuel." JOM, 55(9):59-60. Warrendale, Pennsylvania: The Minerals, Metals \& Materials Society.

Janney, D.E. 2003. "Host Phases for Actinides in Simulated Metallic Waste Forms." Journal of Nuclear Materials, 323:81-92. New York, New York: North-Holland.

Jantzen, C.M.; Pickett, J.B.; and Beam, D.C. 1994. Process/Product Models for the Defense Waste Processing Facility (DWPF): Part I. Predicting Glass Durability from Composition Using a Thermodynamic Hydration Energy Reaction Model (THERMO) (U). Westinghouse Savannah River Co. report WSRC-TR-93-672 (1994). 
Jeong, J.Y.; Fanning, T.H.; Morss, L.R.; and Ebert, W.L. 2002. Corrosion Tests to Determine Temperature and $\mathrm{pH}$ Dependencies of the Dissolution Rates of Sodalite, Binder Glass, and Ceramic Waste Forms. Argonne National Laboratory report ANL-02/32. Argonne, Illinois: Argonne National Laboratory.

Johnson, S.G.; Keiser, D.D.; Frank, S.M.; DiSanto, T.; Warren, A.R.; and Noy, M. 2000. "Leaching Characteristics of the Metal Waste Form From the Electrometallurgical Treatment Process: Product Consistency Testing." Scientific Basis for Nuclear Waste Management XXIII, Symposium held November 29-December 2, 1999. Boston, Massachusetts. Smith, R.W., and Shoesmith, D.W., eds. Vol. 608, pp. 589-594. Warrendale, Pennsylvania: Materials Research Society.

Johnson, S.G.; Noy, M.; DiSanto, T.; and Barber, T.L. 2001. "Release of Neptunium, Plutonium, Uranium, and Technetium from the Metallic Waste from the Electrometallurgical Treatment Process." Scientific Basis for Nuclear Waste Management XXV, Proceedings of the Materials Research Society Symposium held November 26-29, 2001. Boston, Massachusetts. McGrail, B.P., and Cragnolino, G.A., eds. Vol. 713, pp. 705-711. Warrendale, Pennsylvania: Materials Research Society.

Johnson, S.G.; Noy, M.; DiSanto, T.; and Keiser, D.D., Jr. 2002. "Long-Term Immersion Test Results of the Metallic Waste Form from the EMT Process of EBR-II Spent Metallic Fuel." Proceedings of the DOE Spent Nuclear Fuel and Fissile Materials Management Meeting held September 17-20, 2002. Charleston, South Carolina. Waste Form Testing session. La Grange Park, Illinois: American Nuclear Society.

Jones, D.A. 1992. Principles and Prevention of Corrosion. Prentice Hall, Englewood Cliffs, NJ.

Keiser, D.D., Jr.; Abraham, D.P.; Sinkler, W.; Richardson, J.W., Jr.; and McDeavitt, S.M. 2000a. "Actinide Distribution in Stainless Steel-15 wt\% Zirconium High-Level Nuclear Waste Form." Journal of Nuclear Materials, 279:234-244. New York, New York: North-Holland.

Keiser, D.D., Jr.; Abraham, D.P.; and Richardson, J.W., Jr. 2000b. "Influence of Technetium on the Microstructure of a Stainless Steel-Zirconium Alloy." Journal of Nuclear Materials, 277:333-338. New York, New York: North-Holland.

Keiser, D.D., Jr.; Johnson, S.G.; and Ebert, W.L. 2002a. Monitoring the Consistency of the Metal Waste Form. Argonne National Laboratory report ANL-NT-196. Argonne, Illinois: Argonne National Laboratory.

Keiser, D.D., Jr.; Johnson, S.G.; and Ebert, W.L. 2002b. "Monitoring the Consistency of the Metallic Waste Form Derived from Electrometallurgical Processing." Proceedings of the DOE Spent Nuclear Fuel and Fissile Materials Management Meeting held September 17-20, 2002. Charleston, South Carolina. Poster session. La Grange Park, Illinois: American Nuclear Society.

Lambregts, M.J., and Frank, S.M. 2002. "Preliminary Studies of the Disposition of Cesium in a GlassBonded Sodalite Waste Form.” Scientific Basis for Nuclear Waste Management XXV, Proceedings of the Materials Research Society Symposium held November 26-29, 2001. Boston, Massachusetts. McGrail, B.P., and Cragnolino, G.A., eds. Vol. 713, pp. 373-380. Warrendale, Pennsylvania: Materials Research Society.

Lasaga, A.C. and Gibbs, G.V. 1990. "Ab-Initio Quantum Mechanical Calculations of Water-Rock Interactions: Adsorption and Hydrolysis Reactions," Amer. J. Sci., 290, 263-295. 
Lewis, M.A.; Hash, M.; and Glandorf, D. 1997. "Effect of Different Glass and Zeolite-A Compositions on the Leach Resistance of Ceramic Waste Forms." Scientific Basis for Nuclear Waste Management XXIII, Symposium held December2-6, 1996. Boston, Massachusetts. Gray, W.J., and Triay, I.R., eds. Vol. 465, pp. 433-440. Pittsburgh, Pennsylvania: Materials Research Society.

Lewis, M.L. and Ebert, W.L. 2000. Results of Scoping Tests with Ceramic Waste Form Materials Made by Pressureless Consolidation. Argonne National Laboratory report ANL-NT-160. Argonne, Illinois: Argonne National Laboratory.

Lewis, M.A.; Stanley, M.L.; and Ebert, W.L. 2000. Development of a Method for Monitoring the Consistency of Glass-Bonded Sodalite Waste Forms. Argonne National Laboratory report ANL-00/12. Argonne, Illinois: Argonne National Laboratory.

Lewis, M.A.; Hash, M.C.; Ebert, W.L.; Hebden, A.; and Oliver, S.M. 2001. Results of Physical Characterizations and Product Consistency Tests with Ceramic Waste Form Products Prepared at Six Temperatures and Six Hold Times. Argonne National Laboratory report ANL-NT-178. Argonne, Illinois: Argonne National Laboratory.

Lewis, M.A.; Hash, M.C.; Hebden, A.; and Ebert, W.L. 2002. Tests with Ceramic Waste Form Materials Made by Pressureless Consolidation. Argonne National Laboratory report ANL-02/10. Argonne, Illinois: Argonne National Laboratory.

Luo, J.S., Zyryanov, V.N., and Ebert, W.L. 2000. "Microstructural Characterization of Halite Inclusions in a Glass-Bonded Ceramic Waste Form." Environmental Issues and Waste Management Technologies in the Ceramic and Nuclear Industries VI. Ceramic Transactions 119: 477-484.

Luo, J.S., and Abraham, D.P. 2000. "TEM Characterization of Corrosion Products Formed on a Stainless Steel-Zirconium Alloy." Scientific Basis for Nuclear Waste Management XXIII, Symposium held November 29-December 2, 1999. Boston, Massachusetts. Smith, R.W., and Shoesmith, D.W., eds. Vol. 608, pp. 583-588. Warrendale, Pennsylvania: Materials Research Society.

McDeavitt, S.M.; Abraham, D.P.; Keiser, D.D.; and Park, J.Y. 1996a. "Stainless Steel-Zirconium Alloy Waste Forms for Metallic Fission Products and Actinides Isolated during Treatment of Spent Nuclear Fuel." Proceedings of the Spectrum '96 Meeting, Nuclear and Hazardous Waste Management International Topical Meeting held August 18-23, 1996. Seattle, Washington. pp. 2477-2484. La Grange Park, Illinois: American Nuclear Society.

McDeavitt, S.M.; Abraham, D.P.; Keiser, D.D.; and Park, J.Y. 1996b. "Alloy Waste Forms for Metal Fission Products and Actinides Isolated by Spent Nuclear Fuel Treatment." Proceedings of the Second International Symposium on Extraction and Processing for the Treatment and Minimization of Wastes held October 27-30, 1996. Scottsdale, Arizona. pp. 177-189.

McDeavitt, S.M.; Abraham, D.P.; Park, J.Y.; and Keiser, D.D. 1997. "Stainless Steel-Zirconium Waste Forms from Electrometallurgical Treatment of Spent Nuclear Fuel." JOM. 49(7):29-32. Warrendale, Pennsylvania: The Minerals, Metals \& Materials Society.

McDeavitt, S.M.; Abraham, D.P.; and Park, J.Y. 1998. "Evaluation of Stainless Steel-Zirconium Alloys as High-Level Nuclear Waste Forms." Journal of Nuclear Materials, 257:21-34. New York, New York: North-Holland. 
Morris, E.E.; Fanning, T.H.; and Wigeland, R.A. 2001. "Waste Form Performance Assessment in the Yucca Mountain Engineered Barrier System." Proceedings of the International High-Level Radioactive Waste Management Conference held April 29-May 3, 2001. Las Vegas, Nevada. CD-ROM. Session E-3 Source Term-I: General Modeling Topics. La Grange Park, Illinois: American Nuclear Society.

Morss, L.R.; Stanley, M.L.; Tatko, C.D.; and Ebert, W.L. 1999. "Corrosion of Glass-Bonded Sodalite as a Function of $\mathrm{pH}$ and Temperature." Scientific Basis for Nuclear Waste Management XXIII, Symposium held November 29-December 2, 1999. Boston, Massachusetts. Smith, R.W., and Shoesmith, D.W., eds. Vol. 608, pp. 733-738. Warrendale, Pennsylvania: Materials Research Society.

Morss, L.R. and Ebert, W.L. 2001. "Release of Uranium and Plutonium from the EBR-II Ceramic Waste Form." Environmental Issues and Waste Management Technologies in the Ceramic and Nuclear Industries VI. Ceramic Transactions 119: 477-484.

Morss, L.R.; Mertz, C.J.; Kropf, A.J.; and Holly, J.L. 2002a. "Properties of Plutonium-Containing Colloids Released from Glass-Bonded Sodalite Nuclear Waste Form." Scientific Basis for Nuclear Waste Management XXV, Proceedings of the Materials Research Society Symposium held November 26-29, 2001. Boston, Massachusetts. McGrail, B.P., and Cragnolino, G.A., eds. Vol. 713, 421-427. Warrendale, Pennsylvania: Materials Research Society.

Morss, L.R.; Johnson, S.G.; Ebert, W.L.; DiSanto, T.; Frank, S.M.; Holly, J.L.; Kropf, A.J.; Mertz, C.J.; Noy, M.; O’Holleran, T.P.; Richmann, M.K.; Sinkler, W.; Tsai, Y.; and Warren, A.R. 2002b. Corrosion Tests with Uranium- and Plutonium-Loaded Ceramic Waste Forms. Argonne National Laboratory report ANL-02/09. Argonne, Illinois: Argonne National Laboratory.

Moschetti, T.L.; Sinkler, W.; DiSanto, T.; Noy, M.H.; Warren, A.R.; Cummings, D.; Johnson, S.G.; Goff, K.M.; Bateman, K.J.; and Frank, S.M. 2000. "Characterization of a Ceramic Waste Form Encapsulating Radioactive Electrorefiner Salt." Scientific Basis for Nuclear Waste Management XXIII, Symposium held November 29-December 2, 1999. Boston, Massachusetts. Smith, R.W., and Shoesmith, D.W., eds. Vol. 608, pp. 577-582. Warrendale, Pennsylvania: Materials Research Society.

O’Holleran, T.P.; Benedict, R.W.; and Johnson, S.G. 1999a. Waste Form Qualification Strategy for the Metal and Ceramic Waste Forms from Electrometallurgical Treatment of Spent Nuclear Fuel. Argonne National Laboratory report ANL-NT-115. Argonne, Illinois: Argonne National Laboratory.

O’Holleran, T.P.; Abraham, D.P.; Ackerman, J.P.; Goff, K.M.; Johnson, S.G.; and Keiser, D.D. 1999b. Waste Acceptance Product Specifications for the Waste Forms from Electrometallurgical Treatment of Spent Nuclear Fuel. Argonne National Laboratory report ANL-NT-116. Argonne, Illinois: Argonne National Laboratory.

Richardson, J.W., Jr. 1997. "Salt-Occluded Zeolite Waste Forms: Crystal Structures and Transformability." Scientific Basis for Nuclear Waste Management XXIII, Symposium, held December 2-6, 1996. Boston, Massachusetts. Gray, W.J, and Triay, I.R., eds. Vol. 465, 395-400. Pittsburgh, Pennsylvania: Materials Research Society.

Richmann, M.K.; Reed, D.T.; Kropf, A.J.; Asse, S.B.; and Lewis, M.A. 2001. "EXAFS/EXANES Studies of Plutionium-Loaded Sodalite/Glass Waste Forms.” Journal of Nuclear Materials, 297: 303-312.

Simpson, L.J., and Wronkiewicz, D.J. 1997. "Evaluation of Standard Durability Tests Towards the Qualification Process for the Glass-Zeolite Ceramic Waste Form.” Scientific Basis for Nuclear Waste 
Management XXIII, Symposium held December 2-6, 1996. Boston, Massachusetts. Gray, W.J., and Triay, I.R., eds. Vol. 465, pp. 441-448. Pittsburgh, Pennsylvania: Materials Research Society.

Simpson, M.F.; Goff, K.M.; Johnson, S.G.; Bateman, K.J.; Battisti, T.J.; Toews, K.L.; Frank, S.M.; Moschetti, T.L.; O'Holleran, T.P.; and Sinkler, W. 2001. "A Description of the Ceramic Waste Form Production Process from the Demonstration Phase of the Electrometallurgical Treatment of EBR-II Spent Fuel." Nuclear Technology 134:263-277.

Simpson, M.F. 2003. "Two-Site Equilibrium Model for Ion Exchange Between Monovalent Cations and Zeolite-A in a Molten Salt." Industrial Engineering and Chemical Research, 38, 2469-2473.

Sinkler, W.; Esh, D.W.; O’Holleran, T.P.; Frank, S.M.; Moschetti, T.L.; Goff, K.M.; and Johnson, S.G. 1999. "TEM Investigation of a Ceramic Waste Form for Immobilization of Process Salts Generated During Electrometallurgical Treatment of Spent Nuclear Fuel." Environmental Issues and Waste Management Technologies in the Ceramic and Nuclear Industries V, Ceramic Transactions 107:233-240.

Sinkler, W.; O’Holleran, T.P.; Frank, S.M.; Richmann, M.K.; and Johnson, S.G. 2000. "Characterization of a Glass-bonded Ceramic Waste Form Loaded with U and Pu." Scientific Basis for Nuclear Waste Management XXIII, Symposium held November 29-December 2, 1999. Boston, Massachusetts. Smith, R.W., and Shoesmith, D.W., eds. Vol. 608, pp. 423-429. Warrendale, Pennsylvania: Materials Research Society.

Smith, G.L, and Marschman, S.C. 1994. "Nuclear Waste Analytical Round Robins 1-6 Summary Report,"Mat. Res. Soc. Symp. Proc. 333, 461-471.

Snyder, C.T.; Barnes, L.A.; and Fink, J.K. 2004. Metal Waste Form Corrosion Release Data from Immersion Tests. Argonne National Laboratory report ANL-04/15. Argonne, Illinois: Argonne National Laboratory.

Strachan, D.M. and Badad, H. 1979 "Iodide and Iodate Sodalites for the Long-Term Storage of Iodine129," Rockwell International report RHO-SA-83.

Strachan, D.M., Barnes, B.O., and Turcotte, R.P.. 1981 "Standard Leach Tests for Nuclear Waste Materials," Scientific Basis for Nuclear Waste Management III, Symposium held November 17-20, 1980. Boston, Massachusetts. Moore, J.G., ed. Vol. 3, pp. 347-354. Warrendale, Pennsylvania: Materials Research Society.

Wellman, D.M.; Icenhower, J.P.; and Weber. 2005. "W.J. Elemental dissolution study of Pu-bearing borosilicate glasses."Journal of Nuclear Materals, 340:149-162.

Westphal, B.R.; Marsden, K.C.; McDeavitt, S.M.; Keiser, D.D., Jr.; Abraham, D.P.; Rigg, R.H.; Jensen, B.A.; and Laug, D.V. 1999. Metal Waste Form Process Qualification Plan. Argonne National Laboratory report ANL-NT-120. Argonne, Illinois: Argonne National Laboratory.

Wigeland, R.A.; Briggs, L.L.; Fanning, T.A.; Feldman, E.E.; Morris, E.E.; and Petri, M.C. 1999. Waste Form Degradation and Repository Performance Modeling. Argonne National Laboratory report ANL-NT-117. Argonne, Illinois: Argonne National Laboratory. 
VIII-10 


\section{APPENDIX A. CWF AND MWF COMPOSITIONS AND INVENTORIES IN TSPA}

The radionuclide inventories to be immobilized in the CWF and MWF products are listed in Tables A-1 and A-2. The inventories that were averaged with the inventories in HLW glass for use in TSPA calculations (in $\mathrm{Ci}$ ) are listed in Table A-3 with the average HLW inventory, which includes contributions from Hanford, SRS, WVDP, INL INTEC, CWF, and MWF waste forms (Bechtel SAIC Company report CAL-MGR-NU-000002 REV 01 Source Terms for HLW Glass Containers MOL.20000823.0004). The following documents trace how the radionuclide inventories in the ANL ceramic and metallic waste forms are included in the HLW inventory used in TSPA-LA. References to the CWF and MWF are shown in bold font for emphasis. Note that the CWF and MWF are described in most reports as part of the inventory from the Idaho National Energy and Environmental Laboratory (INEEL) rather than as a separate inventory at ANL-W; INEEL and ANL-W were combined as the Idaho National Laboratory (INL) in 2005.

Initial Radionuclide Inventories

Bechtel SAIC Company report ANL-WIS-MD-000020 Rev 00. ACC: DOC.20031110.0002

This report states (on page 32 of 48): "DHLW glass comes from four sites and will be delivered to the repository in either short or long pour-canisters. The Hanford site will produce long canisters. Idaho National Engineering and Environmental Laboratory (INEEL) Site will produce short canisters. The Savannah River Site (SRS) produces short canisters. The West Valley Demonstration Project produced short canisters." It also states on page 39 of 48 that "The inventory abstraction for the SR [Site Recommendation] used information for glass from four sites: (1) Hanford, (2) INEEL, (3) SRS, and (4) the West Valley Demonstration Project (Inventory Abstraction ANL-WIS-MD000006 REV 00 ICN 03). The inventories for Hanford and SRS used in ANL-WIS-MD-000020 Rev 00 are updated from those provided in ANL-WIS-MD-000006 REV 00 ICN 03, whereas the same INL and WVDP inventories in ANL-WIS-MD-000006 REV 00 ICN 03 are used. Table 21 in ANLWIS-MD-000020 Rev 00 provides the average inventories for 32 radionuclides in CSNF, DSNF, and defense HLW glass. The inventory in defense HLW glass includes the inventories in the CWF and MWF.

Inventory Abstraction

Bechtel SAIC Company report ANL-WIS-MD-000006 REV 00 ICN 03. ACC: MOL.20020123.0278

Attachment I - Calculation of Radionuclide Inventory in Grams per Waste Package for TSPA-SR in this report cites the report Waste Package Radionuclide Inventory Approximations for TSPA-SR as providing "average radionuclide activities for each of the thirteen waste package configurations listed (Table I-1)." Only Configuration 6 contains short HLW canisters, and it is assumed that 1100 waste packages will have Configuration 6.

Waste Package Radionuclide Inventory Approximations for TSPA-SR Bechtel SAIC Company report CAL-WIS-MD-000004 Rev. 00. MOL.20000630.0247

This document provides the calculation of the average radionuclide inventories projected at 2040 for each waste package configuration proposed for site recommendation. The report states on page 6 of 19 in Section 5.4: "DEFENSE HIGH-LEVEL WASTE Savannah River Site (SRS), the West Valley Demonstration Project (WVDP), the Idaho National Engineering and Environmental Laboratory (INEEL), and the Hanford Reservation (HR) will be producing DHLW glass packaged in canisters for disposal. SRS, WVDP, and INEEL will be placing their DHLW glass in short standardized canisters. The HR will be placing DHLW glass in long standardized canisters. In addition, INEEL 
will be packaging DHLW metal and DHLW ceramic (INEEL is the only site that will have nonglass DHLW) in short canisters."

In Inventory Abstraction Data Input, the average inventories for individual radionuclides in the two DHLW canister types, short standardized canisters and long standardized canisters, were determined. The average curie value for an individual radionuclide in short standardized canisters was calculated by summing the SRS, WVDP, and INEEL site-wide curie values for that radionuclide in DHLW and dividing the sum by the total number of short DHLW canisters that will be produced. The average curie value for an individual radionuclide in long standardized canisters was calculated as the HR site-wide curie value for that radionuclide in DHLW divided by the number of long DHLW canisters that will be produced (since HR is the only site using the long canisters). The input values [from] Inventory Abstraction Data Input for DHLW short and long canisters are shown in Tables 4 and 5, respectively."

Inventory Abstraction Data Input

Bechtel SAIC Company report PA-WIS-MD-000006 Rev 00. ACC: MOL.20000524.0184

Pages 3 of 6, 4 of 6, 5 of 6, and 6 of 6 of the Table "Average Radionuclide Inventory (Ci) per Short Canister by Site at 2040" list the inventories for 3 INEEL waste forms: INTEC, Ceramic, and Metal.

Cites Bechtel SAIC Company report Source Terms for HLW Glass Canisters, CAL-MGR-NU000002 REV 01 (MOL.20000823.0004).

Source Terms for HLW Glass Canisters

Bechtel SAIC Company report CAL-MGR-NU-000002 REV 01 ACC: MOL.20000823.0004

Table 5-9 gives radionuclide inventory of ANL-W HLW Ceramic Matrix.

Table 5-10 gives radionuclide inventory of ANL-W HLW Metal Matrix.

Table 6-1 gives radionuclide inventories of SRS glass, WVDP glass, INTEC, CWF, and MWF, plus weighted average curie content per canister.

This report cites K.M. Goff 1998, "Revision to Original INEEL Response to Yucca Mountain Site Characterization Office Data Call for High-Level Waste (Ref. Palmer and Benedict to Wichmann, July 2, 1997)." Letter from K.M. Goff (ANL-West) to M.B. Heiser (Lockheed), April 15, 1998, with attachment, "Modifications to Yucca Mountain Data Call.” ACC: MOL.19990608.0032. 
Table A-1. Ceramic Waste Composition

\begin{tabular}{|c|c|c|c|c|c|}
\hline Isotope & Total mass $(\mathrm{g})$ & Isotope & Total mass $(\mathrm{g})$ & Isotope & Total mass $(\mathrm{g})$ \\
\hline$\overline{\text { Li-6 }}$ & 3.79E-01 & $\mathrm{Hf}-142$ & $9.22 \mathrm{E}+03$ & Ra-226 & 1.06E-05 \\
\hline $\mathrm{Li}-7$ & $6.11 \mathrm{E}+00$ & $\mathrm{Hf}-144$ & $4.68 \mathrm{E}+00$ & Ra-228 & $4.93 \mathrm{E}-12$ \\
\hline $\mathrm{Be}-9$ & $7.50 \mathrm{E}-03$ & Pr-141 & $9.71 \mathrm{E}+03$ & Th-227 & $1.08 \mathrm{E}-08$ \\
\hline $\mathrm{Be}-10$ & $8.69 \mathrm{E}-04$ & Pr-142 & $1.92 \mathrm{E}-10$ & Th-228 & $1.23 \mathrm{E}-04$ \\
\hline F-19 & $7.98 \mathrm{E}-06$ & Pr-144 & $1.98 \mathrm{E}-04$ & Th-229 & $5.19 E-05$ \\
\hline $\mathrm{Na}-22$ & $4.57 \mathrm{E}-05$ & Pr-144 & $9.89 \mathrm{E}-07$ & Th-230 & $2.40 \mathrm{E}-01$ \\
\hline $\mathrm{Na}-23$ & $2.66 \mathrm{E}+05$ & Nd-142 & $1.72 \mathrm{E}+01$ & Th-231 & $8.57 \mathrm{E}-06$ \\
\hline $\mathrm{Na}-24$ & $1.88 \mathrm{E}+01$ & $\mathrm{Nd}-143$ & $9.29 \mathrm{E}+03$ & Th-232 & $2.10 \mathrm{E}-02$ \\
\hline $\mathrm{Na}-25$ & $1.31 \mathrm{E}-01$ & Nd-144 & $8.68 \mathrm{E}+03$ & Th-234 & $3.33 \mathrm{E}-04$ \\
\hline $\mathrm{Na}-26$ & 2.91E-01 & $\mathrm{Nd}-145$ & $6.27 \mathrm{E}+03$ & Pa-231 & $3.05 \mathrm{E}-02$ \\
\hline $\mathrm{Cl}-35$ & $1.72 \mathrm{E}-07$ & $\mathrm{Nd}-146$ & $5.01 \mathrm{E}+03$ & $\mathrm{~Pa}-233$ & $4.31 \mathrm{E}-05$ \\
\hline $\mathrm{Cl}-36$ & $1.39 \mathrm{E}-12$ & Nd-148 & $2.92 \mathrm{E}+03$ & $\mathrm{~Pa}-234$ & $3.89 \mathrm{E}-09$ \\
\hline $\mathrm{Cl}-37$ & $4.48 \mathrm{E}-06$ & $\mathrm{Nd}-150$ & $1.28 \mathrm{E}+03$ & $\mathrm{~Pa}-234$ & $1.12 \mathrm{E}-08$ \\
\hline K-39 & $3.94 \mathrm{E}-10$ & $\mathrm{Pm}-147$ & $1.93 \mathrm{E}+02$ & U-232 & $1.21 \mathrm{E}-04$ \\
\hline $\mathrm{K}-40$ & $3.48 \mathrm{E}-05$ & $\mathrm{Pm}-148$ & $3.01 \mathrm{E}-17$ & U-233 & $2.11 \mathrm{E}-02$ \\
\hline K-41 & $2.44 \mathrm{E}-09$ & Pm-148 & $3.36 \mathrm{E}-15$ & $\mathrm{U}-234$ & $1.97 \mathrm{E}+02$ \\
\hline Ca-40 & $1.00 \mathrm{E}-01$ & Sm-147 & $3.39 \mathrm{E}+03$ & U-235 & $5.34 \mathrm{E}+04$ \\
\hline Ca-41 & $1.23 \mathrm{E}-05$ & Sm-148 & $7.15 \mathrm{E}+01$ & $U-236$ & $1.32 \mathrm{E}+03$ \\
\hline Ca-42 & $7.01 \mathrm{E}-04$ & Sm-149 & $1.79 \mathrm{E}+03$ & $\mathrm{U}-237$ & $3.52 \mathrm{E}-08$ \\
\hline Ca-43 & $5.87 \mathrm{E}-04$ & Sm-150 & $9.15 \mathrm{E}+01$ & $\mathrm{U}-238$ & $1.52 \mathrm{E}+05$ \\
\hline $\mathrm{Ca}-44$ & $5.77 \mathrm{E}-03$ & $\mathrm{Sm}-151$ & $6.75 \mathrm{E}+02$ & U-240 & $1.02 \mathrm{E}-18$ \\
\hline Ca-45 & $7.25 \mathrm{E}-09$ & Sm-152 & $5.81 \mathrm{E}+02$ & $\mathrm{~Np}-237$ & $1.23 \mathrm{E}+03$ \\
\hline Ca-46 & $3.91 \mathrm{E}-04$ & Sm-154 & $1.67 \mathrm{E}+02$ & $\mathrm{~Np}-239$ & $2.37 \mathrm{E}-07$ \\
\hline Ca-48 & $2.32 \mathrm{E}-04$ & Eu-151 & $8.92 \mathrm{E}+01$ & $\mathrm{~Np}-240$ & $3.90 \mathrm{E}-19$ \\
\hline Br-79 & $1.40 \mathrm{E}-02$ & Eu-152 & $3.63 \mathrm{E}-01$ & Pu-236 & $4.57 \mathrm{E}-04$ \\
\hline $\mathrm{Br}-81$ & $2.28 \mathrm{E}+02$ & Eu-153 & $3.52 \mathrm{E}+02$ & Pu-238 & $3.38 \mathrm{E}+01$ \\
\hline $\mathrm{Rb}-85$ & $1.18 \mathrm{E}+03$ & Eu-154 & $5.40 \mathrm{E}+00$ & Pu-239 & $2.61 \mathrm{E}+05$ \\
\hline Rb-87 & $2.30 \mathrm{E}+03$ & Eu-155 & $1.93 \mathrm{E}+01$ & Pu-240 & $5.71 \mathrm{E}+03$ \\
\hline Sr-86 & $4.35 \mathrm{E}+00$ & Gd-152 & $6.74 \mathrm{E}-01$ & Pu-241 & $8.20 \mathrm{E}+01$ \\
\hline Sr-87 & $5.38 \mathrm{E}-03$ & Gd-153 & $1.92 \mathrm{E}-06$ & Pu-242 & $1.76 \mathrm{E}+01$ \\
\hline Sr-88 & $3.30 \mathrm{E}+03$ & Gd-154 & $1.03 \mathrm{E}+01$ & Pu-243 & $7.06 \mathrm{E}-20$ \\
\hline Sr-89 & $2.09 \mathrm{E}-10$ & Gd-155 & $1.02 \mathrm{E}+02$ & Pu-244 & $2.36 \mathrm{E}-06$ \\
\hline Sr-90 & $4.01 \mathrm{E}+03$ & Gd-156 & $5.85 \mathrm{E}+01$ & Am-241 & $1.25 \mathrm{E}+02$ \\
\hline Y-89 & $4.56 \mathrm{E}+03$ & Gd-157 & $3.09 \mathrm{E}+01$ & Am-242 & $4.77 \mathrm{E}-06$ \\
\hline Y-90 & $1.01 \mathrm{E}+00$ & Gd-158 & $2.36 \mathrm{E}+01$ & Am-242 & $3.96 \mathrm{E}-01$ \\
\hline Y-91 & $1.08 \mathrm{E}-08$ & Gd-160 & $4.97 \mathrm{E}+00$ & Am-243 & $2.87 \mathrm{E}-01$ \\
\hline I-127 & $4.22 \mathrm{E}+02$ & Tb-159 & $1.00 \mathrm{E}+01$ & Am-244 & $1.83 \mathrm{E}-21$ \\
\hline $\mid-129$ & $1.39 \mathrm{E}+03$ & Tb-160 & $9.27 \mathrm{E}-11$ & $\mathrm{Cm}-242$ & $9.98 \mathrm{E}-04$ \\
\hline Cs-133 & $1.04 \mathrm{E}+04$ & Dy-160 & $2.99 \mathrm{E}-01$ & $\mathrm{Cm}-243$ & $1.10 \mathrm{E}-03$ \\
\hline Cs-134 & $3.00 \mathrm{E}+00$ & Dy-161 & $1.63 \mathrm{E}+00$ & $\mathrm{Cm}-244$ & $5.74 \mathrm{E}-03$ \\
\hline Cs-135 & $1.05 \mathrm{E}+04$ & Dy-162 & $9.40 \mathrm{E}-01$ & $\mathrm{Cm}-245$ & $1.28 \mathrm{E}-04$ \\
\hline Cs-137 & $7.29 \mathrm{E}+03$ & Dy-163 & $4.35 \mathrm{E}-01$ & $\mathrm{Cm}-246$ & $6.66 \mathrm{E}-07$ \\
\hline Ba-134 & $8.50 \mathrm{E}+01$ & Dy-164 & $2.72 \mathrm{E}-01$ & $\mathrm{Cm}-247$ & $2.07 \mathrm{E}-09$ \\
\hline Ba-135 & $9.61 \mathrm{E}-02$ & Ho-165 & $1.21 \mathrm{E}-01$ & $\mathrm{Cm}-248$ & $8.24 \mathrm{E}-12$ \\
\hline Ba-136 & $4.43 \mathrm{E}+01$ & Ho-166 & $3.65 \mathrm{E}-04$ & $\mathrm{Cm}-250$ & $6.22 \mathrm{E}-20$ \\
\hline Ba-137 & $2.91 \mathrm{E}+03$ & Er-166 & $2.75 \mathrm{E}-02$ & Bk-249 & $2.81 \mathrm{E}-17$ \\
\hline $\mathrm{Ba}-137$ & $1.11 \mathrm{E}-03$ & Er-167 & $2.30 \mathrm{E}-04$ & Cf-249 & $2.06 \mathrm{E}-14$ \\
\hline Ba-138 & $1.04 \mathrm{E}+04$ & Fr-221 & $6.27 \mathrm{E}-14$ & $\begin{array}{l}\text { Cf-250 } \\
\text { Cf }\end{array}$ & $1.56 \mathrm{E}-16$ \\
\hline La-138 & $2.06 \mathrm{E}-02$ & Fr-223 & $1.27 \mathrm{E}-13$ & Cf-251 & $1.94 \mathrm{E}-18$ \\
\hline La-139 & $1.03 \mathrm{E}+04$ & Ra-223 & $6.76 \mathrm{E}-09$ & Cf-252 & $1.22 \mathrm{E}-21$ \\
\hline $\mathrm{Hf}-140$ & $1.03 \mathrm{E}+04$ & Ra-224 & $6.30 \mathrm{E}-07$ & & \\
\hline $\mathrm{Hf}-141$ & $1.58 \mathrm{E}-16$ & Ra-225 & $2.83 \mathrm{E}-10$ & & \\
\hline
\end{tabular}


Table A-2. Metal Waste Composition

\begin{tabular}{|c|c|c|c|c|c|}
\hline Isotope & Total mass $(\mathrm{g})$ & Isotope & Total mass $(\mathrm{g})$ & Isotope & Total mass $(\mathrm{g})$ \\
\hline$\overline{\mathrm{H}-1}$ & $8.84 \mathrm{E}+00$ & Fe-59 & 5.80E-15 & Tc-99 & $6.72 \mathrm{E}+03$ \\
\hline $\mathrm{H}-2$ & $6.99 \mathrm{E}-05$ & Co-58 & $3.67 \mathrm{E}-08$ & Ru-99 & $5.55 \mathrm{E}+03$ \\
\hline $\mathrm{H}-3$ & $3.32 \mathrm{E}-01$ & Co-59 & $6.47 \mathrm{E}+03$ & Ru-100 & $5.78 \mathrm{E}+03$ \\
\hline $\mathrm{He}-3$ & $1.18 \mathrm{E}-01$ & Co-60 & $3.56 \mathrm{E}+00$ & Ru-101 & $1.40 \mathrm{E}+04$ \\
\hline $\mathrm{He}-4$ & $8.43 E+00$ & $\mathrm{Ni}-58$ & $4.60 \mathrm{E}+05$ & Ru-102 & $2.03 E+04$ \\
\hline B-10 & $2.06 \mathrm{E}+00$ & $\mathrm{Ni}-59$ & $1.40 \mathrm{E}+02$ & Ru-103 & $1.28 \mathrm{E}-13$ \\
\hline B-11 & $1.07 \mathrm{E}+01$ & $\mathrm{Ni}-60$ & $1.82 \mathrm{E}+05$ & Ru-104 & $1.19 \mathrm{E}+04$ \\
\hline C-12 & $3.84 \mathrm{E}+03$ & $\mathrm{Ni}-61$ & $8.05 \mathrm{E}+03$ & Ru-106 & $2.33 \mathrm{E}+00$ \\
\hline$C-13$ & $4.66 \mathrm{E}+01$ & $\mathrm{Ni}-62$ & $2.59 \mathrm{E}+04$ & Rh-103 & $1.08 \mathrm{E}+04$ \\
\hline C-14 & $5.82 \mathrm{E}-01$ & $\mathrm{Ni}-63$ & $5.91 \mathrm{E}+00$ & Rh-103 & $1.25 \mathrm{E}-16$ \\
\hline $\mathrm{N}-14$ & $1.18 \mathrm{E}+03$ & $\mathrm{Ni}-64$ & $6.78 \mathrm{E}+03$ & Rh-106 & $2.18 \mathrm{E}-06$ \\
\hline $\mathrm{N}-15$ & $4.70 \mathrm{E}+00$ & Cu-63 & $2.43 \mathrm{E}+03$ & Pd-104 & $1.33 \mathrm{E}+03$ \\
\hline $0-16$ & $7.45 \mathrm{E}+01$ & Cu-65 & $1.12 \mathrm{E}+03$ & $\mathrm{Pd}-105$ & $2.93 \mathrm{E}+03$ \\
\hline $0-17$ & $3.19 \mathrm{E}-02$ & Zn-64 & $7.22 \mathrm{E}-01$ & $\mathrm{Pd}-106$ & $2.33 \mathrm{E}+03$ \\
\hline $0-18$ & $1.68 \mathrm{E}-01$ & Zn-66 & $7.14 \mathrm{E}-01$ & Pd-107 & $6.70 \mathrm{E}+02$ \\
\hline$F-20$ & $7.42 \mathrm{E}-01$ & Ga-69 & $4.57 \mathrm{E}-01$ & $\mathrm{Pd}-108$ & $1.55 \mathrm{E}+03$ \\
\hline$F-21$ & $9.30 \mathrm{E}-05$ & Ga-71 & $3.12 \mathrm{E}-01$ & $\mathrm{Pd}-110$ & $6.86 \mathrm{E}+02$ \\
\hline$F-22$ & $8.38 \mathrm{E}-04$ & Ge-72 & $1.77 \mathrm{E}-01$ & $\mathrm{Ag}-107$ & $1.72 \mathrm{E}-03$ \\
\hline Al-27 & $2.40 \mathrm{E}+03$ & Ge-73 & $4.94 \mathrm{E}-01$ & $\mathrm{Ag}-108$ & $5.39 \mathrm{E}-15$ \\
\hline Si-28 & $2.86 \mathrm{E}+04$ & Ge-74 & $1.21 \mathrm{E}+00$ & $\mathrm{Ag}-108$ & $1.98 \mathrm{E}-06$ \\
\hline $\mathrm{Si}-29$ & $1.50 \mathrm{E}+03$ & Ge-76 & $1.31 \mathrm{E}+01$ & Ag-109 & $2.94 \mathrm{E}+02$ \\
\hline Si-30 & $1.03 \mathrm{E}+03$ & As-75 & $5.34 \mathrm{E}+01$ & $\mathrm{Ag}-109$ & $5.06 \mathrm{E}-16$ \\
\hline P-31 & $1.18 \mathrm{E}+03$ & Se-76 & $4.70 \mathrm{E}-02$ & $\mathrm{Ag}-110$ & $8.73 \mathrm{E}-13$ \\
\hline S-32 & $7.91 \mathrm{E}+02$ & Se-77 & $2.91 \mathrm{E}+01$ & $\mathrm{Ag}-110$ & $5.51 \mathrm{E}-05$ \\
\hline S-33 & $6.44 \mathrm{E}+00$ & Se-78 & $5.51 \mathrm{E}+01$ & $\mathrm{Cd}-108$ & $1.78 \mathrm{E}-05$ \\
\hline S-34 & $3.72 \mathrm{E}+01$ & Se-79 & $8.70 \mathrm{E}+01$ & Cd-109 & $5.01 \mathrm{E}-10$ \\
\hline S-35 & $6.55 \mathrm{E}-16$ & Se-80 & $1.56 \mathrm{E}+02$ & Cd-110 & $4.45 \mathrm{E}+00$ \\
\hline S-36 & $1.87 \mathrm{E}-01$ & Se-82 & $3.50 \mathrm{E}+02$ & Cd-111 & $8.40 \mathrm{E}+01$ \\
\hline Ar-36 & $1.74 \mathrm{E}-17$ & $\mathrm{Br}-80$ & $2.35 \mathrm{E}-04$ & Cd-112 & $6.35 \mathrm{E}+01$ \\
\hline Ar-37 & $1.77 \mathrm{E}-23$ & $\mathrm{Br}-81$ & $2.80 \mathrm{E}-06$ & Cd-113 & $5.07 \mathrm{E}+01$ \\
\hline Ar-38 & $5.17 \mathrm{E}-10$ & $\mathrm{Br}-82$ & $1.87 \mathrm{E}+00$ & Cd-113 & $5.86 \mathrm{E}-01$ \\
\hline Ar-39 & $1.06 \mathrm{E}-08$ & $\mathrm{Br}-83$ & $5.26 \mathrm{E}+02$ & Cd-114 & $4.96 \mathrm{E}+01$ \\
\hline Ar-40 & $1.69 \mathrm{E}-08$ & $\mathrm{Br}-84$ & $9.15 \mathrm{E}+02$ & Cd-115 & $8.63 \mathrm{E}-15$ \\
\hline Sc-45 & $9.80 \mathrm{E}-04$ & $\mathrm{Br}-85$ & $1.20 \mathrm{E}+02$ & Cd-116 & $4.93 \mathrm{E}+01$ \\
\hline Sc-46 & $1.40 \mathrm{E}-11$ & $\mathrm{Br}-86$ & $1.79 \mathrm{E}+03$ & $\ln -113$ & $6.23 \mathrm{E}-01$ \\
\hline Ti-46 & $7.02 \mathrm{E}+02$ & Zr-90 & $8.15 \mathrm{E}+04$ & In-114 & $2.48 \mathrm{E}-21$ \\
\hline Ti-47 & $6.56 \mathrm{E}+02$ & Zr-91 & $2.34 \mathrm{E}+04$ & In-114 & $1.54 \mathrm{E}-16$ \\
\hline Ti-48 & $6.75 \mathrm{E}+03$ & Zr-92 & $3.32 \mathrm{E}+04$ & $\ln -115$ & $4.27 \mathrm{E}+01$ \\
\hline Ti-49 & $5.15 \mathrm{E}+02$ & Zr-93 & $6.31 \mathrm{E}+03$ & Sn-112 & $4.45 \mathrm{E}-04$ \\
\hline Ti-50 & $5.17 \mathrm{E}+02$ & Zr-94 & $3.50 \mathrm{E}+04$ & Sn-114 & $4.95 \mathrm{E}-03$ \\
\hline V-49 & $2.07 \mathrm{E}-08$ & Zr-95 & 1.01E-07 & Sn-115 & $1.43 \mathrm{E}+00$ \\
\hline V-50 & $5.00 \mathrm{E}+00$ & Zr-96 & $1.14 \mathrm{E}+04$ & Sn-116 & $4.54 \mathrm{E}-01$ \\
\hline V-51 & $6.57 \mathrm{E}+02$ & $\mathrm{Nb}-93$ & $3.92 \mathrm{E}+03$ & Sn-117 & $4.99 \mathrm{E}+01$ \\
\hline Cr-50 & $3.30 \mathrm{E}+04$ & $\mathrm{Nb}-93$ & $9.57 \mathrm{E}-02$ & Sn-118 & $4.85 \mathrm{E}+01$ \\
\hline Cr-51 & $2.85 \mathrm{E}-22$ & $\mathrm{Nb}-94$ & $1.44 \mathrm{E}+01$ & Sn-119 & $4.98 \mathrm{E}+01$ \\
\hline Cr-52 & $6.63 \mathrm{E}+05$ & $\mathrm{Nb}-95$ & $1.22 \mathrm{E}-07$ & Sn-119 & $6.00 \mathrm{E}-04$ \\
\hline Cr-53 & $7.61 \mathrm{E}+04$ & $\mathrm{Nb}-95$ & $1.21 \mathrm{E}-10$ & Sn-120 & $5.05 \mathrm{E}+01$ \\
\hline Cr-54 & $2.01 \mathrm{E}+04$ & Mo-92 & $1.66 \mathrm{E}+04$ & Sn-121 & 1.65E-02 \\
\hline $\mathrm{Mn}-54$ & $7.22 \mathrm{E}-02$ & Mo-93 & $3.62 \mathrm{E}+01$ & Sn-122 & $6.01 \mathrm{E}+01$ \\
\hline Mn-55 & $5.67 \mathrm{E}+04$ & Mo-94 & $1.05 \mathrm{E}+04$ & Sn-123 & $3.32 \mathrm{E}-05$ \\
\hline $\mathrm{Fe}-54$ & $1.63 \mathrm{E}+05$ & Mo-95 & $2.51 \mathrm{E}+04$ & Sn-124 & $9.93 \mathrm{E}+01$ \\
\hline Fe-55 & $4.87 \mathrm{E}+00$ & Mo-96 & $1.95 \mathrm{E}+04$ & Sn-126 & $2.11 \mathrm{E}+02$ \\
\hline Fe-56 & $2.63 \mathrm{E}+06$ & Mo-97 & $1.79 \mathrm{E}+04$ & Sb-121 & $5.25 \mathrm{E}+01$ \\
\hline $\mathrm{Fe}-57$ & $6.22 \mathrm{E}+04$ & Mo-98 & $3.53 \mathrm{E}+04$ & Sb-123 & $6.77 \mathrm{E}+01$ \\
\hline Fe-58 & $8.69 \mathrm{E}+03$ & Mo-100 & $1.91 \mathrm{E}+04$ & Sb-124 & $1.63 \mathrm{E}-12$ \\
\hline
\end{tabular}


Table A-2. (cont.)

\begin{tabular}{|c|c|c|c|c|c|}
\hline Isotope & Total mass $(\mathrm{g})$ & Isotope & Total mass $(\mathrm{g})$ & Isotope & Total mass $(\mathrm{g})$ \\
\hline Sb-125 & $6.38 \mathrm{E}+00$ & TI-209 & 5.97E-16 & $\overline{U-236}$ & $8.02 \mathrm{E}+02$ \\
\hline Sb-126 & $1.00 \mathrm{E}-05$ & $\mathrm{~Pb}-204$ & $1.61 \mathrm{E}-03$ & $\mathrm{U}-237$ & $3.73 \mathrm{E}-08$ \\
\hline $\mathrm{Sb}-126$ & $7.61 \mathrm{E}-08$ & $\mathrm{~Pb}-206$ & $2.80 \mathrm{E}-02$ & $\mathrm{U}-238$ & $3.47 \mathrm{E}+05$ \\
\hline Te-122 & $4.83 \mathrm{E}-01$ & $\mathrm{~Pb}-207$ & $2.57 \mathrm{E}-02$ & $U-240$ & $6.88 \mathrm{E}-19$ \\
\hline Te-123 & $2.75 \mathrm{E}-03$ & $\mathrm{~Pb}-208$ & $6.17 \mathrm{E}-02$ & $\mathrm{~Np}-237$ & $1.87 \mathrm{E}+01$ \\
\hline Te-123 & $6.18 \mathrm{E}-10$ & $\mathrm{~Pb}-209$ & $2.45 \mathrm{E}-12$ & $\mathrm{~Np}-239$ & $3.61 \mathrm{E}-09$ \\
\hline Te-124 & $2.97 \mathrm{E}-01$ & $\mathrm{~Pb}-210$ & $1.45 \mathrm{E}-08$ & $\mathrm{~Np}-240$ & $5.94 \mathrm{E}-21$ \\
\hline Te-125 & $1.02 \mathrm{E}+02$ & $\mathrm{~Pb}-211$ & $1.41 \mathrm{E}-11$ & Pu-236 & $6.95 \mathrm{E}-06$ \\
\hline Te-125 & $1.52 \mathrm{E}-01$ & $\mathrm{~Pb}-212$ & $7.24 \mathrm{E}-08$ & Pu-238 & $5.14 \mathrm{E}-01$ \\
\hline Te-126 & $1.75 \mathrm{E}+00$ & $\mathrm{~Pb}-214$ & $3.18 \mathrm{E}-13$ & Pu-239 & $3.98 \mathrm{E}+03$ \\
\hline Te-127 & $3.04 \mathrm{E}-08$ & $\mathrm{Bi}-209$ & $9.73 \mathrm{E}-03$ & Pu-240 & $8.69 \mathrm{E}+01$ \\
\hline Te-127 & $8.69 \mathrm{E}-06$ & Bi-210 & $9.46 \mathrm{E}-12$ & Pu-241 & $1.25 \mathrm{E}+00$ \\
\hline Te-128 & $1.03 \mathrm{E}+03$ & Bi-211 & $8.37 \mathrm{E}-13$ & Pu-242 & $2.68 \mathrm{E}-01$ \\
\hline Te-129 & $2.11 \mathrm{E}-20$ & Bi-212 & $6.89 \mathrm{E}-09$ & Pu-243 & $1.08 \mathrm{E}-21$ \\
\hline Te-129 & $2.28 \mathrm{E}-17$ & $\mathrm{Bi}-213$ & $5.91 \mathrm{E}-13$ & Pu-244 & $3.60 \mathrm{E}-08$ \\
\hline Te-130 & $2.99 \mathrm{E}+03$ & $\mathrm{Bi}-214$ & $2.34 \mathrm{E}-13$ & $\mathrm{Am}-241$ & $1.90 \mathrm{E}+00$ \\
\hline $\mathrm{Xe}-128$ & $3.96 \mathrm{E}+00$ & Po-210 & $2.26 \mathrm{E}-10$ & $\mathrm{Am}-242$ & $7.26 \mathrm{E}-08$ \\
\hline Xe-129 & 1.79E-02 & Po-211 & $1.01 \mathrm{E}-17$ & Am-242 & $6.03 \mathrm{E}-03$ \\
\hline Xe-130 & $8.68 \mathrm{E}+00$ & Po-212 & $3.64 \mathrm{E}-19$ & Am-243 & $4.36 \mathrm{E}-03$ \\
\hline Xe-131 & $4.92 \mathrm{E}+03$ & Po-213 & $8.26 \mathrm{E}-22$ & Am-244 & $2.80 \mathrm{E}-23$ \\
\hline Xe-132 & $7.23 \mathrm{E}+03$ & Po-214 & $3.96 \mathrm{E}-20$ & $\mathrm{Cm}-242$ & $1.52 \mathrm{E}-05$ \\
\hline Xe-134 & $1.18 \mathrm{E}+04$ & Po-215 & $1.19 \mathrm{E}-17$ & $\mathrm{Cm}-243$ & 1.67E-05 \\
\hline Xe-136 & $9.54 \mathrm{E}+03$ & Po-216 & $2.90 \mathrm{E}-13$ & $\mathrm{Cm}-244$ & $8.72 \mathrm{E}-05$ \\
\hline Ta-180 & $6.67 \mathrm{E}-02$ & Po-218 & $3.69 \mathrm{E}-14$ & $\mathrm{Cm}-245$ & $1.94 \mathrm{E}-06$ \\
\hline Ta-181 & $5.38 \mathrm{E}+02$ & At-217 & $6.83 \mathrm{E}-18$ & $\mathrm{Cm}-246$ & $1.01 \mathrm{E}-08$ \\
\hline Ta-182 & $1.10 \mathrm{E}-06$ & Rn-219 & $2.70 \mathrm{E}-14$ & $\mathrm{Cm}-247$ & $3.15 \mathrm{E}-11$ \\
\hline W-180 & $1.22 \mathrm{E}+00$ & Rn-220 & $1.10 \mathrm{E}-10$ & $\mathrm{Cm}-248$ & $1.26 \mathrm{E}-13$ \\
\hline W-181 & $3.36 \mathrm{E}-08$ & Rn-222 & $6.78 \mathrm{E}-11$ & $\mathrm{Cm}-250$ & $9.46 \mathrm{E}-22$ \\
\hline W-182 & $2.71 \mathrm{E}+02$ & Rn-225 & $1.87 \mathrm{E}-10$ & Bk-249 & $4.29 \mathrm{E}-19$ \\
\hline W-183 & $1.48 \mathrm{E}+02$ & Rn-227 & $4.75 \mathrm{E}-06$ & Cf-249 & $3.12 \mathrm{E}-16$ \\
\hline W-184 & $3.20 \mathrm{E}+02$ & $\mathrm{Rn}-228$ & $5.14 \mathrm{E}-16$ & Cf-250 & $2.38 \mathrm{E}-18$ \\
\hline W-185 & 1.67E-09 & $\mathrm{U}-232$ & $7.82 \mathrm{E}-05$ & Cf-251 & $2.95 \mathrm{E}-20$ \\
\hline W-186 & $2.99 \mathrm{E}+02$ & U-233 & $1.29 \mathrm{E}-02$ & Cf-252 & $1.86 \mathrm{E}-23$ \\
\hline TI-207 & $1.82 \mathrm{E}-12$ & U-234 & $1.34 \mathrm{E}+02$ & & \\
\hline TI-208 & $1.25 \mathrm{E}-10$ & U-235 & $3.19 \mathrm{E}+04$ & & \\
\hline
\end{tabular}


Table A-3. Average Radionuclide Inventory (Ci) per Canister Used in Calculations for TSPA-LA ${ }^{\text {a }}$

\begin{tabular}{|c|c|c|c|c|c|c|c|}
\hline Nuclide & CWF & MWF & HLW & Nuclide & CWF & MWF & HLW \\
\hline Ac-225 & 1.15E-08 & $3.41 \mathrm{E}-08$ & 3.34E-05 & Po-212 & $1.21 \mathrm{E}-05$ & $8.94 \mathrm{E}-06$ & $5.53 \mathrm{E}-04$ \\
\hline Ac-227 & 3.37E-07 & $1.55 \mathrm{E}-06$ & 1.83E-03 & Po-213 & $1.13 \mathrm{E}-08$ & 3.34E-08 & $3.26 \mathrm{E}-05$ \\
\hline Ac-228 & $2.50 \mathrm{E}-11$ & $4.75 \mathrm{E}-12$ & $2.18 \mathrm{E}-04$ & Po-214 & $1.23 \mathrm{E}-06$ & $4.05 \mathrm{E}-07$ & 1.67E-06 \\
\hline Am-241 & $1.89 \mathrm{E}+01$ & $5.64 \mathrm{E}-03$ & $4.96 \mathrm{E}+01$ & Po-215 & 3.37E-07 & $1.55 \mathrm{E}-06$ & 1.83E-03 \\
\hline $\mathrm{Am}-242$ & 0 & 0 & 3.07E-02 & Po-216 & 1.89E-05 & $1.40 \mathrm{E}-05$ & $8.64 \mathrm{E}-04$ \\
\hline$A m-242 m$ & 0 & 0 & $3.09 \mathrm{E}-02$ & Po-218 & $1.23 \mathrm{E}-06$ & $4.06 \mathrm{E}-07$ & 1.67E-06 \\
\hline Am-243 & $2.88 \mathrm{E}-03$ & $7.95 \mathrm{E}-07$ & 5.02E-02 & Pr-144 & $1.89 \mathrm{E}-13$ & 0 & $2.07 \mathrm{E}-08$ \\
\hline At-217 & $1.15 \mathrm{E}-08$ & $3.41 \mathrm{E}-08$ & 3.34E-05 & Pr-144m & $2.65 \mathrm{E}-15$ & 0 & $2.90 \mathrm{E}-10$ \\
\hline Ba-137m & $3.31 \mathrm{E}+03$ & 0 & $1.72 \mathrm{E}+04$ & Pu-236 & 0 & 0 & 1.12E-04 \\
\hline Bi-210 & 6.04E-07 & 1.27E-07 & 2.92E-07 & Pu-238 & $2.72 \mathrm{E}+00$ & $8.09 \mathrm{E}-04$ & $9.41 \mathrm{E}+02$ \\
\hline Bi-211 & 3.37E-07 & $1.55 \mathrm{E}-06$ & 1.83E-03 & Pu-239 & $1.75 \mathrm{E}+02$ & 5.52E-02 & $1.29 \mathrm{E}+01$ \\
\hline $\mathrm{Bi}-212$ & 1.89E-05 & $1.40 \mathrm{E}-05$ & 8.64E-04 & Pu-240 & $1.55 \mathrm{E}+01$ & $4.85 \mathrm{E}-03$ & $7.59 \mathrm{E}+00$ \\
\hline Bi-213 & 1.15E-08 & 3.41E-08 & 3.33E-05 & Pu-241 & $1.64 \mathrm{E}+01$ & $4.66 \mathrm{E}-03$ & $3.13 E+02$ \\
\hline Bi-214 & $1.23 \mathrm{E}-06$ & $4.05 \mathrm{E}-07$ & 1.67E-06 & Pu-242 & $1.28 \mathrm{E}-03$ & $3.37 \mathrm{E}-07$ & 1.04E-02 \\
\hline C-14 & 0 & $7.12 \mathrm{E}-01$ & 1.87E-02 & Ra-223 & $3.37 \mathrm{E}-07$ & $1.55 \mathrm{E}-06$ & $1.83 \mathrm{E}-03$ \\
\hline Cd-113m & 0 & 0 & $2.44 \mathrm{E}-02$ & Ra-224 & 1.89E-05 & 1.40E-05 & 8.64E-04 \\
\hline Ce-142 & $2.35 \mathrm{E}-06$ & 0 & $5.24 \mathrm{E}-07$ & Ra-225 & $1.15 \mathrm{E}-08$ & $3.41 \mathrm{E}-08$ & 3.34E-05 \\
\hline Ce-144 & $1.89 \mathrm{E}-13$ & 0 & $2.07 \mathrm{E}-08$ & Ra-226 & $1.23 \mathrm{E}-06$ & $4.06 \mathrm{E}-07$ & 1.67E-06 \\
\hline $\mathrm{Cm}-242$ & 0 & 0 & $2.54 \mathrm{E}-02$ & Ra-228 & $2.50 \mathrm{E}-11$ & $4.75 \mathrm{E}-12$ & $2.18 \mathrm{E}-04$ \\
\hline $\mathrm{Cm}-243$ & $6.31 \mathrm{E}-04$ & 1.92E-07 & $5.29 \mathrm{E}-03$ & Rb-87 & $3.85 \mathrm{E}-06$ & 0 & $4.91 \mathrm{E}-08$ \\
\hline $\mathrm{Cm}-244$ & $4.28 \mathrm{E}-03$ & $1.13 \mathrm{E}-06$ & $2.71 \mathrm{E}+01$ & Rh-102 & 0 & 0 & $7.98 \mathrm{E}-10$ \\
\hline $\mathrm{Cm}-245$ & 0 & 0 & $1.17 \mathrm{E}-04$ & Rh-106 & 0 & 5.19E-09 & $2.37 \mathrm{E}-06$ \\
\hline $\mathrm{Cm}-246$ & 0 & 0 & 1.33E-05 & Rn-219 & 3.37E-07 & $1.55 \mathrm{E}-06$ & $1.83 \mathrm{E}-03$ \\
\hline Co-60 & 0 & $2.73 E+00$ & $2.62 \mathrm{E}+00$ & Rn-220 & $1.89 \mathrm{E}-05$ & $1.40 \mathrm{E}-05$ & $8.64 \mathrm{E}-04$ \\
\hline Cs-134 & 1.19E-04 & 0 & 1.11E-02 & Rn-222 & 1.23E-06 & 4.06E-07 & 1.67E-06 \\
\hline Cs-135 & $1.66 \mathrm{E}-01$ & 0 & $1.24 \mathrm{E}-01$ & Ru-106 & 0 & $5.19 \mathrm{E}-09$ & $2.37 \mathrm{E}-06$ \\
\hline Cs-137 & $3.51 \mathrm{E}+03$ & 0 & $1.82 \mathrm{E}+04$ & Sb-125 & 0 & 8.92E-02 & $3.36 \mathrm{E}-01$ \\
\hline Eu-152 & 0 & 0 & $3.59 \mathrm{E}-03$ & Sb-126 & 0 & $6.55 \mathrm{E}-02$ & $5.23 \mathrm{E}-02$ \\
\hline Eu-154 & $8.56 \mathrm{E}-01$ & 0 & $4.45 \mathrm{E}+01$ & Sb-126m & 0 & $4.68 \mathrm{E}-01$ & $3.74 \mathrm{E}-01$ \\
\hline Eu-155 & $5.37 \mathrm{E}-01$ & 0 & $4.59 \mathrm{E}+00$ & Se-79 & 0 & 0 & $1.43 \mathrm{E}-01$ \\
\hline Fe-55 & 0 & 0 & 2.65E-07 & Sm-146 & 0 & 0 & $1.23 \mathrm{E}-11$ \\
\hline Fr-221 & 1.15E-08 & $3.41 \mathrm{E}-08$ & 3.34E-05 & Sm-147 & 9.34E-07 & 0 & 4.85E-07 \\
\hline Fr-223 & $4.65 \mathrm{E}-09$ & $2.14 \mathrm{E}-08$ & $2.52 \mathrm{E}-05$ & Sm-148 & $8.19 \mathrm{E}-12$ & 0 & $1.04 \mathrm{E}-13$ \\
\hline Gd-152 & 0 & 0 & $1.10 \mathrm{E}-15$ & Sm-149 & $7.99 \mathrm{E}-12$ & 0 & $1.02 \mathrm{E}-13$ \\
\hline $\mathrm{H}-3$ & 0 & 0 & $3.58 \mathrm{E}-01$ & Sm-151 & 0 & 0 & $1.58 \mathrm{E}+02$ \\
\hline $\mid-129$ & 3.52E-03 & 0 & $8.22 \mathrm{E}-04$ & Sn-121 & 0 & 0 & $9.53 \mathrm{E}-04$ \\
\hline K-40 & $4.26 \mathrm{E}-05$ & 0 & $4.70 \mathrm{E}-05$ & Sn-121m & 0 & 0 & $1.23 \mathrm{E}-03$ \\
\hline La-138 & $1.02 \mathrm{E}-08$ & 0 & $1.30 \mathrm{E}-10$ & Sn-126 & 0 & 4.68E-01 & 3.74E-01 \\
\hline $\mathrm{Nb}-93 \mathrm{~m}$ & 0 & $8.75 \mathrm{E}-01$ & $7.30 \mathrm{E}-01$ & Sr-90 & $2.77 E+03$ & 0 & $1.94 \mathrm{E}+04$ \\
\hline $\mathrm{Nb}-94$ & 0 & 4.54E-01 & 3.62E-04 & Tc-99 & 0 & $2.12 \mathrm{E}+01$ & $3.13 E+00$ \\
\hline Nd-144 & $4.16 \mathrm{E}-10$ & 0 & $3.17 \mathrm{E}-11$ & Te-125m & 0 & $2.18 \mathrm{E}-02$ & $8.18 \mathrm{E}-02$ \\
\hline $\mathrm{Ni}-59$ & 0 & $1.78 \mathrm{E}+00$ & $3.45 \mathrm{E}-02$ & Th-227 & 3.32E-07 & $1.53 \mathrm{E}-06$ & 1.81E-03 \\
\hline $\mathrm{Ni}-63$ & 0 & $5.21 \mathrm{E}+01$ & $2.76 \mathrm{E}+00$ & Th-228 & $1.89 \mathrm{E}-05$ & $1.40 \mathrm{E}-05$ & $8.64 \mathrm{E}-04$ \\
\hline $\mathrm{Np}-236$ & 0 & 0 & 1.26E-03 & Th-229 & 1.15E-08 & 3.41E-08 & 3.34E-05 \\
\hline $\mathrm{Np}-237$ & $1.41 \mathrm{E}-02$ & 4.07E-06 & 1.15E-02 & Th-230 & $5.90 \mathrm{E}-05$ & $4.71 \mathrm{E}-05$ & $8.21 \mathrm{E}-05$ \\
\hline $\mathrm{Np}-238$ & 0 & 0 & 1.39E-04 & Th-231 & 9.21E-04 & 4.22E-03 & 1.07E-04 \\
\hline $\mathrm{Np}-239$ & $2.88 \mathrm{E}-03$ & 7.95E-07 & 5.02E-02 & Th-232 & $2.54 \mathrm{E}-11$ & $5.98 \mathrm{E}-12$ & $2.18 \mathrm{E}-04$ \\
\hline $\mathrm{Pa}-231$ & 7.76E-07 & $3.57 \mathrm{E}-06$ & $2.02 \mathrm{E}-03$ & Th-234 & $2.88 \mathrm{E}-03$ & 1.62E-02 & $8.50 \mathrm{E}-03$ \\
\hline $\mathrm{Pa}-233$ & 1.41E-02 & 4.07E-06 & 1.15E-02 & TI-206 & 7.97E-13 & $1.67 \mathrm{E}-13$ & $3.85 \mathrm{E}-13$ \\
\hline $\mathrm{Pa}-234$ & 3.74E-06 & 2.11E-05 & 1.11E-05 & TI-207 & 3.36E-07 & 1.55E-06 & 1.83E-03 \\
\hline $\mathrm{Pa}-234 \mathrm{~m}$ & $2.88 \mathrm{E}-03$ & 1.62E-02 & $8.50 \mathrm{E}-03$ & TI-208 & $6.81 \mathrm{E}-06$ & $5.02 \mathrm{E}-06$ & $3.10 \mathrm{E}-04$ \\
\hline Pb-209 & $1.15 \mathrm{E}-08$ & $3.41 \mathrm{E}-08$ & $3.33 \mathrm{E}-05$ & TI-209 & $2.41 \mathrm{E}-10$ & $7.17 \mathrm{E}-10$ & 7.01E-07 \\
\hline $\mathrm{Pb}-210$ & 6.04E-07 & 1.27E-07 & 2.92E-07 & U-232 & 1.84E-05 & 1.36E-05 & $6.29 \mathrm{E}-04$ \\
\hline $\mathrm{Pb}-211$ & 3.37E-07 & $1.55 \mathrm{E}-06$ & $1.83 \mathrm{E}-03$ & U-233 & $4.49 \mathrm{E}-06$ & $9.72 \mathrm{E}-06$ & $1.27 \mathrm{E}-03$ \\
\hline $\mathrm{Pb}-212$ & $1.89 \mathrm{E}-05$ & $1.40 \mathrm{E}-05$ & $8.64 \mathrm{E}-04$ & U-234 & $2.92 \mathrm{E}-02$ & $1.28 \mathrm{E}-01$ & $1.30 \mathrm{E}-01$ \\
\hline $\mathrm{Pb}-214$ & $1.23 \mathrm{E}-06$ & $4.05 \mathrm{E}-07$ & 1.67E-06 & U-235 & 9.21E-04 & 4.22E-03 & 1.07E-04 \\
\hline Pd-107 & 0 & 0 & 1.31E-02 & U-236 & 6.78E-04 & 3.03E-03 & 2.61E-04 \\
\hline Pm-146 & 0 & 0 & $2.73 \mathrm{E}-06$ & U-237 & $3.92 \mathrm{E}-04$ & 1.12E-07 & $7.48 \mathrm{E}-03$ \\
\hline $\mathrm{Pm}-147$ & $1.20 \mathrm{E}-01$ & 0 & $6.91 \mathrm{E}+00$ & U-238 & $2.88 \mathrm{E}-03$ & 1.62E-02 & $8.50 \mathrm{E}-03$ \\
\hline Po-210 & 6.04E-07 & $1.27 \mathrm{E}-07$ & 2.92E-07 & $\mathrm{Y}-90$ & $2.78 \mathrm{E}+03$ & 0 & $1.94 \mathrm{E}+04$ \\
\hline Po-211 & $9.27 \mathrm{E}-10$ & $4.27 \mathrm{E}-09$ & 5.04E-06 & Zr-93 & 0 & 0 & $9.25 \mathrm{E}-01$ \\
\hline
\end{tabular}

${ }^{a}$ Values for CWF and MWF shown in bold exceed the current HLW average. 


\section{APPENDIX B. ANNOTATED BIBLIOGRAPHY OF TECHNICAL PUBLICATIONS}

The following is a list of technical publications produced during the testing, analysis, and modeling activities to support qualification of the CWF and MWF for disposal. The documents are grouped according to the information they provide to support waste form qualification and are briefly annotated regarding content. Some publications are listed in more than one category. Some publications were not directly cited in this report, and some have limited distribution.

\section{Waste Form Specifications}

Benedict, R.W.; McFarlane, H.F.; Henslee, S.P.; Lineberry, M.J.; Abraham, D.P.; Ackerman, J.P.; Ahluwalia, R.K.; Garcia, H.E.; Gay, E.C.; Goff, K.M.; Johnson, S.G.; Mariani, R.D.; McDeavitt, S.; Pereira, C.; Roach, P.D.; Sherman, S.R.; Westphal, B.R. Wigeland, R.A.; and Willit, J.L. 1999. Spent Fuel Treatment Demonstration Final Report. Argonne National Laboratory report ANL-NT-106. Argonne, Illinois: Argonne National Laboratory.

This report provides a summary of activities in the demonstration phase.

Goff, K.M.; Benedict, R.W.; Bateman, K.; Lewis, M.A.; Pereira, C.; and Musick, C.A. 1996. "Spent Fuel Treatment and Mineral Waste Form Development at Argonne National Laboratory-West." Proceedings of the Spectrum '96 Meeting, Nuclear and Hazardous Waste Management International Topical Meeting held August 18-23, 1996, Seattle, Washington. 2436-2443. LaGrange, Illinois: American Nuclear Society.

This report presents summaries of the EBR II spent fuel inventory, electrometallurgical treatment operations, waste form development, and schedule.

Goff, K.M.; Ackerman, J.P.; Simpson, M.F.; Hash, M.C.; Bateman, K.J.; Battisti, T.J.; Hirsche, K.L.; and Kennedy, J.R. 1999. Ceramic Waste Form Process Qualification Plan. Argonne National Laboratory report ANL-NT-118. Argonne, Illinois: Argonne National Laboratory.

This report presents a description and a basis for qualifying a CWF processing plan using HIP and provides background information.

O’Holleran, T.P.; Benedict, R.W.; and Johnson, S.G. 1999. Waste Form Qualification Strategy for the Metal and Ceramic Waste Forms from Electrometallurgical Treatment of Spent Nuclear Fuel. Argonne National Laboratory report ANL-NT-115. Argonne, Illinois: Argonne National Laboratory.

This report provides a top-level description of strategy for waste form qualification and background information.

O’Holleran, T.P.; Abraham, D.P.; Ackerman, J.P.; Goff, K.M.; Johnson, S.G.; and Keiser, D.D. 1999. Waste Acceptance Product Specifications for the Waste Forms from Electrometallurgical Treatment of Spent Nuclear Fuel. Argonne National Laboratory report ANL-NT-116. Argonne, Illinois: Argonne National Laboratory.

This report provides a top-level description of the strategy to develop waste acceptance product specifications and background information. 
Westphal, B.R.; Marsden, K.C.; McDeavitt, S.M.; Keiser, D.D. Jr.; Abraham, D.P.; Rigg, R.H.; Jensen, B.A.; and Laug, D.V. 1999. Metal Waste Form Process Qualification Plan. Argonne National Laboratory report ANL-NT-120. Argonne, Illinois: Argonne National Laboratory.

This report presents a description and a basis for qualifying a metallic waste form processing plan. This report provides background information.

\section{General Characteristics of CWF Materials}

Ebert, W.L; Esh, D.W.; Frank, S.M.; Goff, K.M.; Hash, M.C.; Johnson, S.G.; Lewis, M.A.; Morss, L.R.; Moschetti, T.L.; O’Holleran, T.P.; Richmann, M.K.; Riley, W.P., Jr.; Simpson, L.J.; Sinkler, W.; Stanley, M.L.; Tatko, C.D.; Wronkiewicz, D.J.; Ackerman, J.P.; Arbesman, K.A.; Bateman, K.J.; Battisti, T.J.; Cummings, D.G.; DiSanto, T.; Gougar, M.L.; Hirsche, K.L.; Kaps, S.E.; Leibowitz, L.; Luo, S.S.; Noy, M.; Retzer, H.; Simpson; Sun, D.; Warren, A.R.; and Zyryanov, V.N. 1999. Ceramic Waste Form Handbook, Argonne National Laboratory report ANL-NT-119. Argonne, Illinois: Argonne National Laboratory.

This report provides a summary of laboratory tests and analyses to characterize the microstructure of CWF, physical properties, disposition of radionuclides, corrosion modes, and chemical durability. Laboratory tests used to develop degradation model and measure model parameters are also presented.

Ebert, W.L.; Lewis, M.A.; and Johnson, S.G. 2002. "The Precision of Product Consistency Tests Conducted with a Glass-Bonded Ceramic Waste Form." Journal of Nuclear Materials, 305:37-51. New York, New York: North-Holland.

This paper presents the results of an interlaboratory study to measure the precision of product consistency tests with the CWF. The paper provides insight into the applicability of the PCT for meeting the product consistency requirement in WASRD.

Ebert, W.L.; Dietz, N.L.; and Janney, D.E. 2005. Effects of Heat-Treatment and Formulation on the Phase Composition and Chemical Durability of the EBR II Ceramic Waste Form, Argonne National Laboratory report ANL-05/32. Argonne, Illinois: Argonne National Laboratory.

This report provides data for the effects of heat treatments and amounts of salt, zeolite, and binder glass used to make CWF on phase composition and durability. The report provides time-temperaturetransformation data for phase stability.

Jeong, J.Y.; Fanning, T.H.; Morss, L.R.; and Ebert, W.L. 2002. Corrosion Tests to Determine Temperature and pH Dependencies of the Dissolution Rates of Sodalite, Binder Glass, and Ceramic Waste Forms. Argonne National Laboratory report ANL-02/32. Argonne, Illinois: Argonne National Laboratory.

This report provides data on short-term MCC-1 leach tests in $\mathrm{pH}$-buffered solutions conducted to measure the dependence of dissolution rates of the binder glass, sodalite, and consolidated CWF on $\mathrm{pH}$ and temperature. The report also addresses the effect of sodalite dissolution into binder glass on the binder glass dissolution rate and presents results of dissolution tests at $20^{\circ} \mathrm{C}$ conducted to validate the degradation model. 
Frank, S.M.; Johnson, S.G.; Moschetti, T.L.; O’Holleran, T.P.; Sinkler, W.; Esh, D.; and Goff, M.K. 2000. "Accelerated Alpha Radiation Damage in a Ceramic Waste Form, Interim Results." Scientific Basis for Nuclear Waste Management XXIII, Symposium held November 29-December 2, 1999. Boston, Massachusetts. Smith, R.W., and Shoesmith, D.W., eds. Vol. 608, pp. 469-474. Warrendale, Pennsylvania: Materials Research Society.

This paper presents the results of microstructure, X-ray diffraction, and bulk density measurements and corrosion tests with $\mathrm{CWF}$ doped with $\mathrm{Pu}-238$ to highlight alpha damage. The paper provides short-term data on the effect of radiation on phase composition and stability.

Frank, S.M.; DiSanto, T.; Goff, K.M.; Johnson, S.G.; Jue, J.-F.; Barber, T.L.; Noy, M.; O’Holleran, T.P.; and Giglio, J.J. 2002. "Plutonium-238 Alpha-Decay Damage study of a glass-bonded sodalite ceramic waste form." Journal of Testing and Evaluation, Sept 2002. West Conshohocken, Pennsylvania: American Society for Testing and Materials.

This paper presents the results of microstructure, X-ray diffraction, and bulk density measurements and corrosion tests with $\mathrm{CWF}$ doped with $\mathrm{Pu}-238$ to highlight alpha damage. The paper provides data on the effect of radiation on phase composition and stability.

Frank, S.M. 2002. "Alpha Decay Damage Study of a Glass-Bonded Sodalite Ceramic Waste Form." Scientific Basis for Nuclear Waste Management XXV, Symposium held November 26-29, 2001. Boston, Massachusetts. McGrail, B.P., and Cragnolino, G.A., eds. Vol. 713, pp. 487-494.

This paper summarizes the results of microstructure, X-ray diffraction, and bulk density measurements and corrosion tests with CWF doped with $\mathrm{Pu}-238$ to study the effect of alpha damage.

Lewis, M.A.; Hash, M.; and Glandorf, D. 1997. "Effect of Different Glass and Zeolite-A Compositions on the Leach Resistance of Ceramic Waste Forms." Scientific Basis for Nuclear Waste Management XXIII Symposium held December 2-6, 1996. Boston, Massachusetts. Gray, W.J., and Triay, I.R., eds. Vol. 465, pp. 433-440. Pittsburgh, Pennsylvania: Materials Research Society.

This paper presents the results of MCC-1 tests with CWF materials made by using different cationic forms of zeolite 5A (which contains only sodium cations) and zeolite 4A (which contains sodium and calcium cations), as well as different binder glass compositions. The paper provides background information regarding CWF processing.

Lewis, M.L., and Ebert, W. L. 2000. Results of Scoping Tests with Ceramic Waste Form Materials Made by Pressureless Consolidation, Argonne National Laboratory report ANL-NT-160. Argonne, Illinois: Argonne National Laboratory.

This report presents the results of tests and analyses conducted with CWF made by pressureless consolidation (PC) to support a decision to change from production by hot isostatic pressing to production by PC. The report provides a characterization of PC CWF materials.

Lewis, M.A.; Hash, M.C.; Ebert, W.L.; Hebden, A.; and Oliver, S.M. 2001. Results of Physical Characterizations and Product Consistency Tests with Ceramic Waste Form Products Prepared at Six Temperatures and Six Hold Times. Argonne National Laboratory report ANL-NT-178. Argonne, Illinois: Argonne National Laboratory.

This report describes the examination and testing of CWF made by pressureless consolidation at six different temperatures and for six different hold times. The effect of temperature and time on density, 
microstructure, phase composition, and chemical durability is evaluated. The report provides test data and sensitivity of CWF durability to process conditions.

Luo, J.S., Zyryanov, V.N., and Ebert, W.L. 2000. "Microstructural Characterization of Halite Inclusions in a Glass-Bonded Ceramic Waste Form." Environmental Issues and Waste Management Technologies in the Ceramic and Nuclear Industries VI. Ceramic Transactions 119: 477-484.

Morris, E.E.; Fanning, T.H.; and Wigeland, R.A. 2001. "Waste Form Performance Assessment in the Yucca Mountain Engineered Barrier System." Proceedings of the International High-Level Radioactive Waste Management Conference held April 29-May 3, 2001. Las Vegas, Nevada. CD-ROM. Session E-3 Source Term-I: General Modeling Topics. La Grange Park, Illinois: American Nuclear Society.

This paper provides a methodology to evaluate the impact of CWF and MWF, which account for about $0.1 \%$ of the total inventory at Yucca Mountain. Calculations are provided for release of I, Tc, and Np. The paper illustrates how CWF and MWF can be taken into account in TSPA calculations.

Morss, L.R.; Stanley, M.L.; Tatko, C.D.; and Ebert, W.L. 1999. "Corrosion of Glass-Bonded Sodalite as a Function of $\mathrm{pH}$ and Temperature." Scientific Basis for Nuclear Waste Management XXIII, Symposium held November 29-December 2, 1999. Boston, Massachusetts. Smith, R.W., and Shoesmith, D.W., eds. Vol. 608, pp. 733-738. Warrendale, Pennsylvania: Materials Research Society.

This paper summarizes laboratory measurements of the $\mathrm{pH}$ and temperature dependence of the dissolution rates of sodalite, binder glass, and composite CWF materials. The $\mathrm{pH}$ and temperature dependence of the component phases and the CWF are similar to that of HLW glass. The paper provides data used in CWF degradation model and TSPA calculations.

Morss, L.R. and Ebert, W.L. 2001. "Release of Uranium and Plutonium from the EBR-II Ceramic Waste Form." Environmental Issues and Waste Management Technologies in the Ceramic and Nuclear Industries VI. Ceramic Transactions 119: 477-484.

This paper summarizes the results of tests conducted with CWF materials containing $\mathrm{U}$ and $\mathrm{Pu}$.

Morss, L.R.; Johnson, S.G.; Ebert, W.L.; DiSanto, T.; Frank, S.M.; Holly, J.L.; Kropf, A.J.; Mertz, C.J.; Noy, M.; O'Holleran, T.P.; Richmann, M.K.; Sinkler, W.; Tsai, Y.; and Warren, A.R. 2002. Corrosion Tests with Uranium- and Plutonium-Loaded Ceramic Waste Forms, Argonne National Laboratory report ANL-02/09. Argonne, Illinois: Argonne National Laboratory.

This report provides analysis and test results for CWF materials made with salts containing $\mathrm{U}$ and $\mathrm{Pu}$. Results include those from an examination of materials to determine the distribution of $\mathrm{U}$ and $\mathrm{Pu}$ and laboratory tests to measure the release behavior of $\mathrm{U}$ and $\mathrm{Pu}$ as waste form degrades. In other findings, $\mathrm{U}$ and $\mathrm{Pu}$ are present in oxide crystals as inclusions in binder glass and released as colloidal and dissolved species. The releases of $\mathrm{U}$ and $\mathrm{Pu}$ are slower than the release of $\mathrm{B}$. The report provides data to address WASRD and TSPA issues.

Moschetti, T.L.; Sinkler, W.; DiSanto, T.; Noy, M.H.; Warren, A.R.; Cummings, D.; Johnson, S.G.; Goff, K.M.; Bateman, K.J.; and Frank, S.M. 2000. "Characterization of a Ceramic Waste Form Encapsulating Radioactive Electrorefiner Salt." Scientific Basis for Nuclear Waste Management XXIII, Symposium held November 29-December 2, 1999. Boston, Massachusetts. Smith, R.W., and Shoesmith, D.W., eds. Vol. 608, pp. 577-582. Warrendale, Pennsylvania: Materials Research Society. 
This paper provides the characterization of microstructure and corrosion behavior of CWF made with actual radioactive salt using the HIP method. Most alkali metal and alkaline earth fission products are retained in the sodalite, whereas most actinides and rare earth elements form oxide inclusions in the binder glass. The paper addresses the disposition of radionuclides in CWF.

O'Holleran, T.P. 2002. "Development of a Sampling Method for Qualification of a Ceramic High-Level Waste Form." Proceedings of the American Ceramic Society Annual Meeting held April 29-May 1, 2002. St. Louis, Missouri: American Ceramic Society.

This paper provides a description of the method to produce small-scale samples to monitor the consistency of CWF made by HIP.

Richardson, J.W., Jr. 1997. "Salt-Occluded Zeolite Waste Forms: Crystal Structures and Transformability." Scientific Basis for Nuclear Waste Management XXIII, Symposium held November 29December 2, 1999. Boston, Massachusetts. Gray, W.J., and Triay, I.R., eds. Vol. 465, pp. 395-400. Pittsburgh, Pennsylvania: Materials Research Society.

This paper provides the results of neutron diffraction studies of structures of salt-loaded zeolite 4A, salt-loaded zeolite 5A, and CWF materials. The transformation of salt-loaded zeolite 5A to sodalite is inhibited by the presence of complex chloride clusters in zeolite mixture. Because pores in zeolite 4A and $5 \mathrm{~A}$ are larger than pores in sodalite, less salt is included within the sodalite. The paper provides background information on CWF processing.

Sinkler, W.; Esh, D.W.; O’Holleran, T.P.; Frank, S.M.; Moschetti, T.L.; Goff, K.M.; and Johnson, S.G. 1999. "TEM Investigation of a Ceramic Waste Form for Immobilization of Process Salts Generated During Electrometallurgical Treatment of Spent Nuclear Fuel." Environmental Issues and Waste Management Technologies in the Ceramic and Nuclear Industries V, Ceramic Transactions 107:233-240.

This paper presents TEM studies of HIP CWF without radionuclides and HIP CWF with added Pu.

Sinkler, W.; O’Holleran, T.P.; Frank, S.M.; Richmann, M.K.; and Johnson, S.G. 2000. "Characterization of a Glass-bonded Ceramic Waste Form Loaded with U and Pu" Scientific Basis for Nuclear Waste Management XXIII, Symposium held November 29-December 2, 1999. Boston, Massachusetts. Smith, R.W., and Shoesmith, D.W., eds. Vol. 608, pp. 423-429. Warrendale, Pennsylvania: Materials Research Society.

This paper provides results from the examination of four CWF materials made with zeolite 4A materials that have two different initial water contents and two salts doped with different amounts of $\mathrm{U}$ and $\mathrm{Pu}$. The CWF materials have similar microstructures, except larger clusters of U, Pu-oxides appear in CWF made with zeolite that had high water contents. This paper provides insight into CWF processing and radionuclide disposition.

\section{General Characteristics of MWF Materials}

Abraham, D.P.; McDeavitt, S.M.; and Park, J.Y. 1996. "Metal Waste Forms from the Electrometallurgical Treatment of Spent Nuclear Fuel." Proceedings of the Embedded Topical Meeting on DOE Spent Nuclear Fuel and Fissile Material Management held June 16-20, 1996. Reno, Nevada. 123-128. La Grange Park, Illinois: American Nuclear Society. 
This paper provides measurements of the microstructure, corrosion, mechanical, and thermophysical properties of MWF alloys. The paper provides insight into characterization issues in WASRD and corrosion mechanism issues for TSPA.

Abraham, D.P.; McDeavitt, S.M.; and Park, J.Y. 1996. "Microstructure and Phase Identification in Type 304 Stainless Steel-Zirconium Alloys." Metallurgical and Materials Transactions A, 27A:2151-2159. Warrendale, Pennsylvania: The Minerals, Metals \& Materials Society.

This paper describes the characterization of stainless steel $\mathrm{Zr}$ alloys with up to 92 mass \% $\mathrm{Zr}$ by using scanning electron microscopy and X-ray diffraction. This paper provides a description of MWF.

Abraham, D.P.; Richardson, J.W., Jr.; and McDeavitt, S.M. 1997. "Formation of the $\mathrm{Fe}_{23} \mathrm{Zr}_{6}$ Phase in an Fe-Zr Alloy.” Scripta Materialia, 37:239-244. New York, New York: Elsevier Science.

This paper discusses the identification of $\mathrm{Fe}_{23} \mathrm{Zr}_{6}$ in $\mathrm{Fe}-9.8$ at $\% \mathrm{Zr}$ alloy and proposed mechanism of formation. This paper provides a description of MWF.

Abraham, D.P.; Richardson, J.W., Jr.; and McDeavitt, S.M. 1997. "Laves Intermetallics in Stainless Steel-Zirconium Alloys." Materials Science and Engineering, A239-240:658-664. Amsterdam, The Netherlands: Elsevier Science.

This paper presents the results of neutron diffraction, heat-treatment, and mechanical studies with stainless steel-15Zr and stainless steel-42Zr materials. This paper provides a description of MWF.

Abraham, D.P.; Keiser, D.D.; and McDeavitt, S.M. 1998. "Metal Waste Forms from Treatment of EBR-II Spent Fuel." Proceedings of the International Conference on Decommissioning and Decontamination and on Nuclear and Hazardous Waste Management, Spectrum '98, held September 13-18, 1998. Denver, Colorado. 783-789. La Grange Park, Illinois: American Nuclear Society.

This paper provides a comparison of microstructure and composition of radioactive MWF ingots to nonradioactive surrogate MWF materials. The paper states that actinide-rich regions were detected within intermetallic phase. It also states that discrete actinide-bearing phases were detected only in samples with too little $\mathrm{Zr}$. The paper provides insight that supports the use of $\mathrm{Zr}$ content as part of monitoring MWF consistency and WASRD issues.

Abraham, D.P. and Richardson, J.W. 1999. "Phase Stability of Laves Intermetallics in a Stainless SteelZirconium Alloy." Proceedings of the Long Term Stability of High Temperature Materials Conference. Fuchs, G.E. Dannemann, K.A, and Deragon, T.C., eds. 169-179. Warrendale, Pennsylvania: Materials Research Society.

This paper discusses the characterization of stainless steel-15Zr alloys by in situ neutron diffraction during heat treatment. It reports that high temperatures result in an increase in the amount of $\mathrm{Fe}_{23} \mathrm{Zr}_{6^{-}}$ type intermetallic. Researchers found that $\mathrm{C} 15$ Laves polytype is preferred at temperatures less than $1,230^{\circ} \mathrm{C}$, and $\mathrm{C} 36$ polytype is preferred at higher temperatures. They also found that phase changes are slow at temperatures below $1,100^{\circ} \mathrm{C}$. This paper provides insight regarding phase stability issues in WASRD. 
Abraham, D.P.; Simpson, L.J.; DeVries, M.J.; and Callahan, D.E. 1999. "Corrosion Behavior of Stainless Steel-Zirconium Alloy Waste Forms." Proceedings of the Corrosion '99 Conference held April 25-30, 1999. San Antonio, Texas. Paper No. 466.

This paper provides the results of immersion and electrochemical corrosion tests showing that the corrosion behavior of MWF is similar to that of other metals to be used in the Yucca Mountain disposal system. The paper will be used to support the modeling approach for MWF in TSPA calculations.

Abraham, D.P.; Simpson, L.J.; DeVries, M.J.; and McDeavitt, S.M. 1999. "Corrosion Testing of Stainless Steel-Zirconium Metal Waste Forms.” Material Research Society Symposium Proceedings, 556: 945952. Pittsburgh, Pennsylvania: Materials Research Society.

Abraham, D.P.: Peterson, J.J.; Katyal, N.K.; Keiser, D.D.; and Hilton, B.A. 2000. "Electrochemical Testing of Metal Waste Forms." Proceedings of the Corrosion 2000 Conference held March 26-31, 2000. Orlando, Florida. Paper No. 00205.

These papers provides the results of polarization resistance and galvanic corrosion measurements of MWF. Galvanic corrosion is determined not to be an important corrosion mechanism. The paper supports a modeling approach for MWF degradation.

Abraham, D.P.; Dietz, N.L.; and Finnegan, N. 2001. "Characterization of Oxidation Products on a $\mathrm{ZrFe}_{2}-$ Type Laves Intermetallic Exposed to $200^{\circ} \mathrm{C}$ Steam." Proceedings of the Corrosion 2001 Conference, Paper No. 01139.

This paper provides evidence that radionuclide release from MWF is controlled by corrosion of the $\mathrm{Fe}_{2} \mathrm{Zr}$-type intermetallic phase. The characterization of samples corroded in steam by using Auger electron spectroscopy and transmission electron microscopy shows the formation of iron oxide and probably zirconium oxide. The paper provides a description of MWF corrosion process and modeling.

Abraham, D.P.; Richardson, J.W., Jr.; and McDeavitt, S.M. 2001. "Microscopy and Neutron Diffraction Study of a Zirconium-8 wt\% Stainless Alloy." Journal of Materials Science, 36:5143-5154. London, England: Chapman \& Hall.

This paper describes the microstructural analysis of MWF for Zr-based and Zr-clad spent nuclear fuels. The paper provides a description of MWF.

Abraham, D.P., and Dietz, N.L. 2002. "Role of Laves Intermetallics in Nuclear Waste Disposal." Materials Science and Engineering, A329-331:610-615. Amsterdam, The Netherlands: Elsevier Science.

This paper discusses the metallurgy of stainless steel-Zr alloys and microstructure characterized by transmission electron microscopy. Researchers found that the capacity of Laves intermetallics to sequester actinides is related to $\mathrm{Zr}$ content. This paper provides a description of MWF and the disposition of radionuclides.

Dietz, N.L. 2005. Transmission Electron Microscopy Analysis of Corroded EBR-II Metallic Waste Forms, Argonne National Laboratory report ANL 05/09. Argonne, Illinois: Argonne National Laboratory.

The report provides results of TEM analyses of corroded MWF samples. 
Ebert, W.L.; Lewis, M.A.; Barber, T.L.; DiSanto, T.; and Johnson, S.G. 2003. Static Leach Tests with the EBR-II Metallic Waste Form. Argonne National Laboratory report ANL-03/29. Argonne, Illinois: Argonne National Laboratory.

This report provides test data for evaluating the application of degradation rate in HLW glass model to MWF over a range of temperature and $\mathrm{pH}$.

Janney, D.E. 2003. "Host Phases for Actinide Elements in the Metallic Waste Form." Scientific Basis for Nuclear Waste Management XXVI, Symposium. Boston, Massachusetts. Finch, R.J., and Bullen, D.B., eds. Vol. 757, pp. 343-348. Warrendale, Pennsylvania: Materials Research Society.

This paper addresses MWF microstructure and the disposition of actinide elements.

Janney, D.E. 2003. Characterization of Host Phases for Actinides in Simulated Metallic Waste Forms by Transmission Electron Microscopy. Argonne National Laboratory report ANL-NT-221. Argonne, Illinois: Argonne National Laboratory.

This report presents a characterization of actinide disposition in MWF by means of transmission electron microscopy. The report addresses the disposition of radionuclides between MWF component phases.

Janney, D.E., and D.D. Keiser, D.D., Jr. 2003. "Actinides in Metallic Waste from Electrometallurgical Treatment of Spent Nuclear Fuel." Journal of the Minerals, Metals \& Materials Society, 55(9):59-60. Warrendale, Pennsylvania: The Minerals, Metals \& Materials Society.

This paper examines MWF materials by means of transmission electron microscopy. The paper provides a description of MWF.

Janney, D.E. 2003. "Host Phases for Actinides in Simulated Metallic Waste Forms." Journal of Nuclear Materials, 323:81-92. New York, New York: North-Holland.

This paper presents an examination of MWF materials conducted by means of transmission electron microscopy. The paper provides a description of MWF.

Johnson, S.G.; Noy, M.; DiSanto, T.; and Keiser, D.D., Jr. 2002. "Long-Term Immersion Test Results of the Metallic Waste Form from the EMT Process of EBR-II Spent Metallic Fuel." Proceedings of the DOE Spent Nuclear Fuel and Fissile Materials Management Meeting held September 17-20, 2002. Charleston, South Carolina. Waste Form Testing session. La Grange Park, Illinois: American Nuclear Society.

This paper provides data for corrosion tests on MWF containing $U$ and Tc. The results show that $U$ is released faster than Tc. The paper supports the use of the measured $U$ release rate as an upper bound for release of all radionuclides from the MWF.

Johnson, S.G.; Keiser, D.D.; Frank, S.M.; DiSanto, T.; Warren, A.R.; and Noy, M. 2000. "Leaching Characteristics of the Metal Waste Form from the Electrometallurgical Treatment Process: Product Consistency Testing." Scientific Basis for Nuclear Waste Management XXIII, Symposium held November 29-December 2, 1999. Boston, Massachusetts. Smith, R.W., and Shoesmith, D.W., eds. Vol. 608, pp. 589-594. Warrendale, Pennsylvania: Materials Research Society. 
This paper presents an evaluation of the use of the product consistency test method to assess MWF by using drill or mill shavings instead of crushed material. The paper provides data supporting the use of $\mathrm{Zr}$ concentration to monitor the consistency of MWF instead of PCT.

Keiser, D.D., Jr.; Abraham, D.P.; and Richardson, J.W., Jr. 2000. "Influence of Technetium on the Microstructure of a Stainless Steel-Zirconium Alloy." Journal of Nuclear Materials, 277:333-338. New York, New York: North-Holland.

This paper provides the characterization of the microstructure of stainless steel 15Zr-alloy doped with 2 mass \% Tc. Technetium was found to dissolve preferentially into ferrite and austenite. No separate Tc phases were detected. This paper provides insight regarding radionuclide disposition in the MWF.

Keiser, D.D., Jr.; Sinkler, W.; Abraham, D.P.; Richardson, J.W., Jr.; McDeavitt, S.M. 2000. "The Effect of Actinides on the Microstructural Development in a Metallic High-Level Nuclear Waste Form." Rare Earths and Actinides: Science, Technology and Applications IV. Bautista, R.G., and Mishra, B., eds. pp. 111-121. Warrendale, Pennsylvania: The Minerals, Metals \& Materials Society.

This paper presents the characterization of microstructure of stainless steel $\mathrm{Zr}$ alloys doped with $\mathrm{U}$, $\mathrm{Pu}$, and/or $\mathrm{Np}$. These actinides were found to be segregated into intermetallic phase and to be stable after various heat treatments. This paper describes radionuclide disposition in the MWF.

Keiser, D.D., Jr.; Abraham, D.P.; Sinkler, W.; Richardson, J.W., Jr.; and McDeavitt, S.M. 2000. "Actinide Distribution in Stainless Steel-15 wt\% Zirconium High-Level Nuclear Waste Form." Journal of Nuclear Materials, 279:234-244. New York, New York: North-Holland.

This paper provides data showing that uranium substitutes into $\mathrm{Zr}$ sites in the intermetallic phase. Actinide-rich areas were detected within intermetallic. Discrete uranium-bearing phases were not detected. This paper describes radionuclide disposition in the MWF.

Keiser, D.D., Jr.; Johnson, S.G.; and Ebert, W.L. 2002. "Monitoring the Consistency of the Metallic Waste Form Derived from Electrometallurgical Processing." Proceedings of the DOE Spent Nuclear Fuel and Fissile Materials Management Meeting held September 17-20, 2002. Charleston, South Carolina. Poster session. La Grange Park, Illinois: American Nuclear Society.

This paper summarizes the evaluation of possible methods for monitoring the consistency of MWF and provides a rationale for monitoring the consistency of MWF based on $\mathrm{Zr}$ concentration.

Keiser, D.D. Jr.; Johnson, S.G.; and Ebert, W.L. 2002. Monitoring the Consistency of the Metal Waste Form. Argonne National Laboratory report ANL-NT-196. Argonne, Illinois: Argonne National Laboratory.

This report describes the development of a method to monitor the consistency of MWF. The recommended method is monitoring gross $\mathrm{Zr}$ concentration because minimum $\mathrm{Zr}$ concentration is required to contain actinides in intermetallic phase. The results of analyses of various alloys are presented to demonstrate methodology. The report provides data to address WASRD requirement for monitoring waste form consistency. 
Luo, J.S., and Abraham, D.P. 2000. "TEM Characterization of Corrosion Products Formed on a Stainless Steel-Zirconium Alloy." Scientific Basis for Nuclear Waste Management XXIII, Symposium held November 29-December 2, 1999. Boston, Massachusetts. Smith, R.W., and Shoesmith, D.W., eds. Vol. 608, pp. 583-588. Warrendale, Pennsylvania: Materials Research Society.

This paper describes the examination of MWF corroded in demineralized water for two years by transmission electron microscopy. This paper also discusses the identification of corrosion products trevorite $\left(\mathrm{NiFe}_{2} \mathrm{O}_{4}\right)$ and maghemite $\left(\mathrm{Fe}_{2} \mathrm{O}_{3}\right)$ on the stainless steel, $\mathrm{Zr}$-enrichment, and an "interlocking oxide" interface on the intermetallic that indicates oxide formation due to the diffusion of oxygen into the metal. The paper provides a description of MWF degradation.

McDeavitt, S.M.; Abraham, D.P.; Keiser, D.D.; and Park, J.Y. 1996. "Stainless Steel-Zirconium Alloy Waste Forms for Metallic Fission Products and Actinides Isolated during Treatment of Spent Nuclear Fuel." Proceedings of the Spectrum '96 Meeting, Nuclear and Hazardous Waste Management International Topical Meeting held August 18-23, 1996. Seattle, Washington. pp. 2477-2484. La Grange Park, Illinois: American Nuclear Society.

This paper addresses the disposition of noble metal fission products and actinides in MWF materials.

McDeavitt, S.M.; Abraham, D.P.; Keiser, D.D.; and Park, J.Y. 1996. "Alloy Waste Forms for Metal Fission Products and Actinides Isolated by Spent Nuclear Fuel Treatment." Proceedings of the Second International Symposium on Extraction and Processing for the Treatment and Minimization of Wastes held October 27-30, 1996. Scottsdale, Arizona. pp. 177-189.

This paper provides a summary of testing programs to develop and qualify waste forms for disposal.

McDeavitt, S.M.; Abraham, D.P.; Park, J.Y.; and Keiser, D.D. 1997. "Stainless Steel-Zirconium Waste Forms from Electrometallurgical Treatment of Spent Nuclear Fuel." JOM. 49(7):29-32. Warrendale, Pennsylvania: The Minerals, Metals \& Materials Society.

This paper gives a summary of the processing, alloy metallurgy, and behavior of MWF.

McDeavitt, S.M.; Abraham, D.P.; and Park, J.Y. 1998. "Evaluation of Stainless Steel-Zirconium Alloys as High-Level Nuclear Waste Forms." Journal of Nuclear Materials, 257:21-34. New York, New York: North-Holland.

This paper discusses the metallurgy and microstructure of stainless steel-15Zr and zirconium 8 mass \% stainless steel alloys. The paper presents results of electrochemical corrosion tests conducted at range of $\mathrm{pH}$ values. The paper provides data regarding the microstructure and degradation of the MWF.

Snyder, C.T.; Barnes, L.A.; and Fink, J.K. 2004. Metal Waste Form Corrosion Release Data from Immersion Tests. Argonne National Laboratory report ANL-04/15. Argonne, Illinois: Argonne National Laboratory.

This report is a summary report for tests with non-radioactive MWF materials. 


\section{Information Regarding CWF Production}

Battisti, T.J.; Goff, K.M.; Bateman, K.J.; Simpson, M.F.; and Lind, J.P. 2002. "Ceramic Waste Form Production and Development at ANL-West." Proceedings of the DOE Spent Nuclear Fuel and Fissile Materials Management Meeting held September 17-20, 2002. Charleston, South Carolina. CD-ROM. Poster session. La Grange Park, Illinois: American Nuclear Society.

This paper presents process flow sheets, off-gas studies, and dissolution test results. The paper provides background information on CWF processing.

Benedict, R.W.; McFarlane, H.F.; Henslee, S.P.; Lineberry, M.J.; Abraham, D.P.; Ackerman, J.P.; Ahluwalia, R.K.; Garcia, H.E.; Gay, E.C.; Goff, K.M.; Johnson, S.G.; Mariani, R.D.; McDeavitt, S.; Pereira, C.; Roach, P.D.; Sherman, S.R.; Westphal, B.R. Wigeland, R.A.; and Willit, J.L. 1999. Spent Fuel Treatment Demonstration Final Report. Argonne National Laboratory report ANL-NT-106. Argonne, Illinois: Argonne National Laboratory.

This report provides a summary of demonstration activities.

Ebert, W.L; Esh, D.W.; Frank, S.M.; Goff, K.M.; Hash, M.C.; Johnson, S.G.; Lewis, M.A.; Morss, L.R.; Moschetti, T.L.; O’Holleran, T.P.; Richmann, M.K.; Riley, W.P., Jr.; Simpson, L.J.; Sinkler, W.; Stanley, M.L.; Tatko, C.D.; Wronkiewicz, D.J.; Ackerman, J.P.; Arbesman, K.A.; Bateman, K.J.; Battisti, T.J.; Cummings, D.G.; DiSanto, T.; Gougar, M.L.; Hirsche, K.L.; Kaps, S.E.; Leibowitz, L.; Luo, S.S.; Noy, M.; Retzer, H.; Simpson; Sun, D.; Warren, A.R.; and Zyryanov, V.N. 1999. Ceramic Waste Form Handbook, Argonne National Laboratory report ANL-NT-119. Argonne, Illinois: Argonne National Laboratory.

This report provides a summary of laboratory tests and analyses to characterize the microstructure of CWF, physical properties, disposition of radionuclides, corrosion modes, and chemical durability. Laboratory tests used to develop degradation model and measure model parameters are also presented.

Fink, J.K.; Morris, E.E.; Abraham, D.P.; Johnson, I.; Johnson, S.G.; and Wigeland, R.A. 2000. Status of Metal Waste Form Corrosion and Release Rate Modeling. Argonne National Laboratory report ANL-NT-154. Argonne, Illinois: Argonne National Laboratory.

This report presents an early model for the long-term performance of the metal waste form in the Yucca Mountain repository, on the basis of results of linear polarization measurements. It provides comparisons between the model and various laboratory measurements and tests. This report also provides background and data for modeling the degradation behavior of MWF and accounting for MWF in TSPA.

Goff, K.M.; Benedict, R.W.; Bateman, K.; Lewis, M.A.; Pereira, C.; and Musick, C.A. 1996. "Spent Fuel Treatment and Mineral Waste Form Development at Argonne National Laboratory-West." Proceedings of the Spectrum '96 Meeting, Nuclear and Hazardous Waste Management International Topical Meeting held August 18-23, 1996. Seattle, Washington. 2436-2443. La Grange Park, Illinois: American Nuclear Society.

This paper presents a summary on EBR II spent fuel inventory, electrometallurgical treatment operations, waste form development, and schedule. The paper provides background information. 
Lewis, M.A.; Hash, M.; and Glandorf, D. 1997. "Effect of Different Glass and Zeolite-A Compositions on the Leach Resistance of Ceramic Waste Forms." Scientific Basis for Nuclear Waste Management XXIII Symposium held December 2-6, 1996. Boston, Massachusetts. Gray, W.J., and Triay, I.R., eds. Vol. 465, pp. 433-440. Pittsburgh, Pennsylvania: Materials Research Society.

This paper presents the results of MCC-1 tests with CWF materials made by using different cationic forms of zeolite 5A (which contains only sodium cations) and zeolite 4A (which contains sodium and calcium cations), as well as different binder glass compositions. The paper provides background information regarding CWF processing.

Lewis, M.A.; Stanley, M.L.; and Ebert, W.L. 2000. Development of a Method for Monitoring the Consistency of Glass-Bonded Sodalite Waste Forms, Argonne National Laboratory report ANL-00/12. Argonne, Illinois: Argonne National Laboratory.

This report presents the results of laboratory tests conducted to distinguish between the dissolution of halite, sodalite, and binder glass phases in CWF. The results show that tests used to monitor the consistency of HLW glass waste forms can be used to monitor the consistency of CWF. Data show that PCT can be applied to CWF to address WASRD requirement to monitor waste form consistency.

Lewis, M.A.; Hash, M.C.; Ebert, W.L.; Hebden, A.; and Oliver, S.M. 2001. Results of Physical Characterizations and Product Consistency Tests with Ceramic Waste Form Products Prepared at Six Temperatures and Six Hold Times. Argonne National Laboratory report ANL-NT-178. Argonne, Illinois: Argonne National Laboratory.

This report describes the examination and testing of CWF made by pressureless consolidation at six different temperatures and for six different hold times. The effect of temperature and time on density, microstructure, phase composition, and chemical durability is evaluated. The report provides test data and sensitivity of CWF durability to process conditions.

Lewis, M.A.; Hash, M.C.; Hebden, A.; and Ebert, W.L. 2002. Tests with Ceramic Waste Form Materials Made by Pressureless Consolidation, Argonne National Laboratory report ANL-02/10. Argonne, Illinois: Argonne National Laboratory.

This report discusses various CWF materials made to evaluate the PC method as potential replacement of HIP. Materials were made to evaluate the effects of glass/zeolite mass ratios, processing temperature, processing time, waste form size, and reproducibility. The microstructure, density, and chemical durability of the various materials are similar for materials made by hot HIP and by PC. One beneficial difference is that halite and radionuclide-bearing inclusions are more evenly distributed in the glass phase of PC materials than HIP materials. The report provides data to address WASRD issues.

Simpson, M.F.; Goff, K.M.; Johnson, S.G.; Bateman, K.J.; Battisti, T.J.; Toews, K.L.; Frank, S.M.; Moschetti, T.L.; O'Holleran, T.P.; and Sinkler, W. 2001. "A Description of the Ceramic Waste Form Production Process from the Demonstration Phase of the Electrometallurgical Treatment of EBR-II Spent Fuel.” Nuclear Technology 134:263-277.

This paper provides a description of CWF production using the HIP process. 
Simpson, M.F. 2003. "Two-Site Equilibrium Model for Ion Exchange Between Monovalent Cations and Zeolite-A in a Molten Salt." Industrial Engineering and Chemical Research.

This paper provides background information on CWF processing.

\section{Information Regarding MWF Production}

Abraham, D.P.; McDeavitt, S.M.; and Park, J.Y. 1996. "Metal Waste Forms from the Electrometallurgical Treatment of Spent Nuclear Fuel." Proceedings of the Embedded Topical Meeting on DOE Spent Nuclear Fuel and Fissile Material Management held June 16-20, 1996. Reno, Nevada. 123-128. La Grange Park, Illinois: American Nuclear Society.

This paper provides measurements of the microstructure, corrosion, mechanical, and thermophysical properties of MWF alloys. The paper provides insight into characterization issues in WASRD and corrosion mechanism issues for TSPA.

Abraham, D.P.; McDeavitt, S.M.; Keiser, D.D. Jr.; Johnson, S.G.; Adamic, M.L.; Barker, S.A.; DiSanto, T.; Frank, S.M.; Krsul, J.R.; Noy, M.; Richardson, J.W., Jr.; and Westphal, B.R. 1999. Metal Waste Form Handbook. Argonne National Laboratory report ANL-NT-121. Argonne, Illinois: Argonne National Laboratory.

This report provides test and analysis results for MWF materials.

Benedict, R.W.; McFarlane, H.F.; Henslee, S.P.; Lineberry, M.J.; Abraham, D.P.; Ackerman, J.P.; Ahluwalia, R.K.; Garcia, H.E.; Gay, E.C.; Goff, K.M.; Johnson, S.G.; Mariani, R.D.; McDeavitt, S.; Pereira, C.; Roach, P.D.; Sherman, S.R.; Westphal, B.R. Wigeland, R.A.; and Willit, J.L. 1999. Spent Fuel Treatment Demonstration Final Report. Argonne National Laboratory report ANL-NT-106. Argonne, Illinois: Argonne National Laboratory.

This report provides a summary of demonstration activities.

Goff, K.M.; Benedict, R.W.; Bateman, K.; Lewis, M.A.; Pereira, C.; and Musick, C.A. 1996. "Spent Fuel Treatment and Mineral Waste Form Development at Argonne National Laboratory-West." Proceedings of the Spectrum '96 Meeting, Nuclear and Hazardous Waste Management International Topical Meeting held August 18-23, 1996. Seattle, Washington. 2436-2443. La Grange Park, Illinois: American Nuclear Society.

This paper presents a summary on EBR II spent fuel inventory, electrometallurgical treatment operations, waste form development, and schedule. The paper provides background information.

Keiser, D.D. Jr.; Johnson, S.G.; and Ebert, W.L. 2002. Monitoring the Consistency of the Metal Waste Form. Argonne National Laboratory report ANL-NT-196. Argonne, Illinois: Argonne National Laboratory.

This report describes the development of a method to monitor the consistency of MWF. The recommended method is monitoring gross $\mathrm{Zr}$ concentration because minimum $\mathrm{Zr}$ concentration is required to contain actinides in intermetallic phase. The results of analyses of various alloys are presented to demonstrate methodology. 


\section{Radiation Damage Effects on the CWF}

Battisti, T.J.; Goff, K.M.; Bateman, K.J.; Simpson, M.F.; and Lind, J.P. 2002. "Ceramic Waste Form Production and Development at ANL-West." Proceedings of the DOE Spent Nuclear Fuel and Fissile Materials Management Meeting held September 17-20, 2002. Charleston, South Carolina. CD-ROM. Poster session. La Grange Park, Illinois: American Nuclear Society.

This paper presents process flow sheets, off-gas studies, and dissolution test results. The paper provides background information on CWF processing.

Frank, S.M.; Johnson, S.G.; Moschetti, T.L.; O’Holleran, T.P.; Sinkler, W.; Esh, D.; and Goff, M.K. 2000. "Accelerated Alpha Radiation Damage in a Ceramic Waste Form, Interim Results." Scientific Basis for Nuclear Waste Management XXIII, Symposium held November 29-December 2, 1999. Boston, Massachusetts. Smith, R.W., and Shoesmith, D.W., eds. Vol. 608, pp. 469-474. Warrendale, Pennsylvania: Materials Research Society.

This paper presents the results of microstructure, X-ray diffraction, and bulk density measurements and corrosion tests with $\mathrm{CWF}$ doped with $\mathrm{Pu}-238$ to highlight alpha damage. Analyses show slight expansion of $\mathrm{PuO}_{2}$ and perhaps sodalite matrices. The paper provides short-term data on the effect of radiation on phase composition and stability.

Frank, S.M.; DiSanto, T.; Goff, K.M.; Johnson, S.G.; Jue, J.-F.; Barber, T.L.; Noy, M.; O’Holleran, T.P.; and Giglio, J.J. 2002. "Plutonium-238 Alpha-Decay Damage study of a glass-bonded sodalite ceramic waste form." Journal of Testing and Evaluation, Sept 2002. West Conshohocken, Pennsylvania: American Society for Testing and Materials.

This paper presents the results of microstructure, X-ray diffraction, and bulk density measurements and corrosion tests with CWF doped with $\mathrm{Pu}-238$ to highlight alpha damage. Analyses show slight expansion of $\mathrm{PuO}_{2}$ and perhaps sodalite matrices. The paper provides data on the effect of radiation on phase composition and stability.

Frank, S.M. 2002. "Alpha Decay Damage Study of a Glass-Bonded Sodalite Ceramic Waste Form.” Scientific Basis for Nuclear Waste Management XXV, Symposium held November 26-29, 2001. Boston, Massachusetts. McGrail, B.P., and Cragnolino, G.A., eds. Vol. 713, pp. 487-494.

This paper summarizes the results of microstructure, X-ray diffraction, and bulk density measurements and corrosion tests with CWF doped with $\mathrm{Pu}-238$ to highlight alpha damage.

Goff, K.M.; Benedict, R.W.; Bateman, K.; Lewis, M.A.; Pereira, C.; and Musick, C.A. 1996. "Spent Fuel Treatment and Mineral Waste Form Development at Argonne National Laboratory-West." Proceedings of the Spectrum '96 Meeting, Nuclear and Hazardous Waste Management International Topical Meeting held August 18-23, 1996. Seattle, Washington. 2436-2443. La Grange Park, Illinois: American Nuclear Society.

This paper presents a summary on EBR II spent fuel inventory, electrometallurgical treatment operations, waste form development, and schedule. The paper provides background information. 


\section{Evaluation of CWF Product Consistency}

Ebert, W.L; Esh, D.W.; Frank, S.M.; Goff, K.M.; Hash, M.C.; Johnson, S.G.; Lewis, M.A.; Morss, L.R.; Moschetti, T.L.; O’Holleran, T.P.; Richmann, M.K.; Riley, W.P., Jr.; Simpson, L.J.; Sinkler, W.; Stanley, M.L.; Tatko, C.D.; Wronkiewicz, D.J.; Ackerman, J.P.; Arbesman, K.A.; Bateman, K.J.; Battisti, T.J.; Cummings, D.G.; DiSanto, T.; Gougar, M.L.; Hirsche, K.L.; Kaps, S.E.; Leibowitz, L.; Luo, S.S.; Noy, M.; Retzer, H.; Simpson; Sun, D.; Warren, A.R.; and Zyryanov, V.N. 1999. Ceramic Waste Form Handbook, Argonne National Laboratory report ANL-NT-119. Argonne, Illinois: Argonne National Laboratory.

This report provides a summary of laboratory tests and analyses to characterize the microstructure of CWF, physical properties, disposition of radionuclides, corrosion modes, and chemical durability. Laboratory tests used to develop degradation model and measure model parameters are also presented.

Ebert, W.L.; Lewis, M.A.; and Johnson, S.G. 2002. "The Precision of Product Consistency Tests Conducted with a Glass-Bonded Ceramic Waste Form." Journal of Nuclear Materials, 305:37-51. New York, New York: North-Holland.

This paper presents the results of an interlaboratory study to measure the precision of product consistency tests with the CWF. The paper provides insight into the applicability of the PCT for meeting the product consistency requirement in WASRD.

Ebert, W.L.; Lewis, M.A.; and Johnson, S.G. 2002. "Application of the PCT to the EBR II Ceramic Waste Form," Proceedings of the DOE Spent Nuclear Fuel and Fissile Materials Management Meeting held September 17-20, 2002. Charleston, South Carolina. Waste Form Testing session. La Grange Park, Illinois: American Nuclear Society.

This paper discusses tests and analysis to evaluate the applicability of the PCT method used to monitor consistency of HLW glass to the multiphase CWF material. Researchers found that there was no fractionation of phases during crushing and sieving, crushed CWF is representative of bulk CWF, the PCT response is sensitive to gross CWF composition, and PCT can be conducted as precisely with CWF as with HLW glass. The paper provides insight into the use of the ASTM 1285 test method called for in WASRD for CWF.

Lewis, M.L., and Ebert, W. L. 2000. Results of Scoping Tests with Ceramic Waste Form Materials Made by Pressureless Consolidation, Argonne National Laboratory report ANL-NT-160. Argonne, Illinois: Argonne National Laboratory.

This report presents the results of tests and analyses conducted with CWF made by pressureless consolidation (PC) to support a decision to change from production by hot isostatic pressing to production by PC. The report provides a characterization of PC CWF materials.

Lewis, M.A.; Stanley, M.L.; and Ebert, W.L. 2000. Development of a Method for Monitoring the Consistency of Glass-Bonded Sodalite Waste Forms, Argonne National Laboratory report ANL-00/12. Argonne, Illinois: Argonne National Laboratory.

This report presents the results of laboratory tests conducted to distinguish between the dissolution of halite, sodalite, and binder glass phases in CWF. The results show that tests used to monitor the 
consistency of HLW glass waste forms can be used to monitor the consistency of CWF. Data show that PCT can be applied to CWF to address WASRD requirement to monitor waste form consistency.

Lewis, M.A.; Hash, M.C.; Ebert, W.L.; Hebden, A.; and Oliver, S.M. 2001. Results of Physical Characterizations and Product Consistency Tests with Ceramic Waste Form Products Prepared at Six Temperatures and Six Hold Times. Argonne National Laboratory report ANL-NT-178. Argonne, Illinois: Argonne National Laboratory.

This report describes the examination and testing of CWF made by pressureless consolidation at six different temperatures and for six different hold times. The effect of temperature and time on density, microstructure, phase composition, and chemical durability is evaluated. The report provides test data and sensitivity of CWF durability to process conditions.

Lewis, M.A.; Hash, M.C.; Hebden, A.; and Ebert, W.L. 2002. Tests with Ceramic Waste Form Materials Made by Pressureless Consolidation, Argonne National Laboratory report ANL-02/10. Argonne, Illinois: Argonne National Laboratory.

This report discusses various CWF materials made to evaluate the PC method as potential replacement of HIP. Materials were made to evaluate the effects of glass/zeolite mass ratios, processing temperature, processing time, waste form size, and reproducibility. The microstructure, density, and chemical durability of the various materials are similar for materials made by hot HIP and by PC. One beneficial difference is that halite and radionuclide-bearing inclusions are more evenly distributed in the glass phase of PC materials than HIP materials. The report provides data to address WASRD issues.

O’Holleran, T.P.; Abraham, D.P.; Ackerman, J.P.; Goff, K.M.; Johnson, S.G.; and Keiser, D.D. 1999. Waste Acceptance Product Specifications for the Waste Forms from Electrometallurgical Treatment of Spent Nuclear Fuel. Argonne National Laboratory report ANL-NT-116. Argonne, Illinois: Argonne National Laboratory.

This report provides a top-level description of the strategy to develop waste acceptance product specifications and background information.

O'Holleran, T.P. 2002. "Development of a Sampling Method for Qualification of a Ceramic High-Level Waste Form." Proceedings of the American Ceramic Society Annual Meeting held April 29-May 1, 2002. St. Louis, Missouri: American Ceramic Society.

This paper provides a description of the method to produce small-scale samples to monitor the consistency of CWF made by HIP.

\section{Evaluation of MWF Product Consistency}

Ebert, W.L.; Lewis, M.A.; Barber, T.L.; DiSanto, T.; and Johnson, S.G. 2003. Static Leach Tests with the EBR-II Metallic Waste Form. Argonne National Laboratory report ANL-03/29. Argonne, Illinois: Argonne National Laboratory.

This report provides test data for evaluating the application of degradation rate in HLW glass model to MWF over a range of temperature and $\mathrm{pH}$. 
Johnson, S.G.; Keiser, D.D.; Frank, S.M.; DiSanto, T.; Warren, A.R.; and Noy, M. 2000. "Leaching Characteristics of the Metal Waste Form from the Electrometallurgical Treatment Process: Product Consistency Testing." Scientific Basis for Nuclear Waste Management XXIII, Symposium held November 29-December 2, 1999. Boston, Massachusetts. Smith, R.W., and Shoesmith, D.W., eds. Vol. 608, pp. 589-594. Warrendale, Pennsylvania: Materials Research Society.

This paper presents an evaluation of the use of the product consistency test method to assess MWF by using drill or mill shavings instead of crushed material. The paper provides data supporting the use of $\mathrm{Zr}$ concentration to monitor the consistency of MWF instead of PCT.

Keiser, D.D. Jr.; Johnson, S.G.; and Ebert, W.L. 2002. Monitoring the Consistency of the Metal Waste Form. Argonne National Laboratory report ANL-NT-196. Argonne, Illinois: Argonne National Laboratory.

This report describes the development of a method to monitor the consistency of MWF. The recommended method is monitoring gross $\mathrm{Zr}$ concentration because minimum $\mathrm{Zr}$ concentration is required to contain actinides in intermetallic phase. The results of analyses of various alloys are presented to demonstrate methodology. The report provides data to address WASRD requirement for monitoring waste form consistency.

Keiser, D.D., Jr.; Johnson, S.G.; and Ebert, W.L. 2002. "Monitoring the Consistency of the Metallic Waste Form Derived from Electrometallurgical Processing." Proceedings of the DOE Spent Nuclear Fuel and Fissile Materials Management Meeting held September 17-20, 2002. Charleston, South Carolina. Poster session. La Grange Park, Illinois: American Nuclear Society.

This paper summarizes the evaluation of possible methods for monitoring the consistency of MWF and provides a rationale for monitoring the consistency of MWF based on Zr concentration.

\section{Results of Tests with CWF Materials}

Barber, T.L.; DiSanto, T.; Frank, S.M.; Goff, K.M.; Johnson, S.G.; Jue, J.F.; Noy, M.; and O’Holleran, T.P. 2002. "Study of Alpha-Decay Damage in a Glass-Bonded, Sodalite Ceramic Waste." Proceedings of the DOE Spent Nuclear Fuel and Fissile Materials Management Meeting held September 17-20, 2002. Charleston, South Carolina. CD-ROM. Waste Form Testing session. La Grange Park, Illinois: American Nuclear Society.

This paper describes the effect of alpha damage accelerated by making use of higher activity and higher concentrations of $\mathrm{Pu}-238$ compared to levels of $\mathrm{Pu}-239$ expected in $\mathrm{CWF}$. No swelling, microcracks, or phase separation were observed after 3.5 years. The paper addresses the effects of radiolysis on CWF durability.

Ebert, W.L; Esh, D.W.; Frank, S.M.; Goff, K.M.; Hash, M.C.; Johnson, S.G.; Lewis, M.A.; Morss, L.R.; Moschetti, T.L.; O’Holleran, T.P.; Richmann, M.K.; Riley, W.P., Jr.; Simpson, L.J.; Sinkler, W.; Stanley, M.L.; Tatko, C.D.; Wronkiewicz, D.J.; Ackerman, J.P.; Arbesman, K.A.; Bateman, K.J.; Battisti, T.J.; Cummings, D.G.; DiSanto, T.; Gougar, M.L.; Hirsche, K.L.; Kaps, S.E.; Leibowitz, L.; Luo, S.S.; Noy, M.; Retzer, H.; Simpson; Sun, D.; Warren, A.R.; and Zyryanov, V.N. 1999. Ceramic Waste Form Handbook, Argonne National Laboratory report ANL-NT-119. Argonne, Illinois: Argonne National Laboratory. 
This report provides a summary of laboratory tests and analyses to characterize the microstructure of CWF, physical properties, disposition of radionuclides, corrosion modes, and chemical durability. Laboratory tests used to develop degradation model and measure model parameters are also presented.

Ebert, W.L.; Lewis, M.A.; and Johnson, S.G. 2002. "The Precision of Product Consistency Tests Conducted with a Glass-Bonded Ceramic Waste Form." Journal of Nuclear Materials, 305:37-51. New York, New York: North-Holland.

This paper presents the results of an interlaboratory study to measure the precision of product consistency tests with the CWF. The paper provides insight into the applicability of the PCT for meeting the product consistency requirement in WASRD.

Ebert, W.L.; Lewis, M.A.; and Johnson, S.G. 2002. "Application of the PCT to the EBR II Ceramic Waste Form," Proceedings of the DOE Spent Nuclear Fuel and Fissile Materials Management Meeting held September 17-20, 2002. Charleston, South Carolina. Waste Form Testing session. La Grange Park, Illinois: American Nuclear Society.

This paper discusses tests and analysis to evaluate the applicability of the PCT method used to monitor consistency of HLW glass to the multiphase CWF material. Researchers found that there was no fractionation of phases during crushing and sieving, crushed CWF is representative of bulk CWF, the PCT response is sensitive to gross CWF composition, and PCT can be conducted as precisely with CWF as with HLW glass. The paper provides insight into the use of the ASTM 1285 test method called for in WASRD for CWF.

Frank, S.M.; Johnson, S.G.; Moschetti, T.L.; O’Holleran, T.P.; Sinkler, W.; Esh, D.; and Goff, M.K. 2000. "Accelerated Alpha Radiation Damage in a Ceramic Waste Form, Interim Results." Scientific Basis for Nuclear Waste Management XXIII, Symposium held November 29-December 2, 1999. Boston, Massachusetts. Smith, R.W., and Shoesmith, D.W., eds. Vol. 608, pp. 469-474. Warrendale, Pennsylvania: Materials Research Society.

This paper presents the results of microstructure, X-ray diffraction, and bulk density measurements and corrosion tests with $\mathrm{CWF}$ doped with $\mathrm{Pu}-238$ to highlight alpha damage. Analyses show slight expansion of $\mathrm{PuO}_{2}$ and perhaps sodalite matrices. The paper provides short-term data on the effect of radiation on phase composition and stability.

Frank, S.M.; DiSanto, T.; Goff, K.M.; Johnson, S.G.; Jue, J.-F.; Barber, T.L.; Noy, M.; O’Holleran, T.P.; and Giglio, J.J. 2002. "Plutonium-238 Alpha-Decay Damage study of a glass-bonded sodalite ceramic waste form." Journal of Testing and Evaluation, Sept 2002. West Conshohocken, Pennsylvania: American Society for Testing and Materials.

This paper presents the results of microstructure, X-ray diffraction, and bulk density measurements and corrosion tests with $\mathrm{CWF}$ doped with $\mathrm{Pu}-238$ to highlight alpha damage. Analyses show slight expansion of $\mathrm{PuO}_{2}$ and perhaps sodalite matrices. The paper provides data on the effect of radiation on phase composition and stability.

Frank, S.M. 2002. "Alpha Decay Damage Study of a Glass-Bonded Sodalite Ceramic Waste Form." Scientific Basis for Nuclear Waste Management XXV, Symposium held November 26-29, 2001. Boston, Massachusetts. McGrail, B.P., and Cragnolino, G.A., eds. Vol. 713, pp. 487-494. 
This paper summarizes the results of microstructure, X-ray diffraction, and bulk density measurements and corrosion tests with $\mathrm{CWF}$ doped with $\mathrm{Pu}-238$ to highlight alpha damage.

Jeong, J.Y.; Fanning, T.H.; Morss, L.R.; and Ebert, W.L. 2002. Corrosion Tests to Determine Temperature and $\mathrm{pH}$ Dependencies of the Dissolution Rates of Sodalite, Binder Glass, and Ceramic Waste Forms. Argonne National Laboratory report ANL-02/32. Argonne, Illinois: Argonne National Laboratory.

This report provides data on short-term MCC-1 leach tests in pH-buffered solutions conducted to measure the dependence of dissolution rate on $\mathrm{pH}$ and temperature. It provides the release rate of silicon measured for the separate binder glass and sodalite phases, as well as for the consolidated CWF material. The report also evaluates the effect of sodalite dissolution into binder glass on the binder glass dissolution rate and presents results of dissolution tests at $20^{\circ} \mathrm{C}$ conducted to validate the degradation model.

Lewis, M.A.; Hash, M.; and Glandorf, D. 1997. "Effect of Different Glass and Zeolite-A Compositions on the Leach Resistance of Ceramic Waste Forms." Scientific Basis for Nuclear Waste Management XXIII Symposium held December 2-6, 1996. Boston, Massachusetts. Gray, W.J., and Triay, I.R., eds. Vol. 465, pp. 433-440. Pittsburgh, Pennsylvania: Materials Research Society.

This paper presents the results of MCC-1 tests with CWF materials made by using different cationic forms of zeolite 5A (which contains only sodium cations) and zeolite 4A (which contains sodium and calcium cations), as well as different binder glass compositions. The paper provides background information regarding CWF processing.

Lewis, M.A., Ebert, W.L., and Simpson, L.J. 1999. "Comparison of the Corrosion Behaviors of the GlassBonded Sodalite Ceramic Waste Form and Reference HLW Glasses." Environmental Issues and Waste Management Technologies in the Ceramic and Nuclear Industries V. Ceramic Transactions 107: 281-288.

Lewis, M.L. and Ebert, W. L. 2000. Results of Scoping Tests with Ceramic Waste Form Materials Made by Pressureless Consolidation, Argonne National Laboratory report ANL-NT-160. Argonne, Illinois: Argonne National Laboratory.

This report presents the results of tests and analyses conducted with CWF made by pressureless consolidation (PC) to support a decision to change from production by hot isostatic pressing to production by PC. The report provides a characterization of PC CWF materials.

Lewis, M.A.; Stanley, M.L.; and Ebert, W.L. 2000. Development of a Method for Monitoring the Consistency of Glass-Bonded Sodalite Waste Forms, Argonne National Laboratory report ANL-00/12. Argonne, Illinois: Argonne National Laboratory.

This report presents the results of laboratory tests conducted to distinguish between the dissolution of halite, sodalite, and binder glass phases in CWF. The results show that tests used to monitor the consistency of HLW glass waste forms can be used to monitor the consistency of CWF. Data show that PCT can be applied to CWF to address WASRD requirement to monitor waste form consistency.

Lewis, M.A. and Ebert, W.L. 2001. "Monitoring Consistency of the Ceramic Waste Form." Environmental Issues and Waste Management Technologies in the Ceramic and Nuclear Industries VII. Ceramic Transactions, 132, 397-404. 
Lewis, M.A.; Hash, M.C.; Ebert, W.L.; Hebden, A.; and Oliver, S.M. 2001. Results of Physical Characterizations and Product Consistency Tests with Ceramic Waste Form Products Prepared at Six Temperatures and Six Hold Times. Argonne National Laboratory report ANL-NT-178. Argonne, Illinois: Argonne National Laboratory.

This report describes the examination and testing of CWF made by pressureless consolidation at six different temperatures and for six different hold times. The effect of temperature and time on density, microstructure, phase composition, and chemical durability is evaluated. The report provides test data and sensitivity of CWF durability to process conditions.

Lewis, M.A.; Hash, M.C.; Hebden, A.; and Ebert, W.L. 2002. Tests with Ceramic Waste Form Materials Made by Pressureless Consolidation, Argonne National Laboratory report ANL-02/10. Argonne, Illinois: Argonne National Laboratory.

This report discusses various CWF materials made to evaluate the PC method as potential replacement of HIP. Materials were made to evaluate the effects of glass/zeolite mass ratios, processing temperature, processing time, waste form size, and reproducibility. The microstructure, density, and chemical durability of the various materials are similar for materials made by hot HIP and by PC. One beneficial difference is that halite and radionuclide-bearing inclusions are more evenly distributed in the glass phase of PC materials than HIP materials. The report provides data to address WASRD issues.

Morss, L.R.; Stanley, M.L.; Tatko, C.D.; and Ebert, W.L. 1999. "Corrosion of Glass-Bonded Sodalite as a Function of $\mathrm{pH}$ and Temperature." Scientific Basis for Nuclear Waste Management XXIII, Symposium held November 29-December 2, 1999. Boston, Massachusetts. Smith, R.W., and Shoesmith, D.W., eds. Vol. 608, pp. 733-738. Warrendale, Pennsylvania: Materials Research Society.

This paper summarizes laboratory measurements of the $\mathrm{pH}$ and temperature dependence of the dissolution rates of sodalite, binder glass, and composite CWF materials. The $\mathrm{pH}$ and temperature dependence of the component phases and the CWF are similar to that of HLW glass. The paper provides data used in CWF degradation model and TSPA calculations.

Morss, L.R.; Mertz, C.J.; Kropf, A.J.; and Holly, J.L. 2002. "Properties of Plutonium-Containing Colloids Released from Glass-Bonded Sodalite Nuclear Waste Form." Scientific Basis for Nuclear Waste Management XXV, Proceedings of the Materials Research Society Symposium held November 26-29, 2001. Boston, Massachusetts. McGrail, B.P., and Cragnolino, G.A., eds. Vol. 713, pp. 413-421. Warrendale, Pennsylvania: Materials Research Society.

This paper provides a summary of tests and analyses for tests with U,Pu-loaded CWF.

Morss, L.R.; Johnson, S.G.; Ebert, W.L.; DiSanto, T.; Frank, S.M.; Holly, J.L.; Kropf, A.J.; Mertz, C.J.; Noy, M.; O’Holleran, T.P.; Richmann, M.K.; Sinkler, W.; Tsai, Y.; and Warren, A.R. 2002b. Corrosion Tests with Uranium- and Plutonium-Loaded Ceramic Waste Forms, Argonne National Laboratory report ANL-02/09. Argonne, Illinois: Argonne National Laboratory.

This report provides analysis and test results for CWF materials made with salts containing $\mathrm{U}$ and $\mathrm{Pu}$. Results include those from an examination of materials to determine the distribution of $\mathrm{U}$ and $\mathrm{Pu}$ and laboratory tests to measure the release behavior of $\mathrm{U}$ and $\mathrm{Pu}$ as waste form degrades. In other findings, $\mathrm{U}$ and $\mathrm{Pu}$ are present in oxide crystals as inclusions in binder glass and released as colloidal 
and dissolved species. The release of $\mathrm{U}$ and $\mathrm{Pu}$ is slower than the release of $\mathrm{B}$. The report provides data to address WASRD and TSPA issues.

Moschetti, T.L.; Sinkler, W.; DiSanto, T.; Noy, M.H.; Warren, A.R.; Cummings, D.; Johnson, S.G.; Goff, K.M.; Bateman, K.J.; and Frank, S.M. 2000. "Characterization of a Ceramic Waste Form Encapsulating Radioactive Electrorefiner Salt." Scientific Basis for Nuclear Waste Management XXIII, Symposium held November 29-December 2, 1999. Boston, Massachusetts. Smith, R.W., and Shoesmith, D.W., eds. Vol. 608, pp. 577-582. Warrendale, Pennsylvania: Materials Research Society.

This paper provides the characterization of microstructure and corrosion behavior of CWF made with actual radioactive salt using the HIP method. Most alkali metal and alkaline earth fission products are retained in the sodalite, whereas most actinides and rare earth elements form oxide inclusions in the binder glass. The paper addresses the disposition of radionuclides in CWF.

Richmann, M.K.; Reed, D.T.; Kropf, A.J.; Asse, S.B.; and Lewis, M.A. 2001. "EXAFS/EXANES Studies of Plutionium-Loaded Sodalite/Glass Waste Forms.” Journal of Nuclear Materials, 297:303-312.

This paper provides data for the analysis of Pu-bearing inclusion phases in CWF.

Simpson, L.J., and Wronkiewicz, D.J. 1997. "Evaluation of Standard Durability Tests Towards the Qualification Process for the Glass-Zeolite Ceramic Waste Form." Scientific Basis for Nuclear Waste Management XXIII, Symposium held November 29-December 2, 1999. Boston, Massachusetts. Gray, W.J., and Triay, I.R., eds. Vol. 465, pp. 441-448. Pittsburgh, Pennsylvania: Materials Research Society.

This paper discusses the initial evaluation of the use of the MCC-1 leach test, product consistency test, and vapor hydration test to evaluate the degradation behavior of CWF. The results for static and solution exchange tests in brines, tuff groundwater, and leachants with imposed $\mathrm{pH}$ values are provided. The paper provides background information for the degradation tests with CWF.

\section{Results of Tests with MWF Materials}

Abraham, D.P.; McDeavitt, S.M.; and Park, J.Y. 1996. "Metal Waste Forms from the Electrometallurgical Treatment of Spent Nuclear Fuel." Proceedings of the Embedded Topical Meeting on DOE Spent Nuclear Fuel and Fissile Material Management held June 16-20, 1996. Reno, Nevada. 123-128. La Grange Park, Illinois: American Nuclear Society.

This paper provides measurements of the microstructure, corrosion, mechanical, and thermophysical properties of MWF alloys. The paper provides insight into characterization issues in WASRD and corrosion mechanism issues for TSPA.

Abraham, D.P.; McDeavitt, S.M.; Keiser, D.D. Jr.; Johnson, S.G.; Adamic, M.L.; Barker, S.A.; DiSanto, T.; Frank, S.M.; Krsul, J.R.; Noy, M.; Richardson, J.W., Jr.; and Westphal, B.R. 1999. Metal Waste Form Handbook. Argonne National Laboratory report ANL-NT-121. Argonne, Illinois: Argonne National Laboratory.

This report provides test and analysis results for MWF materials. 
Abraham, D.P.; Simpson, L.J.; DeVries, M.J.; and Callahan, D.E. 1999. "Corrosion Behavior of Stainless Steel-Zirconium Alloy Waste Forms." Proceedings of the Corrosion '99 Conference held April 25-30, 1999. San Antonio, Texas. Paper No. 466.

This paper provides the results of immersion and electrochemical corrosion tests showing that the corrosion behavior of MWF is similar to that of other metals to be used in the Yucca Mountain disposal system. The paper will be used to support the modeling approach for MWF in TSPA calculations.

Abraham, D.P.; Simpson, L.J.; DeVries, M.J.; and McDeavitt, S.M. 1999. "Corrosion Testing of Stainless Steel-Zirconium Metal Waste Forms.” Material Research Society Symposium Proceedings, 556: 945952. Pittsburgh, Pennsylvania: Materials Research Society.

Abraham, D.P.: Peterson, J.J.; Katyal, N.K.; Keiser, D.D.; and Hilton, B.A. 2000. "Electrochemical Testing of Metal Waste Forms." Proceedings of the Corrosion 2000 Conference held March 26-31, 2000. Orlando, Florida. Paper No. 00205.

This paper provides the results of polarization resistance and galvanic corrosion measurements of MWF. Galvanic corrosion is determined not to be an important corrosion mechanism. The paper supports a modeling approach for MWF degradation.

Ebert, W.L.; Lewis, M.A.; Barber, T.L.; DiSanto, T.; and Johnson, S.G. 2003. Static Leach Tests with the EBR-II Metallic Waste Form. Argonne National Laboratory report ANL-03/29. Argonne, Illinois: Argonne National Laboratory.

This report provides test data for evaluating the application of degradation rate in HLW glass model to MWF over a range of temperature and $\mathrm{pH}$.

Ebert, W.L.; Lewis, M.A.; Barber, T.L.; and Johnson, S.G. 2003. "Accounting for EBR-II Metallic Waste Form Degradation in TSPA." Scientific Basis for Nuclear Waste Management XXVI, Symposium held December 2-5, 2002. Boston, Massachusetts. Finch, R.J., and Bullen, D.B., eds. Vol. 757, pp. 71-80. Warrendale, Pennsylvania: Materials Research Society.

The paper provides test data for evaluating the application of degradation rate in HLW glass model to MWF over range of temperature and $\mathrm{pH}$.

Fink, J.K.; Morris, E.E.; Abraham, D.P.; Johnson, I.; Johnson, S.G.; and Wigeland, R.A. 2000. Status of Metal Waste Form Corrosion and Release Rate Modeling. Argonne National Laboratory report ANL-NT-154. Argonne, Illinois: Argonne National Laboratory.

This report presents an early model for the long-term performance of the metal waste form in the Yucca Mountain repository, on the basis of results of linear polarization measurements. It provides comparisons between the model and various laboratory measurements and tests. This report also provides background and data for modeling the degradation behavior of MWF and accounting for MWF in TSPA.

Johnson, S.G.; Keiser, D.D.; Frank, S.M.; DiSanto, T.; Warren, A.R.; and Noy, M. 2000. "Leaching Characteristics of the Metal Waste Form from the Electrometallurgical Treatment Process: Product Consistency Testing." Scientific Basis for Nuclear Waste Management XXIII, Symposium held November 
29-December 2, 1999. Boston, Massachusetts. Smith, R.W., and Shoesmith, D.W., eds. Vol. 608, pp. 589-594. Warrendale, Pennsylvania: Materials Research Society.

This paper presents an evaluation of the use of the product consistency test method to assess MWF by using drill or mill shavings instead of crushed material. The paper provides data supporting the use of $\mathrm{Zr}$ concentration to monitor the consistency of MWF instead of PCT.

Johnson, S.G.; Noy, M.; DiSanto, T.; and Barber, T.L. 2001. "Release of Neptunium, Plutonium, Uranium, and Technetium from the Metallic Waste from the Electrometallurgical Treatment Process." Scientific Basis for Nuclear Waste Management XXV, Proceedings of the Materials Research Society Symposium held November 26-29, 2001. Boston, Massachusetts. McGrail, B.P., and Cragnolino, G.A., eds. Vol. 713, pp. 705-711. Warrendale, Pennsylvania: Materials Research Society.

This paper provides data collected from corrosion tests with MWF containing U and Tc. The results show that $U$ is released faster The paper supports the use of the measured $U$ release rate as an upper bound to the release of all radionuclides from the MWF.

Johnson, S.G.; Noy, M.; DiSanto, T.; and Keiser, D.D., Jr. 2002. "Long-Term Immersion Test Results of the Metallic Waste Form from the EMT Process of EBR-II Spent Metallic Fuel." Proceedings of the DOE Spent Nuclear Fuel and Fissile Materials Management Meeting held September 17-20, 2002. Charleston, South Carolina. Waste Form Testing session. La Grange Park, Illinois: American Nuclear Society.

This paper provides data for corrosion tests on MWF containing $U$ and Tc. The results show that $U$ is released faster than Tc. The paper supports the use of the measured $U$ release rate as an upper bound for release of all radionuclides from the MWF.

Keiser, D.D. Jr.; Johnson, S.G.; and Ebert, W.L. 2002. Monitoring the Consistency of the Metal Waste Form. Argonne National Laboratory report ANL-NT-196. Argonne, Illinois: Argonne National Laboratory.

This report describes the development of a method to monitor the consistency of MWF. The recommended method is monitoring gross $\mathrm{Zr}$ concentration because minimum $\mathrm{Zr}$ concentration is required to contain actinides in intermetallic phase. The results of analyses of various alloys are presented to demonstrate methodology. The report provides data to address WASRD requirement for monitoring waste form consistency.

McDeavitt, S.M.; Abraham, D.P.; and Park, J.Y. 1998. "Evaluation of Stainless Steel-Zirconium Alloys as High-Level Nuclear Waste Forms." Journal of Nuclear Materials, 257:21-34. New York, New York: North-Holland.

This paper discusses the metallurgy and microstructure of stainless steel-15Zr and zirconium 8 mass \% stainless steel alloys. The paper presents results of electrochemical corrosion tests conducted at range of $\mathrm{pH}$ values. The paper provides data regarding the microstructure and degradation of the MWF.

\section{Distribution of Radionuclides in the CWF}

Barber, T.L.; DiSanto, T.; Frank, S.M.; Goff, K.M.; Johnson, S.G.; Jue, J.F.; Noy, M.; and O’Holleran, T.P. 2002. "Study of Alpha-Decay Damage in a Glass-Bonded, Sodalite Ceramic Waste." Proceedings of 
the DOE Spent Nuclear Fuel and Fissile Materials Management Meeting held September 17-20, 2002. Charleston, South Carolina. CD-ROM. Waste Form Testing session. La Grange Park, Illinois: American Nuclear Society.

This paper describes the effect of alpha damage accelerated by making use of higher activity and higher concentrations of $\mathrm{Pu}-238$ compared to levels of $\mathrm{Pu}-239$ expected in CWF. No swelling, microcracks, or phase separation were observed after 3.5 years. The paper addresses the effects of radiolysis on CWF durability.

Ebert, W.L; Esh, D.W.; Frank, S.M.; Goff, K.M.; Hash, M.C.; Johnson, S.G.; Lewis, M.A.; Morss, L.R.; Moschetti, T.L.; O’Holleran, T.P.; Richmann, M.K.; Riley, W.P., Jr.; Simpson, L.J.; Sinkler, W.; Stanley, M.L.; Tatko, C.D.; Wronkiewicz, D.J.; Ackerman, J.P.; Arbesman, K.A.; Bateman, K.J.; Battisti, T.J.; Cummings, D.G.; DiSanto, T.; Gougar, M.L.; Hirsche, K.L.; Kaps, S.E.; Leibowitz, L.; Luo, S.S.; Noy, M.; Retzer, H.; Simpson; Sun, D.; Warren, A.R.; and Zyryanov, V.N. 1999. Ceramic Waste Form Handbook, Argonne National Laboratory report ANL-NT-119. Argonne, Illinois: Argonne National Laboratory.

This report provides a summary of laboratory tests and analyses to characterize the microstructure of CWF, physical properties, disposition of radionuclides, corrosion modes, and chemical durability. Laboratory tests used to develop degradation model and measure model parameters are also presented.

Frank, S.M.; Johnson, S.G.; Moschetti, T.L.; O’Holleran, T.P.; Sinkler, W.; Esh, D.; and Goff, M.K. 2000. "Accelerated Alpha Radiation Damage in a Ceramic Waste Form, Interim Results." Scientific Basis for Nuclear Waste Management XXIII, Symposium held November 29-December 2, 1999. Boston, Massachusetts. Smith, R.W., and Shoesmith, D.W., eds. Vol. 608, pp. 469-474. Warrendale, Pennsylvania: Materials Research Society.

This paper presents the results of microstructure, X-ray diffraction, and bulk density measurements and corrosion tests with $\mathrm{CWF}$ doped with $\mathrm{Pu}-238$ to highlight alpha damage. Analyses show slight expansion of $\mathrm{PuO}_{2}$ and perhaps sodalite matrices. The paper provides short-term data on the effect of radiation on phase composition and stability.

Frank, S.M.; DiSanto, T.; Goff, K.M.; Johnson, S.G.; Jue, J.-F.; Barber, T.L.; Noy, M.; O’Holleran, T.P.; and Giglio, J.J. 2002. "Plutonium-238 Alpha-Decay Damage study of a glass-bonded sodalite ceramic waste form." Journal of Testing and Evaluation, Sept 2002. West Conshohocken, Pennsylvania: American Society for Testing and Materials.

This paper presents the results of microstructure, X-ray diffraction, and bulk density measurements and corrosion tests with $\mathrm{CWF}$ doped with $\mathrm{Pu}-238$ to highlight alpha damage. Analyses show slight expansion of $\mathrm{PuO}_{2}$ and perhaps sodalite matrices. The paper provides data on the effect of radiation on phase composition and stability.

Frank, S.M. 2002. "Alpha Decay Damage Study of a Glass-Bonded Sodalite Ceramic Waste Form." Scientific Basis for Nuclear Waste Management XXV, Symposium held November 26-29, 2001. Boston, Massachusetts. McGrail, B.P., and Cragnolino, G.A., eds. Vol. 713, pp. 487-494.

This paper summarizes the results of microstructure, X-ray diffraction, and bulk density measurements and corrosion tests with CWF doped with $\mathrm{Pu}-238$ to highlight alpha damage. 
Morss, L.R.; Mertz, C.J.; Kropf, A.J.; and Holly, J.L. 2002. "Properties of Plutonium-Containing Colloids Released from Glass-Bonded Sodalite Nuclear Waste Form." Scientific Basis for Nuclear Waste Management XXV, Proceedings of the Materials Research Society Symposium held November 26-29, 2001. Boston, Massachusetts. McGrail, B.P., and Cragnolino, G.A., eds. Vol. 713, pp. 413-421. Warrendale, Pennsylvania: Materials Research Society.

This paper provides a summary of tests and analyses for tests with U,Pu-loaded CWF.

Morss, L.R.; Johnson, S.G.; Ebert, W.L.; DiSanto, T.; Frank, S.M.; Holly, J.L.; Kropf, A.J.; Mertz, C.J.; Noy, M.; O’Holleran, T.P.; Richmann, M.K.; Sinkler, W.; Tsai, Y.; and Warren, A.R. 2002b. Corrosion Tests with Uranium- and Plutonium-Loaded Ceramic Waste Forms, Argonne National Laboratory report ANL-02/09. Argonne, Illinois: Argonne National Laboratory.

This report provides analysis and test results for CWF materials made with salts containing $\mathrm{U}$ and $\mathrm{Pu}$. Results include those from an examination of materials to determine the distribution of $\mathrm{U}$ and $\mathrm{Pu}$ and laboratory tests to measure the release behavior of $\mathrm{U}$ and $\mathrm{Pu}$ as waste form degrades. In other findings, $\mathrm{U}$ and $\mathrm{Pu}$ are present in oxide crystals as inclusions in binder glass and released as colloidal and dissolved species. The release of $\mathrm{U}$ and $\mathrm{Pu}$ is slower than the release of $\mathrm{B}$. The report provides data to address WASRD and TSPA issues.

Moschetti, T.L.; Sinkler, W.; DiSanto, T.; Noy, M.H.; Warren, A.R.; Cummings, D.; Johnson, S.G.; Goff, K.M.; Bateman, K.J.; and Frank, S.M. 2000. "Characterization of a Ceramic Waste Form Encapsulating Radioactive Electrorefiner Salt." Scientific Basis for Nuclear Waste Management XXIII, Symposium held November 29-December 2, 1999. Boston, Massachusetts. Smith, R.W., and Shoesmith, D.W., eds. Vol. 608, pp. 577-582. Warrendale, Pennsylvania: Materials Research Society.

This paper provides the characterization of microstructure and corrosion behavior of CWF made with actual radioactive salt using the HIP method. Most alkali metal and alkaline earth fission products are retained in the sodalite, whereas most actinides and rare earth elements form oxide inclusions in the binder glass. The paper addresses the disposition of radionuclides in CWF.

\section{Distribution of Radionuclides in the MWF}

Abraham, D.P.; Keiser, D.D.; and McDeavitt, S.M. 1998. "Metal Waste Forms from Treatment of EBR-II Spent Fuel." Proceedings of the International Conference on Decommissioning and Decontamination and on Nuclear and Hazardous Waste Management, Spectrum '98, held September 13-18, 1998. Denver, Colorado. 783-789. La Grange Park, Illinois: American Nuclear Society.

This paper provides a comparison of microstructure and composition of radioactive MWF ingots to nonradioactive surrogate MWF materials. The paper states that actinide-rich regions were detected within intermetallic phase. It also states that discrete actinide-bearing phases were detected only in samples with too little $\mathrm{Zr}$. The paper provides insight that supports the use of $\mathrm{Zr}$ content as part of monitoring MWF consistency and WASRD issues.

Abraham, D.P.; McDeavitt, S.M.; Keiser, D.D. Jr.; Johnson, S.G.; Adamic, M.L.; Barker, S.A.; DiSanto, T.; Frank, S.M.; Krsul, J.R.; Noy, M.; Richardson, J.W., Jr.; and Westphal, B.R. 1999. Metal Waste Form Handbook. Argonne National Laboratory report ANL-NT-121. Argonne, Illinois: Argonne National Laboratory. 
This report provides test and analysis results for MWF materials.

Abraham, D.P., and Dietz, N.L. 2002. "Role of Laves Intermetallics in Nuclear Waste Disposal." Materials Science and Engineering, A329-331:610-615. Amsterdam, The Netherlands: Elsevier Science.

This paper discusses the metallurgy of stainless steel-Zr alloys and microstructure by transmission electron microscopy. Researchers found that the capacity of Laves intermetallics to sequester actinides is related to $\mathrm{Zr}$ content. This paper provides a description of MWF and the disposition of radionuclides.

Janney, D.E. 2003. Characterization of Host Phases for Actinides in Simulated Metallic Waste Forms by Transmission Electron Microscopy. Argonne National Laboratory report ANL-NT-221. Argonne, Illinois: Argonne National Laboratory.

This report presents a characterization of actinide disposition in MWF by means of transmission electron microscopy. The report addresses the disposition of radionuclides between MWF component phases.

Janney, D.E., and D.D. Keiser, D.D., Jr. 2003. "Actinides in Metallic Waste from Electrometallurgical Treatment of Spent Nuclear Fuel." Journal of the Minerals, Metals \& Materials Society, 55(9):59-60. Warrendale, Pennsylvania: The Minerals, Metals \& Materials Society.

This paper examines MWF materials by means of transmission electron microscopy. The paper provides a description of MWF.

Janney, D.E. 2003. "Host Phases for Actinides in Simulated Metallic Waste Forms." Journal of Nuclear Materials, 323:81-92. New York, New York: North-Holland.

This paper presents an examination of MWF materials conducted by means of transmission electron microscopy. The paper provides a description of MWF.

Keiser, D.D., Jr.; Abraham, D.P.; and Richardson, J.W., Jr. 2000. "Influence of Technetium on the Microstructure of a Stainless Steel-Zirconium Alloy." Journal of Nuclear Materials, 277:333-338. New York, New York: North-Holland.

This paper provides the characterization of the microstructure of stainless steel 15Zr-alloy doped with 2 mass \% Tc. Technetium was found to dissolve preferentially into ferrite and austenite. No separate Tc phases were detected. This paper provides insight regarding radionuclide disposition in the MWF.

Keiser, D.D., Jr.; Abraham, D.P.; Sinkler, W.; Richardson, J.W., Jr.; and McDeavitt, S.M. 2000. "Actinide Distribution in Stainless Steel-15 wt\% Zirconium High-Level Nuclear Waste Form." Journal of Nuclear Materials, 279:234-244. New York, New York: North-Holland.

This paper provides data showing that uranium substitutes into $\mathrm{Zr}$ sites in the intermetallic phase. Actinide-rich areas were detected within intermetallic. Discrete uranium-bearing phases were not detected. This paper describes radionuclide disposition in the MWF.

Keiser, D.D., Jr.; Sinkler, W.; Abraham, D.P.; Richardson, J.W., Jr.; McDeavitt, S.M. 2000. "The Effect of Actinides on the Microstructural Development in a Metallic High-Level Nuclear Waste Form." Rare 
Earths and Actinides: Science, Technology and Applications IV. Bautista, R.G., and Mishra, B., eds. pp. 111-121. Warrendale, Pennsylvania: The Minerals, Metals \& Materials Society.

This paper presents the characterization of microstructure of stainless steel $\mathrm{Zr}$ alloys doped with $\mathrm{U}$, $\mathrm{Pu}$, and/or $\mathrm{Np}$. These actinides were found to be segregated into intermetallic phase and to be stable after various heat treatments. This paper describes radionuclide disposition in the MWF.

McDeavitt, S.M.; Abraham, D.P.; Keiser, D.D.; and Park, J.Y. 1996. "Stainless Steel-Zirconium Alloy Waste Forms for Metallic Fission Products and Actinides Isolated during Treatment of Spent Nuclear Fuel." Proceedings of the Spectrum '96 Meeting, Nuclear and Hazardous Waste Management International Topical Meeting held August 18-23, 1996. Seattle, Washington. pp. 2477-2484. La Grange Park, Illinois: American Nuclear Society.

This paper addresses the disposition of noble metal fission products and actinides in MWF materials.

\section{Modeling the Degradation Behavior of CWF}

Ebert, W.L; Esh, D.W.; Frank, S.M.; Goff, K.M.; Hash, M.C.; Johnson, S.G.; Lewis, M.A.; Morss, L.R.; Moschetti, T.L.; O’Holleran, T.P.; Richmann, M.K.; Riley, W.P., Jr.; Simpson, L.J.; Sinkler, W.; Stanley, M.L.; Tatko, C.D.; Wronkiewicz, D.J.; Ackerman, J.P.; Arbesman, K.A.; Bateman, K.J.; Battisti, T.J.; Cummings, D.G.; DiSanto, T.; Gougar, M.L.; Hirsche, K.L.; Kaps, S.E.; Leibowitz, L.; Luo, S.S.; Noy, M.; Retzer, H.; Simpson; Sun, D.; Warren, A.R.; and Zyryanov, V.N. 1999. Ceramic Waste Form Handbook, Argonne National Laboratory report ANL-NT-119. Argonne, Illinois: Argonne National Laboratory.

This report provides a summary of laboratory tests and analyses to characterize the microstructure of CWF, physical properties, disposition of radionuclides, corrosion modes, and chemical durability. Laboratory tests used to develop degradation model and measure model parameters are also presented.

Ebert, W.L. 2004. "Application of the TSPA Glass Degradation Model to Non-Conforming Waste Forms." Scientific Basis for Nuclear Waste Management XXVIII, Symposium held April 13-16, 2004. San Francisco, California. Hanchar, J.M., Stroes-Gascoyne, S., and Browning, L., eds. Vol. 824, pp. 301308. Warrendale, Pennsylvania: Materials Research Society.

This paper addresses an approach for testing to support the qualification of HLW forms other than HLW glass.

Fanning, T.H.; Morris, E.E.; Wigeland, R.A.; Ebert, W.L.; Lewis, M.A.; and Morss, L.R. 2001. "Ceramic Waste Form Modeling in the Yucca Mountain Engineered Barrier System." Proceedings of the International High-Level Radioactive Waste Management Conference held April 29-May 3, 2001. Las Vegas, Nevada. CD-ROM. Session I-10 Source Term-V: Ceramic Waste and Colloids. La Grange Park, Illinois: American Nuclear Society.

A model for CWF degradation is developed on the basis of the same transition state theory model of aluminosilicate minerals that is the basis for the HLW glass degradation model. In this paper, parameter values derived from experimental measurements are presented. The paper addresses modeling to show how the HLW glass degradation rate in TSPA can be used as an upper bound to the performance of CWF. 
Fanning, T.H.; Ebert, W.L.; Frank, S.M.; Hash, M.C.; Morris, E.E.; Morss, L.R.; O’Holleran, T.P.; and Wigeland, R.A. 2003. Status of Ceramic Waste Form Degradation and Radionuclide Release Modeling. Argonne National Laboratory report ANL-03/8. Argonne, Illinois: Argonne National Laboratory.

This report provides a summary of tests conducted to develop a model, description of the model, and simulations that compare related CWF durability with that of HLW glass.

Fanning, T.H.; Bauer, T.H.; Morris, E.E.; and Wigeland, R.A. 2002. "A Generalized Definition for Waste Form Durability." Proceedings of the DOE Spent Nuclear Fuel and Fissile Materials Management Meeting held September 17-20, 2002. Charleston, South Carolina. Melt-Dilute session. La Grange Park, Illinois: American Nuclear Society.

This paper provides a definition of proposed durability to account for waste form geometry, density, porosity, and cracking. The proposed approach allows for the direct comparison of performance of different waste forms, regardless of release mechanism, differences in waste form geometry, presence of cladding, or other factors that affect release. The paper provides an approach for taking CWF into account in TSPA calculations.

Fanning, T.H. 2003. Confirmation of the Ceramic Waste Form Degradation and Radionuclide Release Model. Argonne National Laboratory report ANL-NT-225. Argonne, Illinois: Argonne National Laboratory.

This report provides a comparison of model calculations with various laboratory tests, including tests in noncomplexing $\mathrm{pH}$ buffer solutions, tests at $20^{\circ} \mathrm{C}$, tests with modified binder glass composition, and tests in solutions saturated with respect to sodalite. The report addresses the validation of the CWF degradation model for CWF as a source of radionuclides in TSPA calculations.

Fanning, T.H.; Ebert, W.L.; Frank, S.M.; Hash, M.C.; Morris, E.E.; Morss, L.R.; O’Holleran, T.P.; and Wigeland, R.A. 2003. Status of Ceramic Waste Form Degradation and Radionuclide Release Modeling, Argonne National Laboratory report ANL-03/8. Argonne, Illinois: Argonne National Laboratory.

This report describes the model developed for CWF degradation and radionuclide release, as well as the use of test results to determine model parameters. Long-term degradation behavior is based on the measured dissolution rate of binder glass. Scoping calculations using GoldSim are conducted to compare CWF model with HLW glass degradation model used for viability assessment. Performance of CWF under disposal conditions is similar to that of HLW glass. This report provides description of modeling the degradation behavior of CWF and accounting for it in TSPA.

Fanning, T.H. 2004. "Document CWF and MWF Degradation Models: Statistical Comparisons of the Ceramic Waste Form and Defense High-Level Waste Glass Models..” Argonne National Laboratory memo to K.M. Goff, September 15, 2004.

This memo meets a programmatic milestone to update the degradation models developed for CWF and MWF.

Fanning, T.H. and Bauer, T.H. 2005. "Document CWF and MWF Degradation Models: Present Status of Waste Form Performance Modeling and an Assessment of the Role of Deliquescence." Argonne National Laboratory memo to K.M. Goff, January 27, 2005.

This memo meets a programmatic milestone to update the degradation models developed for CWF and MWF. 
Morris, E.E.; Fanning, T.H.; and Wigeland, R.A. 2001. "Waste Form Performance Assessment in the Yucca Mountain Engineered Barrier System." Proceedings of the International High-Level Radioactive Waste Management Conference held April 29-May 3, 2001. Las Vegas, Nevada. CD-ROM. Session E-3 Source Term-I: General Modeling Topics. La Grange Park, Illinois: American Nuclear Society.

This paper provides a methodology to evaluate the impact of CWF and MWF, which account for about $0.1 \%$ of the total inventory at Yucca Mountain. Calculations are provided for release of I, Tc, and Np. The paper illustrates how CWF and MWF can be taken into account in TSPA calculations.

Wigeland, R.A.; Briggs, L.L.; Fanning, T.A.; Feldman, E.E.; Morris, E.E.; and Petri, M.C. 1999. Waste Form Degradation and Repository Performance Modeling. Argonne National Laboratory report ANL-NT-117. Argonne, Illinois: Argonne National Laboratory.

An evaluation of CWF and MWF by using RIP performance assessment code shows these waste forms will have negligible impact on repository performance. The report provides background information for treating CWF and MWF in TSPA calculations.

\section{Modeling the Degradation Behavior of MWF}

Abraham, D.P.; Dietz, N.L.; and Finnegan, N. 2001. "Characterization of Oxidation Products on a $\mathrm{ZrFe}_{2}-$ Type Laves Intermetallic Exposed to $200^{\circ} \mathrm{C}$ Steam." Proceedings of the Corrosion 2001 Conference, Paper No. 01139.

This paper provides evidence that radionuclide release from MWF is controlled by corrosion of the $\mathrm{Fe}_{2} \mathrm{Zr}$-type intermetallic phase. The characterization of samples corroded in steam by using Auger electron spectroscopy and transmission electron microscopy shows the formation of iron oxide and probably zirconium oxide. The paper provides a description of MWF corrosion process and modeling.

Bauer, T.H.; Abraham, D.P.; Fink, J.K.; Johnson, I.; Johnson, S.G.; and Wigeland, R.A. 2001. "Modeling Corrosion and Constituent Release from a Metal Waste Form." Proceedings of the International HighLevel Radioactive Waste Management Conference held April 29-May 3, 2001. Las Vegas, Nevada. CDROM. Session E-3 Source Term-I: General Modeling Topics. La Grange Park, Illinois: American Nuclear Society.

This paper develops a model for the release of radionuclides from MWF on the basis of electrochemical and immersion test results. The paper provides insight into MWF degradation model development.

Bauer, T.H.; Johnson, S.G.; and Snyder, C.T. 2002. "Modeling the Long-Term Degradation of a Metallic Waste Form." Proceedings of the DOE Spent Nuclear Fuel and Fissile Materials Management Meeting held September 17-20, 2002. Charleston, South Carolina. La Grange Park, Illinois: American Nuclear Society.

This paper presents a model for MWF degradation that accounts for passivation and the stability of oxide surface layer. The paper provides insight into the development of the model. 
Bauer, T.H. and Morris, E.E. 2004. "Updating the Model of Metallic Waste Form Degradation-New Data and Anlayses." Argonne National Laboratory intralaboratory memo to R.A. Wigeland, September 30, 2004.

This memo meets a programmatic milestone to update the degradation model developed for MWF.

Ebert, W.L.; Lewis, M.A.; Barber, T.L.; and Johnson, S.G. 2003. "Accounting for EBR-II Metallic Waste Form Degradation in TSPA." Scientific Basis for Nuclear Waste Management XXVI, Symposium held December 2-5, 2002. Boston, Massachusetts. Finch, R.J., and Bullen, D.B., eds. Vol. 757, pp. 71-80. Warrendale, Pennsylvania: Materials Research Society.

The paper provides test data for evaluating the application of degradation rate in HLW glass model to MWF over range of temperature and $\mathrm{pH}$.

Ebert, W.L.; Lewis, M.A.; Barber, T.L.; DiSanto, T.; and Johnson, S.G. 2003. Static Leach Tests with the EBR-II Metallic Waste Form. Argonne National Laboratory report ANL-03/29. Argonne, Illinois: Argonne National Laboratory.

This report provides test data for evaluating the application of degradation rate in HLW glass model to MWF over a range of temperature and $\mathrm{pH}$.

Ebert, W.L. 2004. "Application of the TSPA Glass Degradation Model to Non-Conforming Waste Forms." Scientific Basis for Nuclear Waste Management XXVIII, Symposium held April 13-16, 2004. San Francisco, California. Hanchar, J.M., Stroes-Gascoyne, S., and Browning, L., eds. Vol. 824, pp. 301308. Warrendale, Pennsylvania: Materials Research Society.

This paper addresses an approach for testing to support the qualification of HLW forms other than HLW glass.

Fink, J.K.; Morris, E.E.; Abraham, D.P.; Johnson, I.; Johnson, S.G.; and Wigeland, R.A. 2000. Status of Metal Waste Form Corrosion and Release Rate Modeling. Argonne National Laboratory report ANL-NT-154. Argonne, Illinois: Argonne National Laboratory.

This report presents an early model for the long-term performance of the metal waste form in the Yucca Mountain repository, on the basis of results of linear polarization measurements. It provides comparisons between the model and various laboratory measurements and tests. This report also provides background and data for modeling the degradation behavior of MWF and accounting for MWF in TSPA.

Morris, E.E.; Fanning, T.H.; and Wigeland, R.A. 2001. "Waste Form Performance Assessment in the Yucca Mountain Engineered Barrier System." Proceedings of the International High-Level Radioactive Waste Management Conference held April 29-May 3, 2001. Las Vegas, Nevada. CD-ROM. Session E-3 Source Term-I: General Modeling Topics. La Grange Park, Illinois: American Nuclear Society.

This paper provides a methodology to evaluate the impact of CWF and MWF, which account for about $0.1 \%$ of the total inventory at Yucca Mountain. Calculations are provided for release of I, Tc, and Np. The paper illustrates how CWF and MWF can be taken into account in TSPA calculations.

Wigeland, R.A.; Briggs, L.L.; Fanning, T.A.; Feldman, E.E.; Morris, E.E.; and Petri, M.C. 1999. Waste Form Degradation and Repository Performance Modeling. Argonne National Laboratory report ANL-NT-117. Argonne, Illinois: Argonne National Laboratory. 
An evaluation of CWF and MWF by using RIP performance assessment code shows these waste forms will have negligible impact on repository performance. The report provides background information for treating CWF and MWF in TSPA calculations. 
B-32 
Distribution for ANL/05-43

Internal (Printed and Electronic Copies):

W. L. Ebert (15)

Internal (Printed Copy Only):

M. J. Steindler

Internal (Electronic Copy Only):

M. R. Hale, TIS

D. P. Abraham

C. H. Adams

R. K. Ahluwalia

T. H. Bauer

A. R. Brunsvold

D. B. Chamberlain

Y. I. Chang

J. C. Cunnane

T. H. Fanning

R. J. Finch

A. A. Foley
J. A. Fortner

E. K. Fujita

C. Grandy

D. J. Graziano

R. N. Hill

J. L. Jerden, Jr.

H. S. Khalil

J. J. Laidler

L. Leibowitz

R. M. Lell

D. Lewis

M. A. Lewis
C. J. Mertz

E. E. Morris

M. T. Peters

M. C. Regalbuto

C. T. Snyder

V. S. Sullivan

Y. Tsai

G. F. Vandegrift

R. A. Wigeland

M. A. Williamson

J. L. Willit

External (Printed and Electronic Copies):

R. W. Benedict, Idaho National Laboratory, Idaho Falls, ID (10)

K. M. Goff, Idaho National Laboratory, Idaho Falls, ID

D. E. Janney, Idaho National Laboratory, Idaho Falls, ID

D. D. Keiser, Jr. , Idaho National Laboratory, Idaho Falls, ID

T. P. O'Holleran, Idaho National Laboratory, Idaho Falls, ID

External (Electronic Copies Only):

M. A. Buckley, ANL Library-E

S. E. Aumeier, Idaho National Laboratory, Idaho Falls, ID

K. J. Bateman, Idaho National Laboratory, Idaho Falls, ID

T. J. Battisti, Idaho National Laboratory, Idaho Falls, ID

S. S. Cunningham, Idaho National Laboratory, Idaho Falls, ID

K. B. Davies, Idaho National Laboratory, Idaho Falls, ID

H. E. Garcia, Idaho National Laboratory, Idaho Falls, ID

S. G. Johnson, Idaho National Laboratory, Idaho Falls, ID

M. G. Gougar, Idaho National Laboratory, Idaho Falls, ID

D. D. Hagan, Idaho National Laboratory, Idaho Falls, ID 
K. L. Howden, Idaho National Laboratory, Idaho Falls, ID J. R. Kennedy, Idaho National Laboratory, Idaho Falls, ID C. J. Knight, Idaho National Laboratory, Idaho Falls, ID

J. R. Krsul, Idaho National Laboratory, Idaho Falls, ID

C. E. Lahm, Idaho National Laboratory, Idaho Falls, ID

S. X. Li, Idaho National Laboratory, Idaho Falls, ID

R. P. Lind, Idaho National Laboratory, Idaho Falls, ID

K. C. Marsden, Idaho National Laboratory, Idaho Falls, ID

S. D. McBride, Idaho National Laboratory, Idaho Falls, ID

H. F. McFarlane, Idaho National Laboratory, Idaho Falls, ID

R. L. Parks, Idaho National Laboratory, Idaho Falls, ID

R. D. Phipps, Idaho National Laboratory, Idaho Falls, ID

C. L. Pope, Idaho National Laboratory, Idaho Falls, ID

S. R. Sherman, Idaho National Laboratory, Idaho Falls, ID

G. M. Teske, Idaho National Laboratory, Idaho Falls, ID

D. E. Vaden, Idaho National Laboratory, Idaho Falls, ID

D. L. Wahlquist, Idaho National Laboratory, Idaho Falls, ID

B. R. Westphal, Idaho National Laboratory, Idaho Falls, ID 